\title{
Caracterización estratigráfica y estructural de la evolución temprana (sin-rift y post-rift inicial) del margen sur de la Cuenca Neuquina entre Sañicó (Neuquén) y el río Limay (Río Negro)
}

\author{
Autor
}

Lic. Leandro D'Elia

2010

Director

Dr. Juan R. Franzese

Codirector

Dr. Gonzalo D. Veiga 


\title{
Caracterización estratigráfica y estructural de la evolución temprana (sin-rift y post-rift inicial) del margen sur de la Cuenca Neuquina entre Sañicó (Neuquén) y el río Limay (Río Negro)
}

\author{
Autor \\ Lic. Leandro D’Elia \\ 2010 \\ Director \\ Dr. Juan R. Franzese \\ Codirector \\ Dr. Gonzalo D. Veiga
}

Centro de Investigaciones Geológicas

Facultad de Ciencias Naturales y Museo

Universidad Nacional de La Plata 
D'Elia, Leandro

Caracterización estratigráfica y estructural de la evolución temprana, sin-rift y post-rift inicial, del margen sur de la Cuenca Neuquina entre Sañicó, Neuquén, y el río Limay, Río Negro. - 1a ed. - La Plata : Universidad Nacional de La Plata, 2012.

E-Book.

ISBN 978-950-34-0769-1

1. Volcanismo. I. Título CDD 551.21

Fecha de catalogación: 24/10/2011 
al don al don, al don pirulero, cada cual cada cual, atiende su juego... 


\section{Índice}

Agradecimientos I

Resumen II

$\begin{array}{lll}\text { Abstract } & \text { V }\end{array}$

Capítulo 1

1.1 Introducción 1

1.2 Marco geológico, estratigrafía y antecedentes 2

1.2.1 La Cuenca Neuquina 2

1.2.2 Relleno inicial de la Cuenca Neuquina: aspectos generales 7

1.3 Objetivos 9

$\begin{array}{ll}\text { 1.4 La zona de estudio } & 10\end{array}$

1.4.1 Ubicación y características generales de la zona de estudio 10

1.4.2 Estratigrafía pre-cenozoica del área de estudio 10

1.4.3 Estratigrafía cenozoica del área de estudio 15

1.4.4 Rasgos morfoestructurales y estructurales del área de estudio 15

\section{Capítulo 2: Metodología}

2.1 Tareas de campo $\quad 26$

2.1.1 Mapeo Geológico $\quad 26$

$\begin{array}{ll}\text { 2.1.2 Relevamiento de datos estructurales } & 26\end{array}$

2.1.3 Levantamiento de perfiles estratigráficos y sedimentológicos 26

2.1.4 Muestreo 29

2.2 Trabajo de gabinete 29

2.2.1 Análisis de laboratorio 31

2.2.2 Análisis de facies, asociaciones de facies y ambientes 31

2.2.3 Estudio tecto-estratigráfico del Ciclo Precuyano y la transición

al Ciclo Cuyano 31

\section{Capítulo 3: Análisis litológico y litogeoquímico}

3.1 Introducción 33

3.2 Análisis de las litofacies $\quad 34$

3.2.1 Terminología y organización de las litofacies 34 
3.2.3 Litofacies piroclásticas $\quad 43$

3.2.4 Litofacies sedimentarias

3.2.4.1 Facies epiclásticas psefíticas $\quad 52$

3.2.4.2 Facies epiclásticas psamíticas $\quad 61$

3.2.4.3 Facies epiclásticas pelíticas $\quad 67$

$\begin{array}{ll}\text { 3.2.4.4 Facies carbonáticas } & 70\end{array}$

$\begin{array}{ll}\text { 3.3 Análisis Microscópico } & \mathbf{7 4}\end{array}$

$\begin{array}{ll}\text { 3.3.1 Análisis microscópico de las rocas volcánicas } & 74\end{array}$

3.3.2 Análisis microscópico de las rocas piroclásticas 82

3.3.3 Análisis microscópico de las rocas epiclásticas 88

3.3.4 Análisis microscópico de las rocas carbonáticas 95

$\begin{array}{ll}3.4 \text { Análisis litogeoquímico } & 97\end{array}$

$\begin{array}{ll}3.4 .1 \text { Introducción } & 97\end{array}$

3.4.2 Organización de los datos geoquímicos $\quad 97$

3.4.3 Consideraciones generales acerca de la geoquímica del Precuyano 99

\section{Capítulo 4: Análisis de las unidades de acumulación}

\subsection{Introducción $\quad 106$}

4.2 ¿Qué es una unidad de acumulación y cómo se define?

$\begin{array}{ll}4.3 \text { Organización de las unidades de acumulación } & 107\end{array}$

4.4 Unidades de acumulación de rocas volcánicas y volcaniclásticas asociadas $\quad 108$

$\begin{array}{ll}\text { 4.4.1 Unidades de acumulación de rocas volcánicas andesíticas } & 108\end{array}$

4.4.1.1 Coladas y coladas dómicas 108

4.4.1.2 Domos andesíticos 117

4.4.1.3 Diques andesíticos $\quad 120$

4.4.2 Unidad de acumulación de conducto alimentador 128

$\begin{array}{ll}\text { 4.4.3 Unidades de acumulación de rocas volcánicas ácidas } & 130\end{array}$

4.4.3.1 Criptodomos riodacíticos 130

4.4.3.2 Coladas dómicas riodacíticas $\quad 130$

4.5 Unidades de acumulación piroclásticas $\quad 134$

4.5.1 Unidad de acumulación de depósitos de corrientes piroclásticas $\begin{array}{ll}\text { subaéreas alojada en depresiones } & 134\end{array}$

4.5.2 Unidades de acumulación de depósitos de corrientes piroclásticas subaéreas de gran distribución areal (I, II y III) 139

4.5.3 Unidad de acumulación de depósitos de corrientes piroclásticas subácueas $\quad 148$ 
4.6.1 Unidades de acumulación epiclásticas continentales

4.6.1.1 Sistemas aluviales

4.6.1.2 Sistemas fluviales de carga mixta

4.6.1.3 Sistema de delta de grano grueso/lacustre $\quad 165$

$\begin{array}{ll}\text { 4.6.1.4 Sistema de delta de grano fino } & 168\end{array}$

$\begin{array}{ll}\text { 4.6.2 Unidades de acumulación epiclásticas marinas } & 170\end{array}$

4.6.2.1 Ambiente marino de costa afuera (offshore) 170

$\begin{array}{ll}\text { 4.6.3 Unidad de acumulación carbonática marina } & 172\end{array}$

4.6.3.1 Ambiente marino somero carbonático 172

\section{Capítulo 5: Organización de las unidades de acumulación del Ciclo Precuyano} y Cuyano basal en el espacio y tiempo

\subsection{Introducción}

5.2 Organización de las unidades de acumulación del Ciclo Precuyano y Cuyano basal dentro de los depocentros

5.2.1 Las unidades de acumulación del Ciclo Precuyano y Cuyano basal dentro del depocentro de Sañicó

5.2.2 Las unidades de acumulación del Ciclo Precuyano y Cuyano inferior dentro del depocentro de la Pintada

5.2.3 Las unidades de acumulación del Ciclo Precuyano dentro del depocentro de Piedra del Águila

5.3 Correlación de las asociaciones de unidades de acumulación entre los depocentros

\section{Capítulo 6: Discusión de los resultados}

6.1 Análisis estratigráfico y cronoestratigráfico de las unidades Triásico Superior Jurásico Inferior en el sector sur de la Cuenca Neuquina

6.1.1 Determinación y jerarquización de las superficies clave

6.1.2 Organización cronoestratigráfica de las unidades Triásico Superior Jurásico Inferior para los depocentros de Sañicó, la Pintada y Piedra del Águila

\subsection{Unidades tecto-sedimentarias Precuyana y Cuyana en el borde sur}

6.2.1 Evolución paleoambiental y paleogeográfica del Precuyano y

Cuyano basal en el área de Sañicó y Piedra del Águila

6.2.2 Los controles sobre las unidades tecto-sedimentarias Precuyana y Cuyana 
Capítulo 7: Conclusiones

Bibliografía

235

Anexo I: Mapa geológico detallado del área de estudio

Anexo II: Perfiles litológicos relevados

Anexo III: Tabla de análisis geoquímicos 


\section{Agradecimientos}

A mi director, Juan Franzese y mi codirector, Gonzalo Veiga, por estar siempre presentes, por los consejos y la inspiración. ¡Gracias amigos!, he aprendido mucho más que geología.

Este trabajo es lo que es gracias a la pasión y el profesionalismo de mis compañeros de campaña. Andrés Bilmes, Ignacio Cambon, Dante Disalvo y Mariano Hernández, ¡Gracias por siempre!

A Luis “Chango” Spalletti, quien desde el primer día dio el apoyo a este proyecto. El financiamiento de las tareas de investigación fue posible mediante los proyectos que estuvieron bajo su dirección: "Controles estructurales y volcánicos sobre las secuencias de sin-rift (Precuyano) de la Cuenca Neuquina” y “Evaluación de la influencia de los procesos tectónicos y climáticos en la sedimentación jurásica y cretácica de la Cuenca Neuquina”, otorgados por la Agencia Nacional de Promoción Científica y Tecnológica.

Gracias Alberto Torres y a su familia, por abrirme las puertas de su casa y su corazón. A Felisa Zamora y Carlos Freire de la Estancia La Inmaculada, ¡Gracias Feli y Carli por todos los momentos amenos y el cariño recibido!. Jamás olvidaré las charlas de sobremesa y de picadas. A todas las personas del la Estancia Santa Isabel por su hospitalidad y predisposición, ¡Gracias Marcelo Carulo! y ¡Gracias Polo!

A todos mis amigos del Centro de Investigaciones Geológicas, "todos escribieron alguna página de esta historia”. Gracias Martín Muravchik, Andrés Bilmes, Augusto Varela, Sebastián Richiano, Nicolás Sandoval, Irene Hernado, Noelia Iannizzotto y Daniela Ancheta, por la ayuda, motivación, el fútbol, las picadas y el vino. A Alfredo Benialgo (y si no renuncio), Leonel Pousada, Daniel Mártire, Oscar Nuñez, Pablo García, Jorge “tanito” Wlasiuk y Daniel Poiré, por la alegría. A Carlos Rapela y Sergio Matheos por trabajar todos estos años para mejorar día a día situación de los becarios en el instituto. A Eduardo Llambías, Pablo González, Ana Sato, Carlos Cingolani, Jorge Maggi y Claudia Cavarozzi, por estar siempre dispuestos cuando los necesité.

A mis compañeros de la Cátedra de Petrología I de la Facultad de Ciencias Naturales y Museo de la UNLP. Gracias Yolanda Aguilera y Gerardo “Tito” Páez por los momentos y las 
enseñanzas.

Al jurado, Luis Spalletti, Víctor Ramos e Iván Petrinovic, por dedicarme parte de su tiempo, por su disposición y por las sugerencias que mejoraron la calidad del manuscrito final.

A mis familiares, soy lo que soy gracias a ellos. Gracias Romi por el amor de todos estos años. A mis viejos, por la fuerza, la humildad y la dedicación de siempre, a mis hermanos, sobrinos, tíos, primos y amigos. A mi abuela Ángela, por los fantásticos recuerdos que tengo de ella. “iiGracias Abuela!!”

A la universidad pública y gratuita y a las personas que lucharon para que permanezca en ese estado. 


\section{Resumen}

El presente trabajo se centró en el análisis tecto-estratigráfico de los estadios iniciales de relleno de una cuenca de rift, donde interactúan de manera compleja procesos tectónicos, volcánicos, sedimentarios y eustáticos. Como caso de estudio se tomaron las sucesiones del Triásico Superior-Jurásico Inferior del sector austral de la Cuenca Neuquina, aflorantes en al área de Sañicó y Piedra del Águila, desarrollada al este de los Andes Norpatagónicos y al norte del Macizo Norpatagónico. En esta área asoman algunas de las unidades más antiguas de la Cuenca Neuquina, en particular el basamento ígneo-metamórfico y el relleno inicial (Formación Paso Flores, Ciclo Precuyano y Ciclo Cuyano).

La metodología empleada consistió en el reconocimiento de las sucesiones volcanosedimentarias a través del mapeo geológico, el levantamiento de perfiles estratigráficos y estructurales y el muestreo sistemático de material rocoso. En laboratorio se procesaron las muestras para estudios petrográficos y geoquímicos. El análisis de las sucesiones rocosas permitió constatar su naturaleza volcano-sedimentaria. Mediante el análisis de facies se identificaron litofacies de rocas volcánicas, piroclásticas y sedimentarias epiclásticas y carbonáticas. El análisis petrográfico permitió determinar las características composicionales y los tipos de alteraciones presentes en el relleno (hidrotermal débil, deutérica y diagénesis temprana). El estudio geoquímico reveló un rango continuo composicional desde andesitas basálticas hasta riodacitas, con características comagmáticas, tendencia subalcalinacalcoalcalina y patrones de elementos trazas típicos de series magmáticas orogénicas.

En función de asociaciones de facies genéticamente relacionadas y el control espacial, se definieron unidades de acumulación volcánicas (volcánicas de conducto, diques, domos y coladas y coladas dómicas), piroclásticas (depósitos de corrientes piroclásticas) y sedimentarias (aluviales, fluviales de carga mixta, deltaicas de grano grueso, deltaicas de grano fino, de ambiente marino profundo y de ambiente marino somero carbonático).

El control tecto-estratigráfico sobre las sucesiones iniciales permitió definir tres áreas depocentrales mayores, de oeste a este: depocentro de Sañicó, depocentro de la Pintada y depocentro de Piedra del Águila. El depocentro de Sañicó corresponde a un hemigraben volcánico que posee una orientación NE-SW, polaridad hacia el sureste, limitado por fallas NESW y ENE. Esta relleno principalmente por depósitos precuyanos y minoritariamente por depósitos del Ciclo Cuyano. El hemigraben de la Pintada presenta una orientación N-S y polaridad hacia el oeste y acomoda principalmente a depósitos del Ciclo Cuyano. El depocentro de Piedra del Águila fue definido como otro hemigraben volcánico de una orientación NE-SW, con polaridad hacia el noroeste y está relleno en su totalidad por depósitos precuyanos. 
Teniendo en cuenta las características genéticas y formacionales de las unidades de acumulación y la relación espacial, se identificaron diferentes secciones dentro de los depocentros que fueron correlacionadas entre los depocentros en función de sus atributos genéticos y su posición dentro del relleno. Para el análisis tecto-estratigráfico se utilizó el concepto de unidades tecto-sedimentarias (UTS) - unidades aloestratigráficas limitadas por discontinuidades, originadas por procesos tectónicos o sedimentarios -. La relación entre las diferentes unidades que componen el relleno inicial con los elementos estructurales, sumado a la identificación y jerarquización de superficies clave, permitieron definir a la Formación Paso Flores y los Ciclos Precuyano y Cuyano como unidades tecto-sedimentarias asociadas a eventos tectónicos extensionales. La UTS I, equivalente a la Formación Paso Flores, corresponde a un periodo rift continental caracterizado por ambientes sedimentarios desde aluviales y a lacustres. La UTS II "Precuyana”, corresponde a una etapa de rift con una fuerte actividad magmática y la UTS III “Cuyana basal”, corresponde al último periodo de sinrift del rifting inicial de la cuenca en su borde austral. Este último evento se caracteriza por una reorganización total de las áreas de acomodación y una merma abrupta del volcanismo. El esquema cronoestratigráfico planteado para el borde austral de la Cuenca Neuquina indica que el lapso Triásico Superior - Jurásico Inferior se encuentra conformado por una sucesión de unidades tecto-sedimentarias asociadas a una tectónica extensional (UTS I, UTS II y UTS III), las cuales se presentan en diferentes áreas depocentrales. Las mismas se desarrollaron durante aproximadamente $30 \mathrm{Ma}$, sin interrupciones mayores.

Los resultados de éste análisis, dejaron en evidencia la fuerte influencia de los controles tectónicos y volcánicos sobre el relleno inicial. El control tectónico fue identificado de diferente manera y escalas: a) control en las áreas de acomodación b) control en la orientación de los depocentros por parte de las estructuras heredadas del basamento, c) control en la ubicación y polaridad de los ambientes volcano-sedimentarios y sedimentarios y d) control del nivel relativo del mar. La expresión del volcanismo fue identificada tanto para el Ciclo Precuyano como para la base del Ciclo Cuyano. Su actividad afectó la naturaleza agradacional o excavacional de los aparatos volcánicos, el tipo y cantidad de materiales volcánicos y sedimentos ingresados a los depocentros.

El modelo petrogenético para el Ciclo Precuyano fue evaluado desde dos puntos de vista: la relación volcanismo-zona de aporte magmático superficial y la relación magma-fuente de origen. El magmatismo habría estado relacionado con cámaras magmáticas superficiales, multinyectadas, que suministraron productos volcánicos comagmáticos. Las características geoquímicas indican una fuente con participación de fluidos ocurridos un ambiente geodinámico con la impronta de las series orogénicas. En el macizo Norpatagónico, fuera del ámbito de la Cuenca Neuquina, se desarrollaron simultáneamente rocas volcánicas con fuertes 
similitudes litológicas y geoquímicas. Esto evidenciaría que el magmatismo Triásico SuperiorJurásico Inferior del margen occidental de Gondwana se manifestó en diferentes segmentos de margen protoandino asociado a muy diferentes marcos de evolución tecto-estratigráfica. 


\begin{abstract}
A Tectonostratigraphic analysis of the sinrift stage (Upper Triassic - Lower Jurassic) of the Neuquén Basin at its southern border is presented. The study area is located between the towns of Sañicó and Piedra del Águila (Neuquén province), to the west of the Andean chain and to the north of the Norpatagonian Massif. The units related to the initial extensional phase in this area comprise the Upper Triassic Paso Flores Formation, and the Lower Jurassic Precuyo and Cuyo Cycle.
\end{abstract}

The study was carried out trough geological mapping, measuring of stratigraphic and structural sections, petrography and geochemical analyses. Several lithofacies (volcanic pyroclastic, clastic and carbonate) were determined. The geochemical signature of the volcanic and pyroclastic rocks was studied trough the analysis of thin sections and chemical analyses of Major, Minor and Trace elements. As a result, a continuous range from basaltic andesites to rhyolites with comagmatic and sub-alkaline to calc-alkaline affinities were determined for the volcanic rocks of the Precuyo Cycle. Also, weak hydrothermal, deuteric and early diagenetic alterations were registered. The analysis allows us to define facies associations and, finally, accumulation units. The main framework of accumulation units for the Precuyo Cycle and lower Cuyo Cycle includes: volcanic vents units, dikes, domes and lava flows and coulees, pyroclastic flow units, alluvial and fluvial system units, coarse grained and fine grained deltaic units, offshore marine units and shallow marine carbonate units.

The infill of the sinrift sequence was divided into three depositional areas: the Sañicó, the Pintada and the Piedra del Águila depocentres. Each depocentre shows a different infill pattern and is related to a single hemigraben. The Sañicó area is a NE-SW hemigraben with southeastern polarity. Is filled by volcanic, pyroclastic and volcaniclastic rocks of the Precuyo Cycle covered by rocks belonging to the Cuyo Cycle. The Pintada depocentre is a N-S hemigraben with western polarity, mainly with a Cuyo Cycle infill. Finally, the Piedra del Águila depocentre is a NE-SW volcanic hemigraben with northwestern polarity, filled only by the Precuyo Cycle.

The integrated analysis was performed with the use of allostratigraphic units separated by discontinuity surfaces: Tectosedimentary Units (UTS). Three UTS was defined. The older one is the Paso Flores Formation (not analyzed in detail in this study), an Upper Triassic- Lower Jurassic continental silicoclastic sequence deposited to the west and south of the study area. The UTS 2 is the Precuyo Cycle, a continental unit mainly defined by its volcanic signature. The UTS 3 is represented by the lower Cuyo Cycle, a marine mixed silicoclastic-carbonate unit with 
minor influence of volcanism. The 3 UTS are not deposited into the same depositional areas. The superimposition of these tectosedimentary units represents a multiepisodic rifting that last over 30 My from Upper Triassic to Pliensbachian.

The tectonic controls on these sequences are: 1) accommodation space, 2) the polarity of sedimentary and volcanic environments, 3) the spatial distribution of depocentres, and 4) eustatic cycles. The volcanic controls are represented in the types of volcanic environments and quantity and characteristics of the clastic material provided to the depocentres.

The petrogenetic data implies the development of subsurface magmatic multinjected chambers with an orogenic signature. In the Nortpatagonian Massif, out of the study area and out of the Neuquén Basin, several volcanic sequences coeval to the Precuyo Cycle are registered. All of these rocks share the same geochemical and petrographic characteristics despite the Precuyo rocks integrated the infill of an extensional basin and the rocks in the Northpatagonian Massif are not related to basin at all. This suggests that the Lower Jurassic Magmatic cycle spans over a huge area even with totally different structural and geodynamic evolution. 


\section{Capítulo 1}

\section{1) Introducción}

Las cuencas de rifts activos, paleorifts y cuencas de márgenes pasivos forman un grupo de cuencas genéticamente relacionadas a procesos extensionales (Ziegler y Cloetingh, 2004). Las cuencas extensionales caracterizaron diferentes etapas de la evolución geológica de la tierra y se desarrollan en diferentes ambientes geodinámicos, desde márgenes divergentes a convergentes y aún en sitios de intraplaca (Kearey y Vine, 1992; Condie, 1997; Ziegler y Cloetingh, 2004). En conjunto contienen importantes reservas probadas y potenciales de depósitos minerales y de yacimientos de hidrocarburos (Cuenca del Mar del Norte, Cuenca del W Siberiano, Cuenca del Golfo de Suez, entre muchas otras) (Ziegler y Cloetingh, 2004). Las cuencas de rift se caracterizan por ser depresiones alongadas bordeadas por fallas directas, con dimensiones del orden de las decenas a centenas de kilómetros de ancho y de cientos a miles de kilómetros de largo (Schlische y Anders, 1996; Morley, 1999a; Gawthorpe y Leeder, 2000). Internamente están constituidas por depocentros simétricos (grábenes) y/o asimétricos (hemigrábenes), a menudo segmentados, con polaridades opuestas y con diferentes tipos de conexiones entre sí (zonas de acomodación) (Schlische, 1991; Schlische y Anders, 1996; Morley, 1999a; Gawthorpe y Leeder, 2000; Morley, 2004). Las cuencas extensionales están originadas por dos tipos de subsidencia tectónica, diferentes y sucesivos: mecánica y termal (Gawthorpe y Leeder, 2000; Ziegler y Cloetingh, 2004). La subsidencia mecánica se genera durante el fallamiento, denominándose a este periodo como etapa de sinrift, mientras que la subsidencia termal ocurre finalizado el fallamiento, en el marco del reequilibrio termal de la litosfera y es denominada como etapa de postrift (Gawthorpe y Leeder, 2000; Ziegler y Cloetingh, 2004). Los resaltos topográficos y depresiones desarrollados en estos escenarios producen ciclos de meteorización, erosión y transporte que originan aporte de tipo sedimentario a las cubetas (Gawthorpe y Leeder, 2000; Leeder, 2003). A su vez, el adelgazamiento de la litosfera y el desequilibrio termal pueden producir importantes fenómenos magmáticos, incrementando el rol del volcanismo en el relleno. En este sentido, las cuencas de rift asociadas a una profusa actividad magmática fueron asociadas a rifts "activos", mientras que las cuencas de rift en donde el volcanismo aparece de manera relegada se denominaron como "pasivos" (Ziegler y Cloetingh, 2004). En conjunto las variables estructurales, sedimentarias y magmáticas se relacionan de manera compleja, sobre todo en los estadios iniciales de rifting, donde se registran diferentes procesos episódicos extensionales y volcánicos, conjuntamente con el cambio de ambientes continentales a marinos para muchas cuencas de rift del mundo 
(Schlische, 1992; Morley, 1999a; Kattenhorn y Pollard, 2001; Ziegler y Cloetingh, 2004). Estas condiciones revelan la dificultad para evaluar los controles sobre el relleno en esos estadios iniciales de este tipo de cuencas. La Cuenca Neuquina, con más de un siglo de investigaciones desarrolladas en el marco de la ciencia básica y de exploraciones petrolíferas (Howell et al., 2005), es una de las cubetas de rift del país con la que mayor información se cuenta. A pesar de su vasto conocimiento, el relleno que representa la etapa inicial dista de presentar un marco geológico conciso, en el cual se hayan evaluado los diferentes controles que interactuaron en la configuración inicial de los depocentros. En este sentido, el sector sur de la Cuenca Neuquina conforma un excelente laboratorio natural para el análisis de los depósitos iniciales, donde participan sucesiones continentales y marinas, asociadas a volcanismo, acaecidas en el marco de conspicuos procesos tectónicos y magmáticos. Es en esta región donde se acuñaron términos frecuentemente mencionados en la correlación de la estratigrafía del Jurásico Inferior, tales como el "sañicolitense” (Lambert y Galli, 1950; Galli, 1954; Galli, 1969) o el "Jurásico marino de la Piedra Pintada” (Roth, 1899; Roth, 1902), en referencia a las acumulaciones volcánicas o a las sucesiones marinas más australes de la cuenca. En este trabajo se analiza la constitución de ese relleno volcánico y sedimentario y se integra dentro de la historia inicial de la Cuenca Neuquina.

\section{2) Marco geológico, estratigrafía y antecedentes}

\subsection{1) La Cuenca Neuquina}

La cuenca Neuquina es una cuenca de diseño triangular (fig. 1.1) que cubre una superficie de $160000 \mathrm{Km}^{2}$ (Yrigoyen, 1991). Está localizada al este de la cadena andina argentina entre $\operatorname{los} 32^{\circ}$ y $40^{\circ}$ de latitud S. Limita al noreste con el macizo de la Sierra Pintada y al sureste con el macizo Norpatagónico (Digregorio et al., 1984). Se trata de una cuenca ensiálica iniciada en el Triásico Superior-Jurásico Inferior por procesos acaecidos en el margen occidental de Gondwana (Uliana et al., 1989; Legarreta y Uliana, 1996; Franzese y Spalletti, 2001). Presenta una historia tectónica compleja íntimamente ligada al desarrollo de los Andes y a la geometría de la losa subductada (Ramos y Folguera, 2005). A lo largo de su evolución, la Cuenca Neuquina constituyó un área subsidente, registrándose una columna integrada de hasta $7000 \mathrm{~m}$ de sedimentos (Vergani et al., 1995) y $4000 \mathrm{~m}$ de sedimentos continuos (fig. 1.3) (Howel et al., 2005).

Desde el punto de vista geotectónico, la compleja evolución de la cuenca puede ser sintetizada en tres etapas (fig. 1.2) (Howel et al., 2005): 


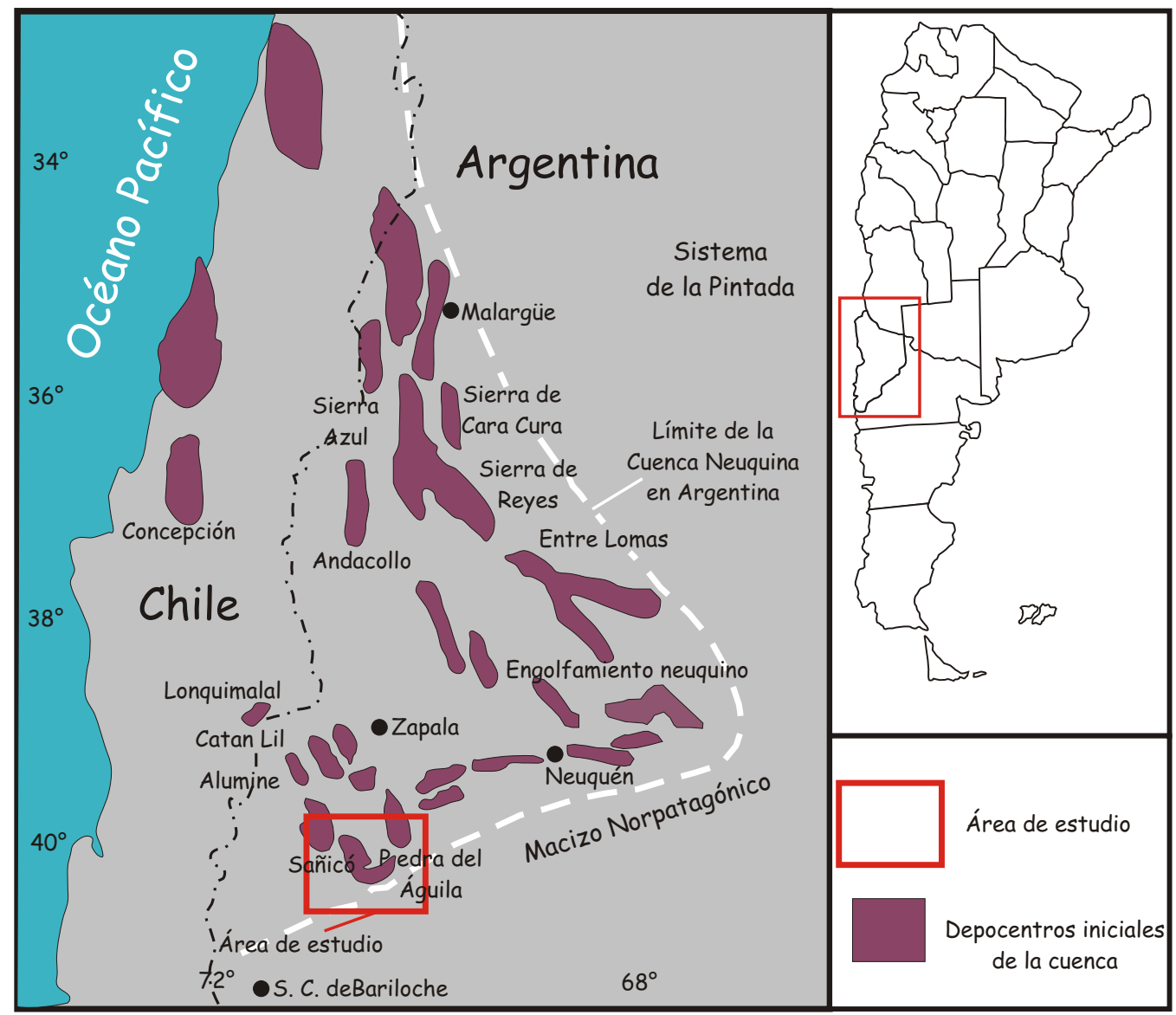

Figura 1.1. Ubicación de los depocentros iniciales de la Cuenca Neuquina tomada de Franzese y Spalletti (2001).

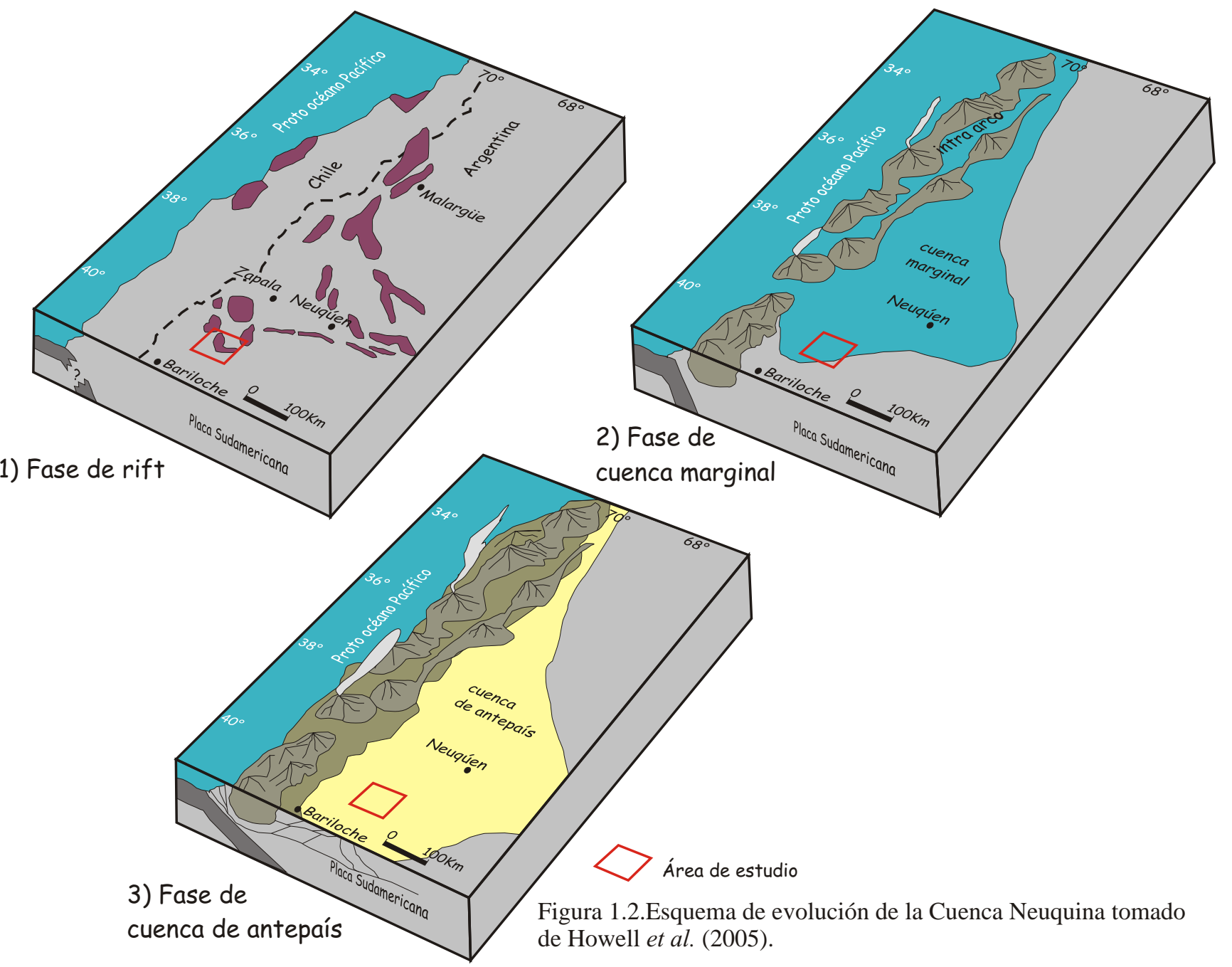


I) Etapa de Sinrift (Triásico Superior - Jurásico Inferior)

La Cuenca Neuquina fue originada en el Triásico Superior como resultado de una extensión intracontinental (Franzese y Spalletti, 2001). Algunos autores relacionaron el inicio de la cuenca con el desmembramiento del supercontinente Gondwana (Uliana et al., 1989), mientras que otros asociaron el periodo extensional Triásico Superior-Jurásico Inferior a la historia del margen activo pre-andino (Franzese y Spalletti, 2001; Franzese et al., 2003; Ramos y Folguera, 2005). La idea más aceptada actualmente es que el colapso extensional del orógeno paleozoico Superior (Uliana et al., 1989; Tankard et al., 1995) o la transición a una subducción de alto ángulo (Ramos, 2009), habrían producido los fenómenos extensionales que afectaron la zona intracontinental adyacente al margen occidental de Gondwana. Es importante destacar que diferentes autores consideraron que la Cuenca Neuquina se habría iniciado en un escenario de segmentación pre-andina (Franzese y Spalletti, 2001; Franzese et al., 2003), con subducción lenta o no subducción al norte de los $40^{\circ}$ de la latitud sur del margen occidental de Gondwana, y un segmento controlado por la subducción de la losa protopacífica que dio origen a un conjunto de batolitos y rocas volcánicas con características orogénicas al sur (Rapela y Pankhurts, 1992; Rapela et al., 2005).

Durante el Triásico Superior y el Jurásico Inferior, los procesos extensionales de intraplaca generaron un conjunto de rifts alargados que dieron origen Cuenca Neuquina (Vergani et al.,1995; Franzese y Spalletti, 2001). Se trata de depocentros con geometría de hemigraben rellenos por cientos de metros de espesor (fig. 1.3) (Uliana, et al., 1989; Legarreta y Uliana, 1996; Vergani et al., 1995). La mayoría de los depocentros muestran una historia relacionada con una profusa actividad magmática contemporánea. El relleno sintectónico de las cubetas iniciales, caracterizado por depósitos continentales volcánicos y piroclásticos con menor participación de facies sedimentarias, fue denominado bajo el nombre de Precuyano (Gulisano, 1981; Gulisano et al., 1984). Estudios desarrollados en el marco de tareas exploratorias identificaron al relleno precuyano en subsuelo y acotaron de manera más precisa las dimensiones de los rifts iniciales, los cuales presentan largos de $150 \mathrm{~km}$, anchos de $50 \mathrm{~km}$ y más de 2000 m de relleno (Legarreta y Gulisano, 1989; Uliana et al., 1989; Manceda y Figueroa, 1993; Vergani et al., 1995; Legarreta y Uliana, 1996). Los depocentros están bordeados por fallas normales lístricas o planares y compuestos por hemigrábenes subparalelos que presentan cambios de polaridad y grados variables de inversión, dependiendo de la posición de la cuenca en que se encuentren (Vergani et al., 1995). La presencia de discontinuidades y discordancias dentro de los depocentros han sido identificadas por varios autores, indicando periodos de reactivación tectónica durante la evolución de los hemigrábenes, las cuales controlaron la asimetría y la distribución de los ambientes depositacionales y sus facies (Franzese y Spalletti 2001; Franzese et al., 2006; Franzese et al., 2007). 
II) Etapa de Postrift (Jurásico Inferior-Cretácico Inferior)

En esta etapa los depocentros iniciales son integrados dentro de una única cuenca. De manera concomitante comienza a desarrollarse el arco magmático andino (Uliana et al., 1989; Franzese y Spalletti, 2001; Ramos y Folguera, 2005; Howel, 2005). La caída del nivel de base en respuesta a un aumento del nivel marino global y a la subsidencia térmica (Legarreta y Uliana, 1996), generó una transgresión marina diacrónica en toda la cuenca (Gulisano, 1981), comenzando en el Hettangiano en el norte y en el Pliensbachiano en el sur (Legarreta y Uliana, 1996). Con esta transgresión comenzó un periodo de sedimentación marina que dominó los ambientes depositacionales acaecidos durante el Jurásico e inicio del Cretácico. Se depositaron $4000 \mathrm{~m}$ de sedimentos (fig. 1.3), en forma de ciclos transgresivos-regresivos de diferentes órdenes, controlados por cambios en el nivel del mar, la subsidencia termal y procesos extensionales de retroarco (Howel et al., 2005). Los primeros ambientes sedimentarios marinocontinentales desarrollados durante la inundación de la cuenca estuvieron controlados fuertemente por la topografía de los grábenes iniciales (Legarreta y Uliana, 1996; Burguess, 2000). Este relleno, con espesores de centenares de metros, limitado en la base por la discordancia intraliásica y en el techo por la discordancia intracaloviana, fue definido como Ciclo Cuyano (Gulisano, 1981; Gulisano et al., 1984). Abarca un ciclo de sedimentación marina-continental, transgresivo-regresivo diacrónico, desarrollado entre lapso Hettangiano Calloviano medio (fig. 1.3) (Gulisano, 1981; Gulisano et al., 1984).

III) Etapa de compresión y cuenca de antepaís (Cretácico Superior-Cenozoico)

Hacia fines del Cretácico Inferior una horizontalización del ángulo de subducción generó un cambio hacia un régimen tectónico compresivo (Ramos, 1999). En este marco, se invirtieron muchas estructuras extensionales previas (Vergani et al., 1995) y se generó la transición desde una cuenca marginal a una cuenca de antepaís (Franzese et al., 2003). Esta etapa se caracterizó por la paulatina continentalización de los ambientes depositacionales, controlados mayoritariamente por una tectónica compresiva (Vergani et al., 1995; Franzese et al., 2003) y minoritariamente por periodos de relajación tectónica (Zapata y Folguera, 2005) e ingresiones marinas (Uliana y Biddle, 1988). Como resultado de los diferentes eventos de deformación dos regiones bien definidas pueden ser reconocidas dentro de la cuenca: los Andes Neuquinos, al oeste y el Engolfamiento Neuquino al este y sureste (Howell et al., 2005). La región andina se encuentra modelada por eventos de deformación del Cretácico Superior y Cenozoico, esbozados por el plegamiento, el fallamiento y la exposición superficial del registro mesozoico de la cuenca. La región del Engolfamiento Neuquino se caracteriza por presentar la mayoría del registro mesozoico de la cuenca en subsuelo, con y sin deformación. 


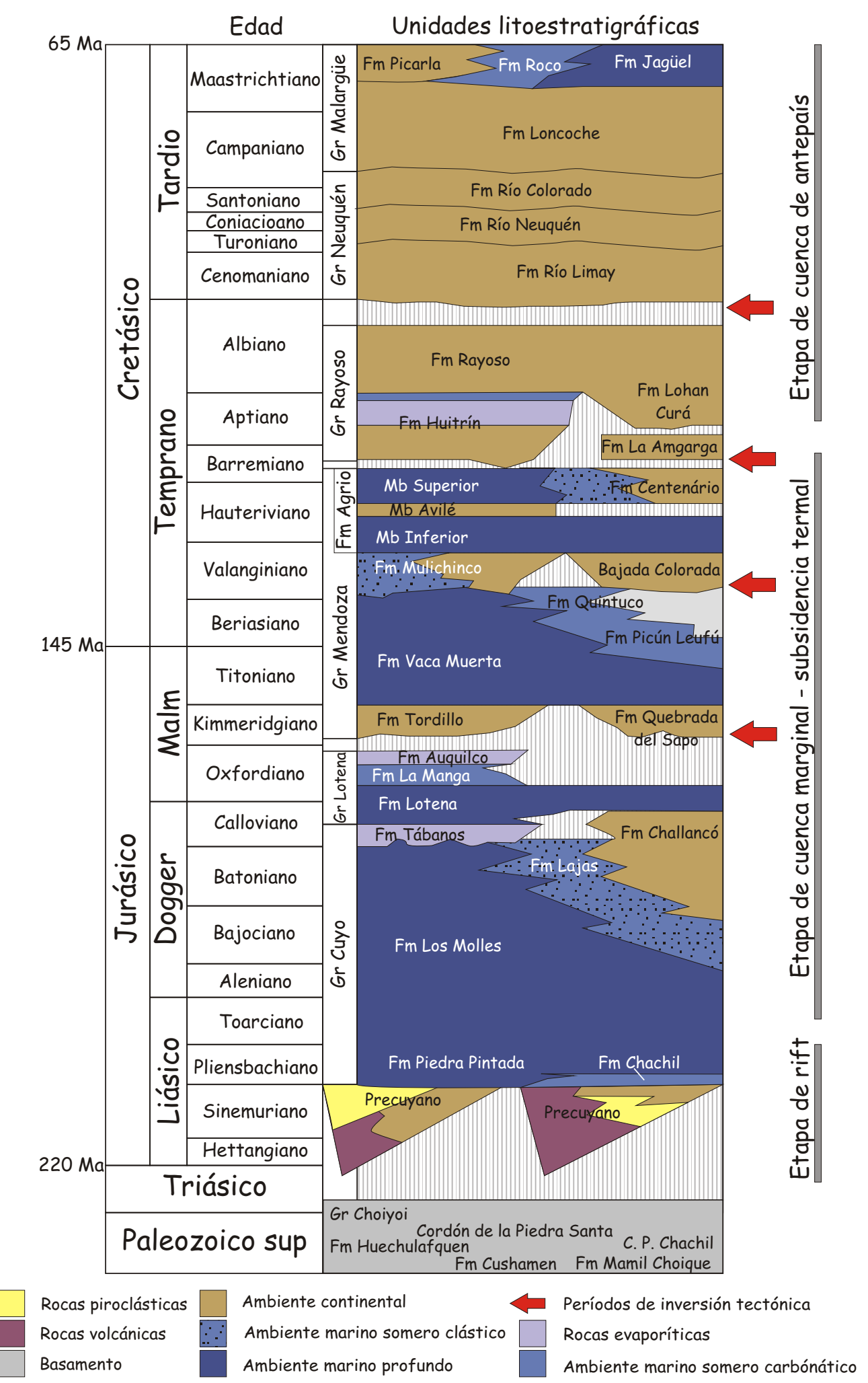

Figura 1.3. Columna estratigráfica integrada del relleno de la Cuenca Neuquina (modificada de Howell, 2005).

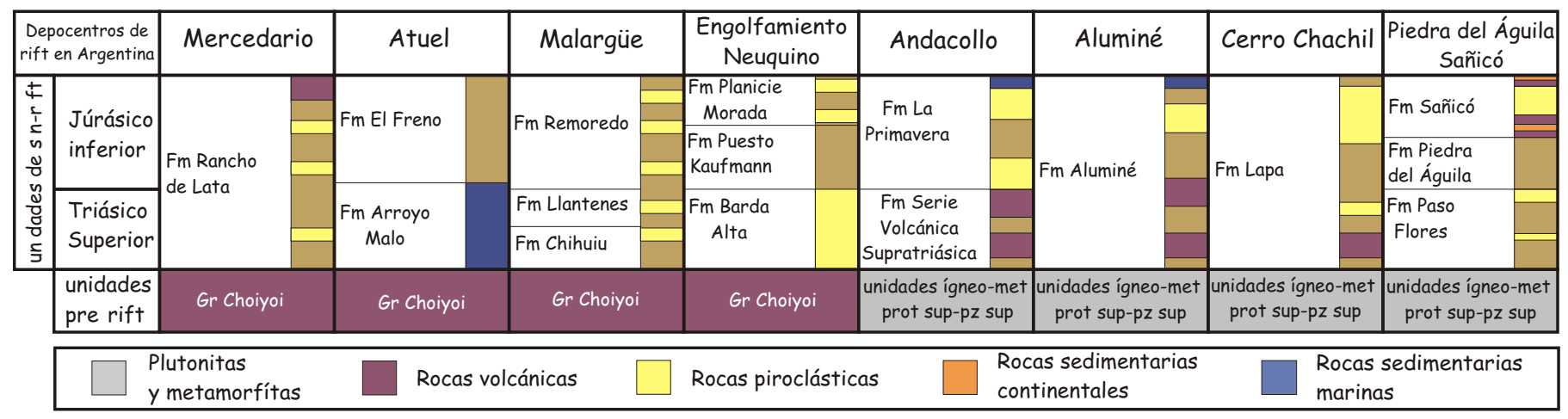

Figura 1.4. Unidades litoestratigráficas adjudicadas a los depósitos de sin-rift iniciales de la Cuenca Neuquina (tomado de Franzese y Spalletti, 2001). 
1.2.2) Relleno inicial de la Cuenca Neuquina: aspectos generales

El presente trabajo se centra en el estudio del relleno de la etapa extensional que dio origen a la cuenca y el inicio de la etapa subsiguiente, caracterizada por la transición a una cuenca marginal desarrollada sobre una litosfera que experimentaba una subsidencia térmica. Por tales razones, el siguiente texto se concentrará en establecer el marco estratigráfico y los antecedentes de los depósitos correspondientes al Ciclo Precuyano. Respecto al Ciclo Cuyano se tomará la definición original presentada en los párrafos anteriores (Gulisano, 1981; Gulisano et al., 1984).

\section{El Ciclo Precuyano}

El término "Precuyano" se utilizó por primera vez para referirse informalmente a un conjunto de rocas sedimentarias y piroclásticas del Jurásico Inferior que se desarrollaban entre el basamento y las sedimentitas del Ciclo Cuyano en el norte de la cuenca (Gulisano, 1981). Las mismas se definieron con geometría marcadamente irregular, de tipo cuña y espesores que alcanzan los $1000 \mathrm{~m}$. Posteriormente otros autores, en el marco de un estudio de estratigrafía secuencial desarrollado para la secuencia jurásica del oeste de la provincia del Neuquén, precisaron al Ciclo Precuyano (Gulisano et al., 1984). Estos depósitos yacen sobre la discordancia Supratriásica, apoyándose sobre las rocas que constituyen el basamento de la cuenca, mientras que el techo está limitado por la discordancia Intralíasica, por sobre la cual se apoyan las sedimentitas marinas del Ciclo Cuyano. Otros estudios posteriores basados en el análisis secuencial del relleno propusieron denominar a este tramo del relleno como Mesosecuencia Precuyo, en la base de la Supersecuencia Inferior de la Megasecuencia Neuquina (Legarreta y Gulisano, 1989). Asimismo otros autores, en el marco de unidades limitadas por discontinuidades, sugirieron al Subsintema Sañicó (Riccardi y Gulisano, 1990) como equivalente del Ciclo Precuyano. En su definición, el Ciclo Precuyano fue acotado al Jurásico Inferior (Hettangiano-Sinemuriano). A posteriori, las unidades que luego le fueron correlacionadas (véase párrafo subsiguiente) asignadas tanto al Triásico Superior como al Jurásico Inferior (fig. 1.4), lo circunscribieron a ese lapso (Gulisano, 1993).

En su definición original, las unidades litoestratigráficas que fueron integradas dentro del Ciclo Precuyano fueron netamente continentales, con una importante impronta del volcanismo (Fm. Remoredo, Fm. Planicie Morada, Fm. Piedra del Águila, Fm. Sañicó, y Fm. Lapa) (Gulisano et al., 1984). Posteriormente diferentes autores (Leanza, 1990; Gulisano y Gutiérrez Plieming, 1994; Legarreta y Uliana, 1996; Riccardi et al., 1997; Álvarez y Ramos, 1999; Franzese y Spalletti, 2001) integraron otras unidades litoestratigráficas dentro de los depósitos de sinrift inicial de la cuenca (fig. 1.4) - Fm. Puesto Kaufmann, Fm. Aluminé, Fm. Rancho de Lata, Fm. Barda Alta, Fm. El Freno, Fm. Arroyo Malo, Serie Porfírica Supratriásica, 
Fm. Paso Flores, Fm. Llantenes, Fm. Chihuiu -, aunque éstas nunca fueron incluidas formalmente dentro del Ciclo Precuyano. Es importante destacar que por su similitud litológica y problemas de índole terminológicos, en ocasiones se ha correlacionado o directamente denominado a los depósitos precuyanos como rocas del Grupo Choiyoi (p.e. Leanza, 1990; Gulisano y Gutiérrez Plieming, 1994). El término Supratriásico y posteriormente Choiyoilense (Groeber, 1918; Groeber, 1946) se utilizó para referirse a rocas de la provincia geológica de la Cordillera Frontal que posteriormente fueron acotadas al Pérmico Superior-Triásico Inferior. Por tales motivos Rolleri y Criado Roqué (1970) propusieron la denominación de Formación Choiyoi - posteriormente Grupo Choiyoi - para incluir a las volcanitas del Pérmico SuperiorTriásico Inferior, apartándose de la definición original. Las diferentes acepciones, sumado a la similitud litológica del Grupo Choiyoi con el Precuyano, han promovido un escenario confuso, en donde muchos autores han propuesto al Grupo Choiyoi como parte del relleno sintectónico inicial de la cuenca (p.e. Leanza, 1990). En el presente trabajo se tuvieron en cuenta las sugerencias de los autores (Franzese y Spalletti, 2001; Llambías y Stipanicic, 2002; Llambías et al., 2007) que propusieron restringir término Choiyoi a las volcanitas y granitoides permotriásicos aflorantes en la Cordillera Frontal y en la Precordillera.

Por último, hasta no ser corroboradas desde el punto de vista tecto-estratigráfico las características del relleno inicial de la cuenca, no se utilizarán términos genéticos para referirse a éste (p.e. secuencias de sinrift o postrift). Por otro lado, las reconocidas variaciones faciales dentro de los depocentros y las características disímiles que se presentan entre los depocentros, limitan utilización de las unidades litoestratigráficas. En este estudio se dividirá el relleno inicial con los términos de Ciclo Precuyano y Ciclo Cuyano.

Como se puede apreciar el marco geológico inicial de la Cuenca Neuquina es complejo y controversial, donde interaccionan el volcanismo, la sedimentación y diferentes eventos y tipos de subsidencia. Sin embargo, a pesar de que en tiempos recientes los esfuerzos exploratorios se han centrado en los depósitos iniciales de la cuenca (Pángaro et al., 2002a; Pángaro et al., 2002b; Bermúdez et al., 2002) y que ciertos depósitos del Ciclo Precuyano y el Cuyano Inferior actúan como roca madre y roca reservorio en diferentes distritos productores de la misma -distrito Catriel, Sur dorsal, Huincul y Estancia Vieja- (Pángaro et al., 2002a; Zumel, et al., 2002; Legarreta, et al., 2008), los trabajos conocidos no pueden vincularse en un análisis integrado. Algunas contribuciones se centran en el estudio desde el punto de vista meramente estratigráfico (Leanza, 1990; Leanza et al., 2005), mientras que los trabajos que abordaron la problemática inicial desde el punto de vista estructural y tectoestratigráfico son escasos (Álvarez et al., 1999; Franzese et al., 2006; Franzese et al., 2007; Muravchik et al., 2008; Giambiagi et al., 2008a; Giambiagi et al., 2008b; Giambiagi et al., 2008c) y en general no tienen en cuenta el 
las vinculaciones que existen entre la extensión y el volcanismo y el control que ejerce el volcanismo sobre los ambientes sedimentarios. Asimismo, los aportes desarrollados sobre el relleno inicial no analizan con la misma rigurosidad los depósitos sedimentarios y volcánicos, tratándose del Precuyano y los depósitos continentales y marinos de la transición entre el Precuyano y el Ciclo Cuyano (p.e. Gulisano y Pando 1981; Gulisano et al., 1984; Bermúdez et al., 2002).

\section{3) Objetivos}

El trabajo propuesto tiene como objetivo principal la caracterización tecto-estratigráfica del relleno correspondiente al período inicial de la Cuenca Neuquina en su sector sur (sur de la provincia del Neuquén y norte de la provincia del Río Negro) en un modelo integrado. La identificación de las variables que controlaron los estadios iniciales de la cuenca es uno de los objetivos más ambiciosos de este trabajo. Los resultados de la investigación serán cotejados con diferentes ejemplos desarrollados en el ámbito de la cuenca y con casos tomados como claves ocurridos en el mundo. Cabe remarcar que la metodología y la temática abordada en este trabajo se encuentran poco desarrolladas en el país. Además, desde el punto de vista de la industria petrolera, se pretende ofrecer un aporte importante al conocimiento del relleno volcánico en áreas de rift y la evolución de los depocentros iniciales de la cuenca.

La realización del presente trabajo avanza en los siguientes tópicos:

- Reconocer en detalle los diferentes componentes que integran el sinrift precuyano y el post rift inicial.

- Realizar una caracterización de los procesos depositacionales que integran las secuencias de estudio.

- Acotar los procesos depositacionales dentro de unidades de acumulación naturales existentes dentro del relleno y determinar los diferentes ambientes y subambientes depositacionales.

- Realizar un estudio litogeoquímico de las rocas del sinrift precuyano.

- Efectuar un modelo evolutivo integrado cotejando los ambientes depositacionales con las observaciones estratigráficas y estructurales.

- Establecer y estimar la influencia de las diferentes variables que controlaron la evolución del relleno de sinrift y la transición al postrift

- Identificar la relación existente entre las unidades de estudio y las unidades contemporáneas o cuasi-contemporáneas que se hallan en las inmediaciones de la zona de estudio y en el ámbito del Macizo Norpatagónico. 
- Comparar el modelo resultante con el de áreas adyacentes dentro de la cuenca y con los modelos de relleno de rift típicos del mundo.

\section{4) La zona de estudio}

1.4.1) Ubicación y características generales de la zona de estudio

El área de estudio se encuentra en la zona subandina desarrollada al este de los Andes Norpatagónicos, ubicada en el sector aledaño a las localidades de Piedra del Águila y Sañicó, cubriendo un área de aproximadamente $1600 \mathrm{~km}^{2}$. Está atravesada en sentido NE-SW por la ruta nacional $\mathrm{N}^{\circ} 237$, al oeste la ruta nacional $\mathrm{N}^{\circ} 40$, y en la parte central, comunicando a las anteriores, la ruta provincial $N^{\circ} 50$ (fig. 1.5). Limita al oeste con la Fosa de Collón Curá (Ramos, 1978), al norte con el sector más occidental del Engolfamiento Neuquino (Bracaccini, 1970) y al este y al sur con el Macizo Norpatagónico (fig. 1.6). Los rasgos estructurales más importantes de la zona de estudio son la presencia de fallas inversas, pliegues regionales y estructuras homoclinales, la mayoría oblicuas a la cadena andina, con rumbos preferentemente NE-SW (fig. 1.7). En las proximidades de estos elementos estructurales el relieve puede presentarse quebrado, pero saliendo de esos dominios, el relieve se presenta más bien llano u onduloso (fig. 1.10). Desde el punto de vista estratigráfico, afloran en la zona de estudio rocas del basamento ígneo-metamórfico, sedimentitas y volcanitas del Triásico Superior y Jurásico Inferior (fig. 1.7) y, por sobre las anteriores, sobre todo en la parte central y oriental del área de estudio, yacen extensas mesetas basálticas y depósitos cenozoicos (fig. 1.7).

\subsection{2) Estratigrafía pre-cenozoica del área de estudio}

El basamento de la zona de estudio está constituido por las metamorfitas de bajo grado de la Formación Cushamen (Volkheimer, 1964), los granitoides y metamorfitas de medio a alto grado de la Formación Mamil Choique (Sesana, 1968) y los granitoides, aplitas y pegmatitas Yuncón (Galli, 1969) (fig. 1.7). Tradicionalmente estas unidades han sido asignadas al Proterozoico Superior - Paleozoico Inferior por diferentes autores (Cingolani et al., 1991, Varela et al., 1991 y Linares et al., 1988), aunque estudios recientes indican una edad más joven (Paleozoica Superior) (Varela et al., 1994; Varela et al., 2005). A los fines prácticos estas formaciones fueron reunidas para este trabajo bajo la denominación informal de: basamento.

En la parte sur de la zona de estudio y al oeste de la localidad de Sañicó, faldeando el borde oriental de la Cuenca de Collón Curá, aflora la Formación Paso Flores (fig. 1.7) (Frenguelli, 1948). Está constituida mayoritariamente por areniscas arcósicas y conglomerados silicoclásticos y minoritariamente por rocas piroclásticas y pelitas (Galli, 1969). Presenta 


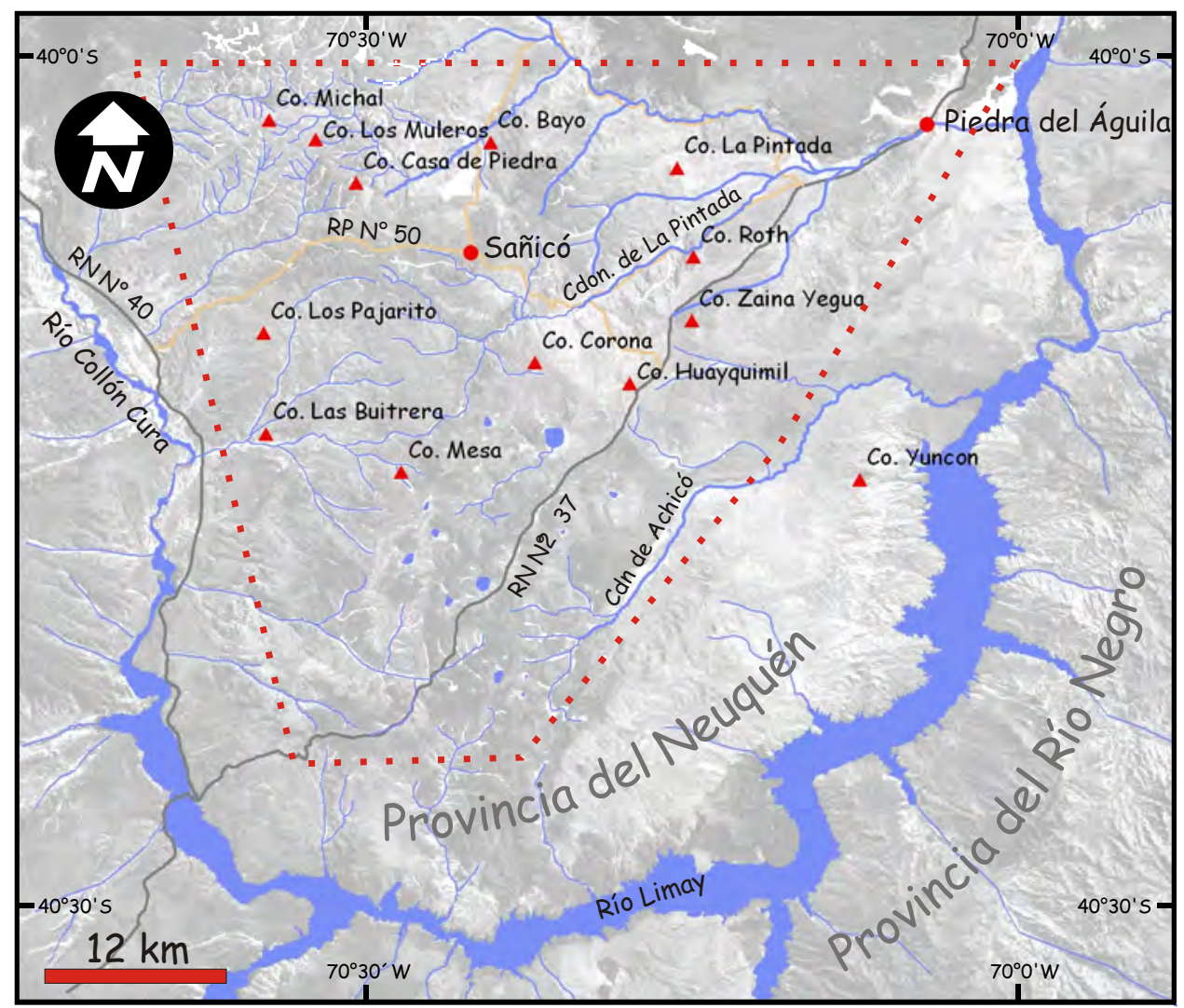

Figura 1.5. Ubicación del área de estudio.

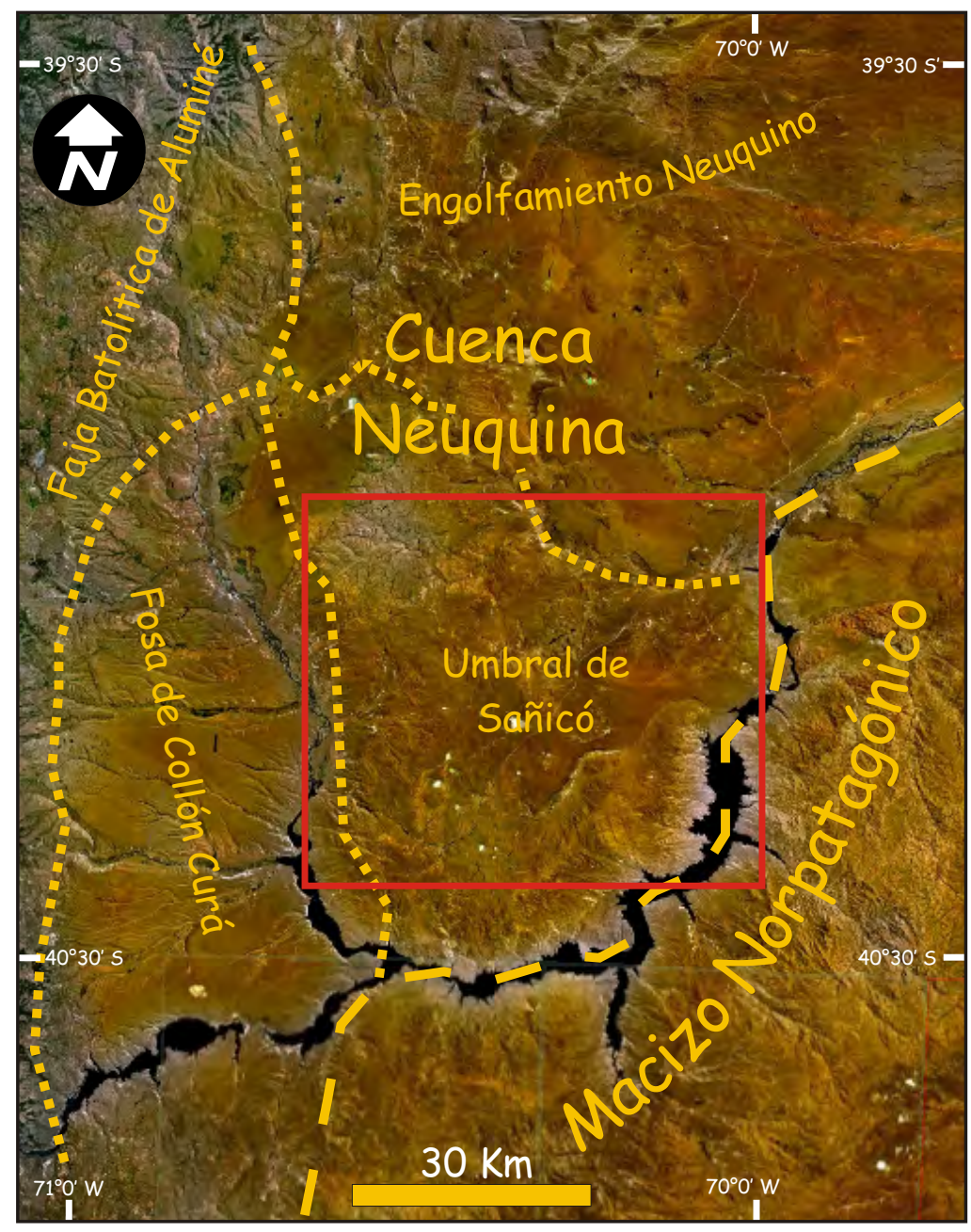

Figura 1.6. Unidades morfoestructurales presentes en el área de estudio (modificado de Ramos, 1978). 
abundante contenido fosilífero representado por una gran variedad frondas y troncos fósiles. Constituye una megasecuencia granodecreciente la cual se caracteriza en su porción basal por un ambiente entrelazado gravo-arenoso y un su porción cuspidal por un ambiente fluvial en una posición más distal, caracterizado por menor gradiente y menor canalización (Spalletti, 1994). En función de su contenido fosilífero ha sido posicionada por varios autores en el Triásico Superior (Morel y Ganuza, 2002 y las referencias allí citadas).

Los depósitos correspondientes al Ciclo Precuyano del área de estudio afloran preferentemente en dos sectores bien definidos (fig. 1.7): uno se encuentra entre la localidad de Piedra del Águila y el Cerro Zaina Yegua, y el otro, se halla en la zona de Sañicó entre el Cerro Corona, al sur y el Cerro Michal, al norte. Minoritariamente se encuentra expresado en el sur del área de estudio, en una posición meridiana, recostado en la parte oriental de un alto de basamento ubicado en sentido N-S al occidente (fig. 1.7). Las rocas del Ciclo Precuyano se apoyan tanto sobre las rocas del basamento cristalino, como sobre las rocas de la Formación Paso Flores, aunque se debe destacar que sólo lo hacen sobre estas últimas en la parte occidental del área de estudio (fig. 1.7). Desde el punto de vista litoestratigráfico, Gulisano y Pando (1981) y Gulisano et al. (1984) integraron a los depósitos de la Formación Piedra del Águila y de la Formación Sañicó dentro del Ciclo Precuyano (fig. 1.7). La Formación Piedra del Águila fue definida por Ferello (1947). Se conocen para ésta sólo descripciones muy generales, en las que se destaca su composición silicoclástica, con participación de conglomerados, areniscas arcósicas, y "arcillas” arenosas micáceas y ferríferas, a las que se asocian capas de tobas de diversas tonalidades (Ferello, 1947; Galli, 1954; Galli, 1969). De acuerdo a estos autores, el espesor de la Formación Piedra del Águila es inferior a los 100 m. Apoya sobre el basamento cristalino y es cubierta por la Formación Sañicó. Se ha indicado para la Formación Piedra del Águila la presencia de restos vegetales que han permitido acotarla al Jurásico Inferior (Ferello 1947).

La Formación Sañicó fue concebida inicialmente como un conjunto de rocas que integraban la Serie Porfirítica Supratriásica, posteriormente denominada como Choyoilitense (Groeber, 1929; Groeber, 1956). Otros autores al revisar la geología del área de Piedra del Águila y Sañicó concluyeron que las porfiritas representaban rocas del Jurásico Inferior, denominado a éstas como "Sañicolitense” (Lambert y Galli, 1950; Galli, 1954; Galli, 1969). La denominación formal de Formación Sañicó corresponde a Stipanicic (1967) y Stipanicic et al., (1968), quienes en función de su posición litoestratigráfica la acotaron entre el Hettangiano y el Sinemuriano (fig. 1.7). La Formación Sañicó representa casi en su totalidad al Ciclo Precuyano del área de estudio (fig. 1.8). En el extremo occidental se apoya sobre el basamento cristalino y de manera concordante o discordante sobre la Formación Paso Flores, mientras que en la región 


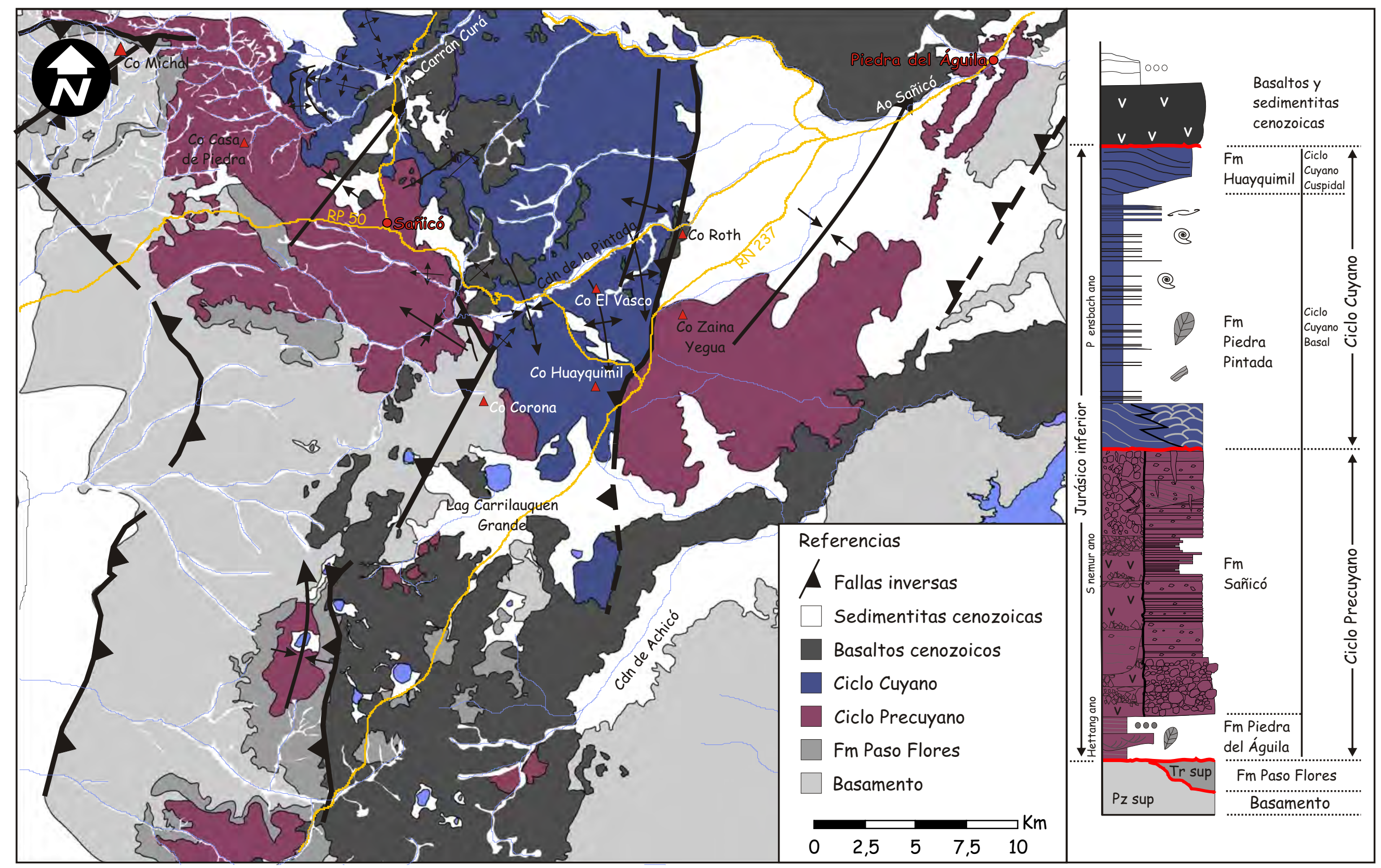

Figura 1.7. Mapa geológico del área de Sanicó y Piedra del Águila modificado de Galli (1969). Esquema estratigráfico modidicado de Gulisano y Pando (1981) y Cucchi et al. (1998)`3 
de Piedra del Águila yace sobre el basamento cristalino y en discordancia por sobre los escasos afloramientos de la Formación homónima. Se expone con espesores que van desde los pocos metros a centenas de metros. Está compuesta principalmente de rocas lávicas de composición andesítica, rocas piroclásticas de composición riodacítica y minoritariamente rocas sedimentarias resultado del retrabajo de las anteriores (fig. 1.7).

El Ciclo Cuyano de esta localidad fue previamente distinguido como: "sedimentos marinos de la Piedra Pintada (Roth, 1899), Lias de la Piedra Pintada (Roth, 1902), Serie Marina Piedra Pintada (Leanza, 1942), Formación Piedra Pintada (Herbst, 1966; Stipanicic et al., 1968; Stipanicic, 1969) y Cuyano Inferior (Galli, 1969). Este último autor a su vez lo subdivide en: “sedimentos marinos” y "rocas píroclásticas”. Subsiguientemente, estos dos términos fueron correlacionados con la Formación Los Molles y la Formación Lajas del Ciclo Cuyano por Gulisano y Pando (1981) y denominados como Formación Piedra Pintada y Formación Huayquimil por Cucchi et al. (1998). Las rocas del Ciclo Cuyano aparecen en un afloramiento de forma triangular en el centro-norte del área de estudio (fig. 1.7). A pesar de que varios autores han definido una relación tectónica entre las rocas de este ciclo y el Ciclo Precuyano, en el presente trabajo se ha constatado que la misma descansa de manera discordante sobre los depósitos precuyanos y el basamento cristalino. Asimismo, se ha verificado que los afloramientos del Ciclo Cuyano corresponden a la distribución acotada por Galli (1969) para la Formación Piedra Pintada, y que de ninguna manera las rocas del Ciclo Cuyano afloran en las inmediaciones de Piedra del Águila como fue propuesto por Gulisano y Pando (1981). Según Galli (1969) el espesor de estos depósitos no superaría los 500 m, mientras que Damborenea et al. (1975) han medido en el Cañadón de la Pintada, 300 m en el Cerro Vasco y 150 m en el Cerro Roth. A grandes rasgos las rocas del Ciclo Cuyano de esta localidad están constituidas por areniscas tobáceas, pelitas oscuras, calizas estromatolíticas y minoritariamente conglomerados. Presentan abundantes restos de briznas vegetales, troncos y abundantes restos de invertebrados marinos, entre ellos los más destacados son bivalvos (fig. 1.7) (Galli, 1969; Damborenea et al., 1975; Gulisano y Pando, 1981; Damborenea y Manceñido, 1993). Con respecto a la edad, en función de su contenido fosilífero el Ciclo Cuyano de esta localidad ha sido acotado al Pliensbachiano (fig. 1.7) (Damborenea et al., 1975). Hacia el norte, fuera del área de estudio, los depósitos cuyanos son cubiertos por rocas de la Formación Carrín Curá (Leanza et al., 1978) de edad Titoniana, la cual pasa transicionalmente a la Formación Vaca Muerta del Grupo Mendoza (Volkheimer y Quattrocchio, 1975). En el presente trabajo los depósitos del Ciclo Cuyano de manera informal se subdividirán en: Cuyano basal - Sedimentos Marinos” (Galli, 1969), Formación Molles (Gulisano y Pando, 1981), Formación Piedra Pintada (Cucchi et al., 1998) - y Cuyano cuspidal - "Rocas Piroclásticas (Galli, 1969), Formación Lajas (Gulisano y Pando, 1981), Formación Huayquimil (Cucchi et al., 1998) -. 
1.4.3) Estratigrafía cenozoica del área de estudio

Las unidades post-mesozoicas del área de estudio han sido integradas bajo la denominación de sedimentitas cenozoicas y basaltos cenozoicos (fig. 1.7). Es importante destacar que generalmente tanto las sedimentitas cenozoicas como los basaltos cenozoicos no se observan deformados. La excepción, la constituyen unas rocas tobáceas de color amarillento que corresponden a la parte inferior de la Formación Collón Curá (Kraglievich, 1930) y unos basaltos olivínicos que corresponden a la Formación Cerro Petiso (Rolleri et al., 1976). Debido a que estas dos unidades serán utilizadas posteriormente para acotar la última deformación en el área de estudio, se avanzará de manera breve en su caracterización. Las sedimentitas tobáceas colloncurenses fueron encontradas inclinadas y en ocasiones conformando discordancias progresivas en la localidad de Piedra del Águila, al norte del Cerro Zaina Yegua y al norte de Sañicó, en el Cerro Bayo (fig. 1.8). Por encima de estas facies, en las últimas dos localidades, se encontraron en posición horizontal o subhorizontal depósitos ignimbríticos (fig. 1.8) que fueron correlacionados con facies piroclásticas de la Formación Collón Curá por Nullo (1979). Con respecto a su edad, si bien la Formación Collón Curá en el área de estudio fue acotada por Cucci et al., (1998) al Mioceno medio-superior, dataciones realizadas sobre la sección media en zonas vecinas, permitirían acotar la edad de estos depósitos entre los 13, 8 y los 16 ma (Marshall et al., 1977; Mazzoni y Benvenuto, 1990), es decir Mioceno medio. Los basaltos de la Formación Cerro Petiso fueron hallados inclinados al norte del Cerro Corona y al este del Cerro Roth (fig. 1.9). Fuera del área de estudio Nullo (1979) ha datado a coladas basálticas equivalentes en 21 ma (Mioceno Inferior).

\subsection{4) Rasgos morfoestructurales y estructurales del área de estudio}

El área de interés se halla localizada dentro de un sector muy particular de la geología Neuquina, el cual fue denominado Umbral de Sañicó (fig. 1.6) para referirse a un área en la que asoman esencialmente las unidades más antiguas de la cuenca, en particular el basamento ígneo-metamórfico y el relleno inicial (Ramos, 1978). Estas características anuncian el predominio de una tectónica fuertemente controlada por el basamento, con algunas particularidades respecto a las áreas circundantes. Al norte del área de estudio se halla la parte más occidental del Engolfamiento Neuquino (fig. 1.6), el cual presenta un potente registro de las secuencias mesozoicas de la cuenca. Al sur y al este del Río Limay se sitúa el Macizo Norpatagónico (fig. 1.6), donde prácticamente no hay registro de las unidades correspondientes a la Cuenca Neuquina. Ramos (1978) propone al Río Limay como una importante zona de fractura que controló la distribución de las unidades de la Cuenca Neuquina hacia el sur. Esta zona de fractura de rumbo preferencial $\mathrm{N} 45^{\circ} \mathrm{E}$ se destaca por afloramientos elevados del basamento, con alturas de entre 800 y 900 m, alcanzando alturas 


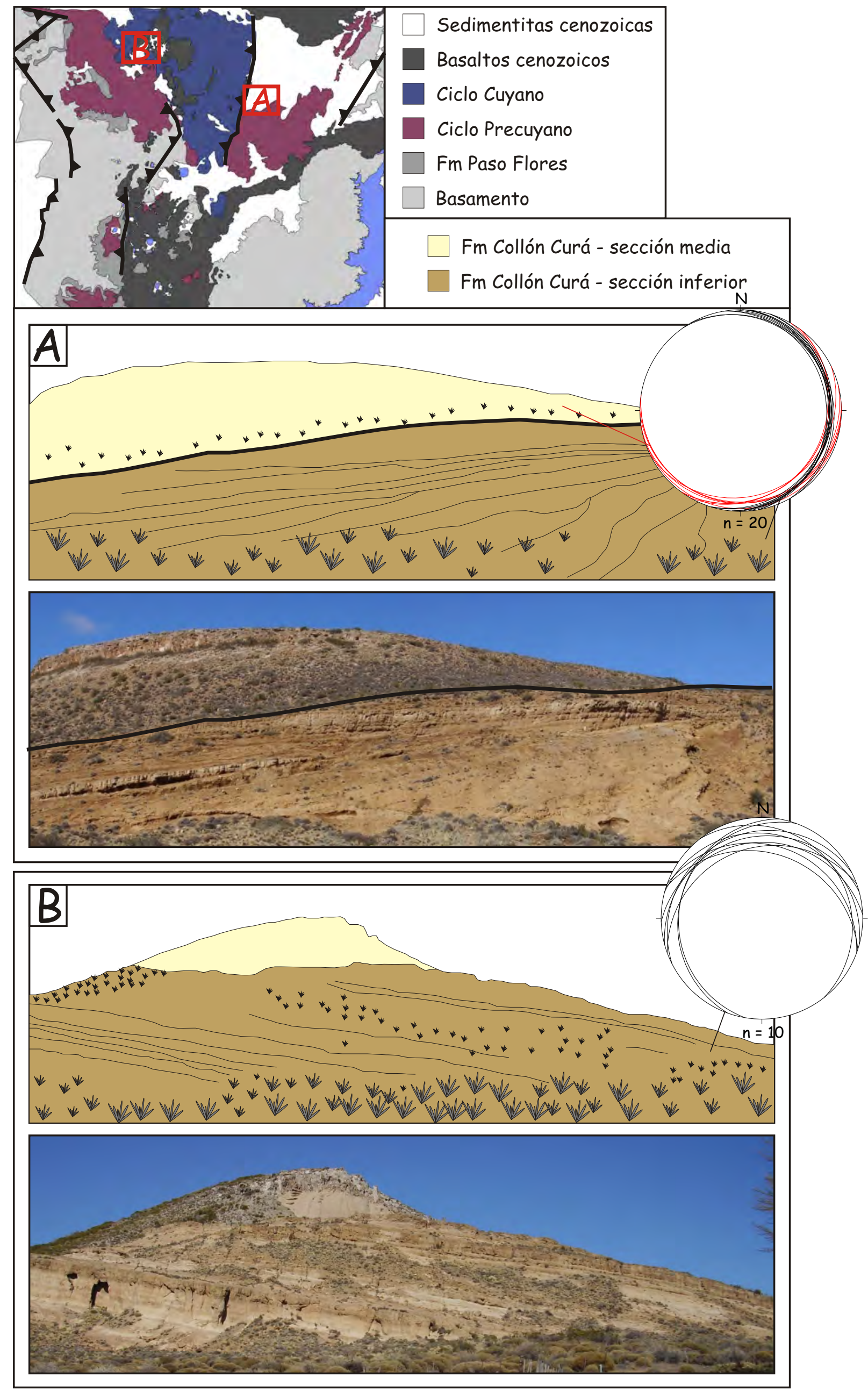

Figura 1.8. Se muestran los depósitos cenozoicos deformados de la Fm Collón Curá aflorantes al norte del $\mathrm{C}^{\circ}$ Zaina Yegua, en la Ea. Yuncón (A) y al norte de Sañicó, en el Cº Bayo (B). 

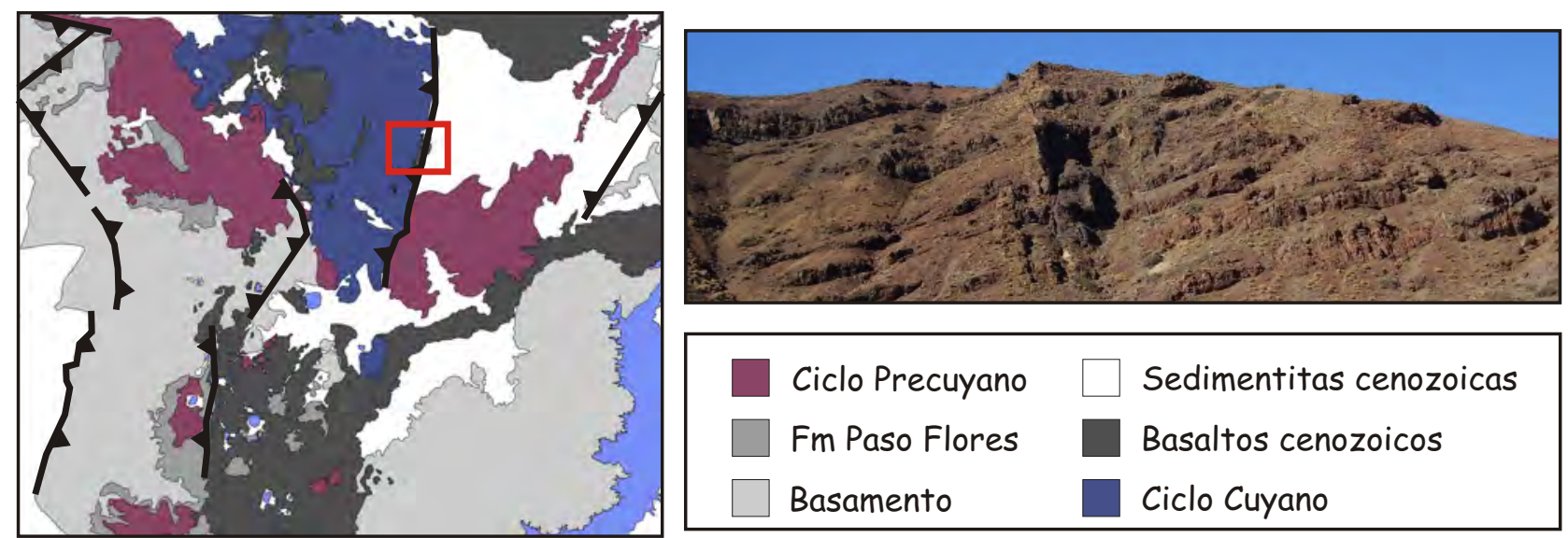

Figura 1.9. Secuencia de basaltos cenozoicos deformados, constituyendo el flanco oeste del $C^{\circ}$ Roth.

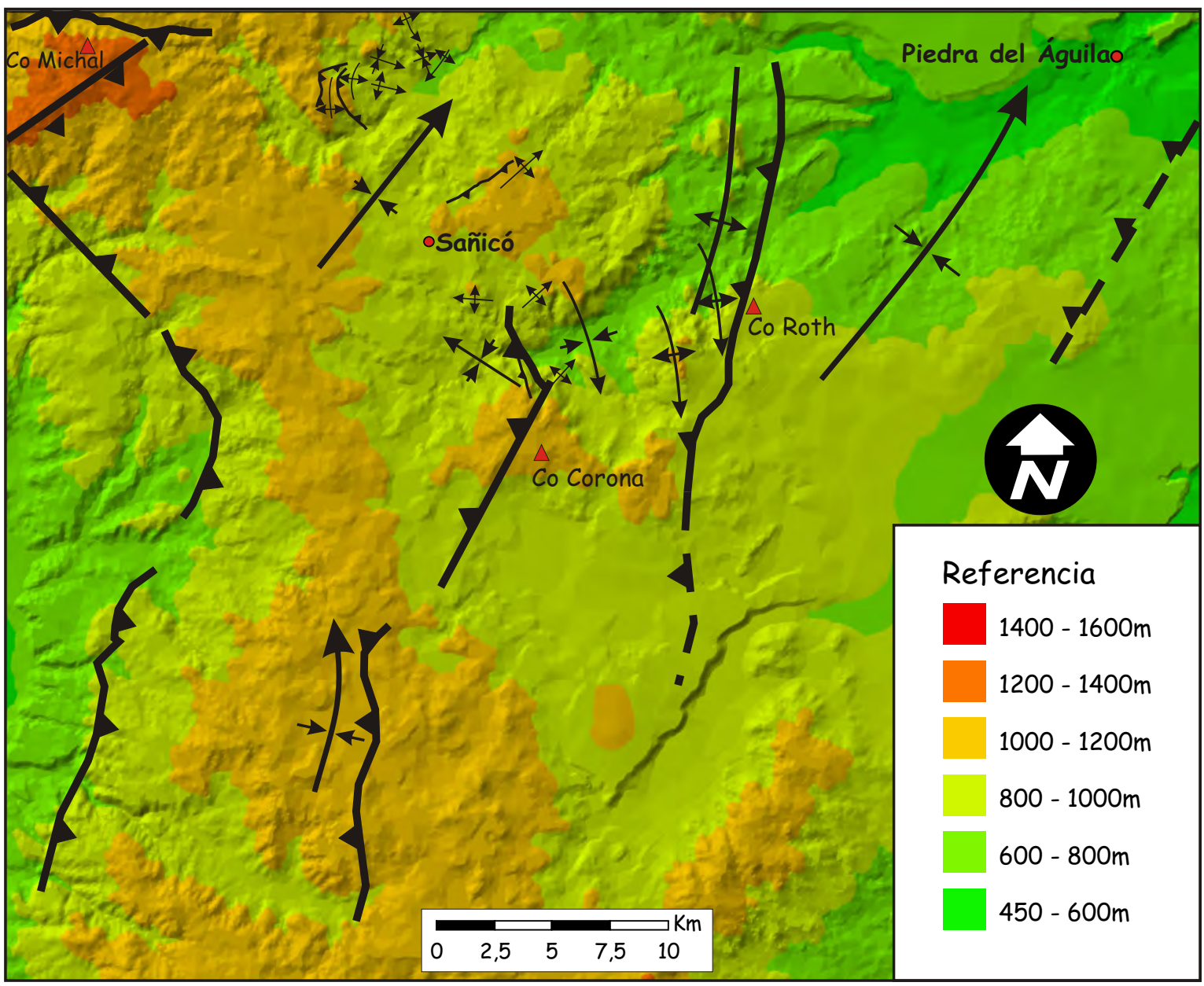

Figura 1.10. Modelo de elevación digital del área de estudio en donde se muestran las estructuras presentes. 
máximas que rondan los $1100 \mathrm{~m}$ (fig. 1.10). El borde occidental de la zona de estudio se caracteriza por otro alto de basamento conformado por un conjunto de fallas inversas con rumbos variables entre $\mathrm{N} 15^{\circ} \mathrm{E} \mathrm{y} \mathrm{N} 30^{\circ} \mathrm{W}$ (fig. 1.7), alturas promedios de $900 \mathrm{~m}$ y alturas máximas que rondan los $1200 \mathrm{~m}$ (fig. 1.10). Es importante destacar que este alto de basamento conforma el límite oriental de la Cuenca de Collón Curá que fue definida como una cuenca extensional por diferentes autores (Ramos, 1978; Ramos y Folguera, 2005, entre otros). En el presente trabajo, las observaciones recolectadas indican que el borde occidental del área de estudio está generado en el marco de una tectónica compresiva, tal como lo indican Giacosa y Heredia (2004) y Diraison et al. (1998). Entre las observaciones más relevantes se pueden mencionar: a) las secuencias mesozoicas y cenozoicas dentro del área de estudio no presentan evidencias de deformación extensional cenozoica, b) de manera contraria todas las evidencias de deformación post-jurásica responden a eventos compresivos (p.e. fallas inversas y pliegues), c) todos los depósitos cenozoicos del área de estudio se encuentran albergados en pequeños depocentros asociados a estructuras compresivas, y d) en sentido meridional, sólo 30 $\mathrm{km}$ al norte del área de estudio, fueron descritas cubetas neógeneas asociadas a fallas inversas y pliegues (Cobbold y Rossello, 2002; D’Elia et al., 2008; García Morabito y Ramos, 2008, entre otros).

Dentro del área de estudio los rasgos morfoestructurales más importantes son la presencia de fallas inversas, pliegues regionales, en ocasiones con basamento emergente y estructuras homoclinales (fig. 1.7 y 1.10). Estas estructuras generalmente se presentan oblicuas a la cadena andina, con rumbos preferentemente NE-SW y ENE-WSW. Minoritariamente se encontraron estructuras de orientaciones aproximadas N-S. A partir de las diferencias morfoestructurales y estratigráficas que presenta el área de estudio claramente se puede dividir a ésta en tres sectores (fig. 1.7, 1.10 y 1.11): un sector oriental al que denominaremos "zona de Piedra del Águila”, un sector central, al que llamaremos “zona de la Pintada” y un sector occidental, el cual será designado como "zona de Sañicó”.

La zona de Piedra del Águila se destaca por afloramientos de rocas precuyanas con espesores que superan los $1500 \mathrm{~m}$ (véase anexo I) que se apoyan sobre un basamento con relieve llano u onduloso. En este sector las rocas del Ciclo Precuyano son levantadas en forma de afloramientos homoclinales de rumbo NE-SW que inclinan entre $40^{\circ}$ y $70^{\circ}$ hacia el noroeste (fig. 1.7). A pesar de la importante deformación que sufren estos depósitos, el resalto topográfico generado apenas alcanza los $100 \mathrm{~m}$. Hacia el oeste y noroeste las capas se sumergen debajo de depósitos cenozoicos en una estructura sinclinal de eje NE-SW que buza al noreste (fig. 1.7 y 1.11). El flanco occidental de este sinclinal aflora en el Cerro Zaina Yegua donde las capas yacen con rumbo NE-SW, inclinando hacia el sureste.

La zona de la Pintada se caracteriza por una estructura anticlinal de carácter regional de 

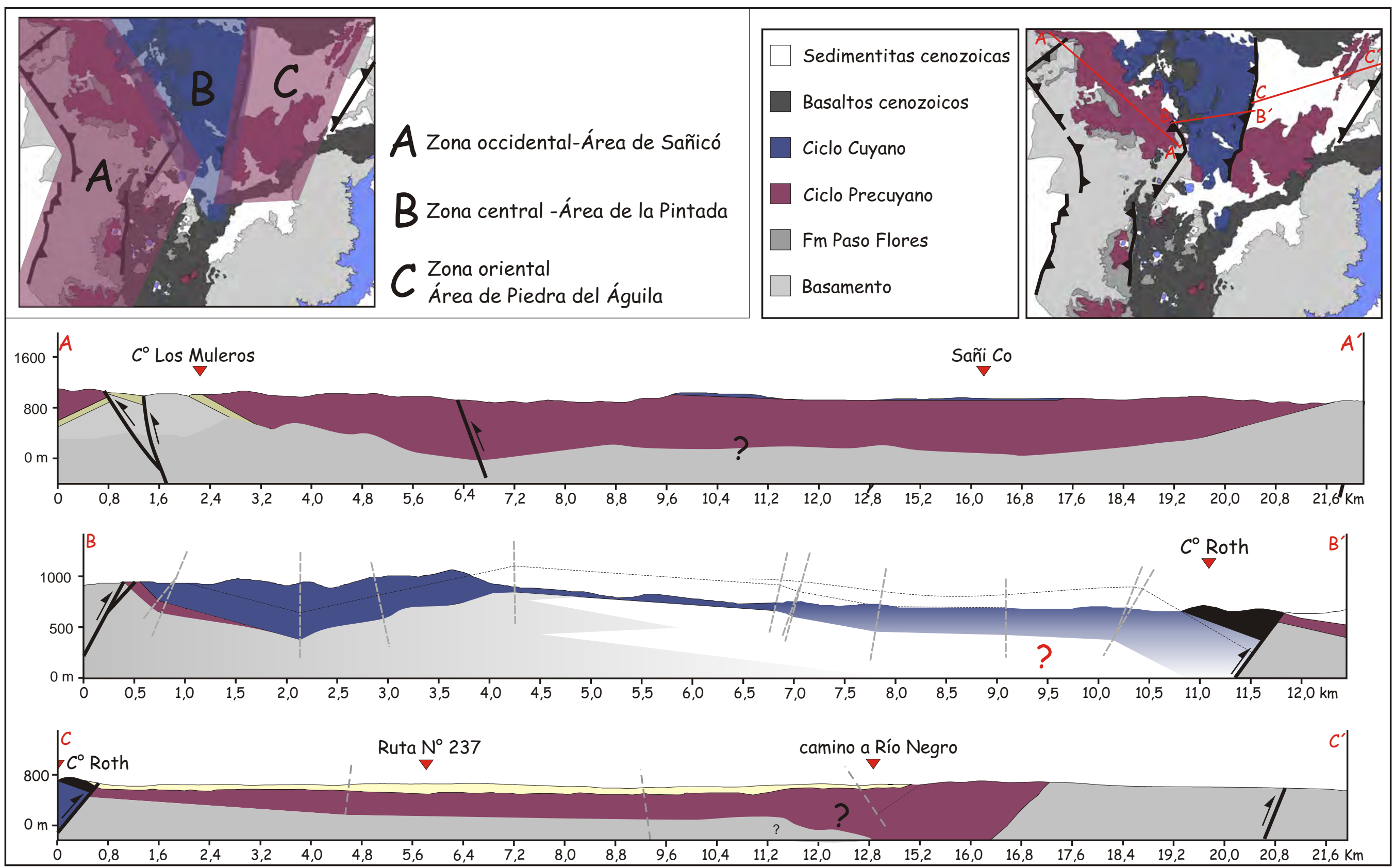

Figura 1.11. Principales diferencias morfoestructurales y estratigráficas presentes en el área de interés. 

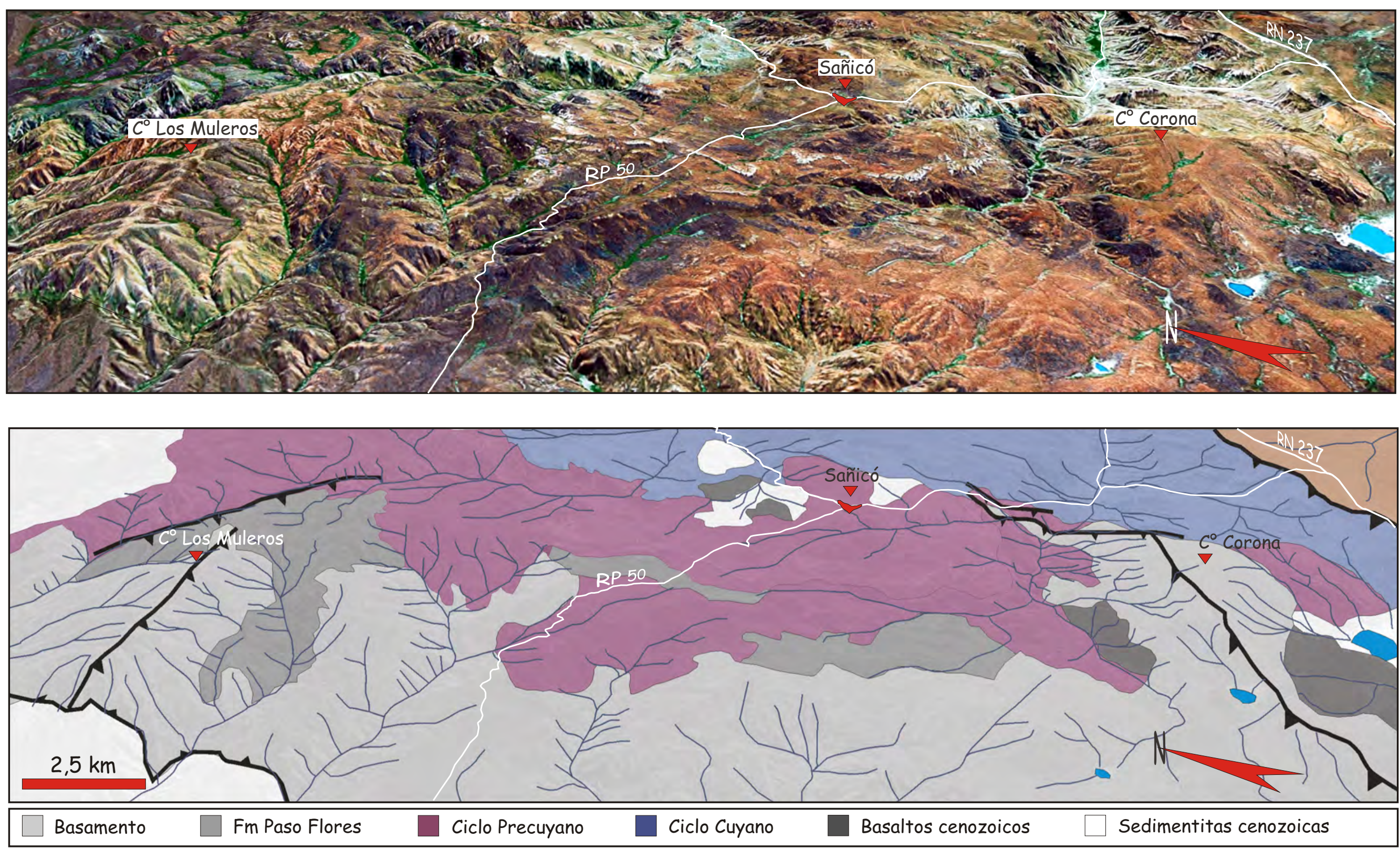

Figura 1.12. Vista 3D donde se muestran las características morfoestructurales y estratigráficas presentes en el área de Sañicó. 
vergencia hacia el este que en sector de mayor envergadura tiene $12 \mathrm{~km}$ de ancho (fig. 1.11). Se presenta con rumbo aproximado N-S y está labrada exclusivamente sobre depósitos del Ciclo Cuyano (fig. 1.7). Al oeste los depósitos cuyanos se apoyan en discordancia sobre rocas del basamento y del Ciclo Precuyano (fig. 1.7), conformando una parte del flanco oriental del anticlinal regional austral del área de Sañicó (véase párrafo subsiguiente). Al este las capas del Ciclo Cuyano que conforman el flanco oriental del pliegue alcanzan inclinaciones que rondan los $40^{\circ}$, éstas abruptamente se apoyan en contacto tectónico sobre las rocas del Ciclo Precuyano y son cubiertas en discordancia por basaltos cenozoicos (fig. 1.7 y 1.11). Esta relación se puede apreciar muy bien en las proximidades del Cerro Roth y Cerro Zaina Yegua. Se trata de una falla inversa de unos $23 \mathrm{~km}$ de largo, con rumbo variable entre N-S y NNE y una inclinación hacia el oeste (fig. 1.7). Dentro la estructura anticlinal regional se presentan pliegues menores, tanto paralelos al rumbo del pliegue mayor, como oblicuos a éste, con ejes de rumbo NW-SE.

Los rasgos morfoestructurales más destacados del área de Sañicó son dos anticlinales que conforman las secuencias del Ciclo Precuyano, los cuales se presentan con rumbos principalmente NE-SW y NNW-SSE, desarrollando un sinforme de unos $12 \mathrm{Km}$ de largo (fig. 1.7, 1.11 y 1.12). El anticlinal más septentrional se manifiesta como una zona elevada (fig. 1.10) ( $\mathrm{C}^{\circ}$ Michal -1330 m-) que corresponde a un anticlinal emergente en donde yacen rocas del basamento, de la Formación Paso Flores y del Ciclo Precuyano (fig. 1.13). Presenta un eje de orientación NE-SW, con inmersión hacia el NE, levemente curvado hacia el ENE, mostrando vergencia hacia el noroeste. Su flanco NW-N presenta inclinaciones de hasta $53^{\circ}$, mientras que el flanco sureste tiene inclinaciones mucho más suaves de entre $32^{\circ}$ y $17^{\circ}$. Sobre éste se desarrollan fallas inversas de alto ángulo, con rumbos N-S a NNW-SSE, de escaso rechazo que originan pliegues por propagación de falla (fig. 1.14). El anticlinal más austral representa otro rasgo elevado (fig. 1.10) ( $\mathrm{C}^{\circ}$ Corona $-1149 \mathrm{~m}$-). Corresponde a un anticlinal emergente en donde afloran rocas del basamento, del Ciclo Precuyano y del Ciclo Cuyano en uno de sus flancos (fig. 1.7 y 1.12). Su eje se presenta con direcciones NNE-SSW, con desviaciones hacia el N-S en su parte más septentrional, con vergencia hacia el sureste y el este. Su flanco noroeste tiene inclinaciones de entre $23^{\circ}$ y $9^{\circ}$, mientras que su flanco ESE - E corresponde a una estructura compleja, en donde conjuntamente con las rocas del Ciclo Precuyano, en discordancia se encuentran las rocas del Ciclo Cuyano. Además, este flanco está atravesado por fallas inversas de rumbo NNW-SSE que se interceptan con el rumbo regional del eje del pliegue, llegando a inclinar las capas hasta $60^{\circ}$ hacia el este (fig. 1.15). El sinclinal que se forma entre los dos anticlinales anteriormente descriptos, presenta un eje de orientación NE-SW, sobre su eje afloran rocas del Ciclo Precuyano con alturas que rondan entre 900 y 800 m (fig. 1.7 y 1.10). A pesar de levantarse más $1000 \mathrm{~m}$ el nivel estructural de las secuencias iniciales, el resalto topográfico que existe en ambas estructuras descriptas, como máximo alcanza unos $300 \mathrm{~m}$. 

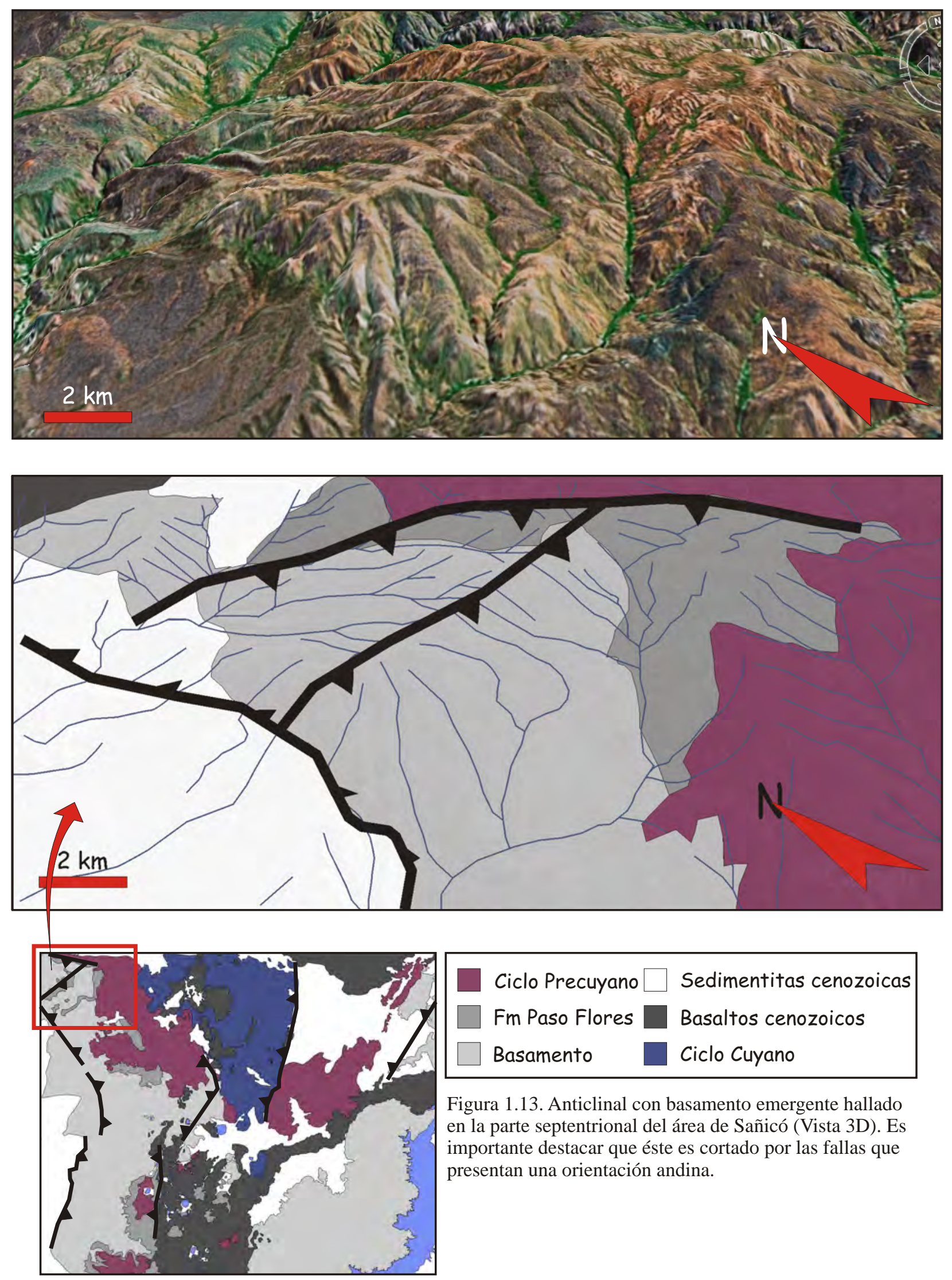

Figura 1.13. Anticlinal con basamento emergente hallado en la parte septentrional del área de Sañicó (Vista 3D). Es importante destacar que éste es cortado por las fallas que presentan una orientación andina. 
También se aprecia que la fallas inversas de rumbo NNE-SSW y NNW-SSE que limitan al occidente el área de estudio, cortan el anticlinal septentrional de eje NE-SW (fig. 1.12 y 1.13), alabeando hacia este las estructuras presentes en la zona de Sañicó (fig. 1.7).

A modo de corolario, es evidente que la zona de estudio presenta rasgos de una tectónica compresiva, en donde los depósitos más antiguos de la Cuenca Neuquina fueron deformados y levantados. Siguiendo la definición de inversión tectónica de Coward (1994), quien se refiere a este término para describir regiones en las que ha habido un cambio desde zonas que fueron subsidentes a elevadas, es indudable que la zona de análisis ha sufrido procesos de inversión tectónica positiva.

El control cronoestratigráfico de la deformación puede realizarse teniendo en cuenta las unidades neógenas del área de estudio (fig. 1.8 y 1.9). El límite inferior de la misma puede ser acotado al Mioceno Inferior alto, teniendo en cuenta que se han encontrado deformados los basaltos de la Formación Cerro Petiso (21 Ma) y la unidad inferior de la Formación Collón Cura (<21 Ma), mientras que límite superior de la misma puede ser acotado por la unidad piroclástica media de la Formación Collón Curá, correspondiente al Mioceno medio (13,8 - 16 Ma). El timing de la deformación correspondería con la etapa de deformación Nazca (Mioceno medio y Mioceno superior) (Mosquera y Ramos, 2005). Fuera de la Cuenca Neuquina para el sector de los Andes Norpatagónicos comprendido ente los $41^{\circ}$ y $42^{\circ} \mathrm{S}$ se mencionan edades de deformación algo más jóvenes, acotadas al Mioceno superior - Mioceno/Plioceno (Giacosa y Heredia, 2004). Se puede concluir que la deformación del área de estudio estaría relacionada al evento deformacional de primer orden originado entre le Mioceno medio y el Mioceno superior que afecto a todo el margen chileno (Ramos, 1999). Cabe señalar que durante el OxfordianoKimmeridgiano un importante evento de inversión tectónica fue mencionado para la Cuenca Neuquina. El mismo generó más de 2000 m de erosión sobre las secuencias de sinrift y postrift cuyanas en el ámbito de la Dorsal de Huincul (Ploszkiewicz et al., 1984; Vergani et al., 1995). En este sentido, hay varias evidencias que indicarían que los anticlinales emergentes, desarrollados en el área de Sañicó y las capas monoclinales aflorantes en el área de Piedra del Águila, estarían en parte relacionadas a la inversión málmica. Por un lado, las orientaciones NESW y ENE y WSW de estas estructuras son muy similares a las encontradas en algunos sectores de la Dorsal de Huincul. Por otro lado, con respecto a su nivel estructural, el levantamiento que sufren los depósitos iniciales de la cuenca es del orden de miles de metros, inclusive llegando a exponer el basamento cristalino. Sin embargo, el resalto topográfico generado por estas estructuras por sobre el nivel de base local, es de 300 m en el área de Sañicó y de tan sólo 100 m en el área de Piedra del Águila. Estas observaciones reflejarían que los anticlinales emergentes y las capas monoclinales pertenecerían a paisajes geomorfológicos modelados por movimientos tectónicos preterciarios. 

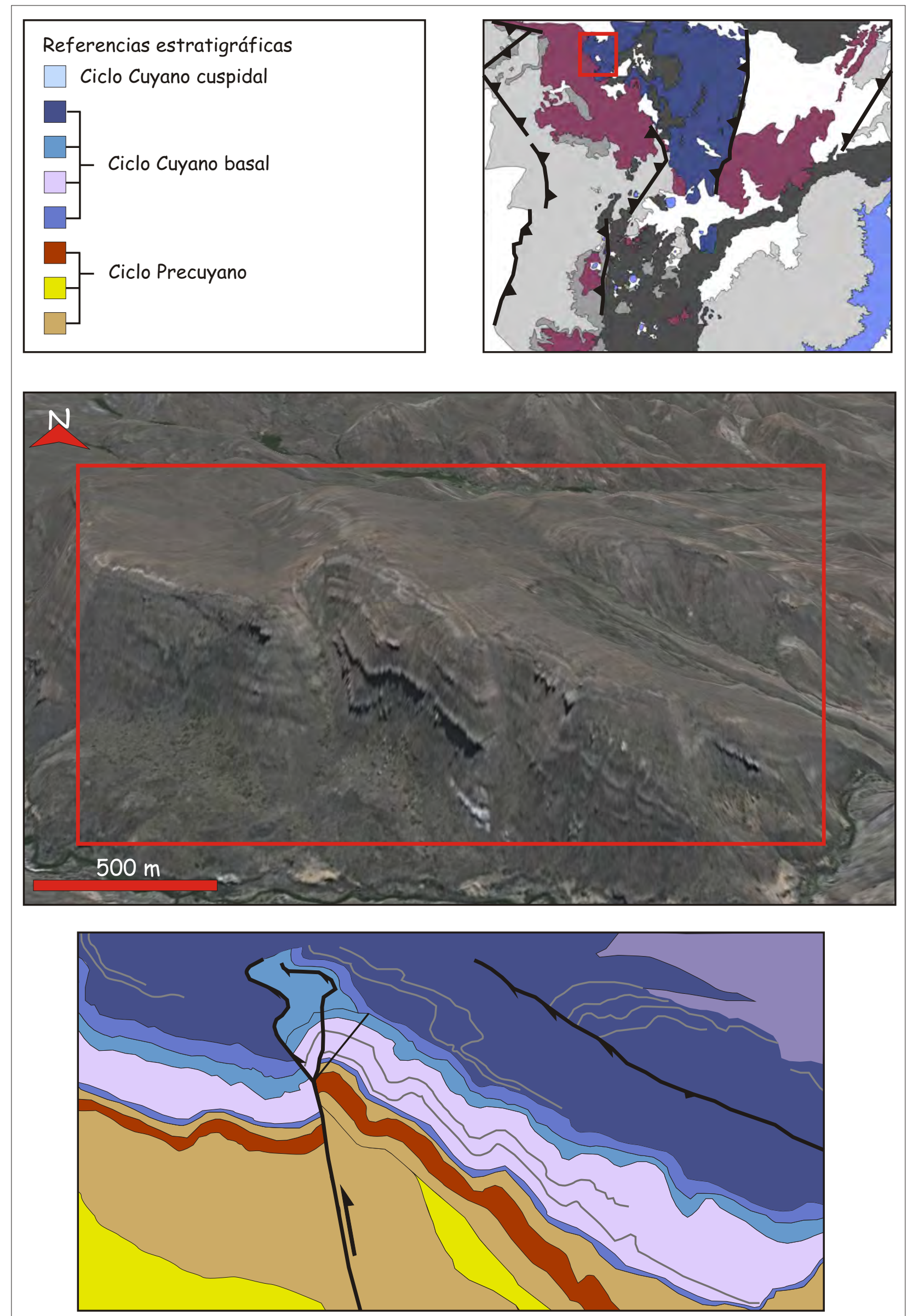

Figura 1.14. Vista 3D de las fallas inversas de alto ángulo y pliegues por propagación de fallas. 


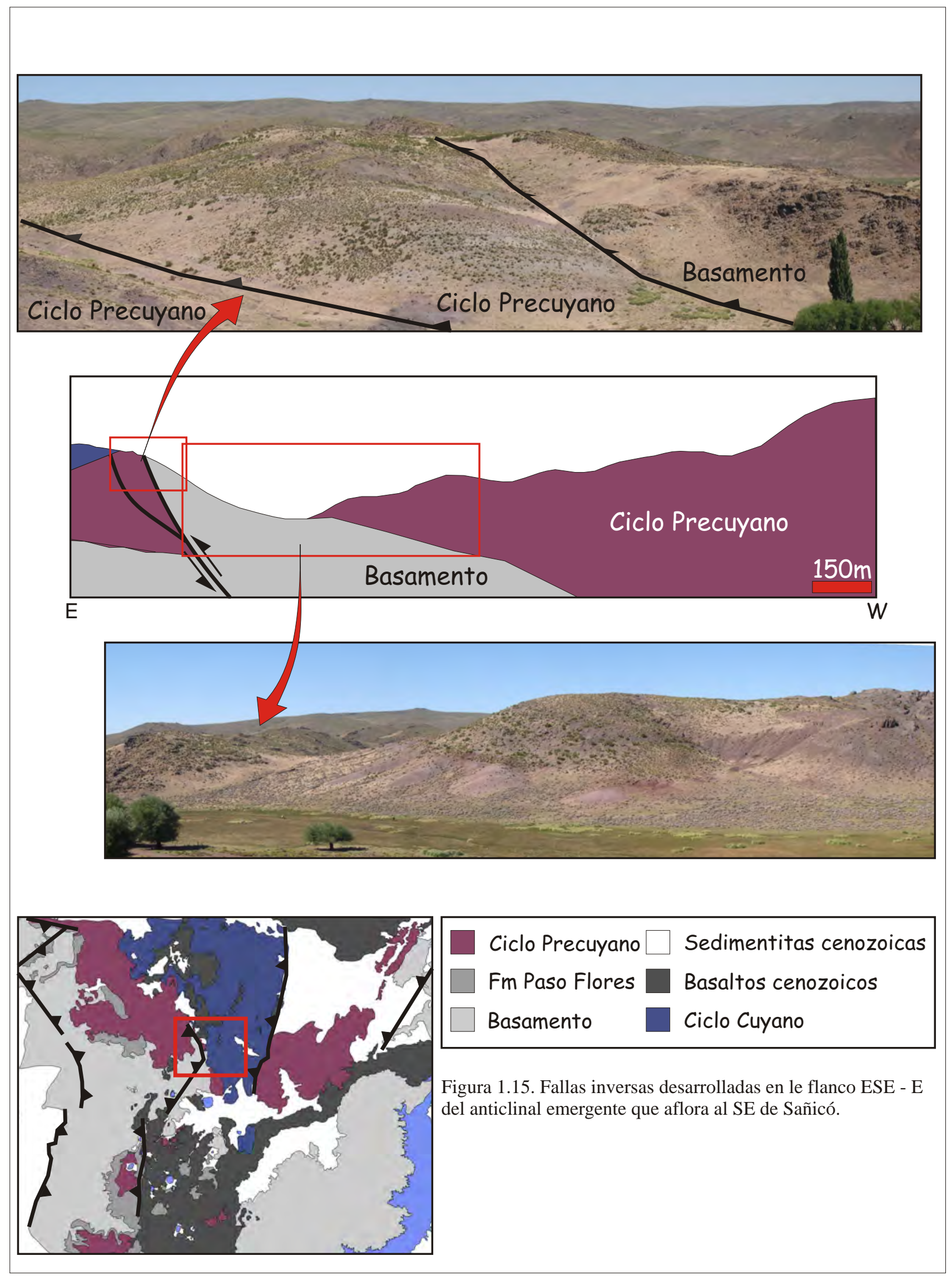




\section{Capítulo 2 - Metodología}

\section{1) Tareas de campo}

Las tareas de campo fueron desarrolladas entre abril de 2005 y diciembre de 2008 y sumaron un total de 130 días. Las labores desenvueltas estuvieron en un principio centradas en el reconocimiento, mapeo geográfico y geológico y el levantamiento de perfiles estratigráficos. Posteriormente, una vez conocidos los atributos estructurales y estratigráficos de la zona de estudio, los trabajos de campo se concentraron en el mapeo a detalle de los afloramientos, el relevamiento de columnas estratigráficas a detalle y el muestreo de material para los diferentes análisis efectuados.

\subsection{1) Mapeo Geológico}

El mapeo se realizó sobre la base de las cartas geológicas 1:200000 (Galli, 1969) y 1:250000 (Cucchi, 1998), imágenes satelitales ASTER y LANSAT TM y fotos aéreas de escala 1:50000. Las cartas y fotos fueron trabajadas con programas para la digitalización y georeferenciación de imágenes y, conjuntamente con las imágenes satelitales, fueron integradas en un Sistemas de Información Geográfica (SIG). Este permitió obtener imágenes de los sitios elegidos como "clave" a escalas de entre 1:100000 y 1:5000. Los datos recolectados en el campo fueron almacenados de dos maneras: una gráfica, volcándolos sobre las imágenes, previamente a las cuales se les montó un papel transparente, y otra escrita, anotando en una libreta de campo el dato de interés y su posición 3D (latitud, longitud y altura) proveniente de un GPS barométrico.

\subsection{2) Relevamiento de datos estructurales}

Durante las etapas de mapeo geológico se tomaron mediciones sistemáticas del rumbo inclinación de capas estratificadas, estructuras plegadas, fallas menores, diques, diaclasas, estrías y estructuras de fabrica planar (esquistosidad/gneisosidad) desarrolladas en el basamento cristalino. La recolección de los datos se realizó mediante una brújula tipo Brunton. Para expresión de los mismos se realizaron diagramas estereográficos mediante el programa Stereonet ${ }^{\circledR}$ (fig. 2.4).

\subsection{3) Levantamiento de perfiles estratigráficos y sedimentológicos}

En total se relevaron 33 columnas estratigráficas distribuidas en toda el área de estudio (fig. 2.1, 2.2 y anexo II), las cuales suman un total de $9110 \mathrm{~m}$ de espesor. Los perfiles relevados en la etapa inicial fueron meramente estratigráficos. Una vez conocido el marco geológico, a partir de la $3^{\circ}$ campaña, se comenzó con el levantamiento de secciones de detalle a escala 1:100 


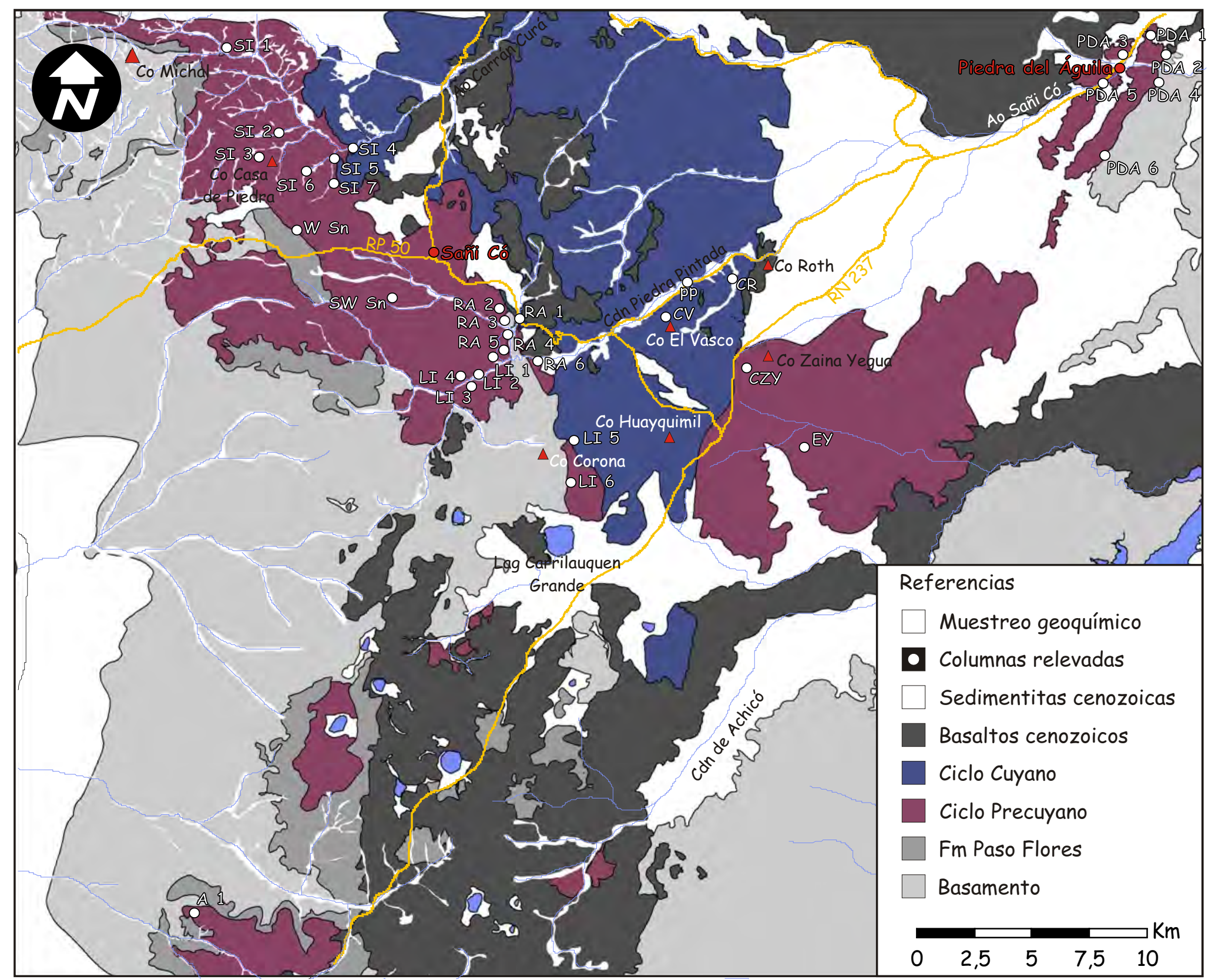

Figura 2.1. Mapa geológico del área de Sanicó y Piedra del Águila donde se muestra la distribución de las columnas relevadas. 


\begin{tabular}{|l|c|c|l|c|}
\hline columna & $x$ & $y$ & \multicolumn{1}{|c|}{ nombre } & esp. total \\
\hline SI 1 & 5567229 & 2369790 & Ea. Santa Isabel 1 & $1390 \mathrm{~m}$ \\
\hline SI 2 & 5563429 & 2372086 & Ea. Santa Isabel 2 & $260 \mathrm{~m}$ \\
\hline SI 3 & 5562371 & 2371315 & Ea. Santa Isabel 3 & $655 \mathrm{~m}$ \\
\hline SI 4 & 5562971 & 2375227 & Ea. Santa Isabel 4 & $100 \mathrm{~m}$ \\
\hline SI 5 & 5562785 & 2374366 & Ea. Santa Isabel 5 & $60 \mathrm{~m}$ \\
\hline SI 6 & 556224 & 2373312 & Ea. Santa Isabel 6 & $310 \mathrm{~m}$ \\
\hline SI 7 & 5561618 & 2374346 & Ea. Santa Isabel 7 & $150 \mathrm{~m}$ \\
\hline W Sn & 5559142 & 2372868 & Oeste de Sañi Có & $150 \mathrm{~m}$ \\
\hline SW Sn & 5556119 & 2376933 & Sudoeste de Sañi Có & $170 \mathrm{~m}$ \\
\hline RA 1 & 5555195 & 2382259 & Reserva Ancatruz 1 & $130 \mathrm{~m}$ \\
\hline RA 2 & 5555459 & 2381775 & Reserva Ancatruz 2 & $70 \mathrm{~m}$ \\
\hline RA 3 & 5555085 & 2381999 & Reserva Ancatruz 3 & $305 \mathrm{~m}$ \\
\hline RA 4 & 5554648 & 2381940 & Reserva Ancatruz 4 & $210 \mathrm{~m}$ \\
\hline RA 5 & 5553789 & 2381747 & Reserva Ancatruz 5 & $310 \mathrm{~m}$ \\
\hline RA 6 & 5553892 & 2382753 & Reserva Ancatruz 6 & $55 \mathrm{~m}$ \\
\hline LI 1 & 5553452 & 2381269 & Ea. La Inmaculada 1 & $100 \mathrm{~m}$ \\
\hline LI 2 & 5552662 & 2380662 & Ea. La Inmaculada 2 & $20 \mathrm{~m}$ \\
\hline LI 3 & 5552084 & 2380324 & Ea. La Inmaculada 3 & $100 \mathrm{~m}$ \\
\hline LI 4 & 5552549 & 2379829 & Ea. La Inmaculada 6 & $25 \mathrm{~m}$ \\
\hline LI 5 & 5549798 & 2384745 & Ea. La Inmaculada 7 & $30 \mathrm{~m}$ \\
\hline LI 6 & 5547810 & 2384120 & Ea. La Inmaculada 8 & $225 \mathrm{~m}$ \\
\hline EA & 5528701 & 2368393 & Ea. Alicurá 1 & $85 \mathrm{~m}$ \\
\hline CV & 5555221 & 2388705 & Cerro Vasco & $211 \mathrm{~m}$ \\
\hline PP & 5556767 & 2389688 & Piedra Pintada & $70 \mathrm{~m}$ \\
\hline CR & 5556356 & 2391500 & Cerro Roth & $69 \mathrm{~m}$ \\
\hline ZY & 5553481 & 2392020 & Cerro Zaina Yegua & $110 \mathrm{~m}$ \\
\hline EY & 5549520 & 2394660 & Estancia Yuncón & $20 \mathrm{~m}$ \\
\hline PDA 1 & 5567851 & 2409821 & Piedra del Águila 1 & $310 \mathrm{~m}$ \\
\hline PDA 2 & 5566966 & 2410037 & Piedra del Águila 2 & $1310 \mathrm{~m}$ \\
\hline PDA 3 & 5566907 & 2408397 & Piedra del Águila 3 & $50 \mathrm{~m}$ \\
\hline PDA 4 & 5565522 & 2409622 & Piedra del Águila 4 & $1120 \mathrm{~m}$ \\
\hline PDA 5 & 5565793 & 2407516 & Piedra del Águila 5 & $20 \mathrm{~m}$ \\
\hline PDA 6 & 5562507 & 2407546 & Piedra del Águila 6 & $910 \mathrm{~m}$ \\
\hline & & & \\
\hline
\end{tabular}

Figura 2.2. Información sobre las columnas relevadas en el área de estudio. 
y 1:10. La elección de los sitios a relevar fue establecida en función de la calidad de los afloramientos y la posición de éstos frente a estructuras tomadas como clave. La posición inicial y final de los perfiles fue acotada mediante puntos GPS, mientras que el levantamiento se hizo con báculo o cinta métrica. Durante esta tarea se realizó una descripción sistemática y jerárquica de todos los tipos litológicos que integran el Precuyano y las unidades que lo infra/suprayacen. Las descripciones fueron apoyadas por la estimación de la composición cualitativa de los componentes de las rocas clásticas y piroclásticas, a través de diagramas de comparación. De presentarse, fueron medidos datos de paleocorrientes (estructuras tractivas, orientación de clastos, base de estructuras erosivas y macroformas acrecionales). Para su utilización los mismos fueron corregidos llevándolos a la horizontal y luego expresados mediante diagramas de rosas con Stereonet ${ }^{\circledR}$. Además, durante el levantamiento de las columnas, se tomaron muestras con fines petrográficos, análisis de RX, análisis de materiales fósiles y se fijaron los sitios para el muestreo con fines geoquímicos.

\subsection{4) Muestreo}

El muestreo para el análisis petrográfico se realizó de manera sistemática durante el relevamiento de las columnas, recolectándose más de 250 muestras. De éstas, a través de la observación con lupa binocular, 100 muestras fueron elegidas para la confección de cortes delgados. Para acotar las asociaciones de minerales de alteración se tomaron 25 muestras para análisis de RX. El muestreo geoquímico se realizó una vez conocida la distribución de las unidades precuyanas, sobre los lugares establecidos durante el mapeo y el levantamiento de las columnas de detalle (fig. 2.3). Cada lugar de muestreo fue testeado a través del análisis petrográfico y de RX, con el fin de analizar muestras representativas y de seleccionar aquellas con menor índice de alteración. En total se tomaron 9 muestras para el análisis geoquímico, cada una fue fragmentada en el campo recogiéndose entre $3 \mathrm{Kg}$ y $5 \mathrm{Kg}$ de material, libre de superficies alteradas. Es importante destacar que para el muestreo de las rocas piroclásticas fue recolectado material pumíceo o muestreo de matriz de ignimbritas con porcentajes de litoclastos inferiores al $3 \%$.

\section{2) Trabajo de gabinete}

A grandes rasgos, las tareas de gabinete estuvieron orientadas por un lado, a la búsqueda de material de lectura temática y de antecedentes, y por el otro, al análisis, asociación e interpretación de los datos recolectados en las diferentes campañas. El procesamiento de los datos se realizó de manera separada para las diferentes aéreas temáticas que conformaron en núcleo del trabajo de tesis doctoral: caracterización morfoestructural y estratigráfica de la zona 


\begin{tabular}{|c|c|c|c|c|}
\hline Lugar & $\bar{X}$ & $\bar{Y}$ & Roca & Código \\
\hline Piedra del Águila & $70^{\circ} 3{ }^{\prime} 42.80^{\prime \prime O}$ & $40^{\circ} 2^{\prime} 41.20^{\prime \prime S}$ & ignimbrita soldada & PDA M2 \\
\hline Piedra del Águila & $70^{\circ} 5 ' 5.44 " \mathrm{O}$ & $40^{\circ} 5 ' 7.71 " \mathrm{~S}$ & ignimbrita & PDA M1 \\
\hline $\mathrm{C}^{\circ}$ Zaina Yegua & $70^{\circ} 15^{\prime} 03.9^{\prime \prime O}$ & $40^{\circ} 9^{\prime} 45.1^{\prime \prime S}$ & lava andesísitica & ZY-S \\
\hline $\mathrm{N}$ del $\mathrm{C}^{\circ}$ Corona & $70^{\circ} 22^{\prime} 59.90 " \mathrm{O}$ & $40^{\circ} 9^{\prime} 00.38 " \mathrm{~S}$ & lava andesítica & SE-SN I2 \\
\hline N de Sañicó & $70^{\circ} 28^{\prime} 40.7^{\prime \prime O}$ & $40^{\circ} 5^{\prime} 14.7^{\prime \prime S}$ & riolita intrusiva & N-SN M \\
\hline $\mathrm{N}$ de Sañicó & $70^{\circ} 31^{\prime} 40.2^{\prime \prime O}$ & $40^{\circ} 2 ' 19.9 " \mathrm{~S}$ & lava andesítica & SE-SN I1 \\
\hline NE del $\mathrm{C}^{\circ}$ Corona & $70^{\circ} 23 ' 37.95 " \mathrm{O}$ & $40^{\circ} 9^{\prime} 44.66^{\prime \prime S}$ & domo riodacítico & SE-SN M1 \\
\hline SW de Sañicó & $70^{\circ} 26^{\prime} 9.14^{\prime \prime O}$ & $40^{\circ} 7^{\prime} 43.19^{\prime \prime S}$ & lava andesítica & W-SN S \\
\hline NE del $\mathrm{C}^{\circ}$ Corona & $70^{\circ} 23 ' 38.09 " \mathrm{O}$ & $40^{\circ} 8 ' 58.86 " \mathrm{~S}$ & pómez en ignimbrita & SE SN M2 \\
\hline
\end{tabular}

Figura 2.3. Tabla donde se muestran las coordenadas donde se realizó el muestreo con fines geoquímicos.

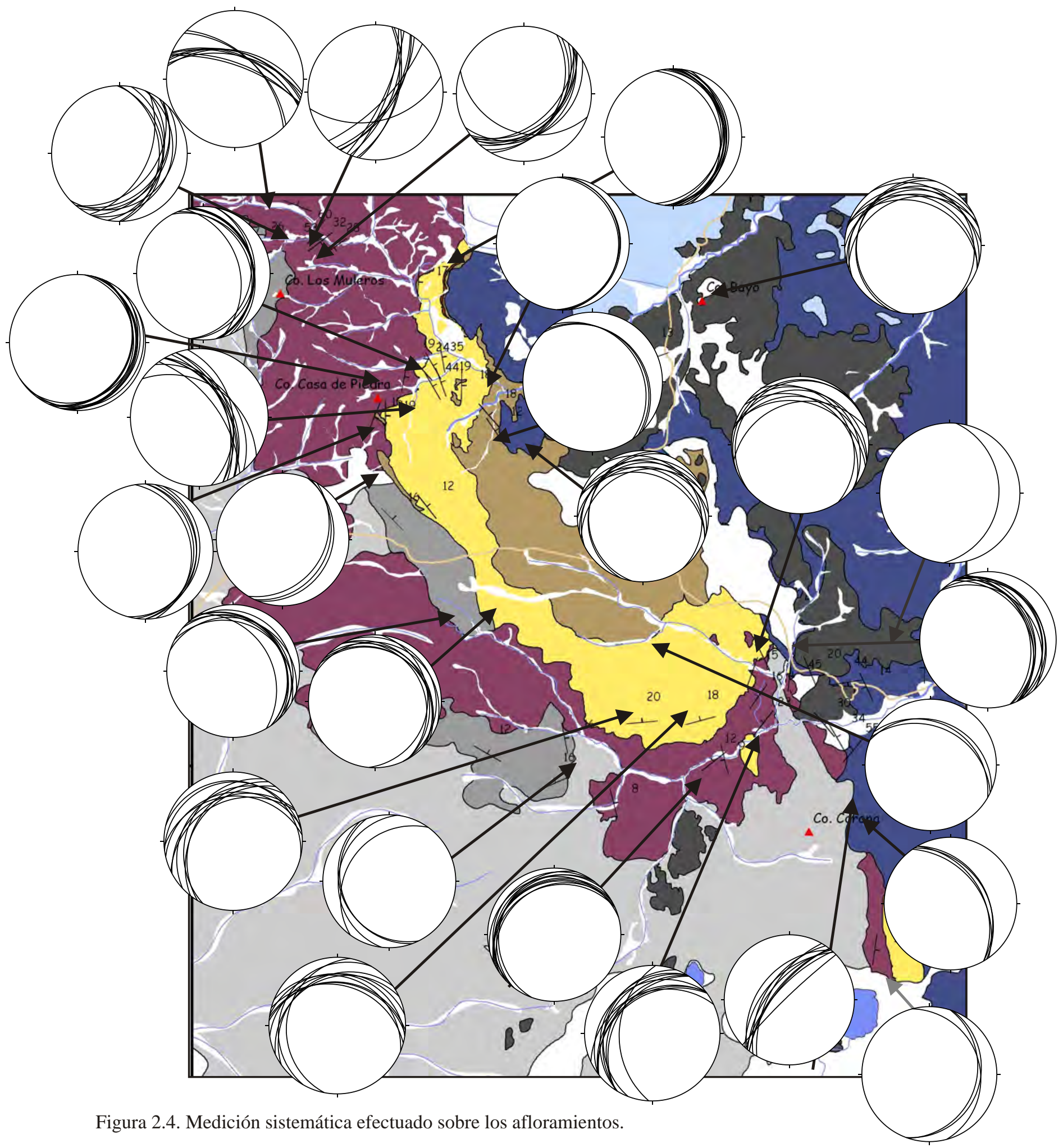


de estudio, análisis de laboratorio, análisis de facies, asociaciones de facies y ambientes y el estudio tectoestratigráfico del Ciclo Precuyano y la transición al Ciclo Cuyano.

\subsection{1) Análisis de laboratorio}

Consistió en la elección, preparado y posterior interpretación de las muestras para el estudio petrográfico, de difracción de RX y geoquímico. Las 250 muestras tomadas para el estudio petrográfico fueron descriptas bajo lupa binocular y posteriormente a alrededor de 100 se les practicó una sección delgada. Para el análisis de RX, 25 muestras fueron seleccionadas y analizadas por personal del laboratorio de RX del Centro de Investigaciones Geológicas. Las muestras para el estudio geoquímico fueron molidas y enviadas a Actlabs (Ontario, Canadá), donde se les practicó el análisis LITHOS 4 (mayoritarios y trazas) (anexo III). La interpretación de los datos fue realizada a través de la confección de diagramas binarios clásicos (Harker, TAS, Spiders, etc.)

\subsection{2) Análisis de facies, asociaciones de facies y ambientes}

Esta fase se caracterizó por la interpretación hidrodinámica y ambiental de las facies volcánicas, piroclásticas y sedimentarias que constituyen el relleno Precuyano y la transición al Ciclo Cuyano. De manera jerárquica fueron determinadas unidades elementales (facies). Posteriormente, en función de asociaciones de facies y la confección de paneles de correlación, se determinaron diferentes unidades de acumulación para el relleno.

\subsection{3) Estudio tecto-estratigráfico del Ciclo Precuyano y la transición al Ciclo Cuyano}

La información generada en las áreas temáticas descriptas en los párrafos anteriores fue integrada a través de columnas estratigráficas, perfiles geológicos y modelos 3D. Sobre la base de las características genéticas y composicionales de las unidades de acumulación y la jerarquización de superficies clave dentro del relleno precuyano, éstas fueron integradas en "secciones" que responden diferentes periodos de evolución dentro del relleno precuyano y la transición con el ciclo Cuyano. Imágenes y modelos de elevación digital georeferenciados fueron integrados con la información estratigráfica, estructural y ambiental, dentro de un Sistema de Información Geográfica (ArcMap 9.2®) (fig. 2.5) y un programa para la visualización en 3D (Google sketchUp 6.4.112®) (fig. 2.6). Esta base de datos permitió la confección de perfiles geológicos y modelos 3D que fueron utilizados para comprender las variaciones estratigráficas, los volúmenes y los controles en la acomodación del relleno precuyano y la transición con el Ciclo Cuyano (fig. 2.5 y 2.6). De esta manera, pudieron ser delimitadas áreas depocentrales con su respectiva evolución. 
File Edit Wiew Insert SElection Iools window Help

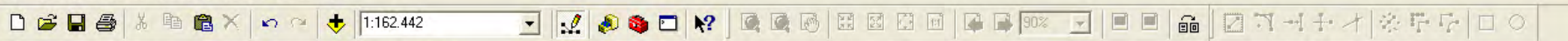

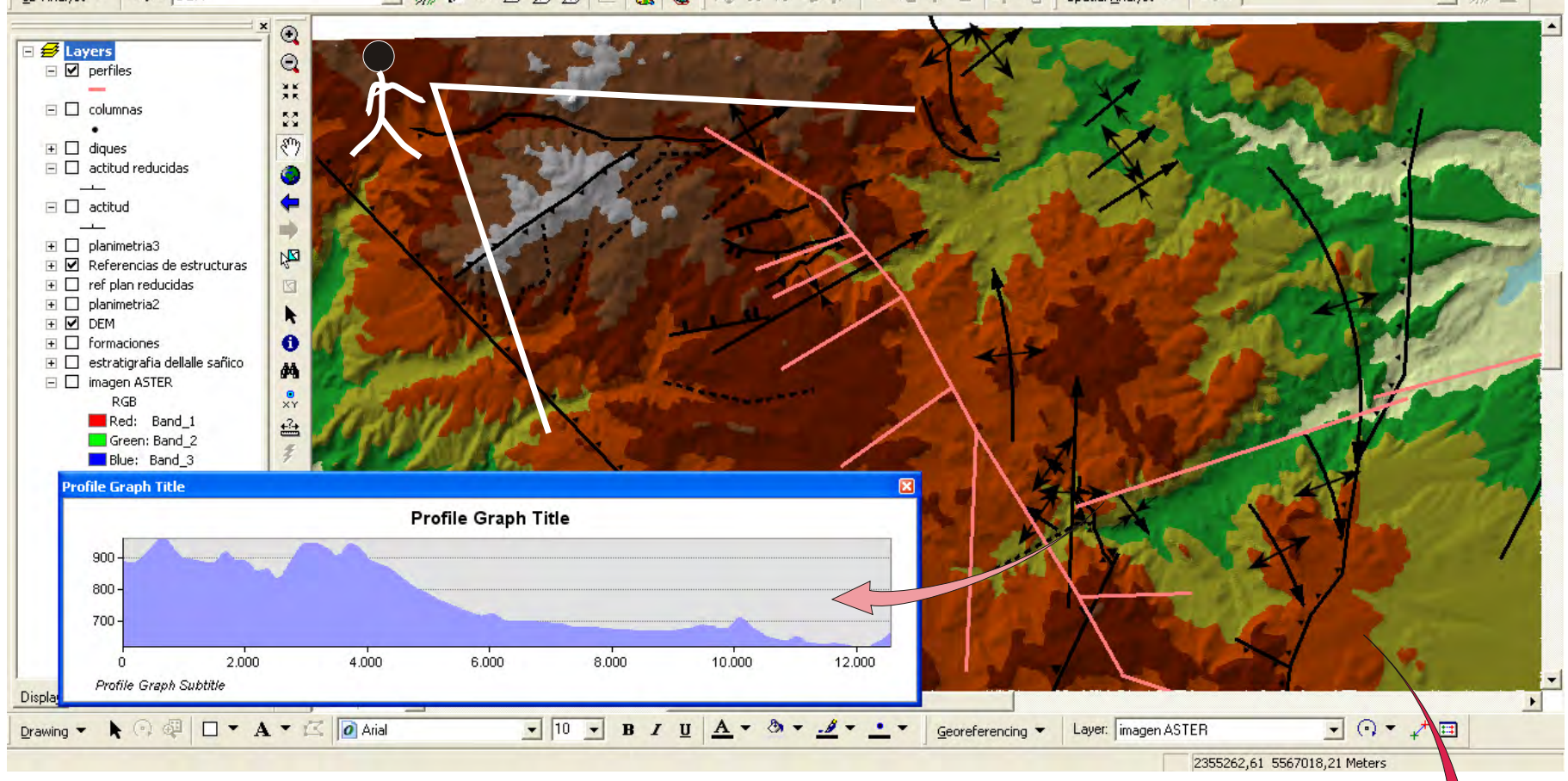

Figura 2.5. División del área de estudio en perfiles topográficos y geológicos desarrollados en posición paralela y perpendicular a las principales estructuras.

perfil Sta Isabel_La Inmaculada -SketchUp

Archivo Edición ver Cámara Dibujo Herramientas Ventana Ayuda

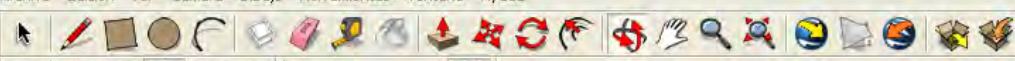

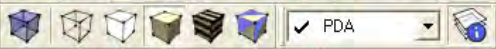

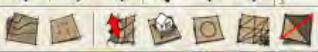

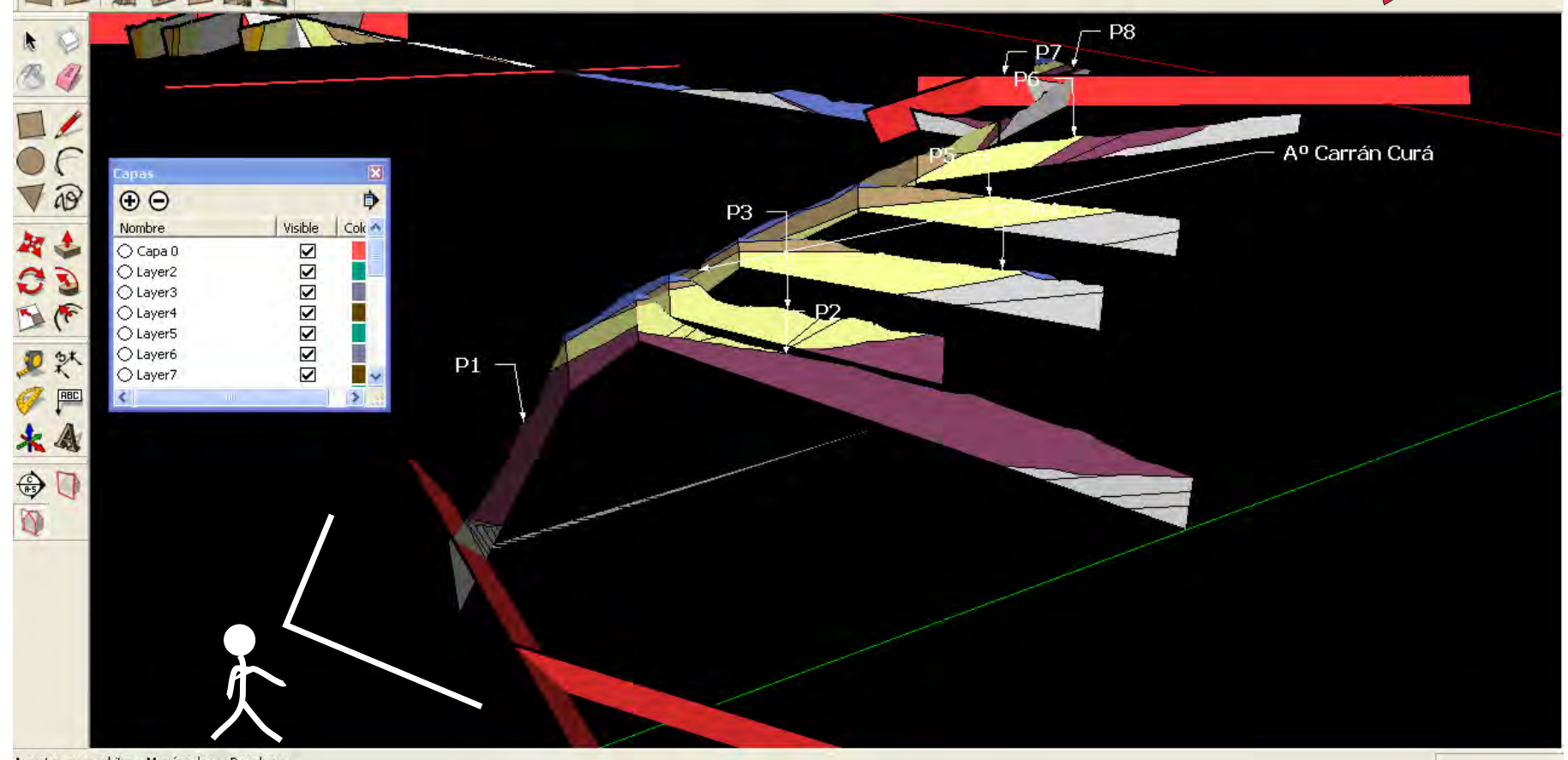

Arrastrapara orbitar. Mavusculas = Desplazer

Figura 2.6. Modelo 3D realizado para el área de estudio. 


\section{Capítulo 3: Análisis litológico y litogeoquímico}

\section{1) Introducción}

En el presente capítulo se realizará un análisis de las facies y microfacies de los depósitos del Ciclo Precuyano y del Cuyano basal. Asimismo, se hará una caracterización litogeoquímica de las rocas volcánicas y piroclásticas del Ciclo Precuyano. La información necesaria y para el desarrollo de esta tarea se obtuvo durante el levantamiento sistemático de columnas estratigráficas de detalle en sitios clave. Durante el relevamiento de las columnas se describieron una gran cantidad de litofacies volcánicas, piroclásticas y sedimentarias. La variedad de tipos litológicos y genéticos hizo necesario su estudio por medio de un modelo jerárquico que permitió avanzar con los objetivos propuestos: el modelo de facies.

El modelo de facies como es comprendido hoy en día, involucra una síntesis de la información de los ambientes depositacionales actuales y antiguos en un esfuerzo por entender la naturaleza, la escala, la heterogeneidad y los controles físicos de los procesos intervinientes en cada ambiente sedimentario (Walker, 2006). Esta herramienta se ha utilizado para ambientes volcánicos desde fines de los 80' (Cas y Wright, 1987), y usualmente utilizada para la descripción e interpretación de ambientes sedimentarios (Walker, 1984; Reading y Levell, 2002 y Walker, 2006). Según Walker (2006), los pasos a seguir para construir un modelo de facies son los siguientes: 1) describir detalladamente y subdividir la unidad estratigráfica en un conjunto de facies descriptivas, luego interpretadas desde el punto de vista hidrodinámico y genético; 2) agrupar las facies dentro de asociaciones de facies relacionadas genéticamente, teniendo en cuenta las superficies que las limitan; 3) unir los elementos depositacionales dentro de un marco tridimensional; 4) realizar una interpretación preliminar de los elementos depositacionales y 5) comparar los elementos depositacionales con modelos de facies preexistentes.

A continuación se efectuará una descripción detallada e interpretación de las facies y microfacies identificadas para el Ciclo Precuyano y el Cuyano basal. De la misma forma, se realizará un análisis litogeoquímico teniendo en cuenta las sugerencias de la IUGS (Le Bas y Streckeisen, 1991), la cual propone la discriminación química como la única clasificación confiable para las rocas volcánicas y piroclásticas. Finalizado este capítulo se habrá avanzado con la caracterización dinámica y composicional de las facies sedimentarias y piroclásticas y química de las rocas volcánicas. En el capítulo subsiguiente se establecerán las diferentes asociaciones de facies dentro de un marco tridimensional y se hará la interpretación depositacional de las diferentes unidades de acumulación identificadas para el relleno. 


\section{2) Análisis de las litofacies}

En el presente inciso se realizará la descripción e interpretación de las litofacies contenidas dentro del Ciclo Precuyano y de las litofacies basales del Ciclo Cuyano. Es importante destacar que si bien Gulisano y Pando (1981) han efectuado un análisis facial de las secuencias en estudio, este trabajo propone un detalle y profundización que no fue contemplado en la contribución de los autores citados. A los efectos de realizar modelos predictivos de facies, se definirán e interpretarán las facies volcánicas, piroclásticas y sedimentarias sobre la base de la observación objetiva y pormenorizada de sus atributos -litología, estructura, geometría, escala, grado de bioturbación y presencia de fósiles- (Miall, 1996; Reading y Levell, 2002; Miall, 2006; Walker, 2006). Cabe aclarar que para la definición de las facies de rocas volcánicas y piroclásticas, a los atributos anteriores, se suman: la composición, el tipo y grado de fragmentación y el tipo y grado de alteración (Fisher y Schmincke, 1984; Cas y Wright, 1987; Mc Phie et al., 1993 y Németh y Ulrike, 2007).

\subsection{1) Terminología y organización de las litofacies}

La utilización del "modelo de facies" a secuencias volcano-sedimentarias no es común. La coexistencia de depósitos lávicos, piroclásticos y sedimentarios, sumado a la dificultad que a menudo se presenta para distinguir entre depósitos primarios de secundarios, hacen dificil la utilización de este modelo. En estos sitios, grandes volúmenes de materiales son aportados en cortos periodos de tiempo, a través mecanismos de transporte y depositación que no son habituales en los ambientes sedimentarios frecuentes, obstaculizando la interpretación fluidodinámica de las facies (Smith, 1991; Smith y Lowe, 1991; Mc Phie et al., 1993; Orton, 2002; Németh y Ulrike, 2007). Asimismo, desde la década del 60 a la actualidad, se ha propuesto una variedad de esquemas de clasificación para las rocas volcánicas y volcaniclásticas (véase Fisher, 1961; Fisher, 1966; Fisher y Schmincke, 1984; Cas y Wright, 1987; Mc Phie, et al., 1993 y White y Houghton, 2006) basados en ideas diferentes. Estos esquemas, no sólo presentan variaciones en sus conceptos, sino también elevadas connotaciones genéticas que contrastan con la sistemática utilizada para el "modelo de facies". Por tales motivos, previamente a la descripción e interpretación de las facies, las mismas debieron ser agrupadas dentro de categorías genéticas mayores, definidas a partir del mecanismo que dio origen a los clastos y el tipo de transporte y depositación (fig. 3.1).

Las categorías mayores definidas son: I) litofacies de rocas volcánicas -facies lávicas y rocas clásticas asociadas a un mecanismo de fragmentación primario no explosivo- (Mc Phie et al., 1993), II) litofacies de rocas piroclásticas -formadas directamente por la fragmentación explosiva del magma- (Cas y Wright, 1987; Mc Phie et al., 1993 y White y Houghton, 2006) y 
III) litofacies de rocas sedimentarias, las cuales fueron subdivididas en epiclásticas, resultado de la erosión, transporte y depositación de rocas preexistentes, y carbonáticas, resultado de la precipitación química u orgánica de carbonatos (Tucker, 2001). Es importante destacar que a los efectos de evitar confusiones, en esta instancia, se dejará de lado el término volcaniclástico, denominándose como epiclásticas a las rocas resultado del retrabajo y depositación de rocas volcánicas y piroclásticas (sensu Cas y Wright, 1987).

Dentro de cada categoría, los códigos utilizados para denominar las facies fueron elegidos o delineados en función de las litofacies a analizar (fig. 3.1). De esta manera, para las litofacies volcánicas, los códigos tuvieron que ser completamente diseñados, para las litofacies piroclásticas se tuvieron en cuenta las abreviaciones sugeridas por Branney y Kokelaar (2002), mientras que para las facies sedimentarias se utilizó y modificó el renombrado esquema propuesto por Miall (1978).

En el presente estudio se han encontrado facies muy disimiles respecto a su génesis y mecanismos de depositación/emplazamiento. Teniendo en cuenta este contexto para la interpretación de las facies dentro de cada grupo, se han empleado diferentes conceptos que permitan maximizar el balance entre observación/medición e interpretación (fig. 3.2). Para la interpretación de litofacies volcánicas se siguieron principalmente los conceptos de: Mc Phie et al. (1993), Sigurdsson et al. (2000), Best y Christiansen (2000), Llambías (2001), Gifkins, et al., (2005), Llambías (2008), Németh y Ulrike (2007), para la interpretación de rocas piroclásticas se utilizaron: Fisher y Scmincke (1984), Cas y Wright (1987), Branney y Kokelaar (2002), Schwarzkopf et al. (2005), Brown et al. (2007), Kokelaar et al. (2007), y por último, para las diferentes litofacies de rocas sedimentarias se remitió a: Smith (1886), Smith (1987), Smith y Lowe (1991), Palmer et al. (1991), Blair y McPherson (1994), Coussot y Meunier (1996), Miall (1996), Bahk y Clough (1996), Schneider y Fisher (1998), Belousov et al. (1999), Reubi y Hernandez (2000), Tucker (2001), Collinson (2002), Orton (2002), Shanmugam (2002), Clavero et al. (2002), Bret et al. (2003), Dasgupta (2003), Miall (2006), Bridge (2006), Dumas y Arnott (2006), Brown y Bell (2007), Shea et al. (2008). 


\begin{tabular}{|c|c|c|c|c|c|c|}
\hline & & CÓDIGo & TEXTURA & ESTRUCTURA & $\begin{array}{l}\text { DIMENSIONES } \\
\text { (estrato - sets) }\end{array}$ & INTERPRETACIÓN ELEMENTAL \\
\hline \multirow{6}{*}{\multicolumn{2}{|c|}{ 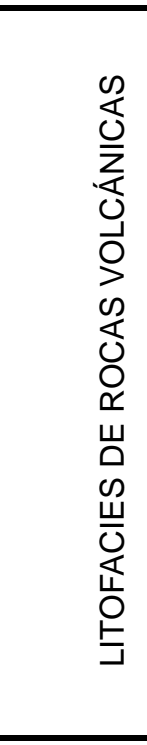 }} & LAC(f) & 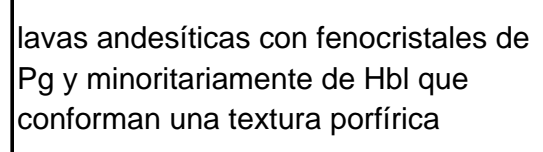 & masiva o con foliación por flujo (f) & & 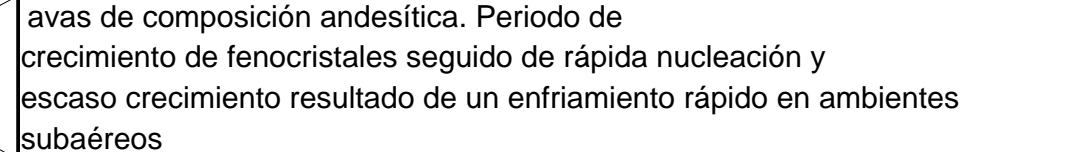 \\
\hline & & LAA & $\begin{array}{l}\text { lavas andesiticas autobrechadas. Los } \\
\text { clastos se presentan masivos y } \\
\text { angulosos }\end{array}$ & masiva & & $\begin{array}{l}\text { avas que experimentaron procesoso autoclassticos no } \\
\text { explosivo: autobrechamiento subaéreo }\end{array}$ \\
\hline & & LAFH & $\begin{array}{l}\text { lavas andesiticas con fenocristales de } \\
\text { Pg con textura porfiricica }\end{array}$ & 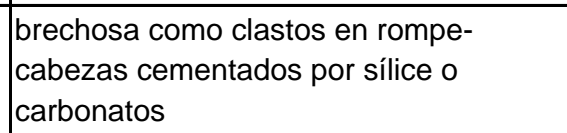 & & $\begin{array}{l}\text { avas con circulación de fluidos siliceos o carbonatícos a altas presiones que } \\
\text { originaron tracturación hicraulicay dementación }\end{array}$ \\
\hline & & LAPB & $\begin{array}{l}\text { lavas andestiticas con "sombras" de } \\
\text { clastos uque le torgan una apariencia } \\
\text { de brecha }\end{array}$ & pseudobrechada & & $\begin{array}{l}\text { avas coherentes con textura pseudobrecchada, } \\
\text { productoto de difierentes fases de a aterafición que actuan sobre fracturas }\end{array}$ \\
\hline & & LDC & 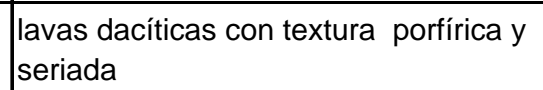 & masiva & & Lavas de composición dacitica de ambiente subvolcánico \\
\hline & & $\operatorname{LRC}(t)$ & $\begin{array}{l}\text { lavas rioliticas y riodacíticas con } \\
\text { textura porfirica }\end{array}$ & masiva a con folliación por flujo (f) & & avas de composición riolitica o riodacitica de ambiente subaéreo \\
\hline & \multirow{11}{*}{ 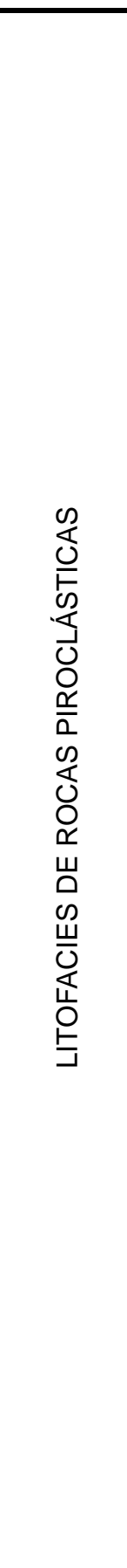 } & $\mathrm{mBr}$ & $\begin{array}{l}\text { brecha con textura clasto sostén } \\
\text { polimodal o matriz sostén, de moderad } \\
\text { a pobre selección }\end{array}$ & $\begin{array}{l}\text { masiva o con clastos orientados } \\
\text { paraleles a los limites externos }\end{array}$ & 2,5 m de espesor & $\begin{array}{l}\text { depósitios de corrientes piroclásticas con limite de flujo inferior dominado } \\
\text { por flujo granular ylo escape de fluidos }\end{array}$ \\
\hline & & mibri & \begin{tabular}{|l}
$\begin{array}{l}\text { brecha de textura clasto sostén } \\
\text { polimodal con poca amtriz apilita- } \\
\text { ftobácaly y pobre seleciion }\end{array}$ \\
\end{tabular} & $\begin{array}{l}\text { masiva o en ocasiones con tendencia a } \\
\text { la gradación inversa grosera }\end{array}$ & 1 a $4 \mathrm{~m}$ de espesor & 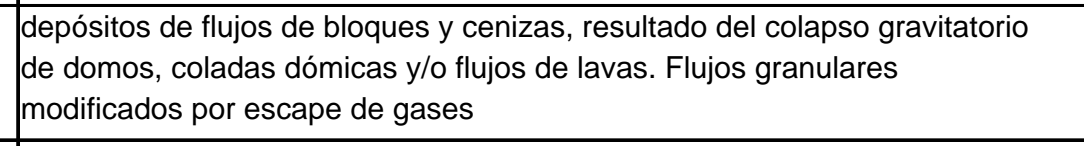 \\
\hline & & mLT(pip)(f) & $\begin{array}{l}\text { tobas lapilliticas masivias, matriz } \\
\text { sosteten, de colores llanguuecinos, } \\
\text { rosados o verdosos }\end{array}$ & $\begin{array}{l}\text { masiva y/o con estructuras de escape } \\
\text { de gases ( (pip) yllo con litcolastos } \\
\text { alineados al Ilimite externo }\end{array}$ & $\begin{array}{l}0,2 \text { a } 1,5 \mathrm{mde} \\
\text { espesoror o sin } \\
\text { limites externos }\end{array}$ & 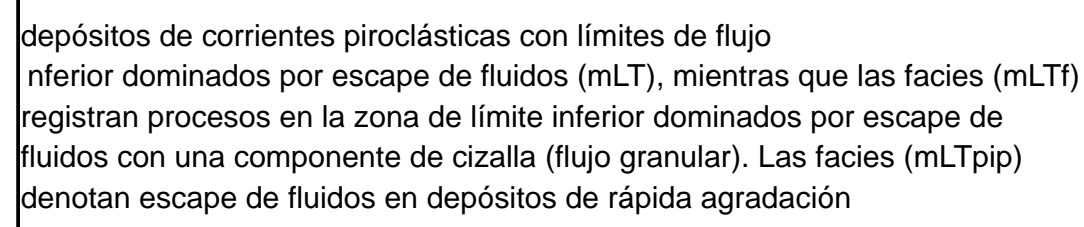 \\
\hline & & emLT & 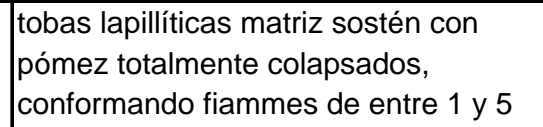 & masiva & $\begin{array}{l}\text { sin límites externos } \\
\text { bien definidos }\end{array}$ & $\begin{array}{l}\text { depositios de corrientes piroclásticas originadas por arriba de la } \\
\text { masiva indica que laturbulencia tue suprimida en la parte inferior de la corrient }\end{array}$ \\
\hline & & dbLT & 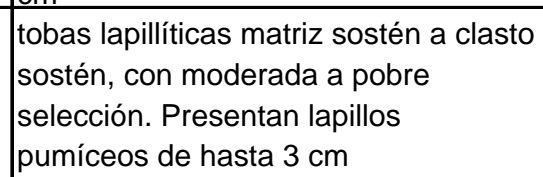 & $\begin{array}{l}\text { estratificación fina difusay en nalgunas } \\
\text { ocasiones puede mostrar gradacioion } \\
\text { normal }\end{array}$ & $\begin{array}{l}1,5 \mathrm{a} 0,1 \mathrm{~m} \text { de } \\
\text { espesor }\end{array}$ & $\begin{array}{l}\text { depósitios de corrientes piroclásticas con un limite inferior de flujo inestable } \\
\text { dominado por condiciones intermedias entre tracción y escape de fluidos }\end{array}$ \\
\hline & & I/sLT & 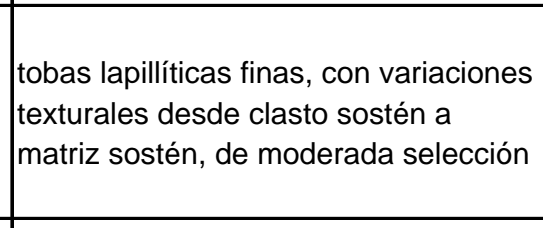 & $\begin{array}{l}\text { estrattificación muy fina a laminación. } \\
\text { estructura de corte y relleno }\end{array}$ & $0,2 \mathrm{~m}$ de espesor & 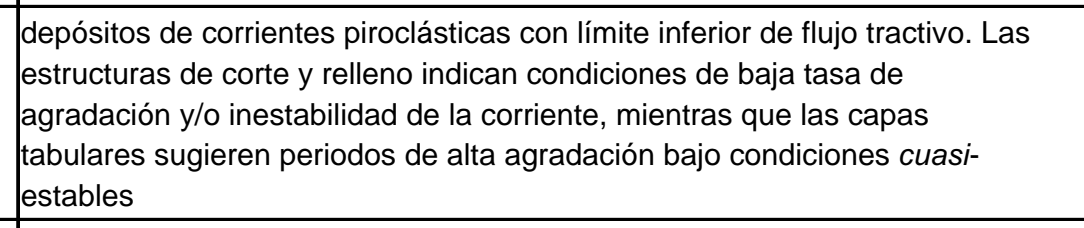 \\
\hline & & xsLT(a) & $\begin{array}{l}\text { tobas lapilliticas rosadas, matriz } \\
\text { sosten, masivas con lapillos } \\
\text { pumiceos de entre } 1 \text { 1., } \mathrm{cm}\end{array}$ & $\begin{array}{l}\text { estratificicación entrecruzadad de gran } \\
\text { escala sobre superficies erosivas. } \\
\text { Variaciones laterales a facies masivas }\end{array}$ & $\begin{array}{l}\text { capas de } 9 \text { a } 22 \mathrm{~cm} \\
\text { de espesor y sets de } \\
1,5 \mathrm{~m}\end{array}$ & 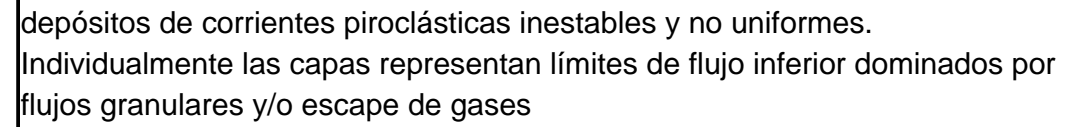 \\
\hline & & $\mathrm{xLLT(b)}$ & $\begin{array}{l}\text { tobas lapilliticas finas, con variaciones } \\
\text { texuturases desde clasto sostén a } \\
\text { matriz } \\
\text { selecciónten con moderada }\end{array}$ & $\begin{array}{l}\text { estratificación entrecruzada. } \\
\text { estructuras de corte y relleno }\end{array}$ & $\begin{array}{l}\text { estratificación fina } \\
\text { que contorma sets } \\
\text { de entre } 0,2 \text { a } 0,7 \mathrm{~m}\end{array}$ & 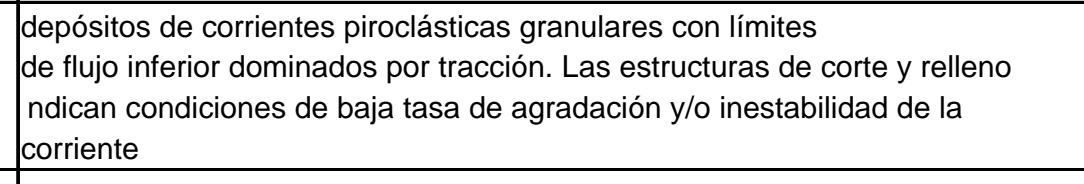 \\
\hline & & xsT & $\begin{array}{l}\text { tobas finas, clasto sostén, muy bien } \\
\text { seleccionadas }\end{array}$ & $\begin{array}{l}\text { estructura en montículo, estratificación } \\
\text { entrecruzada y estructura de antiduna }\end{array}$ & $0,1 \mathrm{~m}$ de espesor & $\begin{array}{l}\text { depósitios de corrientes piroclásticas diluidas con límites de flujo inferior } \\
\text { dominados por traccion }\end{array}$ \\
\hline & & $\mathrm{pmL}$ & $\begin{array}{l}\text { lapillitas pumíceas con textura clasto } \\
\text { sosten polimodal, de moderada } \\
\text { selección }\end{array}$ & masiva & $\begin{array}{l}0,0,1 \text { a } 1,5 \mathrm{~m} \text { de } \\
\text { espesor }\end{array}$ & 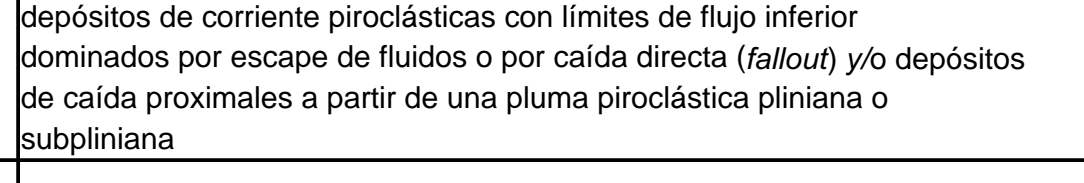 \\
\hline & & mT & \begin{tabular}{|l} 
tobas finas clasto sostén, bien \\
seleccionadas
\end{tabular} & masiva & $\begin{array}{l}0,15 \mathrm{a} 0.5 \mathrm{~m} \text { de } \\
\text { espesor }\end{array}$ & $\begin{array}{l}\text { depósitios de caída distales de una pluma piroclástica pliniana o } \\
\text { subpliniana de ambientes subbácueos o subaréres }\end{array}$ \\
\hline & \multirow{18}{*}{ 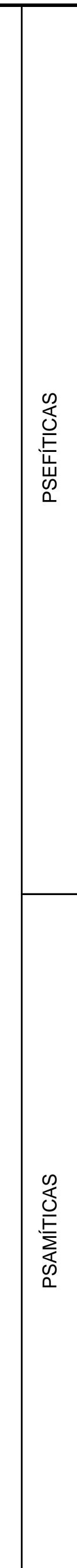 } & Brmm & $\begin{array}{l}\text { brechas matriz sostér con } \\
\text { extremanadamente porte selección. } \\
\text { Megaglastos de hasta decenas de } \\
\text { metros }\end{array}$ & $\begin{array}{l}\text { masiva } \\
\text { megaclastos con estructura en } \\
\text { rompecabezas }\end{array}$ & $\begin{array}{l}\text { sin limites externos } \\
\text { bien deffinidos }\end{array}$ & $\begin{array}{l}\text { depósitios de avalanchas de detritios volcánicicos orgignados por flujos de } \\
\text { sedimentos granulares }\end{array}$ \\
\hline & & Brm & $\begin{array}{l}\text { brechas finas a sabulitasa angulosas, } \\
\text { de moderada selección, Ititacas } \\
\text { pumiceas clasto sosten polimodal }\end{array}$ & $\begin{array}{l}\text { masivas, con gradación inversa o con } \\
\text { gradación inversa-normal }\end{array}$ & $\begin{array}{l}0,05 \text { a } 0,40 \mathrm{~m} \text { de } \\
\text { espesor }\end{array}$ & $\begin{array}{l}\text { deposititos de flujos hiperconcentradosos originados por flujos de sedimentos } \\
\text { de alta densidad, transicionales entre laminares y turbulentos }\end{array}$ \\
\hline & & Gmm(a) & 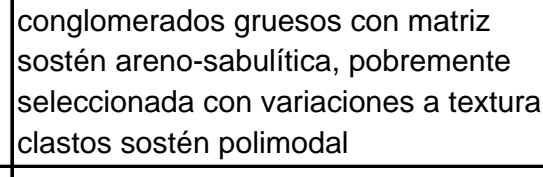 & 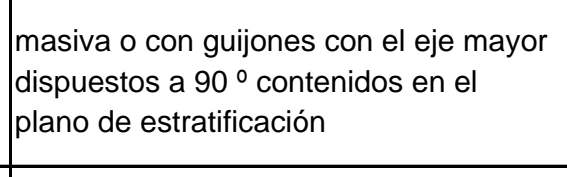 & $\begin{array}{l}1,5 \mathrm{a} 4 \mathrm{~m} \text { de } \\
\text { espesor }\end{array}$ & $\begin{array}{l}\text { depósitos de flujo de detritios no conesivos originaados por flujos de } \\
\text { sedimentos de alta densidad, laminares y reollogicamente plasticos }\end{array}$ \\
\hline & & Gmm(b) & $\begin{array}{l}\text { gravas finas a medias, matriz sostén } \\
\text { fangosa, de pobre selección }\end{array}$ & masiva & $0,5 \mathrm{~m}$ de espesor & $\begin{array}{l}\text { depósitios de flujos de detrittos fangososos cohesivos originados por flujos de } \\
\text { sedimentos de alta densidad, laminares y reológicamente plásticos }\end{array}$ \\
\hline & & Gm & $\begin{array}{l}\text { conglomerados medios con textura } \\
\text { clasto ostán polimodal, de moderada } \\
\text { selección }\end{array}$ & masiva a crudamente estratificada & $\int_{0,5 \mathrm{a} 2 \mathrm{~m} \text { de }}^{\text {espesor }}$ & 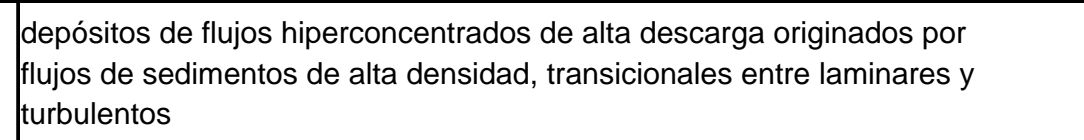 \\
\hline & & Gh & $\begin{array}{l}\text { sabulitias y conglomerados finos con } \\
\text { teturac clasto sosten y moderada } \\
\text { selección }\end{array}$ & $\begin{array}{l}\text { estratificación difiusa } \\
\text { gradación normal }\end{array}$ & $\begin{array}{l}0,15 \text { a } 0,5 \mathrm{~m} \mathrm{de} \\
\text { espesor }\end{array}$ & 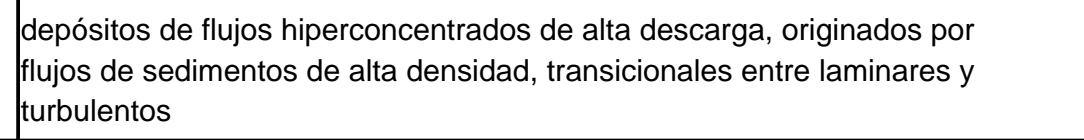 \\
\hline & & Gt & $\begin{array}{l}\begin{array}{l}\text { sabulitas } y \text { conglomerados finos con } \\
\text { tetutura clasto sostén y moderada } \\
\text { selecciocion }\end{array} \\
\end{array}$ & estratificación entrecruzada en artesa & $\begin{array}{l}\text { sets de entre } 0,2 \mathrm{y} \\
0,4 \mathrm{~m} \text { de espesor }\end{array}$ & 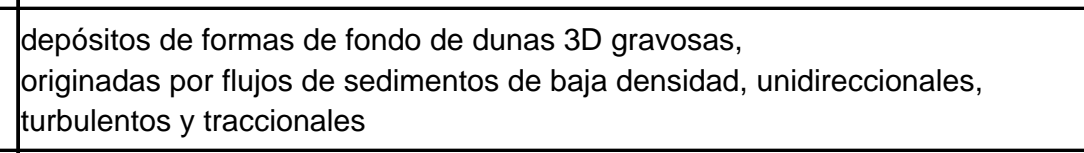 \\
\hline & & Gn & $\begin{array}{l}\text { conglomerados finos con textura } \\
\text { clasto sosten polimodal, de moderada } \\
\text { selección }\end{array}$ & gradación normal y estrattificación & $\begin{array}{l}0,15 \mathrm{a} 0,7 \mathrm{~m} \mathrm{de} \\
\text { espessor }\end{array}$ & $\begin{array}{l}\text { deposisitos marinos de corrientes de turbidez gravosas, originados por flujos } \\
\text { de sedimentos de alta densidad }\end{array}$ \\
\hline & & $\mathrm{Gp(a)}$ & $\begin{array}{l}\text { conglomerados finos clasto sostén, de } \\
\text { moderada a buena selección }\end{array}$ & $\begin{array}{l}\text { estratificacíón entrecruzada a gran } \\
\text { escala }\end{array}$ & $\begin{array}{l}\text { capas de } 0,05 \text { a } 0,15 \\
m \text { de espesor. Sets } \\
\text { de } 1 \text { a } 4 \mathrm{~m} \text { de } \\
\text { espesor }\end{array}$ & 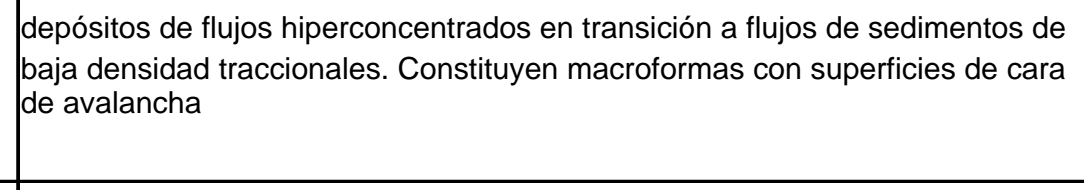 \\
\hline & & $\mathrm{Gp(b)}$ & $\begin{array}{l}\text { gravas finas a sabulitas, Iriticas a } \\
\text { poumiceas, clasto sosten, de } \\
\text { moderada seleccion }\end{array}$ & estratificación entrecruzada planar & $\begin{array}{l}\text { capas de } 0,1 \mathrm{~m} \text {. Sets } \\
\text { de } 1 \mathrm{~m} \text { de espeseror }\end{array}$ & \begin{tabular}{|l} 
depósitios de formas de fondo de dunas $2 \mathrm{D}$ areno-gravosas, \\
originadas por flujos de sediimentos de baja densidad, unidireccionales
\end{tabular} \\
\hline & & sGh & $\begin{array}{l}\begin{array}{l}\text { areniscas guijarrosas de } \\
\text { granulometría gruesa a fina con } \\
\text { textura clalasto sostén, de moderada } \\
\text { selección }\end{array} \\
\end{array}$ & estratificación horizontal & $\begin{array}{l}0,1 \text { a o, } 3 \mathrm{~m} \text { de } \\
\text { espesoro capas } \\
\text { amalgamadas }\end{array}$ & 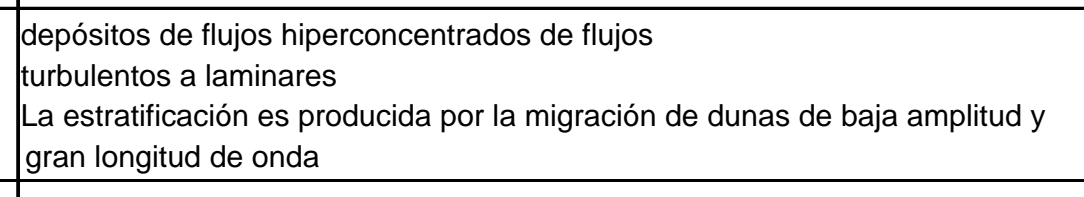 \\
\hline & & St & $\begin{array}{l}\text { areniscas gruesas a finas con } \\
\text { moderada a buena selección }\end{array}$ & $\begin{array}{l}\text { estratificación entrecruzada en artesa } \\
\text { gradación normal }\end{array}$ & sets de $0,01 \mathrm{~m}$ & 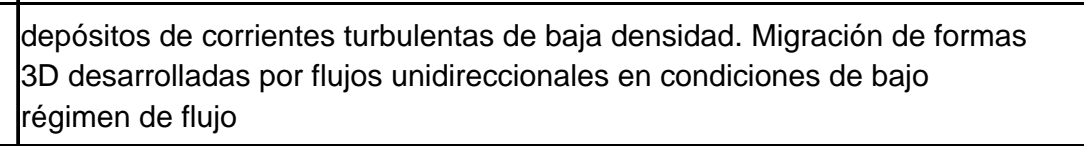 \\
\hline & & Sp & $\begin{array}{l}\text { areniscas gruesas a muy gruesas, de } \\
\text { moderada a buena selección }\end{array}$ & estratificación entrecruzada planar & $\begin{array}{l}\text { capas de } 102 \mathrm{~cm} \\
\text { de espesor. } \\
\text { Sets de } 0,3 \text { a } 0,7 \mathrm{~m}\end{array}$ & 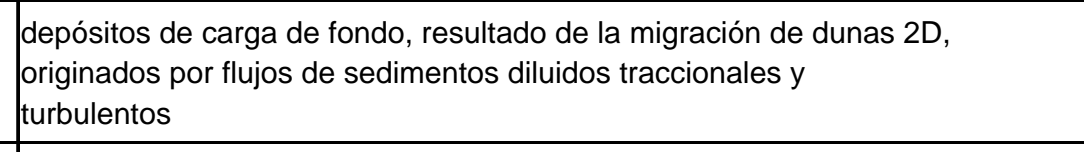 \\
\hline & & Sh & $\begin{array}{l}\text { arenincsas blanquecinas liticas o } \\
\text { tobaccas con granulumetria media a } \\
\text { fina y buena seleccion }\end{array}$ & $\begin{array}{l}\text { estrtatificación myy fina a alaminación } \\
\text { horizontal En ocasiones conn } \\
\text { deformación sinsedimentaria }\end{array}$ & $\begin{array}{l}0,1 \mathrm{a} 0,2 \mathrm{~m} \text { de } \\
\text { espesor }\end{array}$ & $\begin{array}{l}\text { depósitios de capa plana de alto régimen de flujo, originados por flujos de } \\
\text { sedimentos de baja densidad y turbulentos }\end{array}$ \\
\hline & & sm & $\begin{array}{l}\text { areniscas tobaceas o liticas, gruesas } \\
\text { a medias, de buena a moderada } \\
\text { selección }\end{array}$ & masiva o con gradación normal & $\begin{array}{l}0,10 \text { a } 0,2 \mathrm{~m} \mathrm{de} \\
\text { espesor }\end{array}$ & $\begin{array}{l}\text { depósitos de fflujos de detritios arenosos no conesivos, originados por flujos } \\
\text { aminares friccionales }\end{array}$ \\
\hline & & $\mathrm{Sr}$ & $\begin{array}{l}\text { areniscas tobáceas finas a medias, } \\
\text { de buena selección }\end{array}$ & $\begin{array}{l}\text { laminación ondulfitica y óndulas. } \\
\text { Con o sin deformación sinsedimentaria }\end{array}$ & $\mid \begin{array}{l}0,1 \mathrm{a} 0,25 \mathrm{~m} \text { de } \\
\text { espesor }\end{array}$ & 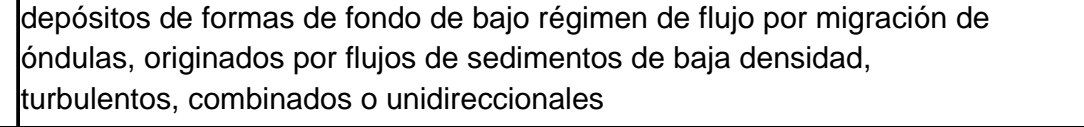 \\
\hline & & Shcs & $\begin{array}{l}\text { areniscas tobaceas blanquecinas, } \\
\text { finas anuy yninas y muy bien } \\
\text { seleccionadas }\end{array}$ & estratificación entrecruzada monticular & $\begin{array}{l}0,1 \mathrm{a} 0,2 \mathrm{~m} \text { de } \\
\text { esspesor }\end{array}$ & $\begin{array}{l}\text { depósitios de flujos de sedimentos de baja densidad combinados } \\
\text { osciliatorios y unidirieccionales }\end{array}$ \\
\hline & & Sn & $\begin{array}{l}\text { areniscas con granulometría variada y } \\
\text { con buena a moderada selección }\end{array}$ & $\begin{array}{l}\text { gradación normaly y laminación o capas } \\
\text { ondulosas en la parte superior }\end{array}$ & $\begin{array}{l}1,5 \text { a } 20 \mathrm{~cm} \mathrm{de} \\
\text { espesor }\end{array}$ & $\begin{array}{l}\text { depósitios marinos de corrientes de turbidez arenosas, originados por flujos } \\
\text { de sedimentos de alta densidad }\end{array}$ \\
\hline & \multirow[t]{2}{*}{ ș } & $\mathrm{PI}(\mathrm{a})$ & 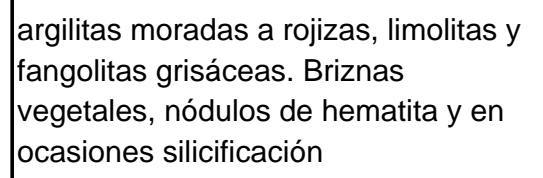 & masiva o laminadas & $\begin{array}{l}0,05 \text { a } 0,3 \mathrm{~m} \mathrm{de} \\
\text { espesor }\end{array}$ & depósitos de decantación de materiales finos en ambientes continentales \\
\hline & & $\mathrm{Pl}(\mathrm{b})$ & 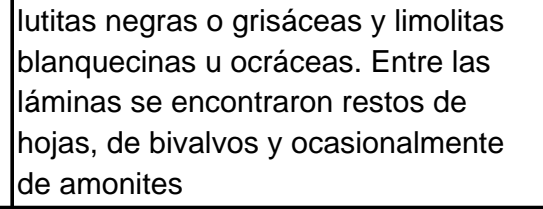 & masiva o laminadas & $\begin{array}{l}0,1 \text { a } 0,6 \mathrm{~m} \text { de } \\
\text { espesor }\end{array}$ & 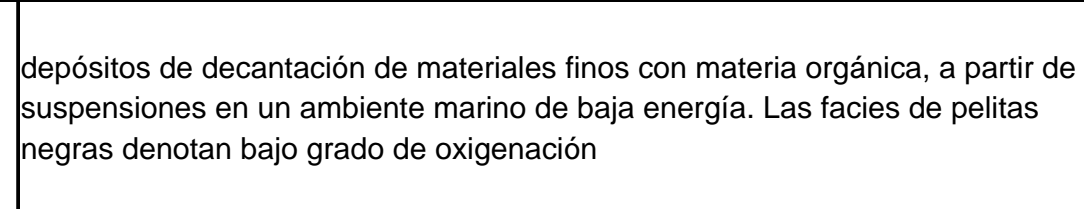 \\
\hline & & GR & $\begin{array}{l}\text { textura clasto sostén conformada por } \\
\text { ooides y fragmentos calcáreos }\end{array}$ & estratificación horizontal y entrecruzada & $\begin{array}{l}0,1,00,4 \mathrm{~m} \mathrm{de} \\
\text { espesor }\end{array}$ & 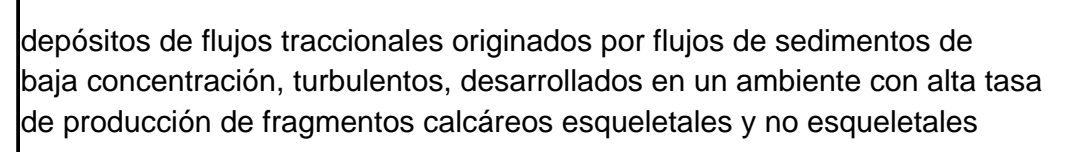 \\
\hline & & MI & $\begin{array}{l}\text { mudstones de colores grisáceos a } \\
\text { negros y tonalildades oscuras, parcial } \\
\text { o totalmente silicificados }\end{array}$ & laminación o estratificación fina & $\begin{array}{l}0,1 \mathrm{a} 0,2 \mathrm{~m} \text { de } \\
\text { espesor }\end{array}$ & $\begin{array}{l}\text { depósitios de decantación en un ambiente de baja energía con atta } \\
\text { producción de tengo carbonáatico y poco aporte clástico }\end{array}$ \\
\hline & & $\mathrm{BE}$ & 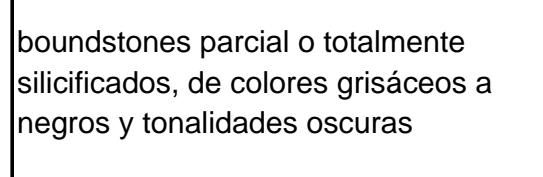 & $\begin{array}{l}\text { laminación, estructurar domosa a } \\
\text { columarar orignada por organismos } \\
\text { bicoconstructores }\end{array}$ & $\begin{array}{l}0,0,0 \text { a } 0,6 \mathrm{mde} \\
\text { espesor }\end{array}$ & 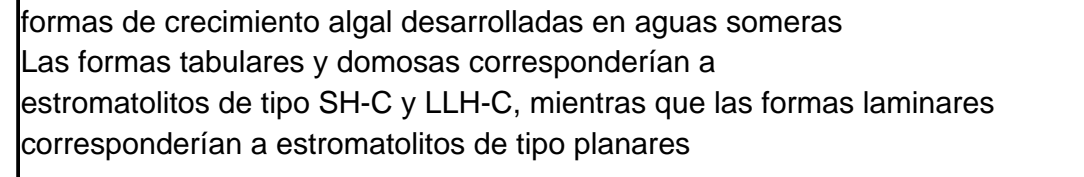 \\
\hline
\end{tabular}

\begin{tabular}{|c|c|c|c|c|c|}
\hline \multicolumn{2}{|c|}{ Rocas volcánicas } & \multicolumn{2}{|c|}{ Rocas piroclásticas } & \multicolumn{2}{|c|}{ Rocas epiclásticas y carbonáticas } \\
\hline código & litologia & código & $\begin{array}{l}\text { litologia } \\
\text { brachac }\end{array}$ & código & $\begin{array}{l}\text { litologia } \\
\text { brachach }\end{array}$ \\
\hline$\frac{\mathrm{LD}}{\mathrm{LD}}$ & lava dacítica & $\frac{\mathrm{Dl}}{\mathrm{L}}$ & $\begin{array}{l}\text { lapillititas } \\
\text { late }\end{array}$ & $\frac{D_{1}}{G}$ & conglomerados \\
\hline LR & lava riolíica & $\frac{T}{n}$ & $\frac{\text { tobas }}{\text { nomime }}$ & $\frac{\mathrm{S}}{\mathrm{P}}$ & $\begin{array}{l}\text { areniscas } \\
\text { pelitiss }\end{array}$ \\
\hline & & & & Gr & grainstones \\
\hline & & & & $\frac{\mathrm{M}}{\mathrm{BE}}$ & $\begin{array}{l}\text { mudsostones } \\
\text { boundstones estromatolitios }\end{array}$ \\
\hline código & estrtuctura & código & estructura & código & estructura \\
\hline $\mathrm{C}_{\mathrm{A}}$ & 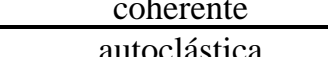 & $\frac{\mathrm{mb}}{\mathrm{dd}}$ & estratifiasica & $c \mathrm{c}$ & clasto sostén \\
\hline$\frac{\mathrm{FH}}{\mathrm{FH}}$ & fracturación hidráulicéc. & & estratificación & $\frac{m}{m}$ & 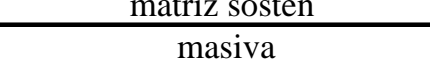 \\
\hline $\mathrm{PB}$ & pseudobrechada & //s & laminación & 1 & laminación \\
\hline$f$ & foliación por flujo & $\mathrm{xs}$ & estratificacíón entrecruzada & $\mathrm{h}$ & estratificación horizontal \\
\hline & & $\mathrm{i}$ & gradación inversa & $\mathrm{p}$ & $\begin{array}{l}\text { estratificación entrecruzada } \\
\text { planar }\end{array}$ \\
\hline & & $\mathrm{n}$ & gradación normal & $\mathrm{t}$ & $\begin{array}{c}\text { estratificación entrecruzada en } \\
\text { artesa }\end{array}$ \\
\hline & & in & gradación inversa-normal & $\mathrm{i}$ & gradación inversa \\
\hline & & pip & $\begin{array}{l}\text { estructura de escape de } \\
\text { gases }\end{array}$ & $\mathrm{n}$ & gradación normal \\
\hline & & e & estructura eutaxíica & in & gradación inversa-normal \\
\hline & os en este trabajo & Tomados & 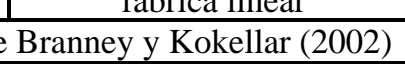 & $\mathrm{M}$ & ficados de Miall (1978) \\
\hline
\end{tabular}

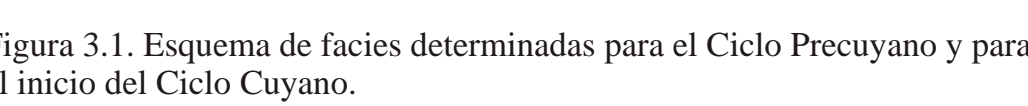




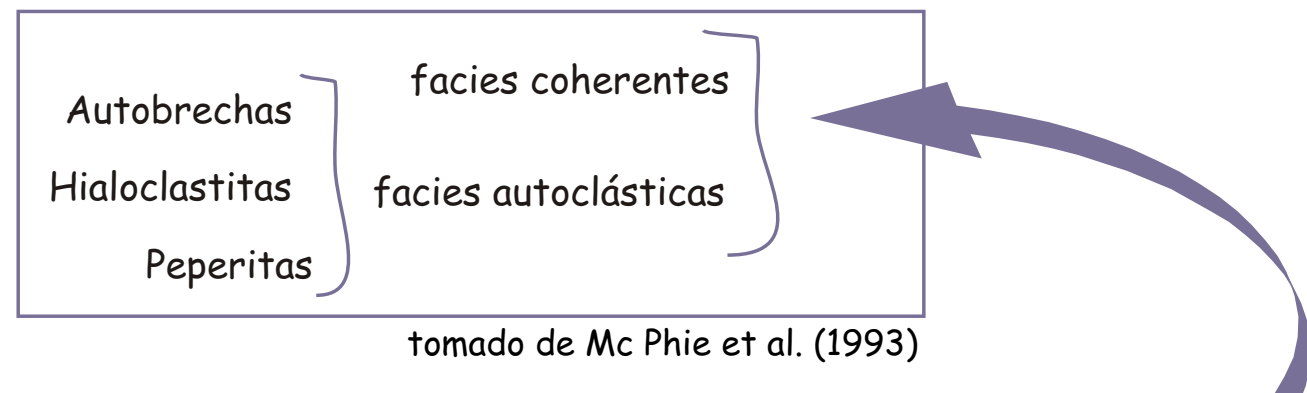

\begin{tabular}{|c|l|l|l|l|l|}
\hline & COD & TEXTURA & ESTRUCTURA & DIMENSIONES & INTERPRETACIÓN \\
\hline LITOFACIES DE & & & & & \\
LAVAS Y ROCAS & & & & & \\
VOLCANICLÁSTICAS & & & & & \\
ASOCIADAS & & & & & \\
\hline LITOFACIES & & & & & \\
PIROCLÁSTICAS & & & & & \\
\hline $\begin{array}{c}\text { LITOFACIES EPICLÁSTICAS } \\
\text { Y CARBONÁTICAS }\end{array}$ & & & & & \\
\hline
\end{tabular}

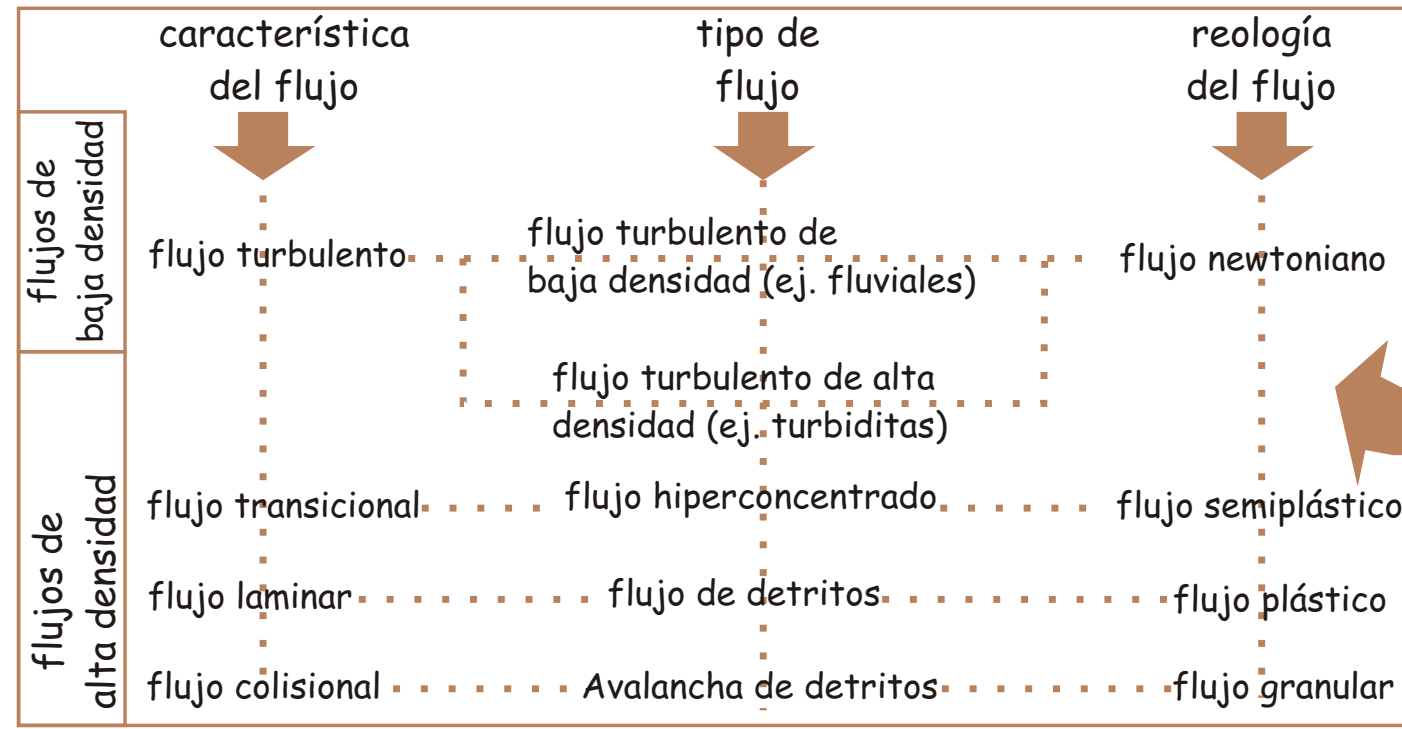

modificado de Dasgupta (2003)

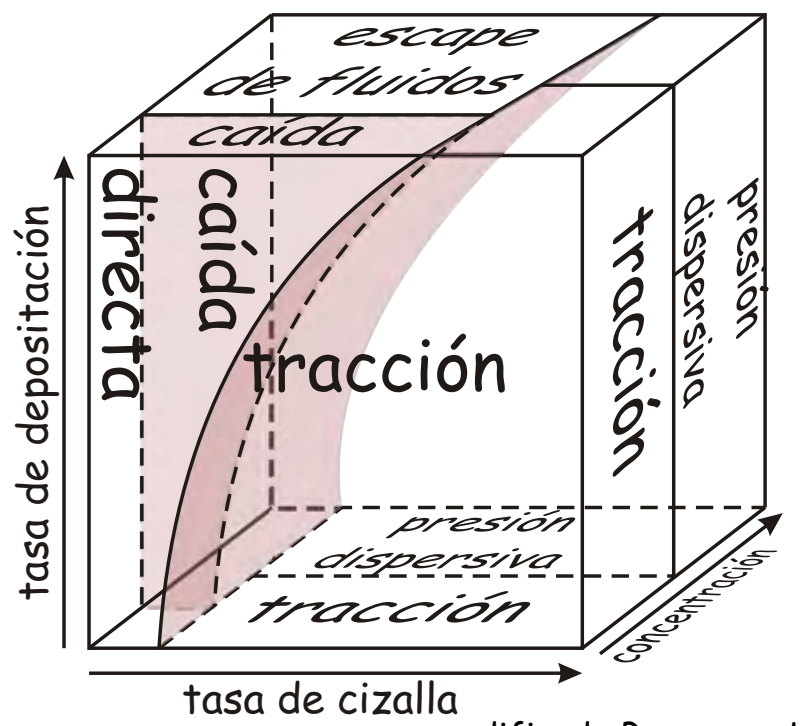

modificado Branney y Kokelaar (2002)

Figura 3.2. Conceptos básicos para la interpretación dinámica de las facies definidas para este estudio. 


\subsection{2) Litofacies volcánicas}

Lavas andesitas coherentes (LAC)

Se presentan como lavas andesíticas coherentes, de colores grisáceos y tonalidades oscuras, con fenocristales de Pg y minoritariamente de $\mathrm{Hbl}$ que conforman una textura porfírica. Desde el punto de vista estructural, se muestran generalmente masivas (fig. 3.3) y ocasionalmente, cuando aparecen con textura microporfírica, con foliación por flujo y pliegues por flujo (fig. 3.4). En ocasiones cuando esta facies se apoyan sobre litofacies de pelitas laminadas $\mathrm{Pl}(\mathrm{a})$, desarrollan en su base una profusa estructura amigdaloide y vesicular evidenciando un significativo proceso de cavitación. Es importante destacar que en algunos afloramientos se encontraron litoclastos de rocas esquistosas de hasta $10 \mathrm{~cm}$ diámetro.

\section{Interpretación}

Se forman por la solidificación de lavas de composición andesítica que experimentaron un período de crecimiento de fenocristales, seguido por una etapa de rápida nucleación y escaso crecimiento, resultado de un enfriamiento rápido en un ambiente subaéreo o próximo a él (Best y Christiansen, 2000).

\section{Lavas andesíticas autoclásticas (LAA)}

Se encuentran asociadas a las facies de lavas andesíticas coherentes. Al igual que éstas están conformadas por lavas andesíticas con texturas porfírica y microporfírica, con fenocristales de Pg y minoritariamente de Hbl. Yacen en cuerpos irregulares, interiormente constituidos por una autobrecha, donde los clastos se presentan masivos, angulosos, total o parcialmente oxidados, con tamaños de centímetros a metros de diámetros (fig. 3.5).

Interpretación

Se originan por la solidificación de una lava de composición andesítica, donde variables como la viscosidad y tasa de deformación se conjugaron favorablemente para que desarrolle un proceso autoclástico no explosivo: autobrechamiento subaéreo (Mc Phie et al., 1993; Sigurdsson et al., 2000).

\section{Lavas andesíticas fracturadas y cementadas (LAFH)}

Corresponden a las facies de lavas andesíticas coherentes que presentan una fracturación importante de tipo rompecabezas, donde los clastos son cementados por sílice o carbonatos (fig. 3.6). Esta facies puede aparecer localmente o desarrollarse por decenas de metros en sentido lateral.

\section{Interpretación}




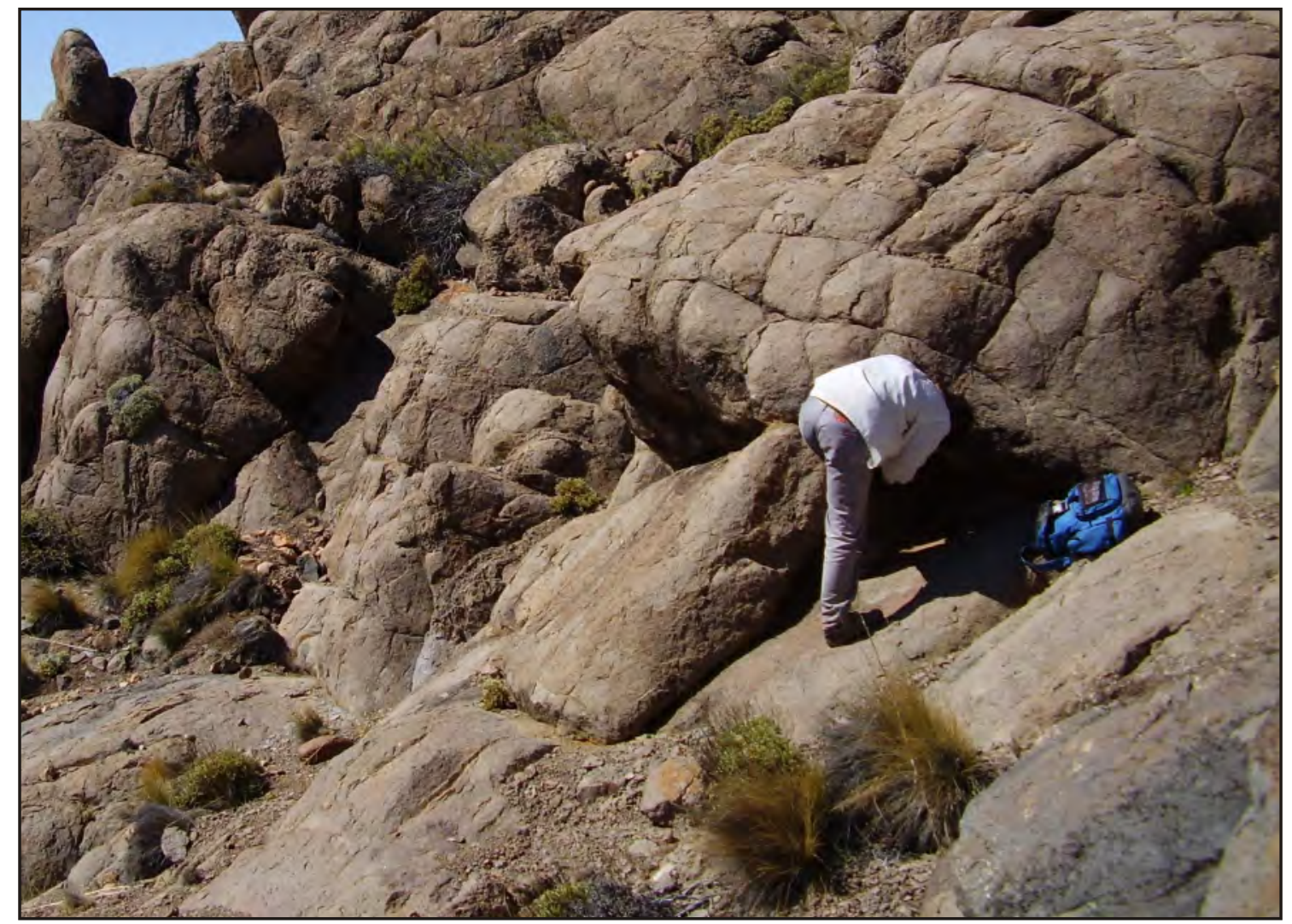

Figura 3.3. Facies de lavas andesíticas coherentes masivas con textura porfírica (LAC).

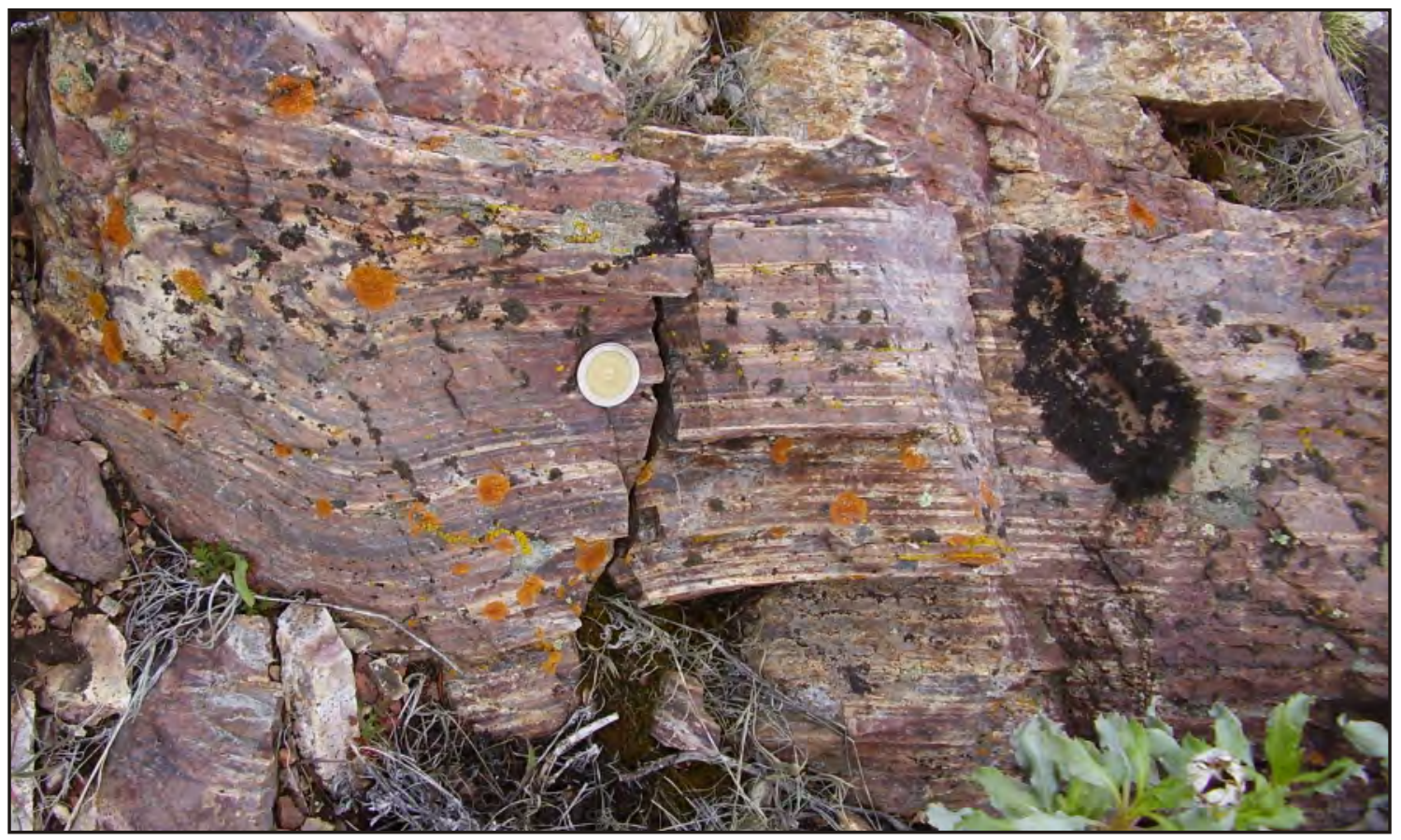

Figura 3.4. Lavas andesíticas coherentes con textura microporfírica y foliación por flujo (LACf). 


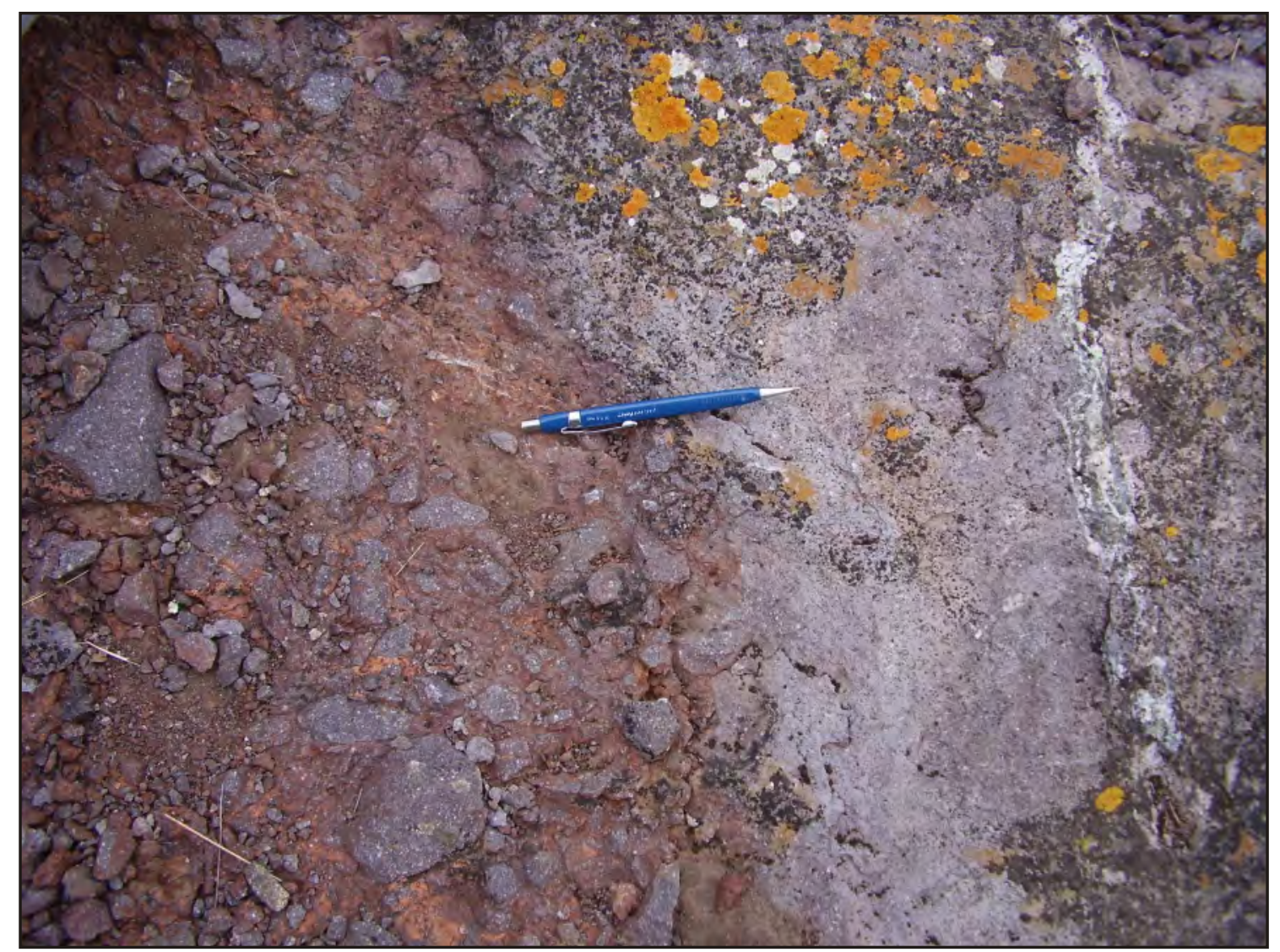

Figura 3.5.Facies de lavas andesíticas coherentes (LAC) que pasan a desarrollar facies de lavas andesíticas autoclásticas (LAA).

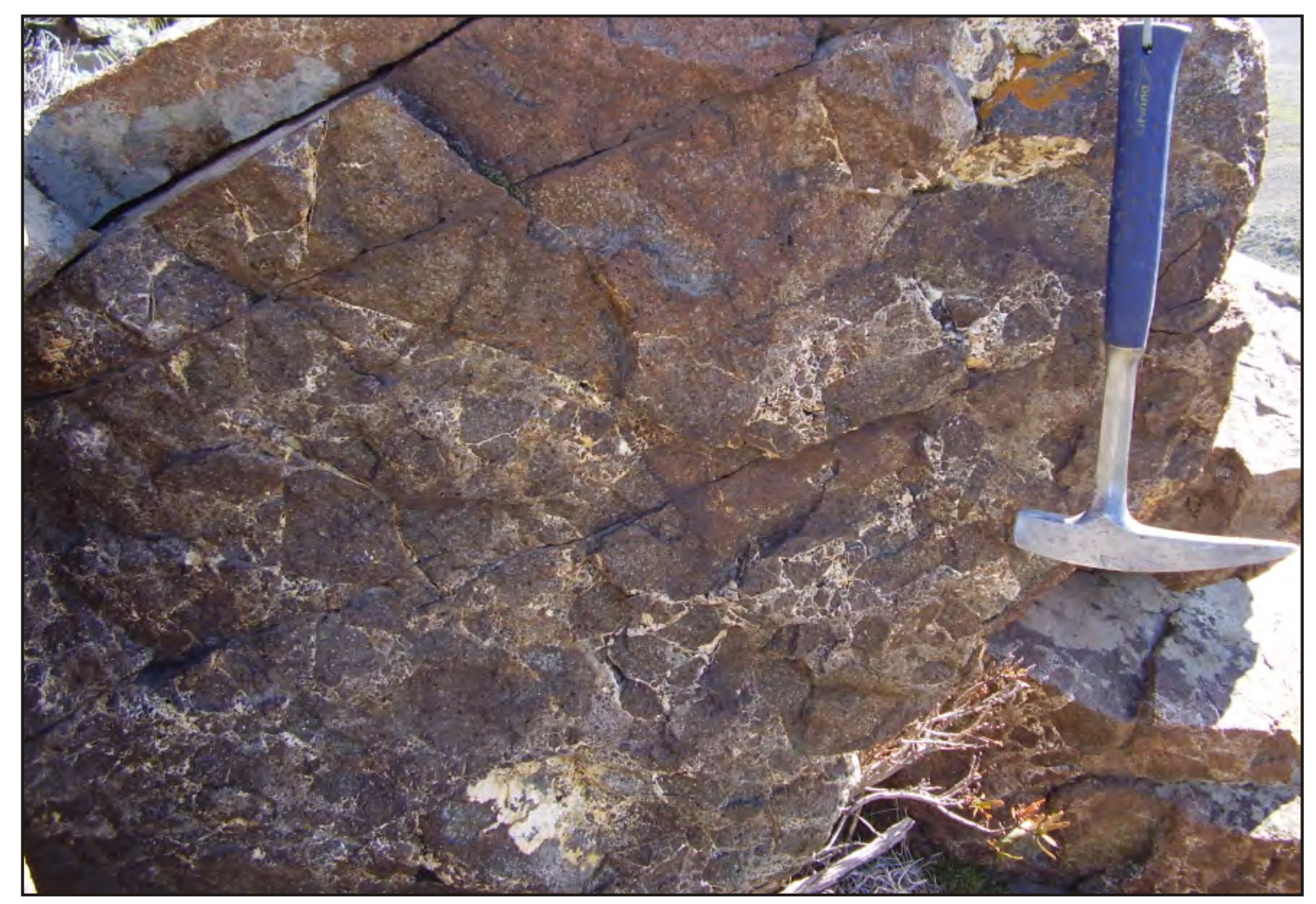

Figura 3.6. Facies de lavas andesíticas fracturadas por la acción de fluidos que circularon a altas presiones (LAFH). 
Se forman por la circulación de fluidos silíceos o carbonáticos a alta presiones que originan la fracturación hidráulica y la cementación de la lava (Mc Phie et al., 1993).

\section{Lavas andesíticas pseudobrechadas (LAPB)}

Lavas andesíticas coherentes, las cuales desarrollan "sombras" de clastos, que le dan una apariencia de autobrecha (fig. 3.7). Esta facies pasa lateralmente a las facies coherentes (LAC).

\section{Interpretación}

Corresponden a lavas coherentes que desarrollan una pseudotextura de tipo pseudobrechada producto de diferentes fases de alteración que actúan sobre fracturas formadas en los cuerpos de las lavas coherentes (Mc Phie et al., 1993; Gifkins et al., 2005).

\section{Lavas dacíticas coherentes (LDC)}

Se componen de lavas de composición dacítica coherentes de colores grisáceos, con texturas porfíricas y seriadas, donde el porcentaje de fenocristales puede llegar al $45 \%$ del volumen de la roca. Los fenocristales más abundantes son los de Pg y Hbl y minoritariamente se encuentran de Qtz. (fig. 3.8).

\section{Interpretación}

Se forman por la solidificación de un magma de composición dacítica en condiciones subvolcánicas que sufrió un enfriamiento intermedio entre una roca volcánica y plutónica.

\section{Lavas riolíticas y riodacíticas coherentes (LRC(f))}

Se muestran como lavas coherentes de composiciones riolíticas o riodacíticas de colores rosados a castaños, con textura porfírica constituida por fenocristales de Qtz, Pg, FK y Bt. Internamente se presentan masivas o con foliación por flujo (fig. 3.9), parcial o totalmente silicificadas, exhibiendo en ocasiones, de manera aislada, fragmentos accidentales de lavas andesíticas.

\section{Interpretación}

Se forman por la solidificación de una lava de composición riolítica/riodacítica que sufrió un enfriamiento rápido en un ambiente subaéreo o próximo a él (Best y Christiansen, 2000). La foliación por flujo evidencia un gradiente de velocidad en el flujo durante su deformación (Best y Christiansen, 2000). 


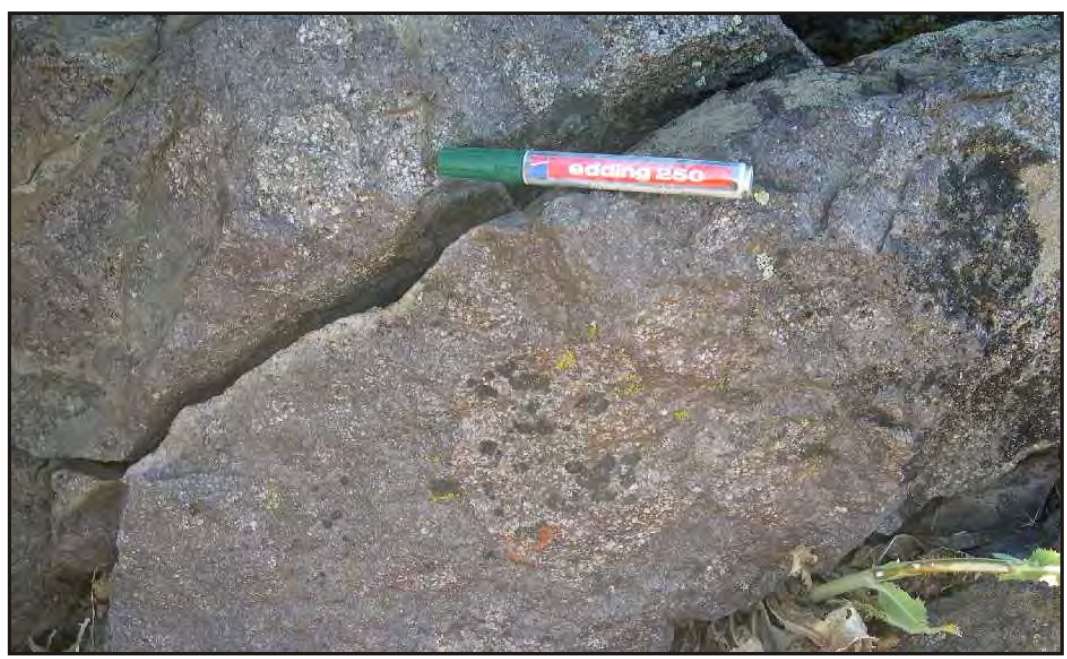

Figura 3.7. Facies de lavas andesíticas coherentes que desarrollan una textura pseudobrechada (LAPB).

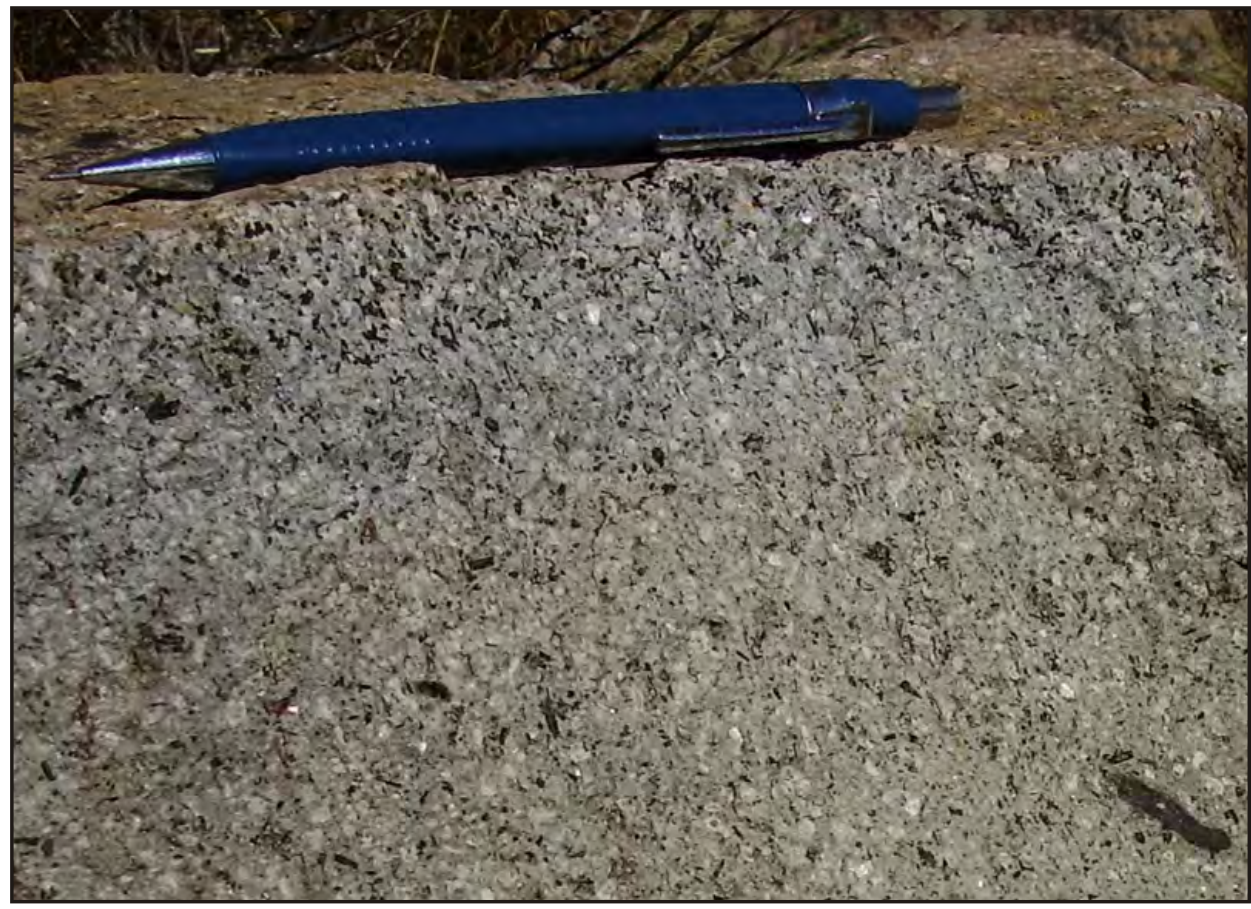

Figura 3.8. Facies de lavas dacíticas coherentes con abundantes fenocristales (LDC).

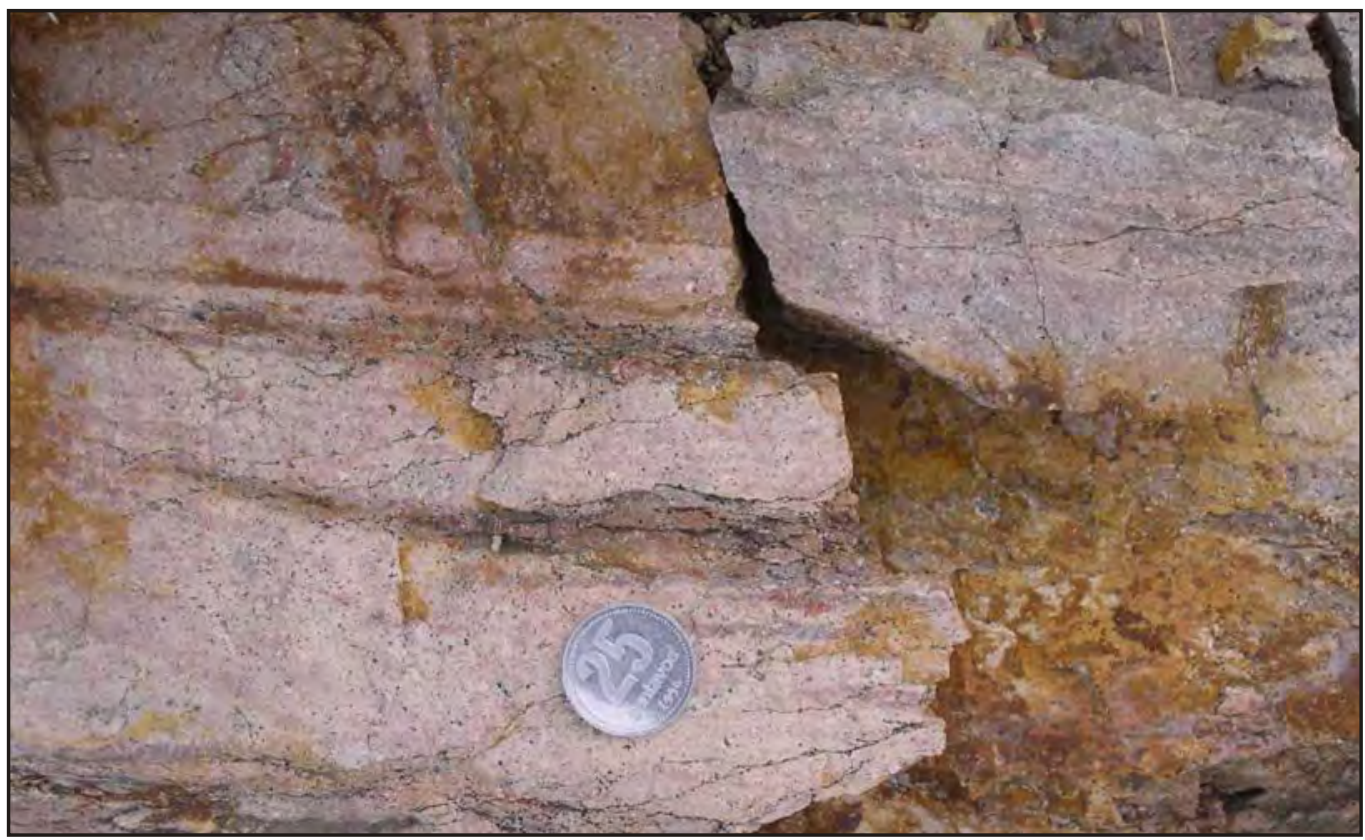

Figura 3.9. Facies de lavas riolíticas y riodacíticas coherentes con foliación por flujo (LRCf). 


\subsection{3) Litofacies piroclásticas}

Brechas líticas masivas ( $\mathrm{mlBr}$ )

Se dan en cuerpos tabulares o lenticulares limitados por estratificación difusa, con espesores de alrededor de 2,5 m. Están constituidos por una brecha con bloques, lapillos y cenizas gruesas que conforman textura clasto sostén polimodal (fig. 3.10) o matriz sostén, de moderada a pobre selección. La matriz de esta facies es de granulometría lapillita fina a una toba gruesa y con lapillos pumíceos de hasta $4 \mathrm{~cm}$. Los fenoclastos son subangulosos, subredondeados y redondeados, y van desde tamaño 0,1 m hasta bloques de 0,6 m. Los litoclastos son de composiciones variables, generalmente de andesitas y del basamento ígneometamórfico. Es importante destacar que en el perfil RA 3 esta facies se presenta con un tronco silicificado de $1 \mathrm{~m}$ de largo y 0,68 $\mathrm{m}$ de diámetro. Internamente esta facies se muestra masiva o en ocasiones con litoclastos orientados con los ejes mayores paralelos a la estratificación difusa externa.

Interpretación

Depósitos de corrientes piroclásticas con límite de flujo inferior dominado por flujo granular (clastos alineados) y/o escape de fluidos (clastos distribuidos al azar) (Branney y Kokelaar, 2002).

Brechas líticas con gradación inversa grosera clasto-sostén (mlBri)

Se presentan como cuerpos de geometría tabular bien definidos, con espesores de entre 1 m y 4 m (fig. 3.11), masivos o con tendencia a la gradación inversa grosera. Poseen textura clasto sostén polimodal, con poca matriz lapillítica-tobácea y pobre selección, con colores morados o grisáceos de tonalidades oscuras. El tamaño de fenoclasto que abunda es de centimétrico a decimétrico, difícilmente superando los 50 centímetros. La morfología de los clastos es generalmente subredondeada, hasta subangulosa. Con respecto a la composición, están constituidas principalmente de volcaniclastos juveniles con homogeneidad textural, conformados de rocas andesíticas porfíricas a microporfíricas y vitroclastos blocosos.

Interpretación

Depósitos de flujos de bloques y cenizas resultado del colapso gravitatorio de domos, coladas dómicas y/o flujos de lavas (Cas y Wright, 1987, Mc Phie et al. 1993, Miller et al., 1999; Schwarzkopf et al., 2005; Németh y Ulrike, 2007). Originados por flujos granulares modificados por escape de gases (Cas y Wright, 1987; Schwarzkopf et al., 2005).

Tobas lapillíticas masivas (mLT), con estructuras de escape de gases (mLTpip), con fábricas direccionales (mLTf) 


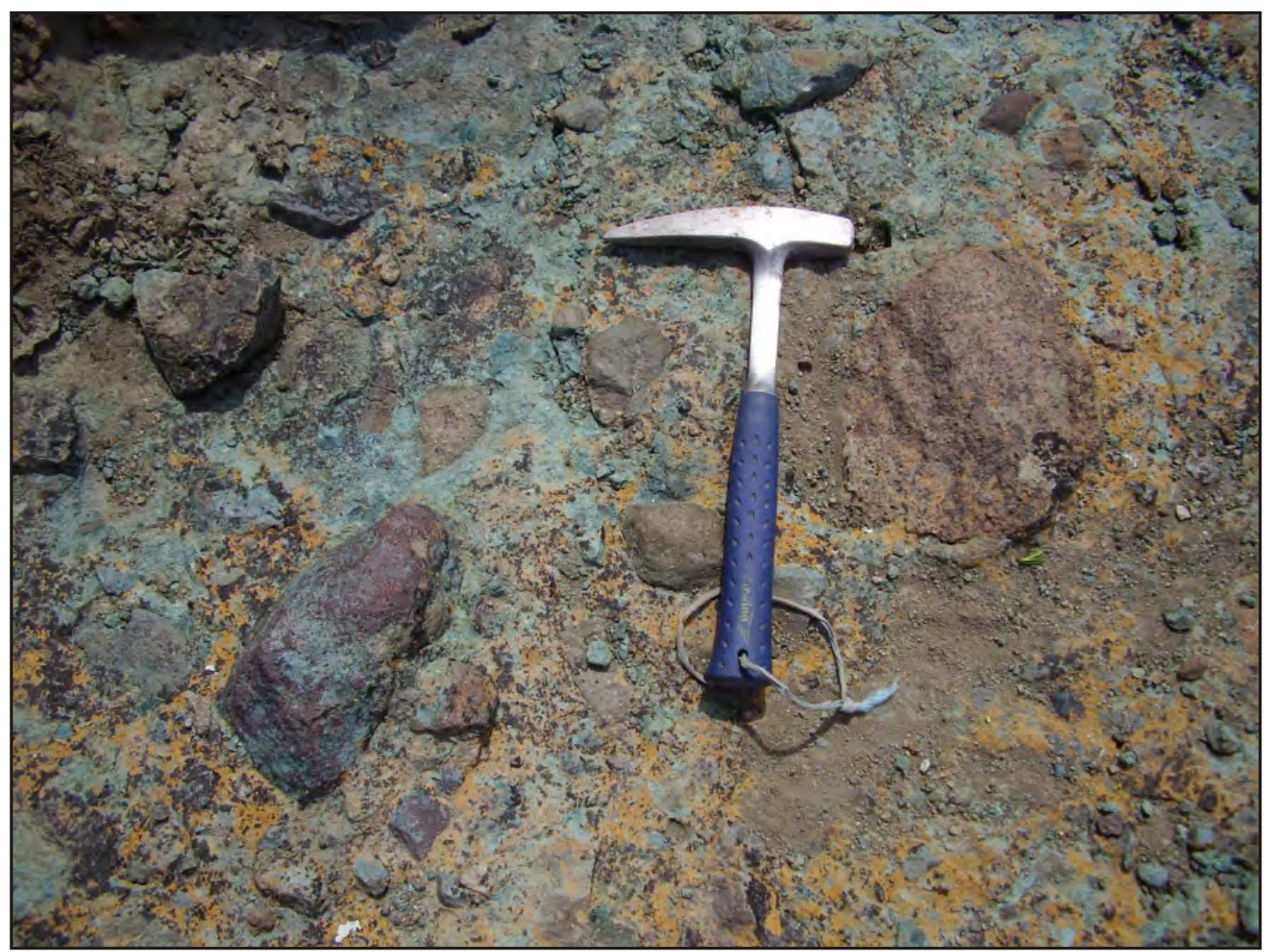

Figura 3.10. Facies piroclásticas de brechas líticas masivas $(\mathrm{mlBr})$ resultado de la depositación de corrientes piroclásticas granulares en base fluida, con límite de flujo inferior dominado por flujo granular y/o escape de fluidos.

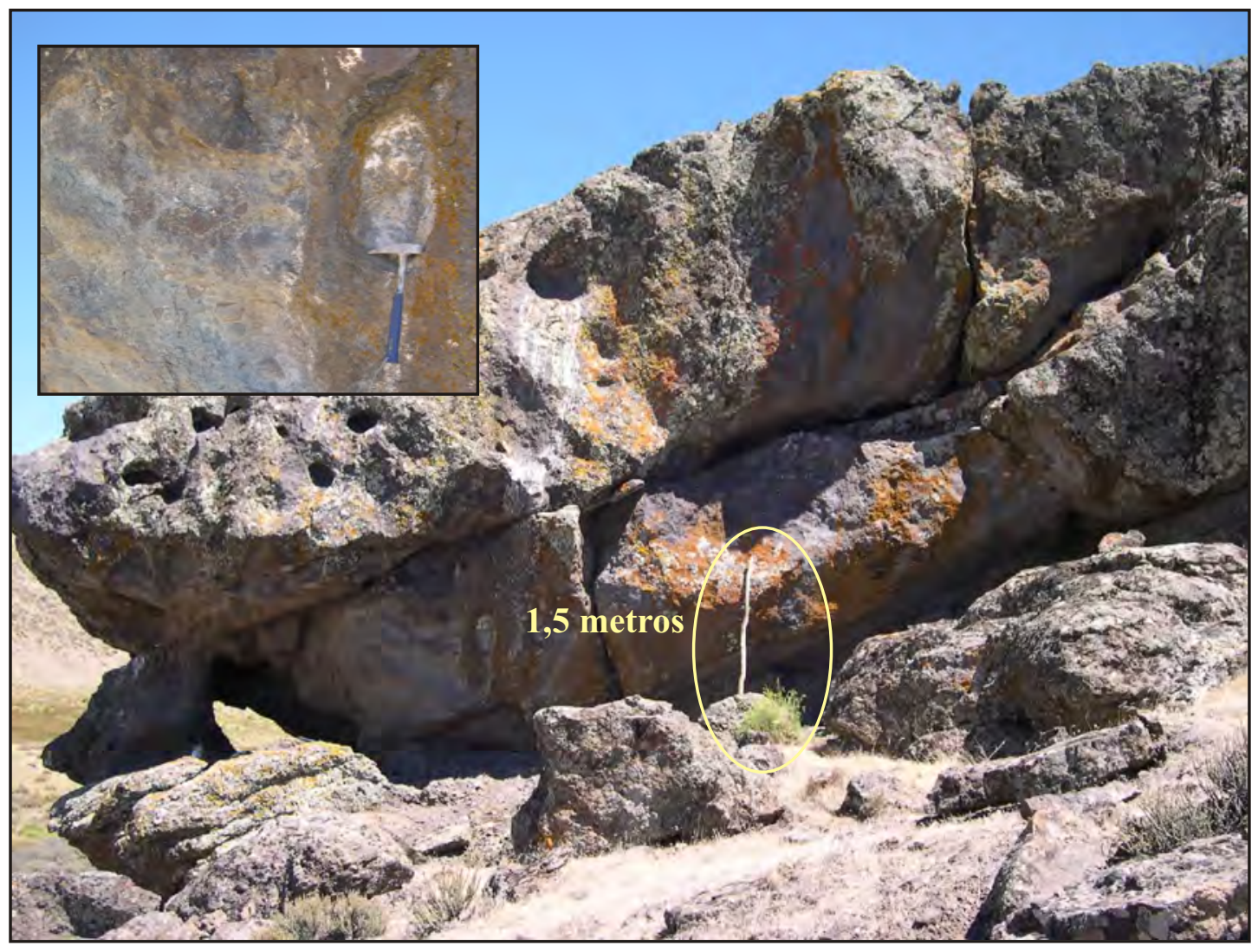

Figura 3.11. Facies piroclásticas de brechas líticas masivas con gradación inversa grosera clasto-sostén (mlBri) originadas por la depositación de depósitos de flujos de bloques y cenizas. 
Se presentan como cuerpos tabulares a levemente lenticulares de $0,2 \mathrm{~m}$ a $1,5 \mathrm{~m}$ de espesor o sin límites externos, formando grandes paquetes amalgamados de decenas de metros de espesor. Internamente se constituyen por tobas lapillíticas masivas, matriz sostén, de colores blanquecinos, rosados o verdosos (fig. 3.12). Poseen lapillos pumíceos angulosos y subangulosos, generalmente con canalículos de escape de gases paralelos y con tamaños de 1 a $2 \mathrm{~cm}$, llegando en ocasiones a $5 \mathrm{~cm}$. Se muestran con cantidades variables de litoclastos, correspondientes al basamento ígneo-metamórfico o a volcanitas ácidas e intermedias, con tamaños de entre $3 \mathrm{~cm}$ y $10 \mathrm{~cm}$ y tamaños máximos de $30 \mathrm{~cm}$. Esta facies puede exhibirse con los lapillos distribuidos aleatoriamente (mLT) o alineados paralelos a la estatificación externa (mLTf). En determinadas ocasiones se exponen estructuras de escape de gases de 7 a $17 \mathrm{~cm}$ de diámetro y de entre 0,6 m y 2 m de alto (fig. 3.13), concentrando internamente cristaloclastos y litoclastos (mLTpip).

\section{Interpretación}

Depósitos de corrientes piroclásticas, donde la naturaleza masiva indica que la turbulencia fue suprimida en la parte inferior de la misma (Branney y Kokelaar, 2002; Brown et al., 2007; Kokelaar, et al., 2007). Las variaciones sin fábrica linear (mLT) responden a corrientes piroclásticas con límites de flujo inferior dominados por escape de fluidos, mientras que las facies con fabrica linear (mLTf) registran procesos en la zona de límite inferior dominados por escape de fluidos con una componente de cizalla, por ende flujo granular (Branney y Kokelaar, 2002). Las facies con estructuras de escape de gases (mLTpip), denotan escape de fluidos en depósitos de rápida agradación.

\section{Tobas lapillíticas masivas con fiammes (emLT)}

Se componen de tobas lapillíticas matriz sostén de colores rosados, coherentes, con pómez totalmente colapsados, sin porosidad, conformando fiammes de entre $1 \mathrm{~cm} \mathrm{y} 5 \mathrm{~cm}$. En general se presentan libres de litoclastos, internamente masivas sin mostrar límites externos bien definidos, conformando grandes “paquetes” de decenas de metros.

\section{Interpretación}

Depósitos de corrientes piroclásticas originadas por arriba de la temperatura de transición del vidrio, las cuales se enfriaron lentamente luego de su depositación. La naturaleza masiva indica que la turbulencia fue suprimida en la parte inferior de la corriente (Branney y Kokelaar, 2002; Brown et al., 2007).

\section{Tobas lapillíticas con estratificación difusa ( $d b L T$ )}

Yacen como una roca friable, de colores grises a blanquecinos de tonalidades claras, en cuerpos tabulares de $1,5 \mathrm{~m}$ a $0,1 \mathrm{~m}$, con contactos planos o irregulares, netos o transicionales 


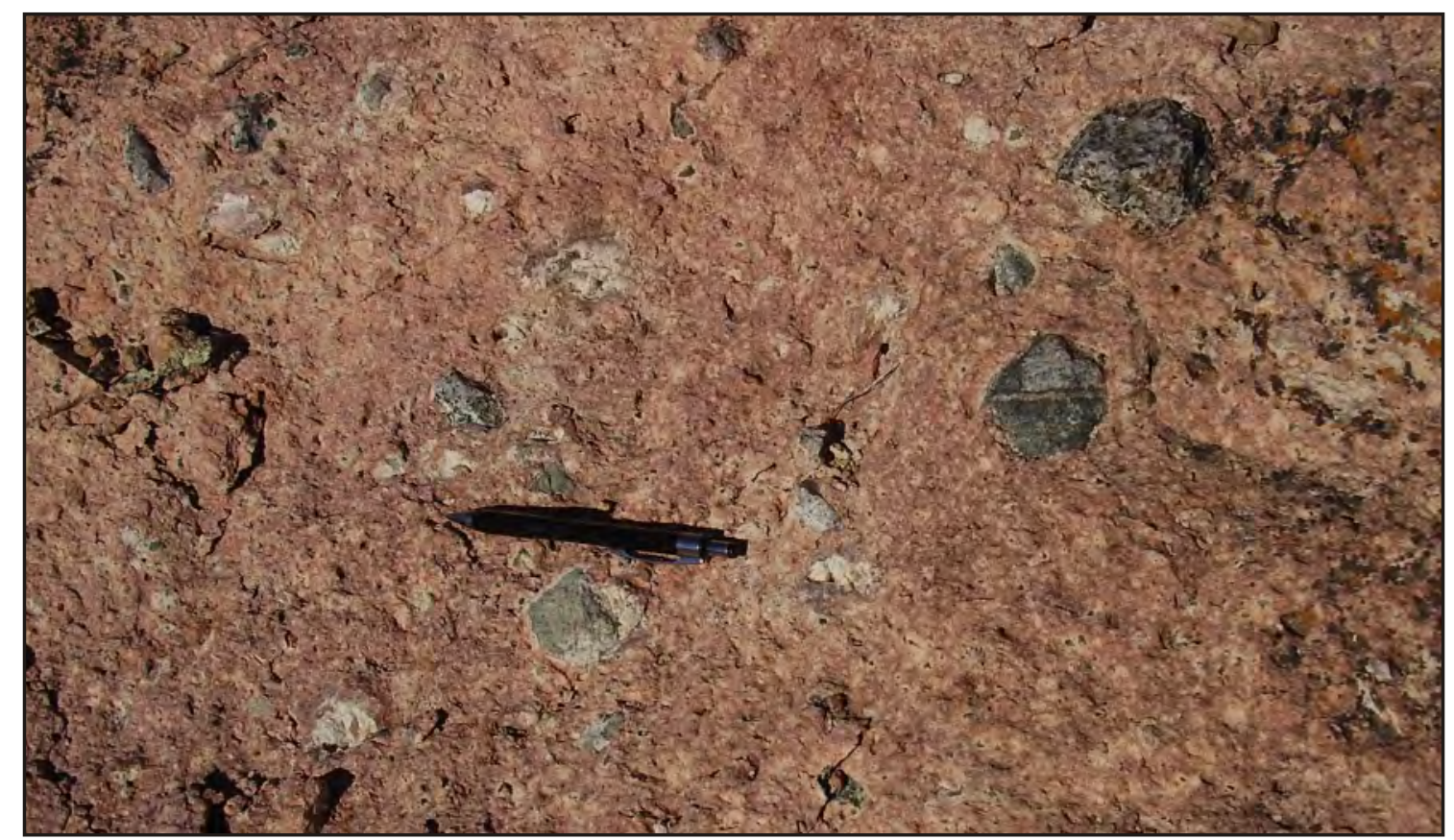

Figura 3.12. Facies piroclásticas de tobas lapillíticas masivas (mLT) originadas por depósitos de corrientes piroclásticas con límites de flujo inferior en donde se suprimió la turbulencia.

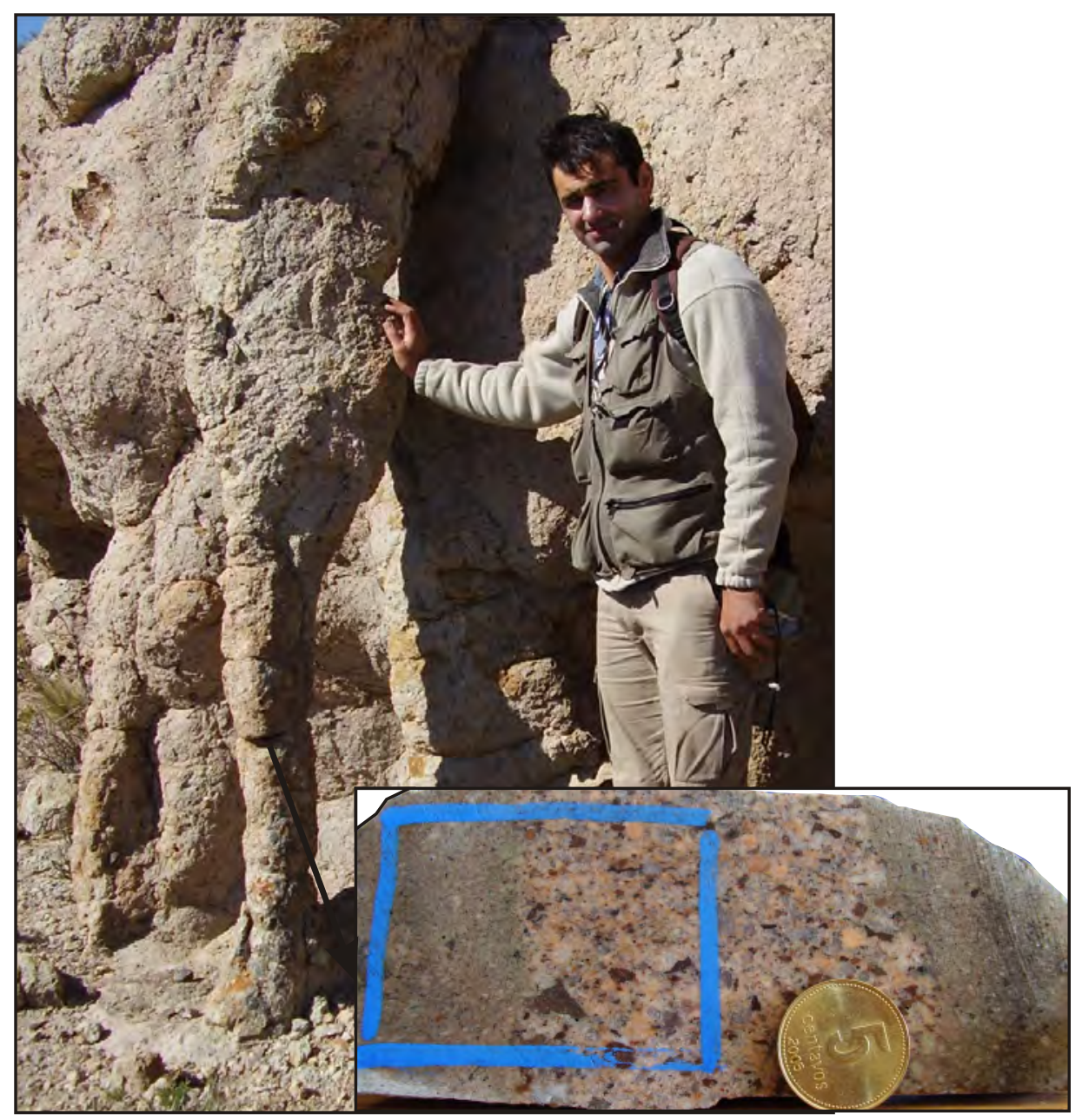

Figura 3.13. Canales de escape de gases desarrollados en las facies piroclásticas de tobas lapillíticas masivas (mLTpip). 
(fig. 3.14). Se caracterizan por ser tobas lapillíticas matriz sostén a clasto sostén, con moderada a pobre selección. Presentan lapillos pumíceos de hasta $3 \mathrm{~cm}$, con canalículos de escape de gases paralelos y, de manera aislada, lapillos líticos de rocas volcánicas. Internamente se presentan con estratificación fina difusa y en algunas ocasiones pueden mostrar gradación normal (fig. 3.14).

Interpretación

Depósitos de corrientes piroclásticas con un límite inferior de flujo inestable dominado por condiciones intermedias entre tracción y escape de fluidos, probablemente con una componente de flujo granular (Branney y Kokelaar, 2002; Brown, et al., 2007; Kokelaar et al., 2007).

Tobas lapillíticas finas con laminación paralela //sLT

Se presentan como cuerpos tabulares de $20 \mathrm{~cm}$ de espesor o conformando estructuras de corte y relleno, con límites inferiores erosivos y espesores variables (fig. 3.15). Desde el punto de vista estructural, tienen una estratificación muy fina a laminación. Están conformadas por tobas lapillíticas finas, con texturas clasto sostén de moderada selección. Al igual que las facies dbLT, los lapillos pumíceos se presentan con tamaños de $3 \mathrm{~mm}$ a $1 \mathrm{~cm}$ y los litoclastos se presentan escasos o ausentes.

Interpretación

Depósitos de corrientes piroclásticas que experimentaron condiciones tractivas en la zona del límite inferior de flujo. Las estructuras de corte y relleno indican condiciones de baja tasa de agradación y/o inestabilidad de la corriente, mientras que las capas tabulares sugieren periodos de alta agradación bajo condiciones cuasi-estables (Branney y Kokelaar, 2002; Brown et al., 2007).

Tobas lapillíticas con estratificación entrecruzada a gran escala (xsLT(a))

Se componen de bancos de entre $9 \mathrm{~cm}$ y $22 \mathrm{~cm}$ de espesor con geometrías tabulares, cuneiformes y lenticulares que conforman una estratificación entrecruzada a gran escala con sets de hasta 1,5 m de espesor depositados sobre una superficie erosiva (fig. 3.16). Internamente las capas frontales están compuestas por tobas lapillíticas rosadas, matriz sostén, masivas, con lapillos pumíceos angulosos con tamaños de entre $1 \mathrm{~cm}$ y 1,5 cm. Es importante destacar que esta facies lateralmente pasa a facies de tobas lapillíticas masivas (mLT) o a facies de tobas y lapillitas masivas con estructura de escape de gases (mLTpip).

Interpretación 


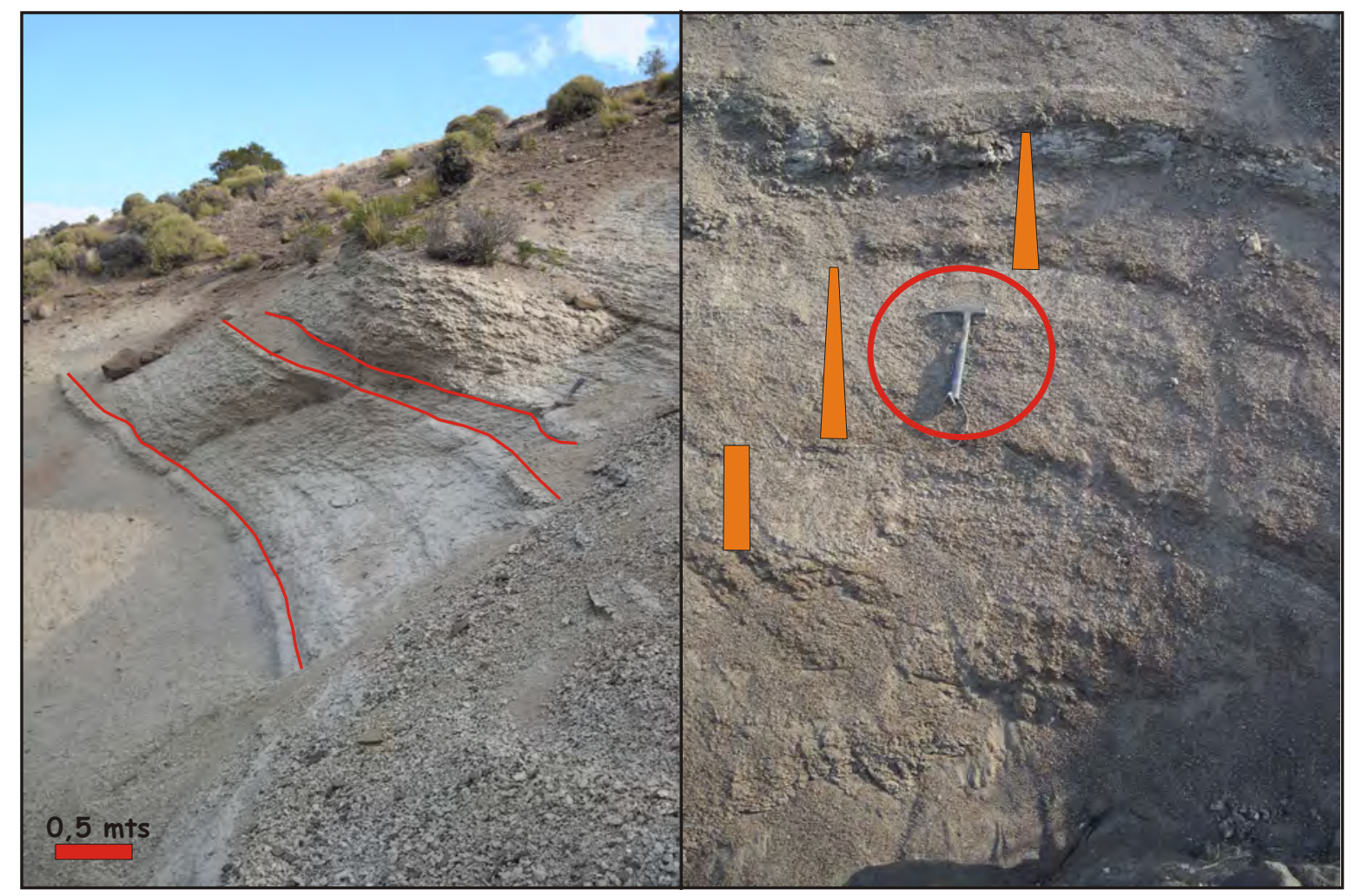

Figura 3.14. Facies piroclásticas de tobas lapillíticas con estratificación difusa (dbLT) originadas por la depositación de corrientes piroclásticas con límites de flujo inferior con condiciones intermedias entre tracción y escape de gases.

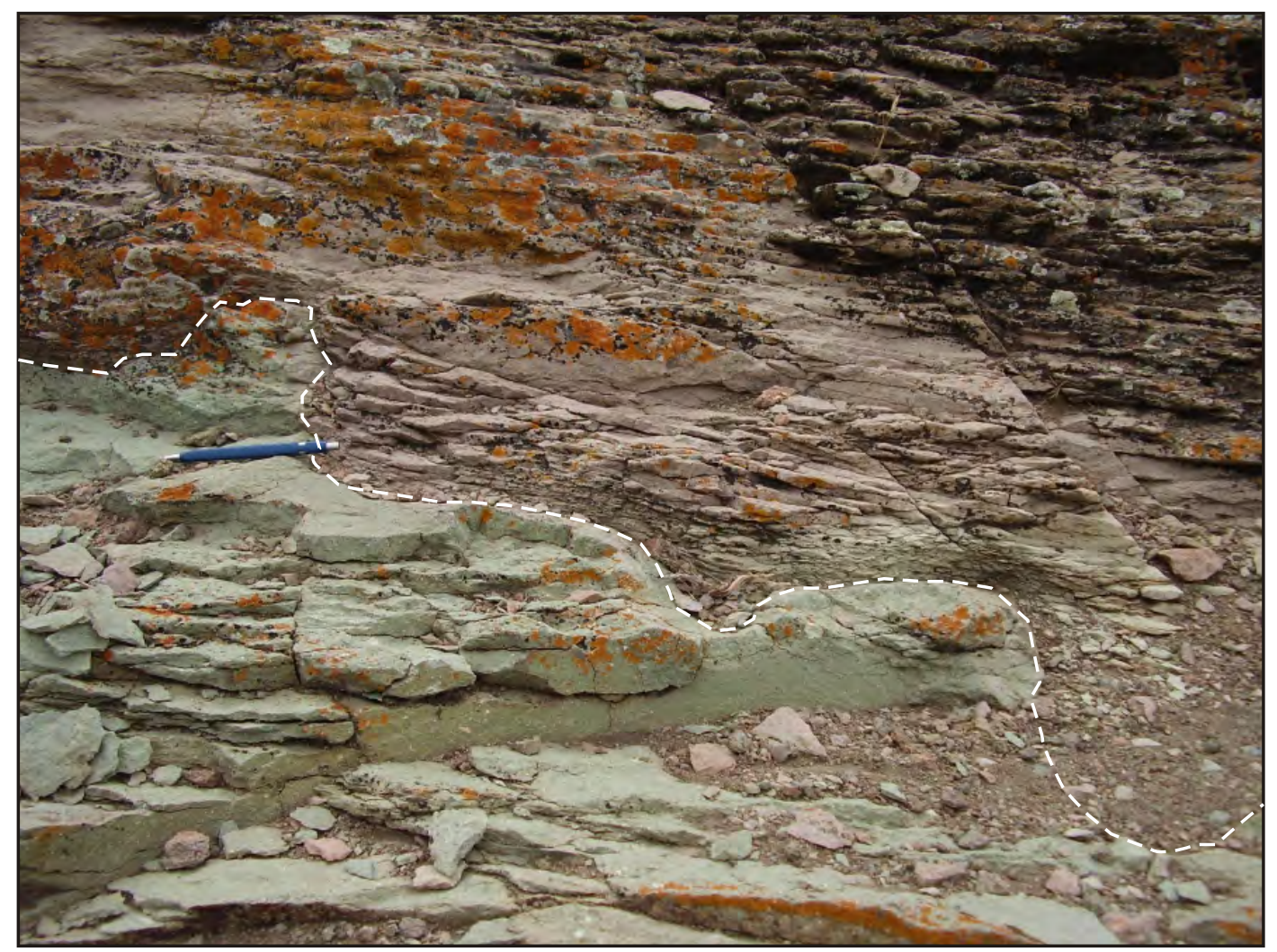

Figura 3.15. Facies piroclásticas de tobas lapillíticas con estratificación paralela (//sLT) rellenando superficies de corte y relleno. Se forman por la depositación de corrientes piroclásticas con límites de flujo inferior dominados por tracción. 
Representan depósitos de corrientes piroclásticas inestables (superficie erosiva) y no uniformes (variación lateral hacia facies masivas). Individualmente las capas representan límites de flujo inferior dominados flujos granulares y/o escape de gases. (Branney y Kokelaar, 2002).

Tobas lapillíticas con estratificación entrecruzada de bajo ángulo (xsLT(b))

Se presentan como cuerpos tabulares a lenticulares con potencias de entre $20 \mathrm{~cm}$ a 70 cm o conformando estructuras de corte y relleno. Internamente se componen de tobas lapillíticas finas, con texturas clasto sostén con moderada selección y estratificación entrecruzada de bajo ángulo. Al igual que la facies dbLT, los lapillos pumíceos se muestran con tamaños de $3 \mathrm{~mm}$ a 1 cm y los litoclastos se presentan escasos o ausentes.

Interpretación

Depósitos de corrientes piroclásticas con límites de flujo inferior dominados por tracción. Las estructuras de corte y relleno indican condiciones de baja tasa de agradación y/o inestabilidad de la corriente (Branney y Kokelaar, 2002; Brown et al., 2007).

\section{Lapillitas pumíceas masivas ( $p m L$ )}

Se componen de lapillitas pumíceas con textura clasto sostén de moderada a buena selección (fig. 3.17). Los pómez se presentan con colores rosados, canalículos de escape de gases paralelos, formas angulosas y subangulosas, y tamaños $1 \mathrm{~cm}$ a $10 \mathrm{~cm}$. Además se presentan litoclastos menores a $1 \mathrm{~cm}$ constituidos de cuarzo policristalino, volcanitas y rocas metamórficas esquistosas.

\section{Interpretación}

Depósitos a partir de una corriente piroclástica con límites de flujo inferior dominados por escape de gases o por de caída directa (fallout) (Branney y Kokelaar, 2002). Asimismo pueden representar depósitos de caída proximal desde una columna eruptiva pliniana o subpliniana (Fisher y Schmincke, 1987; Cas y Wright, 1987; Branney y Kokelaar, 2002).

\section{Tobas con estratificación entrecruzada (xsT)}

Se presentan en cuerpos de 0,1 m de espesor, color castaño claro, límites netos, rectos u ondulosos. Están constituidas por tobas finas de textura clasto sostén muy bien seleccionadas. Internamente presentan estructura en montículo, estratificación entrecruzada con ángulos de entre $9^{\circ}$ y $12^{\circ}$, estructura de antidunas con ángulos de entre $1^{\circ}$ y $3^{\circ}$ y minoritariamente estratificación horizontal (fig. 3.18).

Interpretación

Depósitos de corrientes piroclásticas diluidas con límites de flujo inferior dominados por tracción (Branney y Kokelaar, 2002; Brown et al., 2007). 


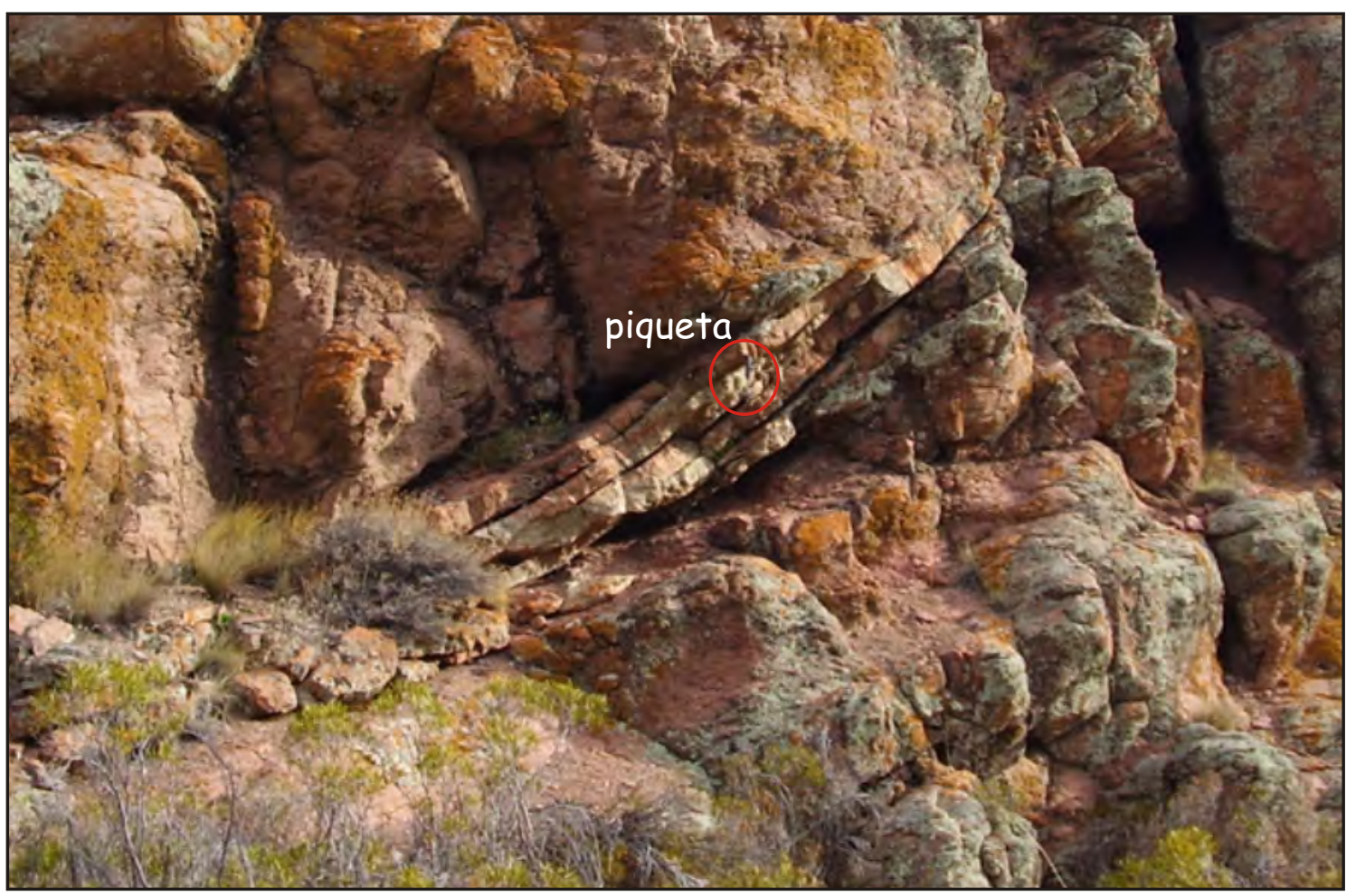

Figura 3.16. Facies piroclásticas con estratificación entrecruzada a gran escala (xsLT(a)) originadas por facies mLT que se depositan rapidamente luego de un salto hidráulico.

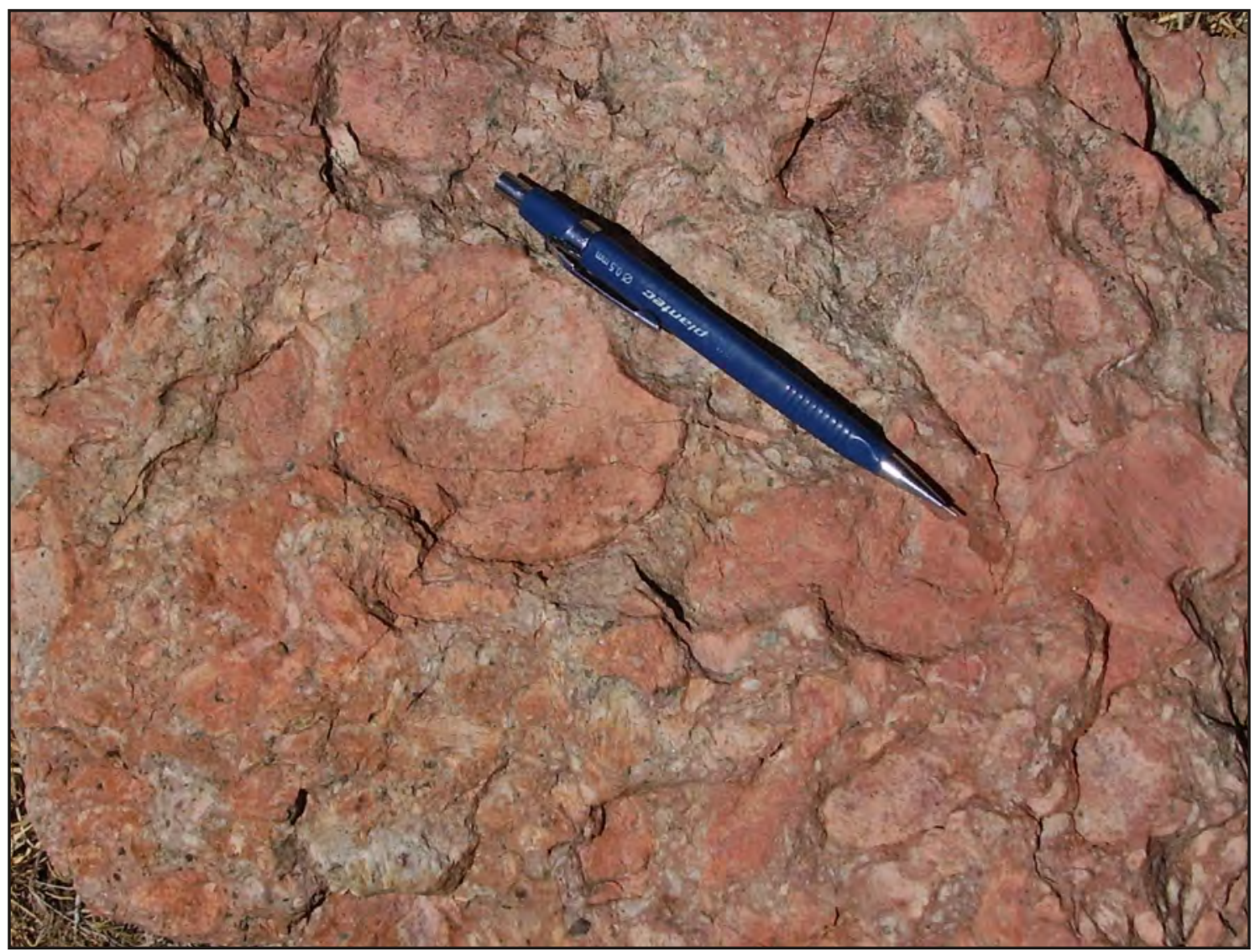

Figura 3.17. Facies piroclásticas conformadas de lapillitas pumíceas masivas (pmL) generadas a partir de la depositación de una corriente piroclástica o como depósitos de caída proximal. 

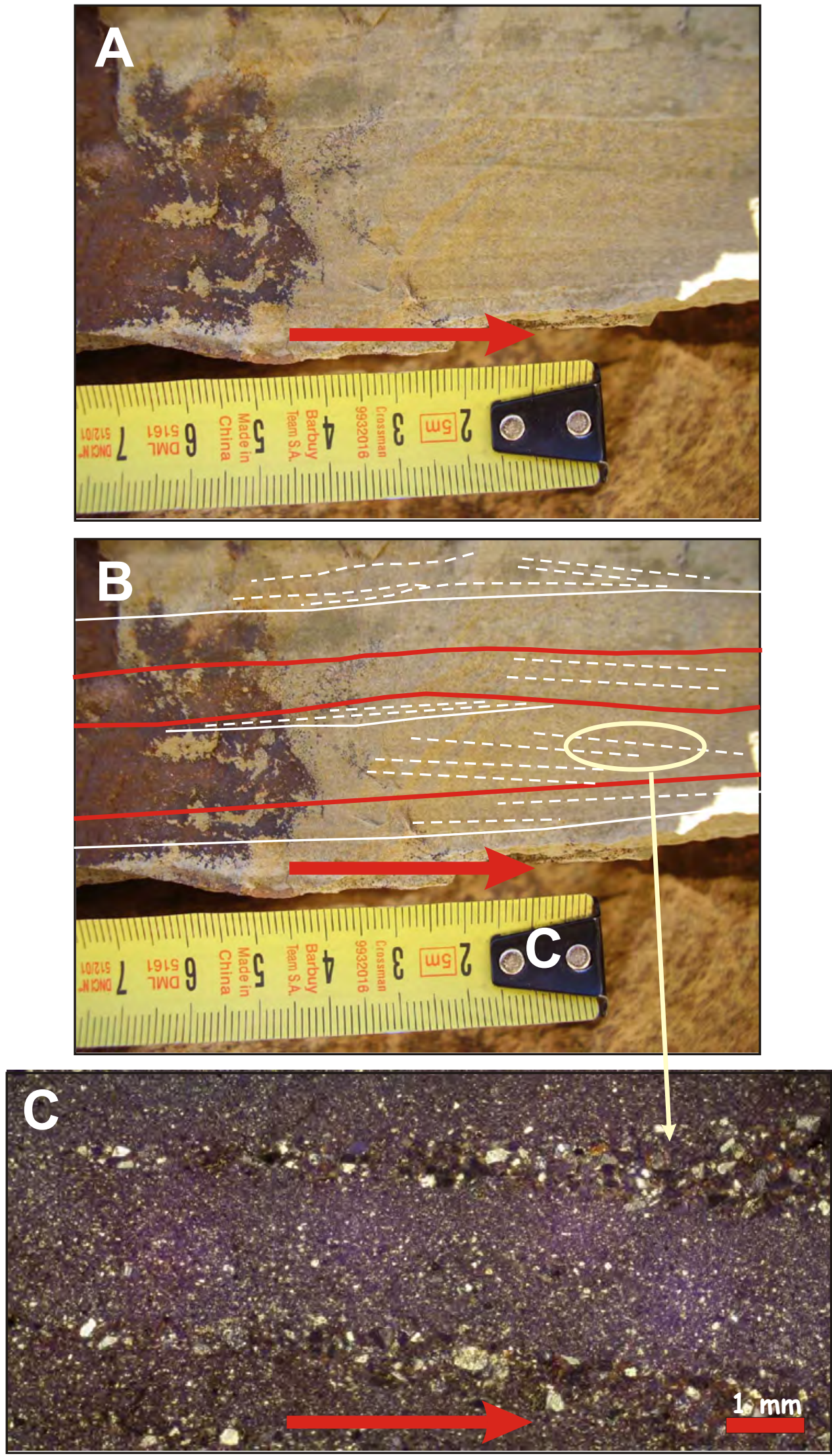

Figura 3.18. Litofacies de rocas piroclásticas de tobas con estratificación entrecruzada (xsT) formadas por corrientes piroclásticas con límites inferior de flujo dominados por tracción. 
Tobas masivas ( $m T$ )

Esta facies se presenta como cuerpos de geometría tabular con una potencia de aproximadamente $15 \mathrm{~cm}$, internamente constituidos por una toba masiva con colores grises 0 blanquecinos.

Interpretación

Depósitos de caída distales a partir de una pluma piroclástica pliniana o subpliniana en un ambiente subácueo o subaéreo (Fisher y Schmincke, 1987; Cas y Wright, 1987; Branney y Kokelaar 2002).

\subsection{4) Litofacies sedimentarias}

\subsubsection{1) Facies epiclásticas psefíticas}

\section{Brechas masivas matriz-sostén (Brmm)}

Se presentan generalmente con textura matriz sostén gravo-arenosa y minoritariamente con textura clasto sostén polimodal. Tienen muy pobre selección, con clastos que van desde centímetros a metros, con morfologías subangulosas, angulosas y ocasionalmente subredondeadas (fig. 3.19). De manera aislada presentan megaclastos con tamaños que alcanzan las decenas de metros (fig. 3.21). Los clastos y megaclastos yacen con diferentes morfologías y estructuras (fig. 3.19), pudiéndose encontrar: a) clastos y megaclastos simples con formas poligonales hexagonales y pentagonales originados a partir lavas que previamente habían desarrollado disyunción columnar, b) clastos y megaclastos redondeados y subredondeados donde sus bordes exhiben disyunción radial producto de enfriamiento, c) clastos y megaclastos simples con formas principalmente angulosas y subangulosas, y d) clastos y megaclastos brechados, donde los fragmentos no han sido desplazados o han sido desplazados levemente, desarrollando una textura en rompecabezas. Desde el punto de vista composicional se constituyen como una mezcla de litoclastos de lavas andesíticas con homogeneidad textural (fig. 3.20A), o como una mezcla de litoclastos de andesitas, andesitas basálticas, pórfidos y lamprófiros, con un amplio espectro de texturas (ej. afíricas, seriadas, microporfíricas, porfíricas y glomeroporfíricas) y de alteraciones (ej. anillos de oxidación, fracturación hidráulica, estructuras de disolución y relleno) (fig. 3.20B). Una particularidad de esta facies es el hallazgo de un tronco silicificado de 0,8 m de largo y 0,3 m de diámetro en los afloramientos que se encuentran en las nacientes del Cañadón de la Pintada (Columna RA 6, anexo I y II) (fig. 3.20C).

\section{Interpretación}

Depósitos de avalanchas de detritos volcánicos, originados por flujos de sedimentos granulares (Palmer et al., 1991; Coussot y Meunier, 1996; Schneider y Fisher, 1998; Reubi y 


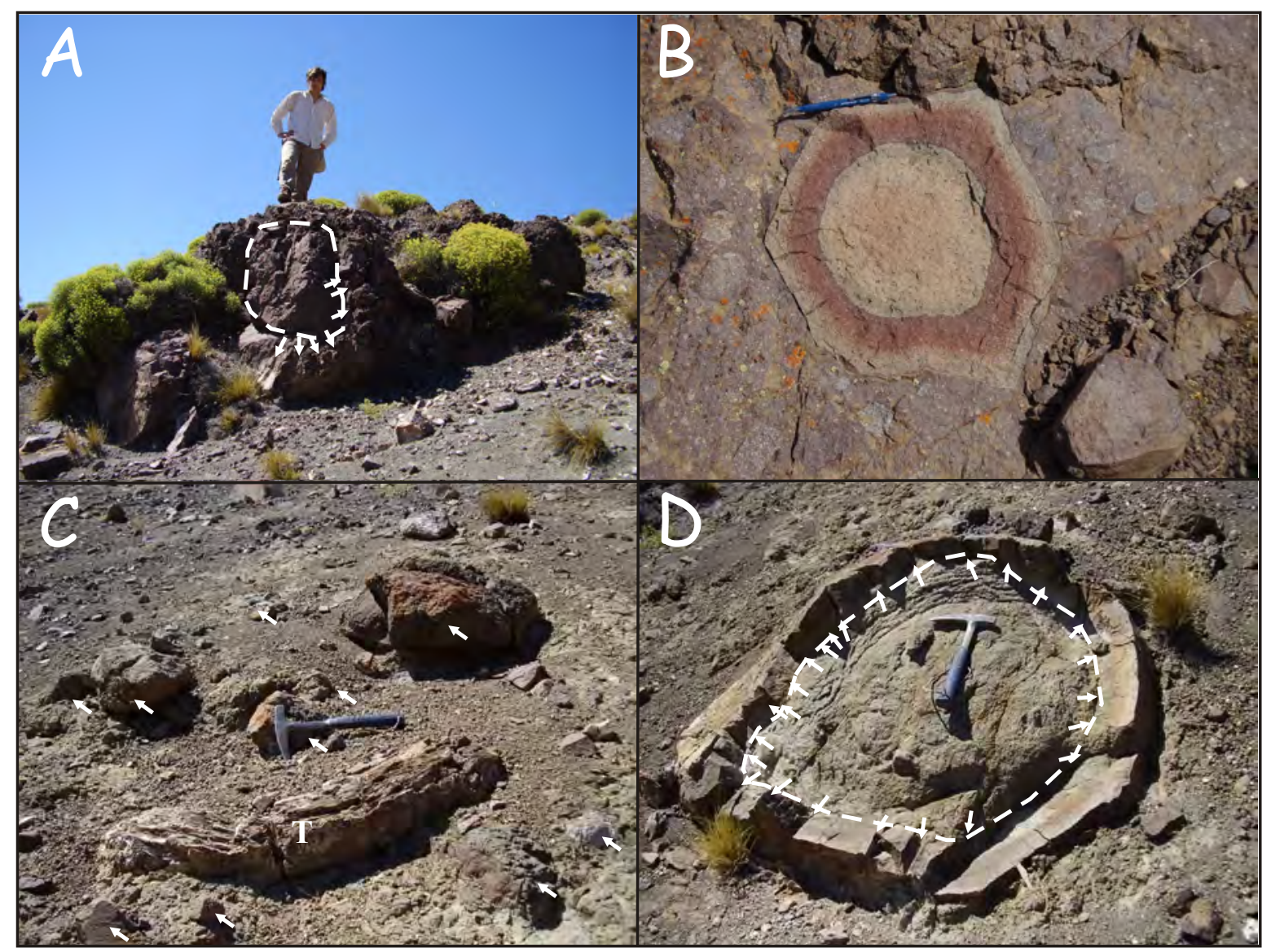

Figura 3.19. Facies epiclásticas constituidas de brechas masivas matriz-sostén (Brmm). A) Megaclasto brechado subanguloso con estructura de disyunción radial. B) Litoclasto de composición andesítica con forma poligonal, hexagonal (disyunción columnar) y con reborde de oxidación. C) Litoclastos simples de composición andesítica y el tronco petrificado encontrado en estas facies (T). D) Megaclasto de composición andesítica que presenta variación en la granularidad desde una textura microgranuda en su interior a una textura afanítica en su parte exterior donde exhibe disyunción radial.

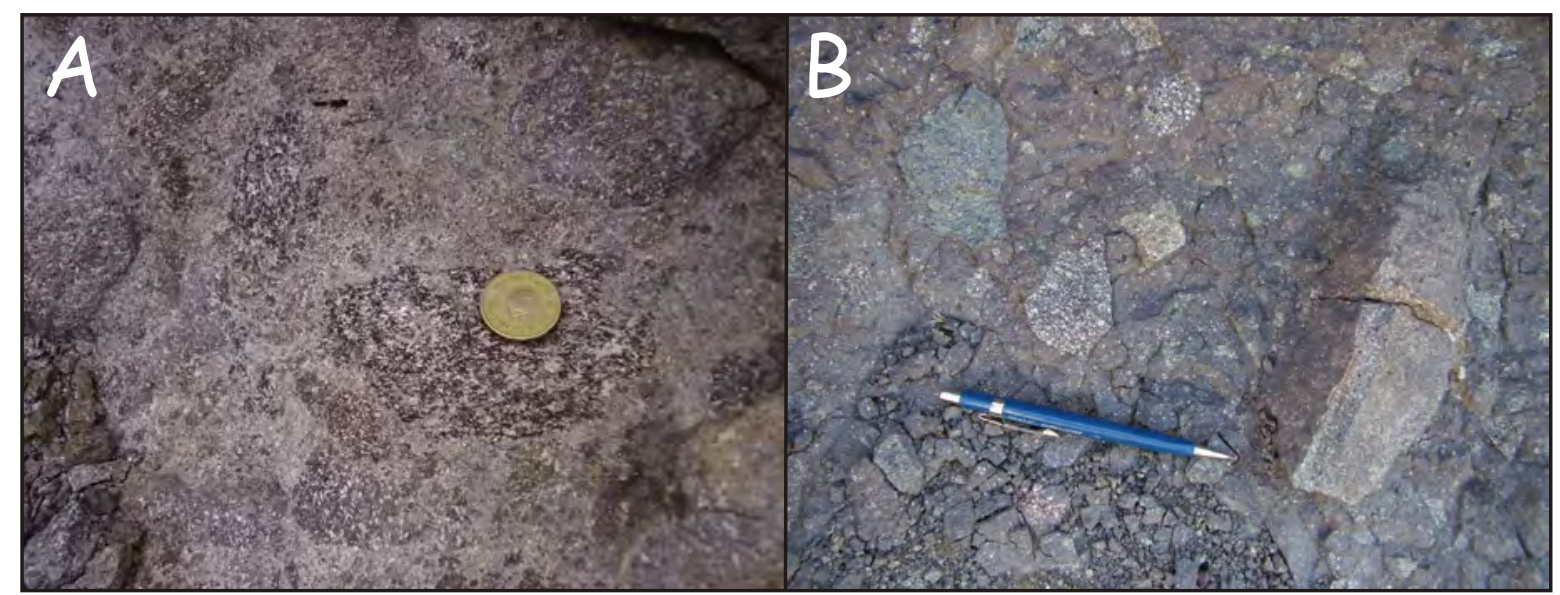

Figura 3.20. Características de la matriz de las facies de brechas masivas matriz-sostén (Brmm). A) monomícticas de similitud textural. B) Monomícticas con litoclastos de diferentes texturas. 


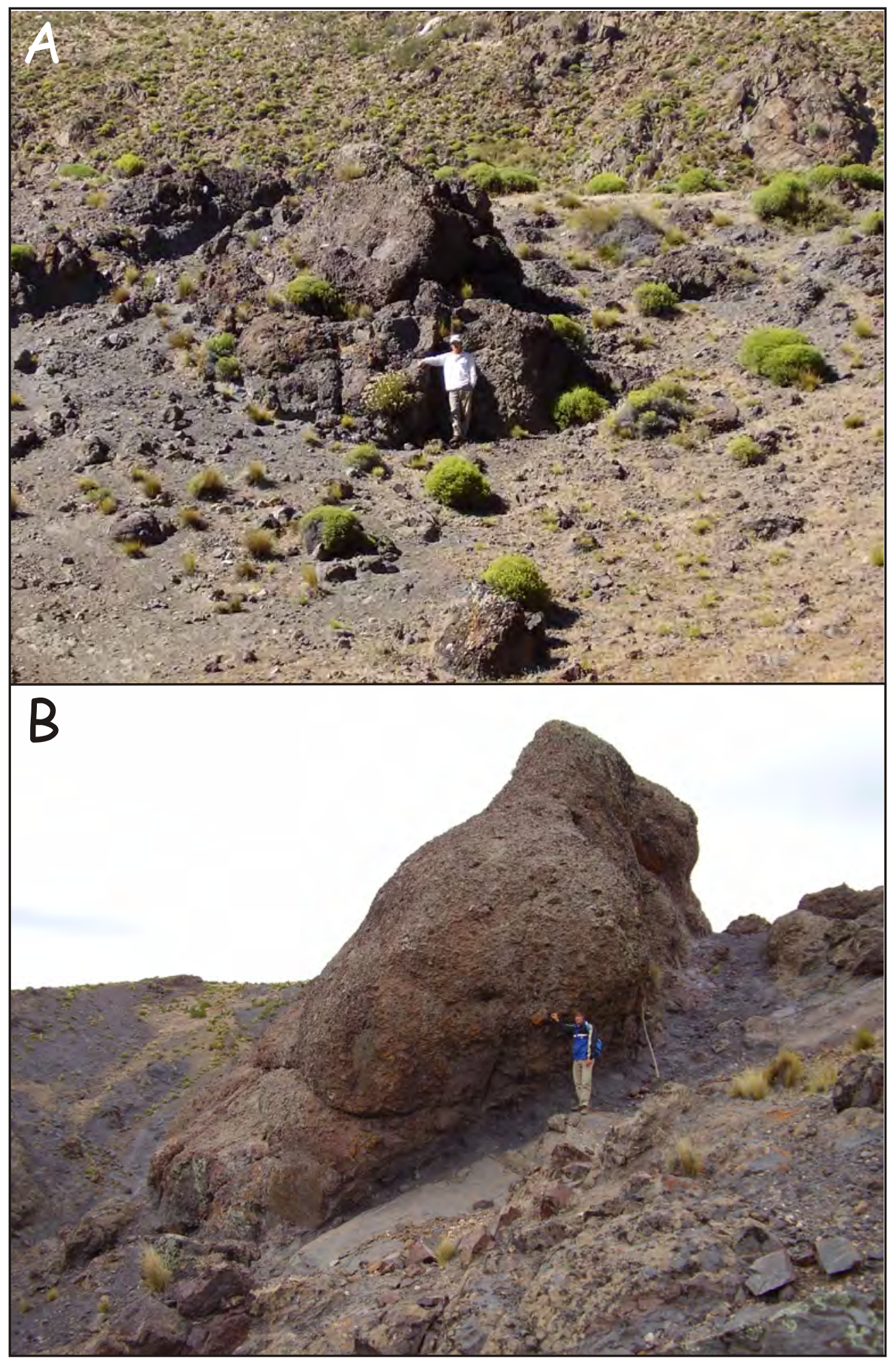

Figura 3.21. Megaclastos de las facies de brechas volcánicas matriz sostén (Brmm). A) Megaclastos brechados con clastos parcialmente desplazados. B) Megaclastos brechados donde los clastos no poseen deplazamiento. 
Hernandez, 2000; Clavero et al., 2002; Shea et al., 2008).

\section{Conglomerados masivos matriz-sostén ( $\mathrm{Gmm}(a))$}

Yacen como cuerpos tabulares de base plana y techo plano o con geometría lobular en cuerpos de límites netos, no erosivos y espesores de 1,5 m a 4 m (fig. 3.22). Internamente están constituidas de conglomerados matriz sostén areno-sabulítica, pobremente seleccionados, con variaciones a textura clasto sostén polimodal. Los litoclastos presentan formas subangulosas, subredondeadas y angulosas, tamaños de entre 2 y $50 \mathrm{~cm}$ y tamaños máximos de hasta 2,9 m (fig. 3.23). Composicionalmente, esta facies varía desde monomíctica a polimíctica con participación de clastos del basamento. Respecto a la estructura, se presentan masivas con clastos distribuidos de manera caótica.

Interpretación

Depósitos de flujo de detritos no cohesivos (Smith, 1986; Smith, 1987, Smith y Lowe, 1991, Coussot y Meunier, 1996), originados por flujos de alta densidad de sedimentos, laminares y reológicamente plásticos (Dasgupta, 2003).

\section{Conglomerados masivos matriz-sostén Gmm(b)}

Yacen en capas de $50 \mathrm{~cm}$ de espesor, compuestas de gravas finas a medias, matriz sostén, con estructura masiva. Se presentan pobremente seleccionadas, con los clastos distribuidos caóticamente en una matriz fangosa (fig. 3.24). Los fenoclastos se componen de litoclastos de procedencia volcánica y silicoclástica, de intraclastos pelíticos y de restos de valvas y de troncos. Esta facies se haya asociada a las facies de lutitas negras marinas.

Interpretación

Depósitos de flujos de detritos marinos fangosos cohesivos (Shanmugam, 2002), originados por flujos de sedimentos de alta densidad, laminares, reológicamente plásticos (Dasgupta, 2003).

\section{Brechas finas masivas o gradadas clasto-sostén (Brm)}

Se muestran como cuerpos tabulares o lenticulares conformando el relleno pasivo de pequeñas depresiones, con espesores de $5 \mathrm{~cm}$ a $30 \mathrm{~cm}$. Internamente están constituidas por brechas finas a sabulitas angulosas, líticas o pumíceas, de moderada selección y textura clasto sostén polimodal. Se exhiben generalmente masivas o gradadas. Entre los arreglos internos presentes, aparecen con gradación inversa desde una arena media-gruesa a una sabulita o brecha fina con clastos promedios de 1 cm (fig. 3.25) o con gradación inversa-normal. 


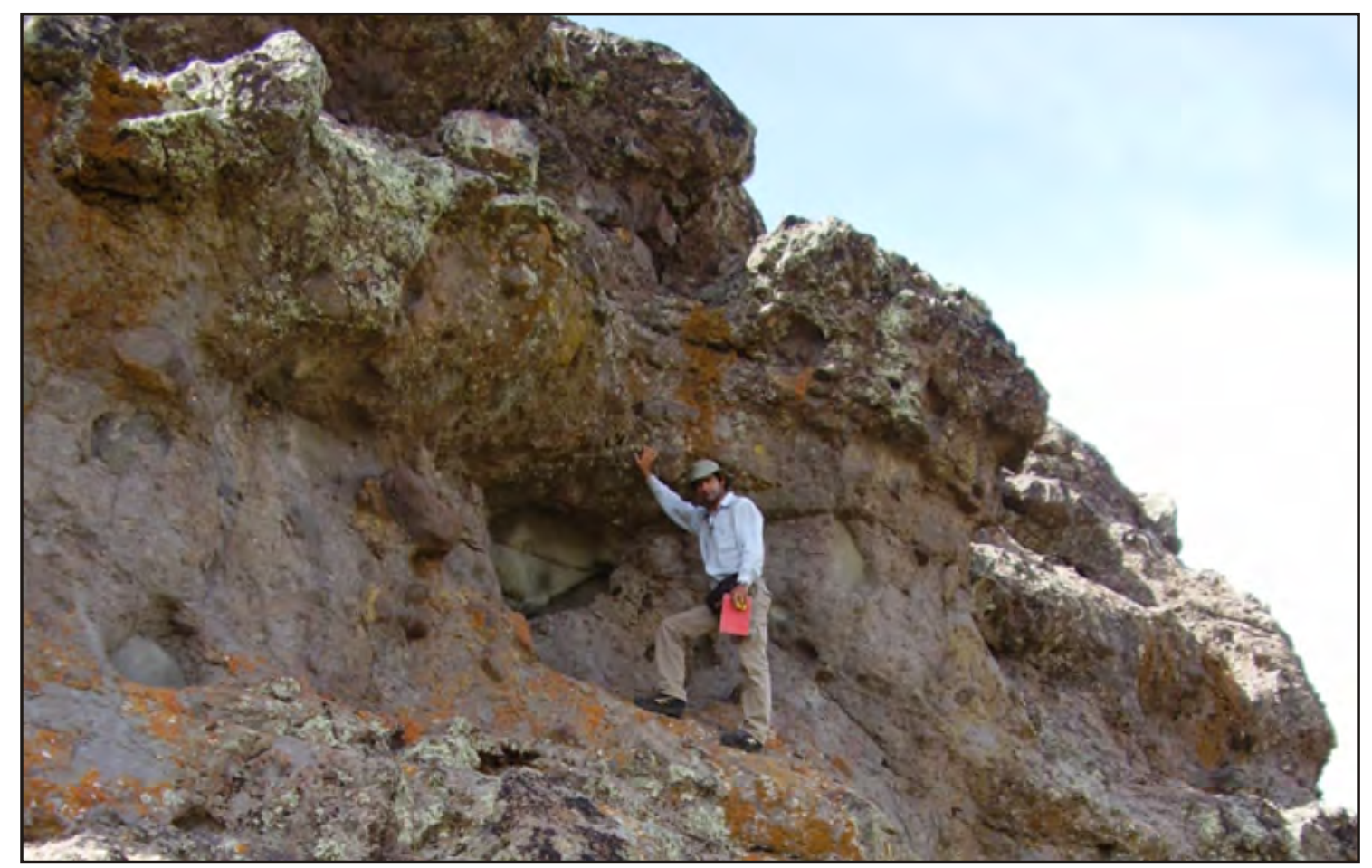

Figura 3.22. Facies epiclásticas de conglomerados matriz-sostén (Gmm(a)) con geometría lobular originadas por depósitos de flujos de detritos.

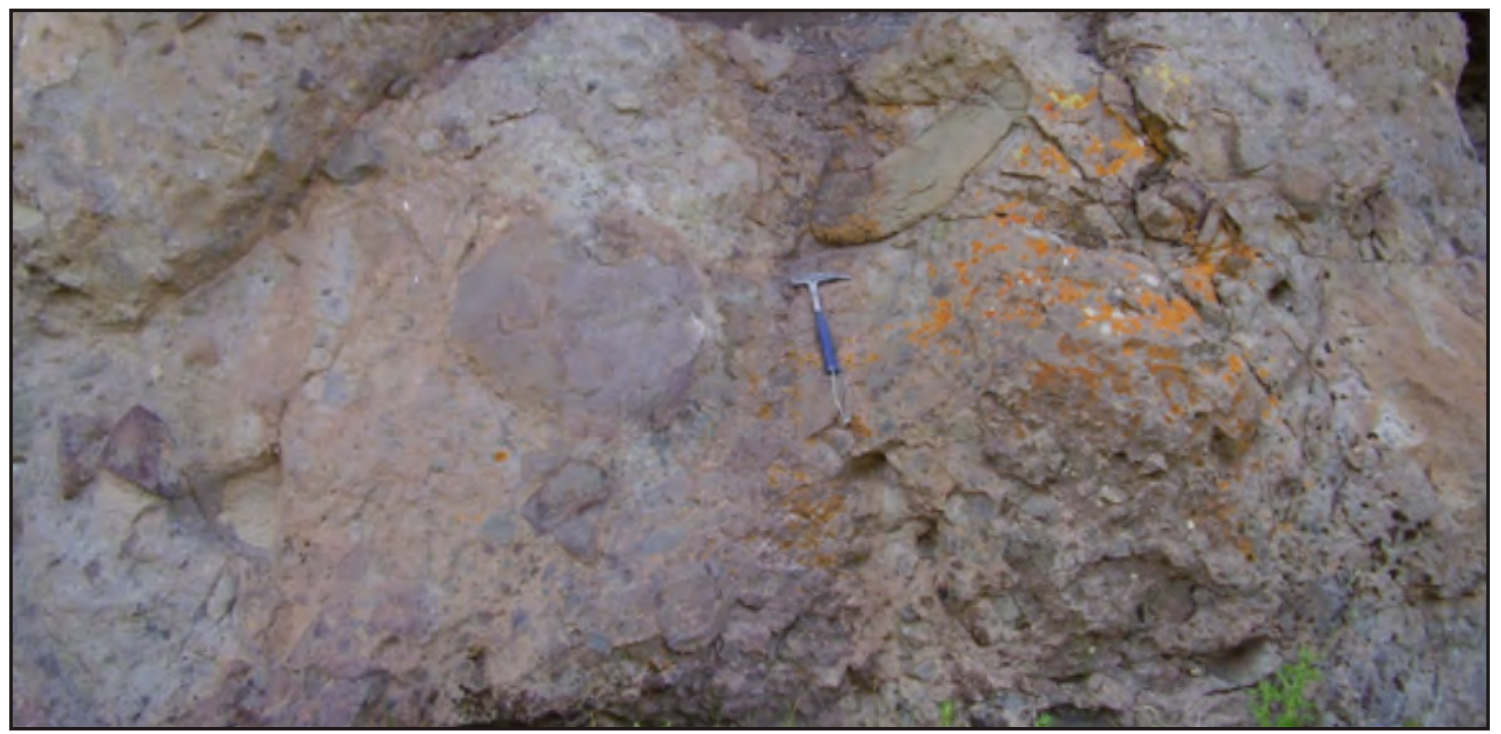

Figura 3.23. Detalle de las facies epiclásticas de conglomerados matriz-sostén (Gmm(a)). 

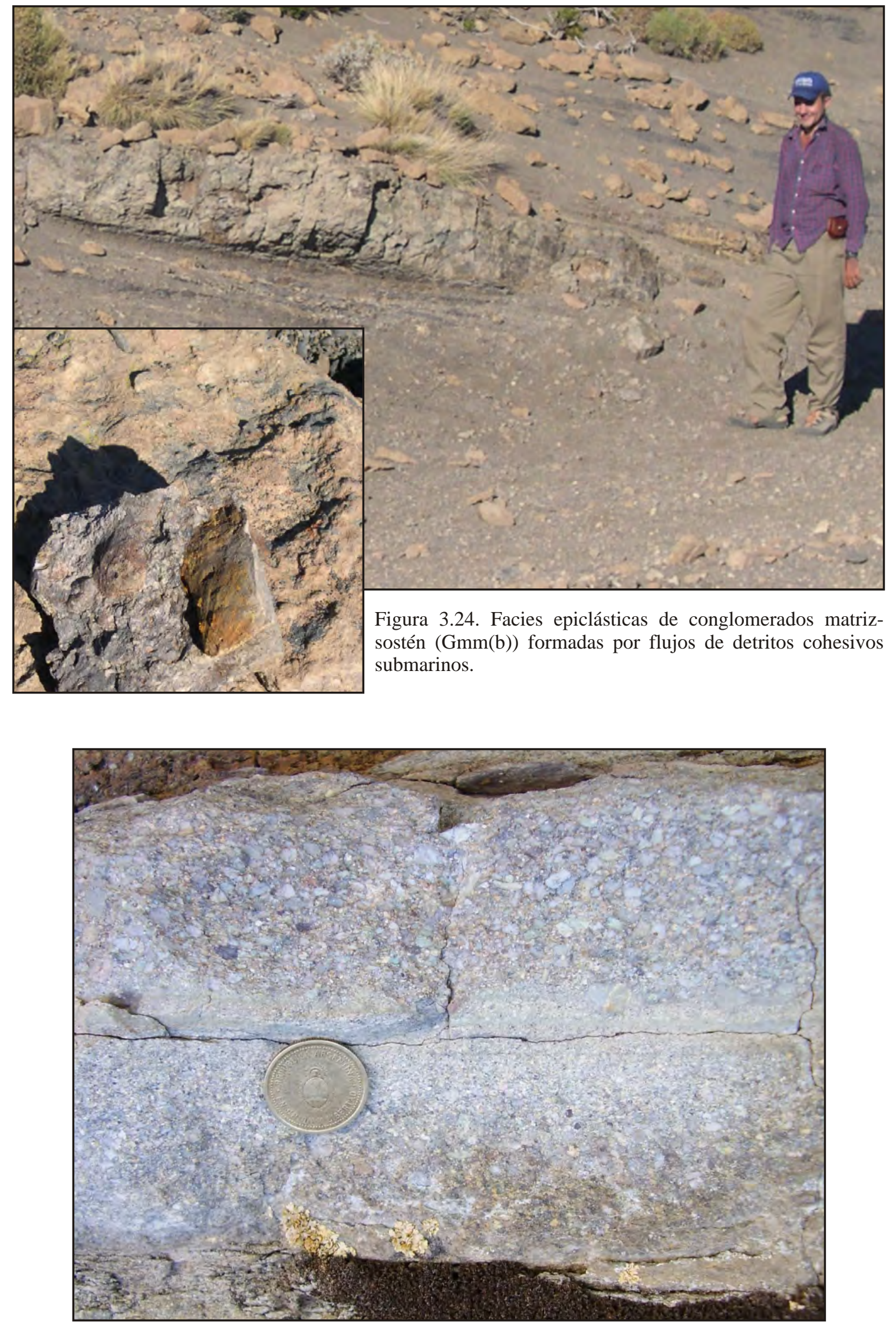

Figura 3.25. Facies epiclásticas de brechas masivas o gradadas (Brm) clasto-sostén. En el presente caso se muestran con gradación inversa. 


\section{Interpretación}

Depósitos de flujos hiperconcentrados de alta descarga (Smith, 1986; Smith, 1987; Smith y Lowe, 1991; Bank y Chough, 1996), originados por flujos de sedimentos de alta densidad, transicionales entre laminares y turbulentos y semiplásticos desde el punto de vista reológico (Dasgupta, 2003).

\section{Conglomerados masivos a crudamente estratificados clasto-sostén (Gm)}

Se muestran como cuerpos tabulares de entre $0,5 \mathrm{~m}$ y $2 \mathrm{~m}$ de espesor, con contactos netos y textura clasto sostén polimodal de moderada selección. Presentan clastos subangulosos a subredondeados y matriz de una arena gruesa a sabulítica. Desde el punto de vista granulométrico, tienen tamaños promedios de $10 \mathrm{~cm}$. Composicionalmente, estas facies son desde monomícticas a polimícticas. Con respecto a la estructura interna, se presentan masivas o crudamente estratificadas, mostrando guijones con el eje mayor paralelo a la estratificación (fig. 3.26).

\section{Interpretación}

Depósitos de flujos hiperconcentrados de alta descarga (Smith, 1986; Smith, 1987; Smith y Lowe, 1991; Bank y Chough, 1996), originados por flujos de sedimentos de alta densidad, transicionales entre laminares y turbulentos y semiplásticos desde el punto de vista reológico (Dasgupta, 2003).

\section{Sabulitas y conglomerados finos estratificados clasto-sostén (Gh)}

Yacen como sabulitas a conglomerados finos, con textura clasto sostén de moderada selección. Presentan litoclastos de rocas volcánicas y de rocas silicoclásticas de hasta $8 \mathrm{~cm}$. La matriz está constituida de una arena con granulometría gruesa a medina. Se exhiben como cuerpos de geometría lenticular o como cuerpos tabulares, con contactos netos de 0,15 m a 0,5 m de espesor (fig. 3.26). Internamente tienen estratificación difusa, con los clastos más pequeños orientados paralelos a la estratificación y en ocasiones poseen gradación normal.

\section{Interpretación}

Depósitos de flujos hiperconcentrados de alta descarga (Smith, 1986; Smith, 1987; Smith y Lowe, 1991), originados por flujos de sedimentos de alta densidad, transicionales entre laminares y turbulentos y semiplásticos desde el punto de vista reológico (Dasgupta, 2003).

Sabulitas y conglomerados finos clasto-sostén con estratificación entrecruzada en artesa (Gt)

Se componen de sabulitas y conglomerados finos clasto-sostén, de moderada a buena selección y de composiciones variables. Se presentan en sets de entre $20 \mathrm{~cm}$ y $40 \mathrm{~cm}$, internamente con estratificación entrecruzada en artesa. 


\section{Interpretación}

Depósitos de corrientes turbulentas de baja densidad (Dasgupta, 2003). Migración de formas 3D desarrolladas por flujos unidireccionales en condiciones de bajo régimen de flujo (Leeder, 1999, Bridge 2006).

Conglomerados con estratificación entrecruzada planar a gran escala clasto-sostén ( $G p(a))$

Se componen de conglomerados clasto sostén con matriz arenosa de moderada a buena selección. Presentan clastos con formas redondeados a subredondeadas con tamaños promedios de $3 \mathrm{~cm}$ y máximos de $14 \mathrm{~cm}$. Los clastos se disponen con el eje mayor contenido en el plano de la estratificación en sentido de la inclinación. Desde el punto de vista composicional, están constituidos por litoclastos de rocas volcánicas andesíticas, riolíticas e ignimbríticas y minoritariamente por litoclastos del basamento. Esta facies se da en cuerpos alongados lateralmente con espesores de hasta 4m, con bases irregulares suavemente erosivas. Desarrollan una estratificación entrecruzada a gran escala conformada por capas de entre $5 \mathrm{~cm}$ y $15 \mathrm{~cm}$ de espesor que inclinan aproximadamente ente $10^{\circ}$ y $20^{\circ}$ (fig. 3.27).

Interpretación

Esta facies representa depósitos de flujos hiperconcentrados (Smith, 1986; Smith, 1987; Smith y Lowe, 1991) en transición a flujos de sedimento de baja densidad traccionales. En función de la macroforma que constituyen, pueden ser interpretados como depositados sobre una "superficie de avalancha” o de fuerte pendiente (Blair y McPherson, 2007).

\section{Conglomerados con estratificación entrecruzada clasto-sostén ( $G p(b))$}

Yacen como cuerpos de bases erosivas con estratificación entrecruzada planar constituida por capas de $5 \mathrm{~cm}$ a $10 \mathrm{~cm}$ de espesor que se agrupan en sets de hasta $1 \mathrm{~m}$ de espesor. Esta facies se caracterizan por gravas finas a sabulitas, de composiciones variadas y textura clasto sostén de moderada selección (fig. 3.28).

\section{Interpretación}

Representan depósitos de formas de fondo de dunas 2D (Leeder, 1999), originadas por flujos de sedimentos de baja densidad, unidireccionales, newtonianos, turbulentos y traccionales (Dasgupta, 2003).

Conglomerados con gradación normal clasto-sostén (Gn)

Esta facies se constituye de conglomerados con textura clasto sostén polimodal de moderada selección con escasa matriz arenosa. Presentan clastos redondeados y subredondeados con tamaños promedios de 1,5 cm. Los mismos corresponden a rocas volcánicas, silicoclásticas y a restos de valvas desarticuladas, orientadas paralelamente a la estratificación difusa, con la 


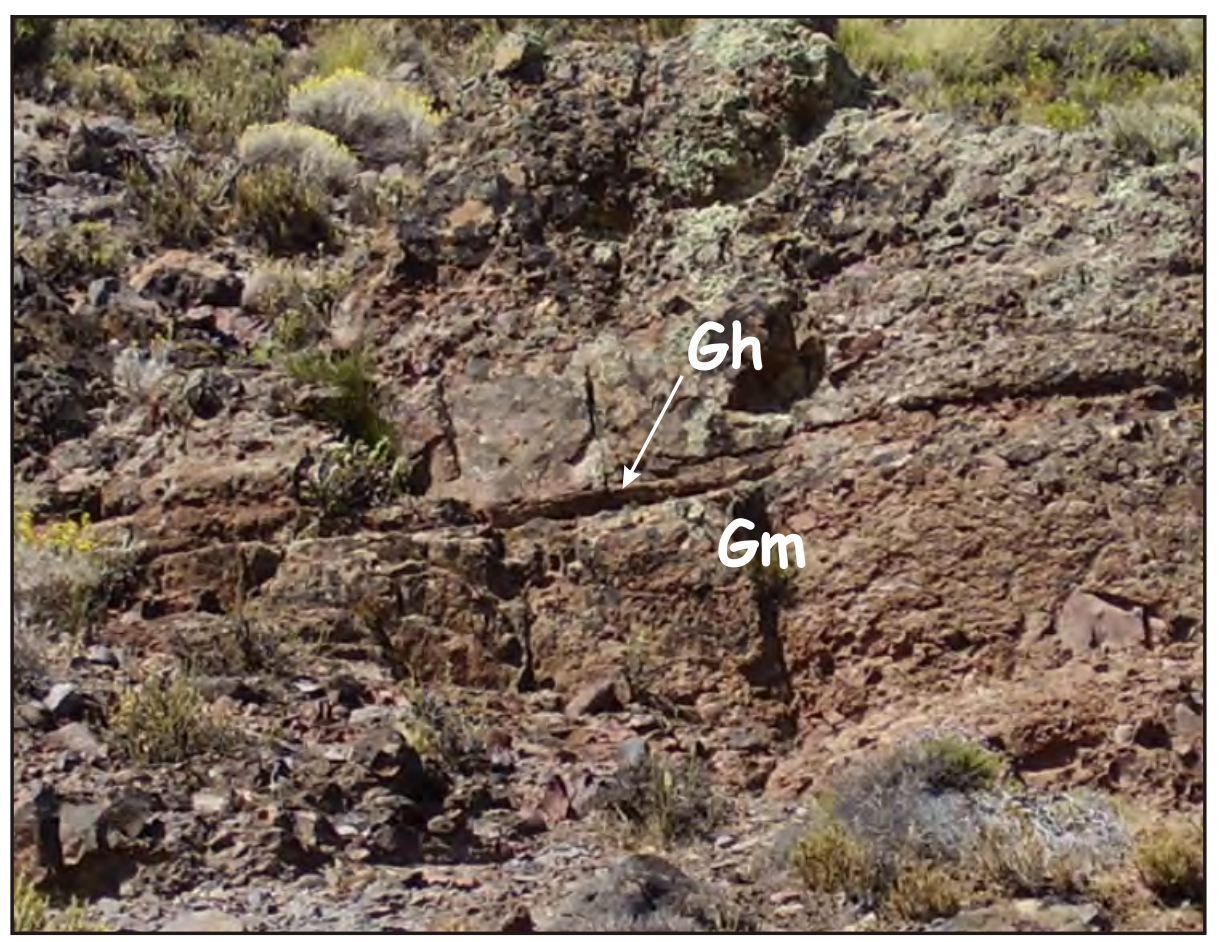

Figura 3.26. Facies epiclásticas de conglomerados masivos a crudamente estratificados clasto-sostén (Gm) generadas por la depositación de flujos hiperconcentrados. Además se pueden apreciar facies epiclásticas constituidas de sabulitas y conglomerados finos con estratificación horizontal clasto-sostén (Gh) que también están originadas a partir de la depositación de flujos hiperconcentrados.

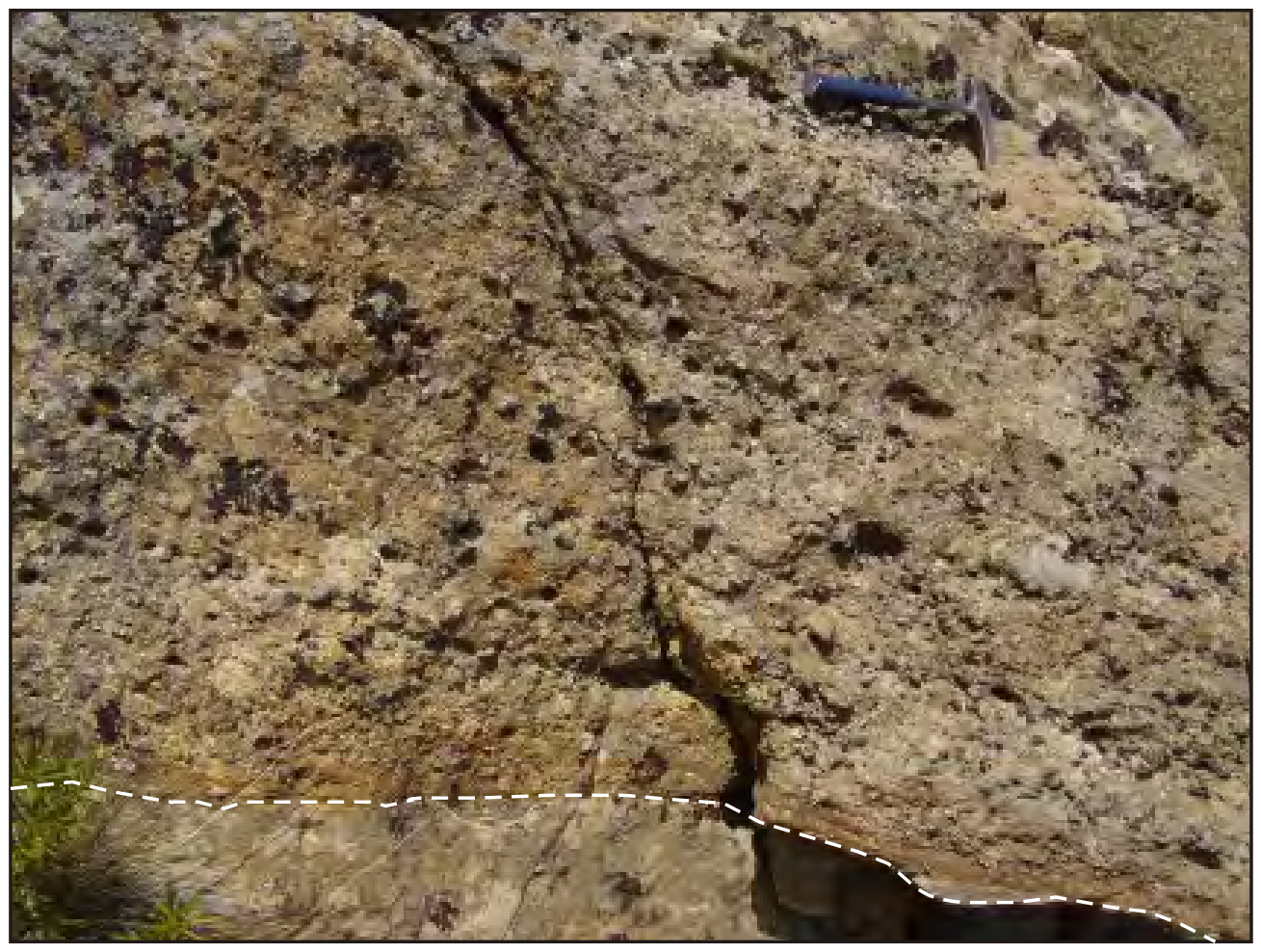

Figura 3.27. Facies epiclásticas conformadas por conglomerados con estratificación entrecruzada a gran escala clasto-sostén $(\mathrm{Gp}(\mathrm{a}))$. Estas facies interpretan como flujos de depósitos hiperconcentrados subácueos desarrollados sobre una cara de avalancha. 
parte cóncava hacia arriba. Se exponen en capas de límites irregulares, de $15 \mathrm{~cm}$ a $70 \mathrm{~cm}$ de espesor, con gradación normal y estratificación difusa (fig. 3.29).

Interpretación

Depósitos marinos de corrientes de turbidez gravosas (Shanmugam, 2002), originados por flujos de sedimentos de alta densidad, newtonianos y turbulentos (Dasgupta, 2003).

\subsubsection{2) Facies epiclásticas psamíticas}

Areniscas tobáceas masivas (Sm)

Se caracterizan por areniscas tobáceas o líticas de procedencia volcánica. Presentan granulometría gruesa a medina, color castaño oscuro y buena a moderada selección. Se muestran en bancos tabulares de entre $10 \mathrm{~cm}$ y $20 \mathrm{~cm}$ de espesor. Internamente se presentan masivas y en ocasiones con gradación normal.

\section{Interpretación}

Depósitos de flujos de detritos arenosos no cohesivos, originados por flujos laminares friccionales, reológicamente plásticos (Dasgupta, 2003).

\section{Areniscas guijarrosas con estratificación horizontal (SGh)}

Las facies SGh están constituidas por areniscas y areniscas guijarrosas monomícticas o polimícticas de granulometría gruesa a fina. Se presentan con textura clasto sostén de moderada selección en cuerpos de geometría tabular, con contactos netos no erosivos o gradacionales, con espesores de $10 \mathrm{~cm}$ a $30 \mathrm{~cm}$ o amalgamados (fig. 3.30). Interiormente presentan estratificación horizontal con capas entre $5 \mathrm{~cm}$ y $2 \mathrm{~cm}$ y arreglos generalmente granodecrecientes. En la base de las capas se pueden encontrar guijas paralelas a la estratificación.

\section{Interpretación}

Depósitos de flujos hiperconcentrados de sedimentos (Smith, 1986; Smith, 1987; Smith y Lowe, 1991), originados por flujos transicionales entre turbulentos y laminares, reológicamente semiplásticos (Dasgupta, 2003).

\section{Areniscas con estratificación entrecruzada en artesa (St).}

Están constituidas por areniscas monomícticas o polimícticas silicoclásticas, de granulometría gruesa a fina. Se muestran con textura bien a moderadamente bien seleccionada. La geometría de los cuerpos es lenticular con contactos netos y erosivos. Interiormente presentan estratificación entrecruzada en artesa con sets aproximadamente $10 \mathrm{~cm}$, con guijarros en su base y arreglos granodecrecientes (fig. 3.31).

\section{Interpretación}

Depósitos de corrientes turbulentas de baja densidad (Dasgupta, 2003). Migración de 


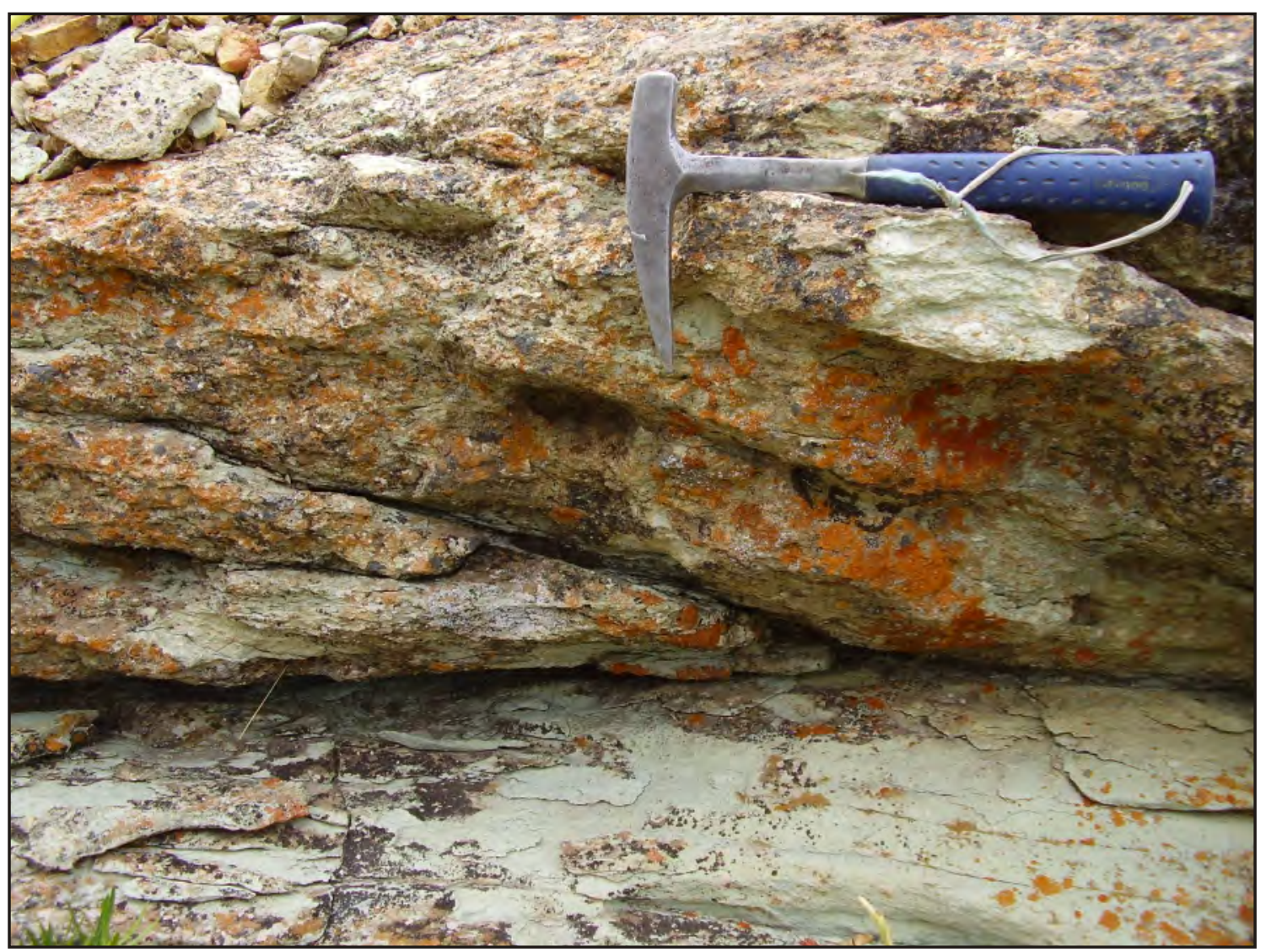

Figura 3.28. Facies epiclásticas constituidas de gravas finas con estratificación entrecruzada planar clasto-sostén (Gp(b)) originadas por la migración de dunas 2D.

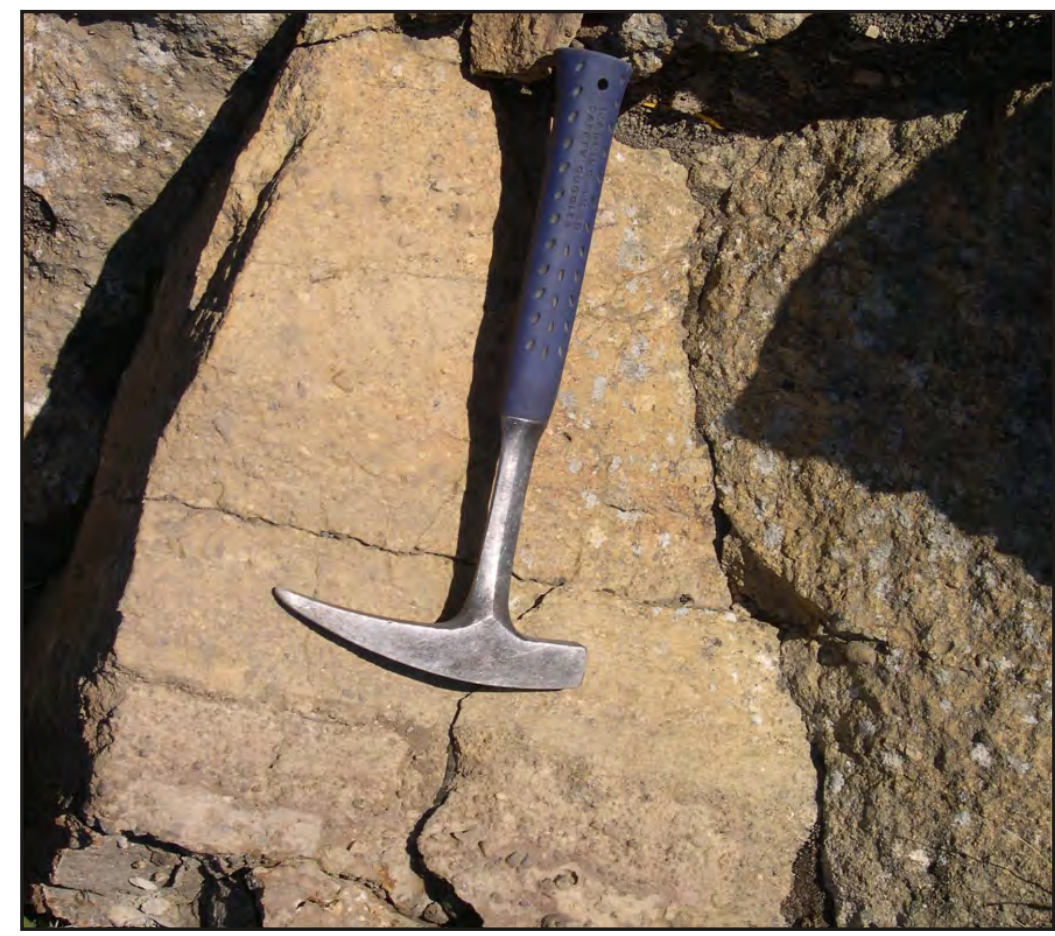

Figura 3.29. Facies epiclásticas conformadas por gravas finas con gradación normal clasto-sostén (Gn) formadas por depósitos de corrientes de turbidez submarinas gravosas. 
formas 3D desarrolladas por flujos unidireccionales en condiciones de bajo régimen de flujo (Leeder, 1999; Bridge 2006).

\section{Areniscas con estratificación entrecruzada (Sp)}

Están constituidas por areniscas tobáceas o arcósicas, de moderada a buena selección, de granulometría gruesa a muy gruesa. Se presentan con estratificación entrecruzada planar y minoritariamente en artesa, en sets de entre $0,3 \mathrm{~m}$ y $0,7 \mathrm{~m}$, integrados por capas de $1 \mathrm{~cm}$ o $2 \mathrm{~cm}$ (fig. 3.32).

\section{Interpretación}

Depósitos de carga de fondo, resultado de la migración de dunas 2D, originados por flujos de sedimentos diluidos traccionales, newtonianos y turbulentos. (Leeder, 1999).

\section{Areniscas con estratificación horizontal (Sh)}

Esta facies se compone de areniscas blanquecinas de granulometría medina a gruesa, de buena selección y composición lítica-tobácea. Se exhiben como cuerpos tabulares de entre 10 cm y $20 \mathrm{~cm}$ de espesor, con estratificación horizontal fina a laminación (fig. 3.33). Es importante destacar que esta facies en ocasiones desarrolla deformación sinsedimentaria suave o profusa (fig. 3.33 y 3.34).

\section{Interpretación}

Depósitos de capa plana, de alto régimen de flujo (Leeder, 1999), originados por flujos de sedimentos de baja densidad, newtonianos y turbulentos (Dasgupta, 2003).

\section{Areniscas con laminación ondulítica y laminación horizontal (Sr)}

Se muestran como capas tabulares de entre $10 \mathrm{~cm}$ y $25 \mathrm{~cm}$ con límites difusos. Se componen de areniscas tobáceas finas a medias, de colores rojizos o blanquecinos, con buena selección. Interiormente se presentan con óndulas o laminación ondulítica (fig. 3.35), a menudo obliteradas por estructuras de deformación sinsedimentaria o por bioturbación. La bioturbación se encuentra conformada por tubos verticales rectos o curvos y tubos horizontales (fig. 3.36), rellenos de arenas de granulometría más gruesa.

\section{Interpretación}

Depósitos de formas de fondo de bajo régimen de flujo por migración de óndulas, originados por flujos de sedimentos de baja densidad, turbulentos, combinados o unidireccionales (Leeder, 1999). 


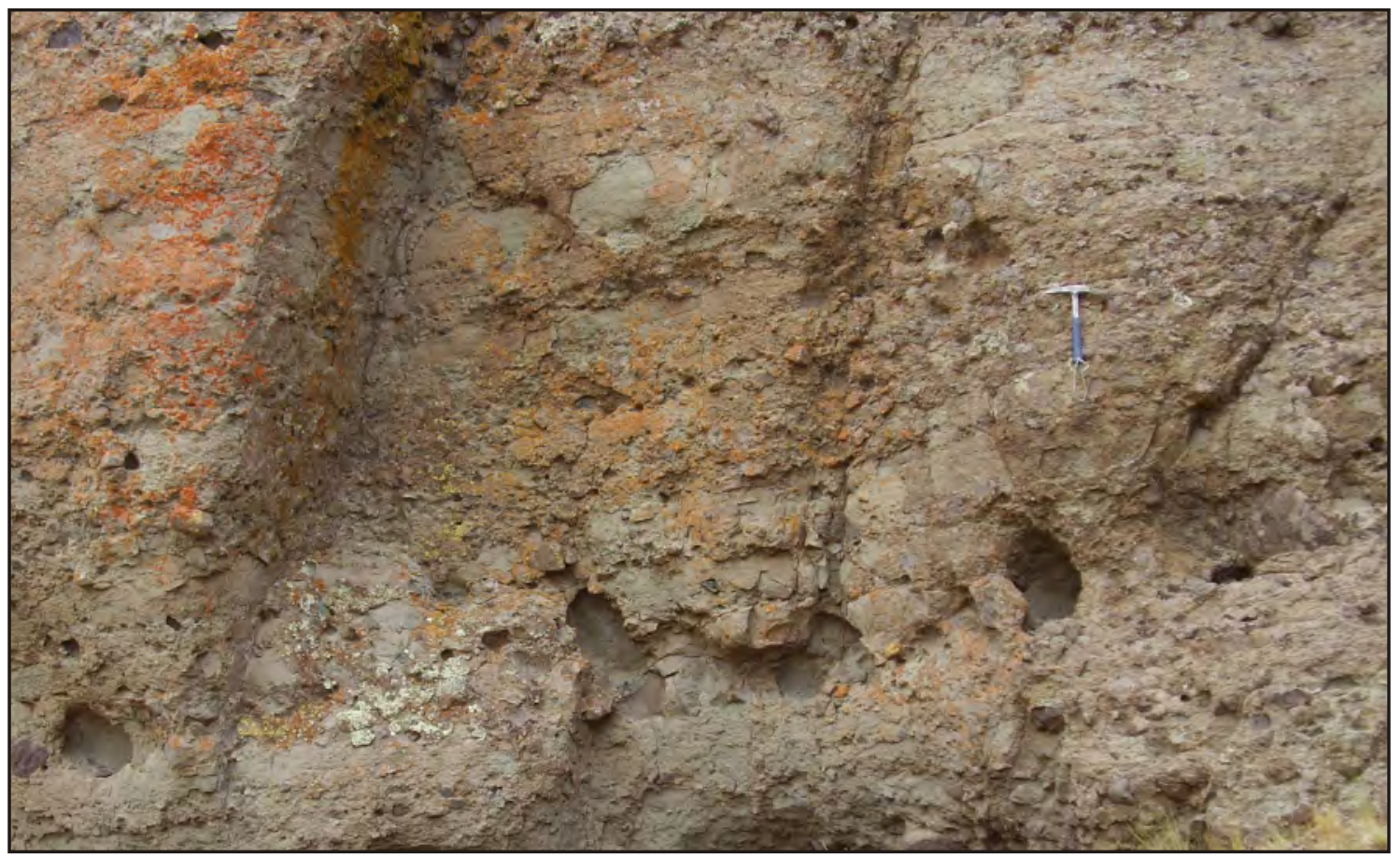

Figura 3.30. Facies epiclásticas conformadas por areniscas guijarrosas con estratificación horizontal (SGh) y límites difusos formadas por la depositación de flujos hiperconcentrados arenosos.

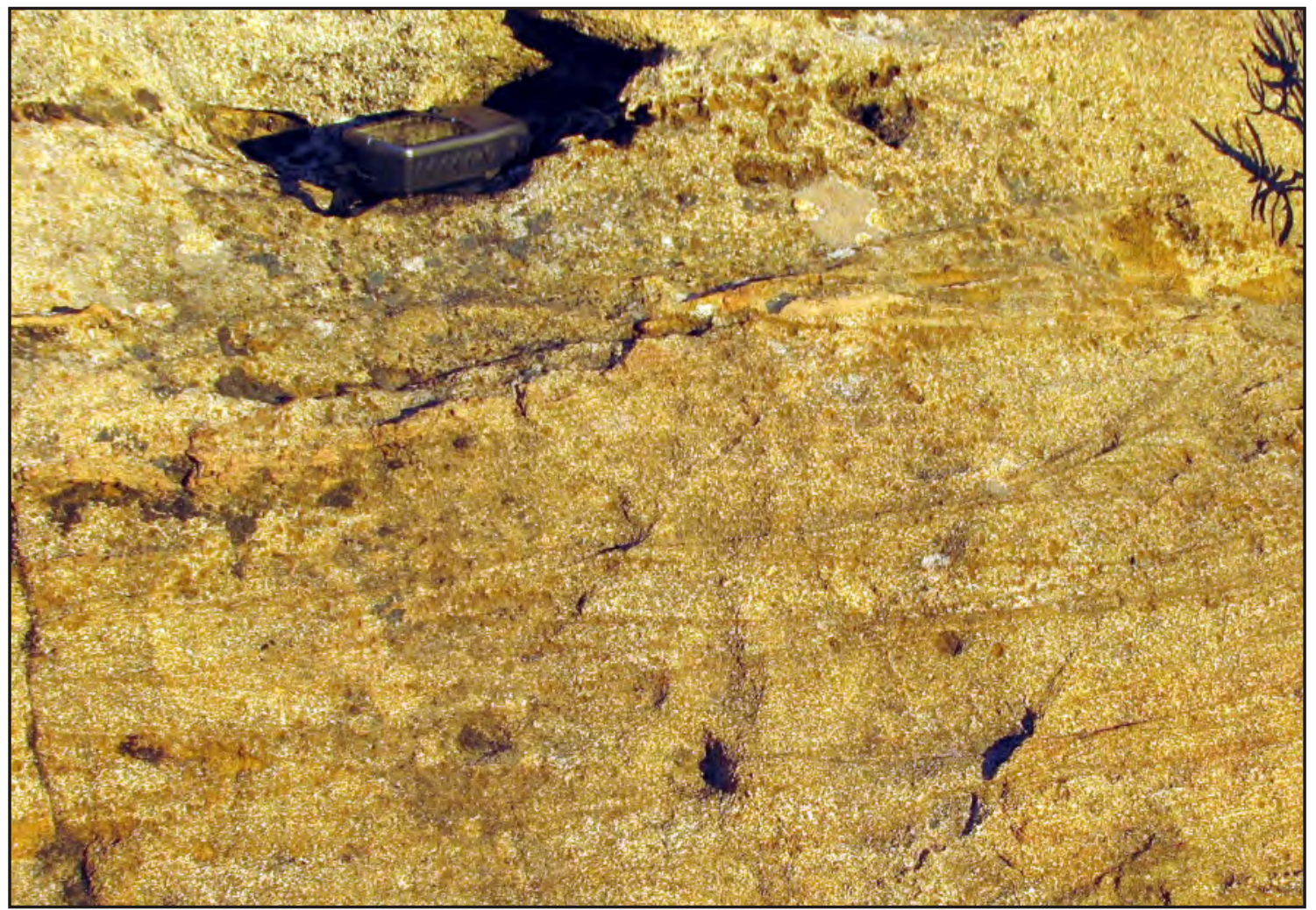

Figura 3.31. Facies epiclásticas constituidas de areniscas con estratificación entrecruzada en artesa (St) formadas por flujos diluidos que desarrollan formas de fondo 3D. 


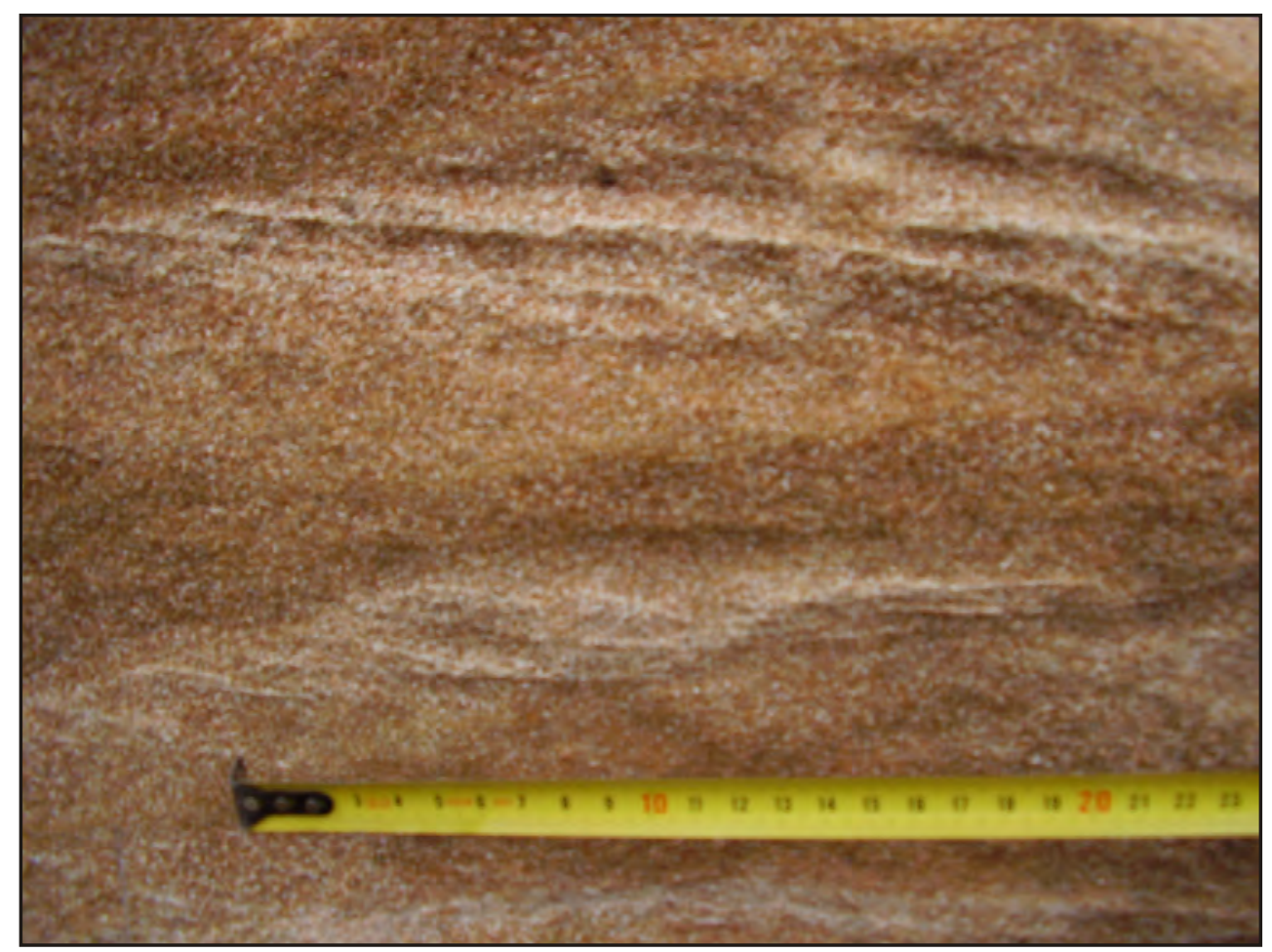

Figura 3.32. Facies epiclásticas de areniscas con estratificación entrecruzada planar (Sp) desarrolladas por la migración de formas de fondo 2D.

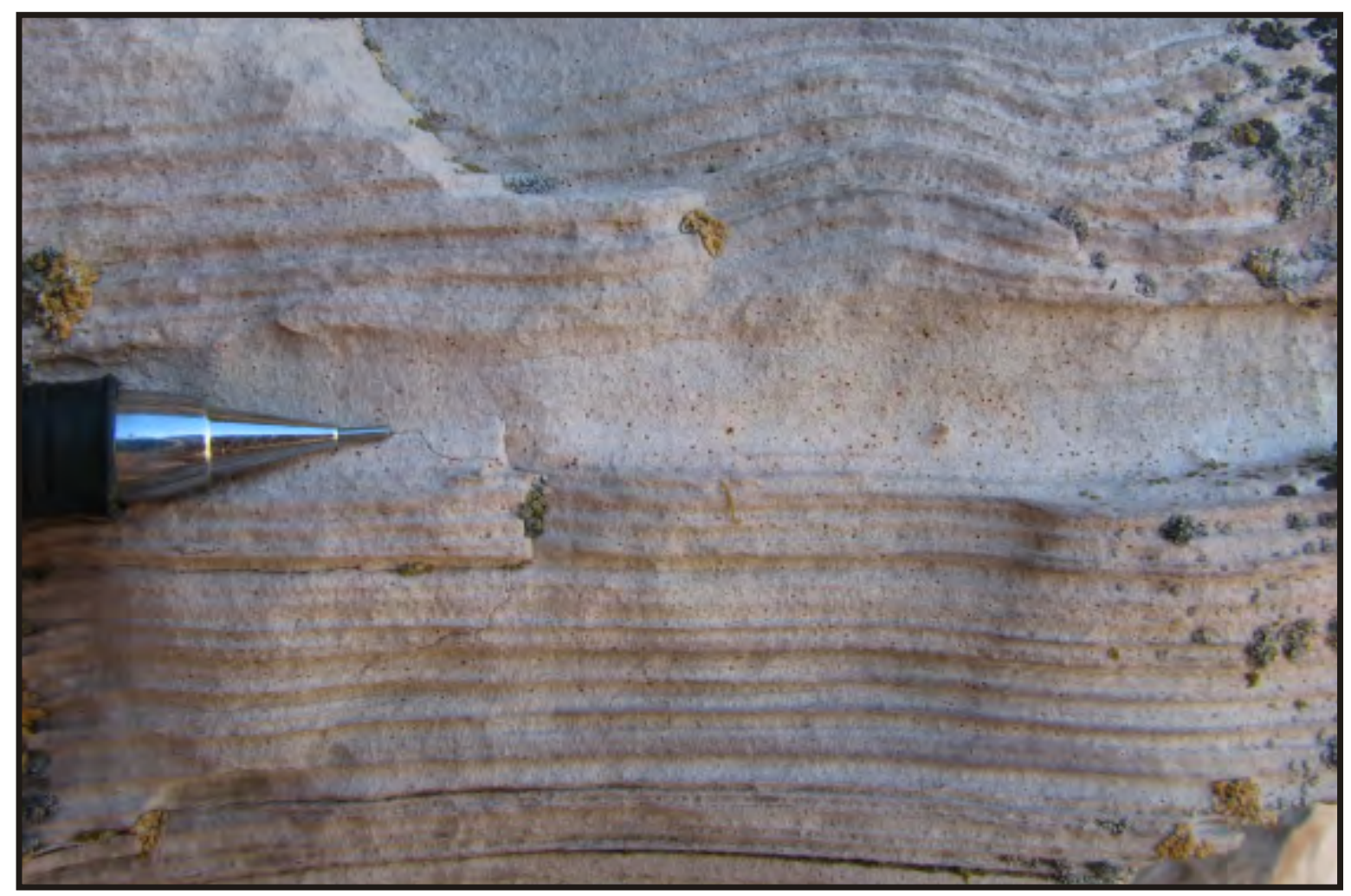

Figura 3.33. Arenas finas con estratificación de horizontal (Sh) formadas por flujos diluidos en condiciones de capa plana cercanas al alto régimen de flujo. También se muestra deformación sinsedimentaria a pequeña escala. 


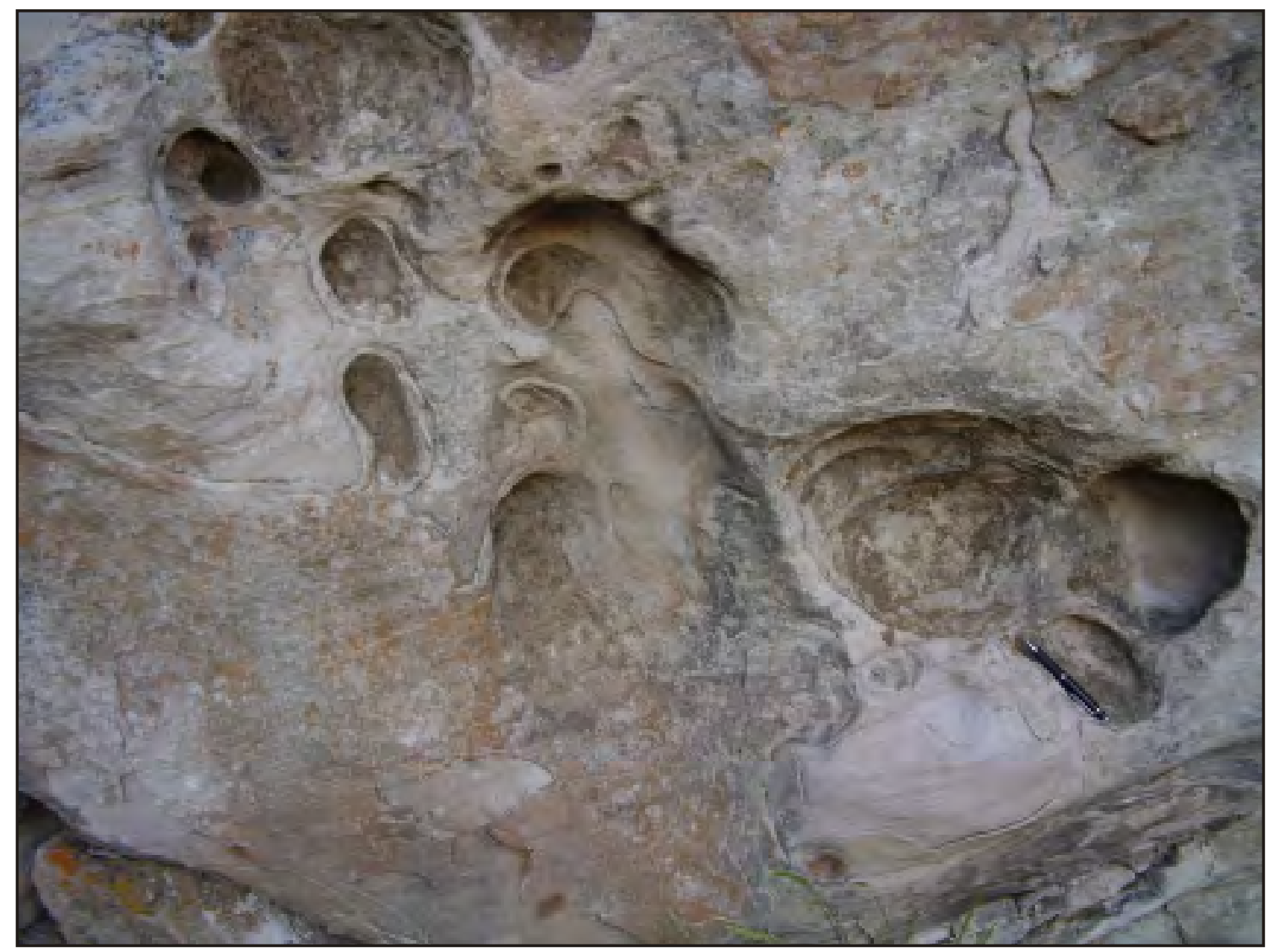

Figura 3.34. Deformación sinsedimentaria a gran escala desarrollada en las arenas que constituyen los tramos basales del Ciclo Cuyano en las nacientes del arroyo Carrán Curá, al N del paraje de Sañicó (véase mapa anexo).

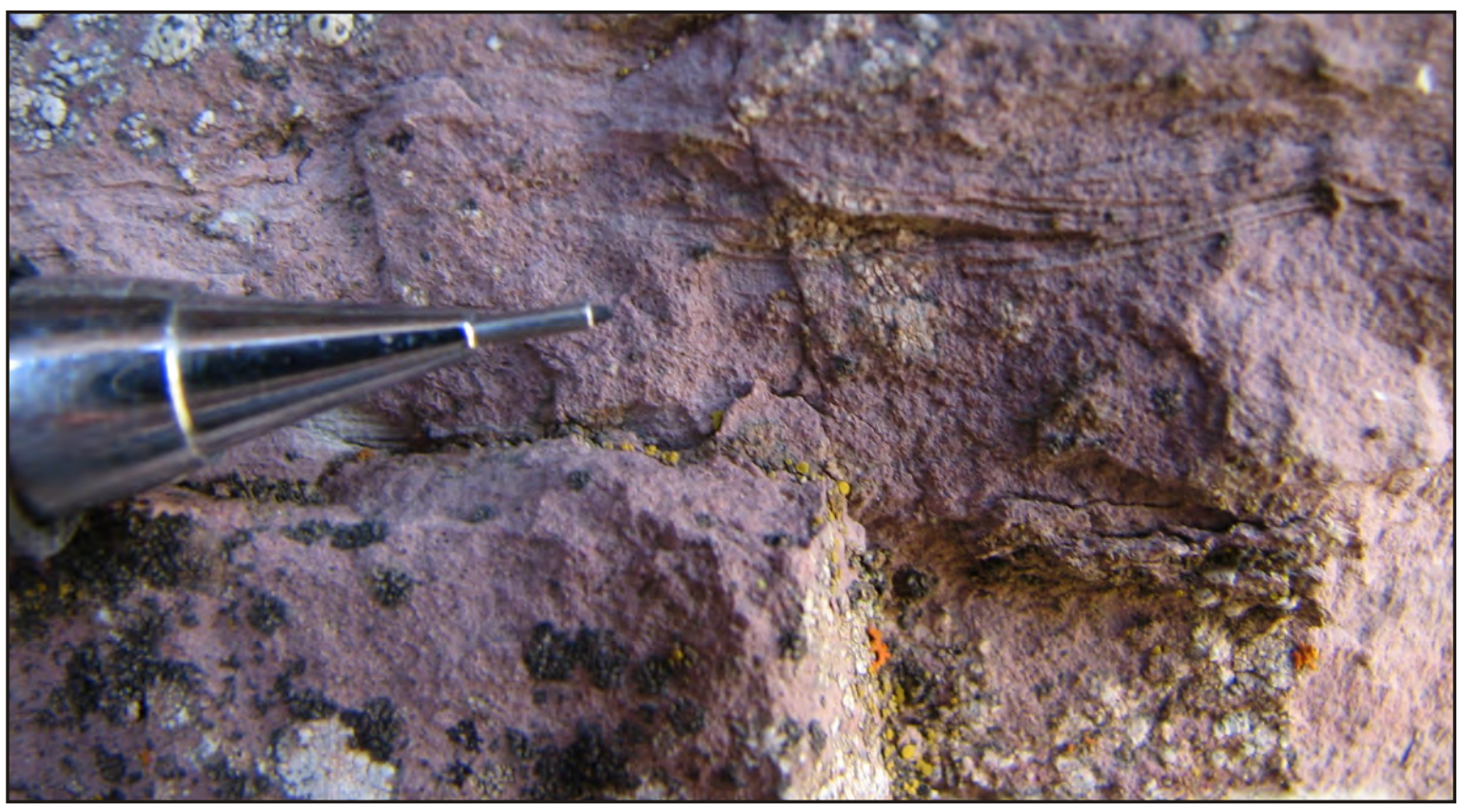

Figura 3.35. Facies epiclásticas conformadas por areniscas finas con estratificación ondulítica (Sr). 
Areniscas con estructuras monticulares (Shcs)

Yacen como capas tabulares de entre $10 \mathrm{~cm}$ a $20 \mathrm{~cm}$ de espesor constituidas por areniscas tobáceas blanquecinas, finas a muy finas y muy bien seleccionadas. Internamente presentan estructura monticular (hummocky cross stratification) (fig. 3.37) y en ocasiones pueden tener variaciones a facies estratificadas, pero con límites inferiores erosivos (fig. 3.38). Esta facies aparece localmente con las láminas entrecruzadas deformadas irregularmente, producto de deformación sinsedimentaria.

\section{Interpretación}

Depósitos de flujos de sedimentos de baja densidad combinados (oscilatorios + unidireccionales) con una componente débil de flujo unidireccional y alta tasa de agradación (Dumas y Arnott, 2006). Las variaciones con estructuras entrecruzadas de base erosiva que se intercalan con esta facies, indican baja tasa de agradación, probablemente relacionadas a posiciones más someras que las facies de Shcs (Dumas y Arnott, 2006).

\section{Areniscas con gradación normal (Sn)}

Se exhiben como areniscas líticas o tobáceas de colores castaños o blanquecinos, con granulometría variada y con buena a moderada selección. Yacen como cuerpos tabulares o lenticulares de bases irregulares erosivas, con espesores de entre $1,5 \mathrm{~cm}$ y $20 \mathrm{~cm}$. Internamente se presentan con gradación normal, ocasionalmente presentan en su parte superior laminación fina o estructura ondulosa (fig. 3.39).

\section{Interpretación}

Depósitos marinos de corrientes de turbidez arenosas (Shanmugam, 2002) originados por flujos de sedimentos marinos de alta densidad turbulentos (Dasgupta, 2003).

\subsubsection{3) Facies epiclásticas pelíticas}

\section{Pelitas laminadas (Pl(a))}

Se constituye de arcilitas moradas a rojizas, limolitas y fangolitas grisáceas. Generalmente se muestran laminadas o masivas, en bancos de entre $5 \mathrm{~cm}$ y $30 \mathrm{~cm}$ de espesor (fig. 3.40). En ocasiones se pueden presentar con nódulos de hematita con tamaños menores a 1 $\mathrm{cm}$. En ocasiones presentan restos de plantas fósiles, mientras que en el perfil PDA 3 (Anexo I y II), presentan briznas vegetales de colores oscuros de aproximadamente $1 \mathrm{~cm}$. Interpretación

Esta facies representa la decantación de materiales finos a partir de suspensiones. Las variaciones en su color, preservación de briznas vegetales y nódulos hematíticos, indican que éstos pueden haber sido el resultado de decantación de suspensiones subácueas con grados 


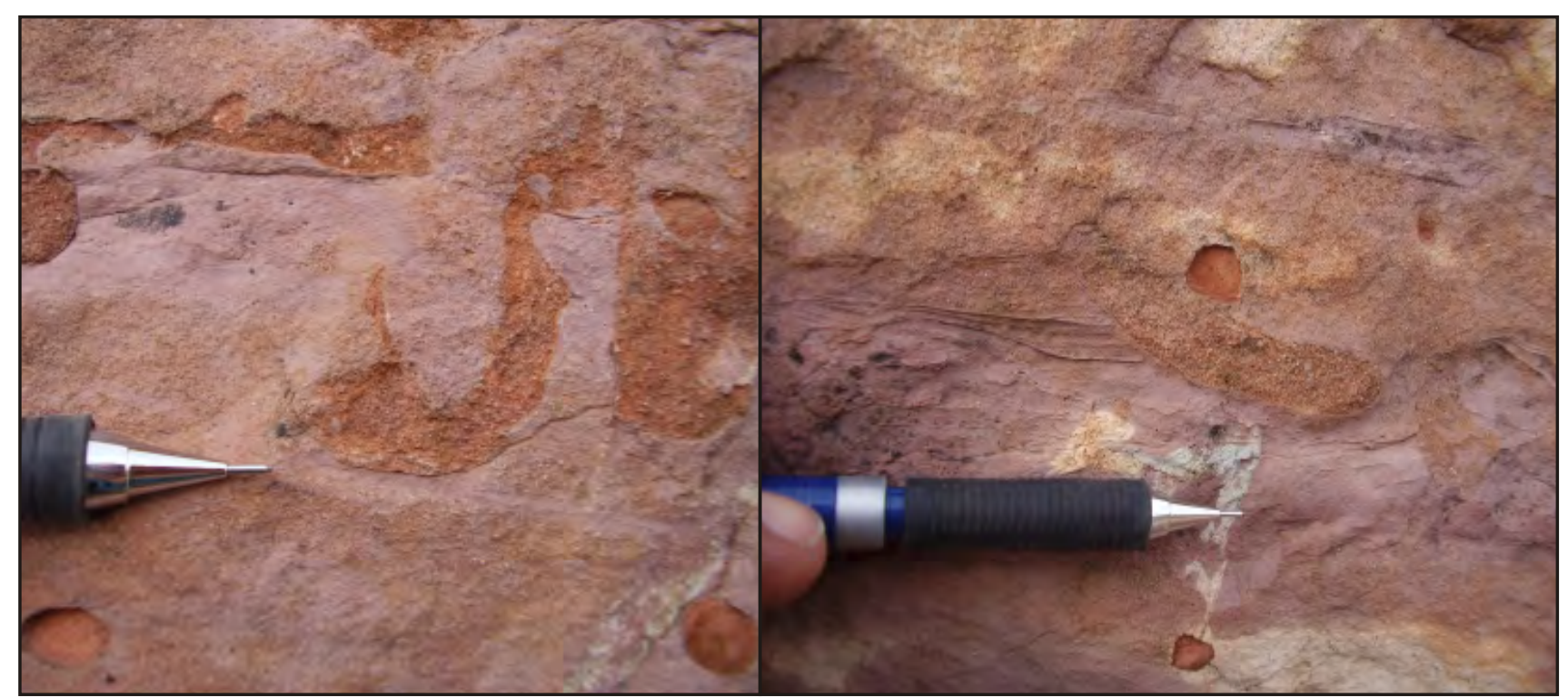

Figura 3.36. Estructuras de bioturbación desarrolladas en las facies de areniscas finas con laminación ondulítica.

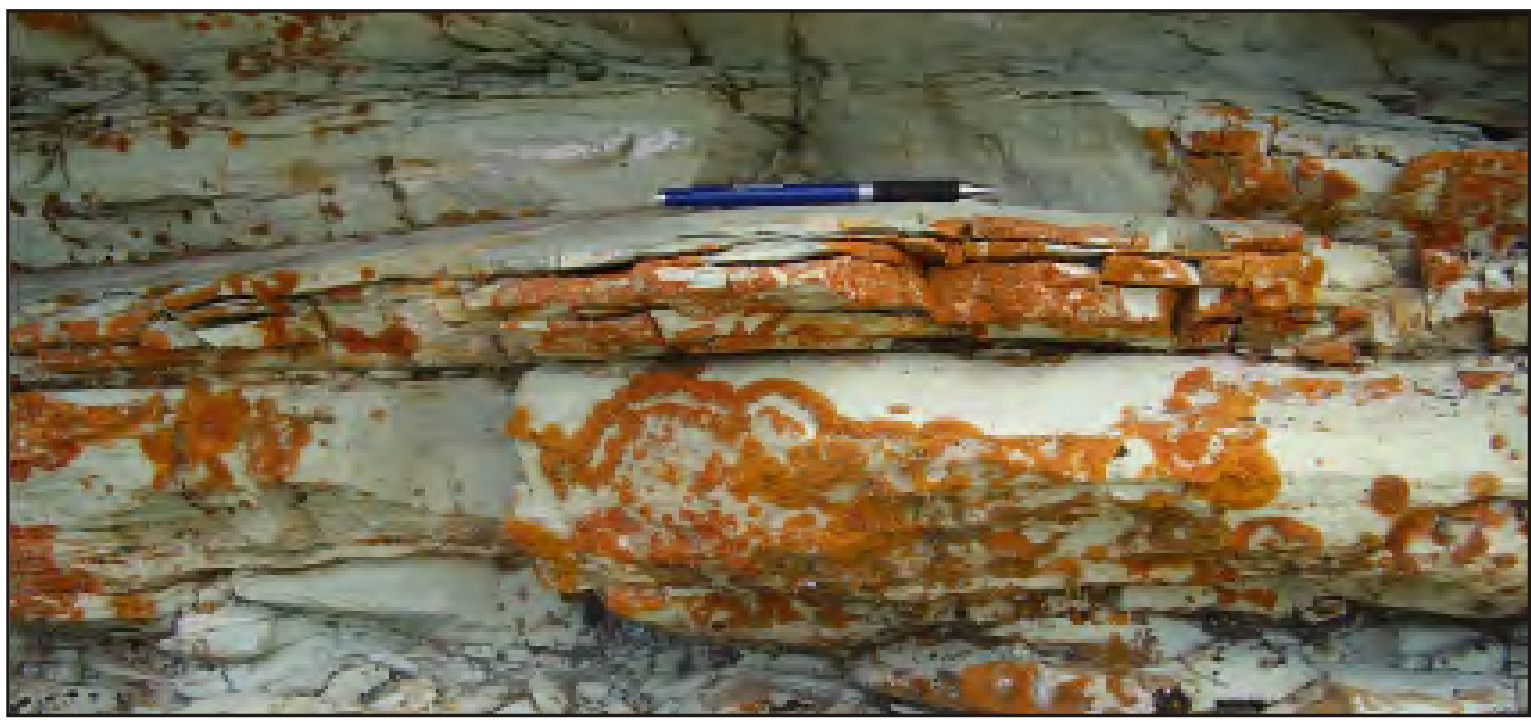

Figura 3.37. Facies epiclásticas de areniscas que desarrollan estructuras monticulares (Shcs) formadas por flujos oscilatorios-unidireccionales en condiciones de alto régimen de flujo.

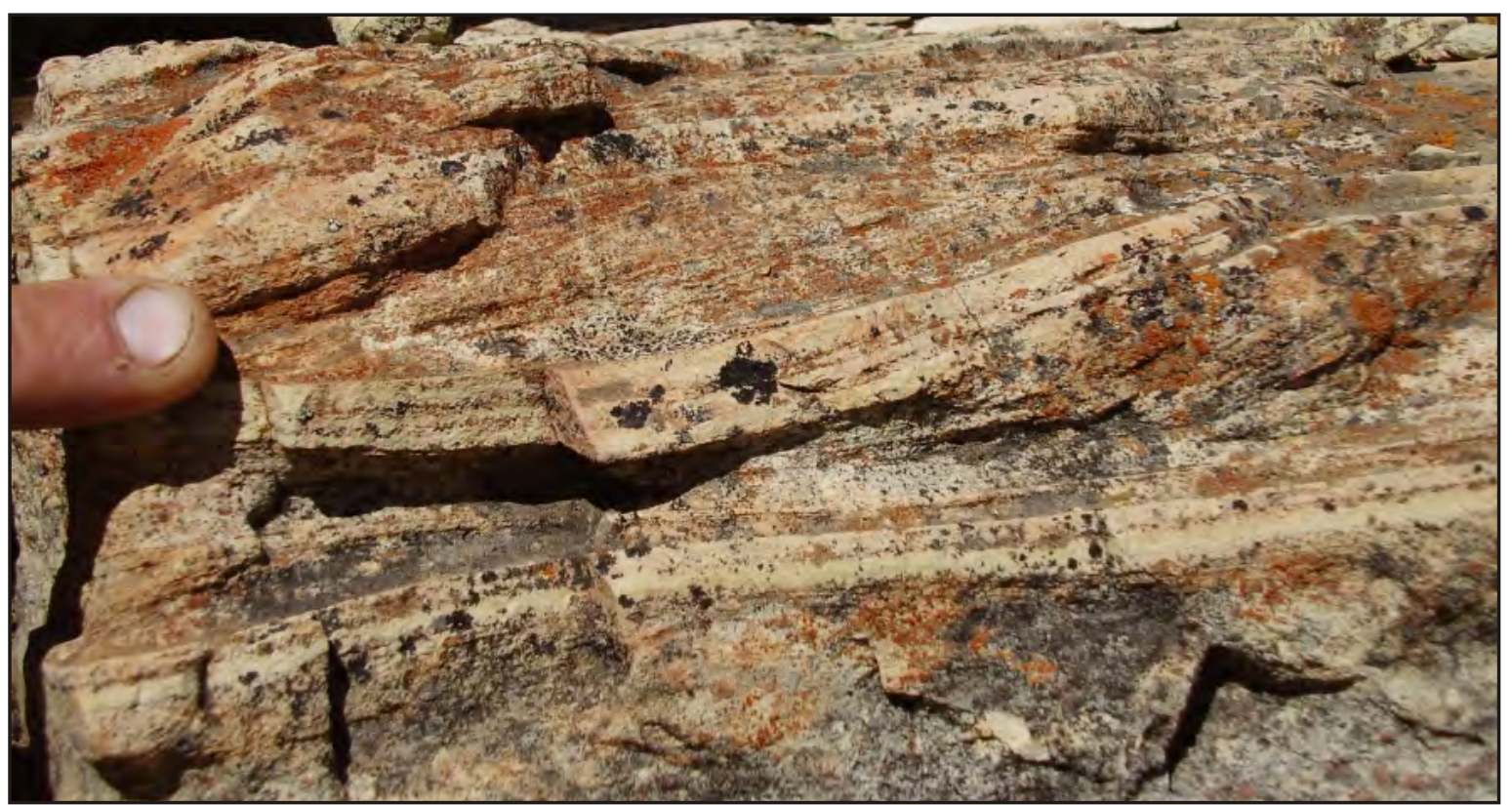

Figura 3.38. Variaciones de las facies de arenas con estructuras monticulares que desarrollan base erosiva, relacionadas a condiciones de menor agradación en áreas más someras. 


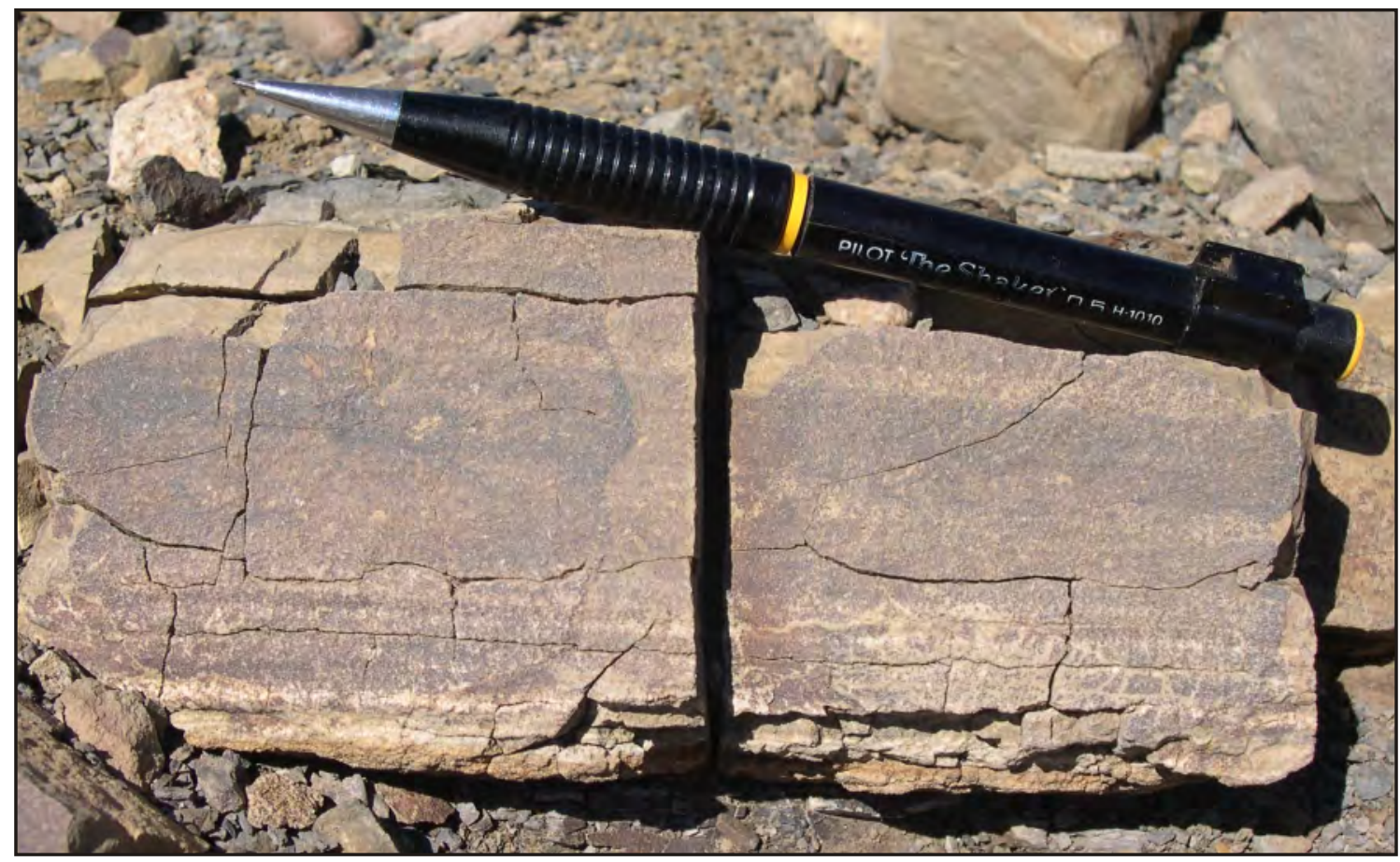

Figura 3.39. Facies espiclásticas constituidas por areniscas con gradación normal (Sn) y bases erosivas interpretadas como depósitos de corrientes de turbidez submarinas.

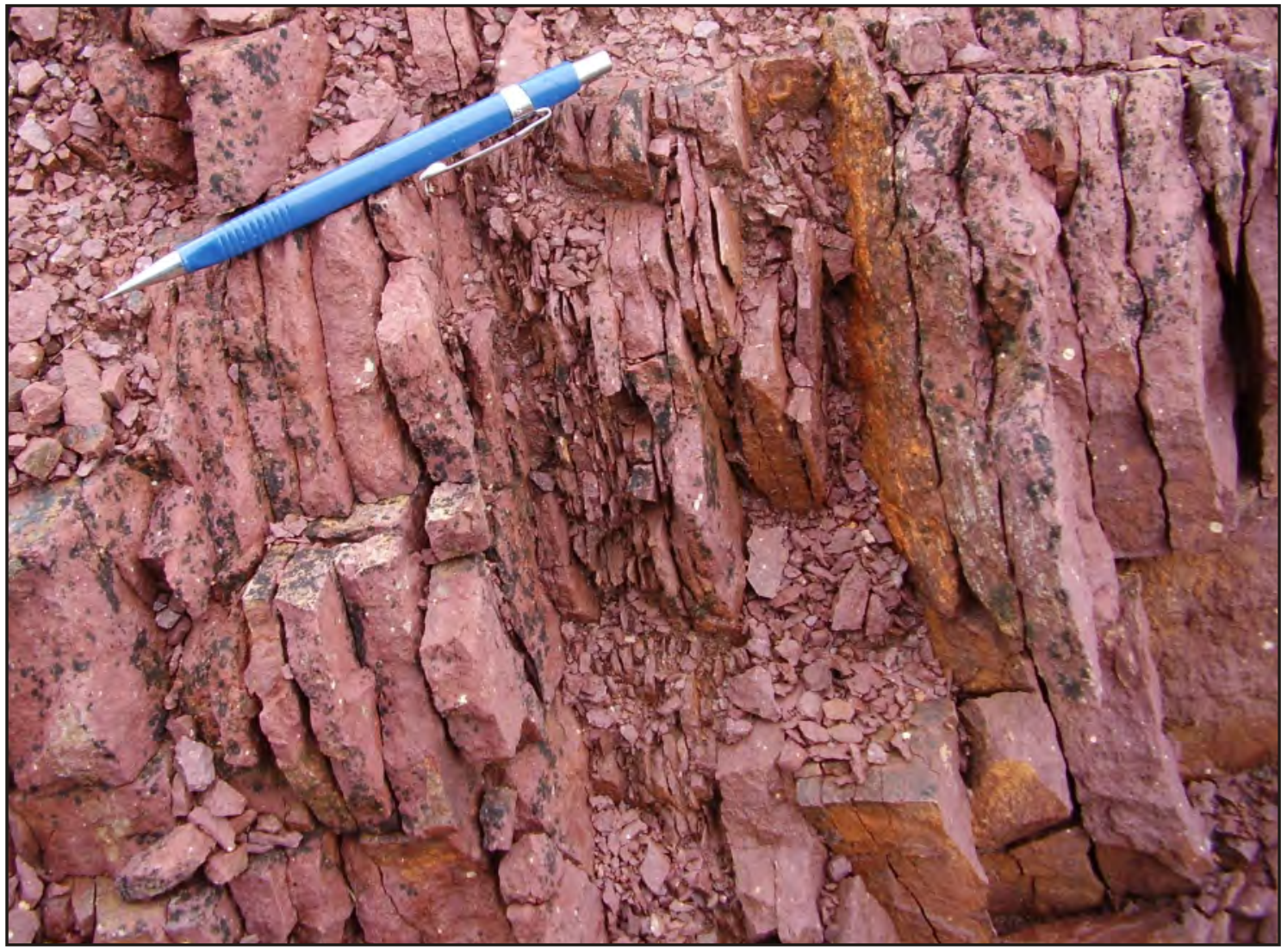

Figura 3.40. Facies epiclásticas conformadas por pelitas masivas o laminadas originadas por decantación en ambientes continentales $(\mathrm{Pl}(\mathrm{a}))$. 
variables de oxigenación en un ambiente continenal (Collinson, 2002; Blair y Mc Pherson, 2007).

Lutitas y limolitas laminadas o masivas (Pl (b))

Se presentan como lutitas negras o limolitas blanquecinas u ocráceas, en bancos tabulares de $10 \mathrm{~cm}$ a $60 \mathrm{~cm}$ de espesor (fig. 3.41). Internamente se muestran laminadas o masivas, con abundantes briznas vegetales, restos de hojas y restos de bivalvos y amonites.

\section{Interpretación}

Depósitos de decantación de materiales finos a partir de suspensiones en un ambiente marino de baja energía, con alta participación de material orgánico. Las facies de pelitas negras denotan bajo grado de oxigenación.

\subsubsection{4) Facies carbonáticas}

\section{Grainstones (GR)}

Se muestran como bancos amalgamados o tabulares de límites netos de entre $10 \mathrm{~cm} \mathrm{y}$ $40 \mathrm{~cm}$ de espesor. Se presentan con estructura depositacional reconocible o no reconocible, producto de un reemplazo parcial o total por sílice (fig. 3.42). Cuando se pueden apreciar sus rasgos primarios, se observa una textura clasto sostén conformada de peloides, bioclastos bivalvos (fig. 3.42) y fragmentos calcáreos de una granulometría medina a muy gruesa. Aisladamente presentan fragmentos calcáreos de hasta $3 \mathrm{~cm}$ de largo y litoclastos de rocas volcánicas intermedias y ácidas. En ocasiones, pueden observarse estructuras de estratificación horizontal y entrecruzada.

\section{Interpretación}

Depósitos de flujos traccionales originados por flujos de sedimentos de baja concentración, turbulentos, desarrollados en un ambiente con alta tasa de producción de fragmentos calcáreos esqueletales y no esqueletales (Tucker, 2001).

\section{Mudstones laminados (Ml)}

Esta facies se constituyen de capas de mudstones de entre $10 \mathrm{~cm}$ y $20 \mathrm{~cm}$ de espesor, de colores grisáceos a negros. Se presentan parcial o totalmente silicificadas, donde generalmente es muy dificultoso observar sus características depositacionales primarias. Cuando éstas se aprecian, se observan finas láminas y una estratificación fina horizontal (fig. 3.43). Interpretación

Depósitos de decantación en un ambiente de baja energía, con alta producción de fango carbonático y poco aporte clástico (Tucker, 2001). 


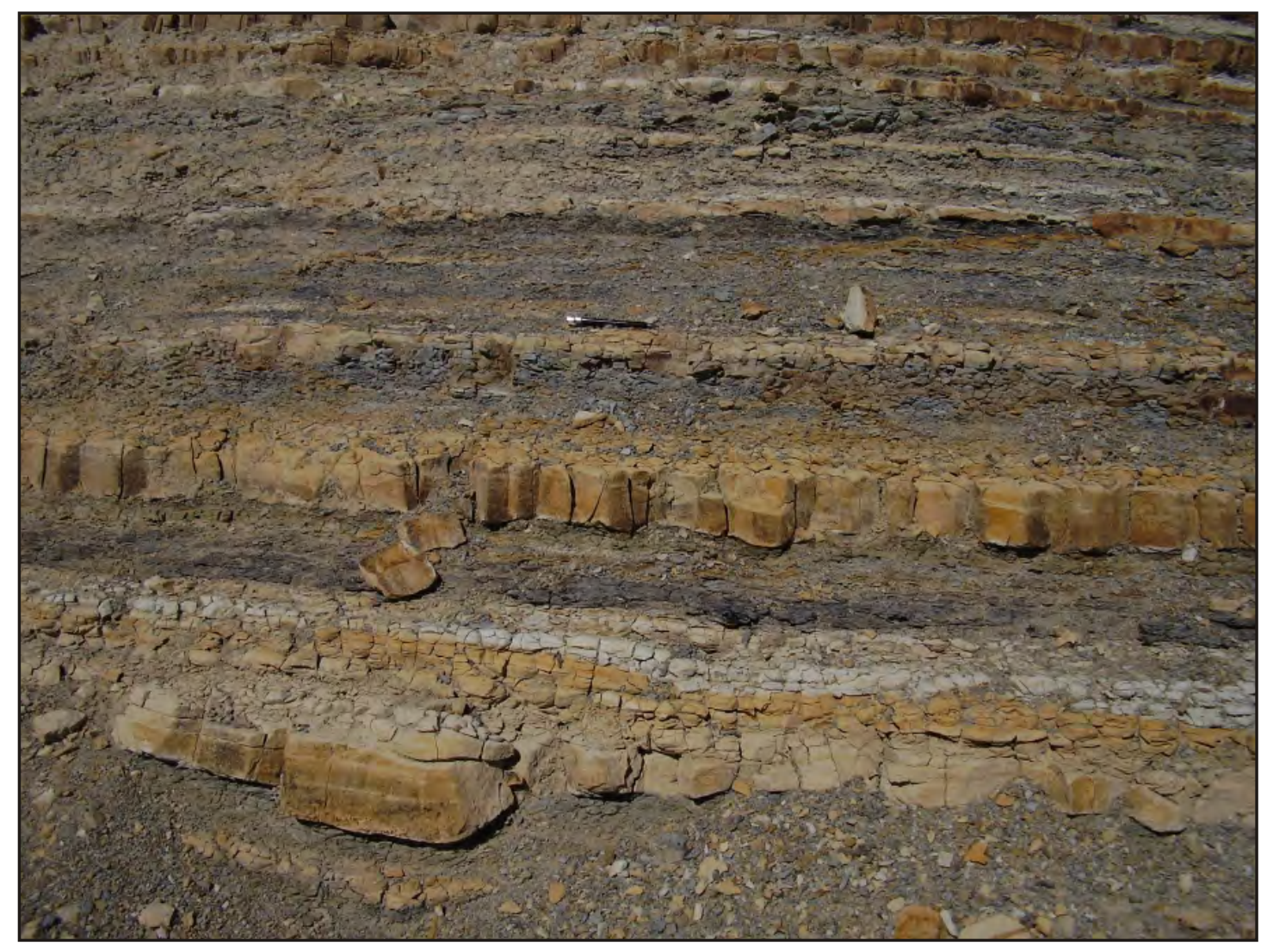

Figura 3.41. Facies de pelitas negras laminadas $(\mathrm{Pl}(\mathrm{b}))$ con restos de vegetales y de invertebrados marinos, originadas por decantación costa afuera (offshore).

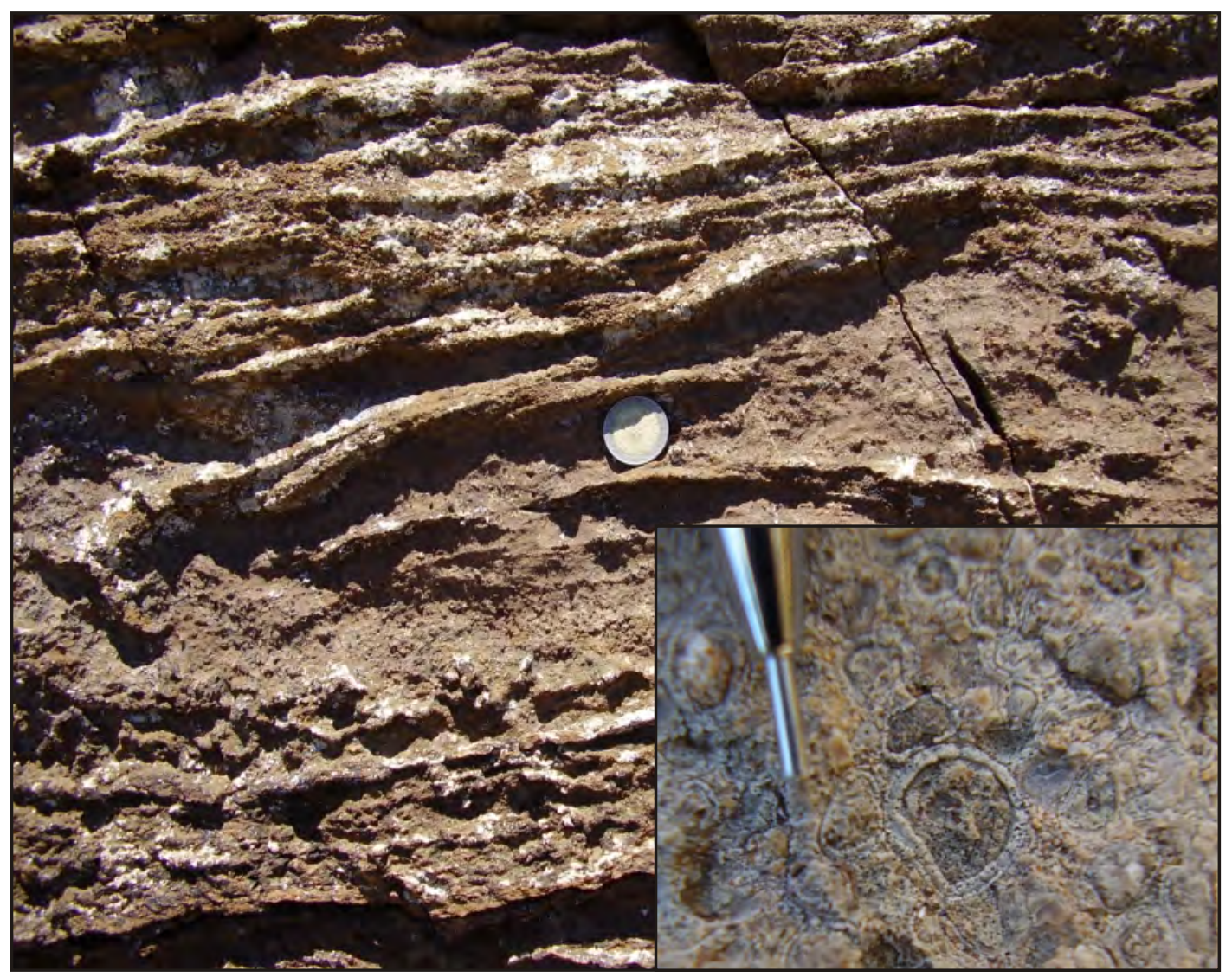

Figura 3.42. Facies carbonáticas conformadas por grainstones peloidales con estructuras tractivas (Gr). 


\section{Boundstones estromatolíticos (BE)}

Esta facies se compone de calizas grisáceas, parcial o totalmente silicificadas, en cuerpos de entre $0,1 \mathrm{~m}$ y 1,5 m. Internamente se presentan laminares o conformando estructuras bulbosas (fig. 3.44) o columnares (fig. 3.45) de $10 \mathrm{~cm}$ a $35 \mathrm{~cm}$ de diámetro y de entre $20 \mathrm{~cm} \mathrm{y}$ $60 \mathrm{~cm}$ de alto. Los bulbos y/o las columnas pueden poseer estructuras bandeadas o monticulares con tabiques internos de escalas milimétricas, o mostrarse interiormente masivos producto del reemplazo silíceo. Es importante destacar que se encontraron formas laminadas totalmente silicificadas intercaladas con bandas compuestas de sílice.

\section{Interpretación}

Formas de crecimiento algal desarrolladas en aguas someras con poco aporte clástico. Las formas tabulares y domosas, corresponderían a estromatolitos del tipo SH-C y LLH-C, mientras que las formas laminares, corresponderían a estromatolitos de tipo planar (Tucker, 2001). 


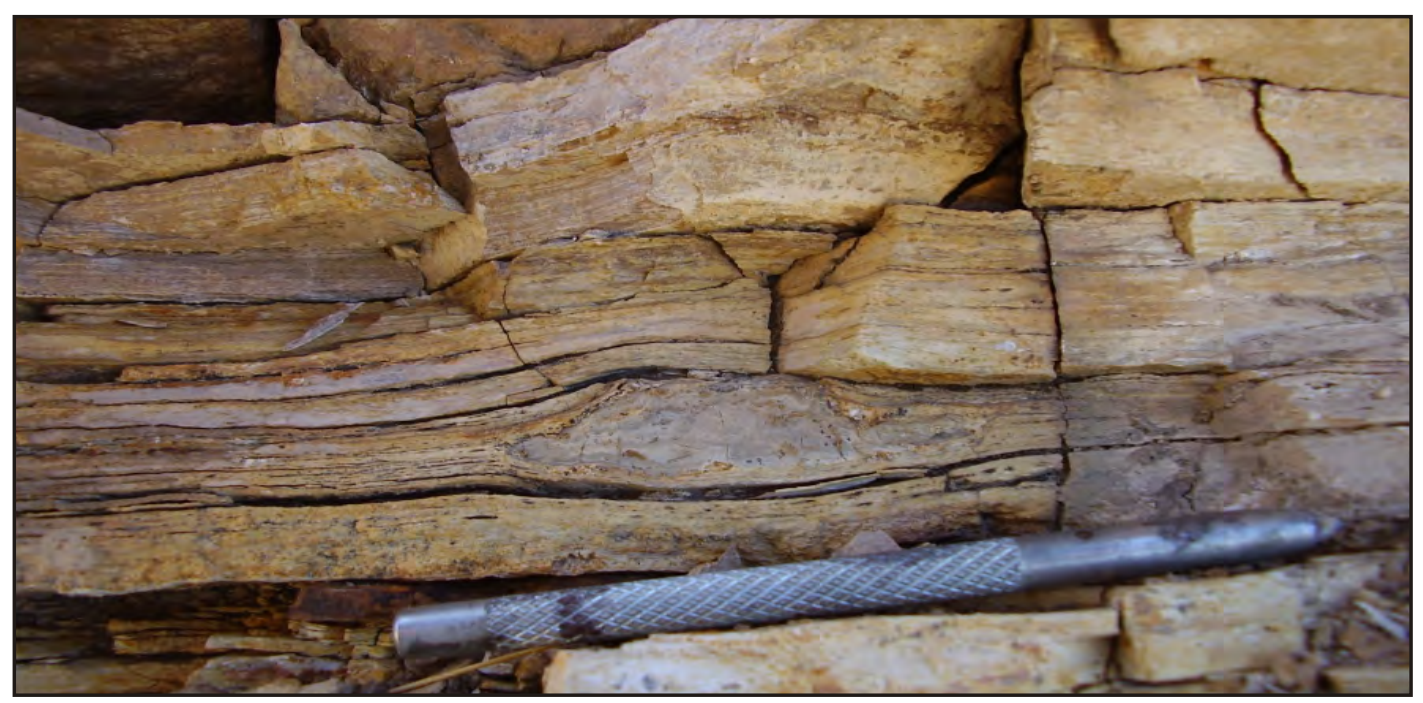

Figura 3.43. Facies carbonáticas de mudstones masivos o laminados (Ml) formadas por decantación en un medio con alta tasa de producción de carbonatos.

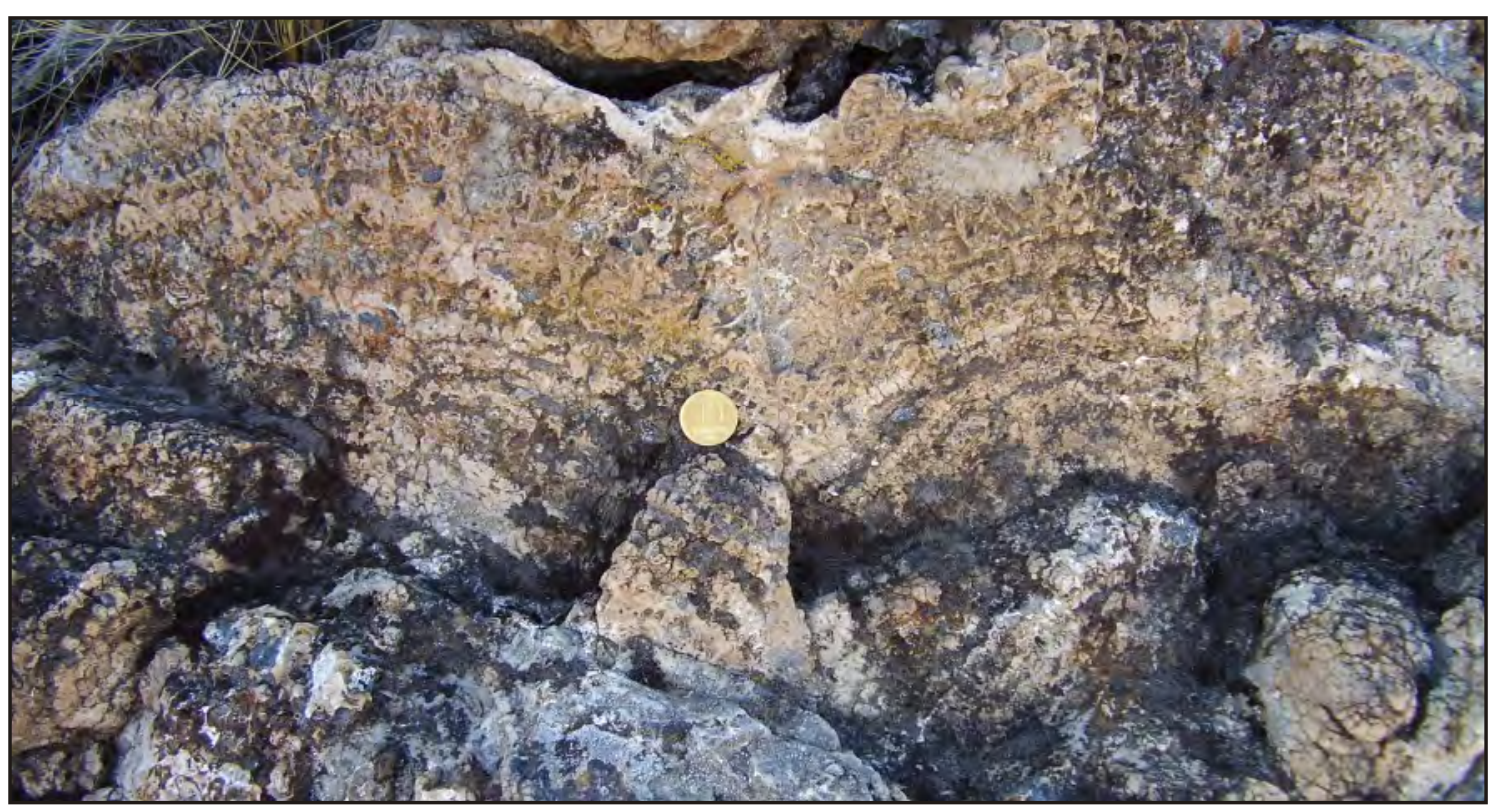

Figura 3.44. Facies de calizas constituidas de boundstones estromatrolíticos (BE) de forma bulbosa.

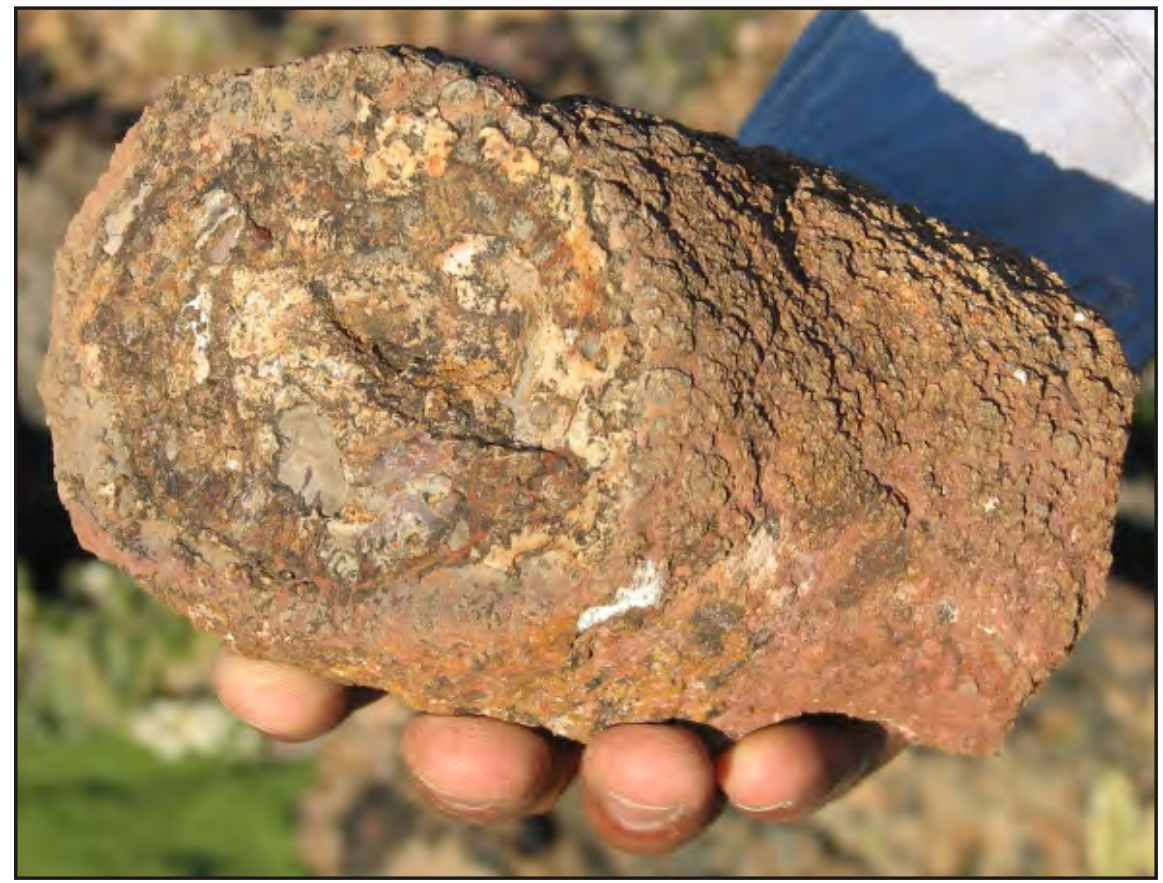

Figura 3.45. Facies de boundstones estromatrolíticos (BE) de forma columnar. 


\section{3) Análisis Microscópico}

En el siguiente inciso se avanzará en la caracterización petrográfica de las litofacies definidas anteriormente. Es importante recalcar que salvo la organización de las microfacies dentro de categorías mayores (rocas volcánicas, piroclásticas, epiclásticas y carbonáticas -véase inciso 3.3.1-), en este apartado no se encontrará un correlato entre el análisis al microscopio y el análisis dinámico de de las litofacies. Generalmente los resultados aportados por el análisis microscópico no tienen injerencia en las interpretaciones hidrodinámicas de las facies. Los mismos apuntan a dilucidar la composición detrítica cualitativa y los procesos postdepositacionales, tratándose de las rocas sedimentarias, y la composición, los parámetros texturales cualitativos y los procesos pre-emplazamiento, sin-emplazamiento y postemplazamiento, tratándose de rocas volcánicas y piroclásticas. Los resultados del análisis microscópico y litofacial serán las “piezas” utilizadas para ensamblar el "rompecabezas” que constituye el modelo de facies.

A continuación, a modo de resumen, se presentarán las microfacies diferenciadas en función de sus características composicionales, parámetros texturales y tipo/grado de alteración (fig. 3.46). Por último, es importante destacar que la interpretación de las microfacies volcánicas, piroclásticas, epiclásticas y carbonáticas se ha realizado mediante conceptos sistemáticos (Hagel, 1979; Ramdohr, 1980; Adams et al., 1984; Stephen y Montanam, 1992; Mc Phie et al., 1993; Askren et al., 1997; Scasso y Limarino, 1997; McArthur et al., 1998; Best y Christiansen, 2000; Tucker, 2001; Allen y Mc Phie, 2003; Gifkins et al., 2004; Gifkins et al., 2005; Quane y Russell, 2005; López y Bellos, 2007).

\subsection{1) Análisis microscópico de las rocas volcánicas}

Microfacies de rocas volcánicas andesíticas (RVA)

Se exhiben con texturas seriadas (fig. 3.47D), microporfíricas a porfíricas y/o glomeroporfíricas (fig. 3.47C), donde los cristales faneríticos (entre el $5 \%$ y $30 \%$ ) se hallan inmersos en pastas con texturas pilotáxicas, traquíticas, vítreas recristalizadas (fig. 3.47B) y minoritariamente intergranunlar con seudomorfos de olivinas (fig. 3.47E). En función de los feno/microfenocristales, se pueden diferenciar tres variedades: andesitas basálticas, andesitas piroxénicas y andesitas hornblendíferas. Las plagioclasas (An30-An44) se presentan con hábitos tabulares a cuadrangulares y formas subhedrales y anhedrales, con tamaños de entre 0,1 cm y $0,7 \mathrm{~cm}$. Se muestran esqueletales, con textura cribada gruesa (coarse sieve-texture) o zonadas con núcleos parcialmente alterados. Los piroxenos se presentan como augita en prismas subhedrales a euhedrales, tamaños de entre $1,2 \mathrm{~mm}$ a $0,5 \mathrm{~mm}$, generalmente libres de alteración. 


\begin{tabular}{|c|c|c|c|c|}
\hline & código & texturas/microestructuras & composición & alteración/diagénesis \\
\hline \multirow{3}{*}{ 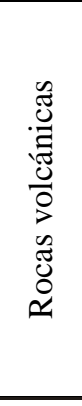 } & RVA & $\begin{array}{l}\text { porfírica, glomeroporfírica, } \\
\text { vitrofírica plagioclasas límpidas o } \\
\text { zonadas, cribadas o límpidas. } \\
\text { Microestructuras de disolución y } \\
\text { reemplazo, cristales fracturados por } \\
\text { enfriamiento brusco }\end{array}$ & andesítica. & $\begin{array}{l}\text { sericítica -clorítica, } \\
\text { carbonática y potásica }\end{array}$ \\
\hline & RVD & porfírica & dacítica & sericítica -clorítica \\
\hline & RVR & $\begin{array}{l}\text { porfírica y vitrofírica. Con venas } \\
\text { silíceas como microestructuras }\end{array}$ & riodacítica & silicificación \\
\hline \multirow{4}{*}{ 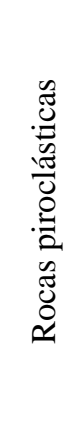 } & IgnSA & vítrica. & riolítica-dacítica & $\begin{array}{l}\text { argílica, sericítica, } \\
\text { potásica y carbonática }\end{array}$ \\
\hline & $\operatorname{IgnS}$ & vítrica. & dacítica & silicificación \\
\hline & IgnD & $\begin{array}{l}\text { vítrica. Esferulitas y litofisas como } \\
\text { microestructuras. }\end{array}$ & riolítica-dacítica. & $\begin{array}{c}\text { desvitrificación a alta } \\
\text { temperatura }\end{array}$ \\
\hline & DFByC & $\begin{array}{l}\text { microestructuras de disolución y } \\
\text { reemplazo }\end{array}$ & andesítica. & $\begin{array}{c}\text { soluciones hidrotermales } \\
\text { que movilizan óxidos de } \\
\text { hierro-ilmenita. }\end{array}$ \\
\hline \multirow{5}{*}{ 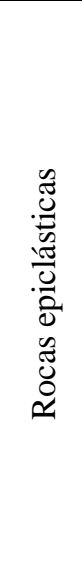 } & REMA & $\begin{array}{l}\text { clastos tangenciales flotantes o } \\
\text { rectos }\end{array}$ & monomíctica andesítica & diagénesis temprana \\
\hline & REMAjs & $\begin{array}{l}\text { clastos tangenciales, flotantes o } \\
\text { rectos. Microestructuras de } \\
\text { disolución y reemplazo. Cristales con } \\
\text { fracturación en rompecabezas } \\
\end{array}$ & monomíctica andesítica & diagénesis temprana \\
\hline & REMP & $\begin{array}{l}\text { clastos tangenciales, flotantes o } \\
\text { rectos }\end{array}$ & monomíctica piroclástica & diagénesis temprana \\
\hline & REV & $\begin{array}{l}\text { clastos tangenciales, flotantes o } \\
\text { rectos }\end{array}$ & $\begin{array}{c}\text { polimícticas de } \\
\text { procedencia volcánica y } \\
\text { silicoclástica } \\
\end{array}$ & diagénesis temprana \\
\hline & RES & $\begin{array}{l}\text { clastos tangenciales, flotantes o } \\
\text { rectos }\end{array}$ & silicoclástica & diagénesis temprana \\
\hline \multirow{3}{*}{ 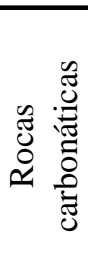 } & RCG & clastos flotantes & $\begin{array}{c}\begin{array}{c}\text { peloides, intraclastos y } \\
\text { bioclastos }\end{array} \\
\end{array}$ & diagénesis temprana \\
\hline & RCLM & $\begin{array}{l}\text { laminación microbial. } \\
\text { microestructura fenestral }\end{array}$ & $\begin{array}{c}\text { cabonatos por } \\
\text { segregación de } \\
\text { microorganismos } \\
\end{array}$ & diagénesis temprana \\
\hline & RCM & microlaminación & fango carbonático & diagénesis temprana \\
\hline
\end{tabular}

Figura 3.46. Características de las microfacies definidas para este estudio. 
En las variedades hornblendíferas, los cristales de hornblenda se exponen con tamaños de 0,3 a 0,6 mm, formas euhedrales a subhedrales, generalmente con bordes reabsorbidos y con reborde de opacos.

Respecto a la alteración, la microfacies andesíticas se encuentran con estados variables, desde incipiente a medio grado. Entre ellas se destacan la carbonatación, donde las plagioclasas están alteradas mayoritariamente a carbonatos de calcio (fig. 3.47H); la cloritización y sericitización, donde las plagioclasas son alteradas a sericitas y los mafitos a cloritas; y la alteración potásica donde las plagioclasas son reemplazadas por adularia esqueletal. Respecto a las estructuras, se ha encontrado microestructura vesicular o amigdaloide (fig. 3.47G), donde las vesículas están rellenas de cloritas o carbonatos, estructuras de disolución (fig. 3.47F) y reemplazo generalmente a agregados de sílice criptocristalina, fracturas hidráulicas rellenas por carbonatos (fig. $3.47 \mathrm{H}$ ), estructuras de disolución y fracturas producto del brusco enfriamiento (quenching) (fig. 3.47B).

Microfacies de rocas volcánicas dacíticas (RVD)

Se presentan con textura porfírica o seriada, masivas o con foliación por flujo. Se muestran con fenocristales de plagioclasa, cuarzo y biotita (fig. 3.48A) o con fenocristales de plagioclasa y hornblenda (fig. 3.48B). Los fenocristales se encuentran inmersos en una pasta afanítica constituida por un arreglo de cuarzo y feldespato que le confiere una textura felsítica, la cual varía desde microcristalina hasta criptocristalina. Los fenocristales de cuarzo se presentan euhedrales o subhedrales con bordes reabsorbidos y tamaños de entre $0,5 \mathrm{~mm}$ y 0,3 mm. Los fenocristales de plagioclasa se exhiben euhedrales con núcleos alterados y cribados (textura cribada gruesa y fina), con tamaños de entre $7 \mathrm{~mm}$ y $0,5 \mathrm{~mm}$, límpidos o zonados. Las biotitas aparecen con tamaños de entre $0,5 \mathrm{~mm}$ y $0,3 \mathrm{~mm}$ y están alineadas con el elemento de fábrica planar cuando se trata de una foliación por flujo y los cristales de hornblenda se muestran con formas euhedrales y tamaños de hasta $1 \mathrm{~cm}$. Los minerales accesorios que se hallan presentes son apatita, circón y minerales opacos. Es importante destacar que en ocasiones se ha encontrado una variedad de dacita hornblendífera con textura porfírica a seriada, constituida por abundantes fenocristales de plagioclasa y hornblenda que puede llegar a constituir hasta el 45 \% del volumen de roca. Se expone con alteración sericítica-clorítica incipiente o con silicificación con grados desde medios a altos (fig. 3.48A).

\section{Microfacies de rocas volcánicas riodacíticas (RVR)}

Se presentan con textura porfírica, fenocristales poco abundantes ( $<15 \%$ en volumen de roca) de cuarzo, biotita, feldespato potásico y plagioclasa. Se hallan inmersos en una pasta afanítica constituida por microlitos de cuarzo y feldespato anhedrales que conforman una 


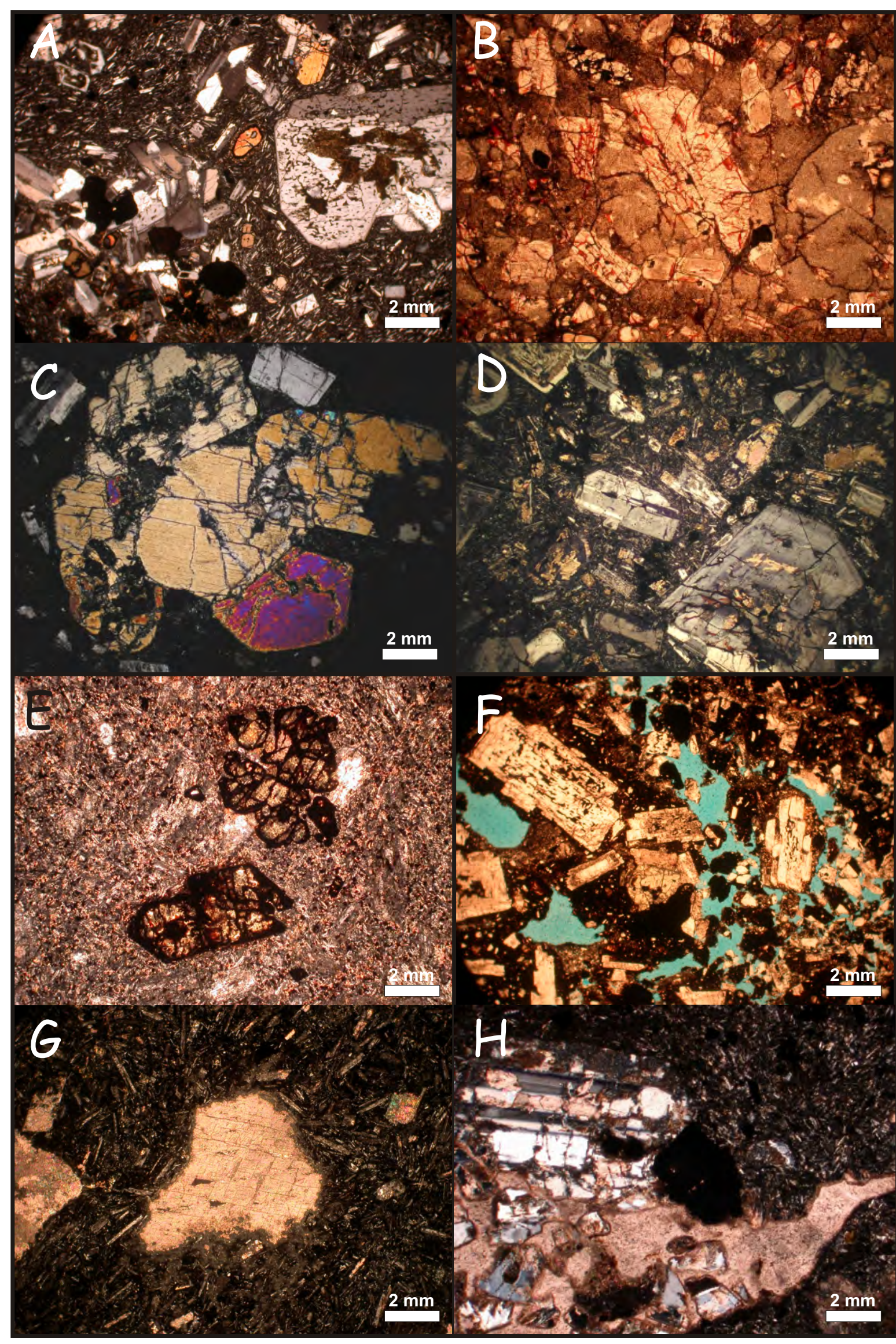

Figura 3.47. Características de las microfacies de rocas volcánicas andesíticas. A) Andesita horbléndica porfítica con pasta seriada. Presenta cumulatos dioríticos, fenocristales de Pg con textura cribada gruesa y cristales de $\mathrm{Hbl}$ con un reborde delgado de opacos. B) Andesita vitrofítica con fracturas producidas por el brusco enfriamiento. C) Andesita con fenocristales Cpx que constituyen una textura glomeroporfírica. D) Andesita con textura seriada y alteración clorítica-sericítica incipiente. E) Andesita basáltica con pasta intergranular y pseudomorfos de Ol. F) Andesita con estructura de disolución (azul = resina). G) Andesita con pasta pilotáxica y vesículas rellenas de carbonatos. H) Andesita con fracturación hidráulica rellena de carbonatos. 
textura felsítica o por microlitos de cuarzo y feldespato con bordes lobados que forman una textura micropoiquilítica (vidrio recristalizado) (fig. 3.48C). Los fenocristales de cuarzo presentan tamaños de entre $3 \mathrm{~mm}$ y 0,5 mm, euhedrales con bordes reabsorbidos (fig. 3.48D) o subhedrales y anhedrales. Los fenocristales de plagioclasa y feldespato potásico se exhiben euhedrales o subhedrales, generalmente límpidos, con tamaños de entre $5 \mathrm{~mm}$ y 0,3 mm. Los cristales de biotita aparecen límpidos con tamaños de aproximadamente entre $1 \mathrm{~mm}$ y 0,5 mm. Esta facies aparece parcialmente o totalmente silicificada con venas y fracturas rellenas de agregados de sílice como estructuras y microestructuras asociadas (fig. 3.48C).

\section{Consideraciones sobre las características de las microfacies volcánicas}

En sentido amplio, las rocas volcánicas analizadas comprenden un rango composicional que se extiende desde andesitas basálticas a riolitas (andesitas basálticas, andesitas, dacitas y riolitas) (fig. 3.49). Las diferentes variedades de microfacies de andesitas (RVA), sugieren diferentes condiciones de composición, temperatura, presión y presión de fluidos. De tal forma, los pseudomorfos de olivinas en las andesitas basálticas, indican una fuente poco evolucionada, de composiciones más básicas y de mayor temperatura (Askren et al., 1997). Por otro lado, las andesitas piroxénicas y andesitas hornbléndicas, indican diferentes condiciones de temperatura, presión de fluidos y presión de confinamiento, necesarias para estabilizar termodinámicamente los fenocristales de hornblenda o clinopiroxenos. Las microfacies de dacitas (RVD) y riodacitas (RVR) presentan fenocristales de hornblenda y/o biotita. La presencia de fenocristales de hornblenda en las microfacies de andesitas y dacitas, indica composiciones hidratadas de los magmas, con concentraciones de agua mayores o iguales al $5 \%$ en peso y presiones de confinamiento de $1 \mathrm{~kb}$ a 3 kb (entre 4 km y 10,5 km) (Best y Christiansen, 2000).

Como se pudo apreciar en los párrafos precedentes, a pesar de las variaciones composicionales, las rocas volcánicas generalmente presentan arreglos texturales similares. Por esta razón, las diferentes texturas serán evaluadas de manera conjunta, en función de sus trayectorias cinéticas y de cristalización (fig. 3.50), realizándose, en caso de ser necesario, la vinculación con las modas composicionales.

Las texturas porfíricas involucran dos estadios en la historia de enfriamiento del líquido magmático. Un estadio inicial, de lento enfriamiento, donde los cristales nucleados se encuentran en "dominios de enfriamiento plutónico", creciendo y alcanzando el tamaño relativo para denominarse fenocristales. En estas condiciones, luego de la cristalización inicial, el magma experimenta un episodio de rápida pérdida de calor, debido a una intrusión somera o extrusión (fig. 3.50), generando una textura afanítica (pasta), la cual implica una alta tasa de nucleación de cristales respecto a la tasa de crecimiento, producto de una rápida disminución de la temperatura. Las variaciones cripto a microcristalinas y la existencia de cristales bien 


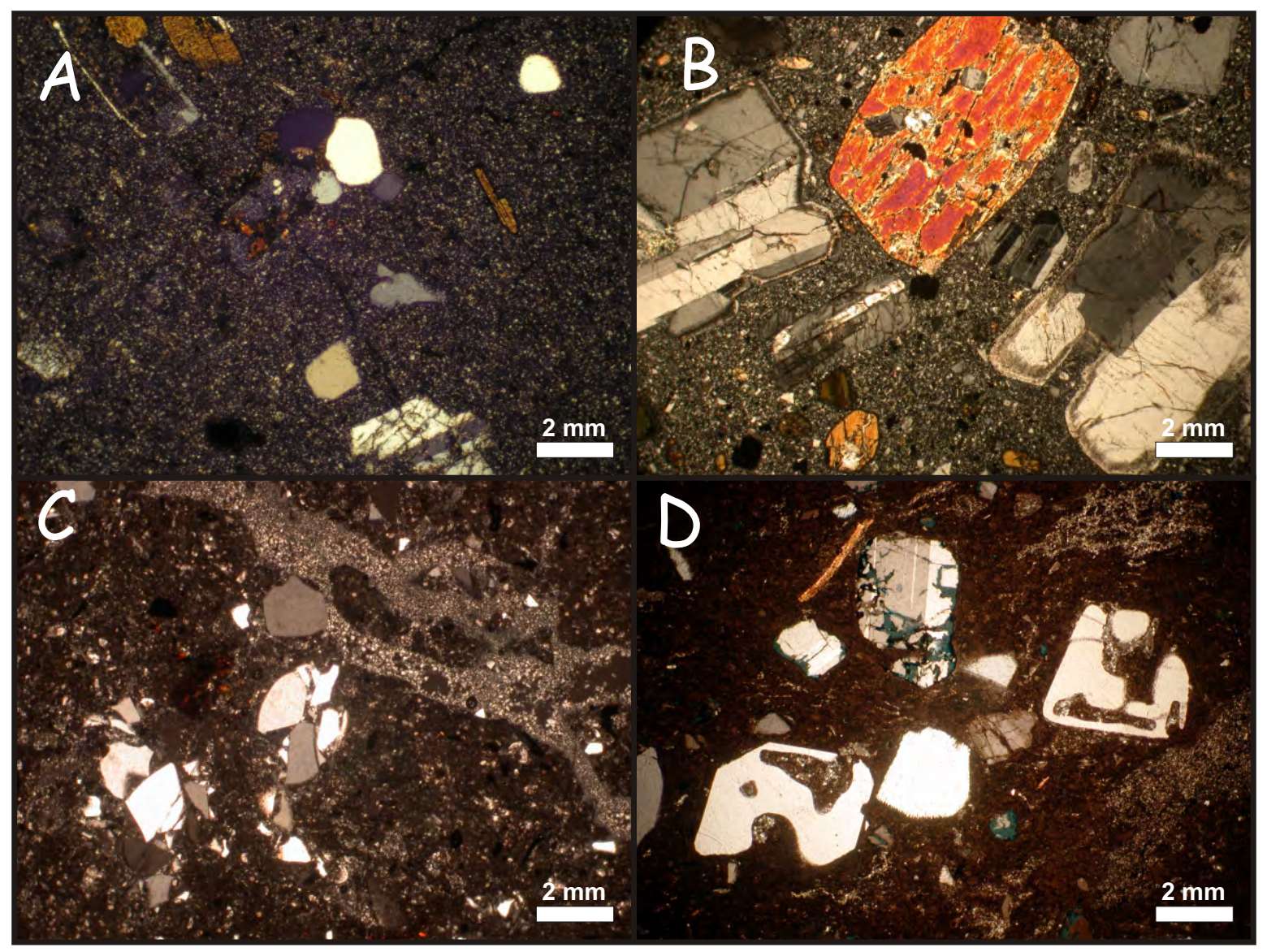

Figura 3.48. A) Microfacies dacíticas con fenos de Qtz y Pg inmersos en una pasta felsítica criptocristalina. B) microfacies dacítica constituida de fenocristales de Hbl límpidos y Pg con textura cribada fina, inmersos en una pasta felsítica microcristalina. C) Microfacies de riodacitas con fenocristales de Qtz y FK fracturados inmersos en un pasta micropoikilítica resultado de la recritalización del vidrio a alta temperatura. También se muestra venas rellenas de material silíceo. D) Microfacie riodacítica donde se aprecian fenocristales de Qtz engolfados, Pg fracturadas y cristales de Bt, inmersos en una pasta criptocristalina con silicificación penetrativa.

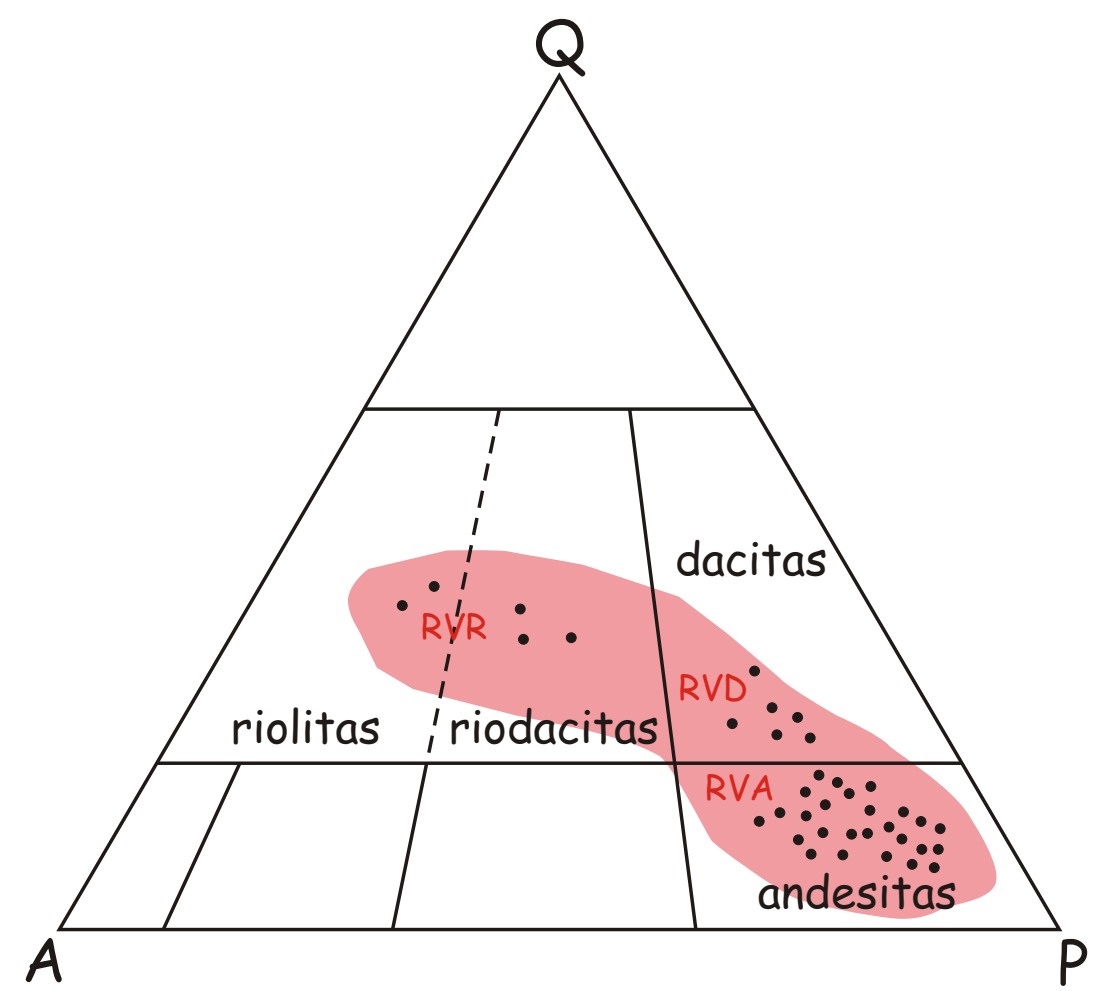

Figura 3.49. Diagráma de clasificación QAP’ esquemático donde se muestra el rango composicional de las 37 muestras rocas volcánicas analizadas para el ciclo Precuyano. Q=Cuarzo, A= Feldespatos alcalinos y $\mathrm{P}=$ Plagioclasas (An 100-An05). 
formados o esqueletales en las pastas afaníticas, indican variaciones en la tasa de enfriamiento/sobreenfriamiento (Best y Christiansen, 2000). La textura vitrofírica es una variedad de textura porfírica, donde el segundo estadio de enfriamiento se produjo bruscamente sin posibilitar la nucleación de cristales, formando un líquido altamente viscoso, desordenado atómicamente, denominado vidrio. Asociadas a las texturas vitrofíricas, se han encontrado fenocristales fracturados producto del rápido enfriamiento (quenching) (Mc Phie et al., 1993; Allen y Mc Phie, 2003). La textura glomeroporfírica es otra variación de textura porfírica, la cual implica que los fenocristales crecieron suspendidos en contactos unos con otros (Best y Christiansen, 2000). La textura seriada sugiere una tasa de enfriamiento gradual, evidenciada por la ausencia de un hiato en el tamaño de los cristales (Llambías, 2008). Esta textura sólo fue encontrada en las variedades de microfacies andesíticas (RVA).

Es importante destacar que, a su vez, los arreglos texturales vistos anteriormente pueden presentar otros indicadores texturales que otorgan información sobre las trayectorias de cristalización. La evaluación de ciertas texturas desarrolladas en una especie de cristal, pueden indicar desequilibrios termodinámicos relacionados a variaciones en las condiciones de temperatura, presión y composición. Aislando las variables primordiales del desequilibrio, de manera cualitativa, se puede realizar una inferencia sobre las trayectorias de cristalización ocurridas en el reservorio magmático (variaciones de temperatura, presión y composición) y sobre las variaciones en la trayectoria de cristalización ocurridas producto de la erupción y emplazamiento (variaciones de presión y temperatura). En las microfacies andesíticas, los cristales de plagioclasa con textura cribada y bordes reabsorbidos, se originan por rápida descompresión (fig. 3.50) con una pérdida mínima de calor (coarse sieve-texture) o por variaciones composicionales ocurridas en la cámara magmática (fine sieve-texture) (Stephen y Montana, 1992; Best y Christiansen, 2000). Las condiciones de descompresión pueden ser alcanzadas durante el ascenso del magma a gran velocidad. Estudios experimentales sugieren que la tasa de ascenso puede superar los $10 \mathrm{~m} / \mathrm{s}$ (Stephen y Montana, 1992). En las microfacies de andesitas (RVA), los fenocristales de hornblenda que aparecen manteados por minerales opacos, se originan por una lenta desvolatilización, la cual disminuye la presión parcial de agua dentro del sistema, estabilizando fases anhidras. Estudios experimentales indican que las tasas de ascenso para desarrollar una lenta desvolatilización deben ser del orden de 15 metros por día a 50 metros por día (Best y Christiansen, 2000; Rutherford y Gardner, 2000). Por último, en las microfacies de dacíticas (RVD) y riodacitas (RVR), los fenocristales de cuarzo con bordes reabsorbidos también pueden ser atribuidos a descompresión.

Con respecto a la alteración, en las microfacies andesíticas y de andesitas basálticas no se desarrolla de manera penetrativa. Exceptuando las zonas de fracturas, donde se pueden presentar de manera avanzada, los grados de alteración van desde débiles a moderados (Gifkins 


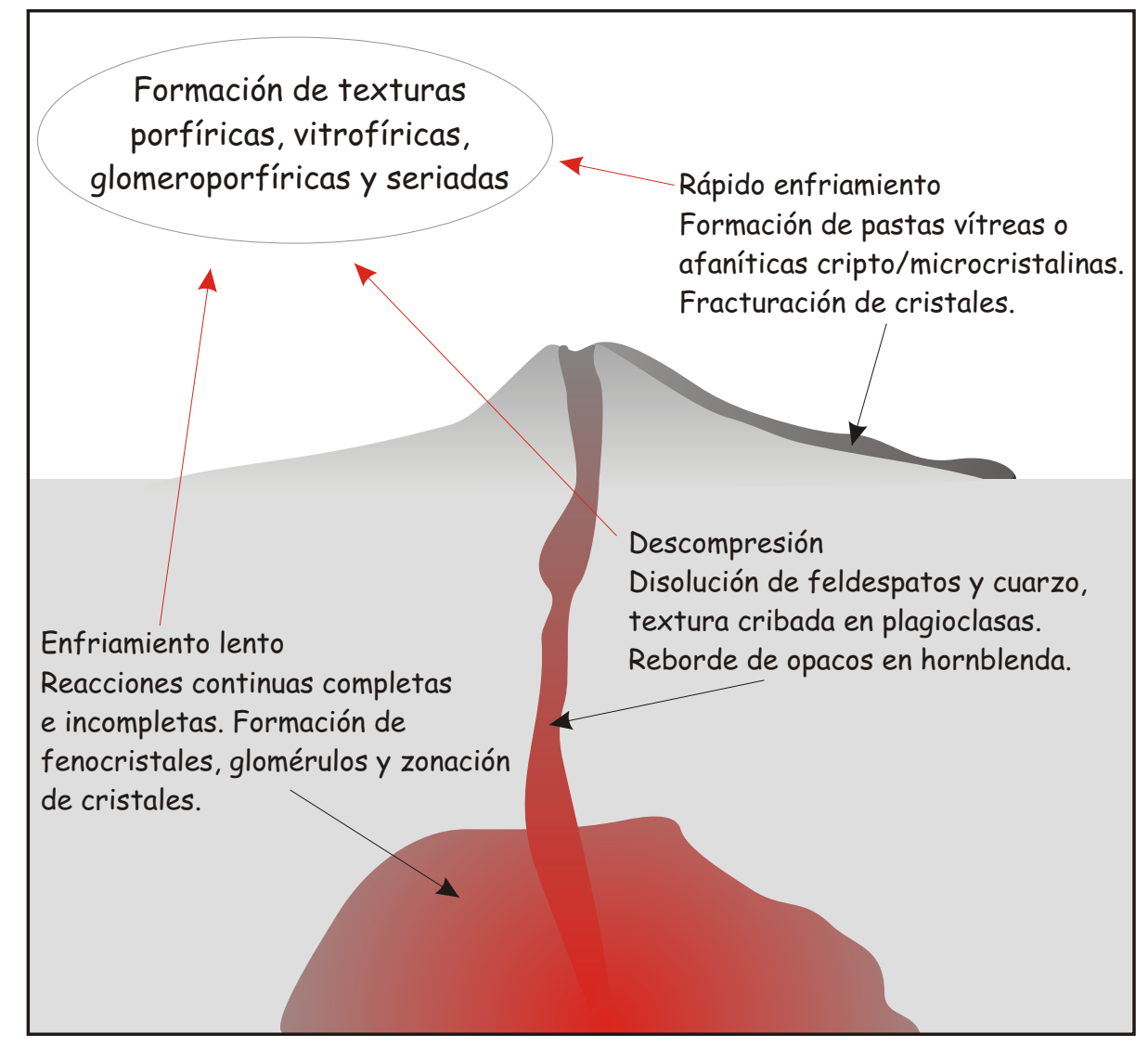

Figura 3.50. Gráfica conceptual donde se muestran los diferentes parámetros y atributos texturales en función de la trayectoria de cristalización. 
et al., 2005), destacándose la alteración clorítica-sericítica y encontrándose de manera saltuaria la alteración potásica y carbonática. Vinculadas a algunas microfacies andesíticas, se han observado vesículas y amígdalas, que se originan por la nucleación, crecimiento e implosión de burbujas producto de la descompresión (López y Bellos, 2007). Las microfacies dacíticas generalmente presentan una alteración clorítica-sericítica incipiente y minoritariamente muestran grados variables de silicificación. En las microfacies de riodacitas, se han encontrado en diferentes sectores una silicificación penetrativa y avanzada, asociada con venas de sílice. Relacionadas a ésta, se hallaron texturas de disolución y de disolución y reemplazo que indican la circulación de fluidos en desequilibrio termodinámico.

\subsection{2) Análisis microscópico de las rocas piroclásticas}

\section{Microfacies de ignimbritas (Ign)}

Las ignimbritas poseen mayoritariamente composiciones riolíticas-dacíticas y minoritariamente andesíticas. Se presentan con texturas vítricas y ocasionalmente cristaloclásticas y litoclásticas. Las ignimbritas vítricas se caracterizan por vitroclastos pumíceos con tamaños de $2 \mathrm{~mm}$ a $15 \mathrm{~mm}$, internamente se exhiben con textura no reconocible, con tubos de escape de gases paralelos o con vesículas redondeadas. Cuando son preservadas sus características primarias, se puede observar que la matriz está constituida por un agregado de trizas vítreas. Generalmente se presentan cuspadas y minoritariamente pumíceas y en plato, con tamaños de $3 \mathrm{~mm}$ a $0,5 \mathrm{~mm}$, dispuestas de manera aislada, con contactos de tipo flotante, juntas, con ausencia de deformación o en contacto, con deformación parcial. Por su parte, los cristaloclastos se encuentran entre el $5 \%$ y $25 \%$, están constituidos de cuarzo, feldespato potásico, plagioclasa y biotita. Los cristaloclastos de cuarzo se exhiben con tamaños de 0,2 mm a $4 \mathrm{~mm}$, formas desde euhedrales a anhedrales, bordes límpidos o reabsorbidos y en ocasiones con microfracturas. Los cristales de plagioclasa y feldespato potásico se encuentran con tamaños de entre $10 \mathrm{~mm}$ y $2 \mathrm{~mm}$ anhedrales y subhedrales. Minoritariamente se encuentran cristaloclastos de biotita con tamaños de entre $0,1 \mathrm{~mm}$ y $4 \mathrm{~mm}$. Los litoclastos se exponen con cantidades de entre el 5 \% y el 30 \% y se componen de rocas volcánicas riolíticas y andesíticas, rocas correspondientes al basamento ígneo-metamórfico, y minoritariamente de rocas sedimentarias. En función del grado y tipo de alteración se dividió a las microfacies de ignimbritas en tres diferentes grupos:

a) Microfacies de ignimbritas con alteración sericítica-argílica (IgnSA)

Se trata de ignimbritas con pómez deformados o redondeados reemplazados por agregados de sericita, óxidos de hierro y arcilla (fig. 3.51A). Sus bordes en ocasiones no se encuentran bien definidos, irradiándose agregados de sericita hacia la matriz. La matriz carece 
de textura vitroclástica primaria, habiendo sido ésta totalmente obliterada por un agregado microcristalino de sericita, cuarzo, óxidos de hierro, clorita, arcilla y minoritariamente carbonato de calcio. En esta facies, los cristaloclastos de feldespato son parcial o totalmente alterados a sericita, carbonatos y adularia esqueletal.

b) Microfacies de ignimbritas con alteración silícea (IgnS)

Se observan totalmente silicificadas, los pómez y las trizas vítreas se muestran mayoritariamente no deformadas, flotantes o en contacto, y minoritariamente se encuentran los pómez deformados y las trizas deformadas y en contacto. Los vitroclastos son totalmente reemplazados por agregados de sílice cripto/microcristalina, en ocasiones teñidos por óxidos de hierro (fig. 3.51B y C). Es importante remarcar que cuando la alteración es avanzada, las texturas vitroclásticas primarias comienzan a ser obliteradas (fig. 3.51D). Asociadas a estas microfacies se encontraron estructuras de escape de gases, las cuales se manifiestan por la concentración de cristaloclastos y litoclastos y la elutriación de finos (fig. 3.51E).

c) Microfacies de ignimbritas desvitrificadas (IgnD)

Se presentan con los pómez constituyendo fiammes y trizas parcialmente deformadas, aunque todavía conservan porosidad (fig. 3.51F). Los vitroclastos son desvitrificados a una textura de cuarzo y feldespato microcristalino en mosaico o a una textura micropoikilítica, en la cual un agregado de cuarzo y feldespato oblitera las texturas primarias de la matriz. En los casos donde se encontró una textura micropoikilítica obliterando todas las texturas primarias de la matriz, de manera aislada, se observaron esferulitas y litofisas de $0,5 \mathrm{~mm}$ a 1,5 $\mathrm{mm}$ de diámetro (fig. 3.51G y H).

Microfacies de depósitos de flujos de bloques y cenizas (DFByC)

Se componen de litoclastos monocomposicionales andesíticos de formas subangulosas y subredondeadas, con texturas porfírica, microporfírica y glomeroporfírica, constituidas de cristales de plagioclasa y clinopiroxenos, inmersos en una pasta vítrea o criptocristalina, formada por cristalitos de plagioclasas (fig. 3.52A y B). Los litoclastos pueden desarrollar una profusa textura vesicular, conformada por vesículas redondeadas. Los cristaloclastos son mayoritariamente de plagioclasas angulosas y subangulosas, límpidas o con texturas cribadas. En ocasiones se encontraron los contactos de los clastos con estructuras de disolución y de disolución y relleno por agregados de argilominerales u opacos. Es importante destacar que los minerales opacos también aparecen en la pasta de muchos litoclastos como cristales bien formados. Su análisis calcográfico reveló que se componen de magnetita y hematita. La magnetita conforma cristales bien formados dentro de los clastos y del relleno de cavidades; en ambos casos se muestra con reflexión moderada, color gris claro a blanquecino y exhibe laminillas de desmezcla de ilmenita rosada que se disponen en orientaciones preferenciales (fig. 


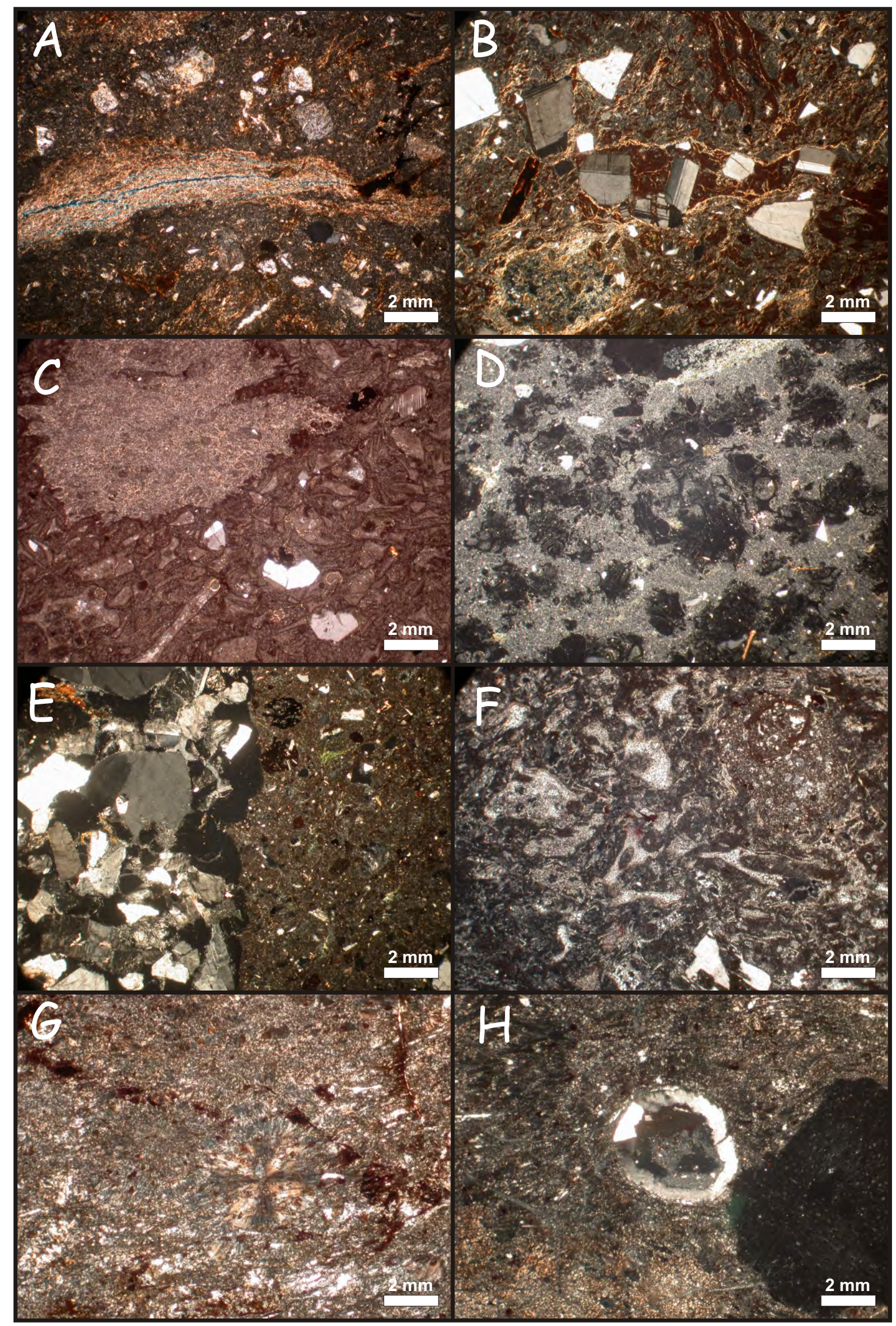

Figura 3.51. A) Microfacies de ignimbritas con alteración sericítica-argílica (IgnSA) donde las texturas primarias de la matriz se encuentran totalmente obliteradas. B, C, D y E) Diferentes grados de alteración por cristalización en fase vapor: B) moderada, C) Fuerte y D) penetrativa, comenzando a obliterar las texturas primarias. E) Corte efectuado sobre un pipe de elutriación donde se aprecia la concentración de los "gruesos". F, G y H) Microfacies de ignimbritas desvitrificasdas a alta temperatura (IgnD): F) trizas parcialmente deformadas recristalizadas a agregados de cuarzo microcristalino, se encuentran inmersas en una matriz con textura micropoikilítica, G) esferulitas aisladas dentro en una textura micropoikilítica, y H) desarrollo de litofísas. aisladas. 


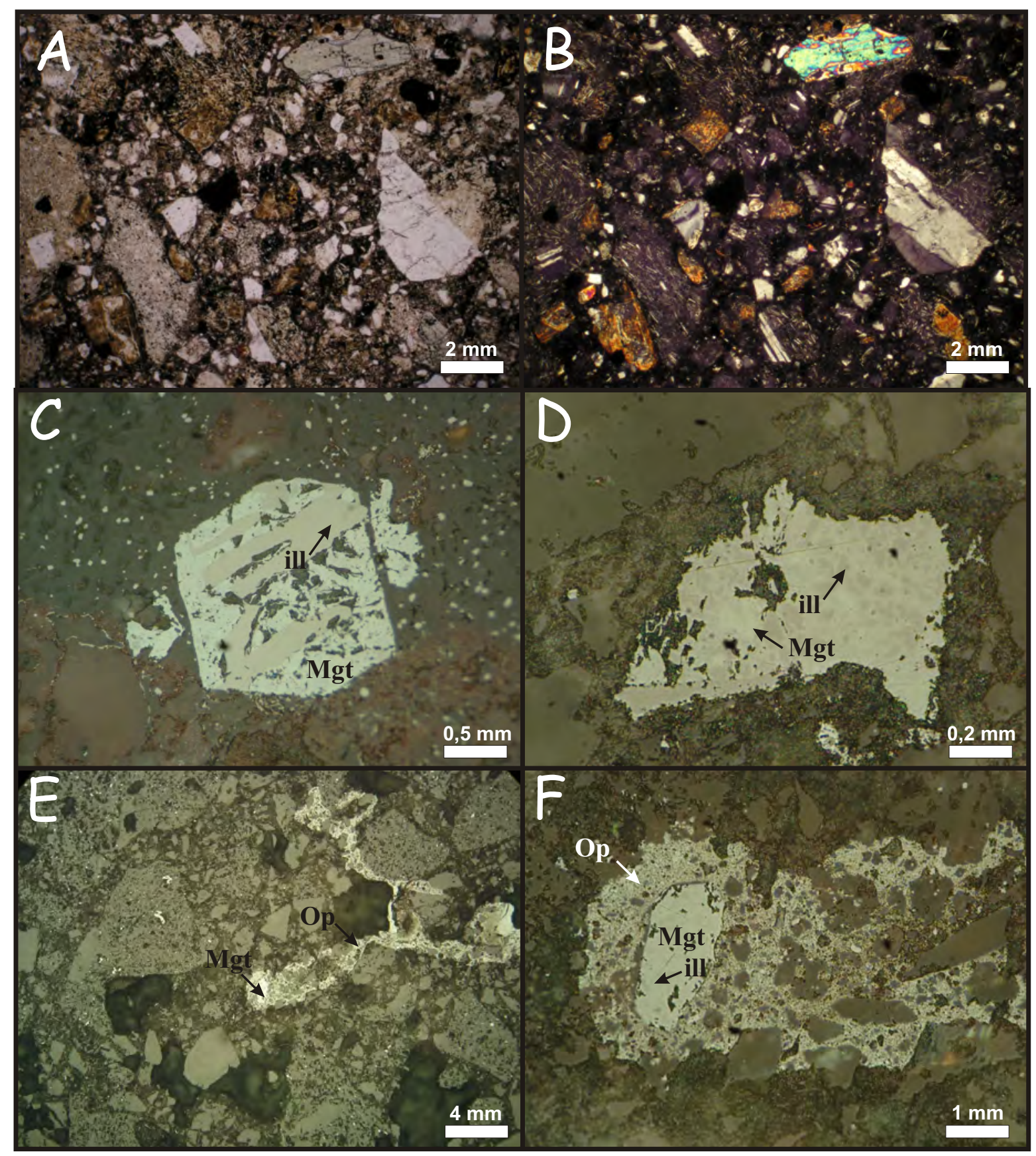

Figura 5.52. A y B) Petrografía de microfacies de depósitos de flujos de bloques y ceniza. Se puede apreciar la característica monomíctica de los materiales juveniles, con texturas vítreas o criptocristalinas y con similitud textural. C, D, E y F) Calcografía de microfacies de depósitos de flujos de bloques y ceniza: Mgt = magnetita, ill = ilmenita. C) Cristales bien formados de Mgt con desmezcla a ill. D) Se exhibe el relleno de una cavidad por Mgt con desmezcla a ilmenita. E y F) Se muestra cómo los cristales primarios de Mgt con desmezcla a ilmenita son disueltos, generandóse soluciones que rellenan los espacios primarios y secundarios. 
3.52C y D). La hematita se presenta como relleno de espacios porosos primarios en las vecindades de los cristales de magnetita, con reflexión moderada, de colores blanquecinos a castaño claro (fig. 3.52E y F).

\section{Consideraciones sobre las características de las microfacies piroclásticas}

Las ignimbritas en estudio corresponden a ignimbritas texturalmente vítreas, de composiciones mayoritariamente riolíticas-dacíticas y minoritariamente andesíticas. Las microfacies de ignimbritas con alteración sericítica-argílica (IgnSA), presentan una alteración penetrativa, de moderada a fuerte (sensu Gifkins et al., 2005). Los pómez en las microfacies IgnSA constituyen pseudofiammes inmersos en una matriz constituida por agregados de arcillas, sericita y óxidos de hierro (fig. 3.51A). Las texturas vitroclásticas primarias fueron totalmente reemplazadas y los cristaloclastos de feldespatos son parcial o totalmente alterados a sericita, carbonato de calcio o adularia esqueletal. El origen de la alteración sericítica y argílica puede deberse a una alteración diagenética o hidrotermal, a menudo inseparables y/o sobreimpuestas en terrenos volcánicos (Mc Phie et al., 1993). Otras evidencias de alteración diagenética se observan en la distribución de los filosilicatos que remplazan a los pómez, los cuales sobrepasan sus límites alineándose perpendicularmente a la máxima dirección de deformación por compactación (Mc Phie et al., 1993; Gifkins et al., 2004; Gifkins et al., 2005). La presencia de adularia sugiere intervención de soluciones de origen hidrotermal o deutérico. Referente al grado de soldamiento, estas ignimbritas se originaron por debajo de la temperatura de transición del vidrio, preservándose con bajo grado de soldamiento, estado vítreo y gran porosidad. Posteriormente fueron afectadas por fluidos diagenéticos/hidrotermales que borraron todas las características primarias de la matriz (fig. 3.54).

Las microfacies de ingnimbritas silicificadas (IgnS), se presentan con los vitroclastos totalmente reemplazados a un agregado cripto/microcristalino de sílice (fig. $3.51 \mathrm{~B}, \mathrm{C}$ y D). Estas características sugieren una alteración por cristalización en fase vapor, resultado de la percolación de gases calientes a través de las mismas. Las aguas pueden ser aportadas por los gases atrapados en los vitroclastos, aguas subterráneas y/o por la desvitrificación (Cas y Wright, 1987; Wilson, 1993; Mc Phie et al., 1993). La cristalización en fase vapor se desarrolla sin alterar las características físicas morfométricas de los vitroclastos (Streck y Grunder, 1995). Por esta razón, no sólo es posible discernir entre ignimbritas soldadas y no soldadas, sino también definir el grado de soldamiento de las mismas. En la mayoría de los casos, se trata de ignimbritas incipiente o parcialmente soldadas (Smith, 1960), de grados II/III de soldamiento (sensu Quane y Russel, 2005), donde las trizas aparecen cuspadas, flotantes o en contacto (fig. 3.53A). Ocasionalmente se encontraron ignimbritas alteradas por cristalización en fase vapor con pómez colapsados y trizas deformadas que corresponderían a ignimbritas densamente 


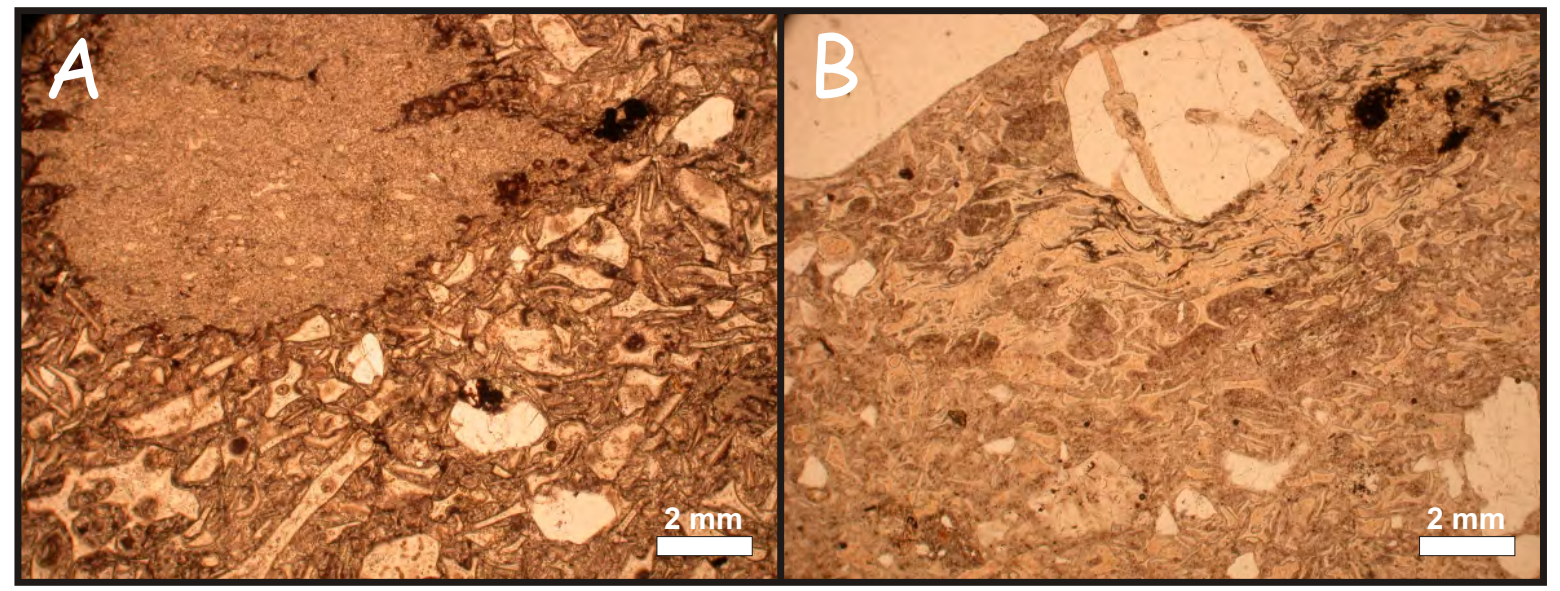

Figura 3.53. Microfotografías que muestran los grados extremos de soldamiento que fueron encontrados dentro del Ciclo Precuyano. A) Ignimbritas con grado de soldamiento incipiente o porcialmente soldadas. B) Ignimbritas densamente soldadas.

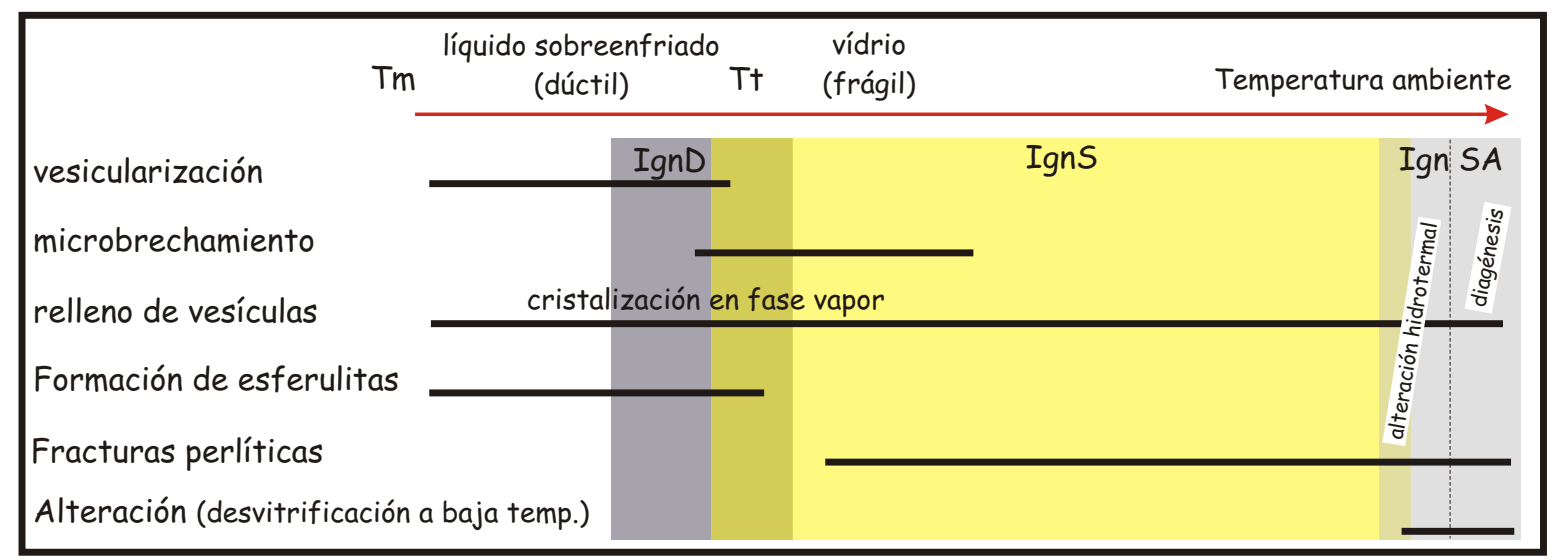

Figura 3.54. Relación entre las microestructuras encontradas en los depósitos piroclásticos y la temperatura . Tm $=$ temperatura del magma, $\mathrm{Tt}=$ temperatura de transición del vidrio (Modificado de McArthur, et al., 1998). Los colores representan las diferentes variedades de microfacies piroclásticas identificadas para el Ciclo Precuyano. 
soldadas (Smith, 1960), de grado IV/V (sensu Quane y Russel, 2005), originadas por arriba de la temperatura de transición del vidrio (fig. 3.54) (Mc Arthur et al., 1998).

Las microfacies de ignimbritas desvitrificadas (Ign D), presentan pómez y trizas deformadas recristalizadas y grados variables de obliteración producto de una textura micropoikilítica, con esferulitas y litofisas aisladas. Estos atributos indican: a) la temperatura de emplazamiento fue mayor o cercana a la temperatura de transición del vidrio, b) la tasa de enfriamiento fue rápida, pero lo suficientemente lenta como para permitir el desarrollo de esferulitas y textura micropoikilítica (fig. 3.54) (Mc Arthur et al., 1998) -estado esferulítico en transición al estado vítreo, sensu Lofgren, 1971-, у c) un alto contenido de volátiles permitiendo el desarrollo de litofisas. En lo que concierne al grado de soldamiento, se pueden clasificar como densamente soldadas (fig. 3.53B) (Smith, 1960) o de grado IV/V (sensu Quane y Russel, 2005).

El análisis petrográfico de los depósitos de flujos de bloques y cenizas, sugiere que los mismos se originaron a partir del colapso de domos o coladas de composición andesítica (Cas y Wright, 1987). El material juvenil de estos depósitos está constituido íntegramente por litoclastos andesíticos y cristaloclastos de plagioclasas. La ausencia de material pumíceo y el grado bajo de vesicularización de los materiales juveniles, indica un colapso de tipo gravitatorio (Cas y Wright, 1987; Mc Phie et al., 1993). Con respecto a la alteración y a las microestructuras, las estructuras de disolución y relleno por magnetita con desmezcla a ilmenita, se generan a temperaturas de entre $400{ }^{\circ} \mathrm{C}$ y $600{ }^{\circ} \mathrm{C}$ (Hagel, 1979; Ramdohr, 1980), sugiriendo el accionar de soluciones deutéricas o hidrotermales.

\subsection{3) Análisis microscópico de las rocas epiclásticas}

Microfacies de rocas epiclásticas monomícticas andesíticas con fracturas en rompecabezas (REMAjs)

Se conforman por una mezcla de litoclastos de lavas de composición andesítica, presentándose con homogeneidad textural o con diferentes texturas (ej. traquíticas, pilotáxicas, intergranular, seriadas y vítricas) y grados de alteración. Asimismo presentan cristaloclastos de plagioclasas y de manera excepcional cristaloclastos de piroxenos y vitroclastos blocosos (fig. 3.55). Los litoclastos constituyen entre un $60 \%$ y $80 \%$ de la roca, presentan un tamaño variado y formas mayormente angulosas y subangulosas. Internamente muestran micro/fenocristales de plagioclasas y clinopiroxenos inmersos en una pasta afanítica, generalmente traquítica o pilotáxica. Con respecto a las microestructuras, se observan principalmente cristaloclastos y secundariamente litoclastos fragmentados y dispersos con grados variables hacia la matriz. En 
un caso incipiente de fragmentación, los cristales presentan estructuras en rompecabezas, exhibiendo ángulos de extinción similares bajo nicoles cruzados. Esto sugiere que los cristales experimentaron una débil deformación en forma de rotación de cuerpo rígido durante su dispersión (fig. 3.56A). Cuando la fragmentación se desarrolla con mayor eficiencia, los neoclastos comienzan a separarse más y a ser menos frecuente la estructura en rompecabezas, aunque se divisa que los fragmentos se corresponden unos con otros (fig. 3.56B y C). En un caso extremo de fragmentación, la mircoestructura en rompecabezas se observa escasamente desarrollada y los clastos muestran contactos de tipo flotante a tangencial, con espacios interclásticos vacíos o rellenos con cementos constituidos de minerales opacos o material arcilloso (fig. 3.56D). Es importante destacar que se han encontrado evidencias de estructuras de disolución y de disolución y relleno en los contactos entre los clastos (fig. 3.57).

\section{Microfacies de rocas epiclásticas monomícticas andesíticas (REMA)}

Los componentes principales de estas microfacies son litoclastos de rocas volcánicas de composición andesítica y cristaloclastos de plagioclasas y clinopiroxenos. Estas microfacies comparten las mismas características composicionales que las microfacies REMAjs (descriptas en el párrafo anterior). A diferencia de ellas, los clastos exhiben morfologías subredondeadas y subangulosas, con contactos tangenciales y levemente rectos (fig. 3.58). El espacio interclástico se encuentra ocluido por cementos argílicos, constituidos por agregados de illita/esmectita y de clorita/esmectita (fig. 3.58).

\section{Microfacies de rocas epiclásticas monomícticas de composición piroclástica (REMP)}

Se componen de litoclastos de ignimbritas con grados variables de alteración, cristaloclastos de cuarzo con bordes netos o reabsorbidos y feldespatos límpidos o alterados (fig. 3.59A). Los clastos se presentan angulosos, subangulosos y subredondeados, con contactos tagenciales o flotantes, presentándose el espacio interclástico parcial o totalmente ocluido por cementación argílica, ferruginosa o silícea.

\section{Microfacies de rocas epiclásticas de procedencia volcánica (REV)}

Los componentes principales son litoclastos de rocas volcánicas y piroclásticas y cristaloclastos. En general los clastos se presentan con morfologías subredondeadas y subangulosas, con contactos tangenciales y levemente rectos. El espacio interclástico se encuentra ocluido o parcialmente ocluido por diferentes tipos de cementos. Entre ellos se pueden mencionar: agregados de arcillas, agregados de óxidos de hierro, carbonato de calcio (poiquiestparítico) y agregados de sílice criptocristalina. Los volcaniclastos de esta facies están constituidos por andesitas, dacitas e ignimbritas, con grados variables de abundancia. Los 


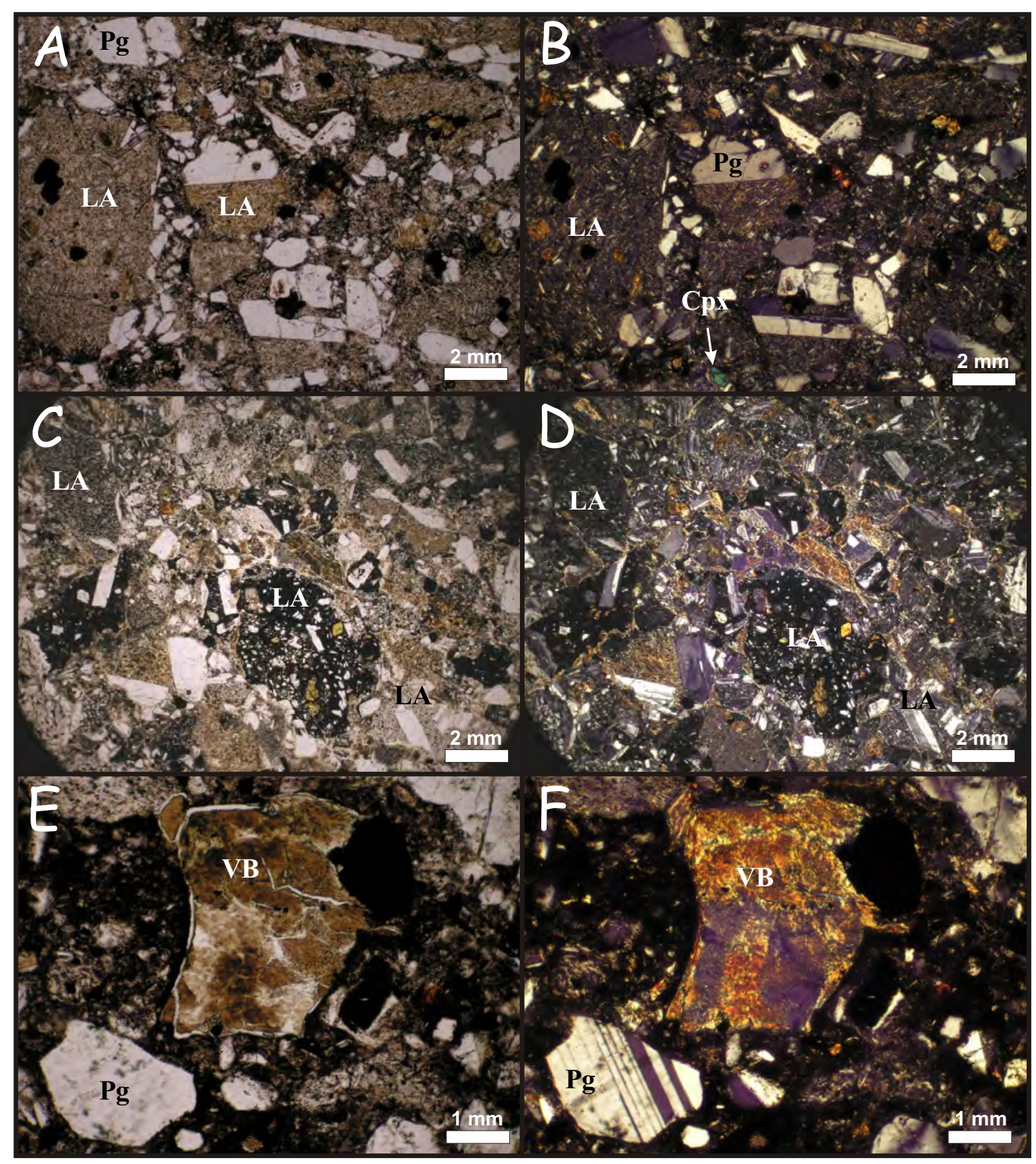

Figura 3.55. Microfacies de rocas epiclásticas monomícticas andesíticas con fracturas en rompecabezas (REMAjs). A y B) Se muestra la matriz monomíctica con homogeneidad textural. (LA= litoclastos andesíticos, $\mathrm{Pg}=$ cristaloclastos de plagioclasas y Cpx cristaloclastos de clinopiroxenos). C y D) Se exhibe la matriz monomíctica con litoclastos de diferentes texturas y alteraciones. E y F) Se muestran vitroclastos blocosos (VB) encontrados de manera escasa en estas microfacies. 


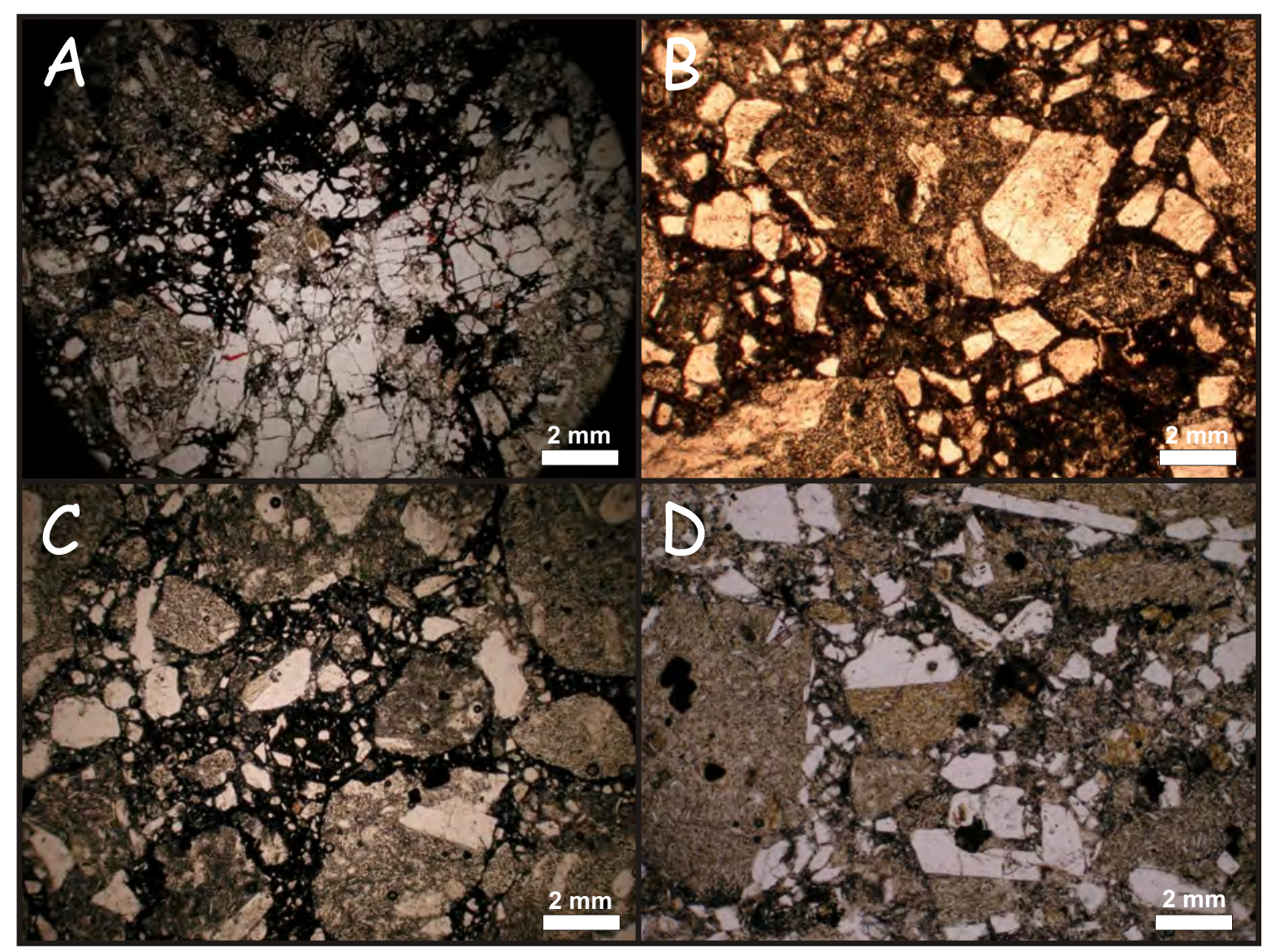

Figura 3.56. Grados variables de fragmentación sedimentaria encontrada en las microfacies de rocas epiclásticas monomícticas andesíticas con estructura en rompecabezas. A) Microestructuras en rompecabezas bien desarrollada, donde los clastos muestran movimiento incipiente. B y C) Se muestra un estado más avanzado de fragmentación, en donde los neoclastos comienzan a separarse más y donde la estructura en rompecabezas es menos frecuente. D) Caso extremo de fragmentación donde la estructura en rompecabezas se presenta escasamente desarrollada.

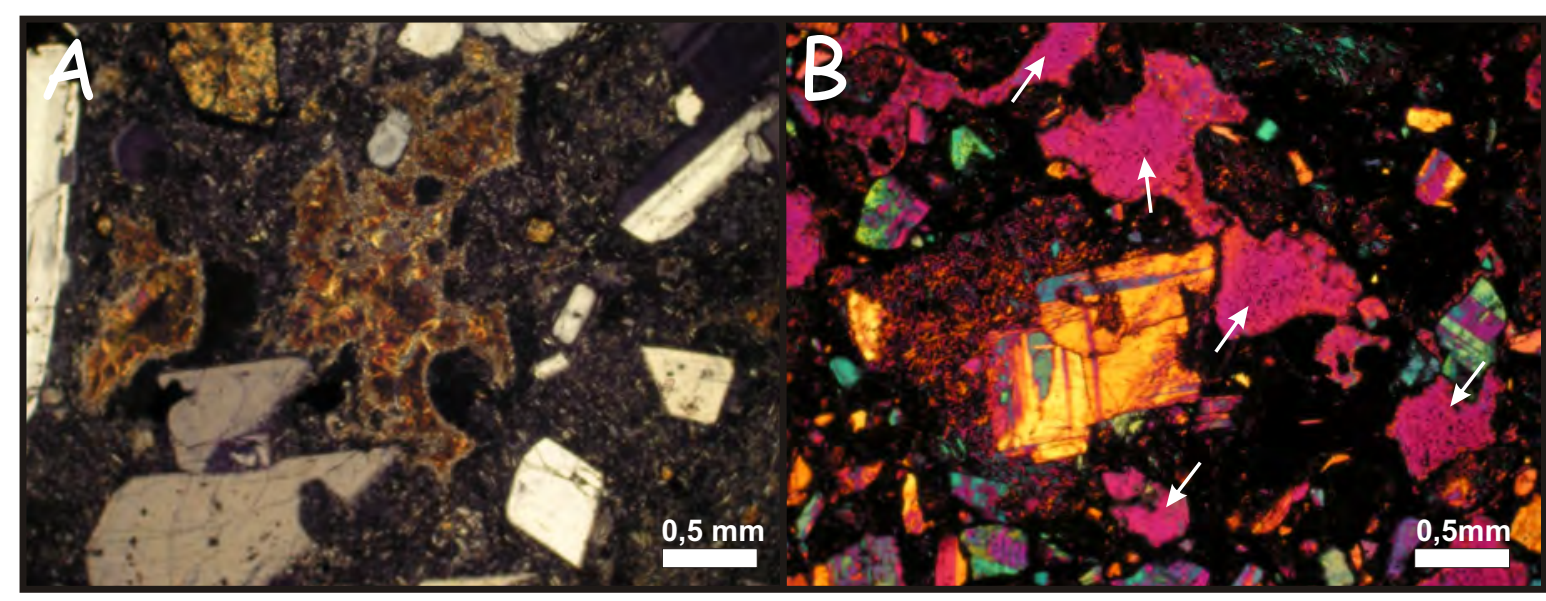

Figura 3.57. Estructuras de disolución y relleno en las microfacies de rocas epiclásticas monomícticas andesíticas con fracturas en rompecabezas (REMAjs). A) Disolución y relleno de material arcilloso. B) Disolución y generación de espacios vacíos. 


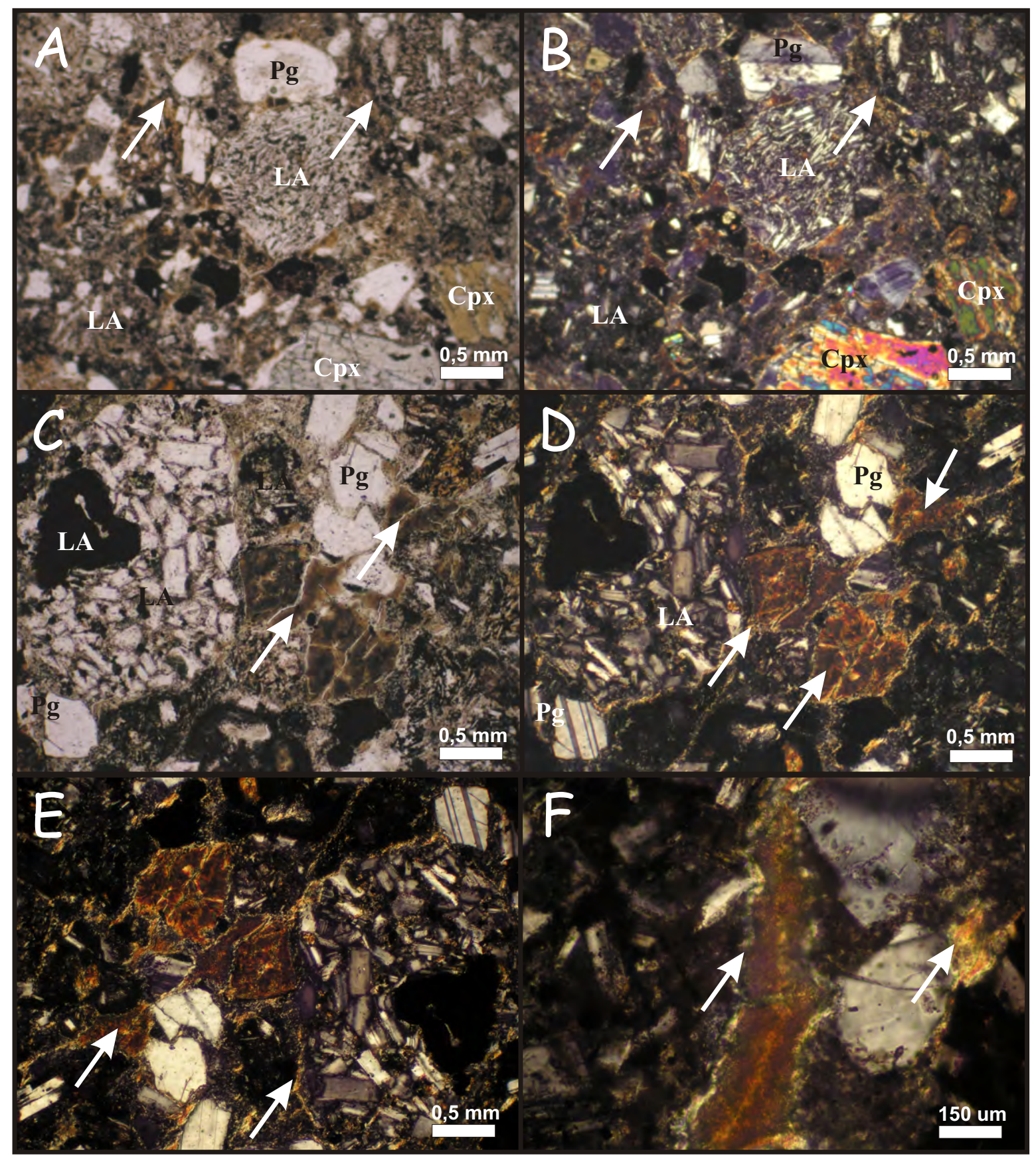

Figura 3.58. Microfacies de rocas epiclásticas monomícticas andesíticas (REMA). A, B, C y D) Se muestran los líticos volcánicos de composición principalmente andesítica (LA), los cristaloclastos de clinopiroxenos (Cpx) y de plagioclasas (Pg).E y F) Detalle del cemento de las microfacies REMA. Con flechas se marca el cemento argílico que rellena el espacio interclástico. 
cristaloclastos frecuentes son cuarzo y feldespatos, encontrándose aisladamente, cuando los litoclastos de andesitas son abundantes, cristaloclastos de clinopiroxenos. Esta facies puede tener participación de fragmentos de rocas provenientes del basamento ígneo-metamófico, con abundancias de entre el $5 \%$ y $30 \%$, conformados por cuarzo policristalino y litoclastos de esquistos, granitos y ortogneises (fig. 3.59B). Es importante destacar que en la columna RA 1, en los depósitos basales del Ciclo Cuyano, se han encontrado abundantes restos de valvas y fragmentos de calizas acompañando a los volcaniclastos (fig. 3.59C).

Microfacies de rocas epiclásticas de procedencia silicoclásticas (RES)

Representan a un grupo de rocas escasamente desarrollado en el área de estudio. Corresponden a areniscas y conglomerados finos que infrayacen a unidades piroclásticas al sur de la localidad de Piedra del Águila. Se componen de clastos angulosos y subangulosos entre los que predominan el cuarzo y el feldespato potásico (fig. 3.59D). El cuarzo se presenta en granos monocristalinos o policristalinos. El feldespato es dominantemente potásico, con grados variables de alteración. Entre los componentes clásticos accesorios de las areniscas se destaca la presencia de muscovita en forma de clastos fuertemente deformados por efectos de compactación física. Esta facies muestra, en general, discreta proporción de matriz arcillosa, estando cementada por incipiente crecimiento de cuarzo y abundante calcita de hábito grano y poiquiesparítico.

\section{Consideraciones sobre las características de las rocas epiclásticas}

A grandes rasgos, las características texturales primarias que dominan en las rocas epiclásticas analizadas, son litoclastos y cristaloclastos de procedencia volcánica con morfologías subredondeadas a subangulosas. Para su análisis se han organizado las microfacies de las rocas epiclásticas en función de sus características composicionales. El resultado permitió realizar algunas consideraciones sobre el origen y acotar aun más la procedencia de las diferentes microfacies. De esta manera, se han reconocido microfacies que poseen texturas monomícticas andesíticas y un grado de fragmentación incipiente, con un rango variado de texturas en rompecabezas (REMAjs). Estas texturas sugieren una vinculación directa con cuerpos volcánicos de tales composiciones, en donde la mezcla de litoclastos fue entre clastos de la misma composición, pero con diferentes texturas y grados de alteración. Con respecto a los diferentes grados de microestructuras en rompecabezas, éstas indican un tipo de transporte por flujos que provocan fragmentación y dilatancia (Schneider y Fisher, 1998; Reubi y Hernandez, 2000). A su vez, también se han reconocido microfacies monomícticas que tienen una vinculación directa con los cuerpos volcánicos, pero que registran mecanismos de fragmentación, retrabajo, transporte y depositación más efectivos. Entre las últimas, se han 


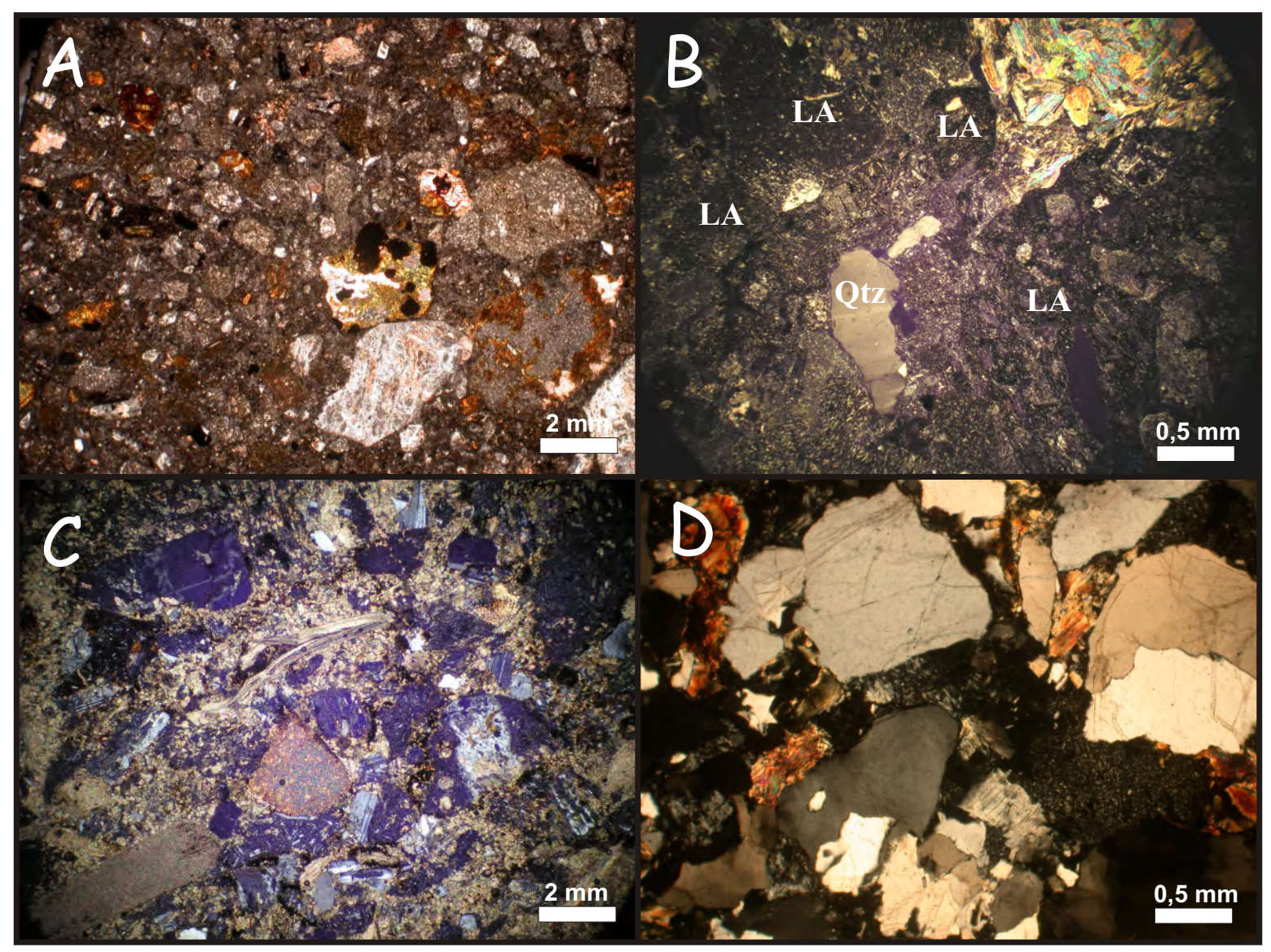

Figura 3.59. A) Microfacies de rocas epiclásticas monomícticas de composición piroclástica. B) Microfacies de rocas epiclásticas de procedencia volcánica con participación de litoclastos procedente del basamento. C) Variante de las microfacies de rocas epiclásticas de procedencia volcánica, donde abundan los restos de valvas y de calizas. D) Microfacies de rocas epiclásticas de procedencia silicoclástica.

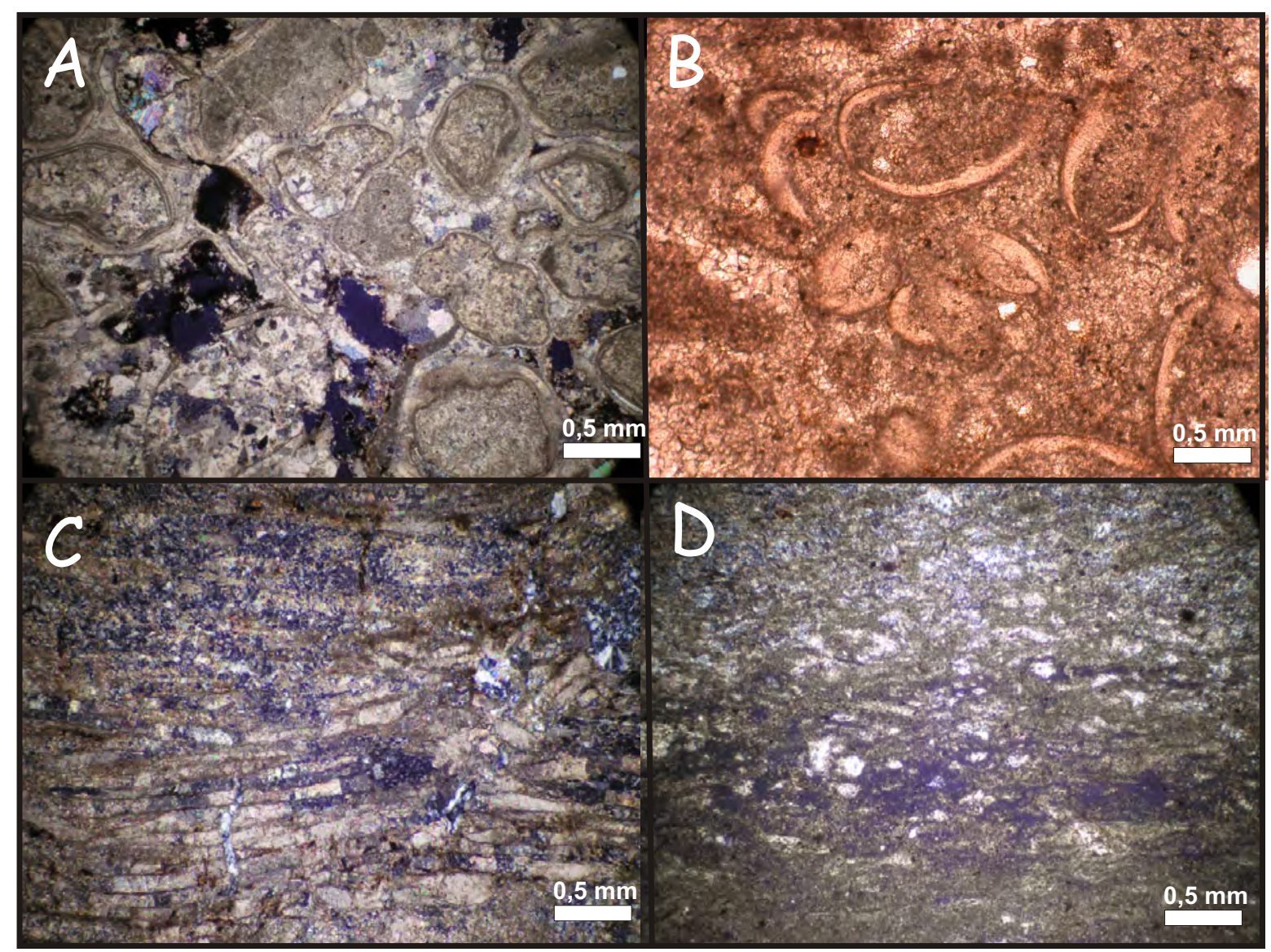

Figura 3.60. A) Microfacies de grainstones constituidos de peloides. B) Microfacies de grainstones constituidos de fragmentos de valvas. C) Microfacies de rocas carbonáticas con laminación microbial. D) Microestructura fenestral desarrollada en las microfacies de rocas carbonáticas con laminación microbial. 
registrado microfacies resultado de la resedimentación de cuerpos volcánicos andesíticos (REMA) y de la resedimentación de cuerpos piroclásticos (REMP). Asimismo, se han reconocido microfacies de procedencia volcánica con un grado de fragmentación y retrabajo avanzado (REV), constituidas por una mezcla de detritos de diferentes orígenes y composiciones, en ocasiones con participación de materiales provenientes del basamento. Las facies REV evidencian periodos largos de degradación del ambiente volcánico probablemente con áreas de aporte integradas. Por último, la presencia de microfacies de rocas epiclásticas silicoclásticas (RES) sugiere procesos de transporte discretos de los materiales clásticos y una procedencia cortical de carácter local, vinculada con la denudación del basamento ígneometamórfico.

Desde el punto de vista de los procesos post-deposicionales, los diferentes tipos de cementos (silíceos, argílicos, clorita-esmectita y ferruginosos), son típicos de rocas volcánicas en estadios de diagénesis tempranos. Estas observaciones coinciden con los tipos de fábricas post-depositacionales encontradas, donde los empaquetamientos se desarrollan con contactos generalmente tangenciales o rectos y minoritariamente flotantes y cóncavo-convexos, evidenciando poco sepultamiento (Scasso y Limarino, 1997). Fábricas de alteración química solo fueron encontradas en casos aislados, especialmente en las microfacies REMAjs, entre las cuales se destacan estructuras de disolución y disolución y relleno asociadas a soluciones hidrotermales (Mc Phie et al., 1993; Gifkins et al., 2005).

\subsection{4) Análisis microscópico de las rocas carbonáticas}

Microfacies de rocas carbonáticas de grainstones (RCG)

Se trata de grainstones constituidos mayoritariamente por peloides de ente $1 \mathrm{~mm}$ y 0,2 mm (fig. 3.60A), fragmentos de valvas (fig. 3.60B), intraclastos carbonáticos de textura interna no reconocible o intraclastos de microfacies con laminación algal. Minoritariamente se encontraron ooides de tamaños similares a los peloides. Los materiales esqueletales y no esqueletales se encuentran de manera flotante, cementados por dos estadios, el primero aparece como corona rodeando los clastos, mientras que el segundo se muestra como un cemento de tipo esparítico en mosaico.

Microfacies de rocas carbonáticas con laminación microbial (RCLM)

Se muestran como láminas de material micrítico constituido por carbonato de calcio o dolomita, parcial o totalmente silicificado. Las láminas se presentan irregulares, con espesores de 100 micrones a 300 micrones y lateralmente discontinuas (fig. 3.60C). Esta facies presenta 
microestructura fenestral de tipo irregular, conformada por “ojos” rellenos de cemento esparítico, distribuidos al azar o siguiendo la laminación primaria (fig. 3.60D).

\section{Microfacies de rocas carbonáticas mudstone (RCM)}

Se caracterizan por laminas de material carbonático micrítico en niveles de 0,2 mm a 1 $\mathrm{mm}$, las cuales en ocasiones se intercalan con niveles constituidos de material carbonatico, pero con abundante participación de material volcaniclástico conformado de cristaloclastos de cuarzo, feldespatos y líticos de rocas volcánicas.

\section{Consideraciones sobre las características de las rocas carbonáticas}

Las microfacies de rocas carbonáticas de grainstones (RCG), sugieren un aporte clástico restringido. Los componentes no esqueletales peloideos, indican sedimentación en zonas protegidas de baja energía, mientras que los componentes no esqueletales con laminación microbial y ooides encontrados excepcionalmente, demuestran mayor energía de los ambientes. (Tucker, 2001). La cementación de esta facies de tipo “en anillo” y calcita esparítica ecuante, es típica de zonas meteóricas (Adams et al., 1984; Tucker, 2001), mientras que la cementación por sílice, al igual que la dolomitización, puede ocurrir durante la diagénesis temprana o tardía (Tucker, 2001). La microfacies de rocas carbonáticas con laminación microbial (RCLM), indica la existencia de condiciones propicias para la proliferación de microorganismos bioconstructores (aguas someras y poco aporte clástico). Según Tucker (2001), la textura fenestral irregular, puede ser producida de manera sindepositacional o durante la diagénesis temprana, por el entrampamiento de gases en sedimentos carbonáticos que están sometidos a la desecación. 


\section{4) Análisis litogeoquímico}

\subsection{1) Introducción}

A los efectos de discriminar las rocas volcánicas y piroclásticas del Ciclo Precuyano desde el punto de vista litogeoquímico, y de evaluar el tipo de asociación petrotectónica y la fuente, se realizó un muestreo de las unidades más representativas del relleno precuyano (fig. 3.61). Se recolectaron nueve muestras del Ciclo Precuyano, en diferentes sectores del área de estudio, de rocas que petrográficamente habían sido clasificadas como andesitas, lavas riolíticas-dacíticas e ignimbritas riolíticas-dacíticas. En el área de Sañicó, se tomaron dos muestras de los tramos basales, tres muestras de la parte media y una muestra de la parte superior del Ciclo Precuyano (fig. 2.1). En la parte oriental del área de estudio se tomaron dos muestras en la parte basal del Ciclo Precuyano en el área de Piedra del Águila y una muestra en la parte superior en el Cerro Zaina Yegua. Los resultados obtenidos se muestran en la figura 3.62 .

\begin{tabular}{|c|c|c|c|c|}
\hline Lugar & $\mathrm{X}$ & $\mathrm{Y}$ & Roca & Código \\
\hline Piedra del Águila & $70^{\circ} 3^{\prime} 42.80^{\prime \prime} \mathrm{O}$ & $40^{\circ} 2^{\prime} 41.20^{\prime \prime} \mathrm{S}$ & ignimbrita soldada & PDA_M2 \\
\hline Piedra del Águila & $70^{\circ} 5^{\prime} 5.44^{\prime \prime} \mathrm{O}$ & $40^{\circ} 5^{\prime} 7.71^{\prime \prime} \mathrm{S}$ & ignimbrita & PDA_M1 \\
\hline $\mathrm{C}^{\circ}$ Zaina Yegua & $70^{\circ} 15^{\prime} 03.9 " \mathrm{9}$ & $40^{\circ} 9^{\prime} 45.1^{\prime \prime} \mathrm{S}$ & lava andesísitica & ZY-S \\
\hline N del C ${ }^{\circ}$ Corona & $70^{\circ} 22^{\prime} 59.90^{\prime \prime} \mathrm{O}$ & $40^{\circ} 9^{\prime} 00.38^{\prime \prime} \mathrm{S}$ & lava andesítica & SE-SN_I2 \\
\hline N de Sañicó & $70^{\circ} 28^{\prime} 40.7^{\prime \prime} \mathrm{O}$ & $40^{\circ} 5^{\prime} 14.7^{\prime \prime} \mathrm{S}$ & riolita intrusiva & N-SN_M \\
\hline N de Sañicó & $70^{\circ} 31^{\prime} 40.2^{\prime \prime} \mathrm{O}$ & $40^{\circ} 2^{\prime} 19.9^{\prime \prime} \mathrm{S}$ & lava andesítica & SE-SN_I1 \\
\hline NE del C Corona & $70^{\circ} 23^{\prime} 37.95^{\prime \prime} \mathrm{O}$ & $40^{\circ} 9^{\prime} 44.66^{\prime \prime} \mathrm{S}$ & domo riodacítico & SE-SN_M1 \\
\hline SW de Sañicó & $70^{\circ} 26^{\prime} 9.14^{\prime \prime} \mathrm{O}$ & $40^{\circ} 7^{\prime} 43.19^{\prime \prime} \mathrm{S}$ & lava andesítica & W-SN_S \\
\hline NE del C ${ }^{\circ}$ Corona & $70^{\circ} 23^{\prime} 38.09^{\prime \prime} \mathrm{O}$ & $40^{\circ} 8^{\prime} 58.86^{\prime \prime} \mathrm{S}$ & pómez en ignimbrita & SE_SN_M2 \\
\hline
\end{tabular}

Figura 3.61. Coordenadas donde tomaron las muestras para el análisis litogeoquímico.

\subsection{2) Organización de los datos geoquímicos}

Los resultados de los análisis geoquímicos (véase anexo III) fueron tabulados y recalculados a base anhidra. En cada muestra se incorporaron los datos provenientes del análisis de microfacies, tipo de alteración y paragénesis de alteración proveniente del análisis petrográfico y de difracción de Rayos X. Posteriormente, con el fin de evaluar la movilidad de los elementos en función de los diferentes tipos de alteración, se efectuaron diagramas de variación para los principales elementos mayoritarios versus $\mathrm{SiO}_{2}$ (fig. 3.63) y para LOI versus $\mathrm{SiO}_{2}$ (fig. 3.64). Una vez identificada la impronta de la alteración en las muestras, y si era viable la utilización de determinados elementos, se procedió con el desarrollo de diagramas de discriminación típicos: Total sílice alkalí (TAS), AFM., Spider y diagramas bivariados basados en elementos inmóviles (fig. 3.65, 3.66, 3.67, 3.68 y 3.69). 


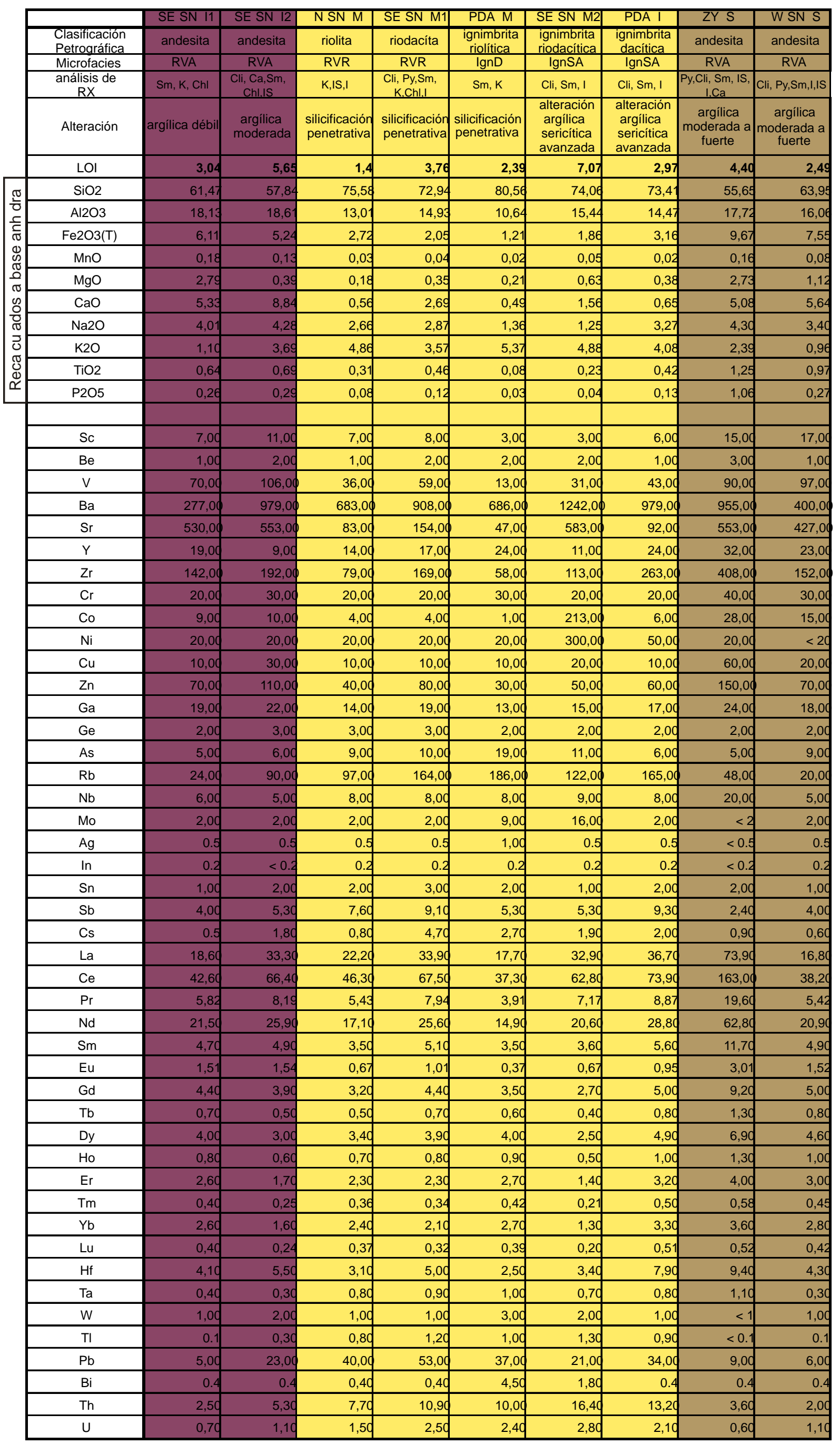

Figura 3.62. Resultado del análisis geoquímico. Cli: Clinoptilolita, Ca: Calcita, Sm: Esmectita, Ch: Clorita,I: Illita, K: Caolinitø̨̧ Py: Pirita. 
3.4.3) Consideraciones generales acerca de la geoquímica del Precuyano

El estudio litogeoquímico de las rocas volcánicas del Ciclo Precuyano, requiere tener en cuenta los procesos de alteración que modifican las características composicionales de las rocas volcánicas y piroclásticas. El análisis de microfacies desarrollado al comienzo de este capítulo, denota que tanto las rocas volcánicas como piroclásticas del Ciclo Precuyano estuvieron involucradas en un marco de alteración complejo, donde participaron fluidos deutéricos, hidrotermales y diagenéticos. En el presente inciso, se pondrá énfasis en las variables que condujeron a la movilización de los elementos, tomándose en sentido amplio el término alteración.

Los diagramas de variación efectuados para los principales elementos mayoritarios muestran patrones lógicos para el $\mathrm{MgO}, \mathrm{Fe}_{3} \mathrm{O}_{2}, \mathrm{Al}_{2} \mathrm{O}_{3}$ y $\mathrm{CaO}$ cuando se los compara con el contenido de $\mathrm{SiO}_{2}$, mientras que los álcalis muestran tendencias anormales $\left(\mathrm{Na}_{2} \mathrm{O}\right)$ o no muestran correlación $\left(\mathrm{K}_{2} \mathrm{O}\right)$ (fig. 3.63) A grandes rasgos, los valores obtenidos de volátiles perdidos por la ignición (LOI), denotan valores de entre 1,4 y 7,07, observándose una disminución hacia los extremos ácidos (fig. 3.64). Es importante destacar que en general, las muestras de rocas volcánicas silicificadas (RVR) y rocas piroclásticas con microfacies desvitrificadas a alta temperatura y silicificación por alteración en fase vapor (IgnD), presentan valores de LOI cercanos a los admisibles (1,4; 2,39; 2,97 y 3,76) (fig. 3.62). En cambio, la muestra SE-SN_M2 (ignimbrita con alteración argílica-sericítica; IgnSA), es la única muestra ácida que presenta valores altos de LOI, y, es la de mayor LOI respecto a todas las muestras (fig. 3.63). Estas observaciones indican que el decrecimiento del LOI frente a los valores más ácidos se asocia al tipo de alteración desarrollada (silicificación), y a pesar que el LOI alcanza valores bajos, los diagramas de variación efectuados para los álcalis indican elevada movilización (fig. 3.64). La gran variación en el LOI, entre muestras ácidas alteradas por silicificación y muestras alteradas por minerales hidratados, índica que el LOI aumenta fuertemente ante la presencia de estos últimos y disminuye en su ausencia (fig. 3.65). Por lo expuesto, se concluye que es inapropiado el uso de elementos mayoritarios para la clasificación química y discriminación petrotectónica de las rocas volcánicas y piroclásticas presentes en el Ciclo Precuyano, siendo fundamental la utilización de elementos inmóviles (Gifkins et al., 2005). Esto queda evidenciado cuando se compara la clasificación entre el típico diagrama total silice alkali (TAS) (Le Bas y Streckeisen, 1991) y el diagrama de elementos inmóviles de Winchester y Floyd (1977). En el diagrama el TAS se observa dos campos definidos: uno mayoritariamente por traquiandesitas basálticas, andesitas y otro, por riolitas que en casos extremos alcanzan hasta $80 \%$ de $\mathrm{SiO}_{2}$, observándose una ausencia de términos dacíticos (fig. 3.66). Esta distribución sería producida por importante silicificación y movilización de álcalis (fig. 3.66). Esta puede haber sido unas de las razones por las cuales el volcanismo del 


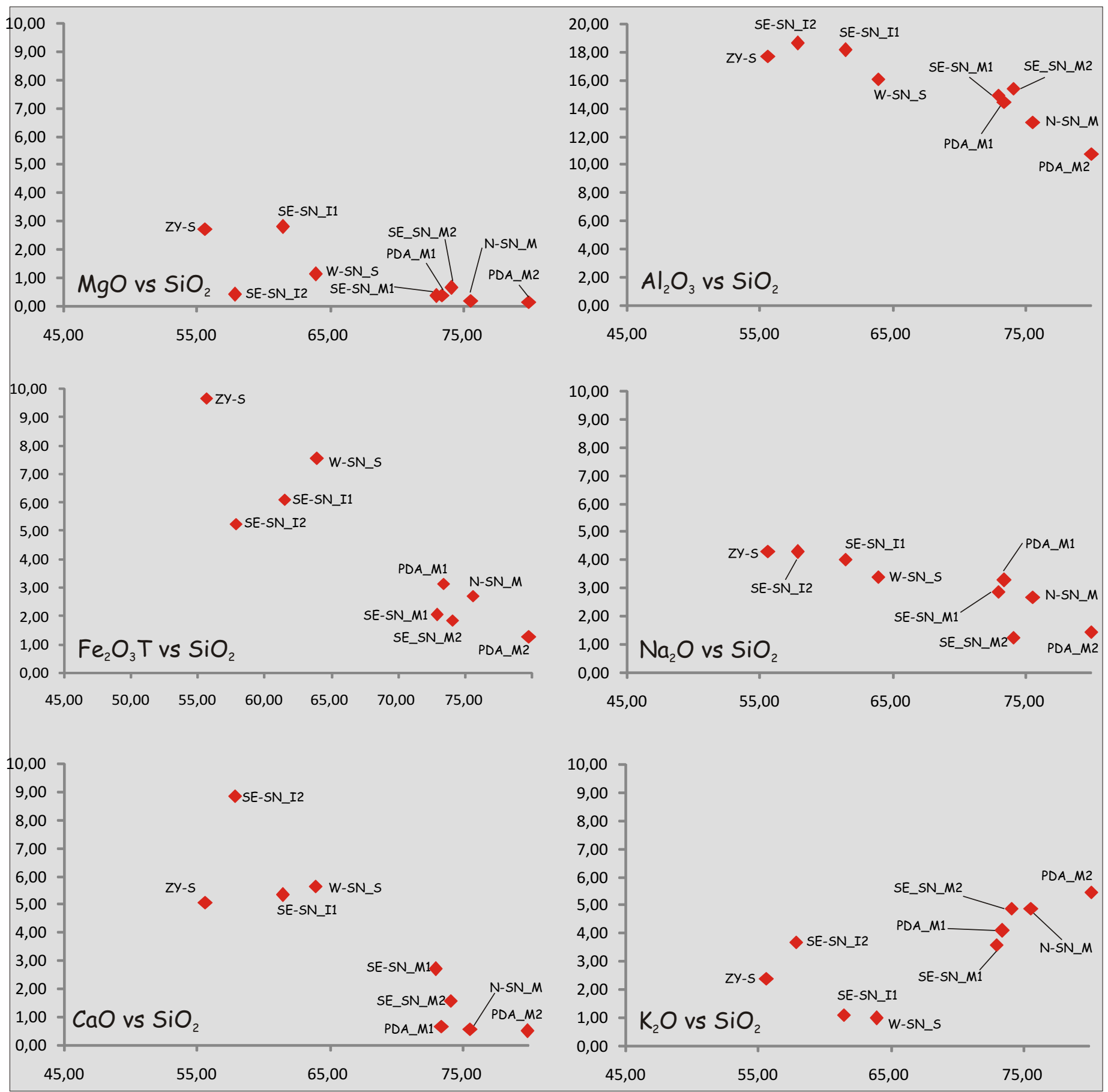

Figura 3.63. Diagrama de variación para los principales elementos mayoritarios de las rocas ígneas.

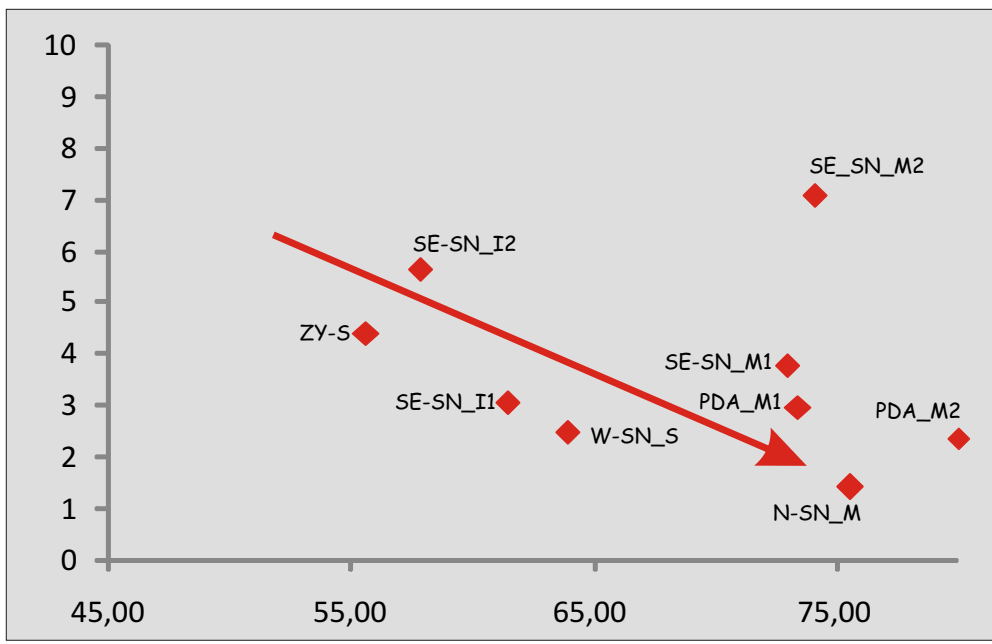

Figura 3.64. Diagrama de variación del LOI versus la sílice. 


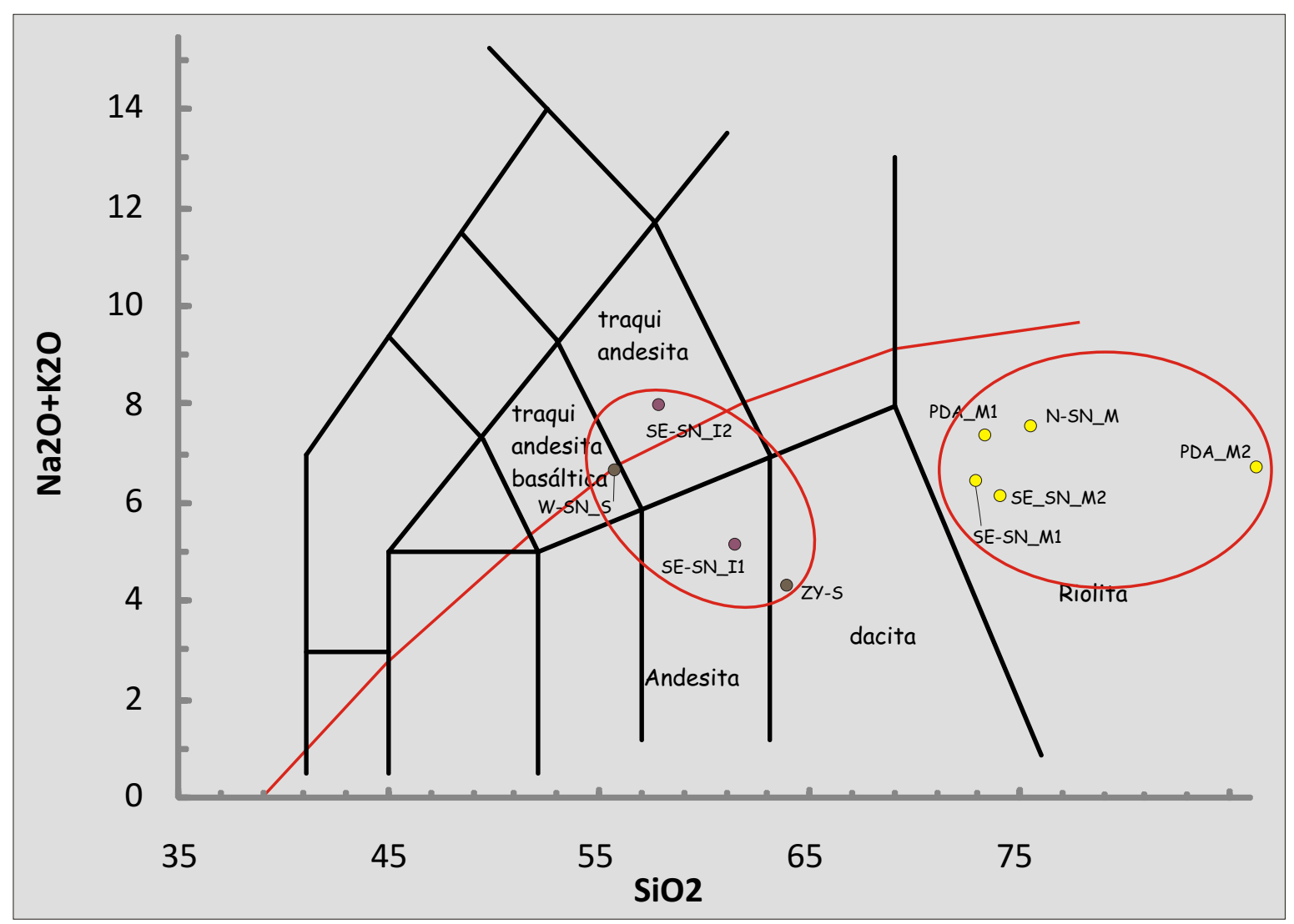

Figura 3.65. Diagrama TAS de clasificación de las rocas ígneas.

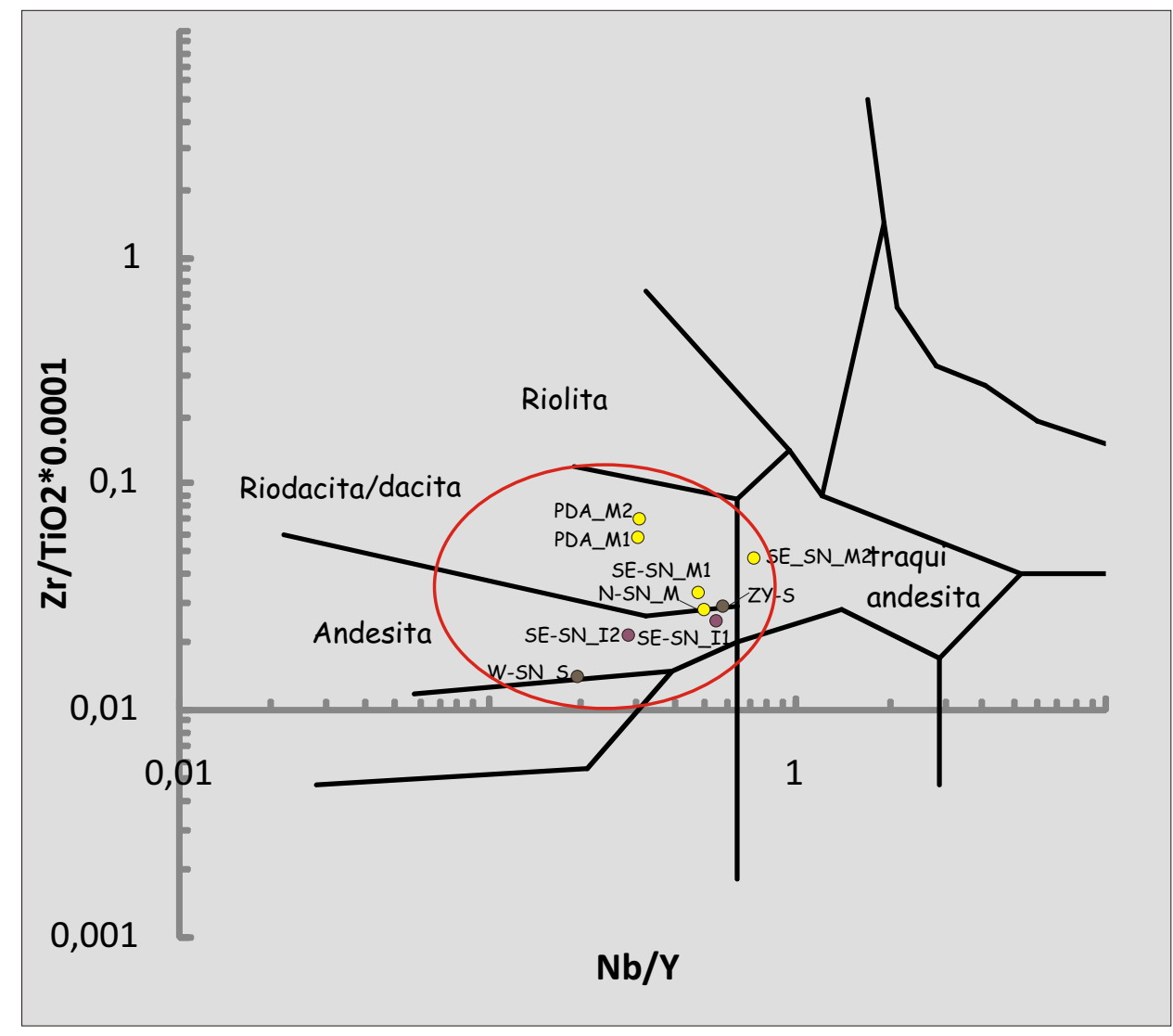

Figura 3.66. Diagrama de clasificación de las rocas ígneas de Winchester y Floyd (1977). 
Precuyano fue definido históricamente como de características bimodal (Franzese y Spalletti, 2001). En contraposición, en el diagrama de Winchester y Floyd (1977), se aprecia que no existe una separación entre las riolitas y las andesitas, observándose un tren de rocas cercanas a andesitas basálticas hasta riodacítas, pasando por andesitas y dacitas (fig. 3.67). Es importante destacar que la muestra SE-SN_M2, constituida de material pumíceo procedente de un depósito ignimbrítico con valores de LOI de 7,07, en este diagrama se dispone en el campo de las traquiandesitas. Esto indica que si se obtienen elevados valores de LOI se debe tener mucha cautela con la interpretación de los datos geoquímicos, ya que inclusive se pueden movilizar los elementos más inmóviles (fig. 3.67).

Respecto a los diagramas de discriminación de asociaciones petrotectónicas, por los motivos anteriormente expuestos se sugiere no tener en cuenta el diagrama AFM. (fig. 3.67) (Irvine y Baragar, 1971). Para esta tarea se utilizó el diagrama Zr versus Y (MacLean y Barrett, 1993), donde se aprecia un clara tendencia subalcalina para las rocas volcánicas y piroclásticas del Ciclo Precuyano, mayoritariamente calcoalcalinas y minoritariamente transicionales a toleíticas (fig. 3.68). Los diagramas spider multielemento y de tierras raras (REE) normalizado a N-MORB y Manto Primitivo (Sun y McDonough, 1989), sugieren que la secuencia volcánica en estudio presenta características comagmáticas, asociadas a la misma fuente (fig. 3.70). En el diagrama multielemento se aprecia un patrón de enriquecimiento en elementos LIL (large-ion lithophile) respecto a los elementos HFS (high field strength). El diagrama de elementos de tierras raras (REE) muestra un enriquecimiento de tierras raras livianas (LREE) respecto a las tierras raras pesadas (HREE) (fig. 3.69). Es importante destacar que el rango composicional de rocas comagmáticas, el desarrollo de texturas que indican reservorios corticales (véase apartado 3.3) y la evidencia de fragmentos de las rocas de caja en las rocas lávicas y piroclásticas, sugieren la posibilidad de que la asimilación cortical haya influido en las características geoquímicas diagnósticas de las rocas. Teniendo en cuenta que las andesitas basálticas serían los tipos litológicos menos diferenciados de este tipo de serie (Best y Christiansen, 2000), y las mismas presentan similares patrones que las rocas más evolucionadas, se infiere que el mecanismo de asimilación no fue lo suficientemente importante como para desestimar las observaciones obtenidas. Con todo, los altos valores de elementos no conservativos (LIL y LREE) y bajos valores de elementos conservativos - Ta, Nb, Zr y Y próximos a la unidad (HFS y HREE), serían consistente con una fuente asociada a la participación de fluidos en una cuña mantélica metasomatizada (Pearce y Peate, 1995). Estas características sugieren un ambiente geodinámico orogénico relacionado a procesos de subducción-deshidratación de la placa y metasomatismo (Pearce, 1982; Pearce, 1984; Gorton y SChandl, 2000). Las similitudes de las rocas del Ciclo Precuyano con las series magmáticas orogénicas son numerosas, entre ellas se pueden destacar: la amplia variación de rocas, desde andesitas basálticas a riodacítas, 


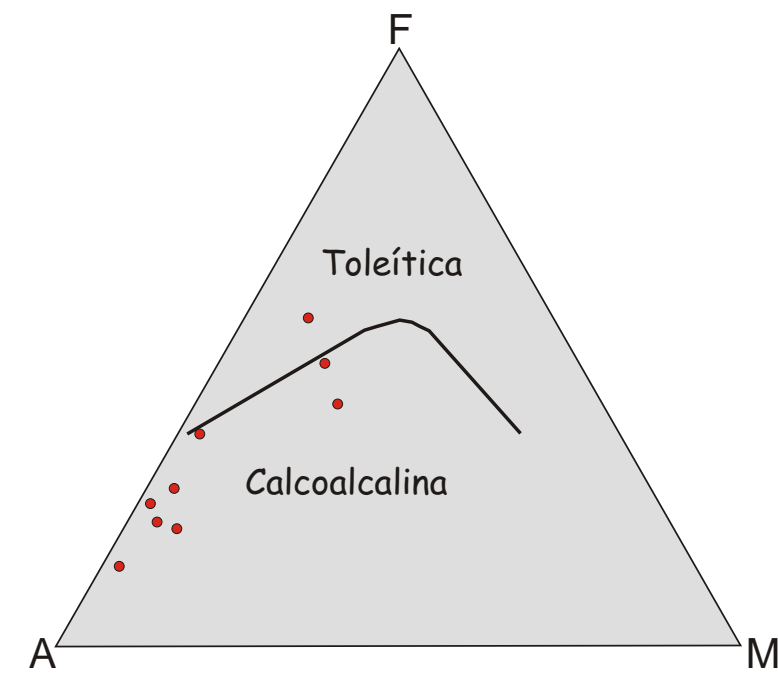

Figura 3.67. Diagrama AFM de Irvine y Baragar (1971) para distinguir series subalcalinas.

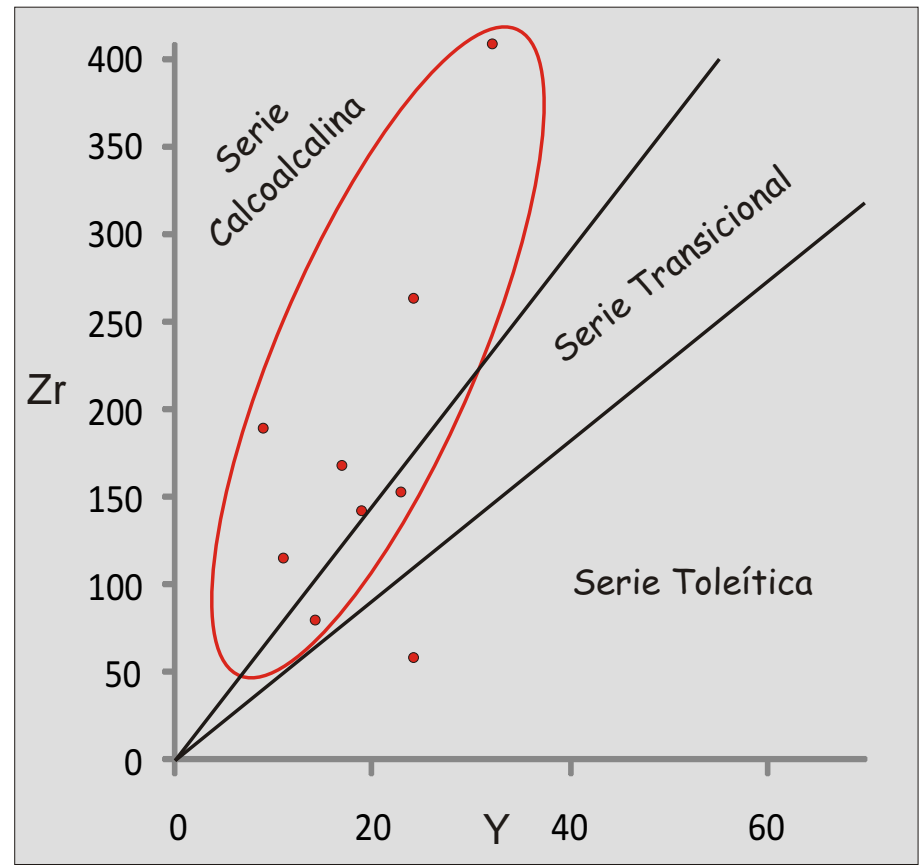

Figura 3.68. Diagrama de discriminación de series subalcalinas de MacLean and Barrett (1993).

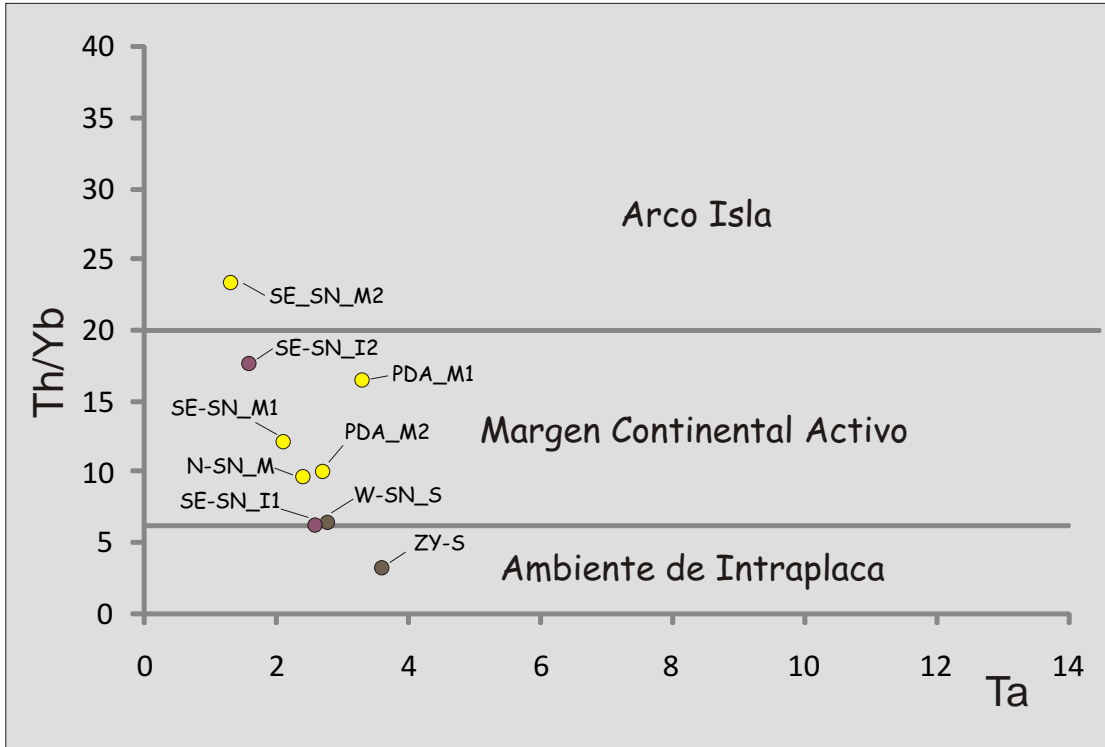

Figura 3.69. Diagrama de discriminación geotectónico de Gorton y Schandl (2000). 

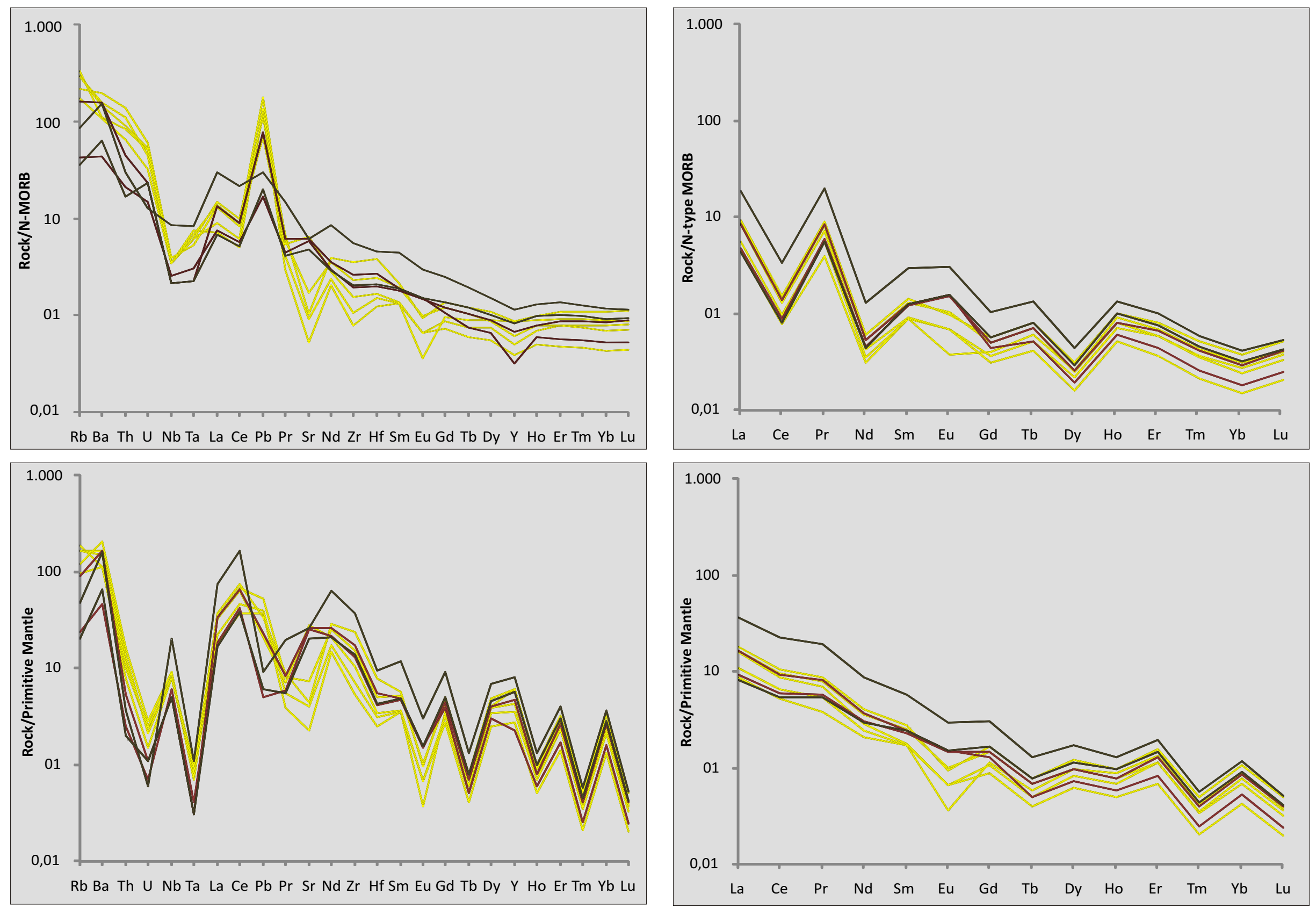

Figura 3.70. Diagramas spider de elementos trazas y de REE normalizados a N-MORB y manto primitivo de Sun y McDonough (1989). 
con una abundancia en los exponentes intermedios; la tendencia subalcalina calcoalcalina; y el enriquecimiento en elementos litófilos (Best y Christiansen, 2000). Las interpretaciones realizadas a partir de los diagramas spider pueden ser constatadas cuando se realiza una discriminación del ambiente geodinámico (fig. 3.70). Gorton y SChandl (2000) proponen una clasificación para rocas intermedias y ácidas en función de elementos (Th, Yb y Ta) que se mantendrían inmóviles inclusive bajo una situación de metamorfismo. La relación promedio de $\mathrm{Th} / \mathrm{Yb}$ de las rocas del Precuyano otorga valores de 12, típicos de orógenos continentales activos (fig. 3.69) (Gorton y SChandl, 2000). Sólo una muestra con una relación Th/Yb de 3,27 sería correspondiente a un ambiente de intraplaca. 


\section{Capítulo 4 - Análisis de las unidades de acumulación}

\section{1) Introducción}

En el presente apartado mediante el análisis de los resultados obtenidos del capítulo precedente (fig. 3.1), sumado a los mapas y columnas estratigráficas de detalle (anexos I y II), se realizará una evaluación de las diferentes unidades de acumulación que integran el relleno precuyano y el Ciclo Cuyano basal. De esta manera, al finalizar este capítulo se obtendrá una idea acabada sobre los diferentes subambientes y ambientes del Jurásico Inferior en el área más austral de la Cuenca Neuquina. Es importante destacar que los depocentros de rift a menudo se muestran como estructuras alargadas conformadas por segmentos de fallas extensionales, internamente asimétricos, presentando una evolución compleja (Schlische y Anders, 1996). La compartimentalización de los depocentros, la interacción y activación o desactivación de determinados segmentos de fallas y cambios en la polaridad de los depocentros, son algunos de los procesos que pueden generarse a través de su evolución (Gawthorpe y Leeder, 2000). Estos factores, conjuntamente con el clima y el tipo de roca de base, ejercen un control fundamental sobre los tipos, distribución, organización y evolución de los ambientes sedimentarios dentro de los depocentros donde el volcanismo aparece de manera subordinada (Leeder, 1999). En cuencas con abundante actividad magmática el volcanismo se convierte en unos de los principales controles de los ambientes, por su capacidad de generar relieve, aportar gran cantidad de detritos en cortos periodos de tiempo y disminuir la cobertura vegetal, entre otros (Smith 1991; Smith y Lowe, 1991; Mc Phie et al., 1993; Orton, 2002; Németh y Ulrike, 2007). Estudios en las últimas décadas han puesto de manifiesto la relevancia del volcanismo en los depósitos iniciales precuyanos de la Cuenca Neuquina (Gulisano y Pando, 1981; Gulisano et al., 1984; Franzese et al., 2005; Franzese et al., 2007; Llambías et al., 2008; entre otros), sin ahondar en los diferentes ambientes y las relaciones existentes entre éstos. Con todo, el estudio de los ambientes iniciales de la cuenca presenta un panorama complicado. Para su abordaje fue necesario contar con una gran cantidad de datos concernientes no sólo a los diferentes procesos depositacionales puntuales, sino también en lo referente a la distribución lateral y vertical de los depósitos en toda el área de estudio. 


\section{2) ¿Qué es una unidad de acumulación y cómo se define?}

En el presente trabajo se define a una unidad de acumulación como un conjunto de facies que presentan una relación genética en común (asociaciones de facies), un arreglo interno, una composición, una geometría y una distribución particular. Bajo esta definición las unidades de acumulación serán presentadas mediante mapas geológicos de detalle, en los cuales se podrá apreciar su distribución areal, columnas estratigráficas y paneles de correlación. De esta manera se realizará una interpretación sobre la evolución de los procesos depositacionales en el tiempo y en el espacio. De presentarse, serán utilizados los datos de paleocorrientes, previamente rebatidos a la horizontal. Cada unidad de acumulación tendrá una asociación de microfacies. Es importante destacar que las características composicionales de las unidades volcánicas y piroclásticas se obtuvieron a partir de los resultados del estudio litogeoquímico, conjuntamente con el análisis composicional fruto de las observaciones petrográficas.

\section{3) Organización de las unidades de acumulación}

Siguiendo con el esquema utilizado para el análisis de facies, las unidades fueron divididas en: unidades de acumulación volcánicas, unidades de acumulación piroclásticas y unidades de acumulación sedimentarias, las cuales en función de las asociaciones de facies y contenido fosilífero han sido subdivididas en unidades de acumulación epiclásticas continentales, unidades de acumulación epiclásticas marinas y unidades de acumulación carbonáticas marinas. Dentro de cada grupo mayor de unidades de acumulación las mismas fueron denominadas en función de nombres genéticos que aluden al tipo de ambiente o rasgos depositacionales (Ej. unidades de acumulación de coladas y coladas dómicas andesíticas, unidades de depósitos de corrientes piroclásticas alojados en depresiones o unidades de acumulación de sistemas fluviales de carga mixta). Hay unidades de acumulación en las cuales su denominación denota a depósitos de menor jerarquía dentro de un ambiente volcánico (Ej. unidades de acumulación de coladas y coladas dómicas andesíticas) y unidades que abarcan en su definición un ambiente sedimentario (Ej. unidades de acumulación de sistemas fluviales de carga mixta). Estas diferencias en la discriminación se fundan en la relevancia que las mismas tienen, desde el punto de vista de la distribución lateral y vertical dentro del relleno precuyano. Esto se debe a que unidades jerárquicas menores de un ambiente volcánico pueden llegar a ser más abundantes y ampliamente distribuidas en un depocentro que una unidad que integra un ambiente sedimentario.

El análisis del relleno precuyano y el Ciclo Cuyano basal para el área de Sañicó y Piedra del Águila arrojó un total de 21 unidades de acumulación: 6 volcánicas (fig. 4.1), 6 
piroclásticas (fig. 4.17), 8 sedimentarias epiclásticas continentales, 1 sedimentaria epiclástica marina y 1 sedimentaria carbonática marina (fig. 4.28). A continuación se realizará una descripción e interpretación de las unidades de acumulación, comenzando por las generadas por procesos volcánicos primarios.

\section{4) Unidades de acumulación de rocas volcánicas y volcaniclásticas asociadas}

\subsection{1) Unidades de acumulación de rocas volcánicas andesíticas}

Bajo esta denominación se han agrupado a todas las unidades resultado de erupciones magmáticas superficiales no explosivas e intrusiones someras que fueron clasificadas petrográfica y litogeoquímicamente como de composición andesítica. A excepción de algunos cuerpos de composición andesita basáltica no se han encontrado términos más máficos dentro del relleno precuyano del área de estudio.

\subsubsection{1) Coladas y coladas dómicas}

Dentro de esta unidad de acumulación se agrupan coladas y coladas dómicas de composiciones andesíticas. Aparecen de manera frecuente en la parte inferior y superior del Ciclo Precuyano. Yacen conformando sucesiones potentes desde decenas hasta $200 \mathrm{~m}$ de espesor y gran distribución areal. Esta unidad se compone de litofacies de lavas andesíticas coherentes (LAC), lavas andesíticas autobrechadas (LAA), lavas andesíticas con fracturación hidráulica (LAFH) y lavas andesíticas pseudobrechadas (LAPB) (fig. 3.1). Las facies mencionadas se encuentran asociadas entre sí conformando sucesiones lávicas dominadas por lavas coherentes, generalmente de geometría tabular y minoritariamente dómica (donde las facies de lavas autobrechadas participan de manera escasa) y sucesiones dominadas por lavas autobrechadas (LAA) con geometrías dómicas a tabulares interpretadas como "lavas en bloque” (Kilburn, 2000). Minoritariamente, intercalando en las secuencias lávicas, se encontraron depósitos de flujos de bloques y cenizas (mlBri), depósitos de flujos de detritos (Gmm(a)) y depósitos arenosos originados por flujos hiperconcentrados (SGh) (fig. 3.1). Es importante destacar que en el mapeo de las unidades de acumulación de las unidades de coladas y coladas dómicas no se ha hecho una separación entre unidades que están dominadas por lavas coherentes y las que están dominadas por lavas en bloques. El motivo fundamental de haberlas mapeado de manera conjunta radica que en determinados sectores no existe un límite preciso entre las mismas en sentido lateral y vertical. Las coladas y coladas dómicas con abundancia de lavas en bloque se presentan como cuerpos de lava de entre $10 \mathrm{~m}$ y $50 \mathrm{~m}$ de espesor y gran distribución lateral, en ocasiones sin límites definidos (fig. 4.2 y 4.3). Se muestran con núcleos de lavas coherentes (LAC) y bordes autobrechados (LAA) o totalmente constituidas por facies 
Unidades de acumulación volcánicas

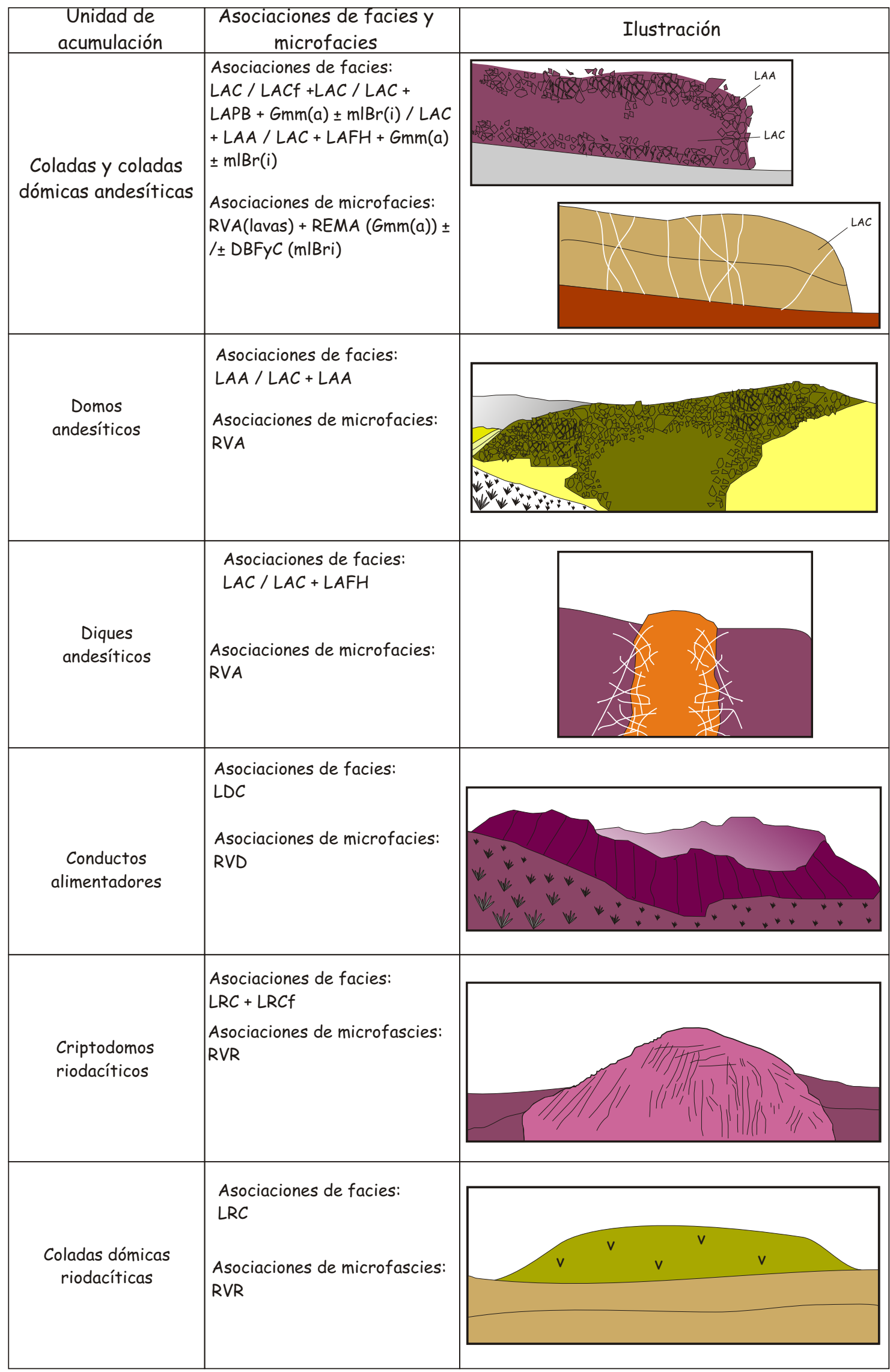

Figura 4.1. Unidades de acumulación volcánicas identificadas para este estudio. 
de lavas autobrechadas (LAA). En muchos casos las facies de lavas coherentes aparecen con texturas pseudobrechadas (LAPB) producto de diferentes fases de alteración que actúan sobre fracturas previamente formadas (Mc Phie et al., 1993; Gifkins et al., 2005). Las coladas y coladas dómicas con predominio de lavas coherentes (fig. 4.4, 4.5 y 4.6) generalmente se expresan como cuerpos tabulares de entre 2 m y 20 m de espesor y gran distribución areal. Habitualmente se muestran masivas aunque en ocasiones se han encontrado estructuras de foliación por flujo paralela a los bordes y disyunción columnar. En determinadas situaciones las lavas que componen esta unidad se presentan con litoclastos accidentales de esquistos de formas angulosas, provenientes del basamento (fig. 4.5). Otra característica sobresaliente es el importante grado de fracturación hidráulica que desarrollan los cuerpos de lavas cuando yacen sobre unidades de acumulación piroclástica y sobre unidades de acumulación sedimentaria. En el último caso, además de las facies de fracturación hidráulica (LAFH) se presentan con un importante desarrollo de vesículas y amígdalas en las partes basales (fig. 4.6).

Las unidades de coladas y coladas dómicas son un importante elemento agradante y de gran distribución areal que modeló el paisaje en diferentes etapas del Ciclo Precuyano. Tanto las unidades con predominio de lavas coherentes como las unidades con predominio de lavas en bloques son asociaciones de facies subaéreas (Mc Phie et. al., 1993; Németh y Ulrike, 2007). El análisis de la composición y asociaciones de estas unidades indica que su expansión areal fue el resultado de sucesivos eventos efusivos desarrollados dentro del mismo periodo eruptivo (Kilburn, 2000). Entre los factores más importantes que controlan la evolución de los flujos de lavas se destacan la tasa efusiva, las propiedades físicas de las lavas (temperatura, composición, cantidad de volátiles y cantidad de fenocristales) y las características geomorfológicas del ambiente (Mc Phie et al., 1993; Kilburn, 2000). Tratándose de lavas que presentan similares características composicionales (fig. 4.11A), el relieve y la tasa de aporte habrían sido las variables que controlaron la abundancia de facies coherentes o autoclásticas dentro del relleno precuyano.

El grado de fracturación hidráulica que desarrollan las secuencias lávicas en determinados sectores del relleno cuando éstas se apoyan sobre unidades piroclásticas, se puede explicar por la circulación de soluciones calientes a altas presiones (Mc Phie et al., 1993), probablemente provenientes del enfriamiento de las unidades piroclásticas. En cambio, el desarrollo de facies de fracturación hidráulica y la vesicularización cuando éstas se apoyan sobre sucesiones sedimentarias se adjudica al aporte de agua procedente de los sedimentos húmedos (López y Bellos, 2007). La presencia de fragmentos de roca de caja evidencia contaminación cortical durante el ascenso del magma a través de fracturas (Ej. diques) (Llambías, 2008).

Las facies no volcánicas que aparecen interdigitadas dentro de esta unidad (depósitos de flujos de bloques y cenizas) son de composición andesítica y están constituidos por materiales 
primarios densos o escasamente vesicularizados. Tales características sugieren un origen a partir del colapso gravitatorio de las unidades de coladas y coladas dómicas (Mc Phie et al., 1993; Cas y Wright, 1987). Los depósitos de flujos de detritos (Gmm(a)) y/o depósitos de flujos hiperconcentrados (SGh) se muestran monomícticos, con espesores delgados y poca continuidad lateral y se originaron por la erosión y retrabajo de los cuerpos de lavas. 


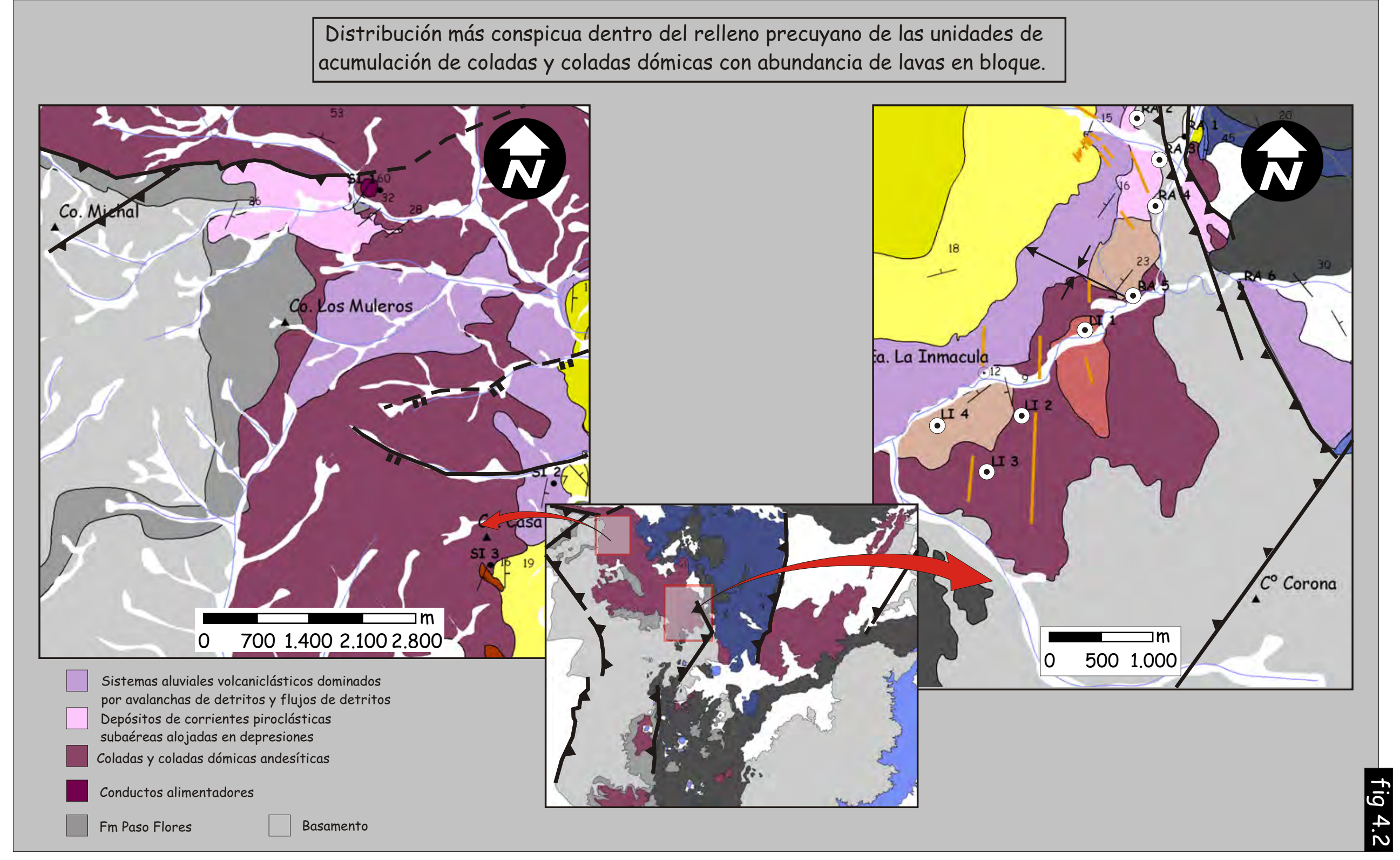

Figura 4.2. Distribución de las unidades de acumulación de lavas y coladas dómicas andesíticas dominadas por lavas en bloques. 
Unidad de acumulación: lavas y coladas dómicas andesíticas

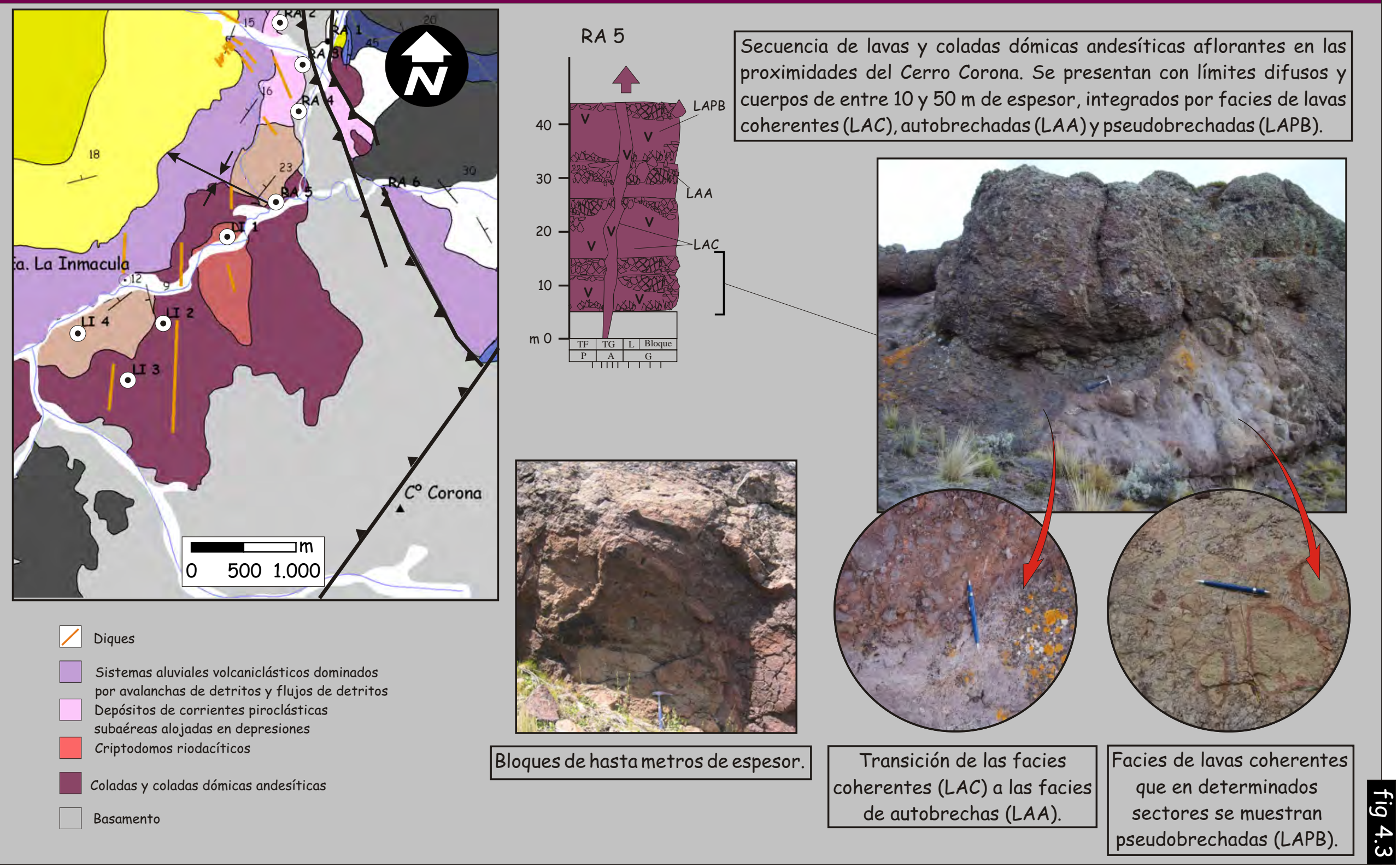

Figura 4.3. Unidad de acumulación de lavas y coladas dómicas andesíticas dominadas por lavas en bloques. 


\section{Unidad de acumulación: lavas y coladas dómicas andesíticas}

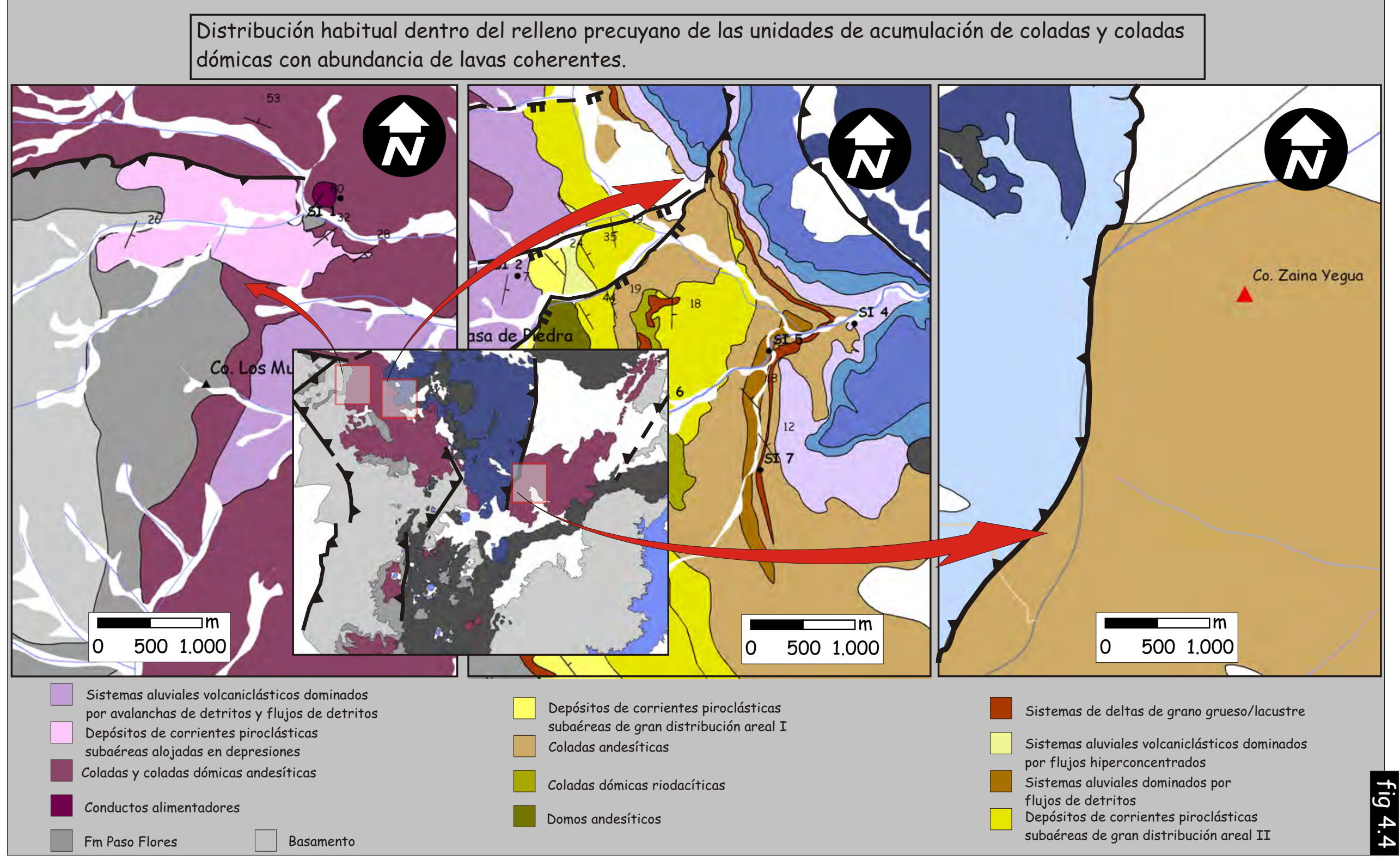

Figura 4.4. Distribución de las unidades de acumulación de lavas y coladas dómicas andesíticas dominadas por facies coherentes. 


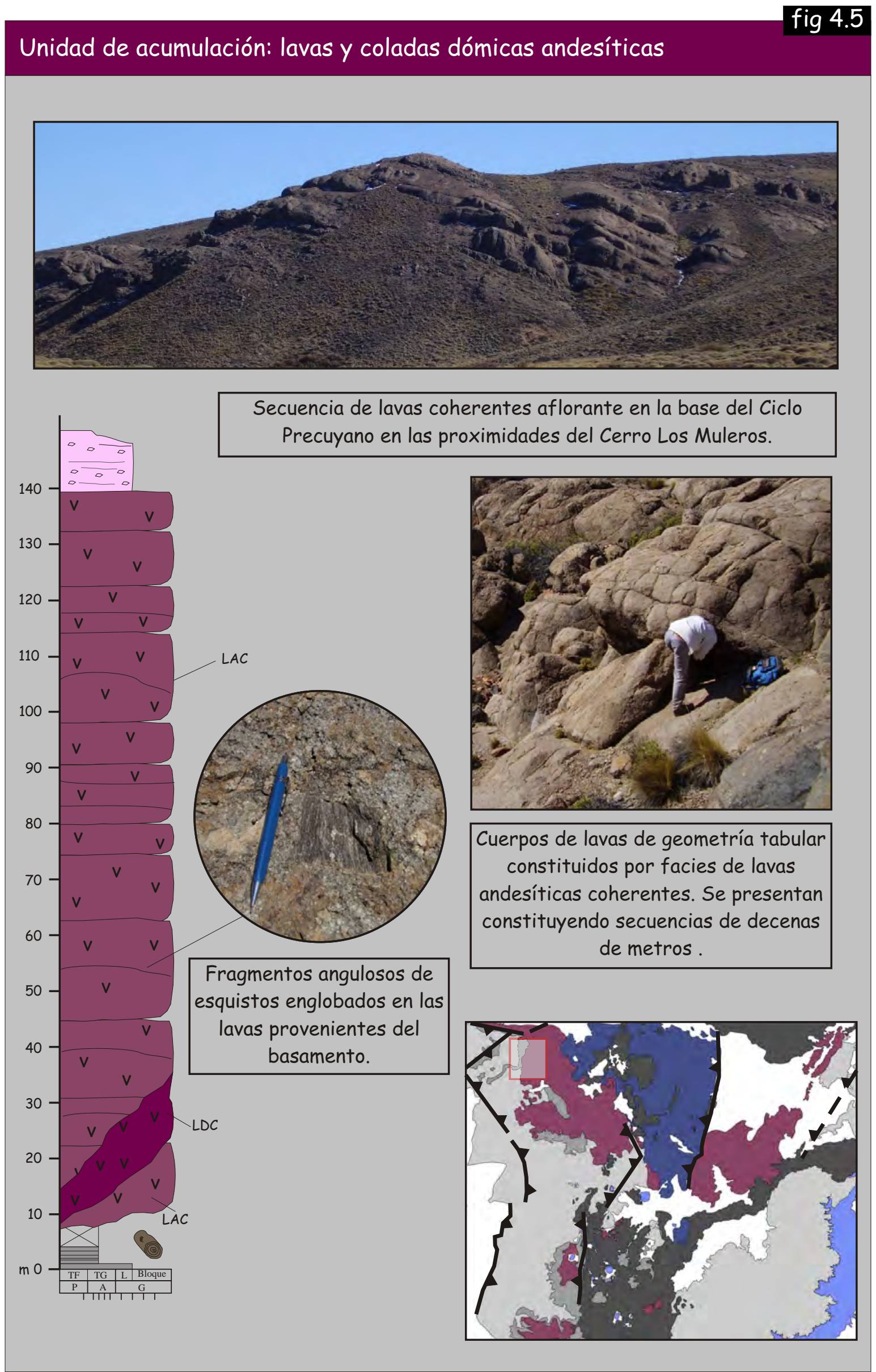

Figura 4.5. Unidad de acumulación de lavas y coladas dómicas andesíticas dominadas por facies coherentes. 
Unidad de acumulación: lavas y coladas dómicas andesíticas

Cuerpos de lavas y coladas dómicas dominadas por lavas coherentes aflorantes en las nacientes del arroyo Carrán Curá sobre las secuencias deltaicas de grano grueso/lacustres

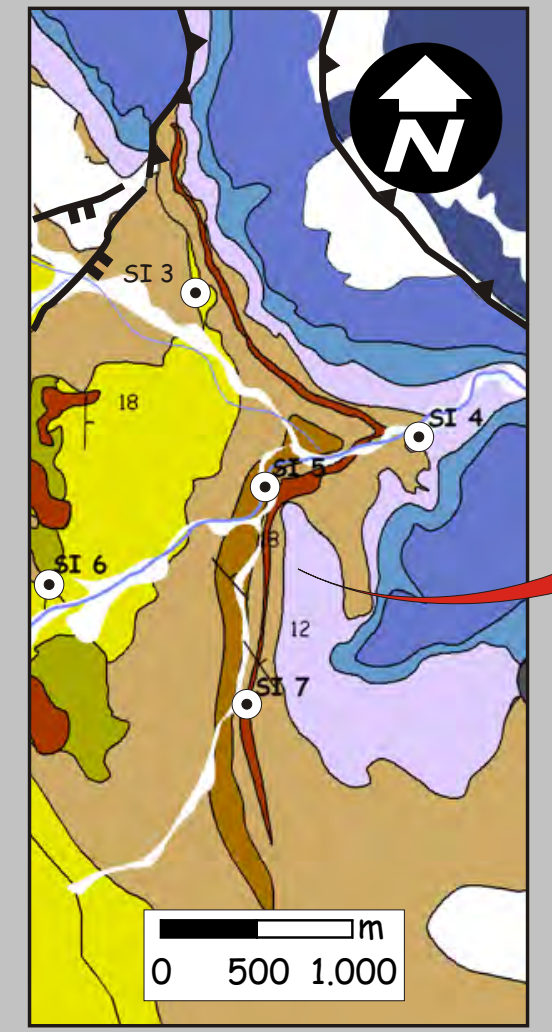

Depósitos de corrientes piroclásticas subaéreas de gran distribución areal I Coladas andesíticas

Coladas dómicas riodacíticas

Domos andesíticos
SI 7
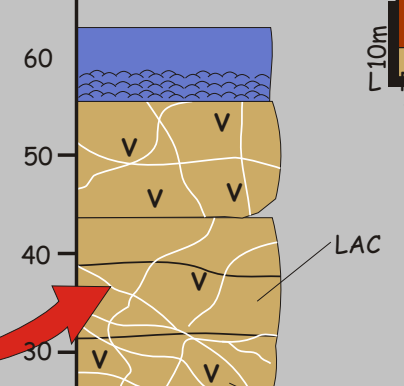

$20-$

$10-$

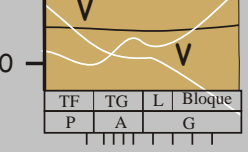

Sistemas de delta de grano grueso/lacustre

Sistemas aluviales volcaniclásticos dominados por flujos hiperconcentrados

Sistemas aluviales dominados por flujos de detritos

Depósitos de corrientes piroclásticas subaéreas de gran distribución areal II

LAC
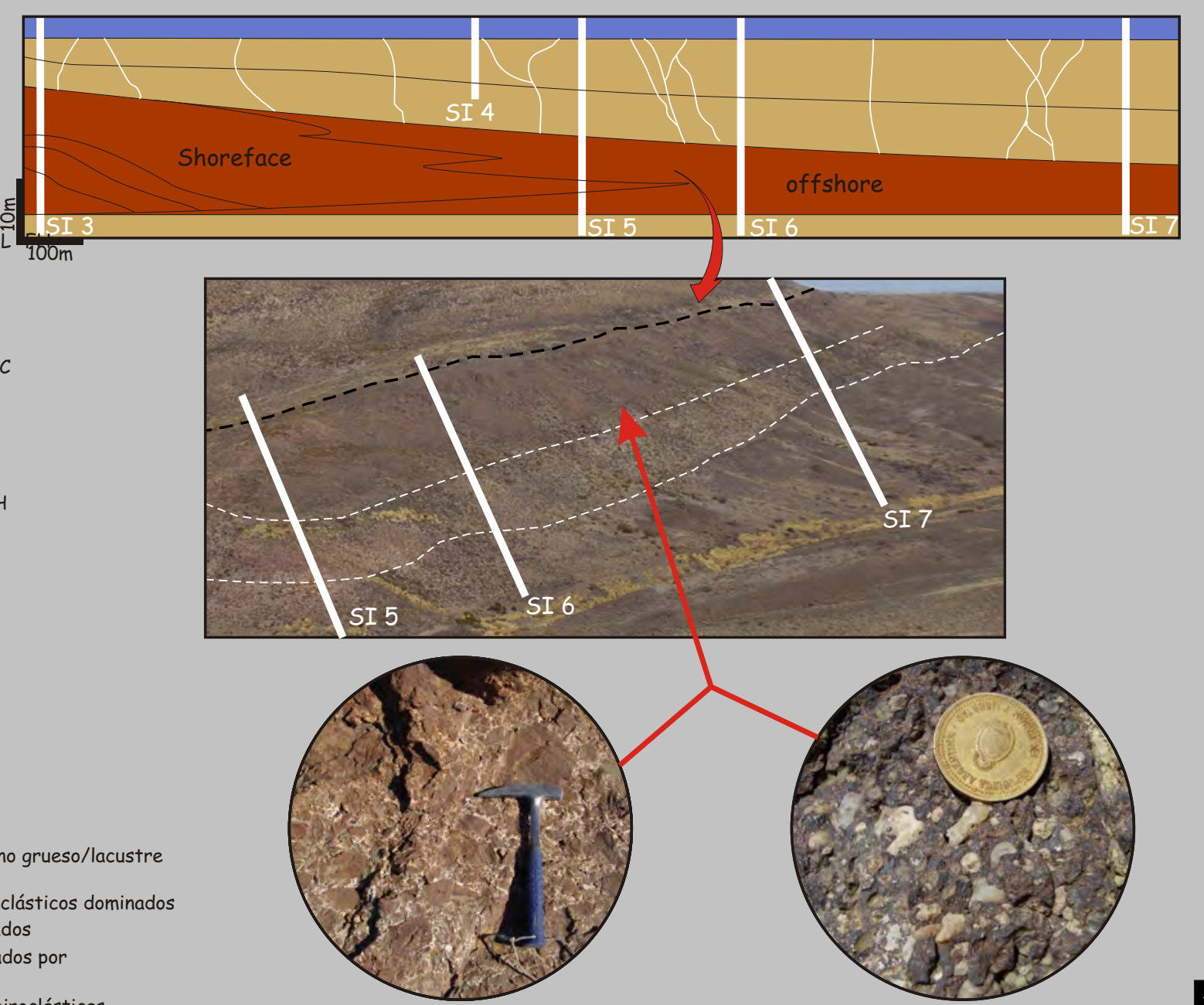

Facies de lavas andesíticas con fracturación hidráulica (LAFH) y con importante proceso de cavitación sobre los sedimentos deltaicos/lacustres.

Figura 4.6. Unidad de acumulación de lavas y coladas dómicas andesíticas dominadas por facies coherentes. 


\subsubsection{Domos andesíticos}

Dentro de esta unidad de acumulación se agruparon los exodomos y cuerpos lávicos de composición andesítica, en parte intrusivos y en parte extrusivos, que conforman entidades volcánicas denominadas como endodomos (Fink y Anderson, 2000). Esta unidad se desarrolla asociada a las unidades de acumulación de coladas y coladas dómicas (fig. 4.7) o se puede encontrar de manera aislada intercalada con unidades de acumulación piroclástica (fig. 4.8). Presenta geometría marcadamente dómica, con límites externos curvados o irregulares, espesores de entre $3 \mathrm{~m}$ y $30 \mathrm{~m}$ y una distribución areal que varía desde metros a cientos metros (fig. 4.7 y 4.8). Internamente esta unidad se compone de lavas con abundantes fenocristales de plagioclasa que conforman litofacies de lavas andesíticas coherentes (LAC) y litofacies de lavas andesíticas autobrechadas (LAA) (fig. 3.1), las cuales constituyen la caparazón externa de estos cuerpos. También se pueden presentar totalmente constituidas por litofacies de lavas andesíticas autobrechadas. En muy pocos casos se ha encontrado la vinculación de estos cuerpos con los diques alimentadores.

Esta unidad de acumulación representa acumulaciones de lavas en forma intrusiva/extrusiva en fracturas cercanas a la superficie. Las partes extrusivas reflejan asociaciones de facies típicas de domos subaéreos de composiciones andesíticas (Mc Phie et. al., 1993; Németh y Ulrike, 2007). 
Unidad de acumulación: domos andesíticos

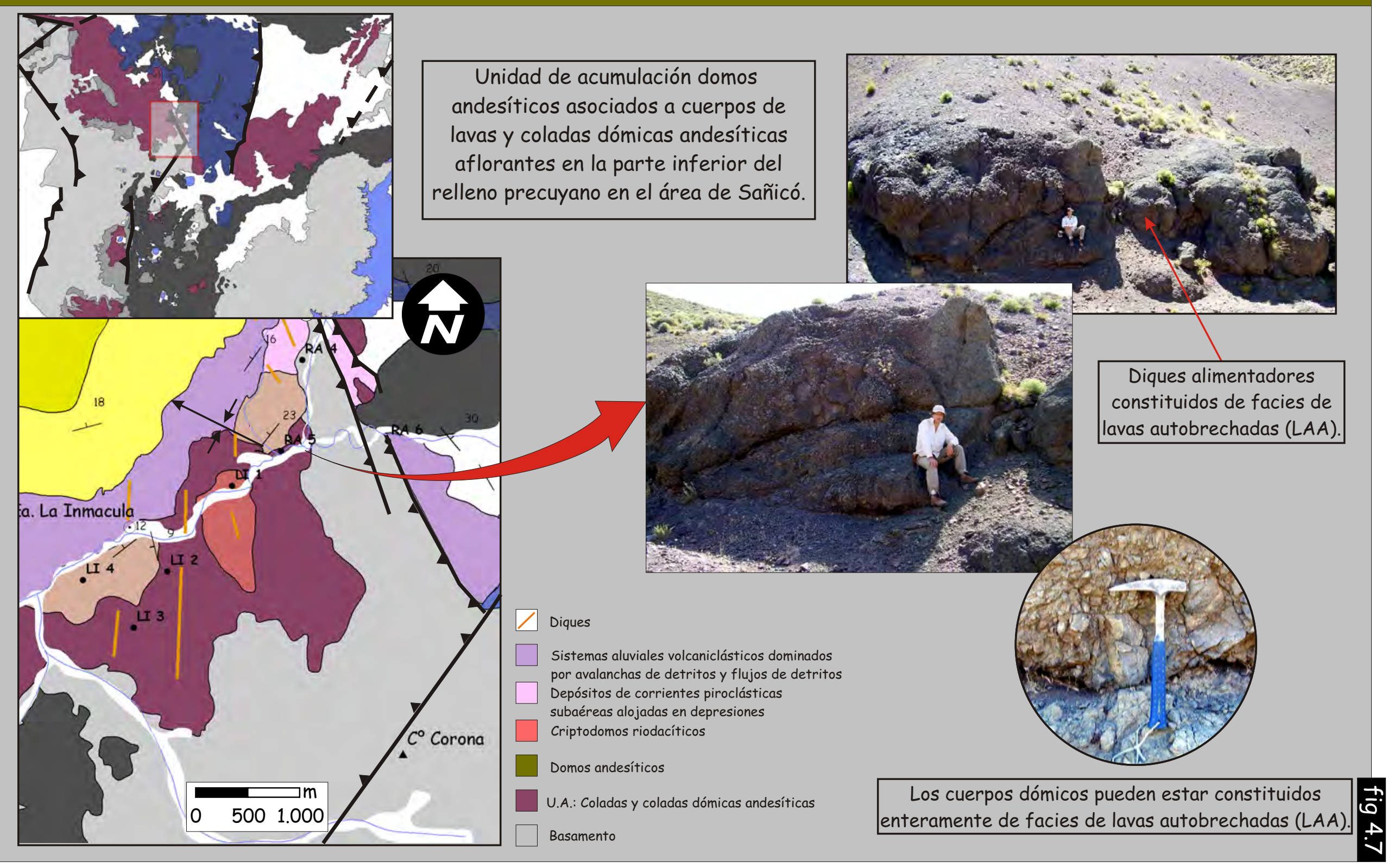

Figura 4.7. Unidad de acumulación de domos andesíticos. 
Unidad de acumulación: domos andesíticos

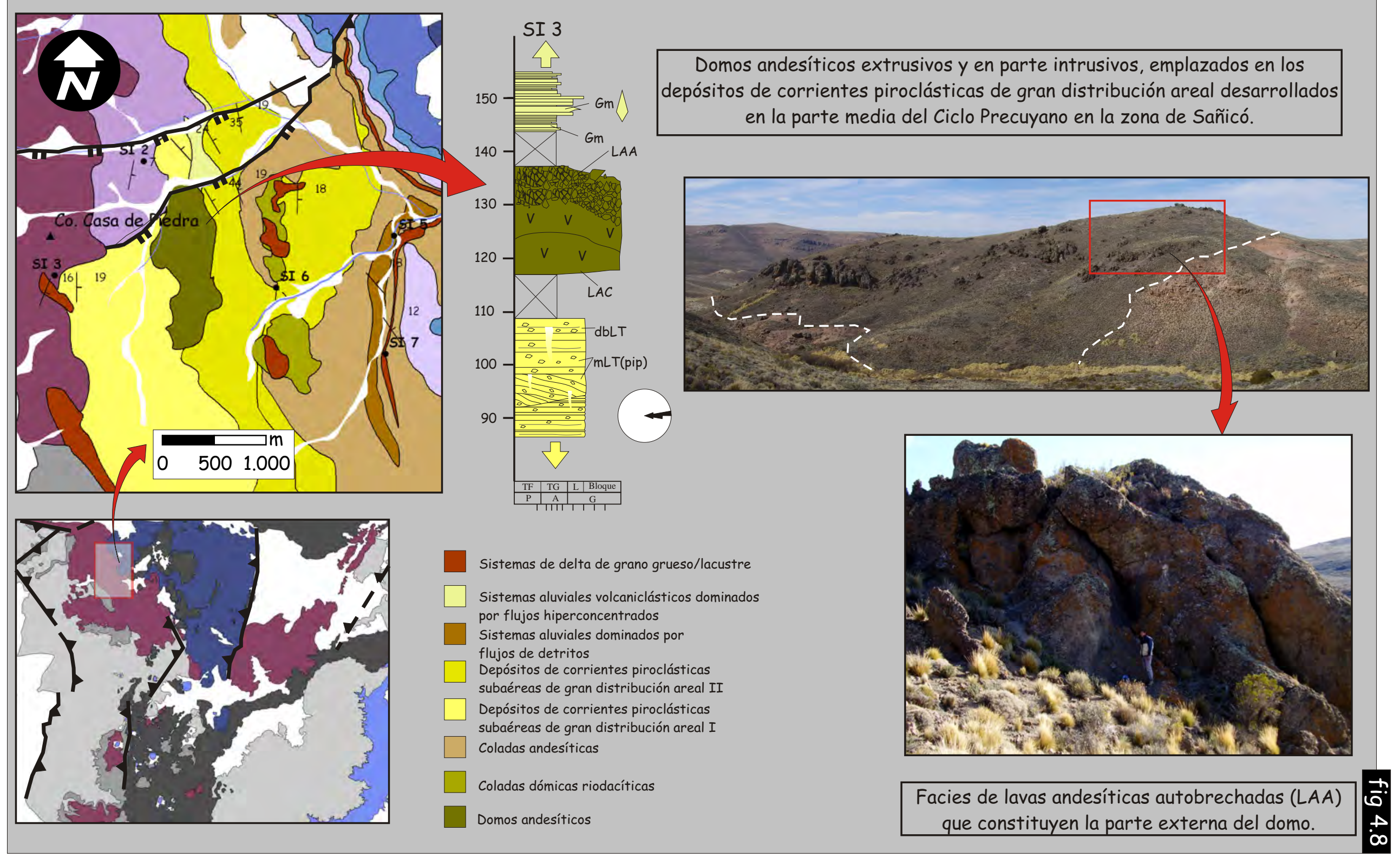

Figura 4.8. Unidad de acumulación de domos andesíticos. 


\subsubsection{Diques andesíticos}

En esta unidad se incluyen los diques volcánicos de composición andesítica que se encuentran intruidos subverticalmente en diferentes secciones del relleno precuyano. Generalmente se muestran con relieve positivo con respecto a las unidades que los contienen, aflorando como cuerpos tabulares de entre 50 m y 1800 m de largo, con afloramientos continuos o discontinuos en el rumbo y espesores promedios de $2 \mathrm{~m}$ (fig. 4.9). Sólo en una ocasión se encontró un dique de composición andesítica de $56 \mathrm{~m}$ de espesor (fig. 4.10). Habitualmente yacen de manera aislada, aunque es importante destacar que en el área de Sañicó, al oeste del Cerro Corona, se encontraron 28 diques en un área de $8 \mathrm{Km}^{2}$, con espaciados del orden de decenas de metros (fig. 4.9). Los diques andesíticos se encuentran intruidos en las diferentes unidades de acumulación que componen el Ciclo Precuyano, encontrándose sólo en pocas ocasiones vinculados con las unidades volcánicas efusivas. Si se rebaten los diques teniendo en cuenta el rumbo e inclinación regional para las capas del Ciclo Precuyano en ese sector, se puede apreciar que los mismos se encuentran preferencialmente intruidos con rumbos $\mathrm{N} 180^{\circ}$ a $160^{\circ}$ y N $160^{\circ}$ a $140^{\circ}$, e inclinaciones hacia el ENE y WSW (fig. 4.9).

Esta unidad está integrada por facies de lavas de andesitas coherentes (LAC) (fig. 3.1) con texturas microporfíricas y porfíricas, con pastas afaníticas pilotáxicas o traquíticas micro o criptocristalinas. Generalmente se presenta con un arreglo interno simple, con un borde de grano fino de $10 \mathrm{~cm}$ de espesor, desarrollando hacia el centro texturas porfíricas con pastas microcristalinas y fenocristales orientados. A menudo, las facies lávicas exhiben vesículas deformadas (< al $15 \%$ ), indicando flujo de lava paralelo a las paredes de los cuerpos. Minoritariamente, esta unidad se expone con contactos que presentan fracturación hidráulica (LAFH), desarrollando hacia el centro facies de lavas coherentes (LAC) o pseudobrechadas (LASB) (fig. 3.1).

En todos los casos esta unidad es el resultado de intrusiones volcánicas simples y monoepisódicas de lavas de composición andesítica (Marioni y Gudmundson, 2000). Las estructuras anisótropas (fenocristales orientados, las vesículas deformadas y la foliación por flujo) indican un gradiente de velocidad vertical en el flujo (Best y Christiansen, 2000). Los bordes de grano fino o vítreos, conjuntamente con los procesos de cavitación observados, evidencian niveles de emplazamiento someros con una roca de caja fría (Marioni y Gudmundson, 2000). Respecto a su modo de yacencia, su relieve positivo frente a otras unidades precuyanas denota periodos de alta tasa degradación, las cuales son características de muchos ambientes volcánicos (Thouret, 1999). A pesar que en muy pocas ocasiones se encontró a las unidades de diques relacionadas con otros cuerpos volcánicos, los niveles de emplazamiento someros sugieren que estas unidades constituyeron una vía de alimentación de magma hacia la superficie. La asociación de diques con similar orientación y el espaciado 
encontrados en el área de Sañicó indican sistema de dique longitudinales de rumbo N-S/ NNWSSE.

En general las unidades de acumulación de rocas volcánicas andesíticas muestran variaciones composicionales dentro de este campo, desde el límite de andesitas basálticas hasta el límite con lavas dacíticas (fig. 4.11A). Respecto a las características petrográficas, se presentan con microfacies de rocas volcánicas andesíticas (RVA) con variaciones de texturas seriadas, porfírica, glomeroporfírica, con pastas micro/criptocristalinas pilotáxicas (fig. 4.11 y 4.12). En ocasiones se encontraron cumulatos de composición diorítica. Estos atributos texturales indican el crecimiento de fenocristales producto de eventos de cristalización dentro de una cámara magmática (Mash, 2000; Best y Christiansen, 2000). Las texturas glomeroporfíricas y cumuláticas evidencian estadios avanzados de cristalización dentro de la cámara magmática (Best y Christiansen, 2000). Las variaciones texturales en la pasta, desde seriadas, pilotáxicas microcristalinas, pilotáxicas criptocristalinas hasta vitrofíricas, sugieren diferentes tasas de enfriamiento que controlaron la elevada nucleación y variación en el ritmo de crecimiento para el caso de las texturas cristalinas y la nucleación para el caso de las texturas vitrofíricas (fig. 4.11 y 4.12). Asociados a las texturas vitrofíricas se han encontrado fenocristales fracturados producto del rápido enfriamiento (quenching) (Mc Phie et al., 1993; Allen y Mc Phie, 2003). Es importante destacar que las unidades efusivas andesíticas presentan texturas de desequilibrio que indican diferentes velocidades de ascenso de los magmas. Por un lado los fenocristales de plagioclasa con textura cribada gruesa (coarse sieve-texture) y bordes reabsorbidos indican rápida tasa de descompresión y ascenso, del orden de los 10 m/s (Stephen y Montana, 1992; Best y Christiansen, 2000). Sin embargo, los cristales de hornblenda manteados por minerales opacos sugieren un ascenso lento los magmas del orden de metro /día (Best y Christiansen, 2000; Rutherford y Gardner, 2000). Las variaciones de andesitas con pseudomorfos de olivina y cristales de clinopiroxeno y hornblenda indican diferentes condiciones de composición, temperatura, presión y presión de fluidos (fig. 4.11 y 4.12). De tal forma, los pseudomorfos de olivina en las andesitas basálticas indican una fuente poco evolucionada, de composiciones más básicas y de mayor temperatura (Askren et al., 1997). Por otro lado, las andesitas piroxénicas y andesitas hornbléndicas indican diferentes condiciones de $\mathrm{T}^{\circ}$, presión de fluidos y presión de confinamiento, necesarias para estabilizar termodinámicamente los fenocristales de hornblenda o clinopiroxenos. La presencia de fenocristales de hornblenda en las microfacies de andesitas y dacitas indica composiciones hidratadas de los magmas, con concentraciones de $\mathrm{H}_{2} \mathrm{O}$ mayores o iguales al 5\% en peso y presiones de confinamiento de $1 \mathrm{~Kb}$ a $3 \mathrm{~Kb}$ (entre $4 \mathrm{~km}$ y 10,5 km) (Best y Christiansen, 2000).

Con respecto a la alteración, en las microfacies andesíticas y de andesitas basálticas no se desarrolla de manera penetrativa (fig. 4.12 y 4.13). Exceptuando las zonas de fracturas, en 
donde se pueden presentar de manera avanzada, los grados de alteración van de débiles a moderados, destacándose la alteración clorítica-sericítica, la alteración potásica y la carbonatación (Gifkins, 2005). A su vez se han encontrado estructuras de disolución y de disolución y reemplazo por argilominerales y sílice. 
Unidad de acumulación: diques

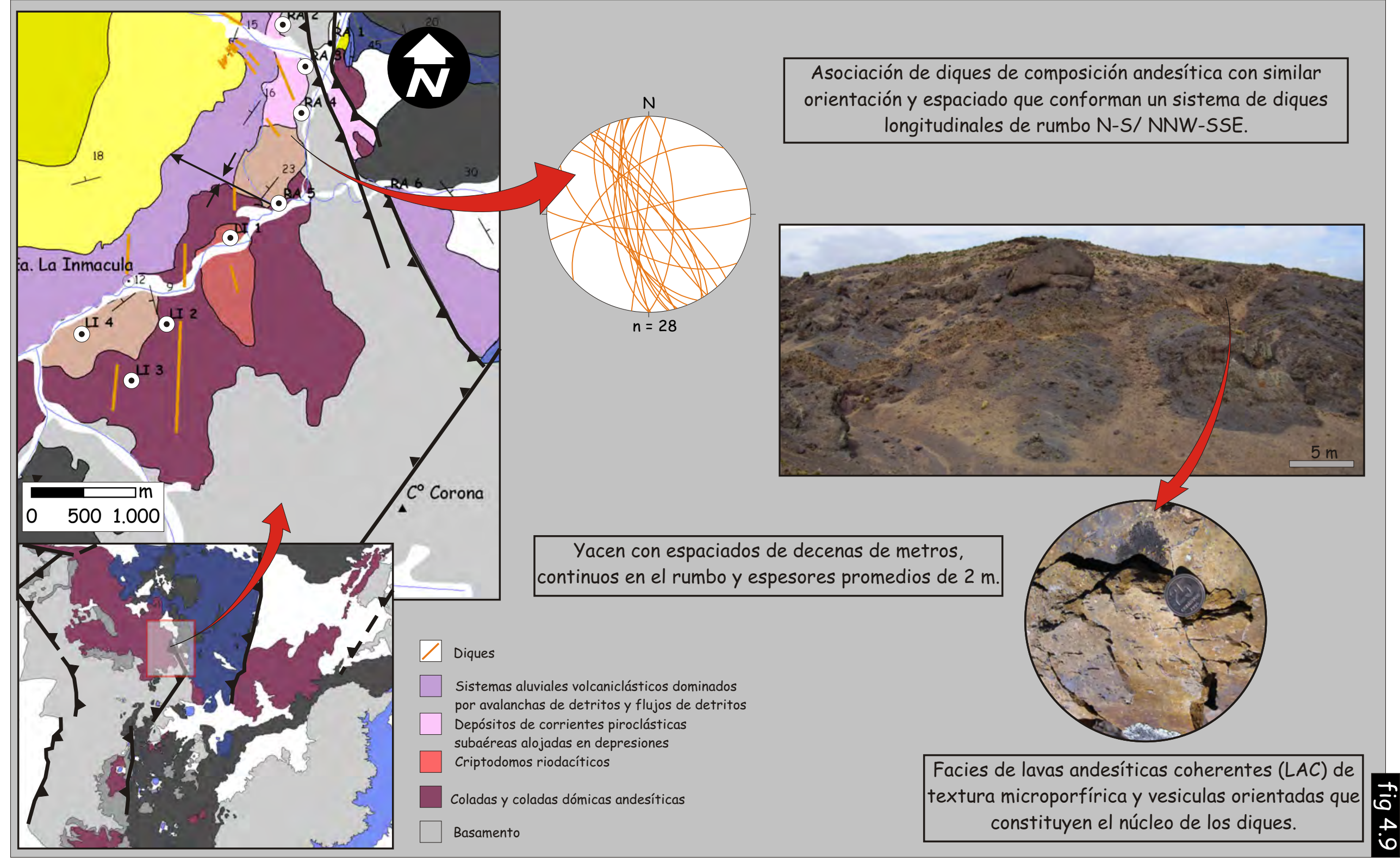

Figura 4.9. Unidad de acumulación de diques. 
Unidad de acumulación: diques
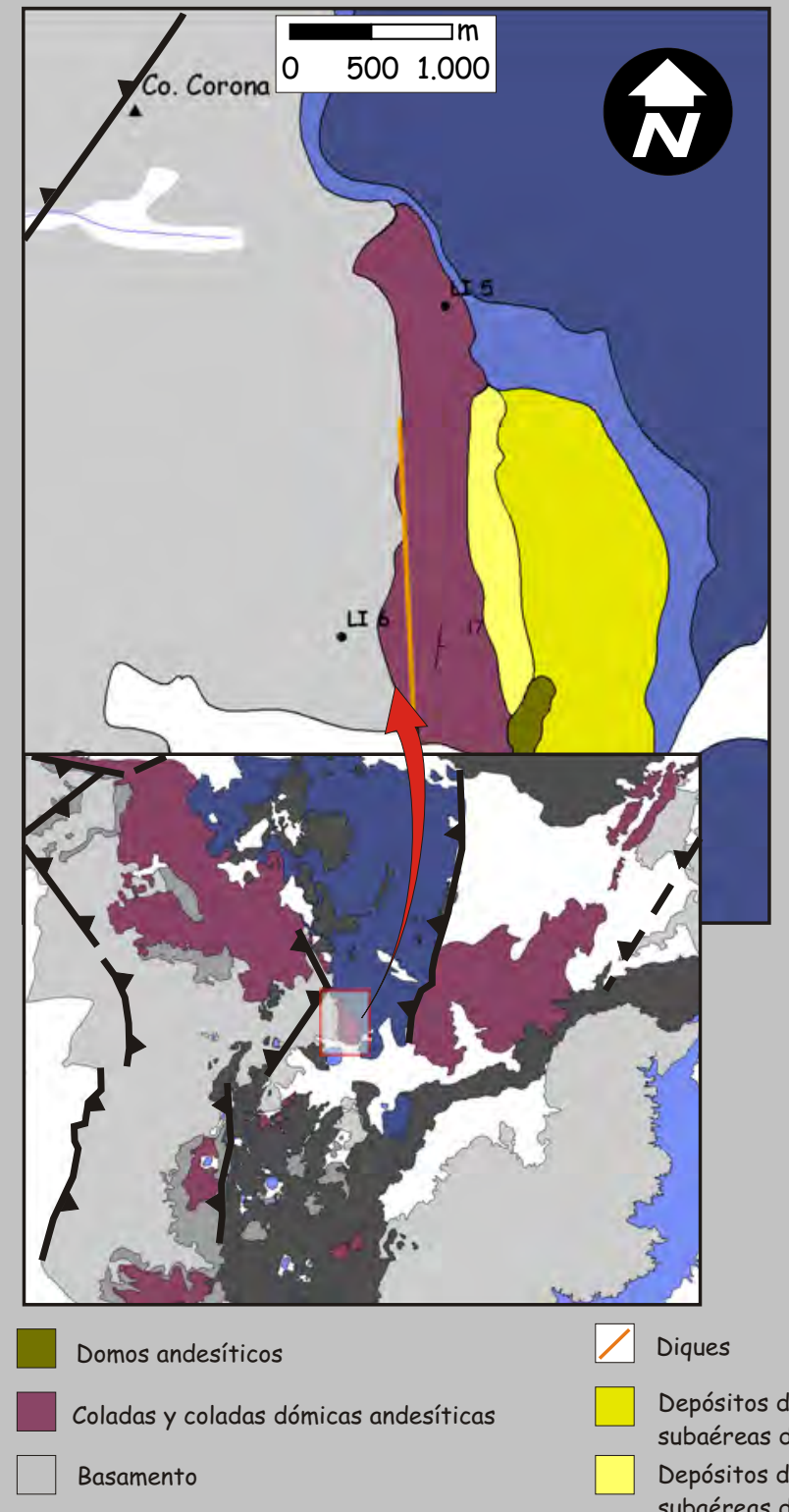

$\triangle$ Diques

Depósitos de corrientes piroclásticas subaéreas de gran distribución areal II

$\square$ Depósitos de corrientes piroclásticas subaéreas de gran distribución areal I
Dique andesítico de rumbo N-S aflorante al SE del Cerro Corona. Se presenta subvertical, segmentado en el rumbo, de $1800 \mathrm{~m}$ de largo y $56 \mathrm{~m}$ de espesor.
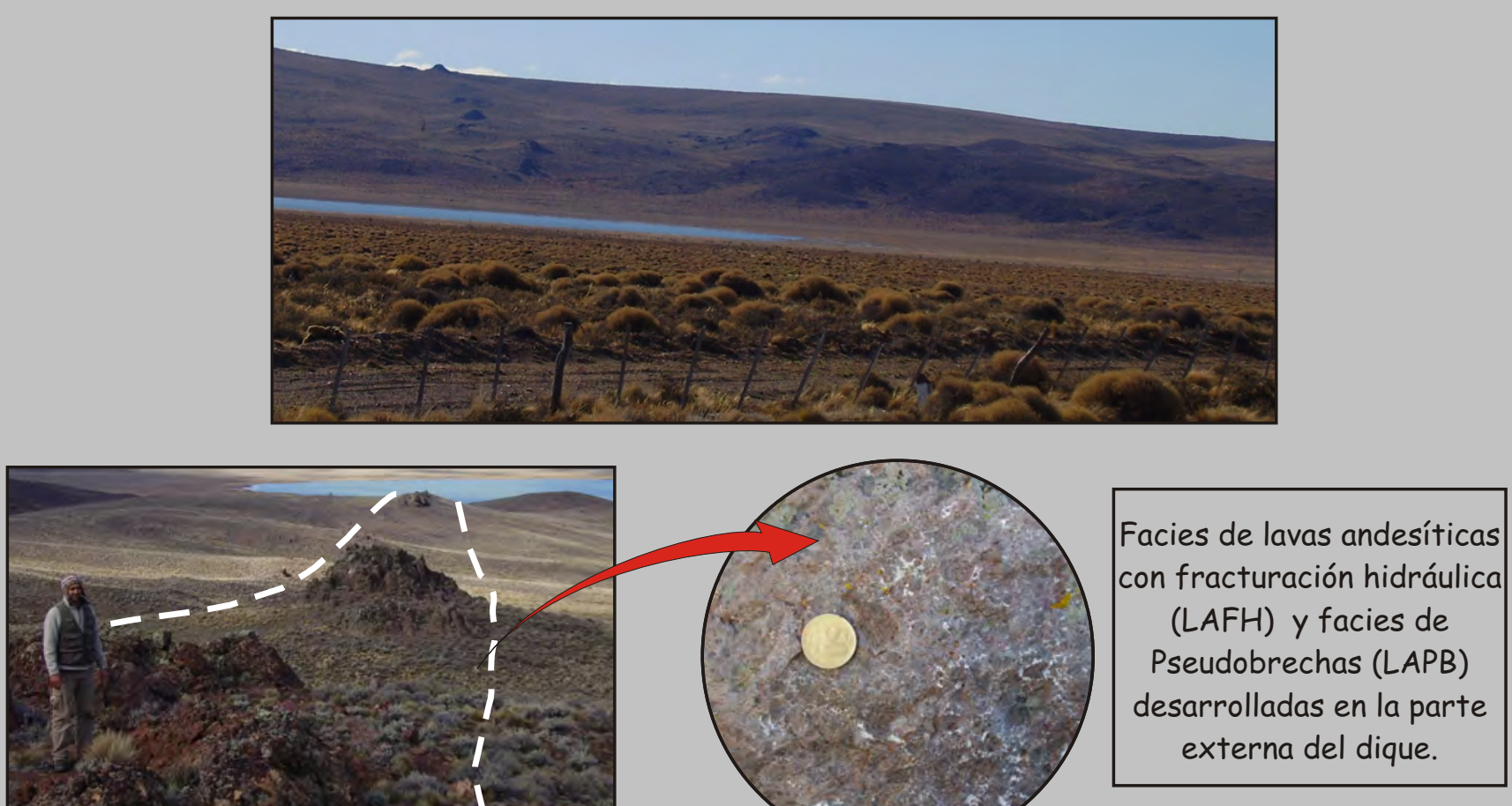
externa del dique.

Figura 4.10. Unidad de acumulación de diques. 
Clasificación y petrografía de las unidades de acumulación de rocas volcánicas andesíticas
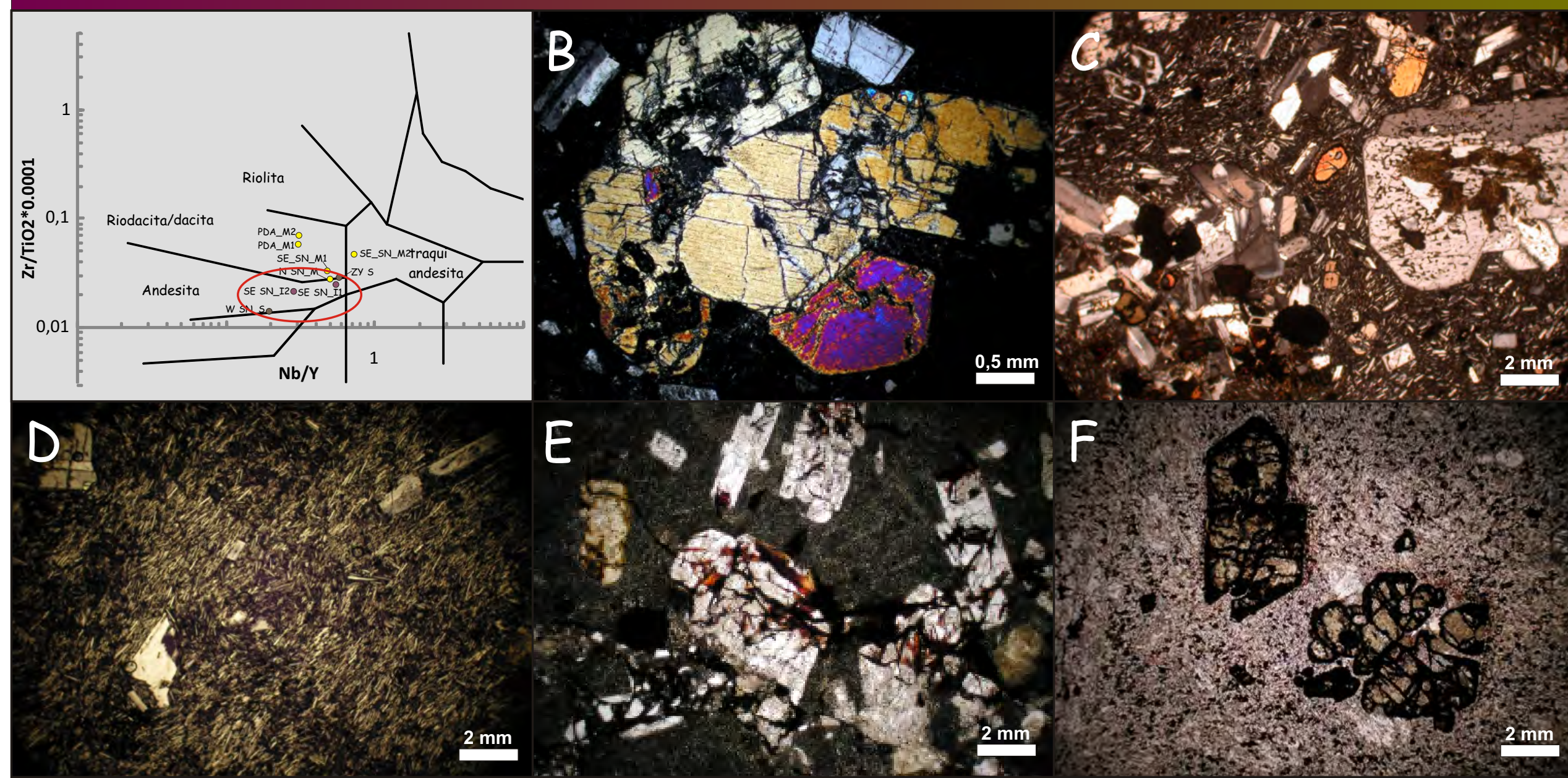

Figura 4.11. Microfacies de rocas volcánicas andesíticas (RVA). A) Diagrama de clasificación de Winchester y Floyd (1977). B) Textura glomeroporfírica integrada por Cpx. C) Textura seriada con cumulatos dioríticos. D) Pasta con textura pilotáxica. E) Textura vitrofírica con fenocristales fracturados por shock térmico. F) Pseudomorfos de Ol en andesitas basálticas. 
Clasificación y petrografía de las unidades de acumulación de rocas volcánicas andesíticas

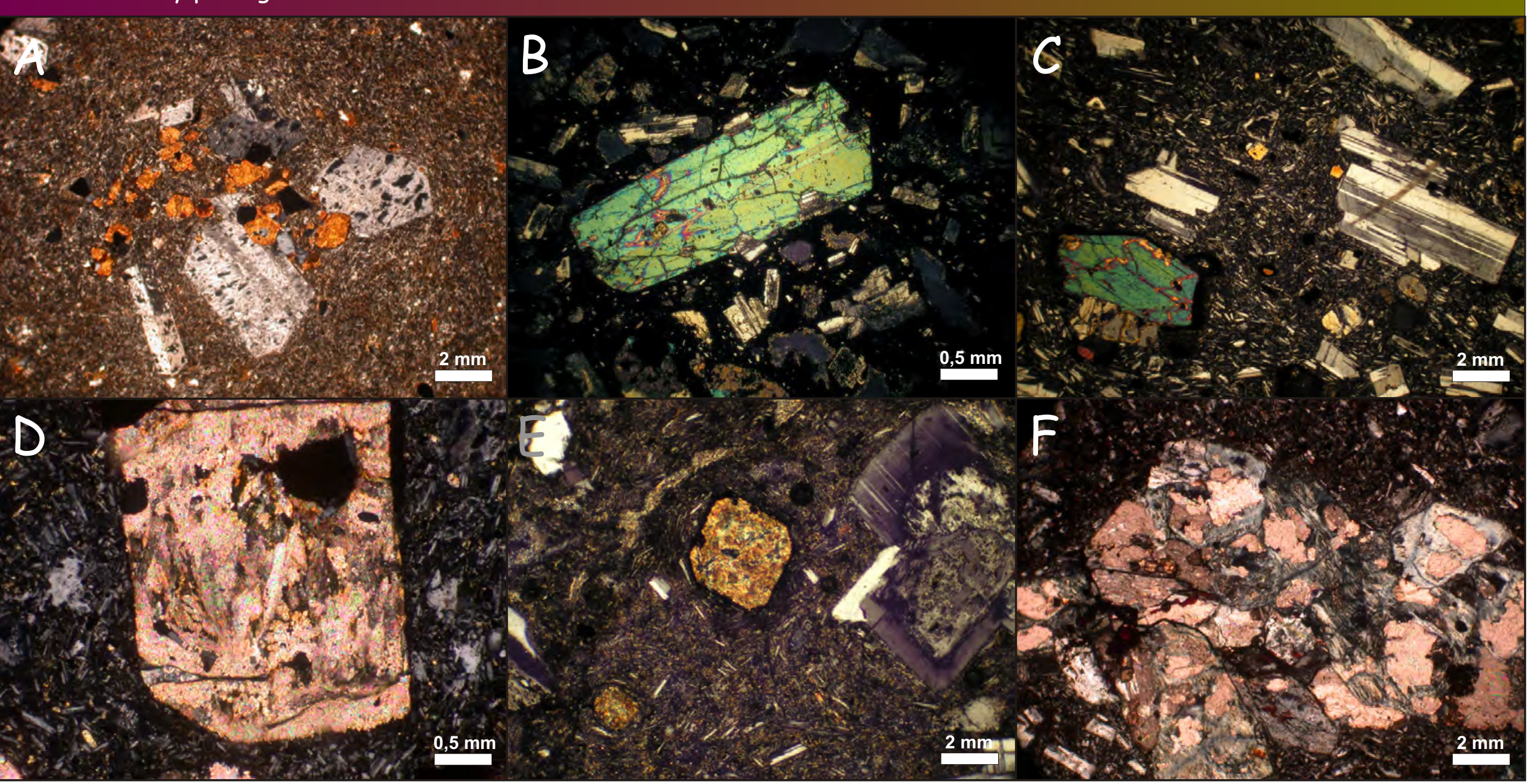

Figura 4.12. Microfacies de rocas volcánicas andesíticas (RVA). A) Textura glomeroporfírica integrada por Pg y Hbl. B) Fenocristal de Cpx. C) Textura porfírica con fenocristales de Pg y Hbl con reborde de opacos. D) Fenocristal de Pg totalmente alterado a agregados de carbonato y epidoto. E) Pseudomorfos de Px alterado a cloritas. F) Alteración por carbonatación. 
Clasificación y petrografía de las unidades de acumulación de rocas volcánicas andesíticas

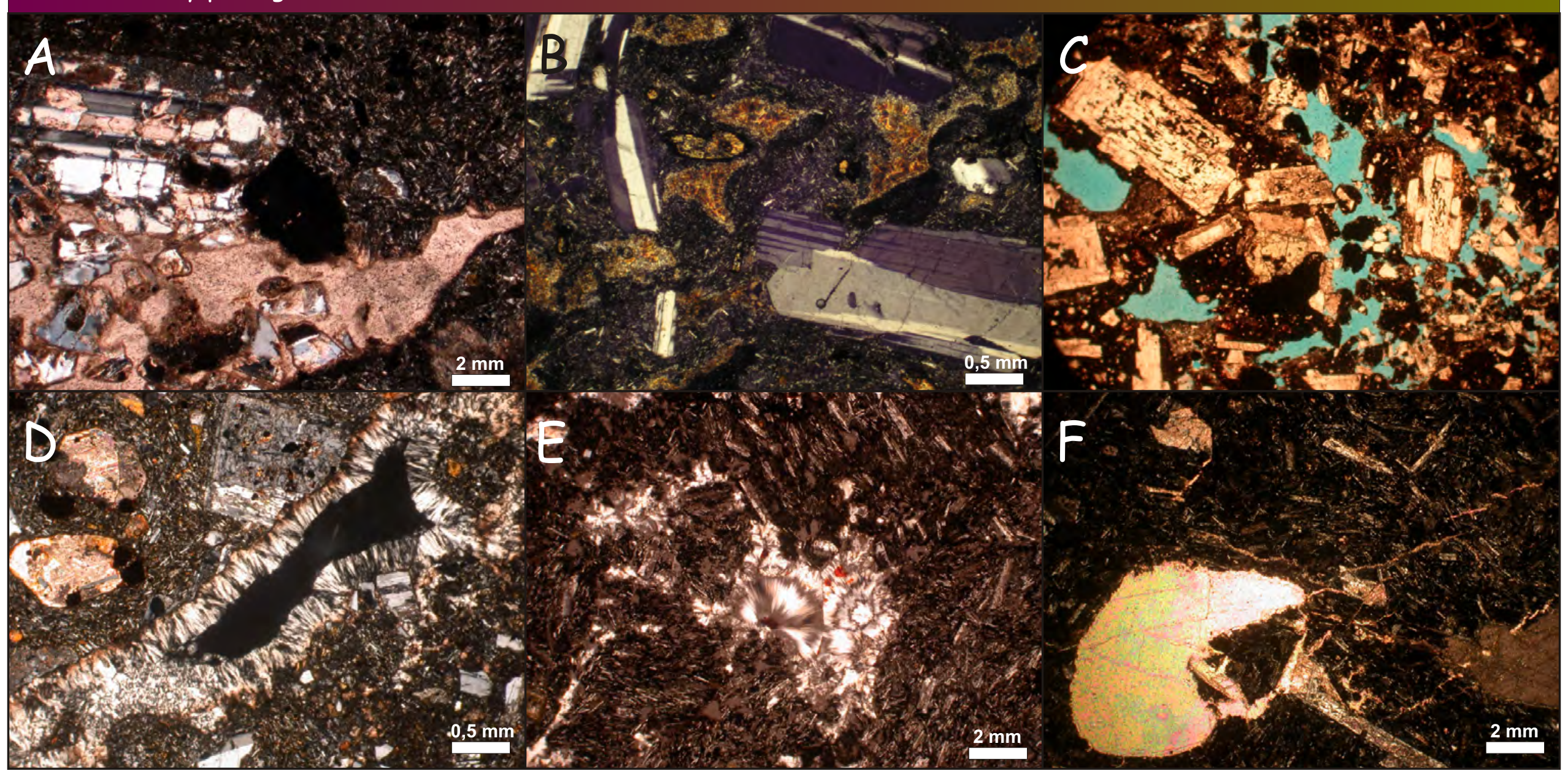

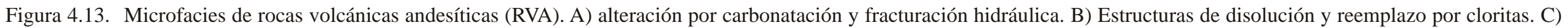
Estructuras de disolución. D y E) estructuras de disolución y reemplazo por sílice. F) Amígdalas de carbonato de calcio. 


\subsubsection{Unidad de acumulación de conducto alimentador}

Esta unidad de acumulación se halla representada sólo por un cuerpo intrusivo que aflora en el área de Sañicó al norte del Cerro los Muleros y al este del Cerro Michal (fig. 4.14). Se muestra como una entidad de geometría subcircular de aproximadamente $100 \mathrm{~m}$ de diámetro que corta de manera vertical a las rocas precuyanas previamente formadas (fig. 4.14). Se presenta con un arreglo simple, constituida por facies de lavas dacíticas coherentes (LDC) (fig. 3.1). Se destacan fracturas verticales que en planta delimitan bloques con formas poliédricas, interpretadas como estructuras de disyunción columnar originadas durante el enfriamiento (Mc Phie et al., 1993; Best y Christiansen, 2000). Se encuentra constituida por microfacies de rocas volcánicas dacíticas (RVD) con variaciones entre una textura porfírica a seriada. Se caracteriza por presentar abundantes fenocristales de plagioclasa y hornblenda, los cuales pueden llegar a constituir el 45\% del volumen de la roca. Al igual que en las microfacies de lavas andesíticas, los cristales de hornblenda manteados por minerales opacos sugieren un ascenso lento del magma del orden de los m/d (Best y Christiansen, 2000; Rutherford y Gardner, 2000). Esta idea está soportada por la abundante cantidad de fenocristales, la cual está cercana al límite que presentan los magmas para poder fluir (Llambías, 2008). La yacencia discordante y la forma subcircular, conjuntamente con las texturas desarrolladas, indican que esta unidad se formó por el taponamiento (plug) de un conducto magmático superficial de primer orden, el cual posiblemente alimentó un aparto volcánico de grandes dimensiones (Best y Christiansen, 2000; Marsh, 2000). 
Unidad de acumulación: conductos volcánicos

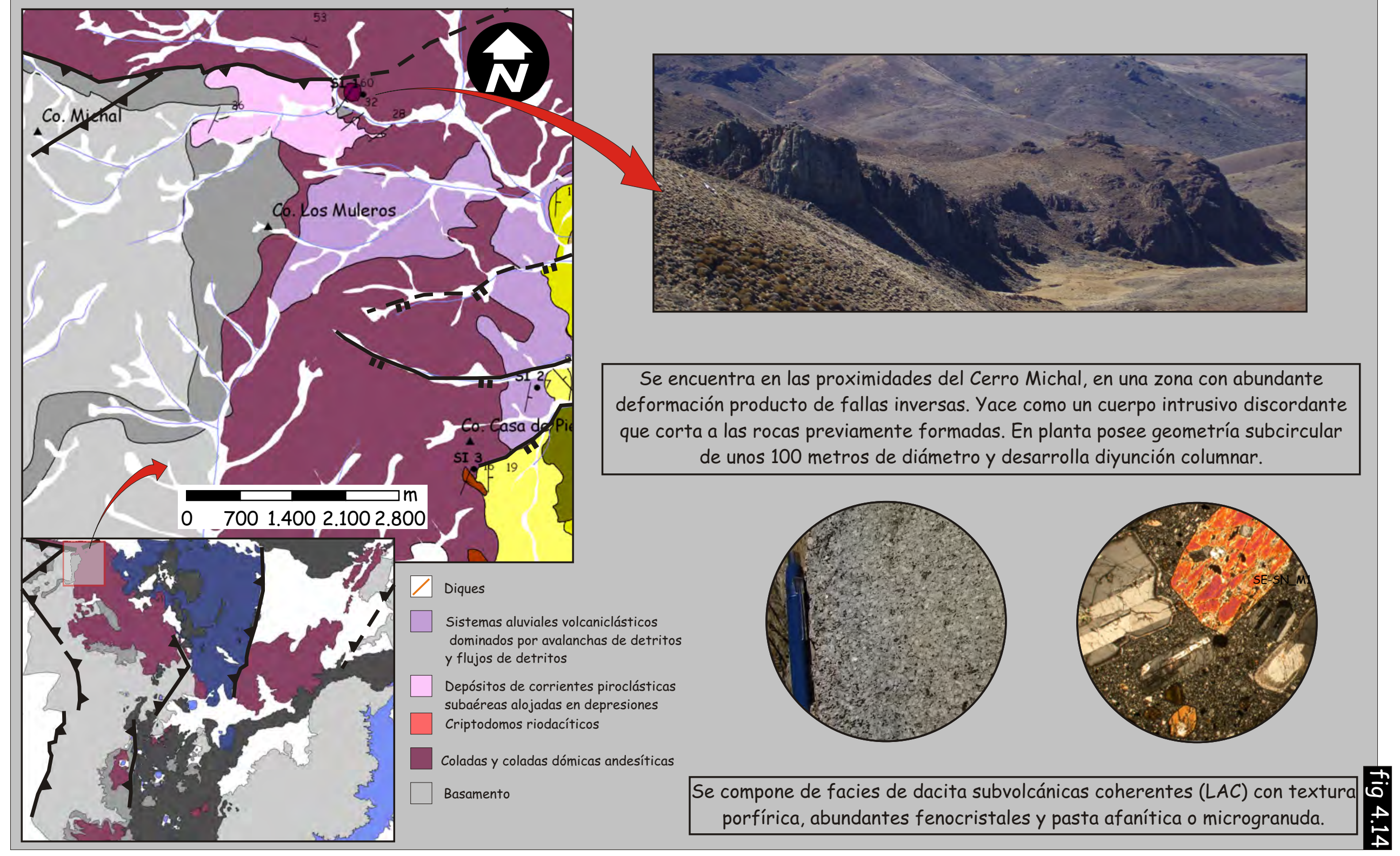

Figura 4.14. Unidad de acumulación de conductos alimentadores. 


\subsubsection{Unidades de acumulación de rocas volcánicas ácidas}

Bajo este denominativo se agruparon unidades de acumulación volcánicas con composiciones riodacíticas y riolíticas (fig. 4.15 y 4.16). Estas unidades no se encuentran ampliamente distribuidas en sentido lateral y vertical dentro del relleno precuyano. Su aparición es puntual como cuerpos intrusivos o efusivos de escaso volumen en la parte media del Ciclo Precuyano. Una característica sobresaliente es que en la mayoría de los casos se hallan afectadas por una silicificación penetrativa y avanzada, asociada con venas de sílice.

\subsubsection{Criptodomos riodacíticos}

Se presentan en planta como cuerpos de geometría elíptica y en perfil de geometría dómica, con espesores que rondan los $60 \mathrm{~m}$ (fig. 4.15). Sus contactos laterales se exhiben con formas rectas, generalmente mal aflorados, sin mostrar características diagnósticas. Se compone de facies de lavas riodacíticas coherentes con estructura foliada (LRCf) (fig. 3.1) y texturas porfíricas. Internamente la estructura foliada se encontró de manera oblicua a los bordes y de manera vertical en las partes centrales del cuerpo. Desde el punto de vista petrográfico se presenta con microfacies de rocas volcánicas riodacíticas (RVR) (fig. 3.1). Las texturas porfíricas se desarrollan con pastas afaníticas criptocristalinas en los bordes del cuerpos a microcristalinas en el centro.

La relación con las rocas que contienen esta unidad y el arreglo de facies presentes reflejan una yacencia intrusiva somera (Mc Phie et al., 1993), mientras que el predominio de lavas coherentes no hubiera sido esperable si la roca de caja se hubiese encontrado húmeda (Stewart et al., 2003).

\subsubsection{Coladas dómicas riodacíticas}

Se presenta con expresión lateral de escasas centenas de metros y espesores que no superan los $50 \mathrm{~m}$. Su parte superior se expone con geometría dómica o irregular (fig. 4.16). Se compone de un arreglo simple de facies de lavas riolíticas coherentes (LRC) y por microfacies de rocas volcánicas riodacíticas (RVR). Presentan una textura porfírica constituida por fenocristales escasos y pequeños de cuarzo y feldespato, inmersos en una pasta micropoiquilítica resultado de la recristalización a alta temperatura de material vítreo (Mc Phie et al., 1993). A su vez, la pasta se encuentra silicificada de manera penetrativa acompañada por venas de sílice y estructuras de disolución y de disolución y reemplazo que indican la circulación de fluidos a alta temperatura. Las características vítricas de la pasta estarían fomentadas por la composición de la presente unidad.

La pobre calidad con que afloran los cuerpos que componen esta unidad, sumado a la intensa silicificación, no permiten avanzar demasiado en la interpretación. Una característica sobresaliente es que estas unidades yacen en todos los casos por sobre las unidades piroclásticas 
de mayor extensión areal. La similitud composicional y la posición en la secuencia hacen que ésta puede estar emparentada con las unidades piroclásticas (Best y Christiansen, 2000; Németh y Ulrike, 2007). 


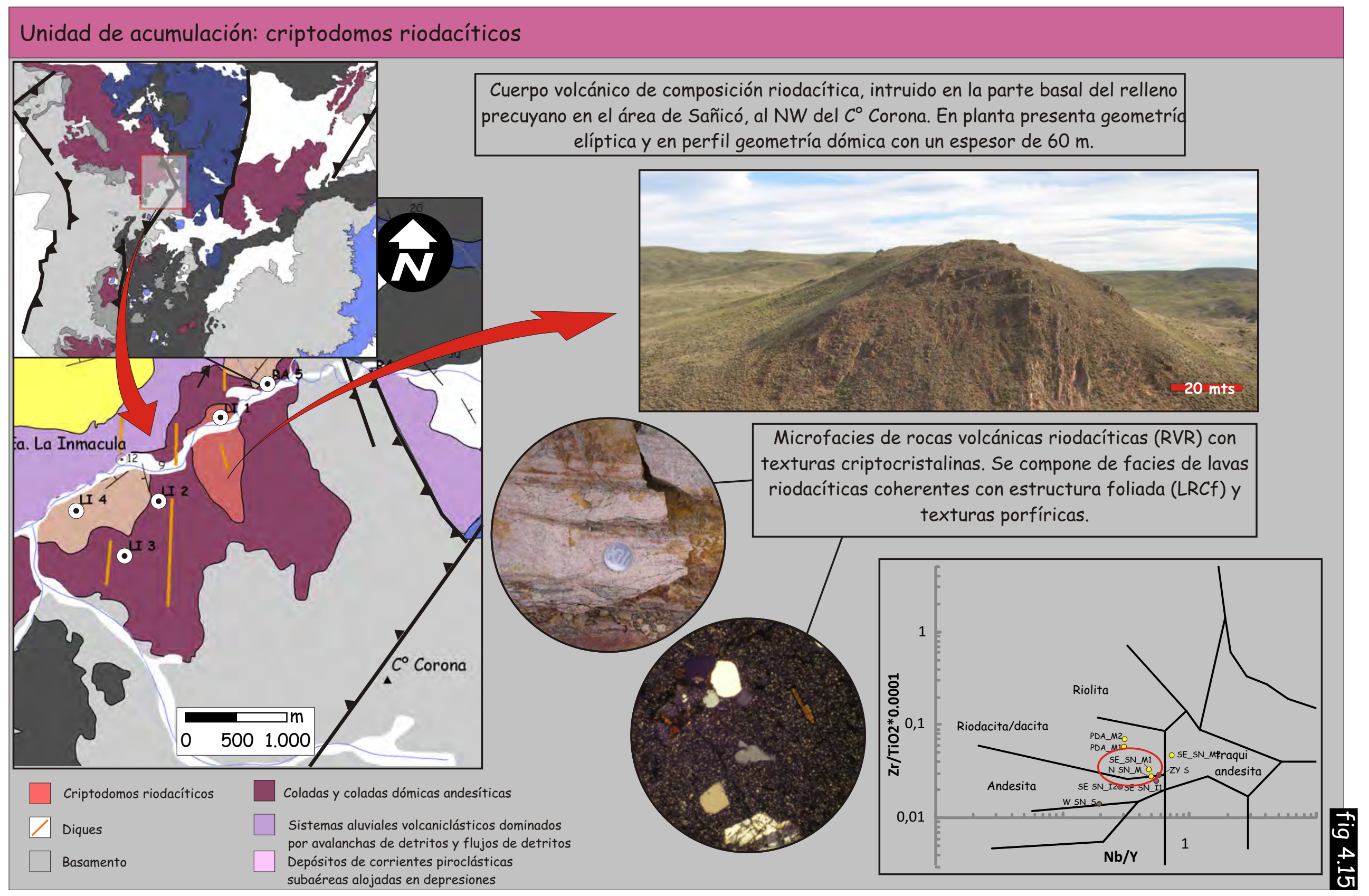

Figura 4.15. Unidad de acumulación de criptodomos riolíticos. 


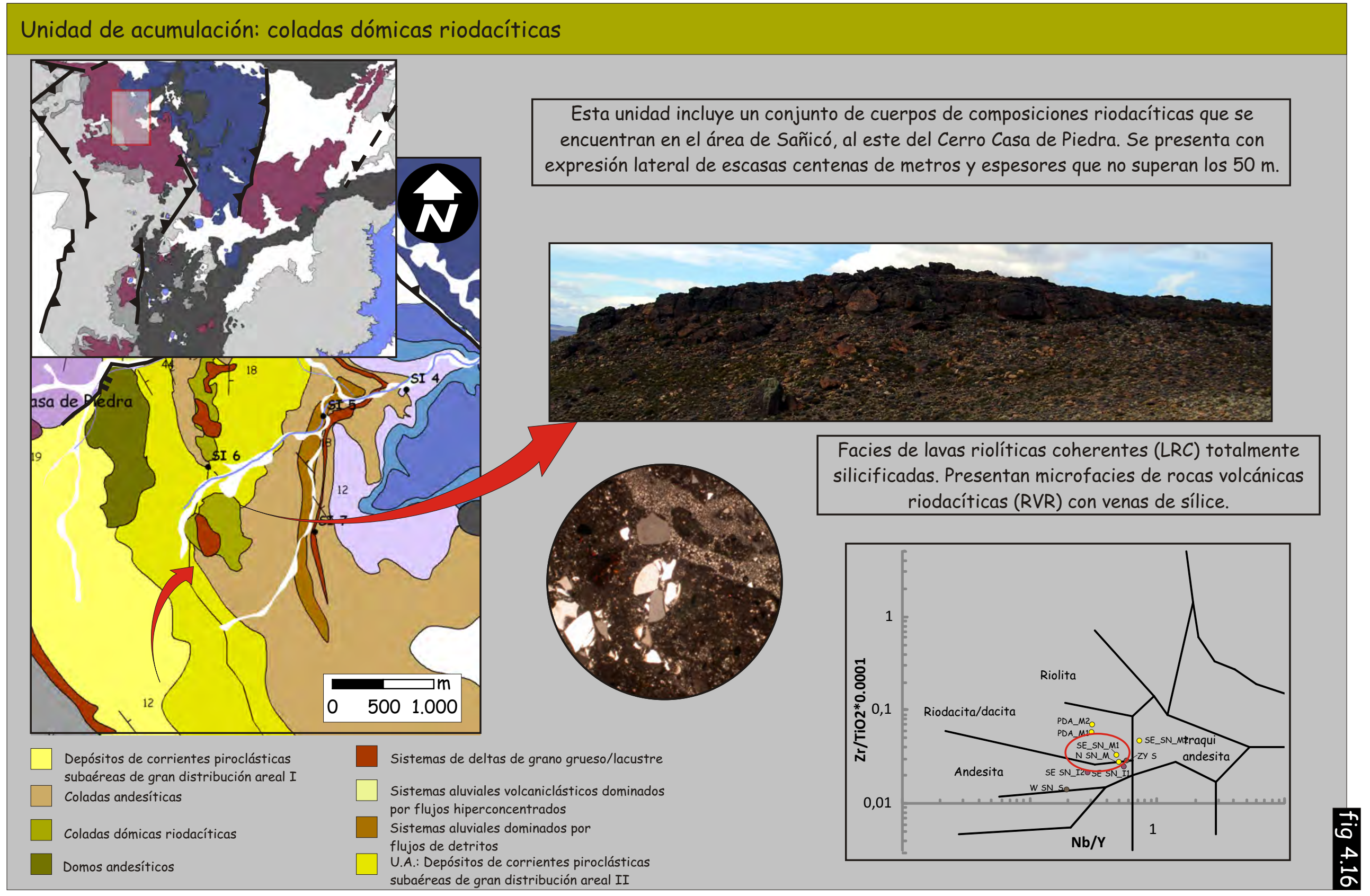

Figura 4.16. Unidad de acumulación de coladas dómicas riolíticas. 


\subsection{Unidades de acumulación piroclásticas}

Bajo esta designación se han agrupado a todos los depósitos constituidos de materiales piroclásticos resultado de erupciones explosivas (Cas y Wright, 1987; Mc Phie et al., 1993; White y Houghton, 2006). Las unidades de acumulación que se desarrollarán a continuación se originaron a partir de la depositación de materiales desde corrientes piroclásticas. Históricamente las corrientes de densidad piroclásticas formadoras de ignimbritas han sido modeladas como flujos granulares (grainflows), flujos semi-fluidizados (semi-fluidized flows), corrientes de turbidez de baja densidad y flujos laminares (plug laminar flows) (Branney y Kokelaar, 2002 y las referencias allí citadas). Sin embargo, aunque la simplificación es necesaria para la realización de los modelos, asumir un solo mecanismo de soporte o propiedades teóricas de las corrientes no es apropiado. Para considerar la sedimentación de una corriente de densidad piroclástica se debe tener en cuenta que las mismas presentan diferentes mecanismos de transporte, son muy heterogéneas en el espacio y tiempo y que sólo registran los procesos acaecidos en la parte inferior del flujo, definido como la superficie entre el flujo y el sustrato donde ocurre la segregación y la depositación variable de las partículas (Branney y Kokelaar, 2002).

Es importante destacar que las unidades de acumulación piroclástica presentan composiciones y asociaciones de facies semejantes. Entre las características que permitieron su denominación se encuentran el ambiente depositacional (subaéreas/ subácueas), el arreglo de las facies, el volumen y los procesos postdepositacionales (fig. 4.17). Debido a que los depósitos de corrientes piroclásticas subácueos y subaéreos pueden presentarse con litofacies similares, éstos se han diferenciado por las asociaciones de facies de las rocas infra/suprayacentes, y de presentarse, por la existencia de fósiles.

4.5.1 Unidad de acumulación de depósitos de corrientes piroclásticas subaéreas alojadas en depresiones

Esta unidad se compone de cuerpos de geometría suavemente lenticular, con dimensiones variables de hasta $1000 \mathrm{~m}$ de ancho y $100 \mathrm{~m}$ de espesor (fig. 4.18). Se halla bien desarrollada en la parte inferior del Ciclo Precuyano y minoritariamente en la parte superior. Se encuentra constituida por arreglos de facies simples (facies de tobas lapillíticas masivas (mLT)) o complejos (tobas lapillíticas masivas -con o sin orientación de clastos- (mLT y mLTf), tobas lapillíticas con estratificación difusa (dbLT), brechas líticas masivas (mlBr) y tobas con estructuras entrecruzadas (xsT)) (fig. 3.1). Respecto a las microfacies, esta unidad está generalmente constituida por ignimbritas con alteración sericítica-argílica (IgnSA) y minoritariamente por ignimbritas silicificadas (IgnS). 
A grandes rasgos las asociaciones de facies indican que esta unidad se generó por depósitos de corrientes piroclásticas con partes basales concentradas (fig. 3.1) (Branney y Kokelaar, 2002). Exceptuando la variación de esta unidad conformada por la agradación de facies masivas generadas en condiciones cuasi-estables (Branney y Kokelaar, 2002), el arreglo multifacial de esta unidad (fig. 4.19) indica la depositación a partir de corrientes inestables que pasaron por periodos cuasi-estables (Branney y Kokelaar, 2002; Brown et al., 2007). En perfil vertical se puede apreciar la agradación compleja, donde se registra aceleración-desaceleración de la corriente (fig. 4.19). Las inestabilidades mayores se reconocen a través de los cambios abruptos en las condiciones depositacionales (límites erosivos y depositación de facies mlBr que registran el clímax de velocidad de la corriente). Los periodos de menor inestabilidad o de cuasi-estabilidad se evidencian por los cambios graduales en el arreglo de las facies (variación con límites difusos o netos entre las facies mLT, mLTf y dbLT). En ocasiones, la transición a condiciones diluidas se muestra por el desarrollo de facies tobáceas con estructuras entrecruzadas (xsT). En sentido lateral (fig. 19) el cambio de arreglo de facies evidencia variaciones en las condiciones de los límites de flujo inferior, reflejándose la no uniformidad de las corrientes (Branney y Kokelaar, 2002; Kokelaar et al., 2007). Las características de la asociación de facies, sumadas a las dimensiones de esta unidad, permiten sugerir que la misma se produjo por el relleno de depresiones topográficas relacionadas al paisaje volcánico. Las microfacies IgnSA y IgnS (véase capítulo 3) reflejan que los materiales primarios se depositaron por debajo de la temperatura de transición del vidrio. 
Unidades de acumulación Piroclásticas

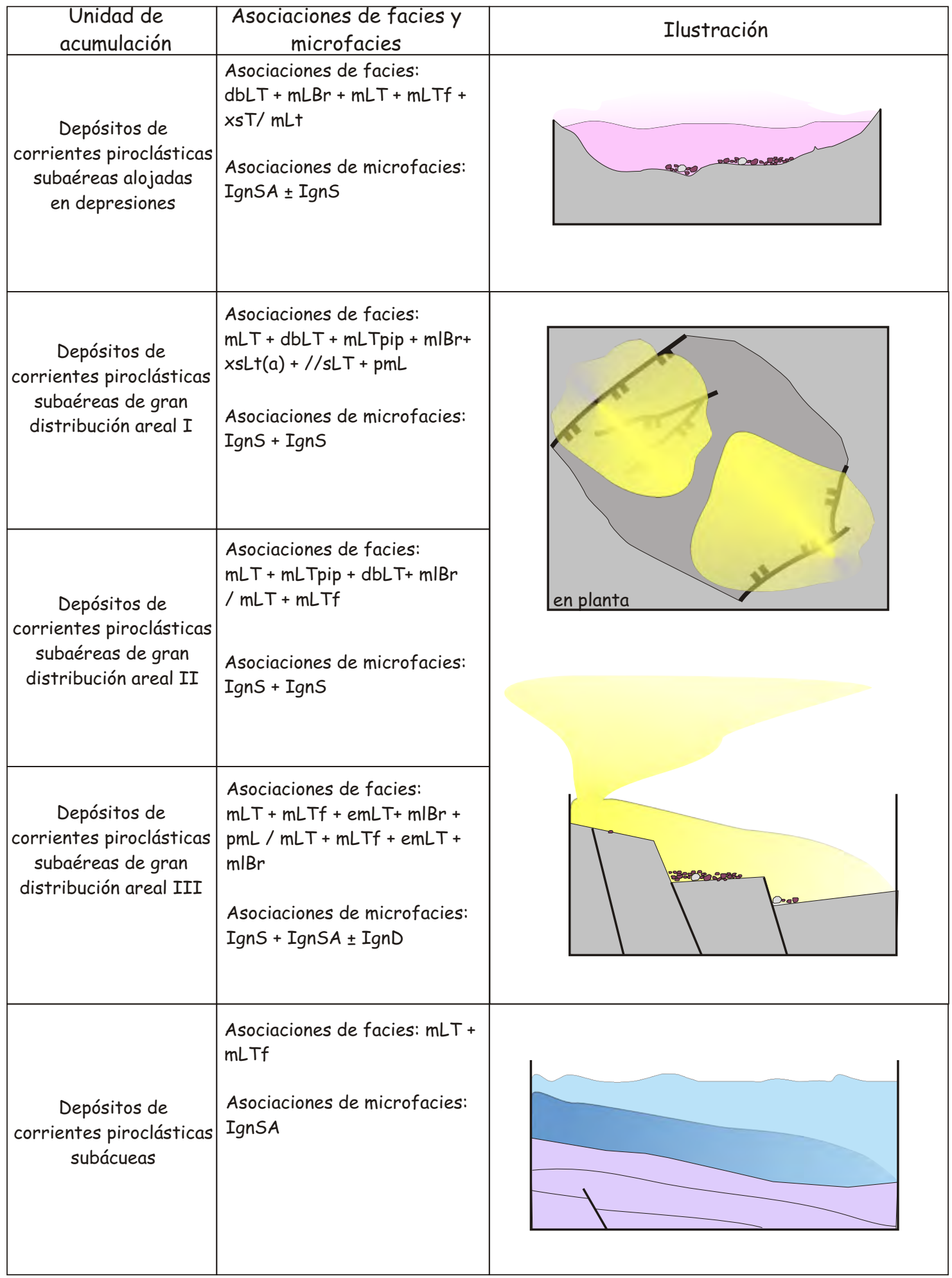

Figura 4.17. Unidades de acumulación piroclásticas distinguidas en el presente estudio. 


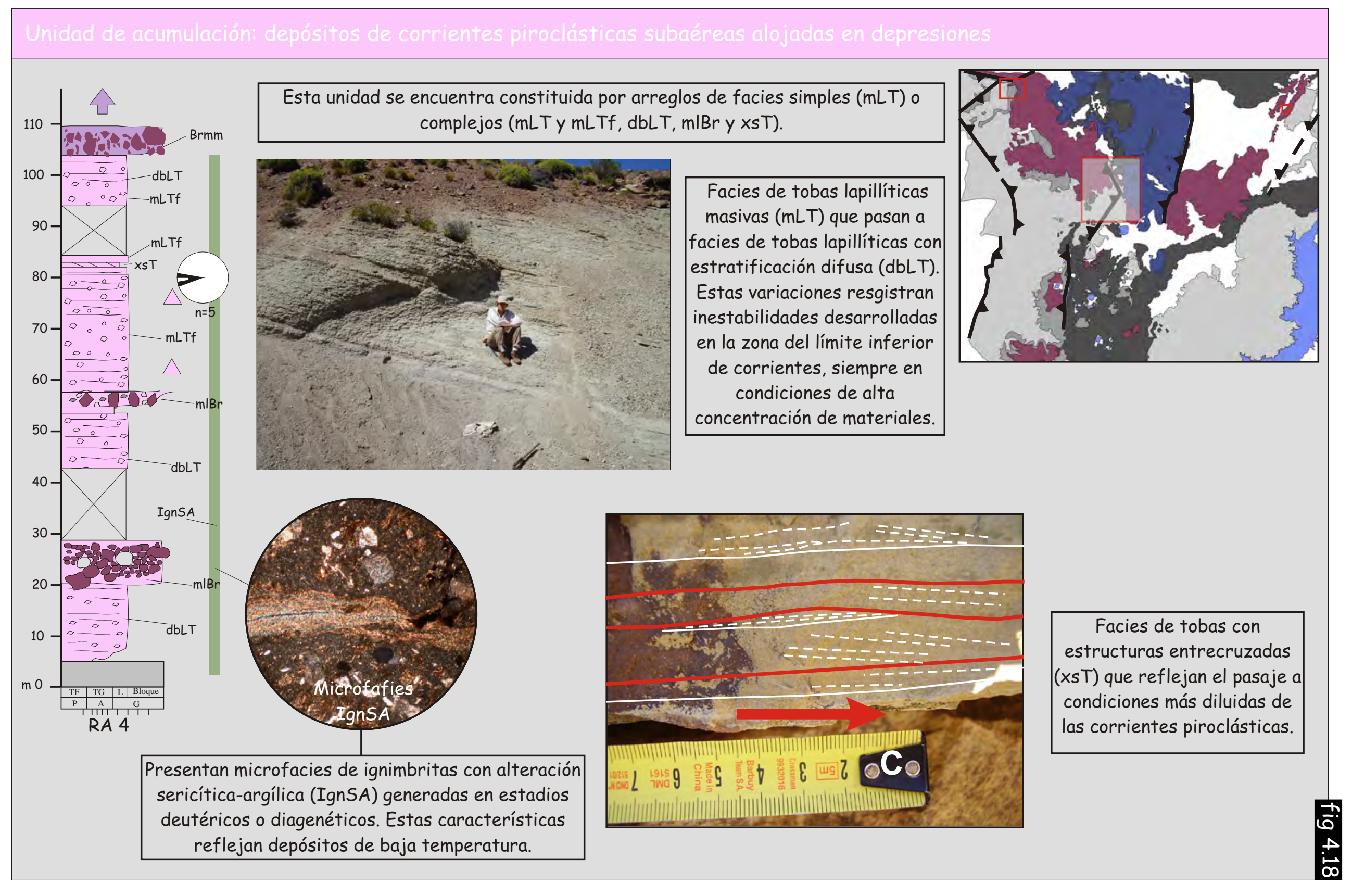

Figura 4.18. Unidad de acumulación constituida de depósitos de corrientes piroclásticas subaéreas alojadas en derpresiones. 


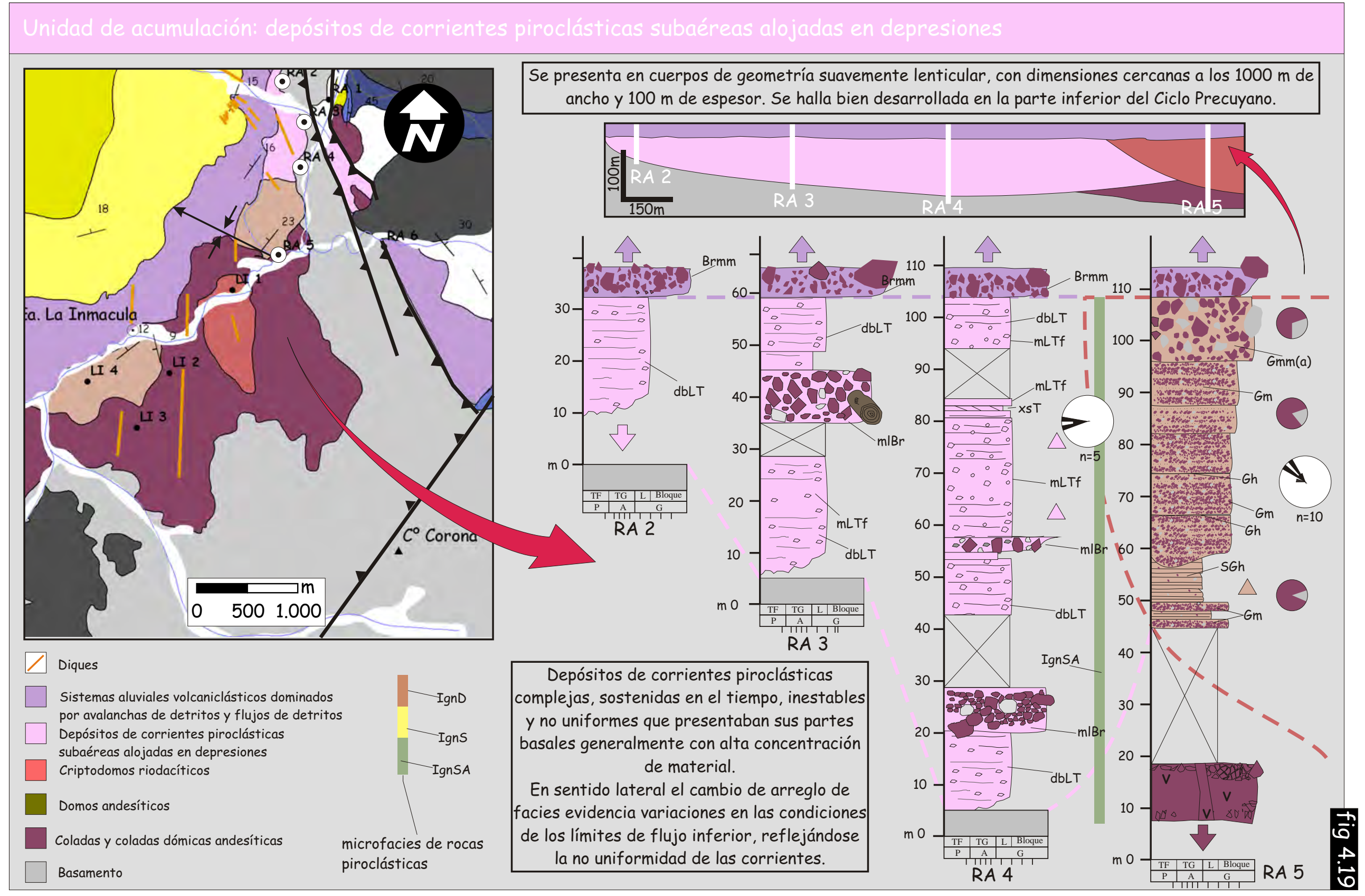

Figura 4.19. Unidad de acumulación constituida de depósitos de corrientes piroclásticas subaéreas alojadas en depresiones. 
4.5.2 Unidades de acumulación de depósitos de corrientes piroclásticas subaéreas de gran distribución areal (I, II y III)

Bajo esta denominación se integró un conjunto de unidades de acumulación caracterizadas por depósitos de corrientes piroclásticas de composición riodacítica, de gran potencia y gran distribución áreal. A grandes rasgos se apoyan tanto en concordancia como en discordancia sobre depósitos volcánicos y epiclásticos. Se presentan con geometría tabular o irregular, de cientos de metros de espesor y miles de metros de ancho (fig. 4.21, 4.23 y 4.25). Se componen por una gran variedad de facies, entre las que se destacan: tobas lapillíticas masivas con o sin orientación de clastos y/o estructura de escape de gases- (mLT, mLTf y mLTpip), tobas lapillíticas masivas con desarrollo de fiammes (emLT), tobas lapillíticas con estratificación difusa (dbLT), tobas lapillíticas con estratificación horizontal (//sLT), tobas lapillíticas con estratificación entrecruzada a diferentes escalas (xsLT(a) y xsLT(b)), brechas líticas masivas (mlBr) y lapillitas pumíceas masivas de variada selección (pmL) (fig. 3.1). Es importante destacar que en determinados sectores estas unidades desarrollan profusas estructuras de escape de gases (fig. 4.22). Con respecto a las microfacies que pueden estar presentes, se destacan las microfacies de ignimbritas con alteración sericítica-argílica (IgnSA), las microfacies de ignimbritas silicificadas (IgnS) y las microfacies de ignimbritas desvitrificadas (Ign D). En función de las asociaciones de facies y las características sindeposicionales y posdepositacionales se han identificado tres tipos diferentes de depósitos de corrientes piroclásticas de gran distribución areal: I, II y III.

Los depósitos de corrientes piroclásticas de gran distribución areal I y II presentan una distribución espacial que supera los $20 \mathrm{~km}$ y espesores que van desde metros a cientos de metros. En ocasiones los cambios de espesores se registraron de manera abrupta a ambos lados de fallas inversas o lineamientos estructurales. Estas características permitieron reinterpretar a estas estructuras como fallas extensionales que controlaron el espacio de acomodación, quedando así definida un área depocentral (fig 4.21 y 4.23). Además, es importante destacar el hallazgo de pequeñas fallas extensionales sindepositacionales en la base de la unidad piroclástica I (fig. 4.23).

Internamente estas unidades están constituidas por un conjunto de facies que reflejan una depositación a partir de corrientes piroclásticas complejas (fig. 4.21 y 4.23), dominadas en su parte inferior por alta concentración de materiales que inhibieron la turbulencia. En una columna tipo, el desarrollo vertical de facies (fig. 4.20 y fig. 4.22) sugiere corrientes altamente inestables que pasaron por cortos periodos de depositación cuasi-estables. La depositación de las unidades $\mathrm{mlBr}$ en la parte basal para la unidad I y en la parte media para la unidad II sugiere que el clímax de velocidad de las corrientes se desarrolló en diferentes etapas de su evolución (Brown et al., 2007). El arreglo de facies en sentido lateral de las unidades I y II muestra 
condiciones de depositación no uniforme. Por ejemplo, dentro del área depocentral definida para las unidades I y II, la unidad I muestra facies que pueden ser adjudicadas a posiciones proximales (pmL y mlBr) (fig. 3.1) en ambos bordes de la misma, mientras que hacia el centro se encontraron facies de tobas lapillíticas finas atribuidas a sectores distales. Estas características evidencian la no uniformidad de las corrientes y que las corrientes se originaron de diferentes canales eruptivos ubicados probablemente en las zonas de borde del depocentro. Esta aseveración es apoyada por los datos de paleocorrientes medidos en estructuras entrecruzadas y ejes de estructuras erosivas (fig. 4.20 y fig. 4.22).

Con respecto a las microfacies, las unidades I y II muestran dos tipos de arreglo vertical: 1) desarrollo de microfacies de alteración sericítica-argílica (IgnSA) en la base de los depósitos, seguida por el desarrollo de microfacies de ignimbritas silicificadas (IgnS) por alteración en fase vapor, y 2) depósitos caracterizados en su mayoría por microfacies de ignimbritas silicificadas (IgnS). La distribución vertical de las microfacies claramente denota que se trata de unidades de depósitos piroclásticos de bajo grado (Llambías, 2008) que presentan grados de soldamiento incipiente o parcial (sensu Smith, 1960), de grados II/III de soldamiento (sensu Quane y Russel, 2005).

La unidad III está integrada por un arreglo de facies más simple (fig. 4.24), siendo dominantes las facies de tobas lapillíticas masivas (mLT, mLTf y emLT). Estas condiciones reflejan depositación a partir de corrientes piroclásticas con alta concentración del material en el límite inferior (fig. 3.1), pero a diferencia de las anteriores evolucionaron generalmente en un contexto cuasi-estable, con límites de flujos dominados en un amplio espectro por condiciones de escape de fluidos y flujos granulares (Branney y Kokelaar, 2002). A diferencia de las unidades I y II, la unidad III presenta una geometría más regular (“tabular”), de cientos de metros de espesor y un largo mínimo de $10 \mathrm{~km}$ (fig. 4.25). La distribución lateral de las facies muestra condiciones más uniformes de las corrientes con respecto a las unidades anteriormente descriptas. Las características petrográficas de la unidad III muestran microfacies de ignimbritas con alteración sericítica-argílica (IgnSA), microfacies de ignimbritas silicificadas (IgnS) y en ocasiones microfacies de ignimbritas desvitrificadas a alta temperatura (IgnD). El arreglo vertical de las microfacies es también típico de ignimbritas de bajo grado (Llambías, 2008), aunque la presencia de las microfacies de ignimbritas desvitrificadas (Ign D) indica que la temperatura de las corrientes piroclásticas estaba cercana a la temperatura de transición del vidrio y que el espesor que presenta esta unidad favoreció la conservación del calor para que se desarrollen arreglos cristalinos a alta temperatura. El rango de soldamiento de estas ignimbritas va desde soldamiento incipiente o parcial (sensu Smith, 1960), de grados II/III de soldamiento (Quane y Russel, 2005) a ignimbritas densamente soldadas (Smith, 1960), de grado IV/V (Quane y Russel, 2005). 
Con todo, las unidades de acumulación de corrientes piroclásticas subaéreas de gran distribución areal (I, II y III) presentan características compartidas que evidencian similitudes en su estilo eruptivo, mecanismos de transporte y depositación y ambiente despositacional. Respecto al estilo eruptivo, los pómez pequeños y generalmente escasos, la composición de los depósitos, la morfometría de las trizas y los indicios de alta cantidad de volátiles primarios, serían evidencias de mecanismos eruptivos magmáticos eficientes que habrían originado erupciones plinianas (Fisher y Schmincke, 1987; Cas y Wright, 1987; Best y Christiansen, 2000; Németh y Ulrike, 2007; Llambías, 2008). La presencia de unidades de acumulación, generalmente por debajo de la temperatura del vidrio, y la existencia de depósitos de lapillitas pumíceas bien seleccionados que pueden ser adjudicados a depósitos de caída pliniana, sugieren que las corrientes piroclásticas se originaron a partir de columnas eruptivas de alturas considerables (Mc Arthur et al., 1998; Fisher y Schmincke, 1987; Branney y Kokelaar, 2002). Las características de los depósitos muestran eventos eruptivos continuos en el tiempo que desarrollaron corrientes piroclásticas sostenidas. 


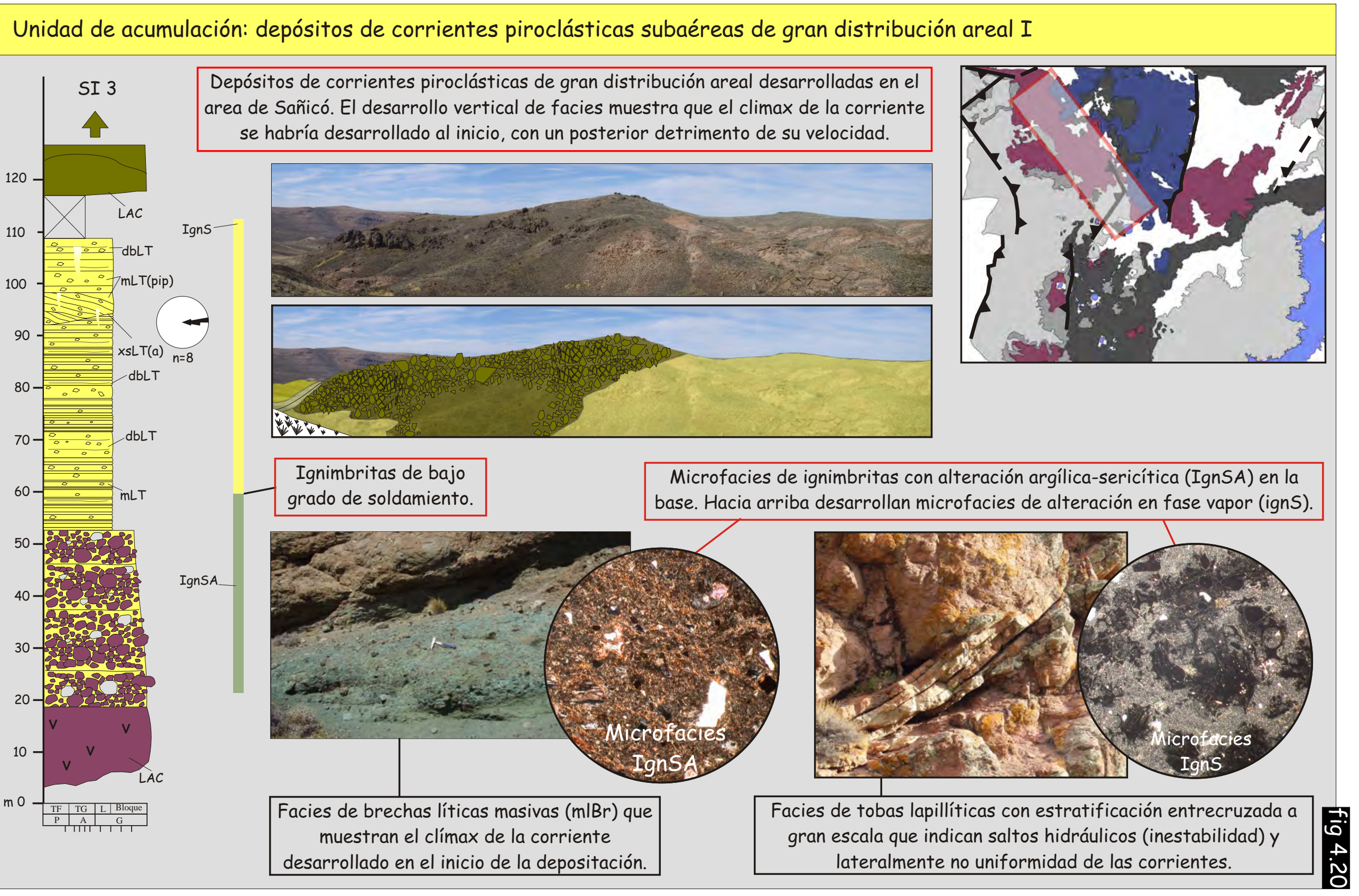

Figura 4.20. Unidad de acumulación constituida de depósitos de corrientes piroclásticas subaéreas de gran distribución areal. 


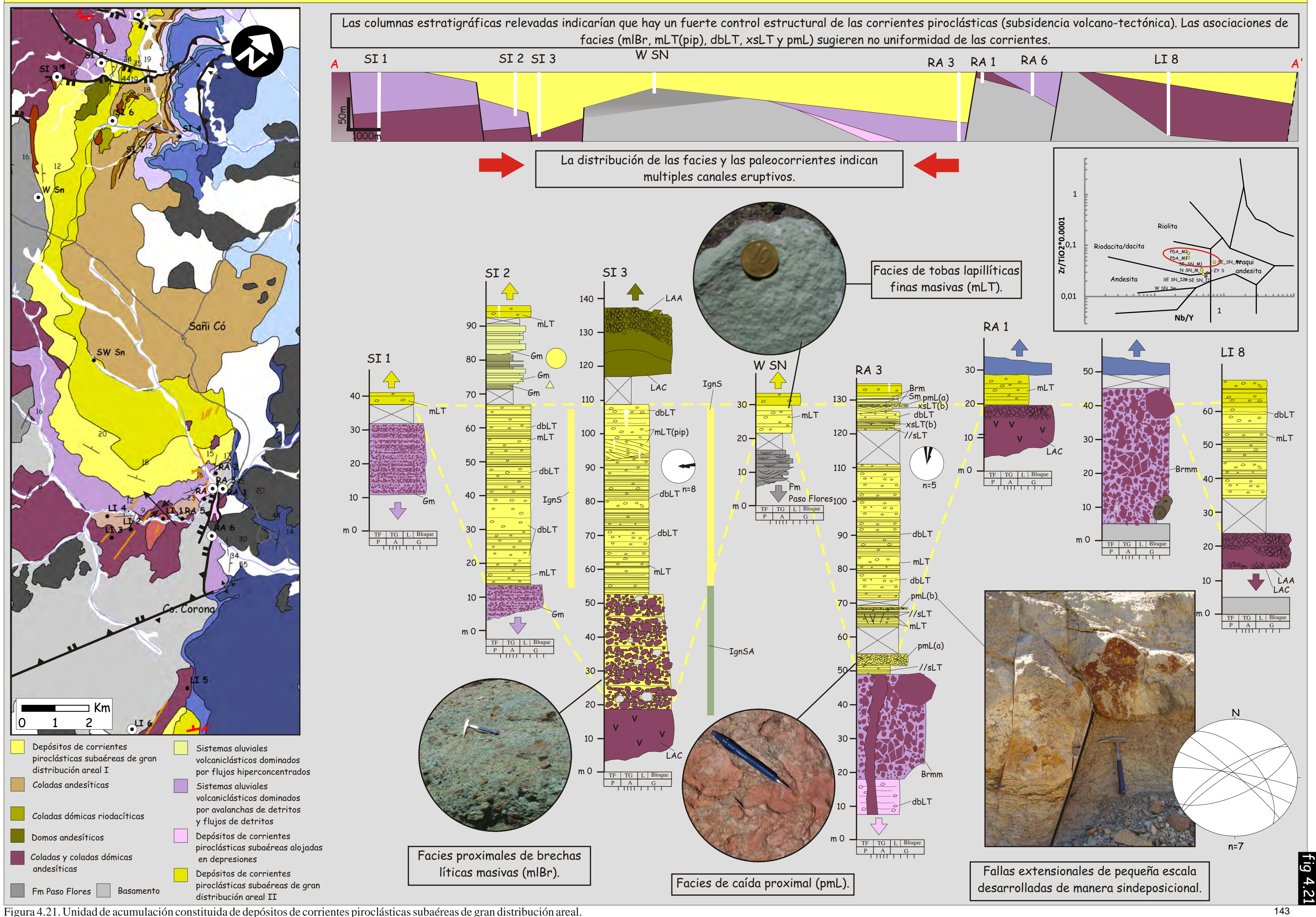


Unidad de acumulación: depósitos de corrientes piroclásticas subaéreas de gran distribución areal II

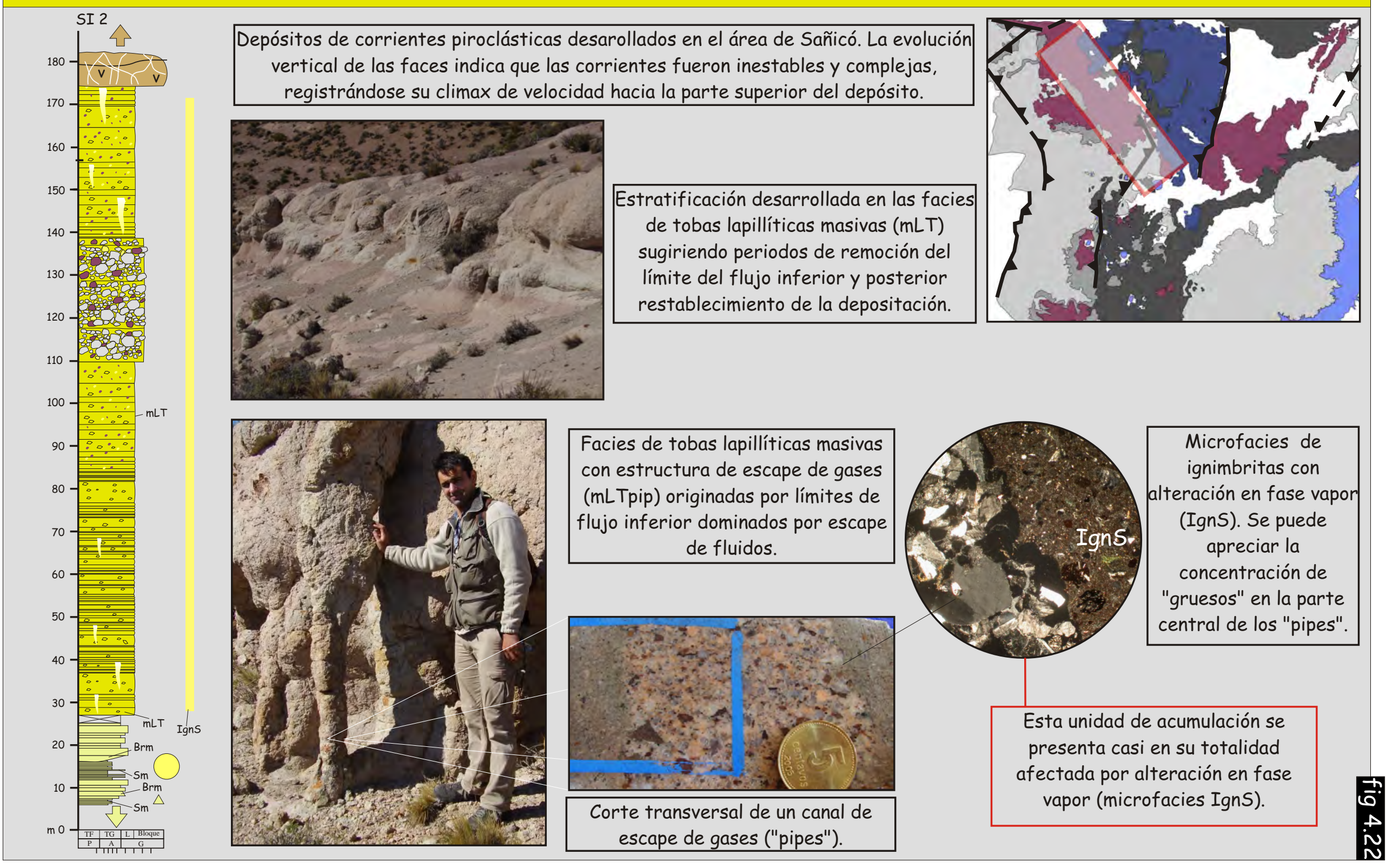

Figura 4.22. Unidad de acumulación constituida de depósitos de corrientes piroclásticas subaéreas de gran distribución areal. 


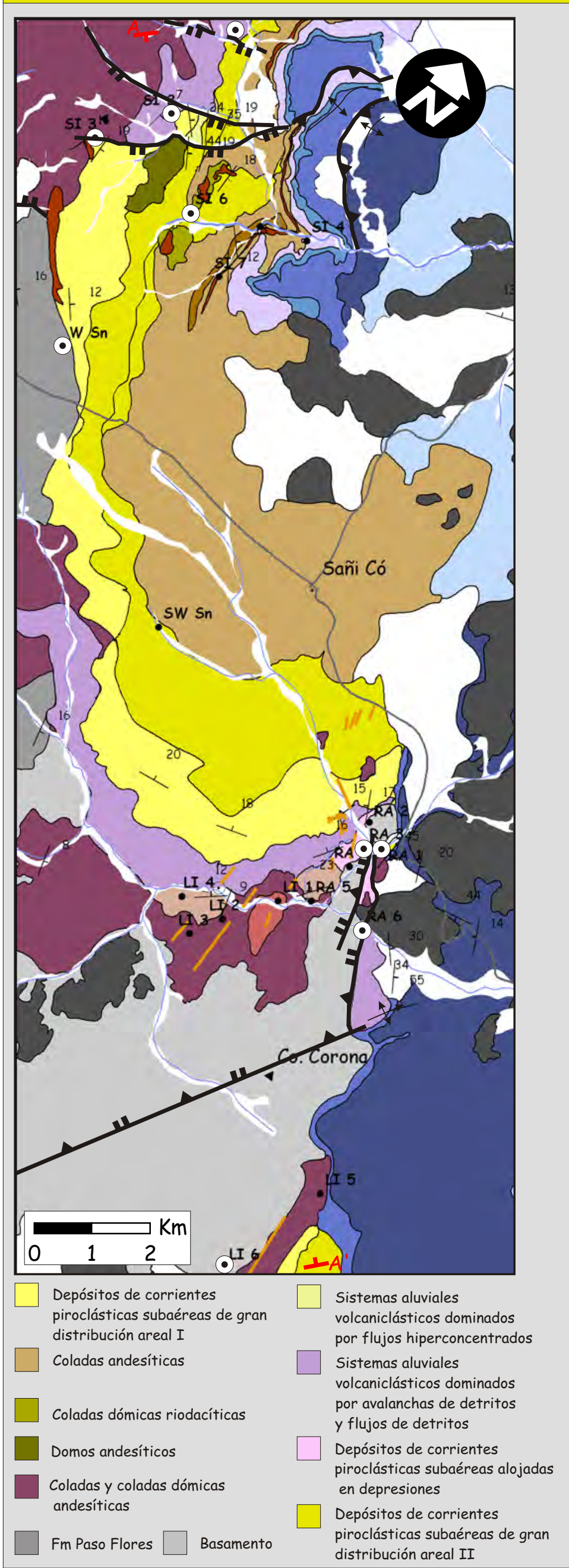

Depósitos de corrientes piroclásticas de gran distribución areal. Muestran un control volcano-tectónico por parte de las estructuras que afectaron otras unidades piroclásticas en el depocentro de Sañicó.
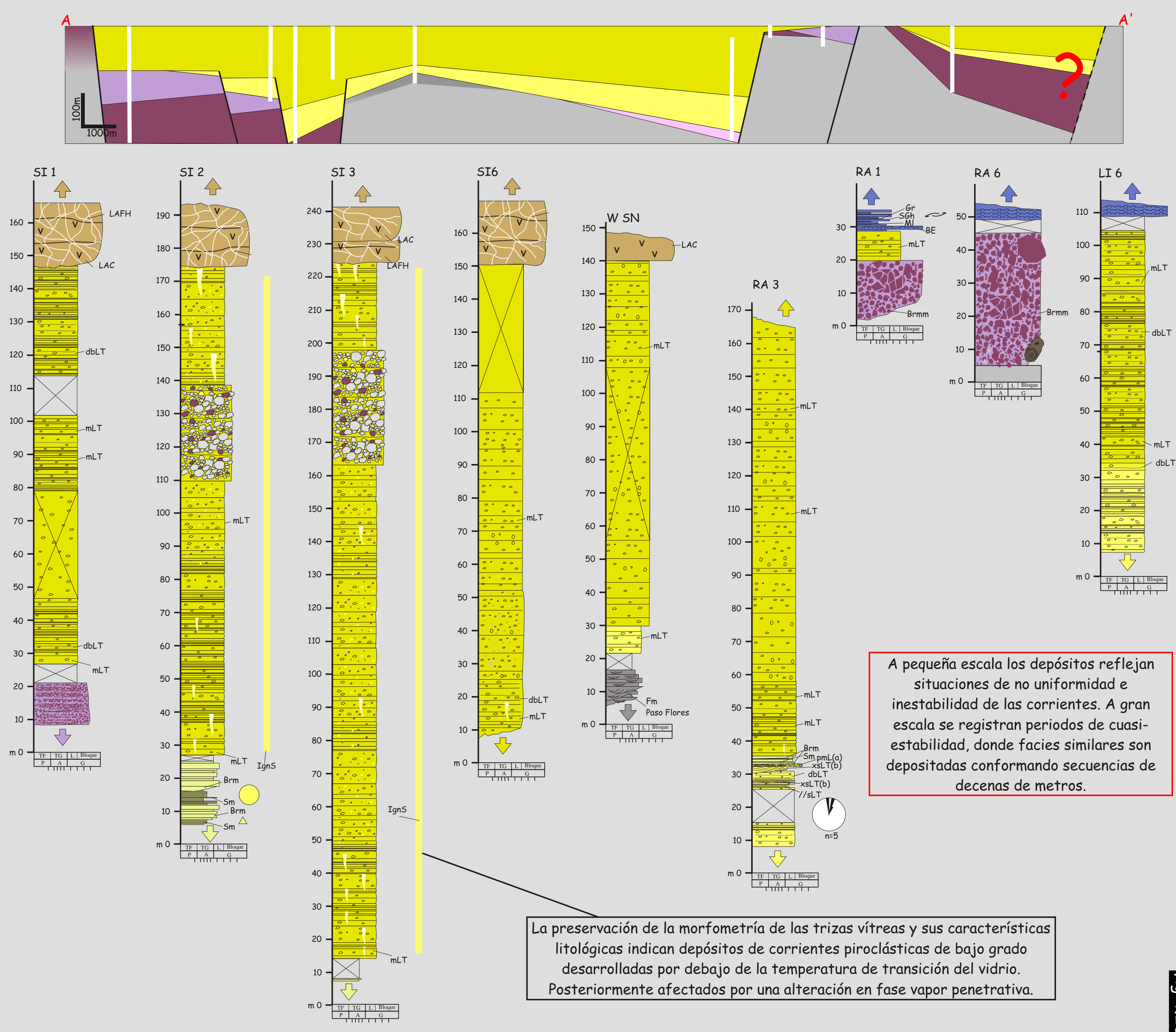

A pequeña escala los depósitos reflejan situaciones de no uniformidad e inestabilidad de las corrientes. A gran

escala se registran periodos de cuasidepositadas conformando secuencias de decenas de metros.

Figura 4.23. Unidad de acumulación constituida de depósitos de corrientes piroclásticas subaéreas de gran distribución areal.

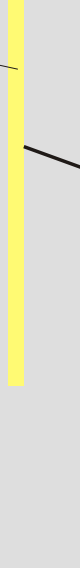

L

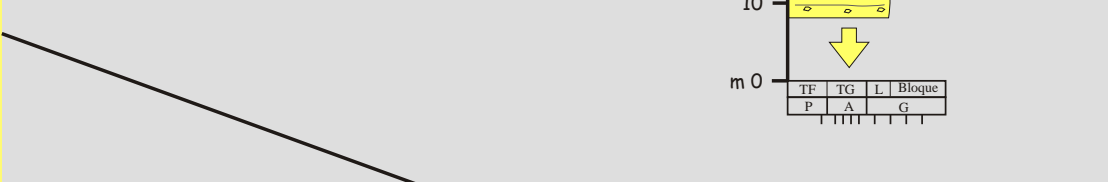

La preservación de la morfometría de las trizas vítreas y sus características

litológicas indican depósitos de corrientes piroclásticas de bajo grado

desarrolladas por debajo de la temperatura de transición del vidrio.

Posteriormente afectados por una alteración en fase vapor penetrativa. 
Unidad de acumulación: depósitos de corrientes piroclásticas subaéreas de gran distribución areal III

Depósitos de corrientes piroclásticas de gran distribución areal desarrollados en el área de Piedra de Águila. Se presentan a gran escala con un arreglo simple de facies ( $m L T, m L T f$, emLT). Denotan deposición en condiciones de cuasi-estabilidad de las corrientes.
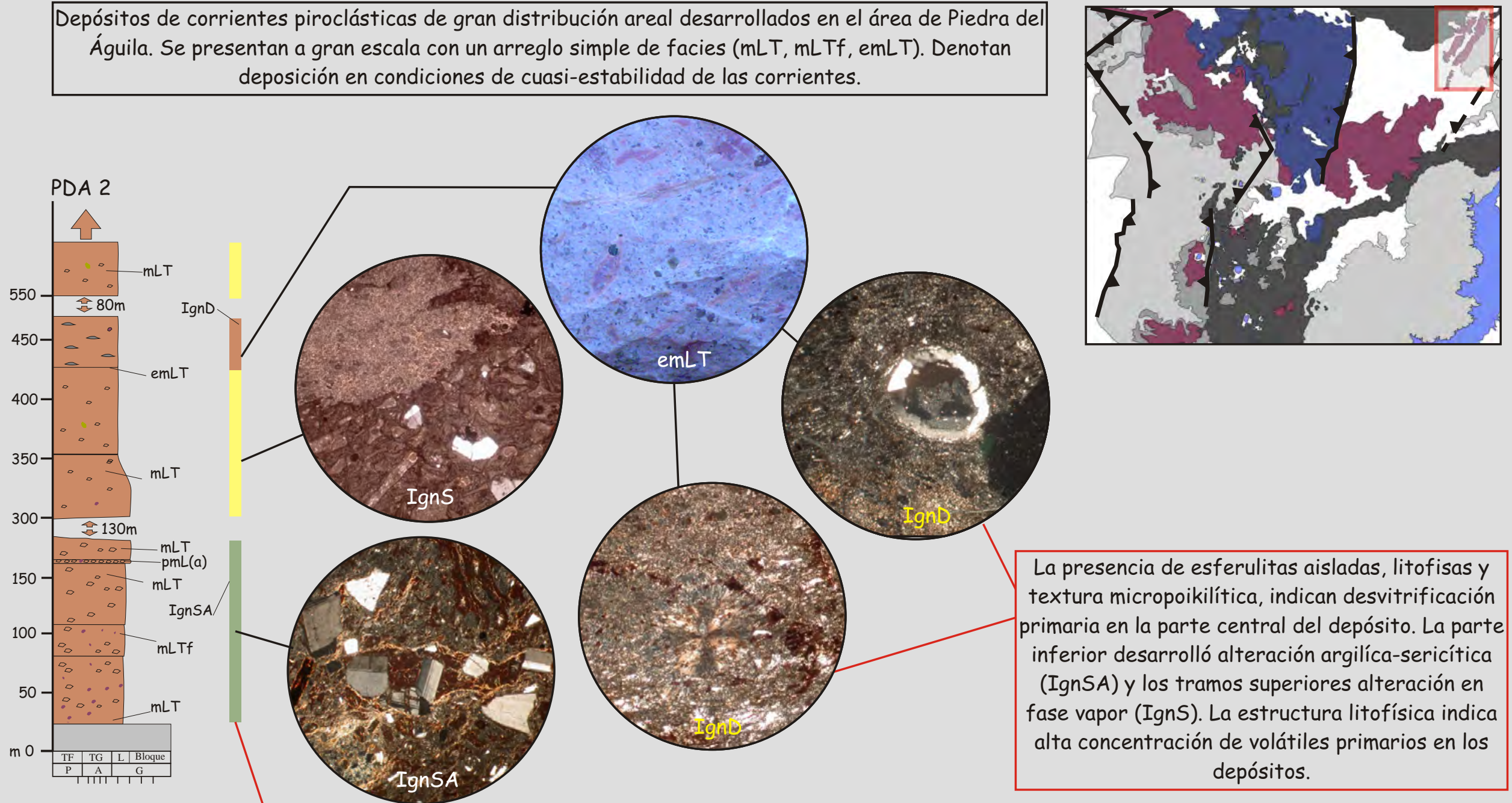

La asociación de microfacies permitió separar unidades eruptivas. El perfil vertical es consistente con depósitos que se originaron cercanos a la temperatura de transición del vidrio y que se enfriaron lentamente debido a su gran espesor. 


\section{Secuencias de unidades de acumulación piroclásticas de gran distribución areal III aflorantes en el área de Piedra del Águila.}
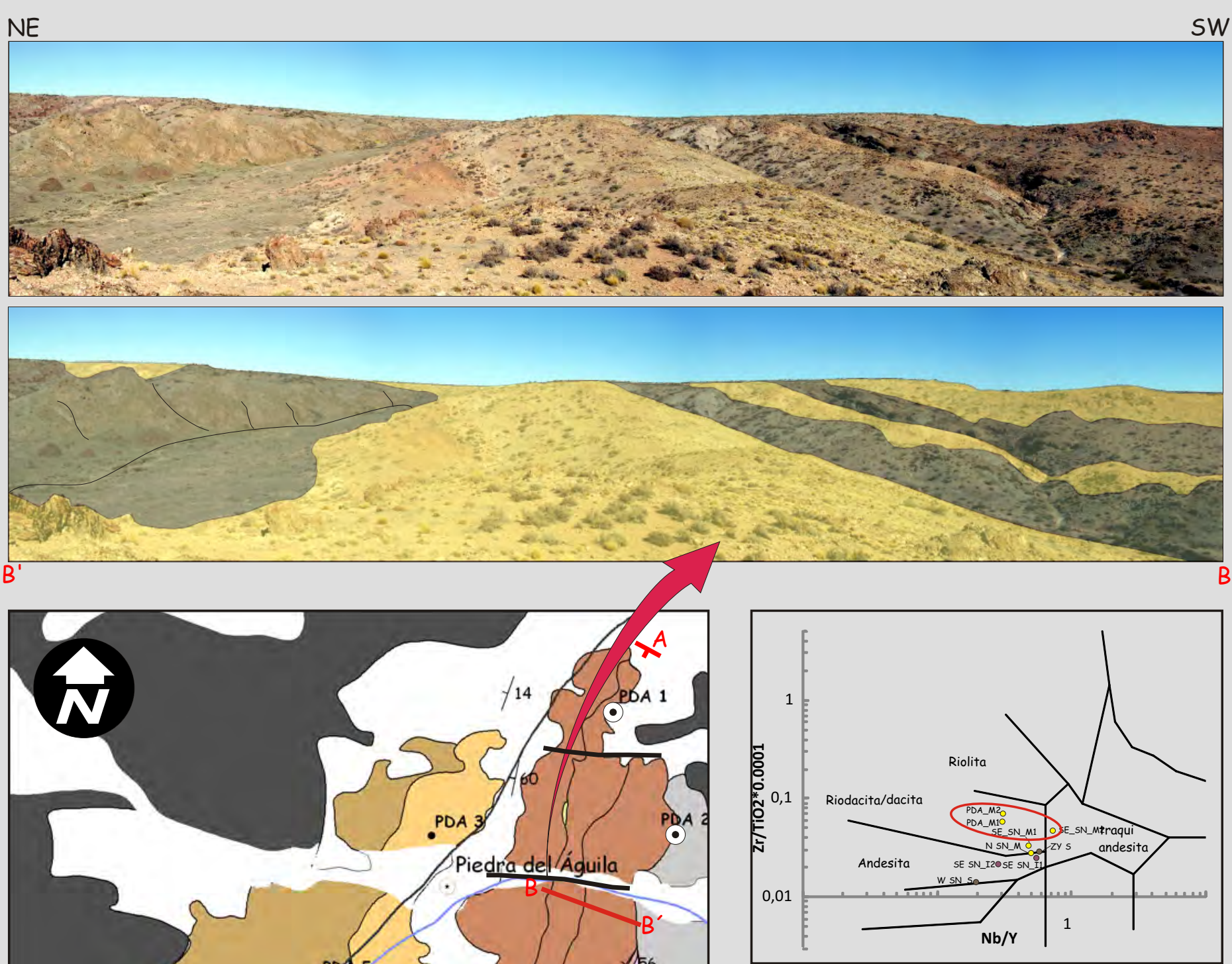

En perfil vertical como lateral se encuentran arreglos simples de facies sugiriendo a gran escala estabilidad y uniformidad de las corrientes. $A$ diferencias de las unidades anteriores, la geometría de esta unidad es

Los elevados volúmenes de material y la forma que presentan estas unidades sugieren el relleno de depresiones volcano-tectónicas.

La regularidad geométrica de las unidades que se superponen en este sector se mantiene, indicando que las condiciones en el espacio de más regular que las halladas en el área de Sañicó. acumulación no variaron durante la evolución.

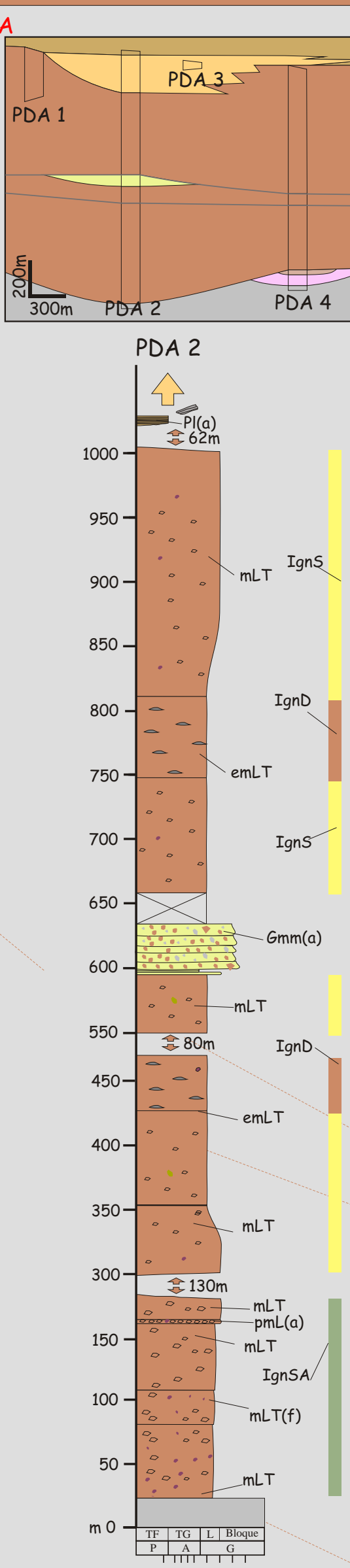

$\square$ Sistemas aluviales volcaniclásticos terminales

Sistemas fluviales de carga mixta
Sistemas aluviales volcaniclásticos dominad

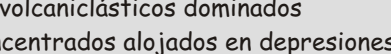
Coladas andesíticas

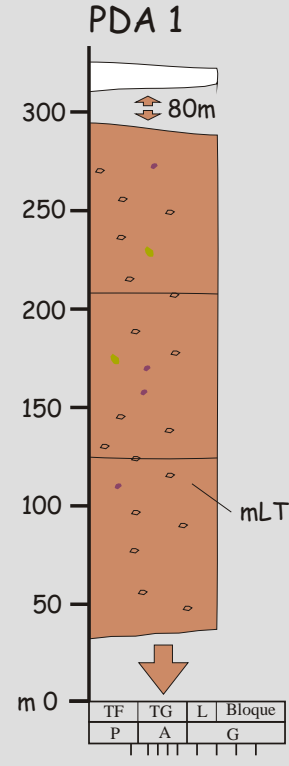

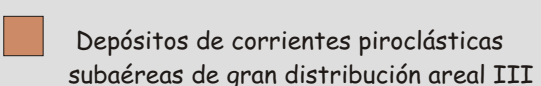

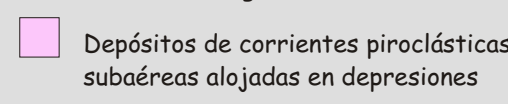


4.5.3 Unidad de acumulación de depósitos de corrientes piroclásticas subácueas

Se presenta como una unidad de geometría tabular a levemente cuneiforme, con espesores máximos que rondan los $10 \mathrm{~m}$. Internamente se encuentra constituida por un arreglo simple de facies de tobas lapillíticas masivas (mLT). Esta unidad se desarrolla interdigitada con depósitos sedimentarios que indican un ambiente de depositación subácueo (fig. 4.26). El arreglo simple vertical y lateral de estas facies sugieren la depositación desde corrientes piroclásticas subácueas de corta vida que evolucionaron con alta concentración de piroclastos en la zona inferior del flujo (Branney y Kokelaar, 2002). Es importante destacar que las corrientes piroclásticas generalmente se desarrollan como corrientes estratificadas, mostrando grandes contrastes de densidad. Esta situación permite que éstas fluyan por debajo del agua como una unidad coherente, originando arreglos de facies subácueos que no pueden diferenciarse de los subaéreos (Fritz et al., 1990; Kokelaar et al., 2007). Por último, esta unidad evidencia la presencia de erupciones plinianas o subplinianas y la continuidad de eventos volcánicos una vez acaecida la inundación de la cuenca. 
Unidad de acumulación: depósitos de corrientes piroclásticas subácueas

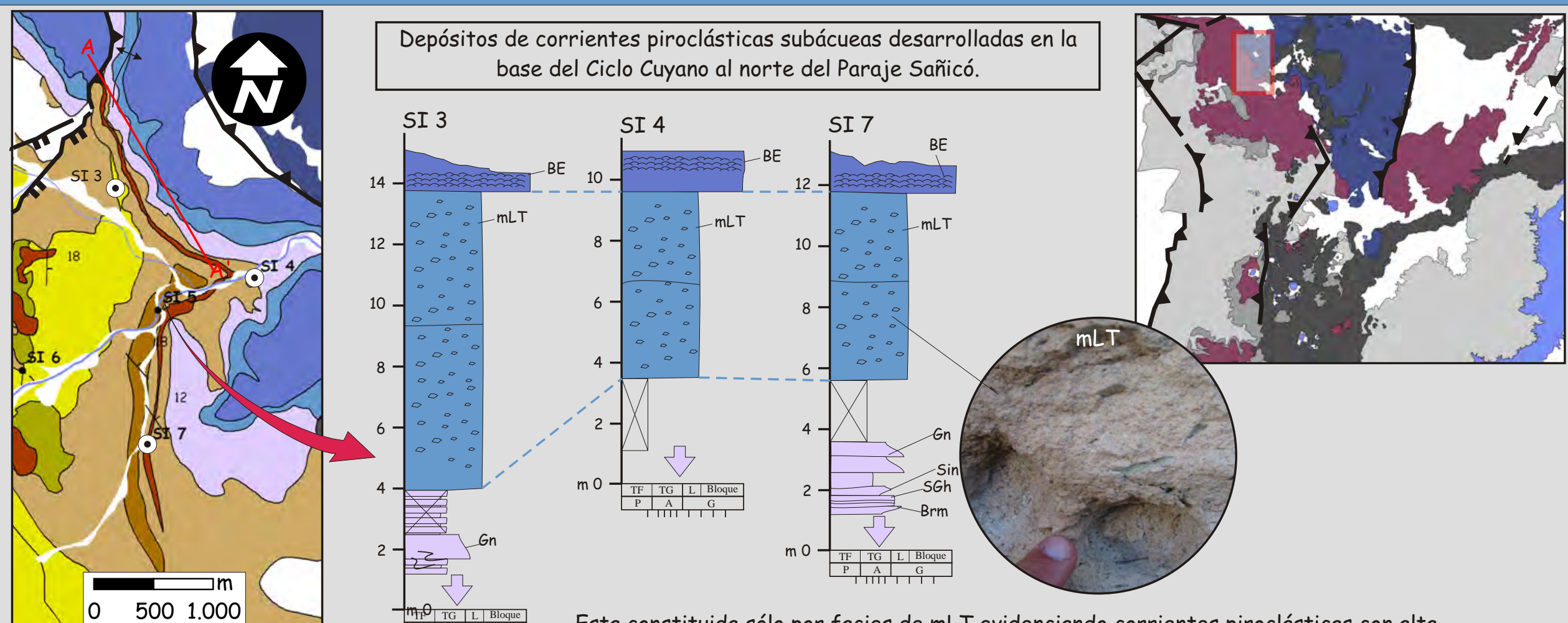

Esta constituida sólo por facies de $\mathrm{mLT}$ evidenciando corrientes piroclásticas con alta concentración de material que probablemente se comportaron como flujos inerciales.

Ambiente marino somero carbónatico

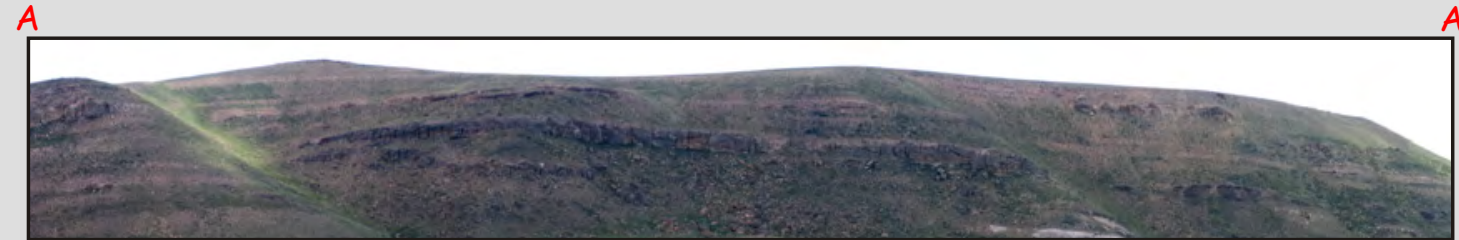

Sistemas de deltas de grano grueso/lacustre

Sistemas aluviales volcaniclásticos dominados por flujos hiperconcentrados

Sistemas aluviales dominados por

flujos de detritos

$\square$ Depósitos de corrientes piroclásticas subácueas

Depósitos de corrientes piroclásticas

subaéreas de gran distribución areal II

Coladas andesíticas

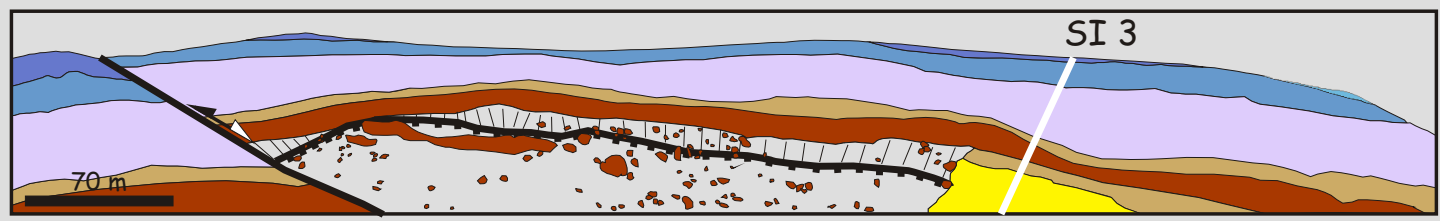

Figura 4.26. Unidad de acumulación constituida de depósitos de corrientes piroclásticas subácueas. 


\subsection{Unidades de acumulación sedimentarias}

Bajo este título se han integrado todas las unidades de acumulación constituidas por facies sedimentarias epiclásticas y/o carbonáticas. Las unidades sedimentarias serán agrupadas para su tratamiento dentro de unidades de acumulación epiclásticas continentales, unidades de acumulación epiclásticas marinas y unidades de acumulación carbonáticas marinas. Para la denominación de cada unidad de acumulación se utilizaron generalmente dos atributos, uno relacionado al ambiente depositacional (Ej. fluvial, aluvial, marino) y otro vinculado al proceso sedimentario más representativo del ambiente (Ej. flujos de detritos, procesos deltaicos) (fig. 4.27). La determinación del ambiente continental/marino se realizó en función de la asociación de facies, la asociación con otras unidades de acumulación y la presencia de fósiles. Los principales procesos depositacionales fueron extraídos de la interpretación dinámica de los depósitos realizada en el capítulo anterior. En ocasiones para resaltar las características composicionales de las unidades se empleó el término volcaniclástico. Es importante destacar que en el capítulo precedente se evitó utilizar esta expresión debido a la confusión que generalmente trae aparejada. El término “volcaniclástico" será utilizado bajo su acepción original, esto es para caracterizar depósitos constituidos predominantemente por individuos volcánicos, sin tener en cuenta su origen, mecanismo de transporte o historia depositacional (Smith, 1961 en Németh y Ulrike, 2007).

\subsubsection{Unidades de acumulación epiclásticas continentales}

\subsubsection{Sistemas aluviales}

Bajo esta denominación se agruparon a unidades sedimentarias generadas por la depositación de materiales a partir de flujos gravitatorios de sedimentos (depósitos de avalanchas de detritos, depósitos de flujos de detritos y flujos hiperconcentrados), flujos diluidos en mantos (sheetfloods), y minoritariamente, flujos diluidos encauzados. Estas características aluden a zonas de pendientes de entre $1,5^{\circ}$ y $25^{\circ}$, fuertemente agradacionales, donde los flujos son rápidamente atenuados (Blair y McPherson, 1994). Dentro del relleno precuyano en función de su extensión, geometría, procesos originarios y composición se distinguieron 5 unidades relacionadas a ambientes aluviales: I) sistemas aluviales volcaniclásticos dominados por avalanchas de detritos y flujos de detritos, II) sistemas aluviales volcaniclásticos dominados por flujos de detritos. III) sistemas aluviales volcaniclásticos dominados por flujos hiperconcentrados alojados en depresiones, IV) sistemas aluviales volcaniclásticos dominados por flujos hiperconcentrados, y V) sistemas aluviales volcaniclásticos terminales. 
Unidades de acumulación de rocas sedimentarias

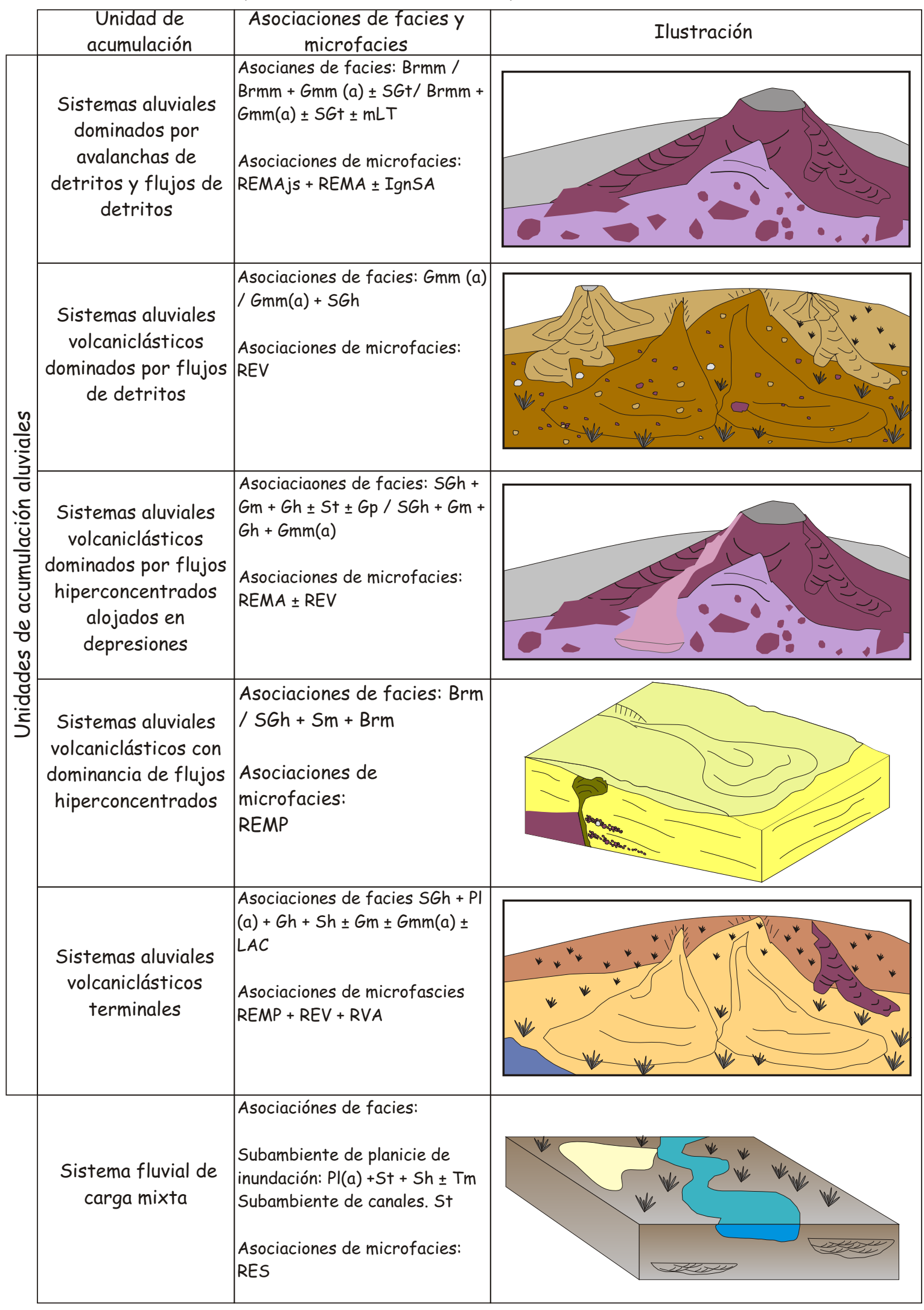


Unidades de acumulación de rocas sedimentarias

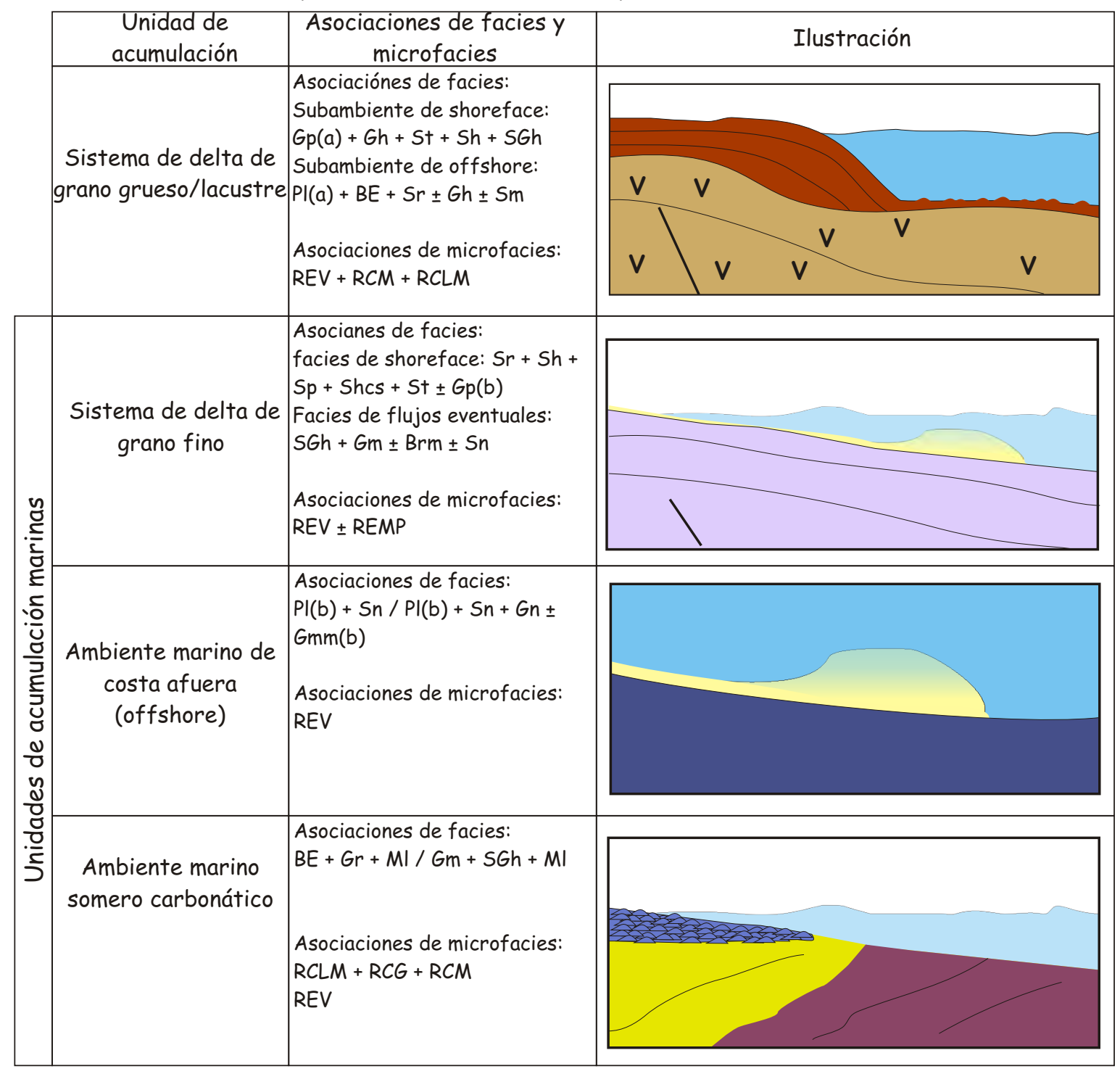

Figura 4.27. Unidades de acumulación sedimentarias distinguidas para el relleno Precuyano y el inicio del Ciclo Cuyano. 
I) La unidad de acumulación de sistemas aluviales dominados por avalanchas de detritos y flujos de detritos se encuentra representada en la parte inferior del Ciclo Precuyano. Generalmente se apoya en concordancia o suave discordancia sobre las unidades volcánicas lávicas y las unidades de corrientes piroclásticas alojadas en depresiones. Se presenta con geometría irregular, ampliamente distribuida lateralmente, con espesores y extensiones de cientos de metros. Se constituye por facies de depósitos de avalanchas de detritos (Brmm) y de flujos de detritos (Gmm(a)), alojados en canales o no canalizados (fig. 3.1 y 4.28). Minoritariamente se encontraron depósitos arenosos hiperconcentrados (SGh) de pocos centímetros y depósitos de corrientes piroclásticas que no superan los $2 \mathrm{~m}$ de espesor (mLT). Esta unidad no muestra ningún arreglo de facies preferencial. Respecto a las características petrográficas, las microfacies de rocas epiclásticas monomícticas andesíticas, sin y con fracturación en rompecabezas (REMA y REMAjs), son las que mayoritariamente caracterizan a las facies de avalanchas de detritos y de flujos de detritos de esta unidad (fig. 4.28).

Las características monomícticas, sumadas a la vinculación espacial con las unidades de rocas volcánicas, indican una relación entre los sistemas aluviales dominados por avalanchas de detritos y flujos de detritos y el volcanismo andesítico presente (Mc Phie et al., 1993). En sentido amplio, los depósitos de avalanchas de detritos conservan la estratigrafía del relieve volcánico previo (Shea et al., 2008). De este modo, las características composicionales de estos depósitos indicarían un origen a partir de un paisaje volcánico dominado preferentemente por materiales lávicos de composiciones uniformes. Los procesos depositacionales, que indican alta tasa de agradación en cortos periodos de tiempo, conjuntamente con los atributos monocomposicionales, sugieren que esta unidad se podría haber desarrollado de manera sineruptiva con el volcanismo andesítico (Palmer et al., 1993; Riggs et al., 1997; Zancheta et al., 2004). Sin embargo, la asociación lateral y vertical con las unidades volcánicas muestra más generalmente una relación intereruptiva con las unidades volcánicas. El desarrollo de las avalanchas de detritos en ambientes volcánicos puede ocurrir por debilidades inherentes a los aparatos volcánicos (erosión, asimetría o hidrotermalismo) y/o por mecanismos que sirven como gatillo (erupciones, terremotos e intrusiones) (Thouret, 1999). La participación de flujos de detritos volcaniclásticos que pueden ser originados a partir de flujos de avalanchas de detritos o por resedimentación de éstos (Bernard et al.,2009), la escasa presencia de arcilla, la ausencia de alteración hidrotermal penetrativa y la carencia de unidades volcánicas primarias, sustentarían que a pesar de las características composicionales y fuertemente agradantes, estos sistemas estarían asociados a eventos intereruptivos relacionados a la erosión e inestabilidad gravitatoria (Belousov et al., 1999; Clavero et al., 2002; Shea et al., 2008). Minoritariamente, en algunos sectores del relleno estas unidades se presentan intercaladas con unidades lávicas, sugiriéndose una eventual condición sineruptiva. 
Los sistemas aluviales dominados por flujos de avalanchas de detritos y flujos de detritos corresponderían a un ambiente aluvial de elevada pendiente (Blair y McPherson, 1994) que representa un importante evento degradacional de corta vida de las unidades volcánicas que conformaban el relieve precuyano. Conjuntamente, constituyen eventos agradacionales de los ambientes sedimentarios desarrollados en este escenario (Palmer et al., 1993), generados mayoritariamente en condiciones intereruptivas y minoritariamente en condiciones sineruptivas.

II) La unidad de acumulación de sistemas aluviales volcaniclásticos dominados por flujos de detritos se presenta como una unidad tabular, con un espesor máximo de $60 \mathrm{~m}$ (fig. 4.29). Internamente se constituye por facies de flujos de detritos (Gmm(a)) con un arreglo de superposición simple. Esta unidad presenta una composición predominantemente volcaniclástica, integrada por microfacies de rocas epiclásticas polimícticas de procedencia volcánica (REV), con clastos volcánicos de variadas composiciones y orígenes. Los procesos depositacionales reflejan un ambiente aluvial. La ausencia de facies de avalanchas de detritos indicaría menor pendiente que los sistemas dominados por flujos hiperconcentrados (Ej. sistemas aluviales dominados por avalanchas de detritos y flujos de detritos) (Blair y McPherson, 1994; Brown y Bell, 2007). Las características composicionales de esta unidad, constituida de una mezcla de detritos volcánicos, inclusive con participación de otros materiales silicoclásticos, reflejan una red de drenaje alimentadora más integrada y periodos de retrabajo más largos que las unidades monomícticas.

III) La unidad de acumulación de sistemas aluviales volcaniclásticos dominados por flujos hiperconcentrados alojados en depresiones se presenta labrando incisiones en unidades previas. Se muestra como una unidad de geometría tabular de decenas de metros espesor y centenas de metros de extensión lateral o como una unidad lenticular de decenas de metros de espesor y extensión lateral (fig. 4.30). Internamente se constituye de facies de flujos hiperconcentrados arenosos (SGh) y gravosos (Gm y Gh) y minoritariamente facies de flujos de detritos (Gmm(a)) y depósitos de corrientes tractivas arenosos (St) y gravosos (Gp) (fig. 3.1). Entre las microfacies que presenta esta unidad se destacan las de rocas epiclásticas monomícticas andesíticas (REMA), habiéndose encontrado en algunos casos microfacies de rocas epiclásticas con abundante procedencia volcánica andesítica, conjuntamente con la participación de litoclastos y cristaloclastos de rocas derivadas del basamento cristalino (REV). Generalmente, las facies que constituyen estos sistemas se presentan conformando secuencias con tendencia grano-estratocreciente (fig. 4.30). Comienzan con depósitos de flujos hiperconcentrados arenosos, desarrollando hacia arriba depósitos de flujos hiperconcentrados gravosos y en ocasiones, depósitos de flujos de detritos. Las facies tractivas gravosas (Gp) pueden aparecer en la base de la unidad constituyendo formas de fondo de canales, mientras que 
las facies tractivas arenosas (St) aparecen intercaladas entre las facies de flujos hiperconcentrados arenosos. Éstas se muestran como relleno de pequeñas depresiones originadas como retrabajo de las facies de flujos hiperconcentrados arenosos, durante la etapa de merma del evento depositacional (Cossout y Meunier, 1996; Zancheta et al., 2004).

Las características atrincheradas de esta unidad, que reflejan periodos degradacionales (Palmer et al., 1993), la abundancia de arenas de composición mayoritariamente andesítica que implican grandes periodos de retrabajo, y la participación eventual de rocas procedentes del basamento, sugieren condiciones intereruptivas (Palmer et al., 1993; Riggs et al., 1997; Orton, 2002; Zancheta et al., 2004). La presencia, en ocasiones, de materiales tractivos en la base de las depresiones indica que las mismas fueron labradas por acción fluvial, rellenadas luego de manera pasiva por depósitos de flujos densos (Palmer y Walton, 1990; Blair y McPherson, 1994; Zancheta et al., 2004). El arreglo con tendencia grano-estratocreciente indica un aumento de la energía de los ambientes o la restauración de la producción de detritos gruesos.

IV) La unidad de acumulación de sistemas aluviales volcaniclásticos dominados por flujos hiperconcentrados se presenta como secuencias poco potentes, desde el metro a los 20 m de espesor y extensión lateral de unas pocas decenas de metros (fig. 4.31). Aparece siempre interdigitada entre las unidades piroclásticas de gran distribución areal. Se encuentra enteramente constituida por depósitos de flujos hiperconcentrados monomícticos de procedencia piroclástica, caracterizados por areniscas tobáceas masivas (Sm) y brechas masivas o con gradación normal o inversa (Brm) (fig. 3.1). Esta unidad presenta microfacies de rocas epiclásticas monomícticas de procedencia piroclástica (REMP) que muestran en su composición piroclastos con indicios de cristalización en fase vapor.

Estas facies se desarrollan sin un arreglo preferencial, en forma de descargas en manto y/o rellenando pequeñas depresiones bordeadas por superficies erosivas (fig. 4.31). Tomando los criterios usuales para distinguir secuencias eruptivas de intereruptivas - tamaño de grano, composición, origen de los clastos y geometría de las unidades- , esta unidad correspondería a un evento agradacional sineruptivo (Smith et al., 1987; Smith, 1987; Smith, 1991; Bahk y Chough, 1996; Orton, 2002). Es importante destacar que Smith (1991) no sólo incluye dentro de los periodos sineruptivos a los procesos volcánicos y sedimentarios contemporáneos durante la erupción, sino también, a los procesos sedimentarios penecontemporáneos al volcanismo, mientras permanecen disturbadas las condiciones hidrológicas y geomorfológicas. Indudablemente, la unidad en estudio está netamente controlada por las unidades piroclásticas previas, pero existen varias razones a ser tenidas en cuenta antes de adjudicarle un origen sineruptivo. Primero, las unidades eruptivas piroclásticas son de tal volumen que el impacto geomorfológico originado dentro del relieve precuyano debió haber sido tan grande que las nuevas condiciones de equilibrio tienen que haber sido controladas por el nuevo escenario. 
Segundo, los modelos mencionados requieren lapsos mayores y ambientes sedimentarios integrados (véase Smith, 1991), condiciones muy disimiles para el ambiente en cuestión. Con todo, la asociación espacial que presenta este ambiente con las unidades de corrientes piroclásticas, sumado a la presencia de litoclastos afectados por procesos de cristalización en fase vapor que sugieren periodos de retrabajo de las unidades piroclásticas, indican una naturaleza interuptiva para esta unidad. La importancia de su registro radica en comprender que las diferentes unidades de corrientes piroclásticas de gran distribución areal no se desarrollaron de manera súbita dentro del Ciclo Precuyano. Así, esta unidad de acumulación refleja condiciones aluviales intereruptivas, de gradientes moderados, caracterizada por procesos depositacionales principalmente controlados por el tipo de material (Blair y McPherson, 1994).

V) La unidad de acumulación de sistemas aluviales volcaniclásticos terminales se encuentra asociada íntimamente a unidades piroclásticas, apareciendo por encima de potentes secuencias ignimbríticas (fig. 4.32). Se presenta como una unidad de geometría irregular a tabular, de cientos de metros de extensión lateral y hasta 200 m de espesor. Está constituida mayoritariamente de facies de depósitos pelíticos, preferentemente limolíticos de procedencia piroclástica, con briznas vegetales $(\mathrm{Pl}(\mathrm{a})$ ) que intercalan con facies de depósitos de flujos hiperconcentrados arenosos y gravosos (SGh, Gm y Gh) (fig. 3.1). En algunas ocasiones se han encontrado arenas con estratificación entrecruzada en artesa como rellenos de canales pequeños episódicos (fig. 4.32). Los depósitos de flujos hiperconcentrados se muestran preferentemente en manto aunque en ocasiones se presentan alojados en canales. En forma subordinada se encontraron facies de flujos de detritos (Gmm(a)), flujos diluidos en mantos (Sh) y cuerpos delgados de lavas de composición andesítica (LAC) (fig. 3.1). Con respecto a las características petrográficas, esta unidad se caracteriza principalmente por microfacies de rocas epiclásticas de composiciónes piroclásticas (REMP) y volcaniclásticas (REV).

Las litofacies presentes en esta unidad generalmente se exhiben con una disposición particular, caracterizada por tramos de entre $10 \mathrm{~m}$ a $20 \mathrm{~m}$, con arreglo grano-estratocreciente (fig. 4.32). Evolucionan desde facies de flujos hiperconcentrados arenosos (SGh) - en ocasiones desde facies de flujos diluidos en mantos - seguidas por facies de flujos hiperconcentrados gravosos y circunstancialmente, facies de flujos de detritos. Todas las facies yacen conjuntamente con el desarrollo de tramos conspicuos de pelitas laminadas ( $\mathrm{Pl}(\mathrm{a})$ ) que marcan periodos de quietud dominados por procesos de decantación. Este arreglo se condice con la secuencias originadas como resultado de la progradación de lóbulos terminales en ambientes aluviales (Miall, 1996).

Las características anteriormente mencionadas indican una ambiente aluvial de bajo gradiente, en posiciones distales, con pendientes menores a $2^{\circ}$ (Blair y Mc Pherson, 1994). El arreglo de facies presentes, con una abundancia considerable de tramos finos, permite sugerir un 
sistema aluvial terminal (Collinson, 2002; Miall, 2006). La abundancia de materiales limosos y arenosos de procedencia piroclástica y la baja participación de arcilla, típica en ambientes volcánicos (Smith, 1986, Smith y Lowe, 1991), explica el dominio de flujos hiperconcentrados (Blair y McPherson, 1994). El desarrollo de secuencias progradantes evidencia la participación de controles autocíclicos (Miall, 1996), situación atípica para las unidades sedimentarias continentales descriptas. 


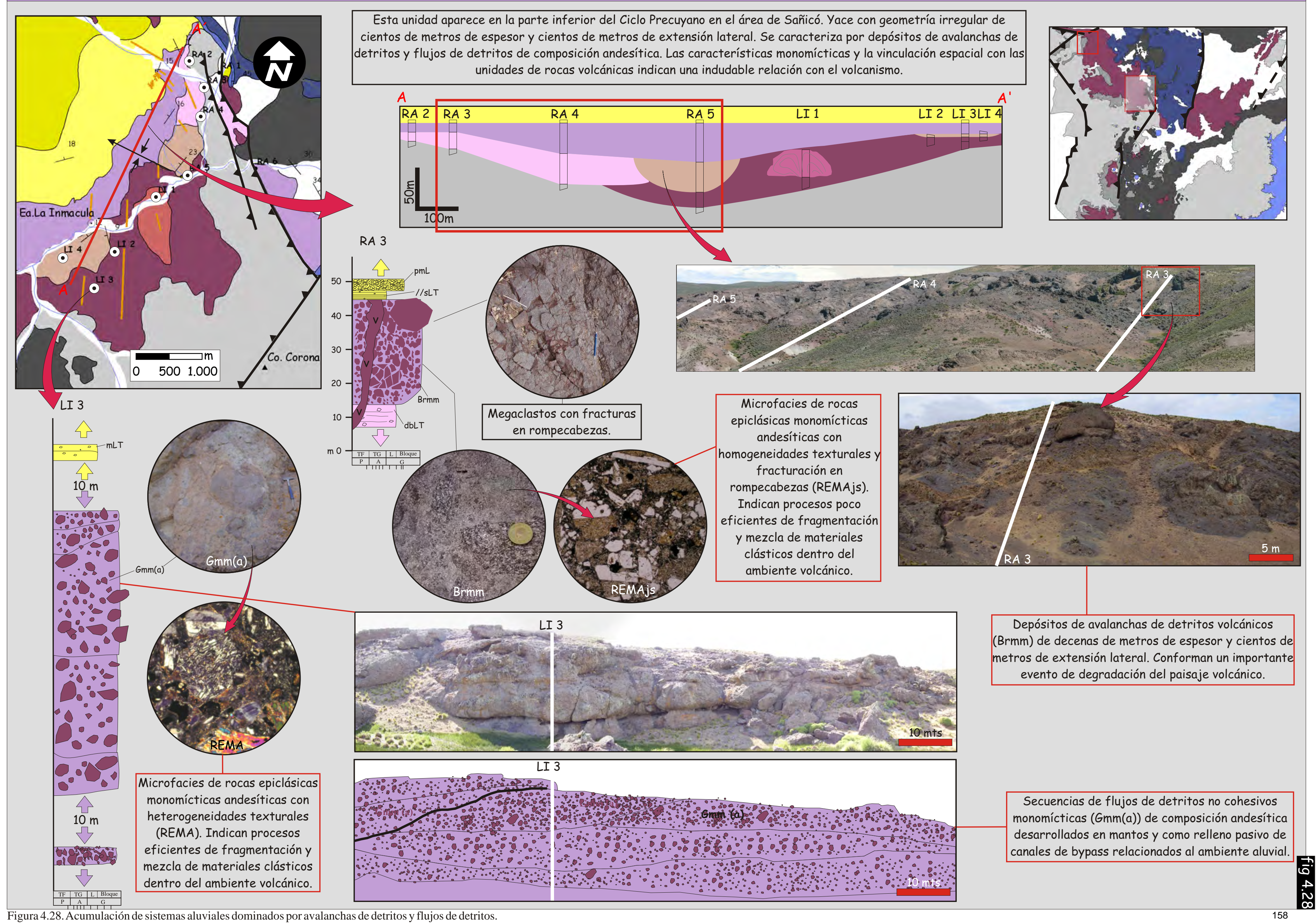


Unidad de acumulación: sistemas aluviales volcaniclásticos dominados por flujos de detritos

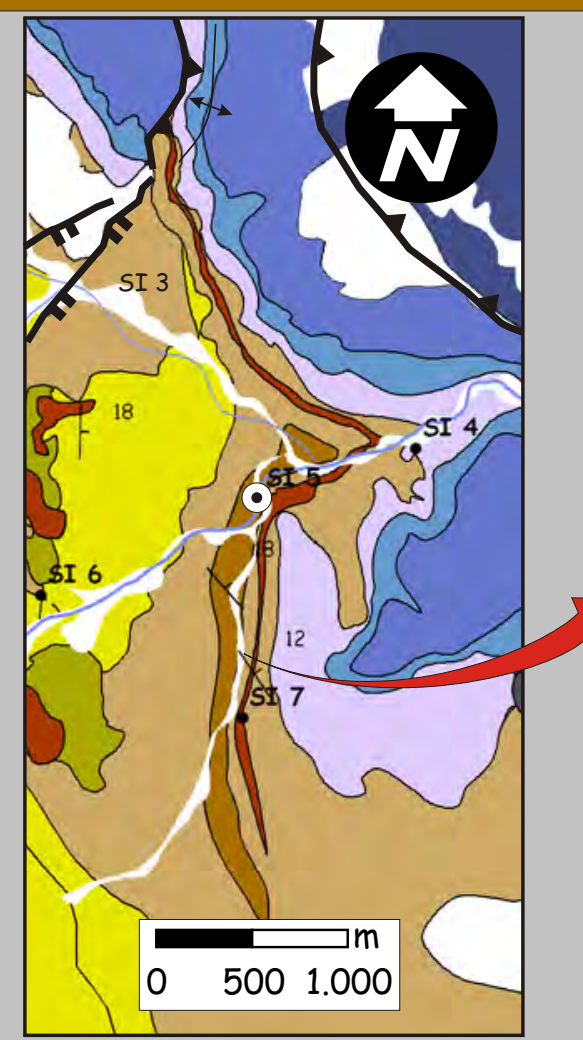

Sistemas de delta de grano grueso/lacustre Sistemas aluviales dominados por flujos de detritos

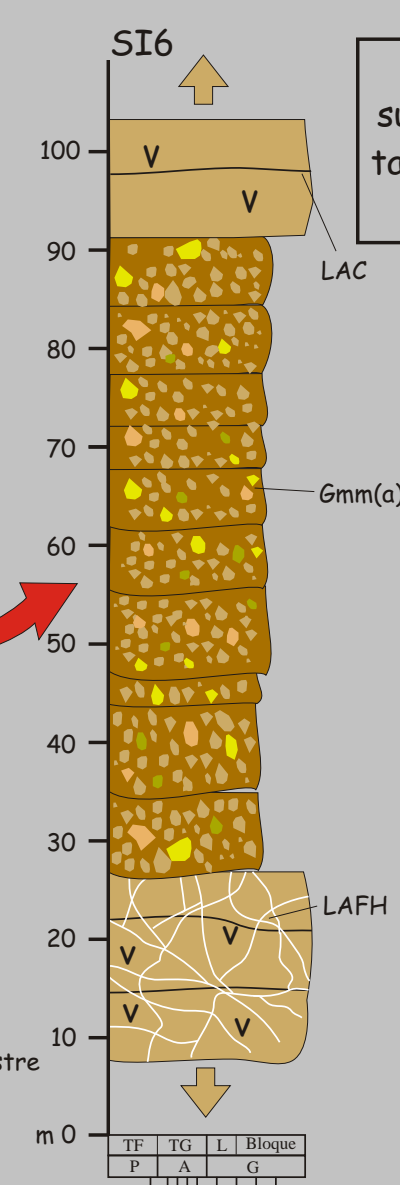

Sistemas aluviales volcaniclásticos dominados por flujos hiperconcentrados

Depósitos de corrientes piroclásticas subaéreas de gran distribución areal II

Depósitos de corrientes piroclásticas subaéreas de gran distribución areal I

Esta unidad se encuentra al $\mathrm{N}$ de Sañicó en la parte superior del Ciclo Precuyano. Se muestra con geometría tabular y un espesor de $60 \mathrm{~m}$. Se integra en su totalidad por flujos de detritos desarrollados en mantos.

Coladas andesíticas

Coladas dómicas riolíticas
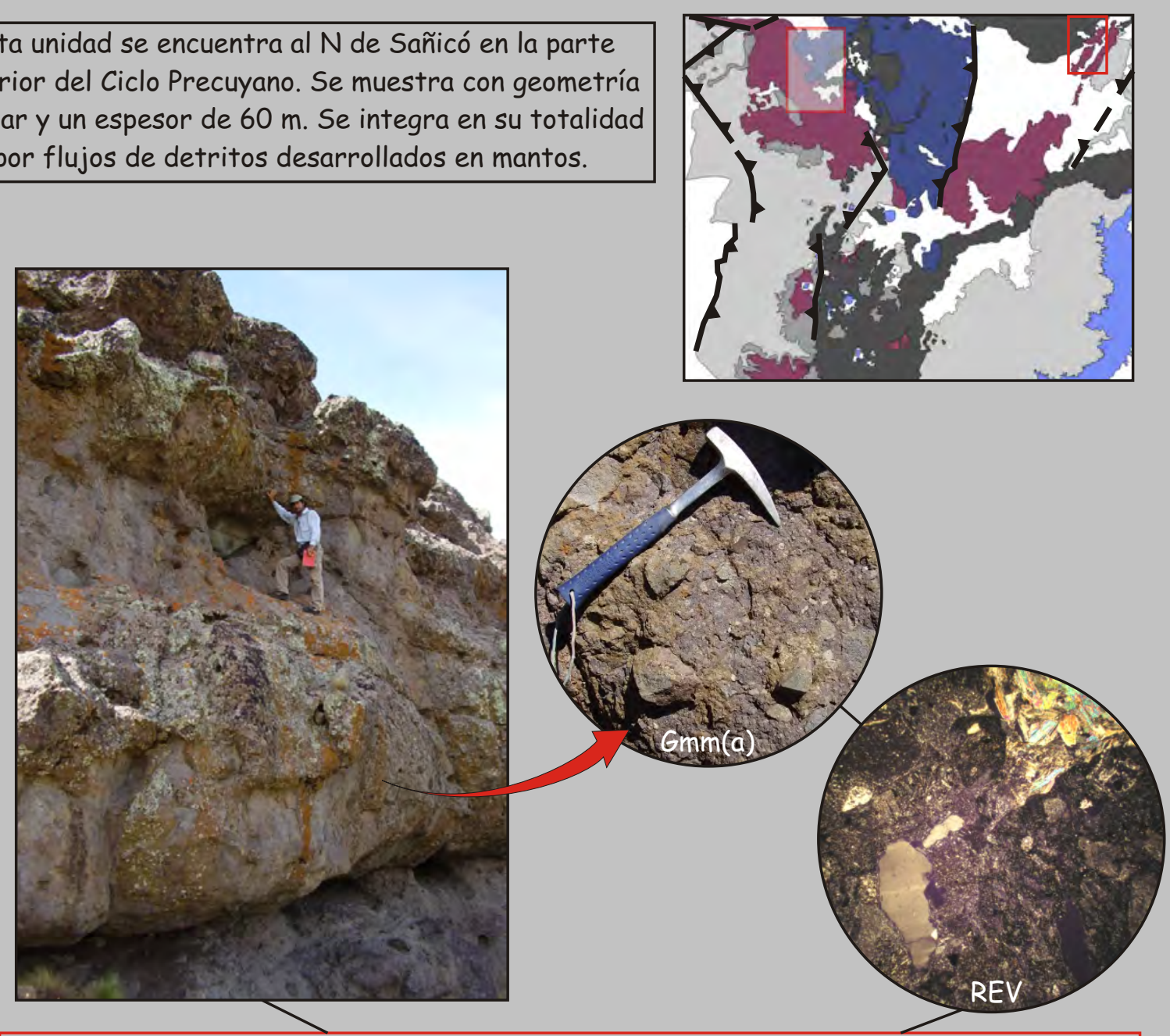

Depósitos de flujos de detritos en mantos de procedencia volcaniclástica (Gmm(a)). Los clastos de rocas volcánicas son de variadas composiciones y orígenes (microfacies REV), en ocasiones participando litoclastos del basamento. Estas características indican áreas de aporte más integradas y periodos de retrabajo mayor hacia el tope del Ciclo Precuyano.

Figura 4.29.Unidad de acumulación: sistemas aluviales volcaniclásticos dominados por flujos de detritos. 


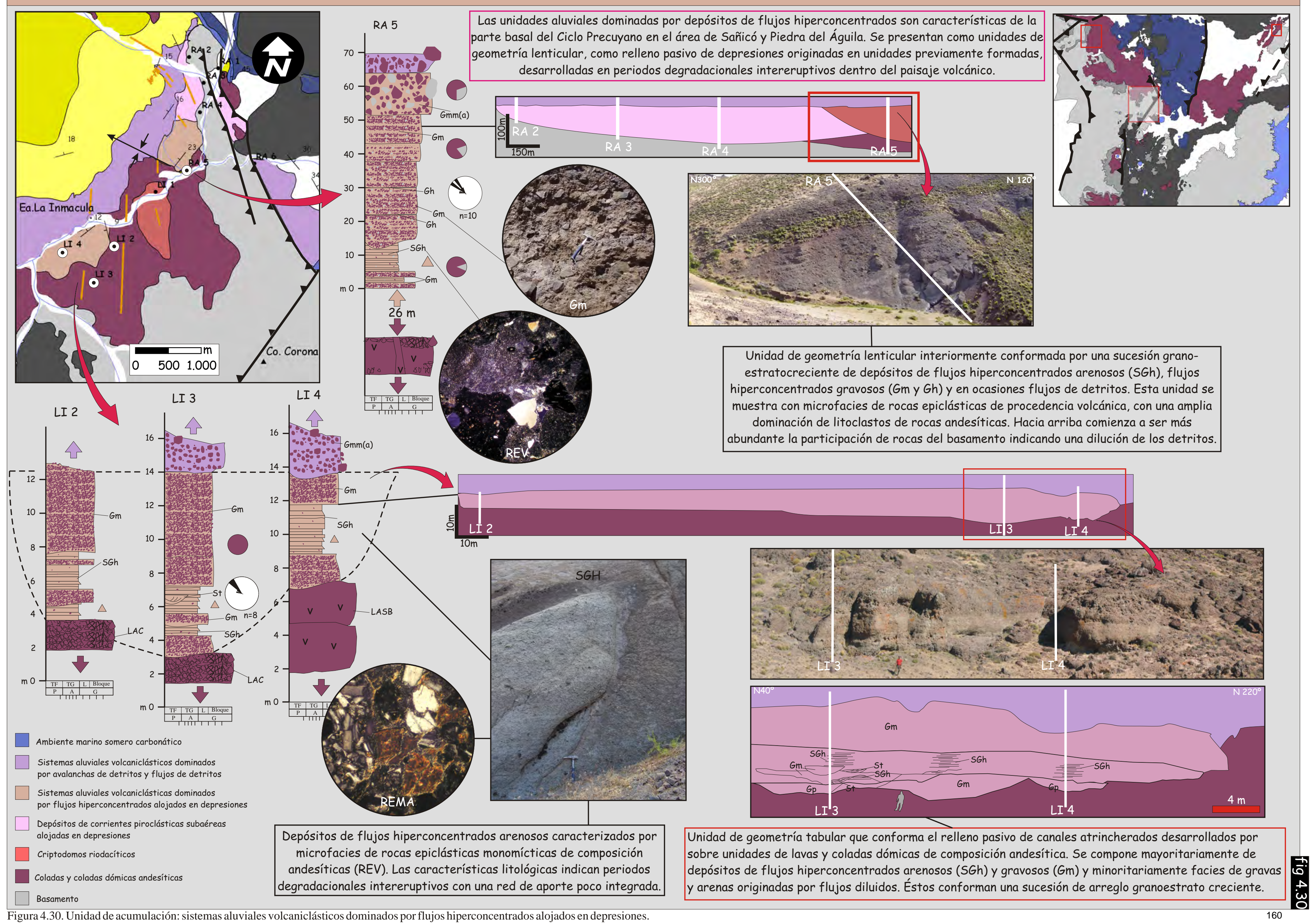




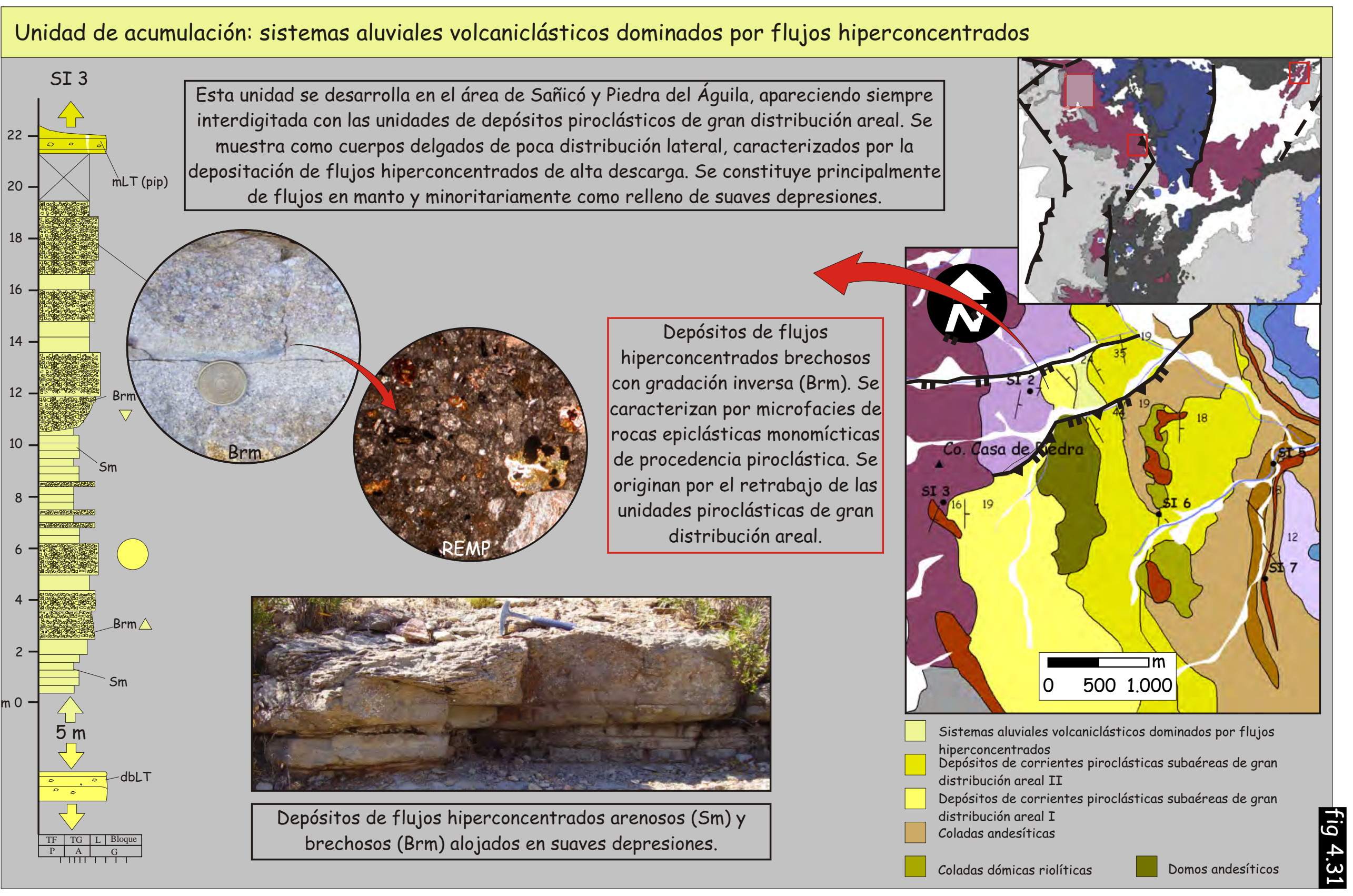

Figura 4.31. Unidad de acumulación: sistemas aluviales volcaniclásticos con dominancia de flujos hiperconcentrados. 
Unidad de acumulación: sistemas aluviales volcaniclásticos terminales

Esta unidad sólo aflora en localidad de Piedra del Águila, sobreyaciendo a una potente
secuencia de $1100 \mathrm{~m}$ de espesor constituida por flujos piroclásticos. Presenta una geometría
irregular a tabular, de cientos de metros de extensión lateral y hasta $200 \mathrm{~m}$ de espesor.

\section{PDA 3}

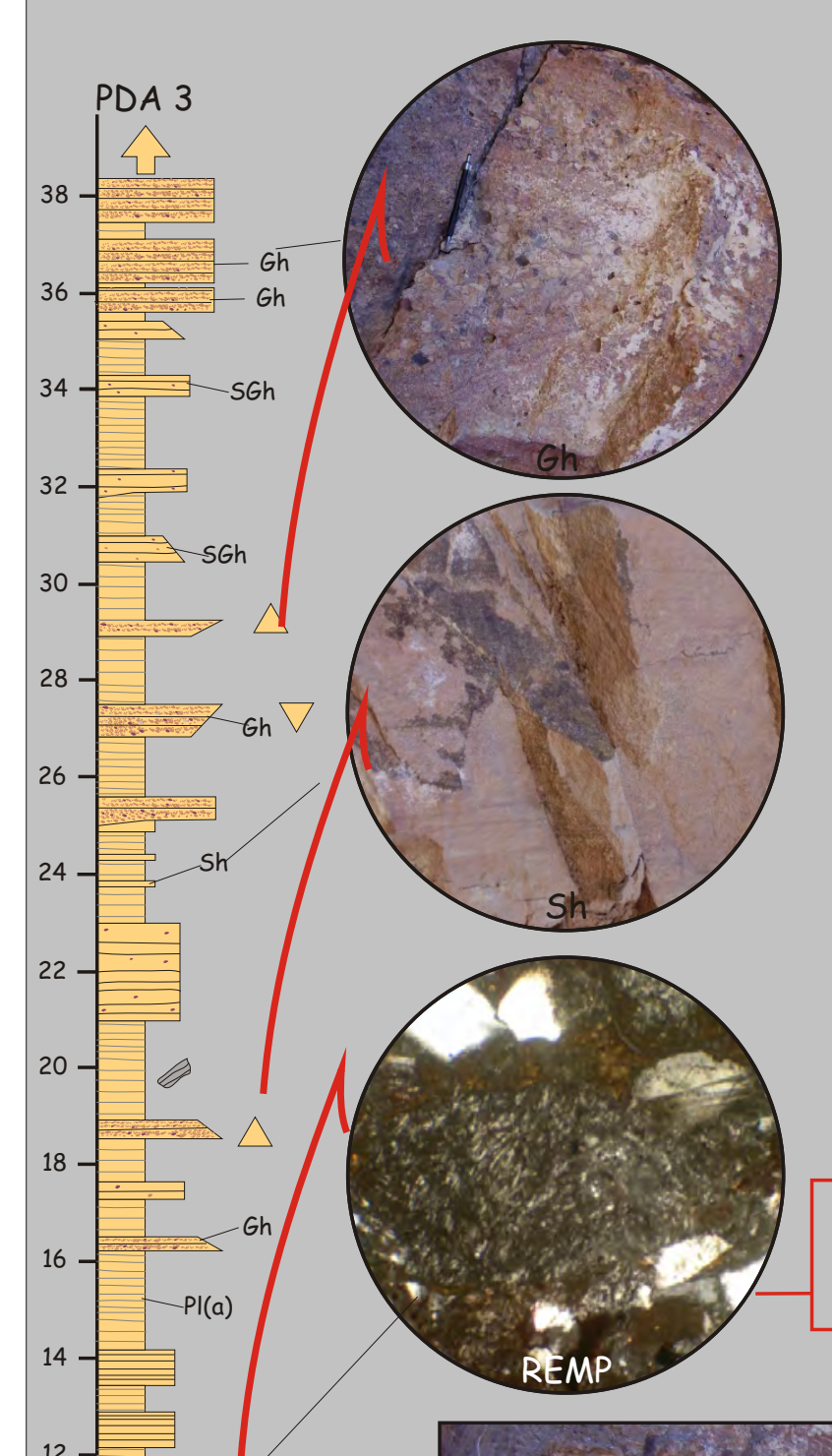

$$
\begin{aligned}
& 36 \\
& 34
\end{aligned}
$$
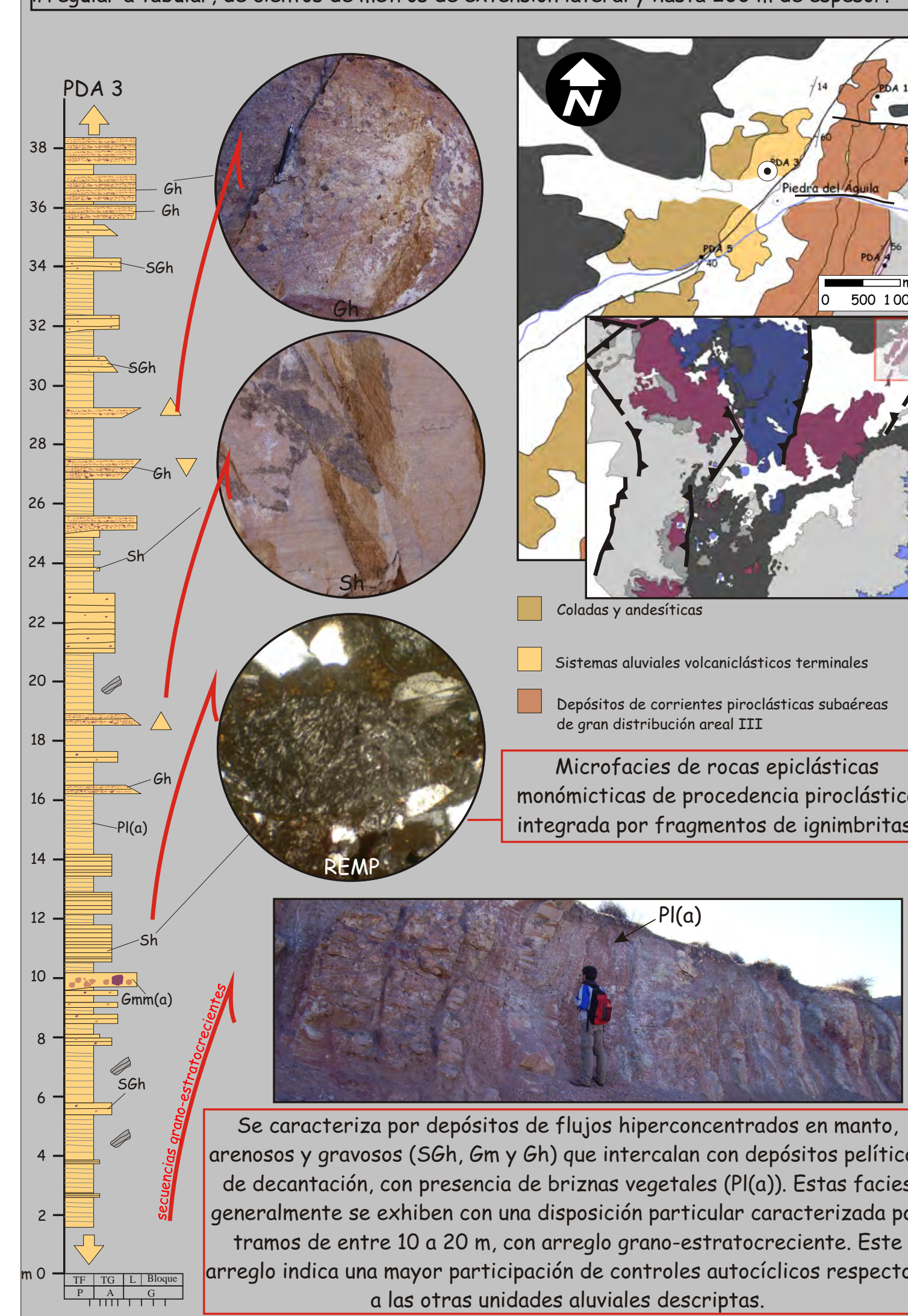

Se caracteriza por depósitos de flujos hiperconcentrados en manto, arenosos y gravosos ( $S G h, G m$ y $G$ ) que intercalan con depósitos pelíticos de decantación, con presencia de briznas vegetales (PI(a)). Estas facies generalmente se exhiben con una disposición particular caracterizada por tramos de entre 10 a $20 \mathrm{~m}$, con arreglo grano-estratocreciente. Este arreglo indica una mayor participación de controles autocíclicos respecto a a las otras unidades aluviales descriptas.

Figura 4.32. Unidad de acumulación: sistemas aluviales volcaniclásticos terminales. 


\subsubsection{Sistemas fluviales de carga mixta}

Se desarrolla como una unidad de geometría irregular que alcanza unos $70 \mathrm{~m}$ de espesor y se extiende lateralmente por unos cientos de metros. Apoya en discordancia sobre rocas del basamento cristalino y es cubierta en suave discordancia por unidades piroclásticas de gran distribución areal (fig. 4.33). Internamente está constituida por un arreglo simple de arenas y arenas conglomerádicas con estratificación entrecruzada en artesa (St) y facies de pelitas laminadas castañas, con nódulos y restos de hojas ( $\mathrm{Pl}(\mathrm{a})$ ) (fig. 3.1 y 4.33). Las facies de arenas se presentan generalmente amalgamadas en cuerpos canalizados de $1 \mathrm{~m}$ a $3 \mathrm{~m}$ de potencia y de poca extensión lateral (<10 m). También se encontraron cuerpos de arenas de geometría tabular que no superan el metro de espesor intercalados con facies pelíticas y un cuerpo tabular constituida de tobas masivas (Tm), interpretado como un depósito piroclástico de caída en zonas distales. Con respecto a las microfacies, las arenas de esta unidad están integradas enteramente por microfacies de rocas epiclásticas silicoclásticas (RES) que sugieren procesos de transporte discretos de los materiales clásticos y una procedencia relacionada directamente al basamento cristalino.

Sobre la base del arreglo de litofacies y microfacies, el diseño de superposición y las estructuras primarias, esta unidad puede ser atribuida a un ambiente fluvial silicoclástico caracterizado por dos sistemas de acumulación principales. Por una parte, aparece un importante registro de depósitos asignados a planicies de inundación (Pl(a), Sh y St) (Bridge, 2006), y por otra, se identifican sedimentos gruesos que son el producto del relleno de canales (dunas subácueas o megaóndulas tridimensionales) (Bridge, 2006). Los depósitos de planicie de inundación poseen dos asociaciones de facies, una en la que prevalecen los depósitos finos de decantación y otra en la que se identifican materiales más gruesos producidos por acumulaciones de carga traccional, interpretados como rellenos de canales/lóbulos de desbordamiento. La geometría, el arreglo y composición de estas facies y su vinculación con amplios tramos dominados por materiales finos de planicie de inundación y depósitos de crecidas, permiten interpretar un sistema fluvial de carga mixta (Collinson, 2002; Bridge, 2006). La ausencia de formas de acreción lateral sumado a la elevada participación de depósitos de planicie de inundación y el escaso desarrollo lateral de los canales indican sistemas fluviales de baja sinuosidad (Miall, 1996; Collinson, 2002). 


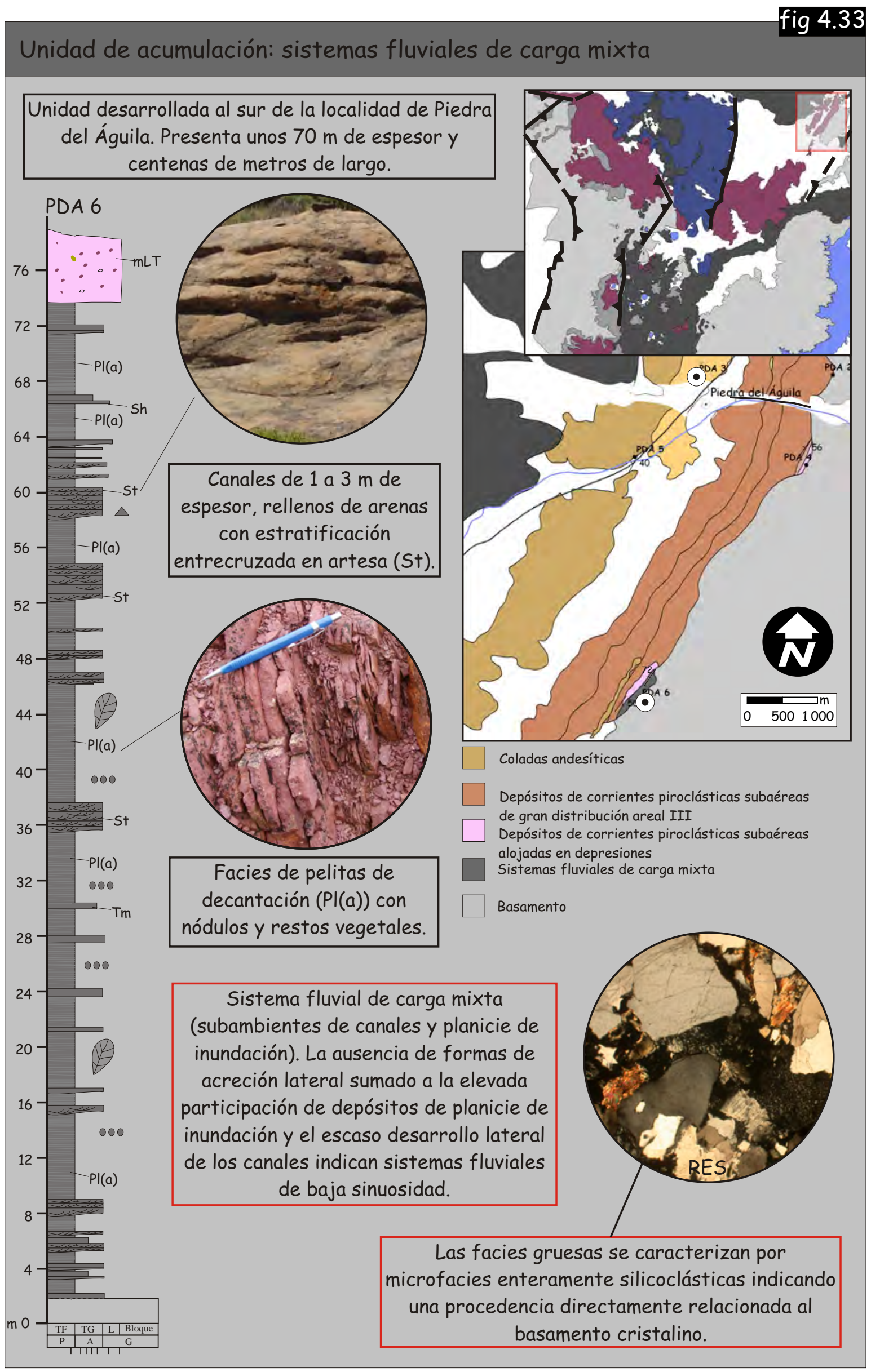

Figura 4.33. Unidad de acumulación: sistema fluvial de carga mixta. 


\subsubsection{Sistema de delta de grano grueso/lacustre}

Esta unidad de acumulación presenta geometría tabular a cuneiforme, de unos cientos de metros de ancho y un espesor máximo de $35 \mathrm{~m}$ (fig. 4.34). Se constituye por una gran variedad de facies que se presentan en dos asociaciones bien distintivas: asociaciones de facies de grano grueso y asociaciones de facies de grano fino. La asociaciones de facies de grano grueso están representadas por conglomerados finos con estratificación entrecruzada a gran escala (Gp(a)), con base suavemente erosivas, de hasta $4 \mathrm{~m}$ de espesor, resultado de la depositación de flujos hiperconcentrados sobre una "cara de avalancha" (Blair y McPherson, 2008). Las facies anteriores son seguidas por capas delgadas de conglomerados finos con estratificación horizontal (Gh) y facies de areniscas guijarrosas (SGh), resultado de la depositación de flujos hiperconcentrados (fig. 3.1) y minoritariamente depósitos de areniscas (St, Sp y Sh), producto de la depositación de corrientes diluidas en condiciones de bajo y alto régimen de flujo (fig. 3.1). A grandes rasgos, estas facies conforman una secuencia con geometría tabular que ronda los $20 \mathrm{~m}$ de espesor y presentan un diseño de superposición estratocreciente, pero sin un aumento el tamaño de grano (fig. 4.34). Hacia arriba las facies de grano grueso evolucionan a una sucesión de unos $10 \mathrm{~m}$ de espesor conformada por conglomerados y areniscas guijarrosas con estratificación horizontal, originadas por flujos hiperconcentrados que intercalan con delgadas capas de areniscas producto de la depositación a partir de flujos diluidos (St, Sh) (fig. 4.34). La asociación de facies de grano fino se compone de diferentes facies que varían su arreglo en función de la distancia respecto a las facies de grano grueso. Proximalmente a éstas, las facies de grano fino se caracterizan por depósitos de pelitas laminadas $\mathrm{Pl}(\mathrm{a})$, resultado de la decantación y de arenas con laminación ondulítica (Sr) y minoritariamente facies de calizas silicificadas con laminación estromatolítica (BE) (fig. 3.1). Intercalándose con las anteriores, se encontraron depósitos de arenas con estructuras tractivas (Sp) alojados sobre bases suavemente erosivas, interpretados como flujos traccionales (Reading y Collinson, 2002) de underflow (Blair y McPherson, 2008) y depósitos de flujos hiperconcentrados gravosos y arenosos (Gh y Sm), interpretados como depósitos de flujos friccionales de underflow (Reading y Collinson, 2002). En posición más distal la asociación de facies de grano fino se compone de pelitas laminadas producto de decantación ( $\mathrm{Pl}(\mathrm{a})$ ) y facies de calizas silicificadas con laminación estromatolítica (BE). Respecto a las microfacies presentes en esta unidad, las facies sedimentarias epiclásticas se caracterizan por microfacies constituidas por litoclastos de rocas volcánicas de procedencias variables (REV), mientras que las facies de rocas carbonáticas presentan microfacies con laminación microbial (RCLM).

El arreglo horizontal y vertical de las asociaciones de facies de grano grueso y de grano fino indicaría diferentes subambientes de un sistema deltaico de grano grueso. La asociación de facies de grano grueso representa un subambiente de frente deltaico progradante en dirección NNNE, que hacia la parte superior pasa a un sistema alimentador aluvial (Reading y Collinson, 
2002; Blair y McPherson, 2008). La asociación de facies de grano fino, en función de la ausencia de fósiles marinos y la presencia de estromatolitos laminares que reflejan un medio estresado, se interpretan como un ambiente subácueo en posiciones desde prodelta hacia un offshore lacustre (Blair y McPherson, 2008; Rohais et al., 2008). Respecto a la profundidad de las aguas, la presencia de estromatolitos desarrollados en el subambiente lacustre indicaría una profundidad menor a los $30 \mathrm{~m}$ (Talbot y Allen, 2002), mientras que los espesores de las macroformas $\mathrm{Gp}(\mathrm{a})$ desarrolladas en el frente deltaico (entre $1 \mathrm{~m}$ y $4 \mathrm{~m}$ ) indicarían que las profundidades debieron ser menores (Garcia-Garcia et al., 2006; Blair y McPherson, 2008; Rohais et al., 2008). Por último, es importante destacar que las láminas de estromatolitos silicificadas, que en ocasiones muestran bandas de material silíceo, pueden representar la interacción de estos cuerpos con un sistema de circulación de aguas calientes relacionadas al ambiente volcánico (Kralner y Spöl, 1998). 


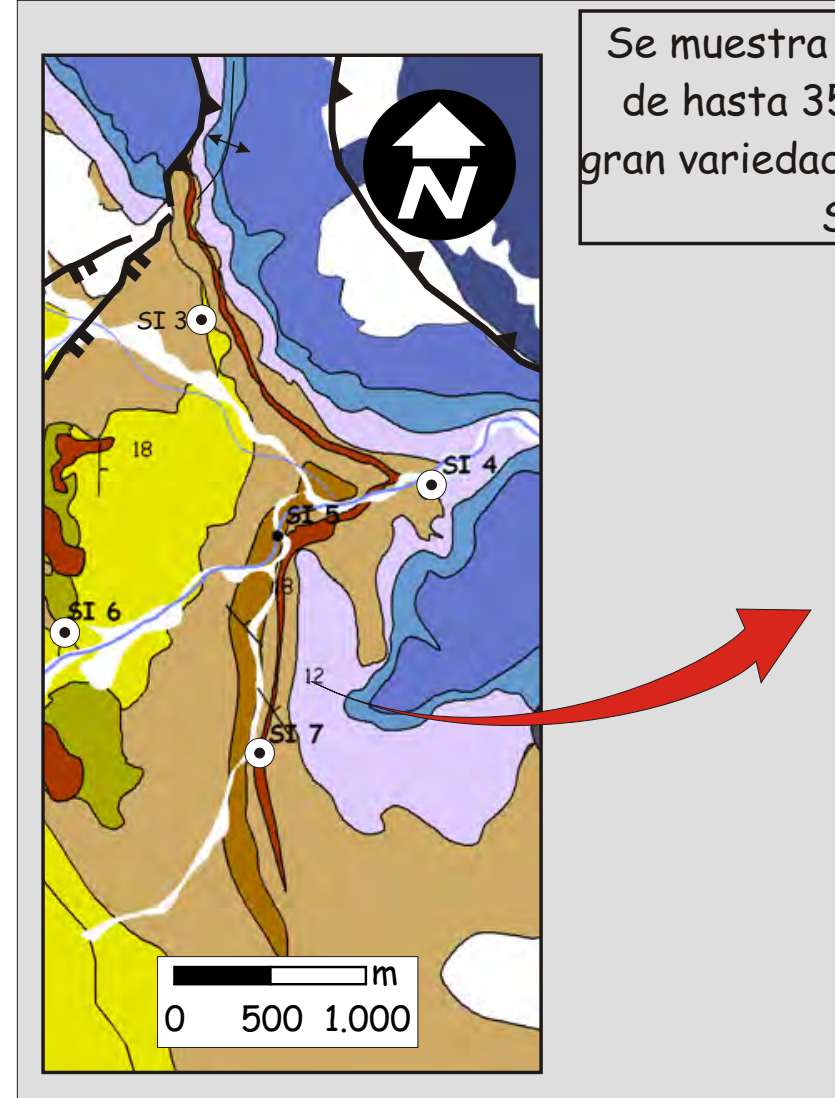

Sistemas de deltas de grano grueso/lacustre

Sistemas aluviales dominados por flujos de detritos

Sistemas aluviales volcaniclásticos dominados por flujos hiperconcentrados

Depósitos de corrientes piroclásticas subaéreas de gran distribución areal II

Depósitos de corrientes piroclásticas subaéreas de gran
distribución areal I

Coladas andesíticas

$\square$ Coladas dómicas riolíticas

$\square$ Domos andesíticos

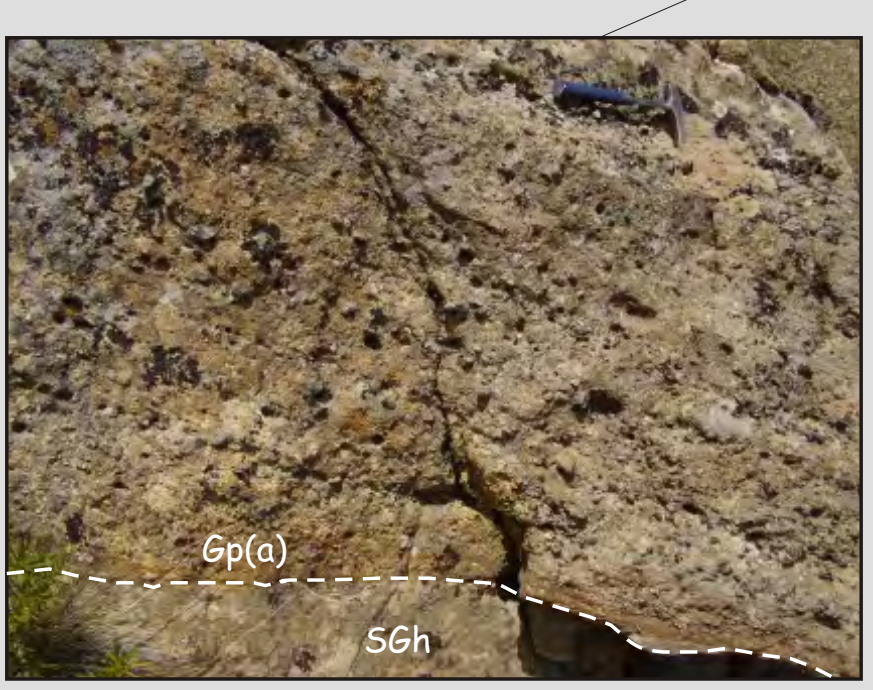

Depósitos de flujos hiperconcentrados gravosos constituyendo el frente deltaico de grano grueso. de facies que presentan dos asociaciones bien distintivas: Asociación de facies de grano grueso (Gh, Gp(a)), SGh $S h, S p$ y St) y asociación de facies de grano fino (PI(a) y Sr) con desarrollo de mudstones algales (BE).

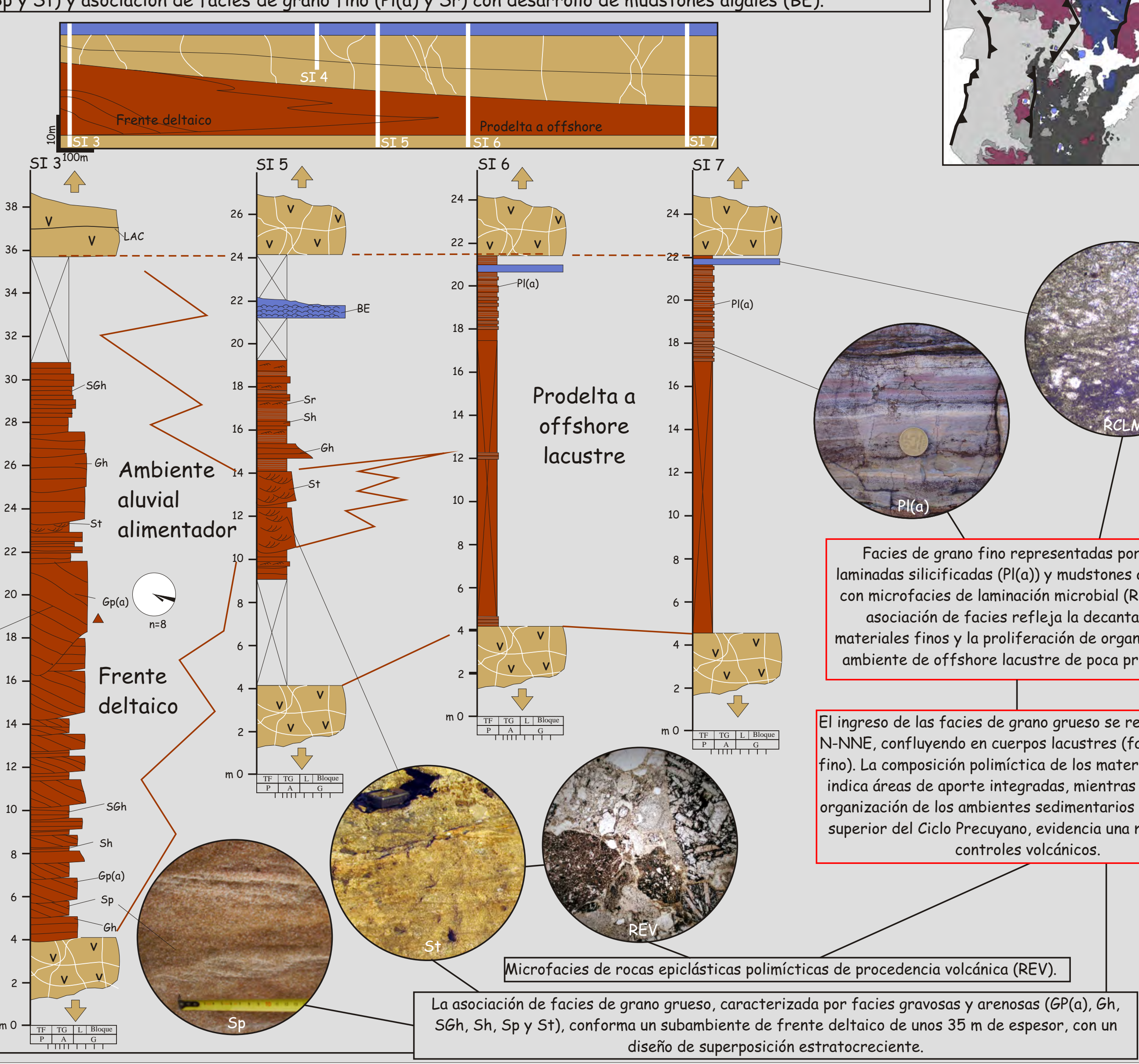
diseño de superposición estratocreciente.

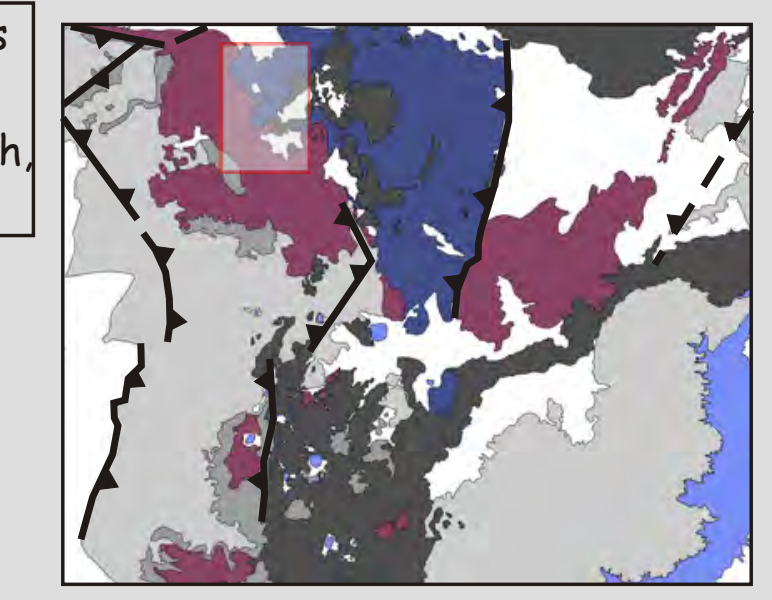




\subsubsection{Sistema de delta de grano fino}

La unidad de acumulación de sistema de delta de grano fino se presenta con una geometría tabular, de unos $50 \mathrm{~m}$ de espesor y cientos de metros de ancho. Se compone mayoritariamente por facies de areniscas, con abundante participación de material piroclástico y con diferentes grados de deformación sinsedimentaria. Las arenas se muestran con diferentes tipos de estructuras traccionales (Sr, Sh, Sp, Shcs, St y SGh) (fig. 3.1) o desarrollando gradaciones internas (Sn) (fig. 3.1 y 4.35). Minoritariamente, se encontraron cuerpos delgados de calizas estromatolíticas con una fina laminación microbial (BE) y facies de psefitas finas con estructuras entrecruzadas (Gp(b), gradacionales (Gn) o masivas (Brm y Gm) (fig. 3.1 y 4.35). En función de los principales procesos depositacionales que dieron origen a las facies presentes en esta unidad (véase capítulo 3), las mismas pueden ser divididas en dos asociaciones de facies, una dominada por la depositación o retrabajo de corrientes unidireccionales u oscilatorias, y la otra dominada por la depositación de flujos eventuales (fig. 4.35). La asociación de facies dominada por depósitos de corrientes se compone principalmente de areniscas con estructuras traccionales, con deformación sinsedimentaria, ocasionalmente bioturbadas ( $\mathrm{Sr}$, Sh, Sp, Shcs y St). Minoritariamente, estas facies presentan depósitos de gravas finas y sabulitas con estratificación entrecruzada planar $(G p(b))$. Es importante destacar que de manera aislada, interdigitándose con éstas se encontraron cuerpos delgados de calizas estromatolíticas con una fina laminación microbial (BE). La asociación de facies dominada por la depositación de flujos eventuales está integrada mayoritariamente por depósitos de flujos densos arenosos, depósitos de flujos hiperconcentrados gravosos y arenosos, con abundante material piroclástico (Gm, Brm y SGh) y minoritariamente depósitos de corrientes de turbidez gravosas y arenosas (Gn y Sn).

Los arreglos lateral y vertical de las facies muestran condiciones agradacionales a suavemente progradacionales, siempre dominadas por una granulometría arenosa, ampliamente relacionadas a condiciones costaneras (shoreface) (Clifton, 2006). El dominio de una granulometría arenosa, sumado a la presencia de deformación sinsedimentaria y la escasa bioturbación, permiten sugerir un sistema deltaico de grano fino (Reading y Collinson, 2002; Bhattacharya 2006). A su vez, las asociaciones de facies dominadas por depósitos de corrientes tractivas, y minoritariamente depósitos de flujos eventuales, indican un ambiente costanero deltaico influenciado por olas y por procesos fluviales (Reading y Collinson, 2002; Bhattacharya 2006). 

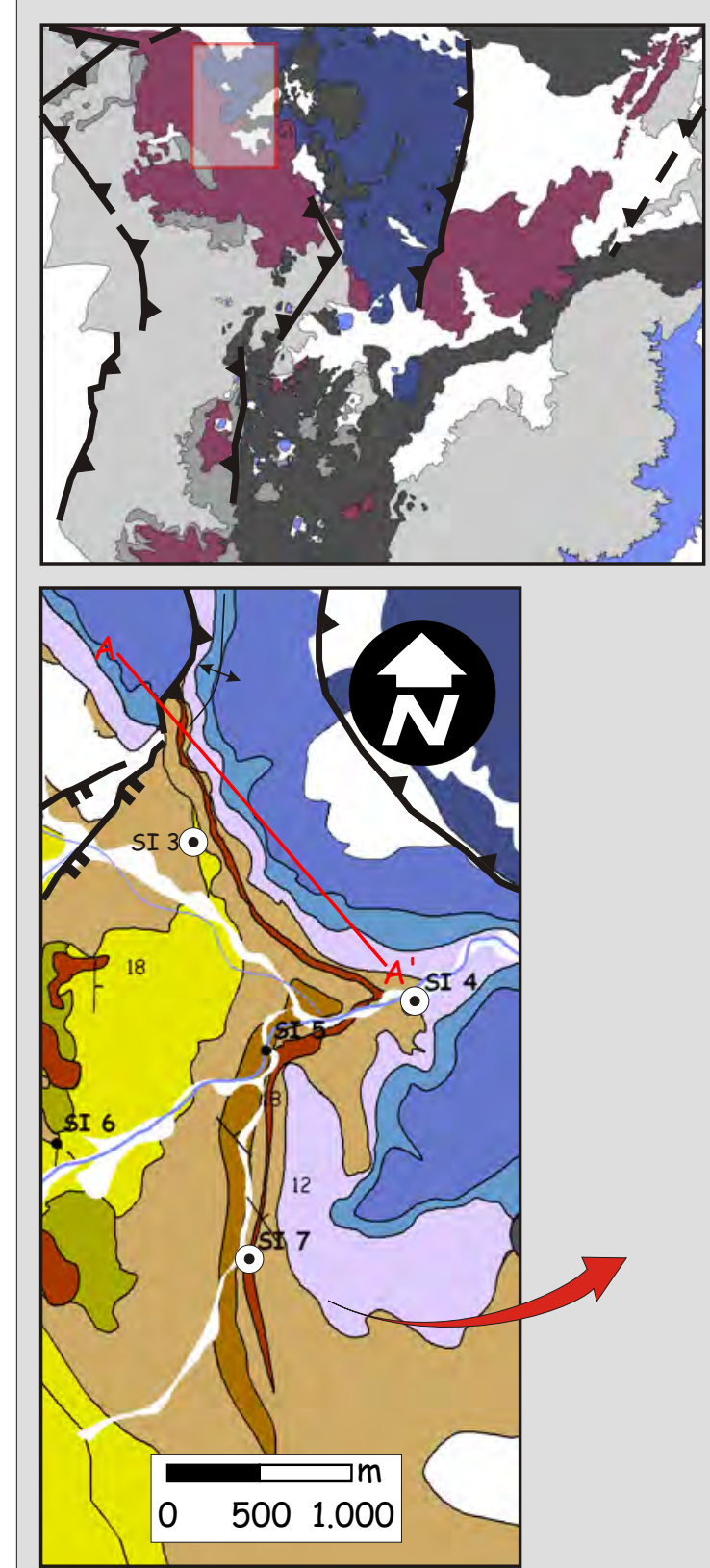

Ambiente marino somero carbonático

$\square$ sistemas deltaicos de grano fino

Sistemas de deltas de grano grueso/lacustre

Sistemas aluviales dominados por flujos de detritos

Sistemas aluviales volcaniclásticos dominados por flujos hiperconcentrados

Depósitos de corrientes piroclásticas Depósitos de cor
subácueas

Depósitos de corrientes piroclásticas
subaéreas de gran distribución areal II

Deeósitos de corrientes piroclásticas
subaéreas de gran distribución areal I

$\square$ Coladas andesíticas

$\square$ Coladas dómicas riolíiticas

$\square$ Domos andesíticos
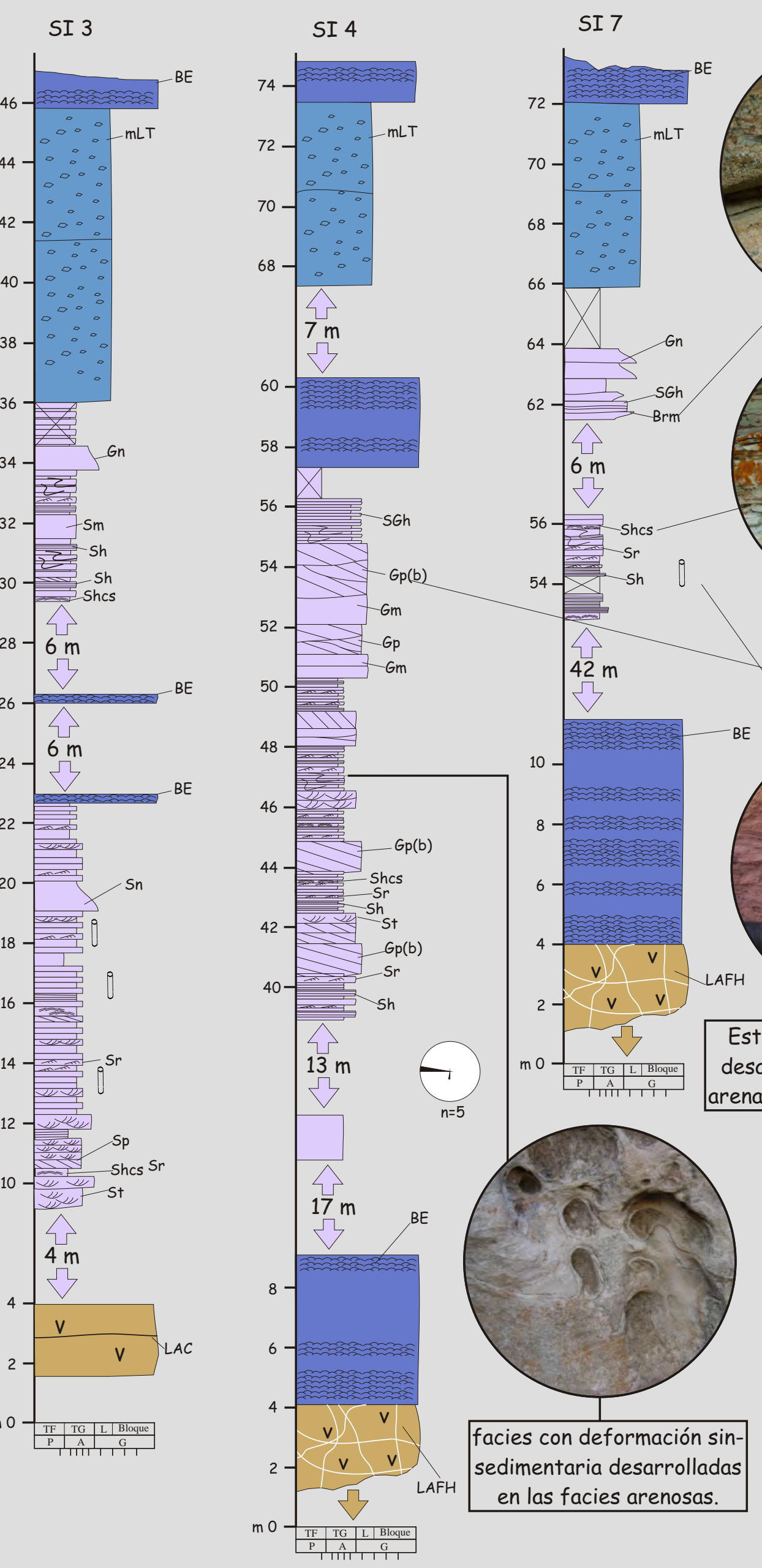

Esta unidad aparece al $\mathrm{N}$ de Sañicó en la parte basal del Ciclo Cuyano sobre depósitos carbonáticos de ambiente marino somero. Se presenta con unos $60 \mathrm{~m}$ de espesor y cientos de metros de largo. Se compone mayoritariamente por facies de arenas con abundate participación de material piroclástico ( $S r$, Sh, Sp, Shcs, St, Sn, Sin y SGh) y minoritariamente de psefitas inas $(G p(b), G m, G n$ y Brm). Eventualmente aparecen capas delgadas de calizas algales estromatoíticas (BE).

Presenta dos asociaciones de facies: a) asociación de facies originada por el retrabajo o sedimentación a partir de corrientes oscilatorias o unidireccionales (Sr, Sh, Sp, Shcs, St y Gp(b)) y b) asociación de facies desarrollada por la depositación de flujos eventuales densos (Brm, Sin, Gm, SGh, Sn, Gn).

gran participación de granulometría psamítica en esta unidad la define como un cuerpo ampliamente relacionado a condiciones costaneras. La presencia de deformación sinsedimentaria, la escasa bioturbación y dominio de asociaciones de facies dominadas por depósitos de corrientes y minoritariamente depósitos de flujos eventuales, indican un ambiente deltaico influenciado por oleaje y ocasionalmente por procesos fluviales. La elevada participación de material piroclástico indicaría la influencia de volcanismo en los tramos basales del Ciclo Cuyano.

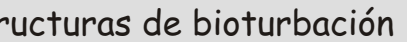
desarrolladas en las facies de a con laminación ondulítica.
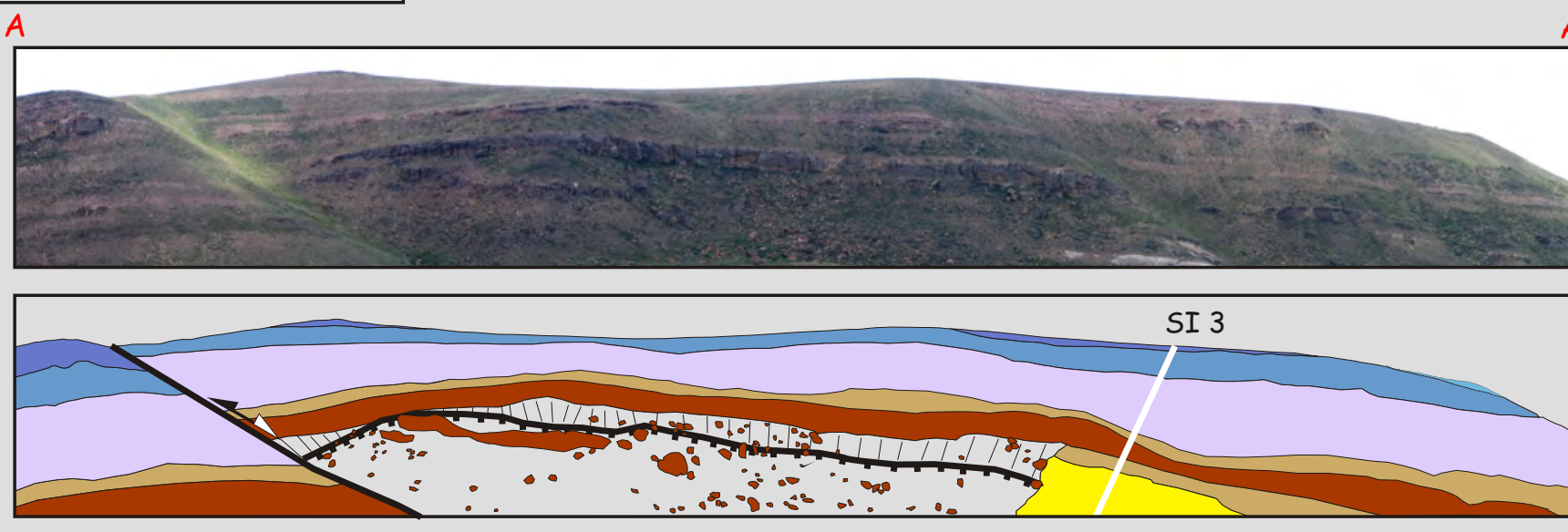

Se presenta con geometría tabular, espesores de hasta $60 \mathrm{~m}$ y cientos de metros extensión lateral. En sentido vertical se puede apreciar un arreglo agradante a suavemente progradante. 
4.6.2 Unidades de acumulación epiclásticas marinas

\subsubsection{Ambiente marino de costa afuera (offshore)}

Se caracteriza como una unidad potente de decenas de metros de espesor y gran distribución lateral. Internamente se compone de facies de lutitas negras ( $\mathrm{Pl}(\mathrm{b})$ ) con abundantes restos de invertebrados marinos que se intercalan con facies de arenas con estructuras gradacionales (Sn, Sin), las cuales presentan en su parte superior gran cantidad de restos de vegetales y en ocasiones estructuras tractivas. Minoritariamente, aparecen depósitos psefíticos clasto y matriz sostén (Gn y Gmm(b)), desarrollados en mantos o en pequeños canales. Es importante destacar que en determinados sectores las facies que componen esta unidad mostraron fallas extensionales de pequeña escala, con orientaciones N-S y NE-SW y desmoronamientos con microfallas extensionales y compresivas (fig. 4.36).

En función del arreglo de facies y de los procesos depositacionales intervinientes se pueden establecer dos tipos diferentes de asociaciones de facies para esta unidad. Por un lado, se destaca la asociación de facies constituida por depósitos de decantación submarina en condiciones anóxicas, de baja circulación, con abundantes restos de invertebrados marinos (Pl(a)) (fig. 3.1) (Stow et al., 2002; Posamentier y Walker, 2006). Por otro lado, los depósitos delgados de corrientes de turbidez, mayoritariamente arenosos (Sn) y minoritariamente gravosos (Gn), los depósitos de flujos de detritos cohesivos (Gmm(b)) y los flujos densos estratificados (Sin), representan una asociación de facies de depósitos eventuales de resedimentación submarina (fig. 3.1) (Stow et al., 2002; Posamentier y Walker, 2006). La mayoría de los eventos de resedimentación se generan en manto, aunque minoritariamente han tenido lugar en pequeños canales submarinos $(\mathrm{Gn})$. La presencia de estructuras tractivas desarrolladas en el tope de los depósitos de corrientes de turbidez arenosos indican retrabajo por parte de corrientes de fondo submarinas (Shanmugam, 2002). Por todas estas razones, la interpretación dinámica y el arreglo de las asociaciones de facies presentes indican depósitos de ambiente marino por debajo de la acción de olas, de bajo gradiente, con baja relación arena/arcilla. La ausencia de secuencias que indiquen la progradación de lóbulos sugieren un ambiente de bajada submarina, mientras que la presencia de restos vegetales en los depósitos de resedimentación arenosos, indicarían un probable aporte desde un frente deltaico (Stow et al., 2002). 
Los depósitos de esta unidad apoyan sobre una discontinuidad sobre rocas del Ciclo Precuyano y el basamento cristalino y en concordancia sobre depósitos de ambiente marino somero de la parte basal del Ciclo Cuyano. Los depósitos de ambiente marino profundo se encuentran bien representados al este de Sañicó. Esta unidad está constituida por facies de lutitas negras y minoritariamente limolitas, resultado de decantación $(P(b))$ y flujos densos submarinos eventuales $(G n, S n, G m m(b))$.
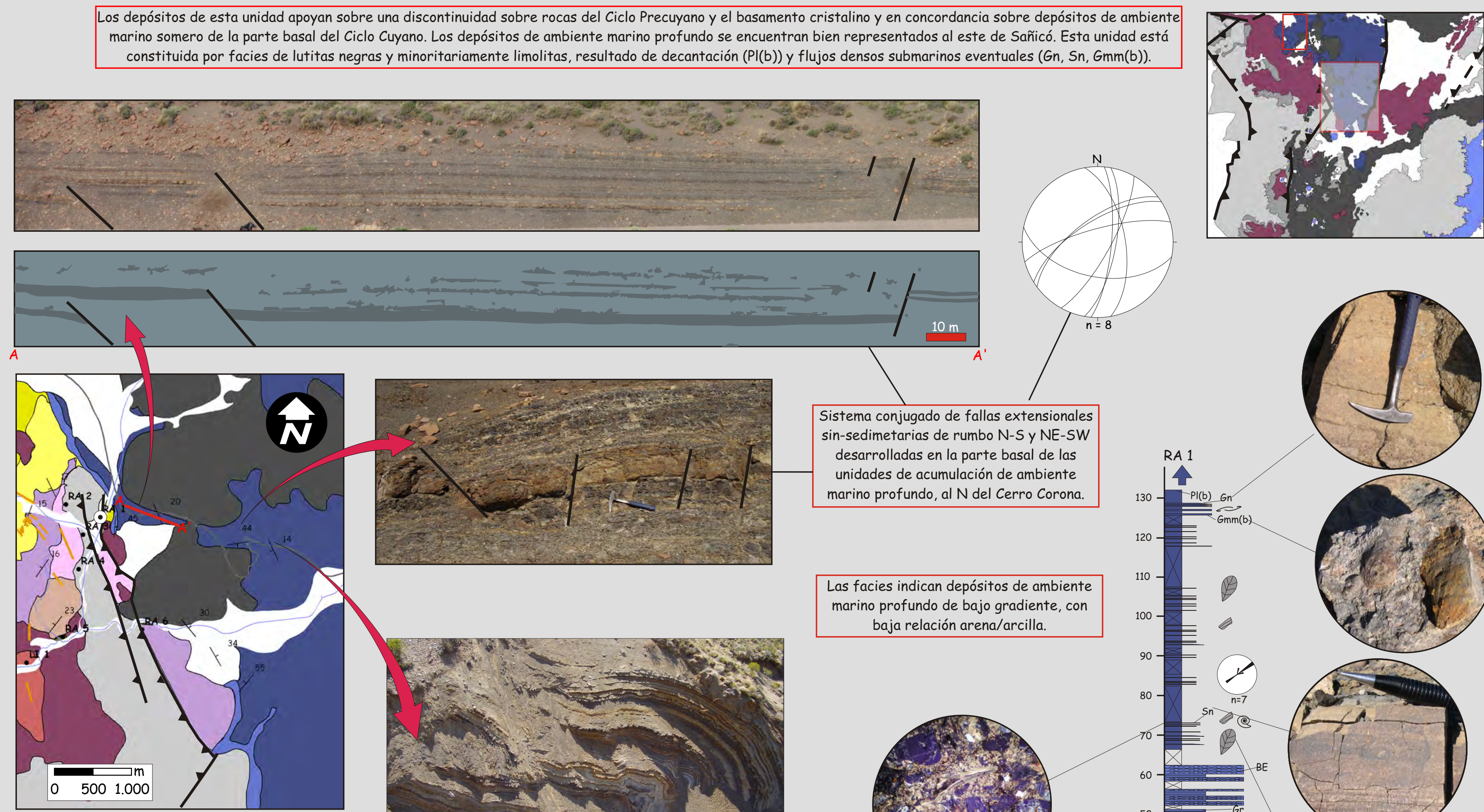

sin-sedimetarias de rumbo N-S y NE-SW desarrolladas en la parte basal de las unidades de acumulación de ambiente marino profundo, al $\mathrm{N}$ del Cerro Corona.
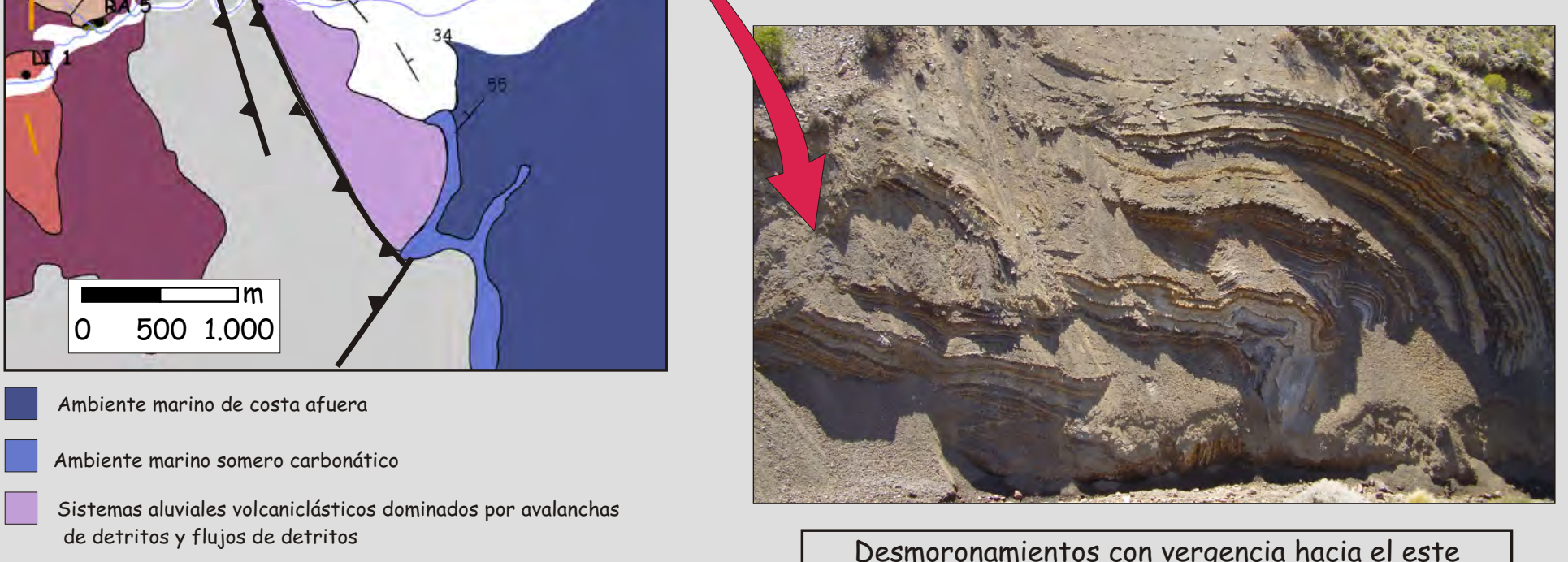

Sistemas aluviales volcaniclásticas dominados por flujos os alojados en depresiones

Depósitos de corrientes piroclásticas subaéreas alojadas en

Criptodomos riodacíticos

Coladas y coladas dómicas andesíticas

$\square$ Basamento
Desmoronamientos con vergencia hacia el este

desarrollados al $\mathrm{N}$ del Cerro Corona. Internamente desarrollan fallas extensionales y compresivas.

\section{as facies indican depósitos de ambiente marino profundo de bajo gradiente, con baja relación arena/arcilla.}
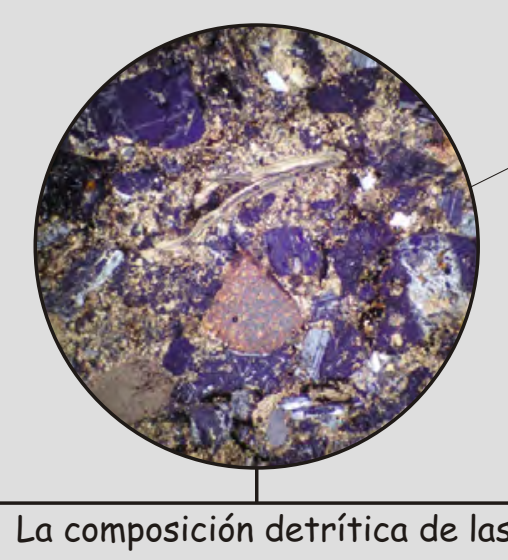
facies gruesas se constituye principalmente de facies polimícticas de procedencia volcaniclástica con restos de rocas carbonáticas y de invertebrados.

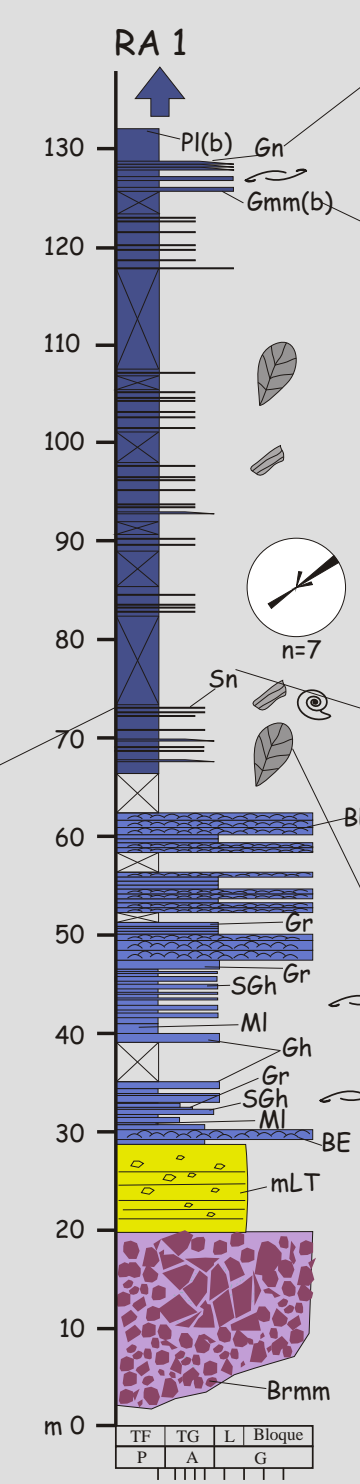

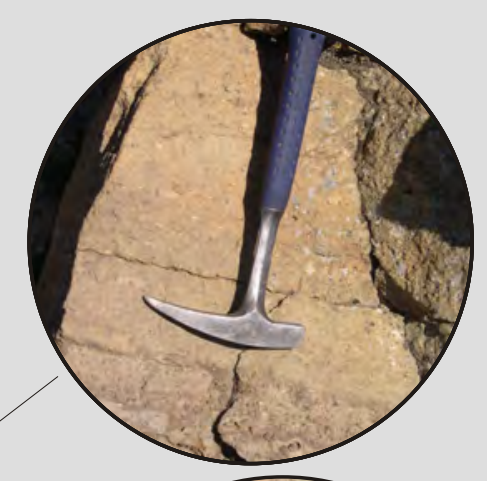
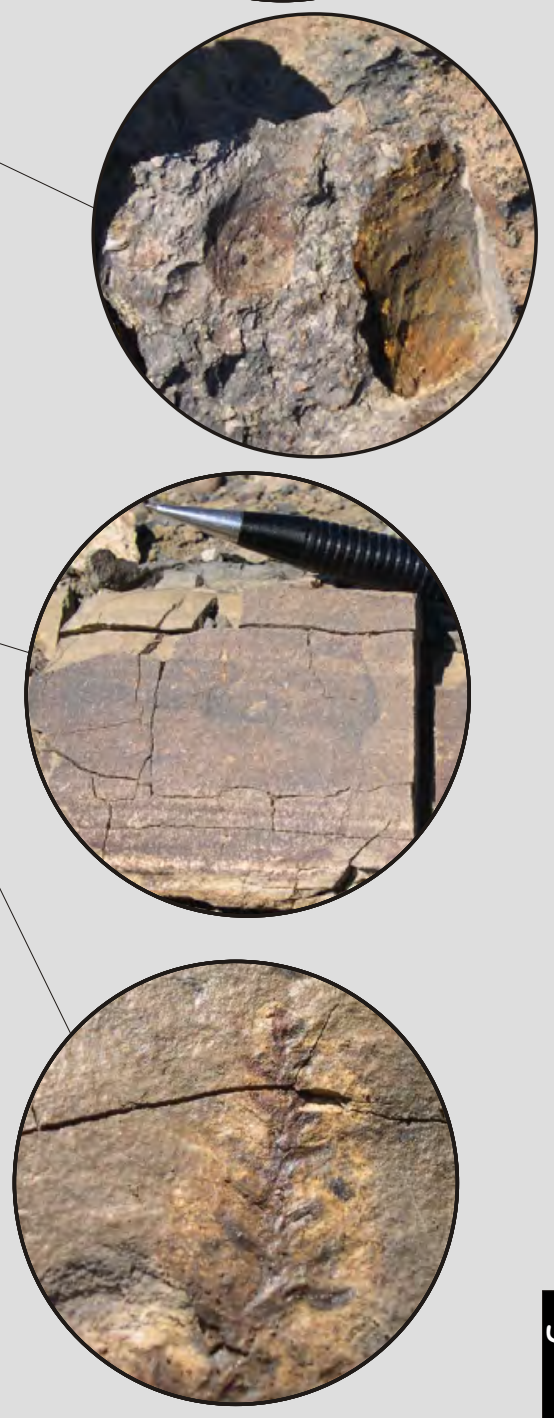


\subsubsection{Unidad de acumulación carbonática marina}

\subsubsection{Ambiente marino somero carbonático}

Esta unidad se muestra con geometría tabular, gran distribución areal y un espesor máximo de $30 \mathrm{~m}$. Se apoya en discordancia o paraconcordancia sobre diferentes unidades correspondientes al Ciclo Precuyano y en ocasiones no concordante sobre rocas del basamento ígneo-metamórfico. A pesar de la gran distribución que muestra esta unidad, sólo presenta características dignósticas en algunos sitios reducidos del área de estudio, debido a la importante modificación que exhibe por parte de procesos postdepositacionales (silicificación). Está integrada por litofacies de calizas de tipo boundstone con estromatolitos (BE), mayoritariamente columnares y bulbosos y minoritariamente laminares; grainstones peloidales y esqueletales (Gr), en ocasiones con estructuras traccionales; y mudstones laminados (Ml) (fig. 3.1 y 4.37). De manera restringida se encontraron facies gravosas $(\mathrm{Gm})$ y arenosas (SGh) constituidas por intraclastos de las facies estromatolíticas, fragmentos carbonáticos sin estructura reconocible y litoclastos volcánicos de composiciones variables (fig. 4.37). Respecto a las particulares petrográficas de esta unidad, se caracteriza por microfacies de rocas carbonáticas con laminación microbial (RCLM) y microfacies de grainstones y mudstones (microfacies RCG y RCM).

Las características de las asociaciones de facies totalmente dominadas por rocas carbonáticas indican un ambiente de plataforma carbonática favorable para la proliferación de organismos bioconstructores. Estas condiciones se generaron en aguas tranquilas, de baja energía, aporte terrígeno ausente y poca profundidades (<20 m) (Wright y Burchette, 2002; Leeder, 1999). Eventualmente, las facies Gm y SGh indican periodos de destrucción de la plataforma carbonática. 
Unidad de acumulación: ambiente marino somero carbonático

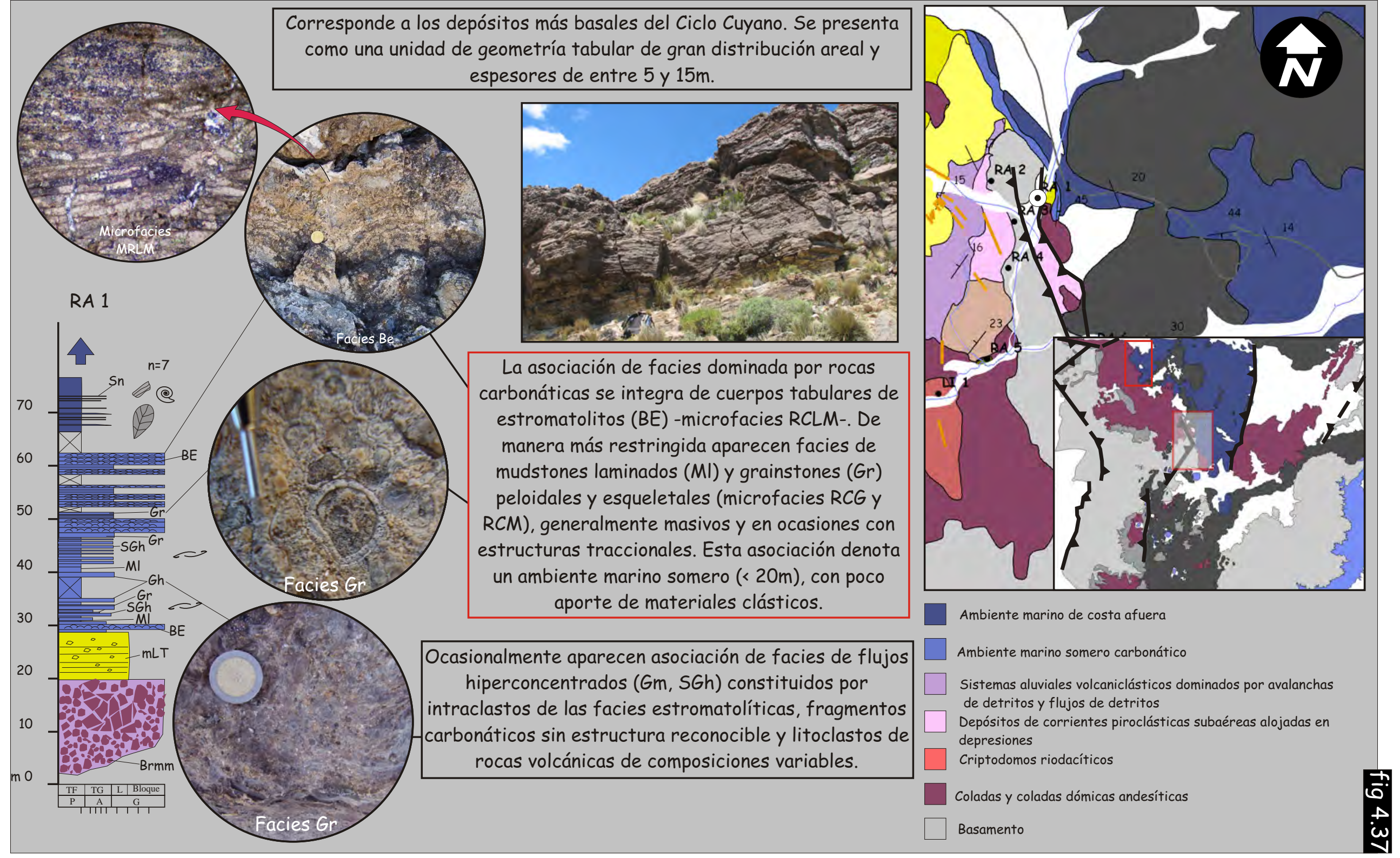

Figura 4.37. Unidad de acumulación: ambiente marino somero carbonático. 


\section{Capítulo 5 - Organización de las unidades de acumulación del Ciclo Precuyano y Cuyano basal en el espacio y tiempo}

\section{1) Introducción}

En el capítulo previo se identificaron las diferentes unidades de acumulación (volcánicas, piroclásticas y sedimentarias) que integran al relleno precuyano y la base del Ciclo Cuyano. El estudio y la discriminación de las unidades de acumulación muestra la existencia de variaciones genéticas y espacio-temporales así como fuertes variaciones de espesor a ambos lados de fallas inversas de alto ángulo y lineamientos, habiéndose interpretado el control tectónico/volcano-tectónico extensional para el relleno inicial y la determinación de áreas depocentrales. Estos rasgos deben ser evaluados de manera integral. La correlación de las columnas estratigráficas del Ciclo Precuyano y Ciclo Cuyano, sugieren que las fuertes variaciones de espesores pueden ser observadas en diferentes sectores del área de trabajo (fig. 5.2). En la zona occidental del área de estudio los espesores del Ciclo Precuyano varían en sentido NW-SE, de manera muy asimétrica, desde espesores cercanos a los $1200 \mathrm{~m}$ al noroeste, hasta espesores que rondan los $220 \mathrm{~m}$ al sureste, estando ausente en las proximidades del Cerro Corona (fig. 5.2). En sentido perpendicular, en dirección suroeste, los espesores del Ciclo Precuyano disminuyen notablemente, mientras que en dirección noreste son cubiertos por depósitos marinos correspondientes al Ciclo Cuyano (fig. 5.1). En la parte central del área de estudio, al norte y este del Cerro Corona los depósitos de la base del Ciclo Cuyano apoyan sobre espesores mínimos del Ciclo Precuyano (<50 m) y sobre rocas del basamento (fig. 5.1 y 5.2). No obstante, al sureste del Cerro Corona las rocas del Ciclo Cuyano apoyan sobre alrededor de unos 220 m de rocas correspondientes al Ciclo Precuyano que se sumergen hacia el ESE. Las columnas parciales levantadas para el Cuyano basal y las columnas levantadas hasta base del Cuyano cuspidal indican que los espesores del Ciclo Cuyano basal aumentan hacia el este (fig. 5.2). Los espesores máximos se encontraron en el Cerro Vasco, donde se midieron $220 \mathrm{~m}$. Es importante subrayar que entre el Cerro Vasco y el Cerro Roth, en la base de la columna Piedra Pintada (PP) (véase anexo II) se muestran sedimentitas cuyanas apoyando sobre lavas interpretadas como unidades de acumulación pertenecientes al Ciclo Precuyano (fig. 5.2). En dirección norte se puede apreciar cómo los afloramientos del Ciclo Cuyano continúan, mientras que hacia el sur disminuyen hasta desaparecer sobre rocas del basamento y escasos afloramientos del Ciclo Precuyano (fig. 5.1). La parte oriental del área de estudio se caracteriza por la existencia de afloramientos del Ciclo Precuyano que alcanzan su máximo espesor (1300 m) en las inmediaciones de la localidad de Piedra del Águila, disminuyendo su espesor hacia el 
oeste y el suroeste, donde alcanzan el espesor mínimo (fig. 5.2). En este sector del área de trabajo los afloramientos del Ciclo Cuyano se encuentran ausentes.

Si se tiene en cuenta la distribución y variación de los espesores del Ciclo Precuyano y Cuyano, las tres áreas morfoestructurales definidas en el capítulo introductorio (zona oriental de Piedra del Águila, zona central de la Pintada y zona occidental de Sañicó) se corresponden con áreas que controlaron el espacio de acomodación para los depósitos del Jurásico Inferior del sur de la Cuenca Neuquina (fig. 5.2). Se proponen denominar a estas tres áreas de acomodación como:

- Depocentro de Sañicó

- Depocentro de la Pintada

- Depocentro de Piedra del Águila

Los límites de estos depocentros son precisados por estructuras visibles hoy como fallas inversas y redefinidas en función del control que ejercieron sobre las secuencias precuyanas y cuyanas como fallas extensionales reactivadas. Es importante destacar que no todas las estructuras inversas representan fallas extensionales invertidas, habiéndose constatado que muchas de ellas no habrían participado en la acomodación de los depósitos del inicio del la cuenca. Entre ellas se pueden mencionar a las fallas de orientación NNE-SSW y NW-SE desarrolladas hacia el borde occidental del área de estudio (fig. 5.2).

El depocentro de Sañicó es el depocentro más occidental del área de estudio. Se trata de un hemigraben de $27 \mathrm{~km}$ de ancho, de orientación NE-SW con polaridad hacia el sureste, limitado por fallas de orientación NE y ENE. Internamente presenta estructuras oblicuas de rumbo ENE y NNW y bloques que presentan subsidencia diferencial (fig. 5.2). En efecto, en su extremo sureste se puede apreciar que el área del Cerro Corona constituye un alto que controló fuertemente el espesor de las secuencias precuyanas. Al sureste de este alto, los depósitos precuyanos con espesores de alrededor de 200 se sumergen por debajo de sedimentitas del Ciclo Cuyano. Este sector se define como el límite de menor acomodación del depocentro de Sañicó. Es importante destacar que este depocentro coincide con el área de las unidades de acumulación piroclástica de gran distribución areal I y II definidas en el capítulo previo.

El depocentro de la Pintada se desarrolla en la parte central del área de trabajo. Corresponde a un hemigraben de rumbo N-S, de un ancho máximo de $20 \mathrm{~km}$, con polaridad hacia el oeste (fig. 5.2). Se caracteriza por afloramientos del Ciclo Cuyano que sobreyacen a depósitos del Ciclo Precuyano con espesores mínimos. Se halla limitado al este por una falla de rumbo N-S a NNE-SSW, la cual restringe la distribución de los depósitos del Ciclo Cuyano hacia el este (fig. 5.2). Hacia el oeste, los depósitos del Ciclo Cuyano yacen sobre rocas del Ciclo Precuyano y del basamento. 


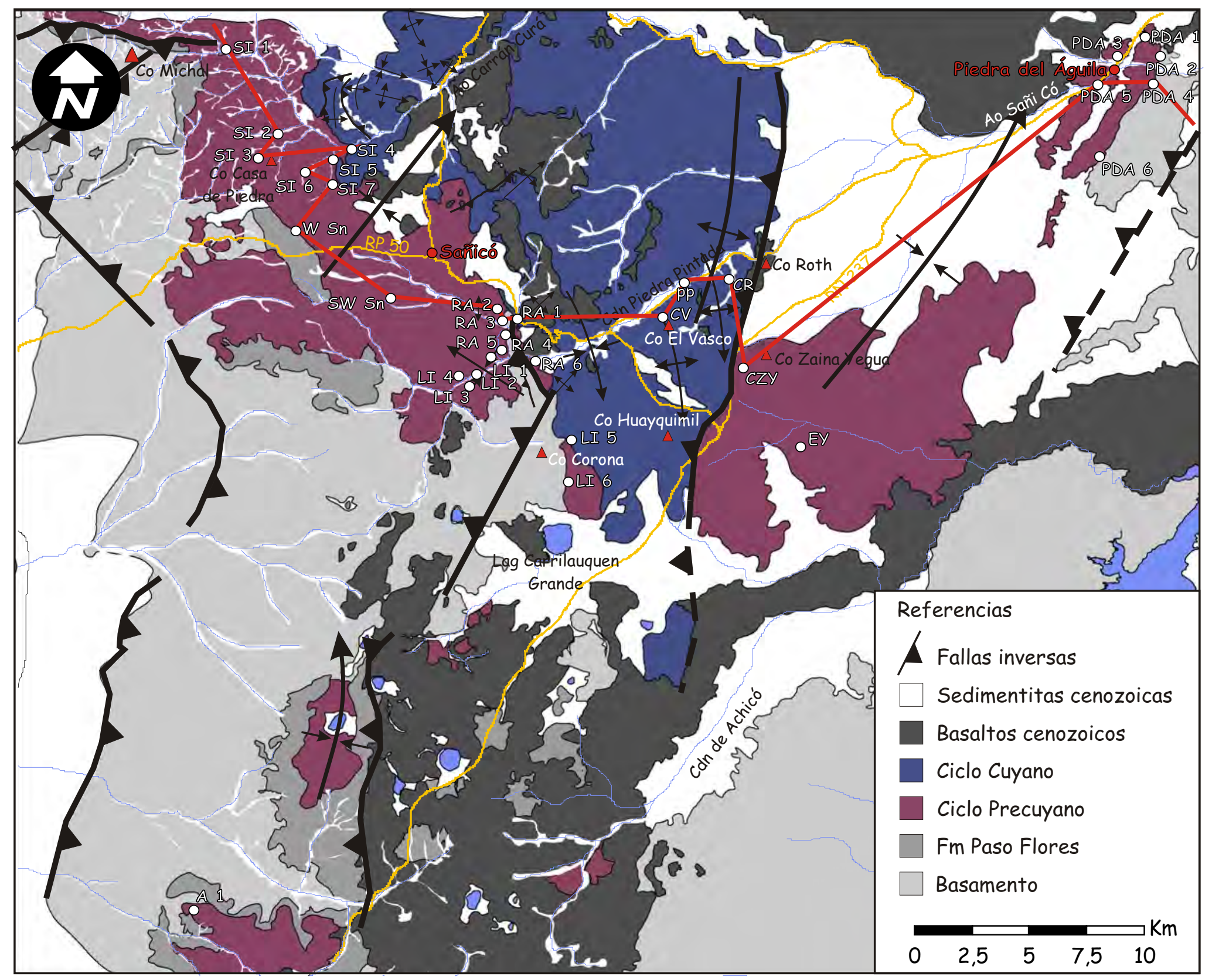

Figura 5.1. Distribución del Ciclo Precuyano y Cuyano en el área de estudio. Se muestra transecta elejida para efectuar el panel de correlación sobre la base de las columnas levantadas en el area de estudio (véase fig. 5.2). 


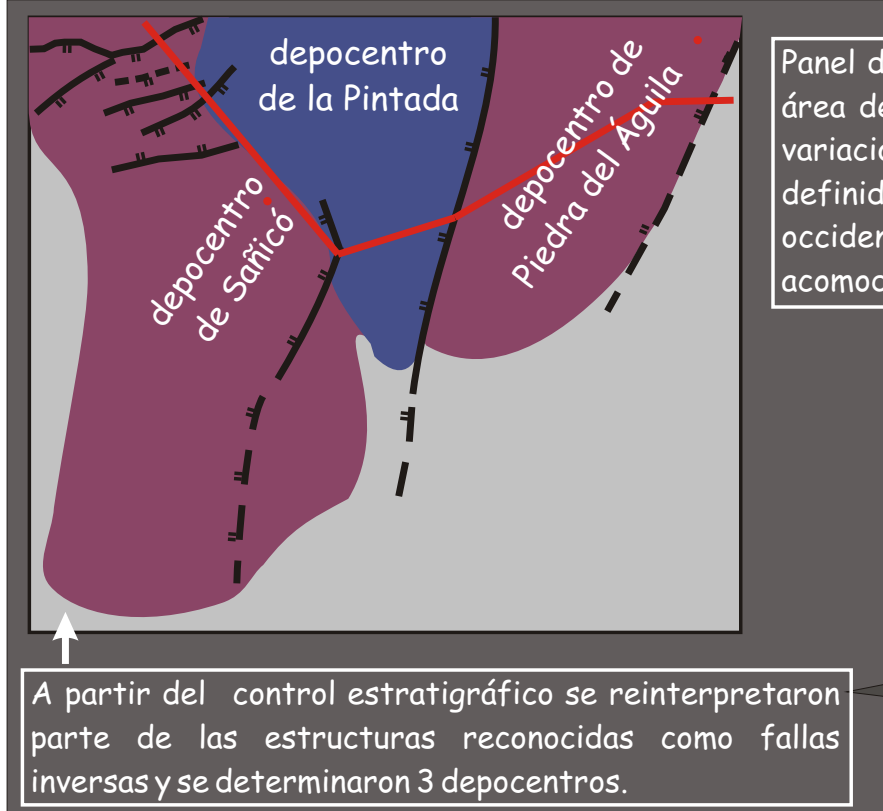

C $C^{\circ}$ Los Muleros

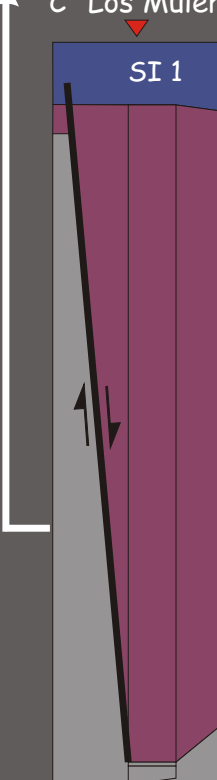

Panel de correlación estratigráfico realizado con las columnas levantadas para el área de estudio. Los espesores del Ciclo Precuyano y Cuyano presentan fuertes variaciones que corresponden con las 3 áreas morfoestructurales previamente efinidas (zona oriental de Piedra del Águila, zona central de la Pintada y zona ccidental de Sañicó). Estas 3 zonas responden a áreas que controlaron la comodación para los depósitos del Jurásico inferior del sur de la Cuenca Neuquina.
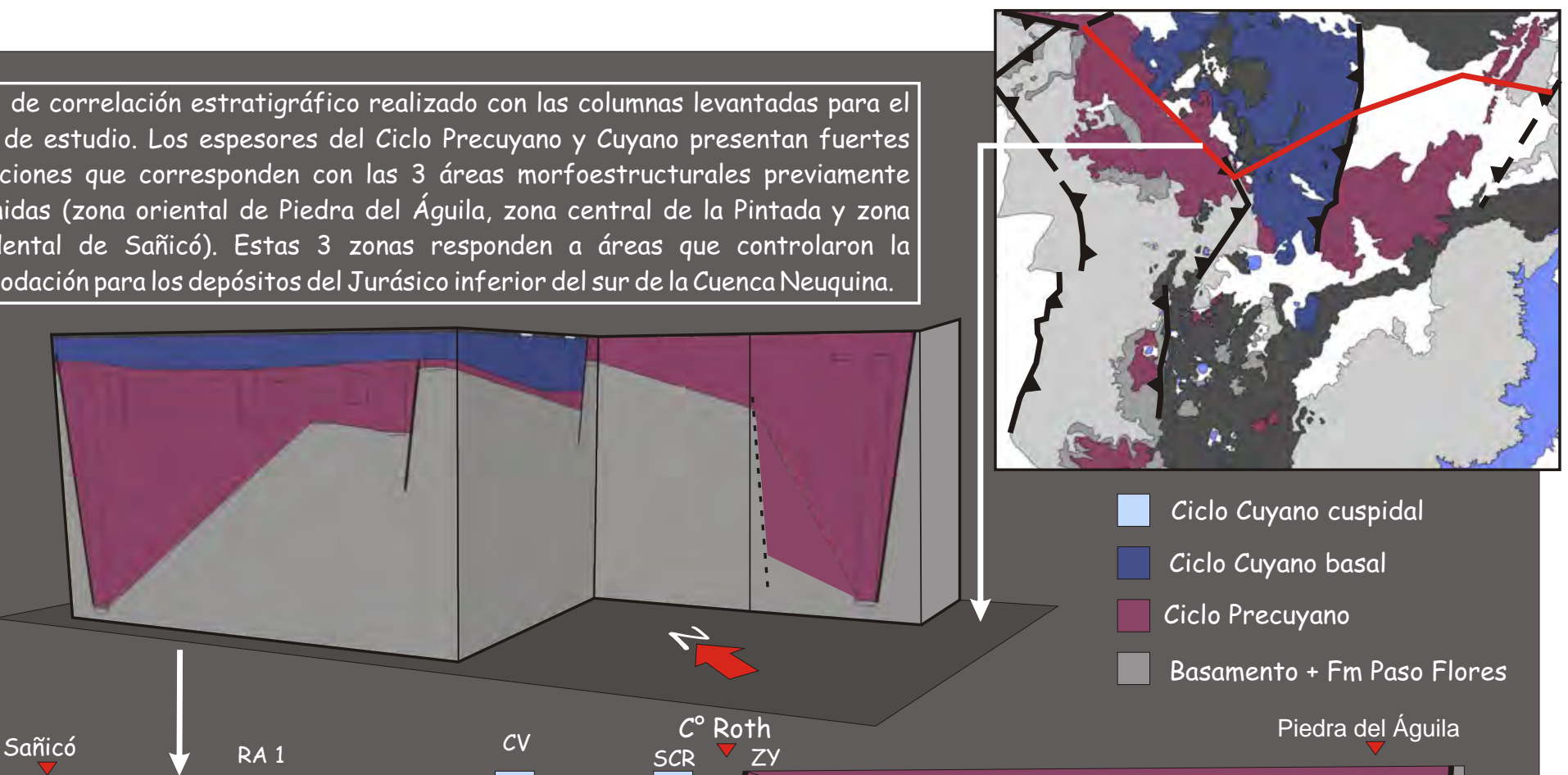

Ciclo Cuyano cuspidal

Ciclo Cuyano basal

Ciclo Precuyano

Basamento + Fm Paso Flores Piedra del Águila PDA 5 PDA 2

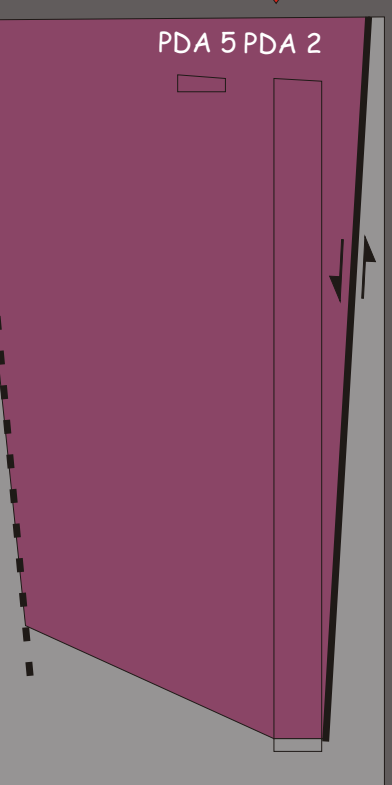


El depocentro de Piedra del Águila se halla en la parte oriental del área de estudio y se encuentra relleno enteramente por depósitos del Ciclo Precuyano (fig. 5.2), fuertemente invertido, sin poderse reconocer las fallas que acomodaron las secuencias precuyanas. La parte más profunda se halla en las inmediaciones de la localidad de Piedra del Águila y coincide con el área de acomodación para los depósitos de corrientes piroclásticas de gran distribución areal III (véase capítulo previo). Fuera de este sector el relleno se sumerge por debajo de basaltos cenozoicos hacia el noroeste (fig. 5.1) y disminuye fuertemente su espesor hacia el este. Es importante destacar que, al igual que el depocentro de Sañicó, aflora en sentido NE-SW, habiéndose interpretado a la falla NE situada hacia el Macizo Norpatagónico como la estructura que habría controlado las secuencias precuyanas de este depocentro (fig. 5.2).

\section{2) Organización de las unidades de acumulación del Ciclo Precuyano y Cuyano inferior dentro de los depocentros}

En el presente apartado se analizará la distribución específica las asociaciones de unidades de acumulación dentro de los tres depocentros definidos, teniendo en cuenta las relaciones espaciales, composicionales y formacionales. La integración de las unidades volcánicas, piroclásticas y sedimentarias dentro de un esquema genético para cada área de acomodación otorgará un marco claro y propicio para la discusión de los controles más relevantes que tuvieron lugar en la etapa inicial para este sector de la cuenca.

5.2.1) Las unidades de acumulación del Ciclo Precuyano y Cuyano inferior dentro del depocentro de Sañicó

A grandes rasgos, el depocentro de Sañicó se encuentra relleno por unidades pertenecientes al Ciclo Precuyano, de índole netamente volcánica y piroclástica, con menor participación de unidades de acumulación sedimentarias (fig. 5.3). El Ciclo Cuyano dentro del depocentro de Sañicó, en cambio, aparece en su parte NE como una faja de afloramientos continua, constituido principalmente por unidades de acumulación sedimentarias epiclásticas (fig. 5.3).

Evaluando la distribución lateral y vertical y la relación entre las unidades volcánicas y piroclásticas, conjuntamente con la composición de las unidades de acumulación epiclásticas, el Ciclo Precuyano de este depocentro puede ser dividido en tres secciones: inferior (DS-1), media (DS-2) y superior (DS-3) (fig. 5.3). Cada una de las secciones puede ser limitada por una superficie de discontinuidad que se expresa en todo el depocentro a través de discordancias o sus concordancias correlativas. 
La sección inferior (DS-1) se caracteriza por la acumulación de unidades lávicas y secundariamente por unidades piroclásticas y sedimentarias epiclásticas resultado de la resedimentación y retrabajo de las primeras. Presenta su espesor máximo hacia el noroeste (1100 m), en el Cerro Los Muleros, posicionado en las proximidades de la falla de borde del hemigraben, donde apoya en fuerte discordancia angular por sobre la Formación Paso Flores (fig. 5.3). Su espesor dentro del depocentro es altamente variable, reflejando un control estructural por parte de las fallas extensionales oblicuas a los bordes del mismo. Hacia el sureste, en las zonas aledañas al Cerro Corona, esta sección apoya sobre el basamento, mientras que en dirección oeste apoya en concordancia o suave discordancia sobre las sedimentitas de la Formación Paso Flores. Al noroeste del Cerro Corona, en una dirección paralela a las fallas presentes, la sección inferior muestra espesores que van desde los $60 \mathrm{~m}$ a los $300 \mathrm{~m}$, describiendo una geometría de sinforme perpendicular a las fallas (fig. 5.3). Internamente la sección inferior presenta un arreglo similar en ambos bordes del depocentro. Comienza generalmente con una potente secuencia de coladas y coladas dómicas de composición andesítica, desarrollando hacia arriba unidades de acumulación aluvial dominadas por depósitos de flujos de avalanchas de detritos y flujos de detritos intercaladas minoritariamente con unidades de acumulación de depósitos de corrientes piroclásticas alojadas en depresiones y unidades de sistemas aluviales volcaniclásticos dominados por flujos hiperconcentrados alojados en depresiones (fig. 5.3). Es importante destacar que hacia los bordes del depocentro se identificaron unidades volcánicas intrusivas, atribuidas en el capítulo previo a conductos alimentadores. En el sector noroeste del depocentro, sobre la traza de la falla que limitó al graben, se encontró una unidad de acumulación de conducto alimentador (fig. 4.14), mientras que en la parte sureste, en los alrededores del Cerro Corona, se halló un sistema de diques longitudinales de composición andesítica, de rumbos preferentemente N-S y NNW-SSE (fig. 4.9 y 4.10) y un criptodomo de composición riodacítica, alineados en un sistema de fractura de rumbo N-S (fig.4.15).

La sección media (DS-2) se distribuye enteramente dentro del depocentro de Sañicó, sin encontrarse afloramientos de ésta por afuera de sus límites. Se define principalmente por unidades piroclásticas con discordancias internas, que apoyan también discordantemente sobre depósitos de la Formación Paso Flores y de la sección inferior (fig. 5.3). Secundariamente, esta sección muestra unidades de acumulación lávicas y sedimentarias volcaniclásticas, asociadas a la resedimentación y retrabajo de las primeras. Se desarrolla con un espesor variable, pero mucho más uniforme que la sección inferior. Los espesores máximos se encuentran al sureste de la falla de borde de graben (500 m) (fig. 5.3). Las unidades de acumulación de corrientes piroclásticas de gran distribución areal I y II definidas en el capítulo anterior, conforman casi la totalidad del volumen de esta sección. Se desarrollan de manera conspicua, extendiéndose con potentes espesores en todo el depocentro. Como ya fuera mencionado oportunamente en el 
capítulo previo, las unidades de acumulación de corrientes piroclásticas de gran distribución areal presentan un fuerte control tecto-estratigráfico. Este control se ejerce tanto por las fallas que conforman el borde de graben como por las fallas internas del mismo, en ocasiones variando abruptamente el espesor en magnitudes del orden de centenas de metros (fig. 5.3). Las unidades de acumulación de domos de composición andesítica y unidades de coladas dómicas riolíticas se encuentran asociadas espacialmente a fallas internas del depocentro (fig. 5.3), mientras que las unidades de coladas andesíticas con dominio de lavas coherentes se desarrollan hacia la parte superior de la sección en las proximidades de la falla de borde del hemigraben (fig. 5.3). De manera muy restringida, interdigitándose con las unidades de corrientes piroclásticas de gran distribución areal, se exhiben las unidades de acumulación de sistemas aluviales dominadas por flujos hiperconcentrados. Éstas se muestran con afloramientos poco potentes y de escasa distribución lateral.

La sección superior (DS-3) al igual que la sección media se encuentra restringida sólo a la parte interna del depocentro de Sañicó, sin sobrepasar sus límites. El área de acomodación para esta sección se traslada a la parte central del depocentro, alcanzando espesores cercanos a los 200 m, donde se apoya en discordancia por sobre unidades de acumulación correspondientes a las secciones inferior y media anteriormente descriptas (fig. 5.3). A grandes rasgos se caracteriza por presentar unidades de acumulación volcánicas y sedimentarias epiclásticas y carbonáticas. El arreglo interno de las unidades que integran la sección superior varía respecto a la posición dentro del depocentro. En las proximidades de la falla de borde del graben, la sección superior comienza con unidades de acumulación de coladas andesíticas dominadas por lavas coherentes que intercalan con unidades de acumulación de sistemas aluviales dominados por flujos de detritos. Por sobre ellas se depositan unidades de acumulación que representan sistemas de delta de grano grueso que pasan a sistemas lacustres y por último, unidades de acumulación de coladas andesíticas con dominancia de lavas coherentes de poco espesor (fig. 5.3). Al NW del borde del "pasivo" del depocentro, la sección superior presenta un arreglo simple, estando conformada por una potente secuencia de unidades de acumulación de lavas andesíticas dominadas por lavas coherentes (fig. 5.3).

El Ciclo Cuyano basal en el depocentro de Sañicó aparece como una faja de afloramientos continua desarrollada hacia el noreste del depocentro. Se apoya mediante una superficie de discontinuidad regional, sobre rocas que constituyen el basamento de la cuenca y también, depósitos de diferentes secciones del Ciclo Precuyano (fig. 5.1 y 5.4). En sentido NWSE, transversal al hemigraben, las unidades de acumulación del Ciclo Cuyano basal se desarrollan con importantes variaciones. En la zona próxima a la falla de borde, el Ciclo Cuyano basal alcanza un espesor parcial cercano a los de $100 \mathrm{~m}$. Comienza con unidades de acumulación de ambiente marino somero carbonático, pasando hacia arriba a un sistema de delta de grano fino que culmina con una unidad de acumulación de corrientes piroclásticas 
subácueas (fig. 5.4). Posteriormente se desarrollan nuevamente unidades de acumulación de ambiente marino somero carbonático que rápidamente pasan a unidades de acumulación de ambiente marino profundo de costa afuera (fig. 5.4). Hacia el sureste, sobre el alto estructural que presenta el depocentro de Sañicó y zonas aledañas (fig. 5.4), las características Ciclo Cuyano basal son muy disímiles a las descriptas anteriormente. Se caracteriza por una sucesión de unos $50 \mathrm{~m}$ de espesor, constituida por unidades de acumulación de un ambiente marino somero carbonático (fig. 5.4). Por arriba se desarrollan unidades de acumulación de ambiente marino de costa afuera con espesores que superan los $100 \mathrm{~m}$ (fig. 5.4).

5.2.2) Las unidades de acumulación del Ciclo Precuyano y Cuyano inferior dentro del depocentro de la Pintada

En sentido amplio el depocentro de la Pintada está mayoritariamente relleno por sedimentitas correspondientes al Ciclo Cuyano y minoritariamente por depósitos correspondientes a unidades del Ciclo Precuyano (fig. 5.1 y 5.2). La fuerte inversión que presenta este depocentro, tanto en el borde de menor acomodación, como en el borde del graben, dificulta la observación total del su relleno. En el borde oeste se pueden apreciar con mejor desarrollo las unidades del Cuyano basal, donde apoyan en discordancia o concordancia correlativa sobre depósitos precuyanos. En los sectores más próximos a la falla de borde, en cambio, yacen bien afloradas las sedimentitas correspondientes al Ciclo Cuyano cuspidal y minoritariamente las sedimentitas del Ciclo Cuyano basal, sin estar expuesta la base de éste. Los depósitos del Ciclo Precuyano del depocentro de la Pintada aparecen en los sectores basales, generalmente con espesores poco potentes. A unos $4 \mathrm{~km}$ al oeste de la falla de borde se encontraron lavas coherentes que fueron interpretadas como unidades de acumulación correspondientes al Ciclo Precuyano. Respecto a la distribución transversal de las unidades de acumulación del Ciclo Cuyano basal, en el sector sur del mismo, en las cercanías del Cerro Corona, comienza con unidades de acumulación de ambiente marino somero carbonático con espesores que rondan los $50 \mathrm{~m}$. Hacia arriba, en concordancia, se desarrolla una potente secuencia constituida por unidades de acumulación de ambiente marino de costa afuera (fig. 5.4). Al oeste del Cerro Roth, a unos $4 \mathrm{~km}$ al oeste de la falla de borde, el Ciclo Cuyano se inicia de modo diferente, con unidades de acumulación de ambiente marino de costa afuera sin desarrollarse las unidades de acumulación de ambiente marino somero. Hacia arriba las unidades de ambiente marino de costa afuera conforman una potente secuencia que alcanza la base del Cuyano cuspidal (fig. 5.1 y 5.4). 
Organización de las unidades de acumulación en el depocentro de Sañicó

\section{$C^{\circ}$ Corona}

$C^{\circ}$ Los Muleros

$\begin{array}{cc}C^{\circ} \text { Los Muleros } \\ \nabla \\ \text { SI } 1 & \text { SI } 3 \text { SI } 4 \text { SI } 5 \text { SI } 6 \text { SI } 7\end{array}$
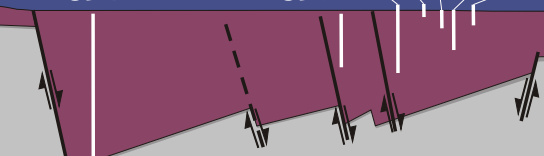

(1)

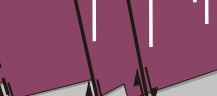

Sañicó

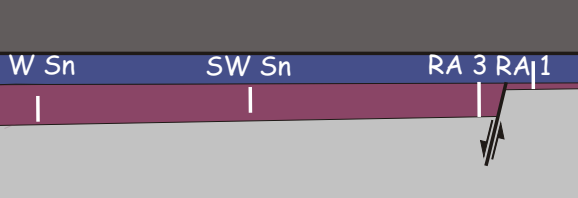

División del relleno precuyano en 3 secciones en función de la asociación de unidades de acumulación genética y espacio-temporalmente relacionadas

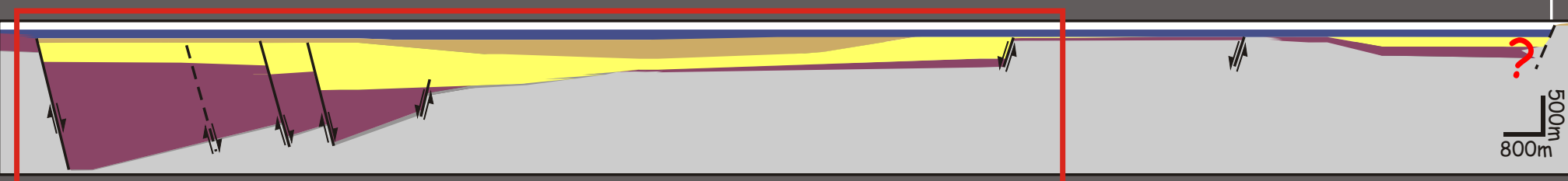

\section{Distribución espacial de las unidades de acumulación en una sección transversal al depocentro}

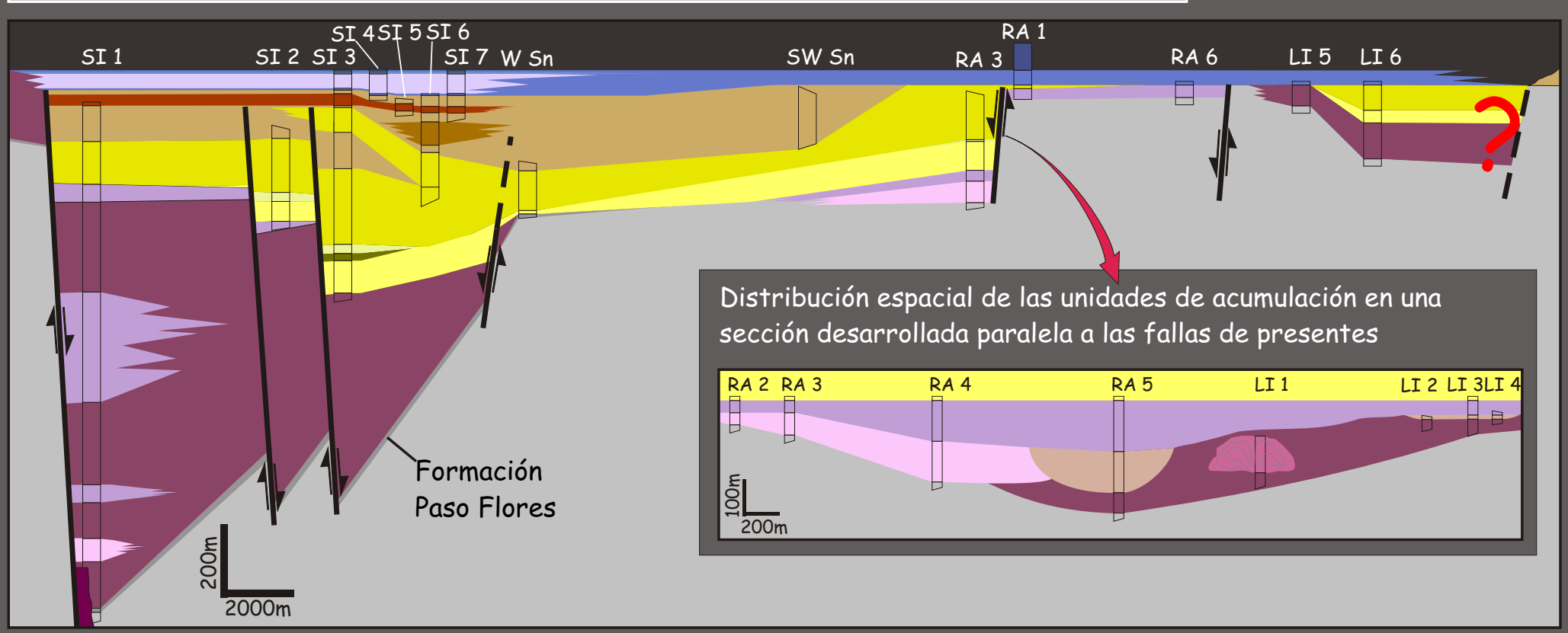

$\square$ Ciclo Precuyano $\square$ Basamento $\square$ Sección superior (DS-3)] $\square$ Sección media (DS-2) Sección inferior (DS-1)

Unidades de acumulación Ambiente marino de costa afuera (offshore)

$\square$ Ambiente marino somero carbónatico

Sistema de delta de grano fino Sistema de delta de grano grueso/lacustre Sistemas aluviales dominados por flujos de detritos

Sistemas aluviales dominados por flujos hiperconcentrados alojados en depresiones Sistemas aluviales piroclásticos dominados por flujos hiperconcentrados

Sistemas aluviales volcaniclásticos dominados Depósitos de corrientes piroclásticas bácueas

Depósitos de corrientes piroclásticas de gran distribución areal II

Depósitos de corrientes piroclásticas de gran distribución areal I

de gran distribución areal I
Depósitos de corrientes piroclásticas Depositos de corrientes pir alojadas en depresiones
Coladas y coladas andesíticas

Coladas y coladas andesiticas

Criptodomos riodacíticos

Domos andesíticos

Coladas y coladas dómicas andesíticas

Conductos volcánicos de borde cuenca

Figura 5.3. Organización de las unidades de acumulación en el depocentro de Sañicó y definición de secciones en función de asociaciones de unidades que comparten un relación génética. 


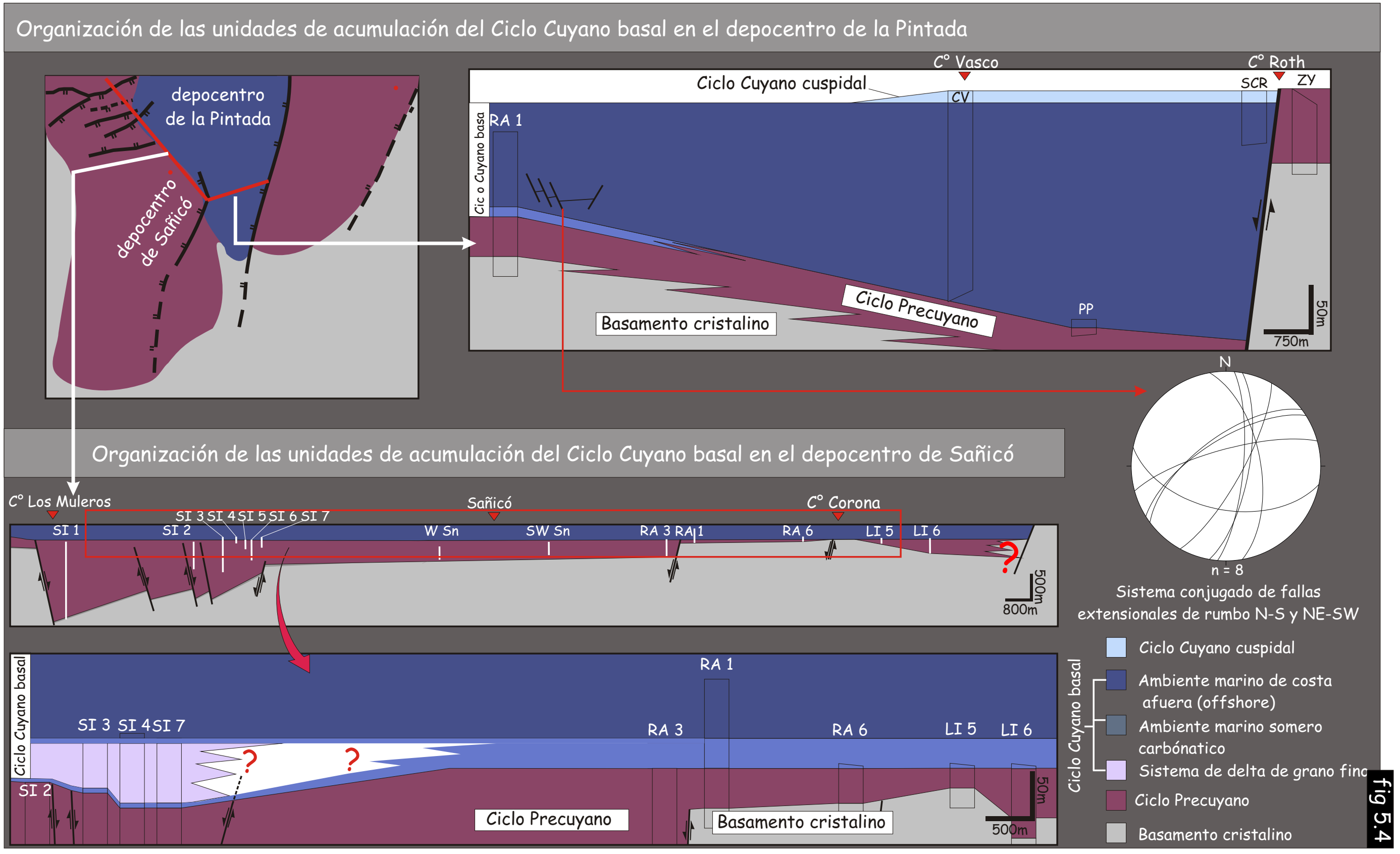

Figura 5.4. Organización de las unidades de acumulación del Ciclo Cuyano en el depocentro de Sañicó y de la Pintada. 
5.2.3) Las unidades de acumulación del Ciclo Precuyano dentro del depocentro de Piedra del Águila

Como fuera oportunamente mencionado la falla de borde del hemigraben de la Pintada limita la distribución de los depósitos del Ciclo Cuyano hacia el este. Por esta razón el depocentro de Piedra del Águila está totalmente relleno por unidades correspondientes al Ciclo Precuyano (fig. 5.1). Lamentablemente, la fuerte inversión que presenta este depocentro y los escasos afloramientos presentes, dificultan estimar con precisión la distribución en sentido transversal de las unidades de acumulación del Precuyano. Al igual que en el depocentro de Sañicó, si se evalúa la distribución y la relación entre las unidades volcánicas, piroclásticas y sedimentarias, conjuntamente con la composición de las unidades de acumulación epiclásticas, el relleno precuyano de este depocentro puede ser dividido en tres secciones: una sección inferior sedimentaria (DPDA-1) y una sección media (DPDA-2) y superior (DPDA-3) asociadas a la evolución de un ambiente ampliamente dominado por el volcanismo (fig. 5.5). Es importante destacar que las secciones están separadas por superficies de discontinuidad representadas por discordancias o correlativas concordancias.

La sección inferior (DPDA-1) sólo está representada por escasos afloramientos desarrollados al sur de la localidad de Piedra del Águila. Se constituye por una unidad de acumulación de sistemas fluviales de carga mixta, con materiales de acarreo relacionados directamente a la erosión del basamento ígneo-metamórfico. Se presenta en una no concordancia por sobre el basamento, con una centena de metros de largo y un espesor máximo que ronda los $70 \mathrm{~m}$ (fig. 5.5).

La sección media (DPDA-2) conforma la parte más profunda del depocentro de Piedra del Águila. Aflora sobre el basamento y discordantemente sobre la sección inferior, con un espesor máximo de 1300 m, presentando espesores bastante constantes. Está constituida principalmente por unidades de acumulación piroclásticas y minoritariamente por unidades de acumulación volcánicas y sedimentarias. Las unidades volcánicas y piroclásticas que se interdigitan con las unidades piroclásticas de gran distribución areal, se hallan con poco espesor y características proximales. Contrariamente, hacia el tope de esta sección, aparece de manera conspicua una potente unidad que representa un ambiente sedimentario aluvial con características terminales (fig. 5.5). Los depósitos de corrientes piroclásticas de gran distribución areal III (véase capítulo 4) conforman una secuencia que supera los $1000 \mathrm{~m}$ de espesor, extendiéndose lateralmente por varios kilómetros, representando casi todo el volumen de esta sección (fig. 5.5). Minoritariamente, en la parte basal de esta sección y en intercalación con las anteriores, se presentan unidades de acumulación de corrientes piroclásticas alojadas en depresiones y unidades de sistemas aluviales dominados por flujos hiperconcentrados. Hacia la parte superior de desarrolla una potente unidad sedimentaria caracterizada por sistemas aluviales volcaniclásticos terminales (fig. 5.5). 


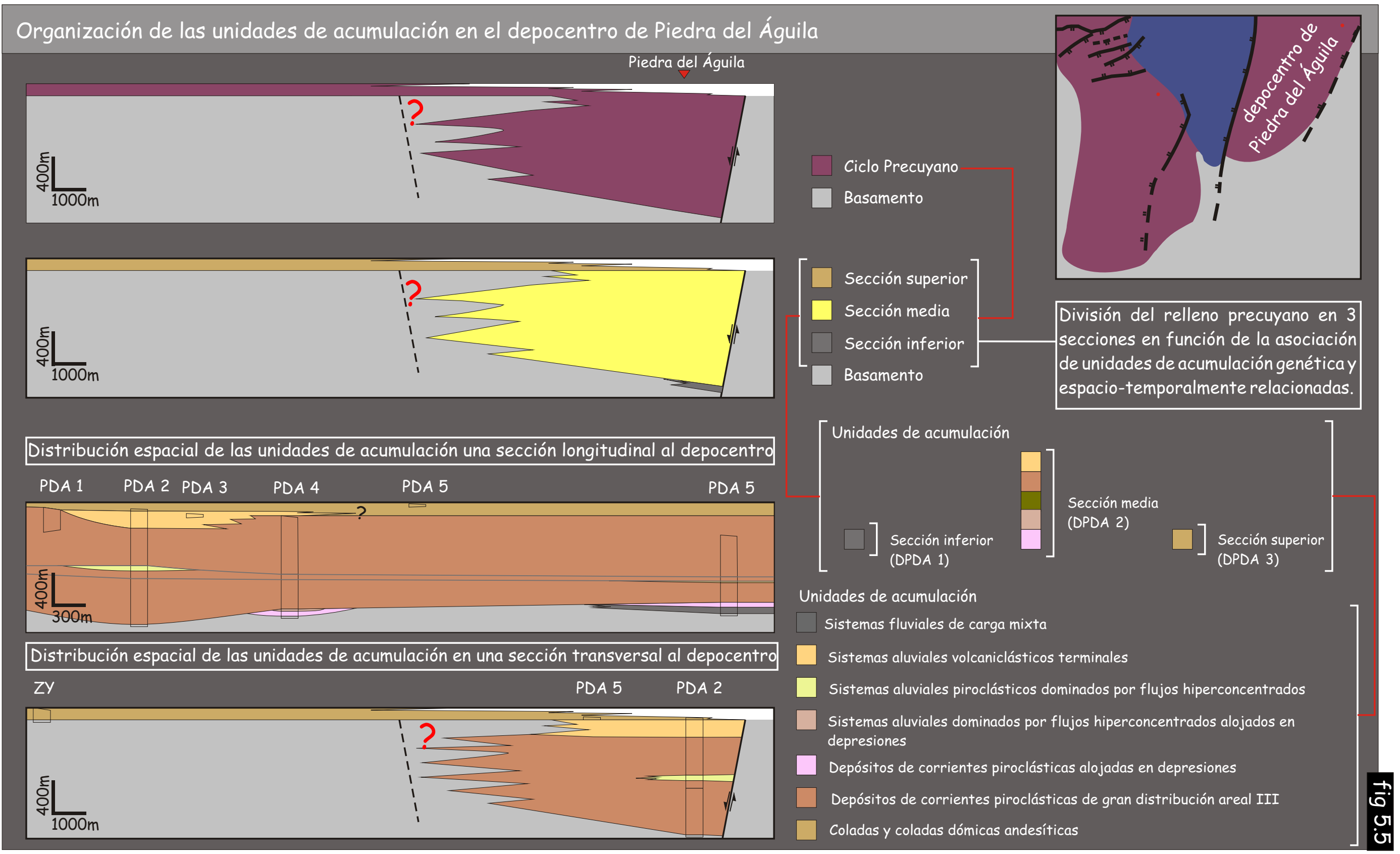

Figura 5.5. Organización de las unidades de acumulación en el depocentro de Piedra del Águila y definición de secciones en función de asociaciones de unidades que comparten un relación genética. 
La sección superior (PDA-3) es la de mayor distribución areal de este depocentro. Se desarrolla en las proximidades de la localidad de Piedra del Águila, apoyando sobre las sección media y se extiende hasta el Cerro Zaina Yegua, próximo a la falla de borde del depocentro de la Pintada, donde sobreyace en una no concordancia rocas del basamento ígneo-metamórfico (fig. 5.5). Esta sección está constituida principalmente por unidades de acumulación de coladas y coladas dómicas de composición andesítica y minoritariamente de unidades aluviales volcaniclásticas aluviales y unidades de corrientes piroclásticas.

\section{3) Correlación de las asociaciones de unidades de acumulación entre los depocentros}

El análisis realizado en detalle sobre el relleno y la confección de paneles arquitecturales y de correlación estratigráfica, permitieron establecer el arreglo interno dentro y entre las unidades de acumulación en los tres depocentros identificados (fig. 5.3, 5.4 y 5.5). La figura 5.6 muestra un mapa donde se unificaron las secciones identificadas para los depocentros de Sañicó y Piedra del Águila, mientras que para apreciar la relación que en conjunto éstas guardan con los elementos estructurales, se elaboró un perfil geológico integrado, el cual fue retrodeformado geométricamente al estadio previo a la deformación compresiva (fig. 5.7).

Para el Ciclo Precuyano, la sección media del depocentro de Sañicó, caracterizada por una asociación de unidades de acumulación que responden a un volcanismo explosivo con unidades sedimentarias y volcánicas asociadas, se correlacionó con la sección media del depocentro de Piedra del Águila de características homólogas. Asimismo, la sección superior del depocentro de Sañicó caracterizada por asociaciones de facies volcánicas lávicas mesosilícicas y unidades sedimentarias volcaniclásticas asociadas, pudo ser correlacionada con la sección superior del depocentro de Piedra del Águila, de similares atributos. Se debe aclarar que las secciones inferiores de ambos depocentros no son correlacionables bajo ningún punto de vista, debido a las diferencias genéticas -unidades de acumulación dominadas por un volcanismo efusivo mesosilícico (DS-1) versus sistemas fluviales de carga mixta (DPDA-1)-, en los espesores y en su distribución areal. A pesar de estas discrepancias, debido a la edad (Hettangiana), por su posición en la secuencia y la ausencia de volcanismo, la sección DPDA-1 fue posicionada por debajo de la sección inferior del depocentro de Sañicó (DS-1), interpretándose como los depósitos precuyanos más antiguos de la zona de estudio.

El Ciclo Cuyano basal fue hallado en el depocentro de Sañicó y de la Pintada sin haberse registrado en el depocentro de Piedra del Águila. En el depocentro de Sañicó y de la Pintada se presentan con características diferentes, aunque sin cambios bruscos desde el punto de vista genético. Las diferencias en los ambientes depositacionales en su inicio estarían controladas por la posición dentro de los depocentro. 

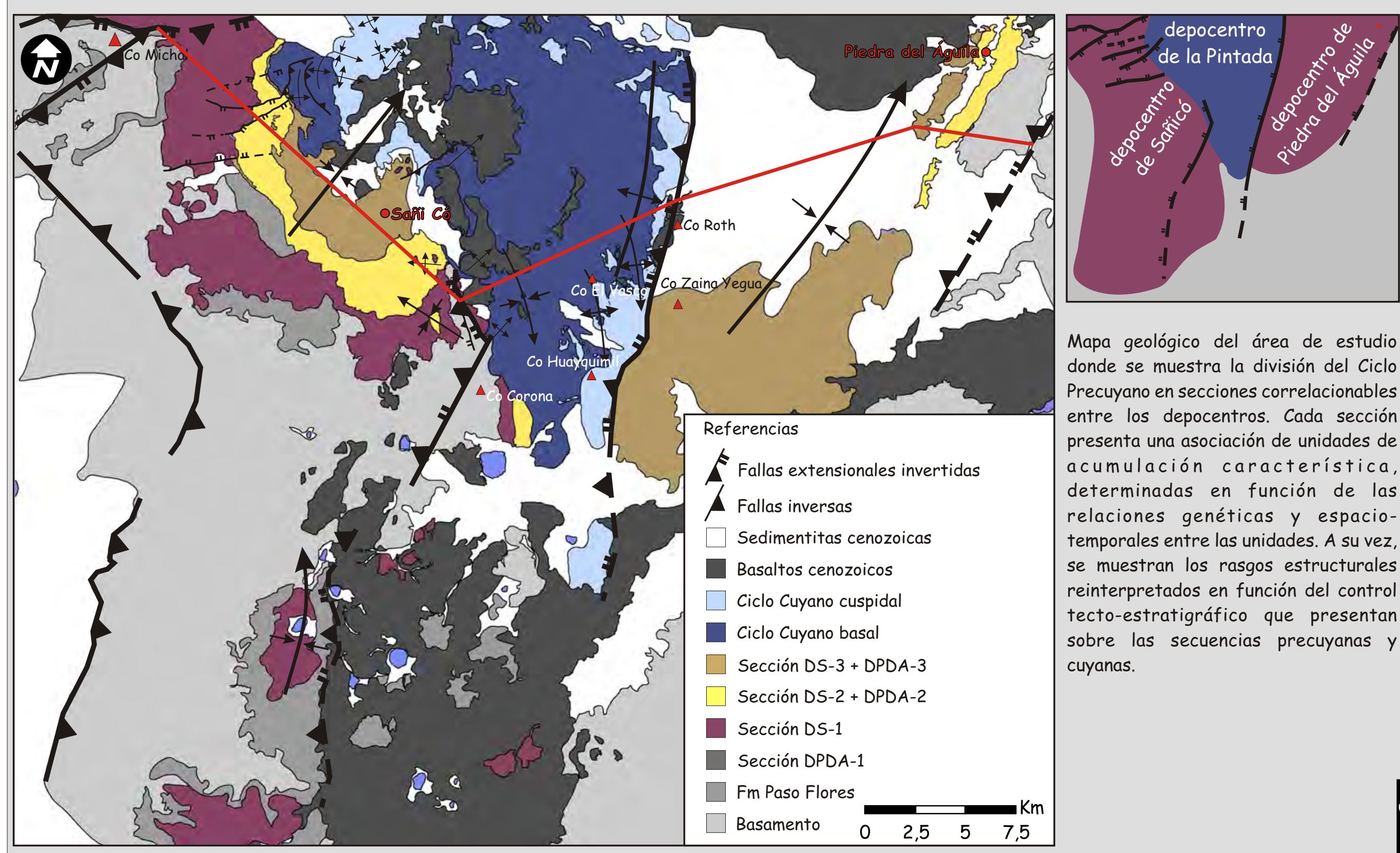

Mapa geológico del área de estudio donde se muestra la división del Ciclo Precuyano en secciones correlacionables entre los depocentros. Cada sección presenta una asociación de unidades de acumulación característica, determinadas en función de las relaciones genéticas y espaciotemporales entre las unidades. A su vez, se muestran los rasgos estructurales reinterpretados en función del control tecto-estratigráfico que presentan sobre las secuencias precuyanas y cuyanas.

Figura 5.6. Mapa geológico donde se muestra la división del Ciclo Precuyano en secciones y las estructuras reinterpretadas en función del control tecto-estratigráfico. 
Perfil geológico integrado desarrollado de manera transversal a los depocentros
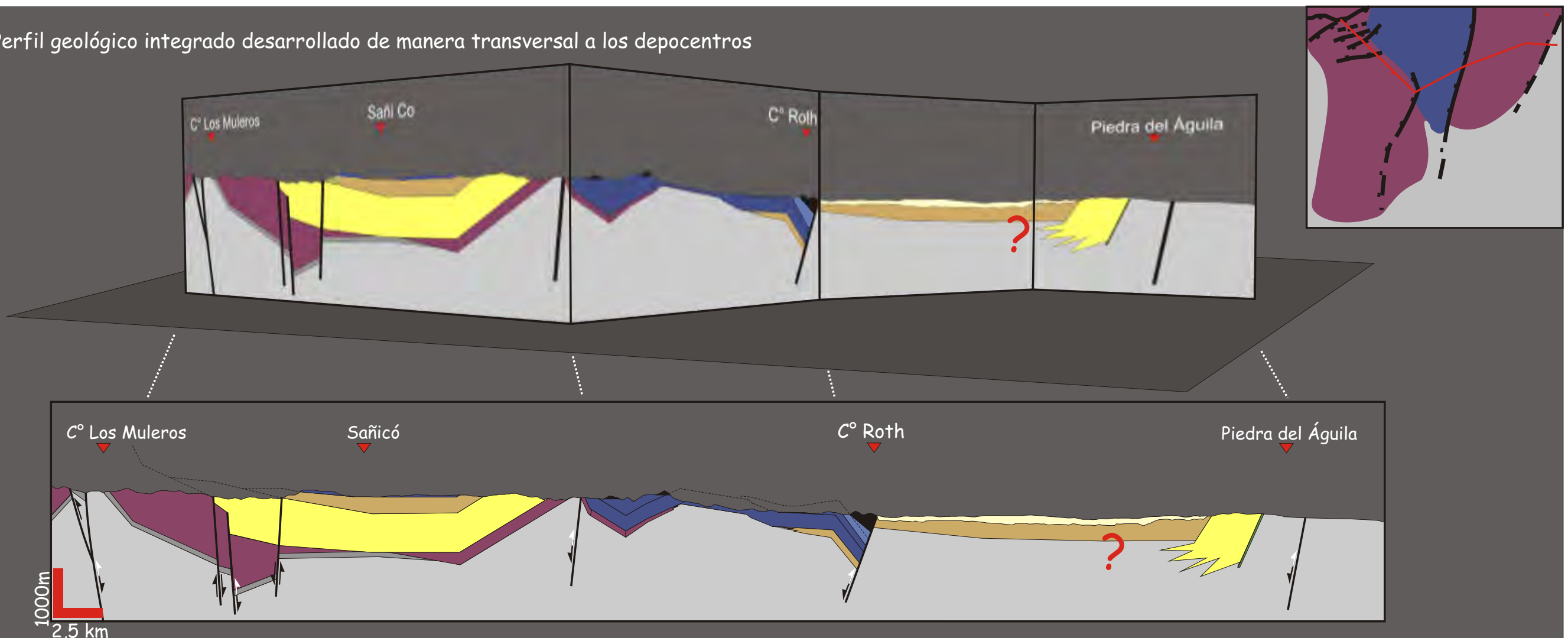

Perfil geológico retrodeformado a un estadio previo a la deformación compresiva

$C^{\circ}$ Los Muleros

Sañicó

$C^{\circ}$ Roth

Piedra del Águila

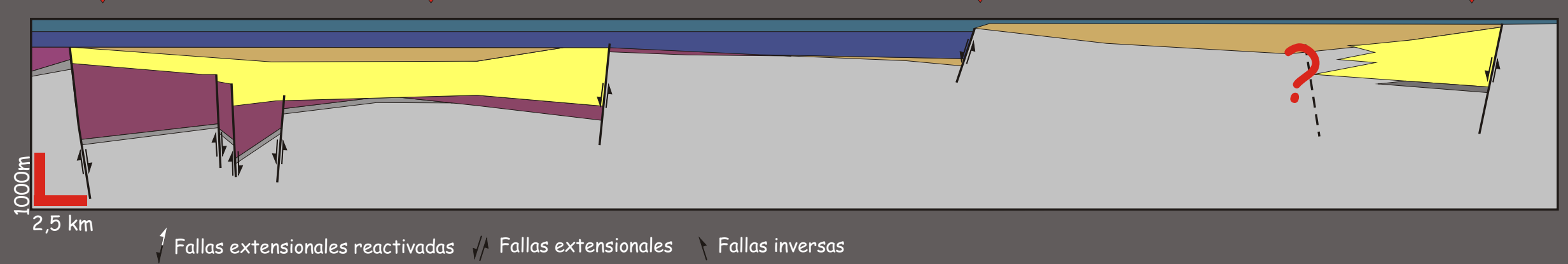

Figura 5.7. Correlación de las secciones identificadas dentro del relleno precuyano, mostradas en un perfil retrodeformado integrado de toda el área de estudio. 


\section{Capítulo 6 - Discusión de los resultados}

La zona de Sañicó y Piedra del Águila se caracteriza principalmente por rocas del basamento ígneo-metamórfico, conjuntamente con depósitos continentales y marinos que constituyeron la etapa de relleno inicial de la Cuenca Neuquina durante el Triásico SuperiorJurásico Inferior. Esta área constituyó el límite austral de la cuenca, desarrollándose hacia al sur y sureste el macizo Norpatagónico con características geológicas muy diferentes para el Jurásico Inferior. En este sector aparece un delgado registro Mesozoico, conformado mayoritariamente por sucesiones volcánicas y batolitos que se habrían desarrollado de manera contemporánea con los depósitos que rellenaron las cubetas iniciales de la Cuenca Neuquina. A pesar de la vasta información que se presenta sobre las sucesiones iniciales de la cuenca (Ciclo Precuyano y su pasaje al Ciclo Cuyano basal), al presente existe la necesidad de avanzar sobre la caracterización y correlación de los paleoambientes y sus controles, sobre un ordenamiento estratigráfico y cronoestratigráfico dentro y entre los depocentros, y sobre la relación con los ciclos sedimentario-magmáticos acaecidos en zonas vecinas. Los resultados obtenidos en el presente trabajo serán discutidos a los efectos de avanzar sobre estos interrogantes.

\section{1) Análisis estratigráfico y cronoestratigráfico de las unidades Triásico Superior - Jurásico Inferior en el sector sur de la Cuenca Neuquina}

La organización de la estratigrafía interna y las correlaciones dentro del relleno inicial son una cuestión aún no resuelta en la geología de la Cuenca Neuquina. Entre los problemas que han conspirado en contra de la comprensión de los procesos evolutivos iniciales de la Cuenca Neuquina, se destaca el uso de una terminología poco clara con profusión de diferentes términos y unidades estratigráficas para referirse a sus depósitos iniciales. Los intentos de agruparlos y correlacionarlos se han sucedido a través del tiempo desde los inicios del conocimiento geológico de la cuenca. A escala del relleno general, los depósitos iniciales han sido concebidos como ciclos sedimentarios (Groeber, 1946), unidades litoestratigráficas (p.e. Stipanicic, 1969), secuencias depositacionales (p.e. Gulisano et al., 1984), unidades limitadas por discontinuidades (Riccardi y Gulisano, 1990), tectosecuencias (p.e. Vergani et al., 1995; Franzese y Spalletti, 2001) y unidades limitadas por discordancias (p.e. Leanza et al., 2005). La gran variabilidad lateral del relleno en pocas centenas de metros registrada por diversos autores y corroborada en este trabajo, indica que el abordaje de las unidades propuestas por Groeber (1946) como unidades litoestratigráficas (p.e. Stipanicic, 1969), no habilita que sean utilizadas como 
unidades genéticas de correlación. Las características de las cuencas de rift hacen poco significativo el empleo de unidades litoestratigráficas como unidades de correlación, tanto dentro, como entre los depocentros. La presencia de discordancias angulares locales en las cuencas de rift, donde las unidades de sinrift pueden yacer de manera discordante en el borde activo y de manera concordante en el margen pasivo (Morley, 1995; Morley 1999a), hacen inviable la utilización de unidades limitadas por discordancias (p.e. Leanza et al., 2005). En este sentido, parece ser más apropiado el uso de unidades limitadas por discontinuidades, debido que éstas no sólo incluyen a las discordancias, sino también a las correlativas concordancias identificadas por cambios genéticos, paleogeográficos, en la sedimentación o hiatos en el relleno (Riccardi y Gulisano, 1990). A pesar de ser más adecuada, esta metodología no tiene en consideración los controles tectónicos acaecidos durante la evolución inicial de la cuenca. Por todos los motivos expuestos, para el ordenamiento cronoestratigráfico del relleno inicial se utilizó el concepto de análisis de unidades tecto-sedimentarias (UTS) (Riva, 1989, Riccardi y Gulisano, 1990). Una UTS se define como una unidad aloestratigráfica cuya evolución en la vertical y en la horizontal está caracterizada por una polaridad sedimentaria y geométrica, genéticamente relacionada. Los límites de las UTS están representados por superficies de discontinuidad o rupturas sedimentarias originadas por procesos tectónicos y sedimentarios (superficies clave).

\subsection{1) Determinación y jerarquización de las superficies clave}

El análisis de unidades tecto-sedimentarias trae aparejado por un lado el conocimiento del arreglo interno del relleno y, por el otro, el reconocimiento de las superficies de discontinuidad que las limitan. En el capítulo 5 se realizó un ordenamiento espacio-temporal de las unidades de acumulación y, a grandes rasgos, los contactos entre las diferentes etapas del relleno identificados esbozaron diferentes tipos de superficies de discontinuidad. El uso de las mismas es poco significativo si no son jerarquizadas en función de la relación que guardan con el relleno. La jerarquización de las superficies clave es una tarea común en el estudio de ambientes sedimentarios continentales y marinos desarrollados en diferentes tipos de cuencas (p.e. Reading y Level, 2002, Miall, 2006; Jackson et al., 2005). Sobre la base del análisis en detalle efectuado es posible trazar diferentes órdenes de superficies clave dentro del relleno inicial de la cuenca, partiendo desde superficies internas en las unidades de acumulación, hasta superficies que limitan unidades y asociaciones de unidades (secciones), o incluso secuencias mayores que responden a la reorganización de los ambientes sedimentarios y de las áreas depocentrales - unidades tecto-sedimentarias (UTS) -. Se han definido siete órdenes de superficies clave a través de su jerarquización (fig. 6.1 y 6.2). Las superficies de $1^{\circ}$ a $4^{\circ}$ orden corresponden a discontinuidades desarrolladas dentro de las unidades de acumulación 
sedimentarias y piroclásticas, sin presentarse equivalentes dentro de las unidades volcánicas. Estas superficies aluden a un conjunto de procesos depositacionales asociados desde la depositación de una capa hasta la acreción de formas mayores dentro de una unidad de acumulación. Las superficies de $5^{\circ}$ orden indican el límite natural de unidades de acumulación volcánicas, piroclásticas y sedimentarias. Estas superficies se expresan cuando se ponen en contacto diferentes unidades de acumulación. Las superficies de $6^{\circ}$ orden agrupan unidades de acumulación espacio-temporalmente asociadas, con características genéticas comunes. Estas superficies marcan cambios de los ambientes depositacionales a escala del depocentro. Un ejemplo para las superficies de discontinuidad de $6^{\circ}$ orden estaría manifestado en las superficies que limitan las secciones contenidas en los depocentros de Sañicó y Piedra del Águila definidas en el apartado previo. Por último, las superficies de $7^{\circ}$ orden agrupan diferentes secciones del relleno que comparten singularidades genéticas y espacio-temporales dentro de secuencias que representan eventos regionales mayores (unidades tecto-sedimentarias sensu Riva, 1989). Estas superficies marcan cambios abruptos en los ambientes depositacionales y/o en la tasa de volcanismo y una reorganización mayor de las áreas de acomodación disponible para la preservación de los sedimentos.

\begin{tabular}{|c|c|c|c|}
\hline $\begin{array}{c}\text { Orden } \\
\text { jerárquico de } \\
\text { las superficies }\end{array}$ & U. volc. & Unidades Piroclásticas & Unidades Sedimentarias \\
\hline $1^{\circ}$ & & $\begin{array}{c}\text { Depositación de lámina o } \\
\text { estrato }\end{array}$ & Depositación de lámina o estrato \\
\hline $2^{\circ}$ & & $\begin{array}{l}\text { Cuerpos originados por la } \\
\text { rápida agradación en la zona } \\
\text { de límite de flujo inferior de } \\
\text { una corriente piroclástica }\end{array}$ & $\begin{array}{l}\text { Cuerpos originados por la migración } \\
\text { de formas de fondo (set) }\end{array}$ \\
\hline $3^{\circ}$ & & $\begin{array}{l}\text { Remoción de límite de flujo } \\
\text { inferior momentánea de una } \\
\text { corriente piroclástica }\end{array}$ & $\begin{array}{l}\text { Evento depositacional mayor o } \\
\text { cambio en las condiciones } \\
\text { hidrodinámicas de un flujo que } \\
\text { origina el agrupamiento dentro de } \\
\text { coset o grupos de coset }\end{array}$ \\
\hline $4^{\circ}$ & \begin{tabular}{c|} 
Eventos \\
acrecionales \\
de coladas o \\
coladas \\
dómicas
\end{tabular} & $\begin{array}{c}\text { Cambio sustancial en las } \\
\text { condiciones de límite de flujo } \\
\text { inferior de una corriente } \\
\text { piroclástica }\end{array}$ & $\begin{array}{l}\text { Eventos acrecionales discretos } \\
\text { ocurridos dentro de una unidad de } \\
\text { acumulación (Ej. progradación de } \\
\text { lóbulos) }\end{array}$ \\
\hline $5^{\circ}$ & \multicolumn{3}{|c|}{ Límite de unidades de acumulación } \\
\hline $6^{\circ}$ & \multicolumn{3}{|c|}{$\begin{array}{c}\begin{array}{c}\text { Asociaciones de unidades de acumulación con vinculación genética y espacio- } \\
\text { temporal. Marcan cambios en los ambientes depositacionales a escala del } \\
\text { depocentro }\end{array} \\
\end{array}$} \\
\hline $7^{\circ}$ & \multicolumn{3}{|c|}{$\begin{array}{l}\text { Superficies de expresión regional que definen bruscos cambios en los } \\
\text { ambientes de los depocentros y una reorganización de las áreas depocentrales }\end{array}$} \\
\hline
\end{tabular}

Fig. 6.1. Jerarquización de las superficies de discontinuidad definidas en el presente estudio. 
Esquema relativo de jerarquización de las superficies de discontinuidades

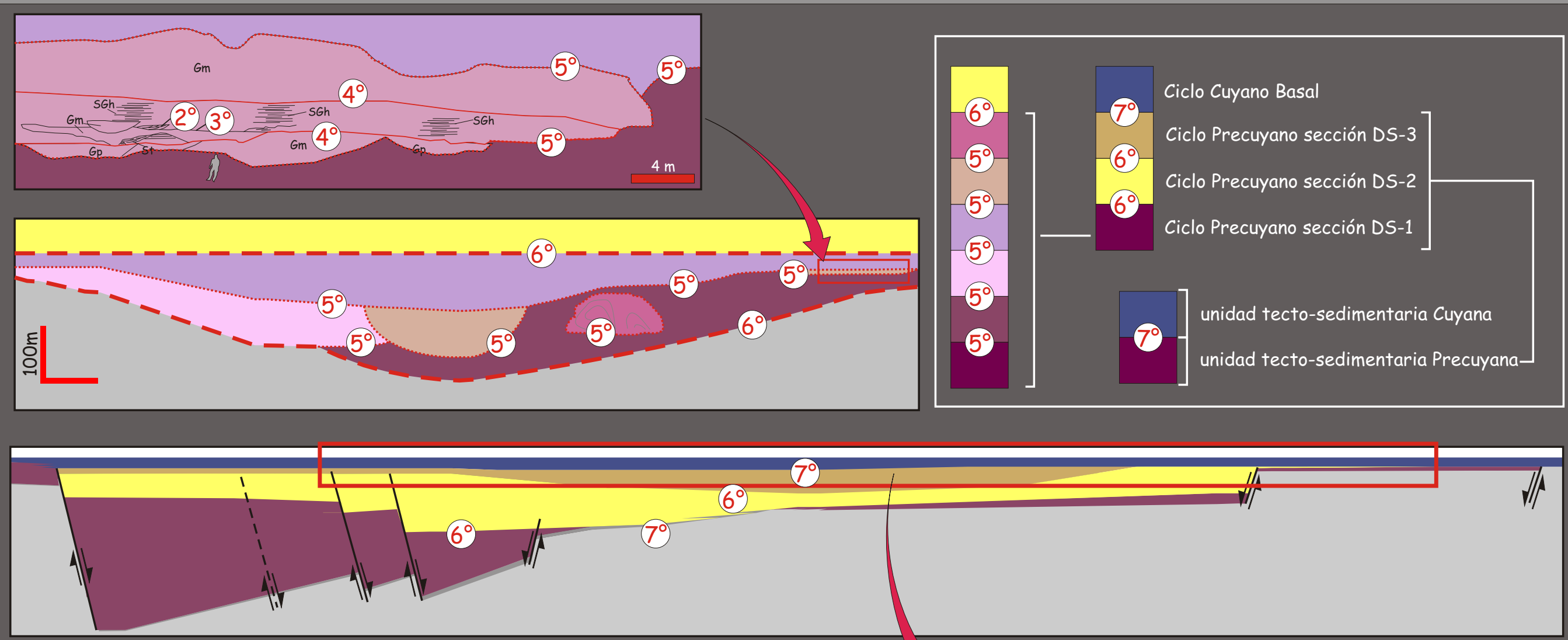

Orden de las discontinuidades

$5^{\circ}$ orden: límite de unidades de acumulación

69 orden: límite de tramos evolutivos dentro de las unidades tecto sedimentárias

$7^{\circ}$ orden: límite de las unidades tecto sedimentárias

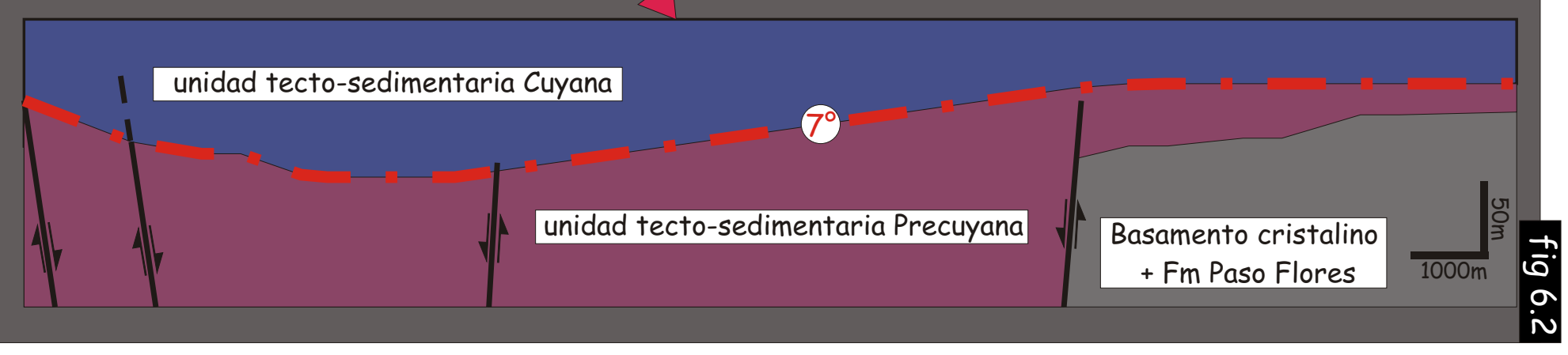


Es de suma importancia recalcar que las diferentes superficies de discontinuidades internas desarrolladas en las unidades de acumulación ( $1^{\circ}$ a $4^{\circ}$ orden) corresponden a unidades originadas por procesos muy diferentes, sobre todo desde el punto de vista cronológico. Por esta razón las discontinuidades fueron determinadas en función de las formas deposicionales y de los atributos geométricos, siendo éstas diacrónicas para los diferentes grupos de unidades de acumulación genéticas.

La correlación de las secciones identificadas para el relleno en el capítulo 5 (fig. 6.3) y la identificación de las superficies clave (fig. 6.1 y 6.2), permitió desarrollar una carta cronoestratigráfica del área de estudio, donde se volcaron los principales rasgos estructurales (fig. 6.4). La utilización de este tipo de metodología permitió diferenciar tres tipos de unidades tecto-sedimentarias, las cuales serán desarrolladas a continuación.

6.1.2) Organización cronoestratigráfica de las unidades Triásico Superior - Jurásico Inferior para los depocentros de Sañicó, la Pintada y Piedra del Águila

A grandes rasgos, la Formación Paso Flores, el Ciclo Precuyano y el Cuyano representan tres etapas de relleno claramente diferenciables en función de sus características genéticas y su distribución controlada por elementos estructurales disímiles (fig. 5.2, 6.3 y 6.4). Los tres periodos depositacionales, se hallan limitados por superficies de discontinuidad de $7^{\circ}$ orden, pudiéndose definir, por lo tanto, como unidades tecto-sedimentarias asociadas a eventos tectónicos extensionales:

1. unidad tecto-sedimentaria I (UTS I) equivalente a la Formación Paso Flores

2. unidad tecto-sedimentaria II (UTS II) "Precuyana”

3. unidad tecto-sedimentaria III (UTS III) “Cuyana”

La UTS I está integrada por los depósitos del Triásico Superior de la Fm. Paso Flores, compuestos principalmente por sedimentitas silicoclásticas con menor participación de materiales volcánicos, que revelan áreas de proveniencia del basamento (Galli, 1954). Se caracteriza por ambientes sedimentarios organizados (abanicos aluviales, ambientes fluviales y lacustres) (Spalletti, 1994; Ganuza et al., 1995), con menor participación de depósitos piroclásticos primarios (Galli, 1969). Se desarrolla principalmente hacia el macizo Norpatagónico. En el área de estudio está representada en su sector más occidental, por escasos afloramientos de poco espesor, distribuidos en dirección meridional (fig. 6.3 y 6.4). El contraste litológico y ambiental, conjuntamente con la diferencia de las áreas depocentrales, hacen distinguible a la UTS I de la UTS II (Ciclo Precuyano). Es importante destacar que las secuencias de la Formación Paso Flores fueron atribuidas a una secuencia de sinrift continental (Spalletti,1999). 
La UTS II se halla conformada por los depósitos correspondientes al Ciclo Precuyano y presenta una distribución areal que se extiende ampliamente sobre el área de estudio (fig. 6.3 y anexo I). Está limitada en su base por una superficie de discontinuidad regional de $7^{\circ}$ orden que marca el cambio de las áreas depocentrales respecto a la UTS I (Formación Paso Flores) y la instauración de un ciclo ampliamente dominado por el volcanismo (fig. 6.4). La unidad tectosedimentaria "Precuyana" comienza con el desarrollo de la sección inferior del depocentro de Piedra del Águila (DPA-1) -Formación. Piedra del Águila-, representada por escasos afloramientos desarrollados al sur de la localidad homónima. En el subambiente de planicie de inundación fue reconocido un depósito piroclástico de caída datado en 191,7 \pm 2,8 Ma (Spalletti et al. en prensa). Este depósito estaría marcando el preludio de la importante actividad magmática que se desarrollaría a posteriori. El inicio del profuso volcanismo que caracteriza a la UTS II tuvo comienzo con el desarrollo de la sección inferior del depocentro de Sañicó (DS1), la cual representa un ambiente volcánico efusivo mesosilícico con ambientes sedimentarios aluviales asociados. Se desarrolla ampliamente en el depocentro de Sañicó, inclusive superando los límites estructurales del mismo, habiéndose encontrado al sur de esta área depocentral (fig. 6.3 y 6.4). Esta sección es la de mayor distribución areal dentro del Ciclo Precuyano de la región, aunque es importante subrayar que la misma no fue registrada en el depocentro de Piedra del Águila (fig. 6.3 y 6.4). Por arriba de una superficie de discontinuidad de $6^{\circ}$ orden que representa un cambio abrupto del ambiente volcánico en el depocentro de Sañicó y un hiato depositacional en el depocentro de Piedra del Águila, se habría desarrollado un ambiente volcánico explosivo controlado por fallas volcano-tectónicas, con actividad volcánica y ambientes sedimentarios aluviales volcaniclásticos asociados (DS-2 + DPDA-2) (fig. 6.3, 6.4, 6.5 y 6.6). En ambos depocentros esta sección se encuentra restringida a las áreas depocentrales, sin haberse encontrado por fuera de los bordes estructurales. Por sobre otra superficie de $6^{\circ}$ orden que representa un cambio en las características del ambiente volcánico, la UTS II evoluciona hacia un ambiente volcánico dominado por el volcanismo efusivo mesosilícico, con ambientes sedimentarios asociados (DS-3 + DPDA-3). Este periodo se encuentra en los dos depocentros y, a grandes rasgos, se caracterizó por una reducción del espacio de acomodación (fig. 6.4).

La UTS III está conformada por el Ciclo Cuyano del área de estudio y se distribuye como un afloramiento de forma triangular en la parte centro-norte de la misma (fig. 6.3). Comienza con el desarrollo del Cuyano basal sobre una superficie de discontinuidad de $7^{\circ}$ orden que marca una merma abrupta del volcanismo, conjuntamente con una reorganización de las áreas depocentrales (fig. 6.7) y se corresponde con una superficie de transgresión marina. La parte basal de la UTS III (Ciclo Cuyano basal) corresponde a un ambiente de sedimentación 


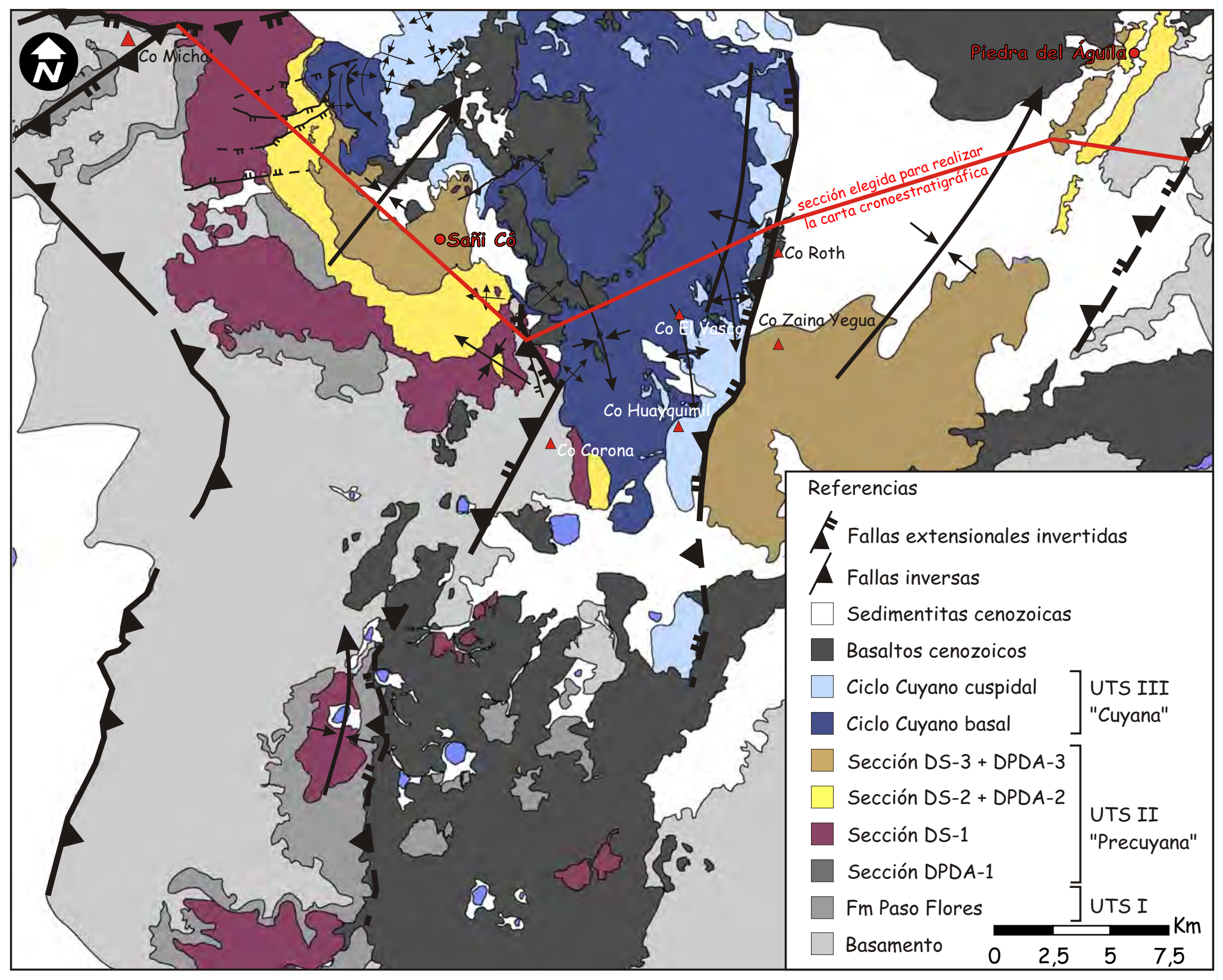

Figura 6.3. Mapa geológico donde se muestran las unidades tecto-sedimentarias interpretadas para el área de estudio y sus subdivisiones. 
Análisis estratigráfico y cronoestratigráfico

$C^{\circ}$ Los Muleros

Sañicó

$C^{\circ}$ Roth

Piedra del Águila
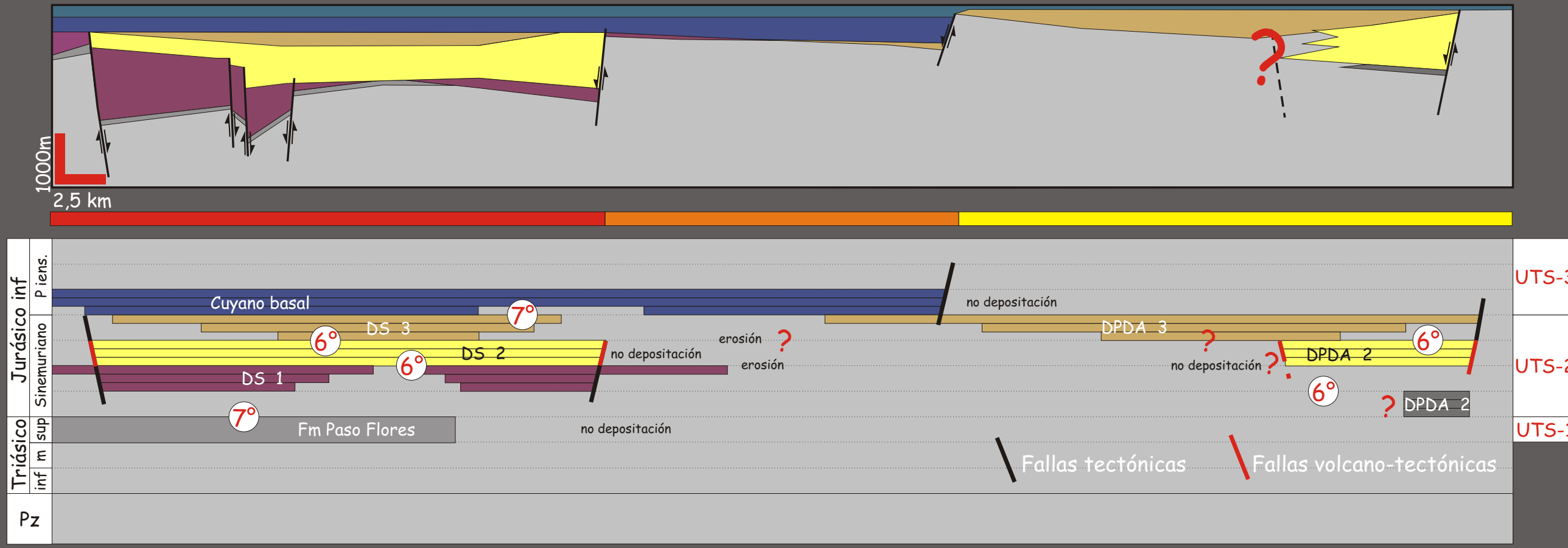

Ciclo Cuyano inferior

unidad tecto-sedimentaria III

(Ciclo Cuyano)

Ambiente volcánico mesosilísico y ambientes sedimentarios organizados asociados

$\square$ Ambiente volcánico explosivo y sistemas aluviales y volcanismo efusivo asociado

Ambiente volcánico efusivo mesosilísico con sistemas aluviales y volcanismo

explosivo asociado

Ambiente fluvial de carga mixta

Fm Paso Flores (Tr sup)

Basamento

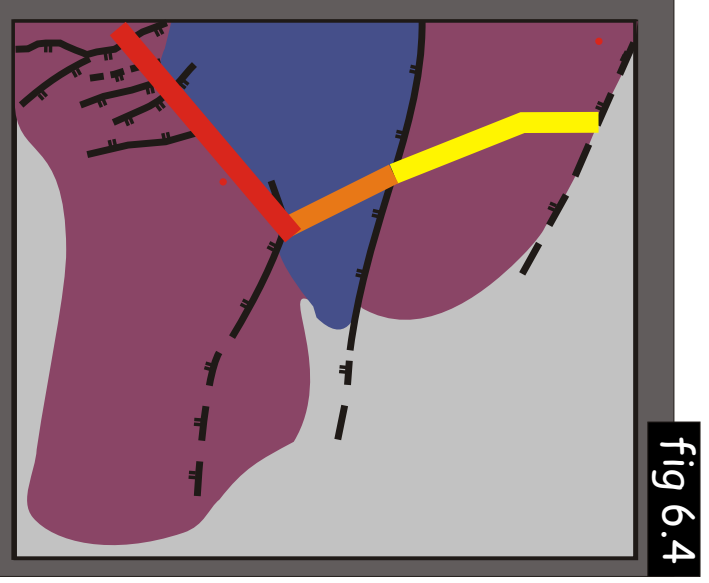

Figura 6.4. Carta cronoestratigráfica del área de estudio e interpretación tecto-estratigráfica del relleno inicial en el área de Sañicó y Piedra del Águila. 


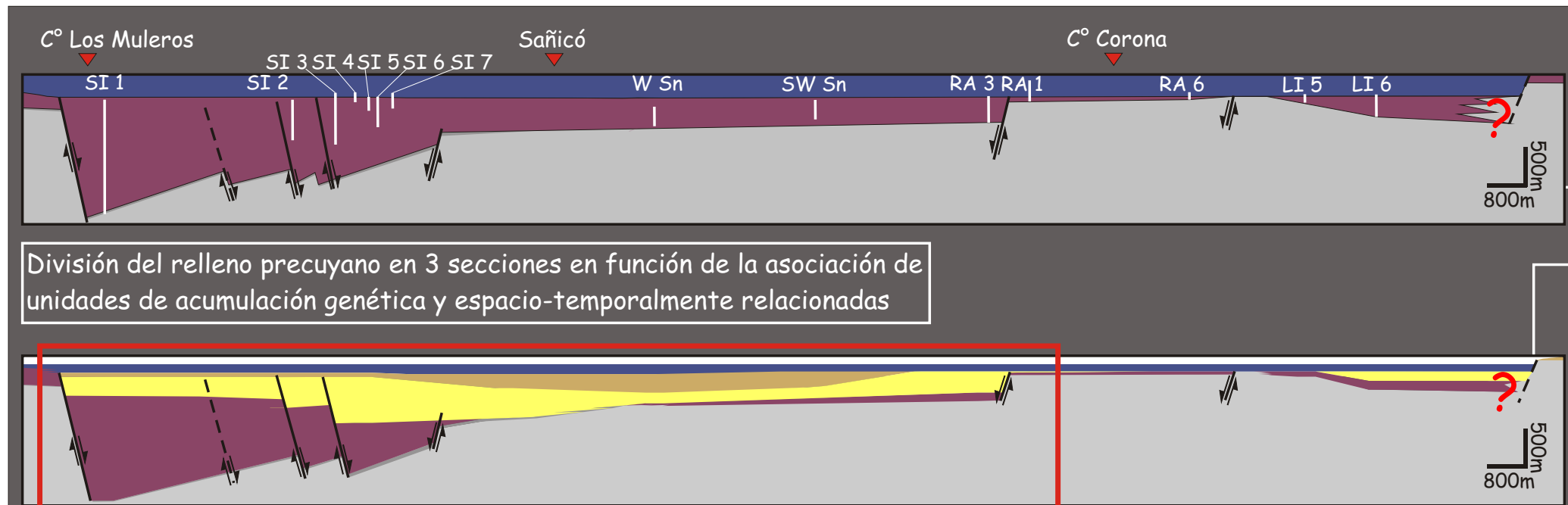

Distribución espacial de las unidades de acumulación en una sección transversal al depocentro

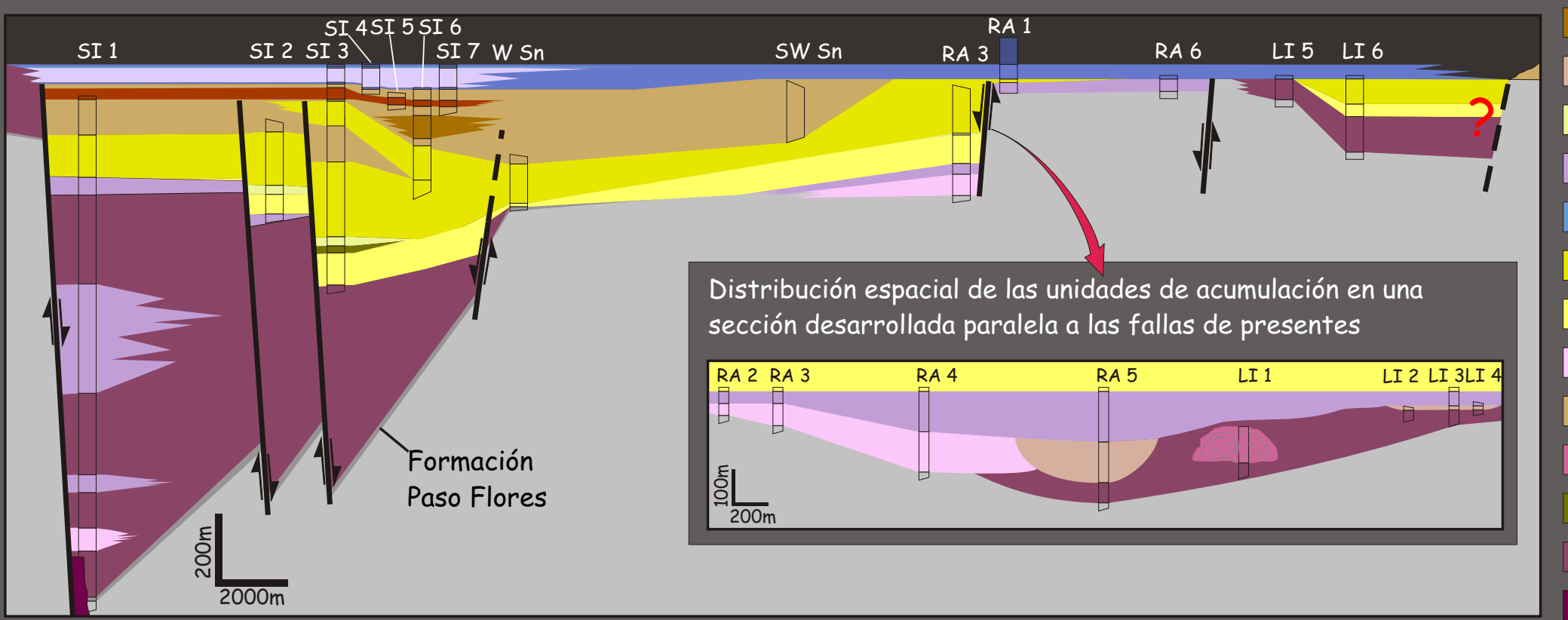

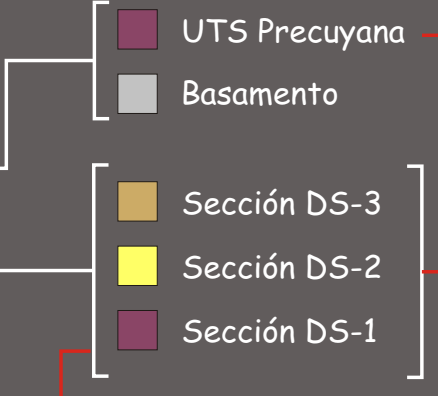

Unidades de acumulación

Ambiente marino de costa afuera (offshore)

Ambiente marino somero carbónatico

Sistema de delta de grano fino Sistema de delta de grano grueso/lacustre Sistemas aluviales dominados por flujos de detritos

Sistemas aluviales dominados por flujos hiperconcentrados alojados en depresiones Sistemas aluviales piroclásticos dominados por flujos hiperconcentrados

Sistemas aluviales volcaniclásticos dominados por avalanchas de detritos y flujos de detritos Depósitos de corrientes piroclásticas subácueas

Depósitos de corrientes piroclásticas de gran distribución areal II Depósitos de corrientes piroclásticas de gran distribución areal I

Depósitos de corrientes piroclásticas alojadas en depresiones

Coladas y coladas andesíticas

Criptodomos riodacíticos

Domos andesíticos

Coladas y coladas dómicas andesíticas Conductos volcánicos de borde cuenca 


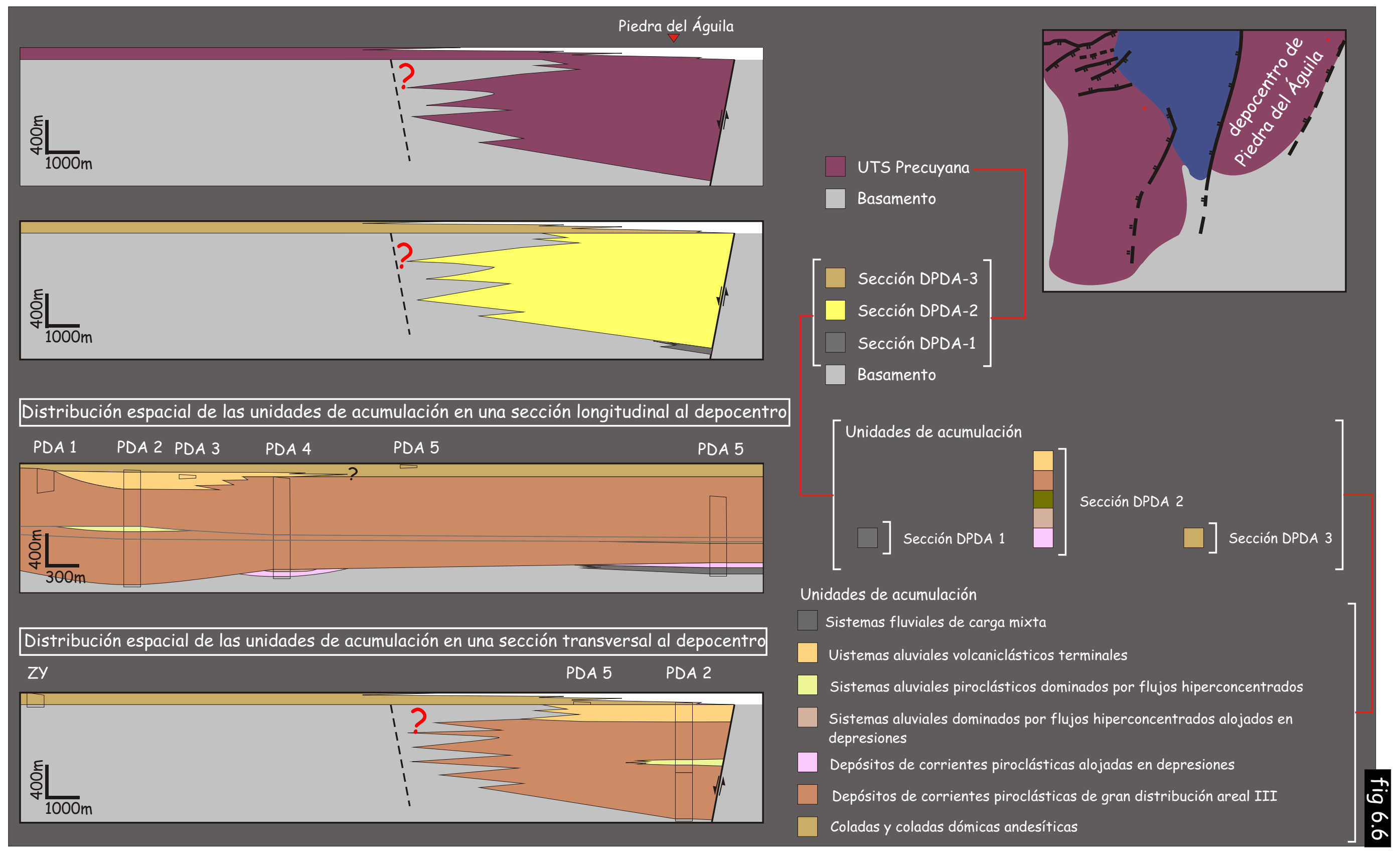

Figura 6.6. Organización de las unidades de acumulación y secciones del depocentro de Piedra del Águila. 


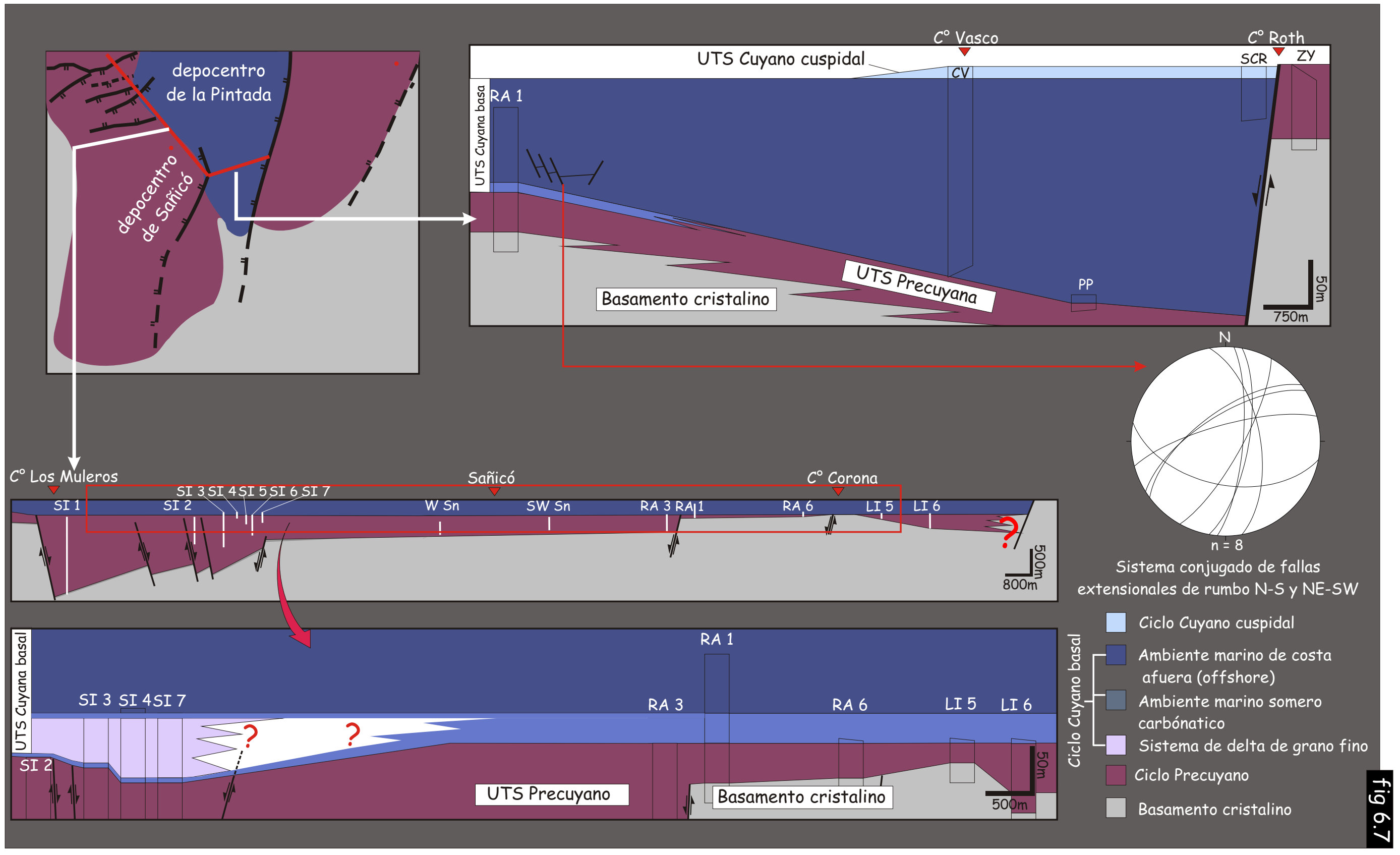

Figura 6.7. Organización de las unidades de acumulación del Ciclo Cuyano en los depocentros de Sañicó y de la Pintada. 
marina que se desarrolla tanto en el depocentro de Sañicó como en el depocentro de la Pintada, aunque el arreglo de las unidades de acumulación y el espesor es diferente.

Integrando la información obtenida a partir del ordenamiento cronoestratigráfico, conjuntamente con los antecedentes del área de estudio, se puede avanzar sobre un marco cronológico más preciso para las unidades tecto-sedimentarias identificadas para el Triásico Superior-Jurásico Inferior en el sector más austral de la cuenca. En este sentido, con prudencia, se pueden utilizar las edades provenientes de estudios bioestratigráficos y geocronológicos $\mathrm{y}$, en el marco de la carta estratigráfica internacional (International Commission on Stratigraphy, 2009), establecer el lapso máximo de depositación de cada UTS. La UTS I constituida por las sedimentitas de la Formación Paso Flores, interpretada como una secuencia de sinrift continental, fue acotada bioestratigráficamente al Triásico Superior medio a alto (Ganuza et al., 1995; Spalletti, 1999). Teniendo en cuenta esta edad, se habría extendido hasta el límite con el Jurásico, representando un lapso depositacional máximo de 15 ma. La UTS II correspondiente al Ciclo Precuyano, está integrada por diferentes estadios evolutivos (secciones DPDA-1, DS-1, DS-2 + DPDA-2 y DS-3 + DPDA-3) (fig. 6.3 y 6.4). El Ciclo Precuyano de esta localidad fue acotado al Hettangiano - Sinemuriano inferior (Gulisano y Pando, 1981), aunque recientemente un estudio geocronológico desarrollado sobre la sección DPDA-1 (Formación Piedra del Águila), interpretada como la parte más antigua del Ciclo Precuyano, ha revelado una edad de 191,7 \pm 2,8 Ma - Sinemuriano - (Spalletti et al., en prensa). De esta manera, la unidad tectosedimentaria Precuyana (UTS II) habría comenzado en el Sinemuriano y, en función del control estratigráfico que muestra el Ciclo Cuyano - de edad Pliensbachiana -, se habría extendido durante todo este piso, presentando una duración máxima de 5 ma (fig. 6.4). Teniendo en cuenta la edad de inicio de esta unidad tecto-sedimentaria, la superficie de discontinuidad de $7^{\circ}$ orden que limita la UTS I de la UTS II correspondería a un hiato depositacional mínimo de aproximadamente 3 Ma. Finalmente, la unidad tectosedimentaria Cuyana (UTS III) representaría el inicio de un nuevo ciclo tectónico y una merma abrupta del volcanismo que hacia el tope registra el desarrollo de las sedimentitas regresivas del Cuyano cuspidal (Gulisano y Pando, 1981). El Ciclo Cuyano de esta localidad - Formación Piedra Pintada - fue acotado para esta región al lapso Pliensbachiano inferior a superior (Damborenea y Manceñido, 1993). De esta forma, la UTS III tendría un tiempo máximo de depositación de unos 6 ma, estando limitada en su base por una superficie de discontinuidad de $7^{\circ}$ orden que representaría un hiato ínfimo con la UTS II (fig. 6.4). 
El esquema cronoestratigráfico planteado para el borde austral de la Cuenca Neuquina indica que el lapso Triásico Superior - Jurásico Inferior se encuentra conformado por una sucesión de unidades tecto-sedimentarias asociadas a una tectónica extensional (UTS I, UTS II y UTS III). Las mismas se desarrollaron durante aproximadamente $30 \mathrm{ma}$, sin interrupciones mayores. Una duración de la etapa de rifting de magnitud similar fue propuesto ya por otros autores (Franzese y Spalletti, 2001; Franzese et al., 2003). Es importante destacar que se mantiene la postura de posicionar a la Formación Paso Flores fuera del Ciclo Precuyano, aunque se coincide con los autores que la proponen como parte del evento inicial de rifting (p.e Franzese y Spalletti, 2001). En este sentido, las tres UTS corresponderían a tres episodios de rift (Formación Paso Flores, Ciclo Precuyano y Ciclo Cuyano) que pueden ser agrupados dentro de un mismo periodo extensional acaecido en el margen occidental de Gondwana para esos tiempos. Cuencas de rifting episódicas con registro de diferentes periodos tectónicos y magmáticos y reorganización de los depocentros (p.e. Rift Africano, Cuenca del Mar del Norte, Graben de Oslo, Cuenca de Wessex, Cuenca de Newark) han sido descriptas en el registro geológico por muchos autores (Schlische, 1992; Morley, 1999; Kattenhorn y Pollard, 2001; Ziegler y Cloetingh, 2004, entre otros). El inicio de la Cuenca Neuquina fue propuesto como resultado de un rifting episódico, desde el punto de vista tectónico (p.e. Vergani et al. 1995; Giambiagi et al., 2005) o tecto-estratigráfico (p.e. Franzese y Spalletti, 2001; Franzese et al., 2003) en diferentes contribuciones. Las variaciones registradas para las UTS definidas en este estudio, indican que esos episodios habrían estado controlados por la reorganización del marco tectónico y magmático, los cuales habrían influido en los estilos de sedimentación y tipo de ambiente y en la ubicación y orientación de las áreas depocentrales. Es importante destacar que los depósitos del Ciclo Cuyano han sido señalados como una tecto-secuencia de postrift por diferentes autores (Legarreta y Uliana, 1996; Franzese y Spalletti, 2001). Los resultados del presente trabajo permiten incluir a los depósitos pliensbachianos del Ciclo Cuyano (UTS III) como parte del evento de rifting inicial que dio origen a la cuenca. Este esquema tectoestratigráfico es similar al presentado por otros autores quienes proponen que el periodo extensional continuo durante el Pliensbachiano y parte del Toarciano (Vergani et al., 1995).

A escala regional, el arreglo interno y las relaciones temporales dentro de las diferentes unidades correspondientes al rifting inicial no es el mismo en toda la cuenca. Por ejemplo, en el depocentro del Atuel, ubicado en el área cordillerana del sur de Mendoza, los depósitos marinos del Triásico Superior de la Formación Arroyo Malo, se habrían depositado en los mismos depocentros de rift del Jurásico Inferior (Formación El Freno y sección inferior de la Formación Puesto Araya) (Giambiagi et al., 2008; Lanés et al., 2008). La misma relación puede ser encontrada para la Formación Lapa (Triásico Superior-Jurásico Inferior) en el depocentro de 
Chacacico (Franzese et al., 2007). Contrariamente, en el área de estudio los depósitos del Triásico Superior de la Formación Paso Flores (UTS I) se depositaron en áreas depocentrales diferentes a las registradas para los depósitos precuyanos (UTS II) (fig. 6.4). El mismo tipo de relación puede ser descripto entre los depósitos correspondientes a los Ciclos Precuyano y Cuyano, que tampoco comparten enteramente su área de depositación. En el sector norte y sur de la cuenca algunos autores señalaron que los depósitos del Ciclo Cuyano se depositaron en las mismas áreas depocentrales que controlaron el relleno precuyano (Giambiagi et al., 2008c; Lanés et al., 2008; Muravchik, 2008a y 2008b). No obstante, en el área de Sañicó y Piedra del Águila, las principales áreas depocentrales entre los depósitos del Ciclo Precuyano y Cuyano no fueron coincidentes. A su vez, es importante destacar que la afinidad tecto-estratigráfica del Ciclo Cuyano ha sido considerada de diferente modo por diferentes autores, en distintos lugares de la cuenca. Recientemente, para el sector norte de la cuenca se ha indicado que los depósitos del Ciclo Cuyano como correspondientes a la etapa de postrift (Lanés et al., 2008). En cambio, para el sector central (Muravchik, 2008a y 2008b) un carácter sintectónico extensional fue reconocido para los depósitos marinos pliensbachianos del Ciclo Cuyano. Los resultados obtenidos del análisis tecto-estratigráfico en el área de estudio permiten reconocer que, en el borde austral de la Cuenca Neuquina, al menos la parte basal del Ciclo Cuyano también estuvo asociada a una etapa sinextensional y debe ser incluida dentro de la etapa de rift de la cuenca.

El marco cronológico de las etapas iniciales de la cuenca también se presenta de manera controversial. Referente al inicio del Ciclo Precuyano, las edades aportadas recientemente permiten constatar el carácter diacrónico mencionado por algunos autores (p.e Vergani et al., 1995; Franzese y Spalletti, 2001). En el área de estudio el Ciclo Precuyano (UTS-II) se inició con los depósitos de la sección inferior del depocentro de Piedra del Águila (sección DPDA-1) Formación Piedra del Águila (191,7 \pm 2,8 Ma; Spalletti et al., en prensa). En cambio, en el ámbito de la Dorsal de Huincul otros autores presentaron edades para el Ciclo Precuyano más antiguas, de 203,75 \pm 0,26 Ma y $199 \pm$ 1,5 Ma (Schiuma y Llambías, 2008b; Schiuma y Llambías, 2008b), Triásico Superior alto - Hettangiano (International Commission on Stratigraphy, 2009).

Lo anteriormente expuesto denota el carácter diacrónico y la diversidad de relaciones geométricas y genéticas que existen entre las diferentes unidades que tuvieron lugar durante rifting que dio origen a la Cuenca Neuquina. Entre las más destacadas se encuentran: la permanencia o cambios de las áreas depocentrales, el fuerte diacronismo en el inicio de la actividad magmática - entre el Retiano y Sinemuriano - y las diferencias en la finalización del periodo de rifting. En función de todo ello, algunas consideraciones pueden realizarse referentes al empleo del término Precuyano, a la utilidad de unidades estratigráficas y al esquema tecto- 
estratigráfico comúnmente utilizado para la etapa inicial de la cuenca. La discriminación entre el Ciclo Precuyano y el Cuyano no puede hacerse sobre la base de consideraciones estrictamente ambientales. La aseveración de que el Precuyano es continental y el Cuyano marino carece de sentido si se tienen en cuenta tanto la presencia de depósitos continentales en la base del Ciclo Cuyano (Gulisano y Pando, 1981), como la presencia de secuencias marinas en el Ciclo Precuyano (Franzese y Spalletti, 2001; Giambiagi et al., 2008c; Lanés et al., 2008). Quizá, la característica más diferenciable es el volcanismo. A pesar que han sido descriptos depósitos volcánicos en la base del Ciclo Cuyano - p.e. Formación Los Molles en el área Chacaico y Cordillera del Viento (Gómez-Pérez, 2003; Suárez y de la Cruz, 1997; Llambías et al., 2007) es evidente la merma abrupta que presenta el volcanismo en las etapas finales de la evolución del rifting que dio origen a la cuenca. Por tales motivos, se propone el uso del término Precuyano para referirse a un ciclo magmático diacrónico.

Respecto al uso de unidades estratigráficas, la dinámica de las cuencas de rift (Morley, 1999a; Gawthorpe y Leeder, 2000) y el diacronismo presente en los depocentros de la Cuenca Neuquina (Vergani et al., 1995), hacen no recomendable el empleo de unidades litoestratigráficas y de unidades limitadas por discordancias para el estudio del relleno inicial de la cuenca. Asimismo, se recomienda la utilización de las unidades limitadas por discontinuidades (unidades tecto-sedimentarias) sólo en sentido cronoestratigráfico local, siendo no recomendable su utilización con valor cronoestratigráfico regional. Un ejemplo claro de los errores que acarrea la utilización de discontinuidades como superficies isócronas puede ser mencionado para la discontinuidad Intraliásica. La misma ha sido propuesta como el límite inferior del Ciclo Cuyano, pero ¿Cuál es la edad de esta superficie? A pesar de que originalmente se sugiriera un evento de transgresión escalonada para la cuenca, entre el Hettangiano y el Plienbachiano (Gulisano, 1981), algunos autores acotaron esta superficie al Pliensbachiano (Gulisano et al., 1984), mientras que otros la fecharon en el Hettangiano inferior (Riccardi y Gulisano, 1990). El diacronismo existente para las superficies de discontinuidad cubre edades diferentes, expresando hiatos de diferente magnitud dentro de la cuenca.

Por último, la transición del Ciclo Precuyano al Cuyano merece particular atención en los diferentes sectores de la cuenca. Mediante estudio de imágenes sísmicas, algunos autores han definido como sinextensional a la parte inferior del Ciclo Cuyano (Pliensbachiano Toarciano), mientras que los depósitos más jóvenes del ciclo corresponderían al estadio de postrift (Vergani et al., 1995). A su vez, para el norte de la cuenca, se han señalado que la totalidad de los depósitos del Ciclo Cuyano constituyen secuencias de postrift (Giambiagi et al., 2008c; Lanés et al., 2008), en tanto que para depocentros del centro (Franzese et al., 2007; Muravchik, 2008a y 2008b) y sur de la cuenca (en este trabajo) se ha constatado el carácter sintectónico de la parte inferior de la sucesión cuyana. De acuerdo a estos antecedentes, es 
importante considerar que lateral y verticalmente el Ciclo Cuyano puede estar representando diferentes tipos de tecto-secuencias (sinrift y/o postrift).

\section{2) Unidades tecto-sedimentarias Precuyana y Cuyana en el borde sur de la Cuenca Neuquina}

6.2.1) Evolución paleoambiental y paleogeográfica del Precuyano y Cuyano basal en el área de Sañicó y Piedra del Águila

Los depocentros extensionales localizados en el borde sur de la cuenca, se formaron durante el estadio de rifting Triásico Superior-Jurásico Inferior. El primer episodio dio lugar a los depocentros que albergaron a los depósitos de la Formación Paso Flores (UTS I), desarrollados principalmente fuera del área de estudio (Spalletti, 1999). El segundo episodio de sinrift dio como resultado la generación de los depocentros de Piedra del Águila y Sañicó (fig 5.2), los cuales fueron rellenados por la unidad tecto-sedimentaria "Precuyana" (UTS II). El registro más antiguo de la UTS II ha sido preservado en el depocentro Piedra del Águila. Allí se depositó la sección inferior de este depocentro (DPDA-1), luego de un hiato depositacional que la separa de la UTS-I. La misma representa un ambiente fluvial de carga mixta (fig. 4.33), donde los canales estrechos, la ausencia de formas de migración lateral y la presencia sustancial de depósitos de planicie de inundación, indicarían condiciones de alta acomodación (fig. 4.33) (Orton, 2002; Miall, 2006) asociada al bloque colgante (fig. 6.8) (Gawthorpe y Leeder, 2000). Para esos tiempos, el inicio de la actividad magmática que caracteriza a esta UTS todavía no había comenzado, manifestándose sólo como escasos depósitos de caída piroclástica en el subambiente de planicie de inundación. La naturaleza silicoclástica del material de acarreo revela que el aporte al sistema sedimentario todavía estaba controlado por la relación entre la tasa de acomodación y la tasa de aporte, gobernada por la naturaleza del basamento (bedrock) y las características atmosféricas (Leeder, 1999; Reading y Levell, 2002).

La evolución de la UTS-II continuó con el desarrollo de la sección inicial del depocentro de Sañicó (fig. 6.9). Esta sección de gran distribución areal, inclusive aflorando por fuera de los límites del depocentro, se halla integrada por coladas y coladas dómicas con dominación de lavas en bloques, de domos y diques de composición andesítica y conductos alimentadores de composición dacítica (Fig. 6.5). Conjuntamente se desarrollan depósitos de corrientes piroclásticas alojadas en depresiones y sistemas aluviales dominados por flujos gravitacionales de sedimento (depósitos de avalanchas, de flujos de detritos y de flujos hiperconcentrados). Por su relación espacio-temporal y genética, estas unidades representan un volcanismo dominantemente andesítico con sistemas aluviales volcaniclásticos asociados (fig. 


\section{Modelo Paleoambiental y Paleográfico}

Unidad tecto-sedimentaria Precuyana (UTS II)

Sistemas fluviales de carga mixta
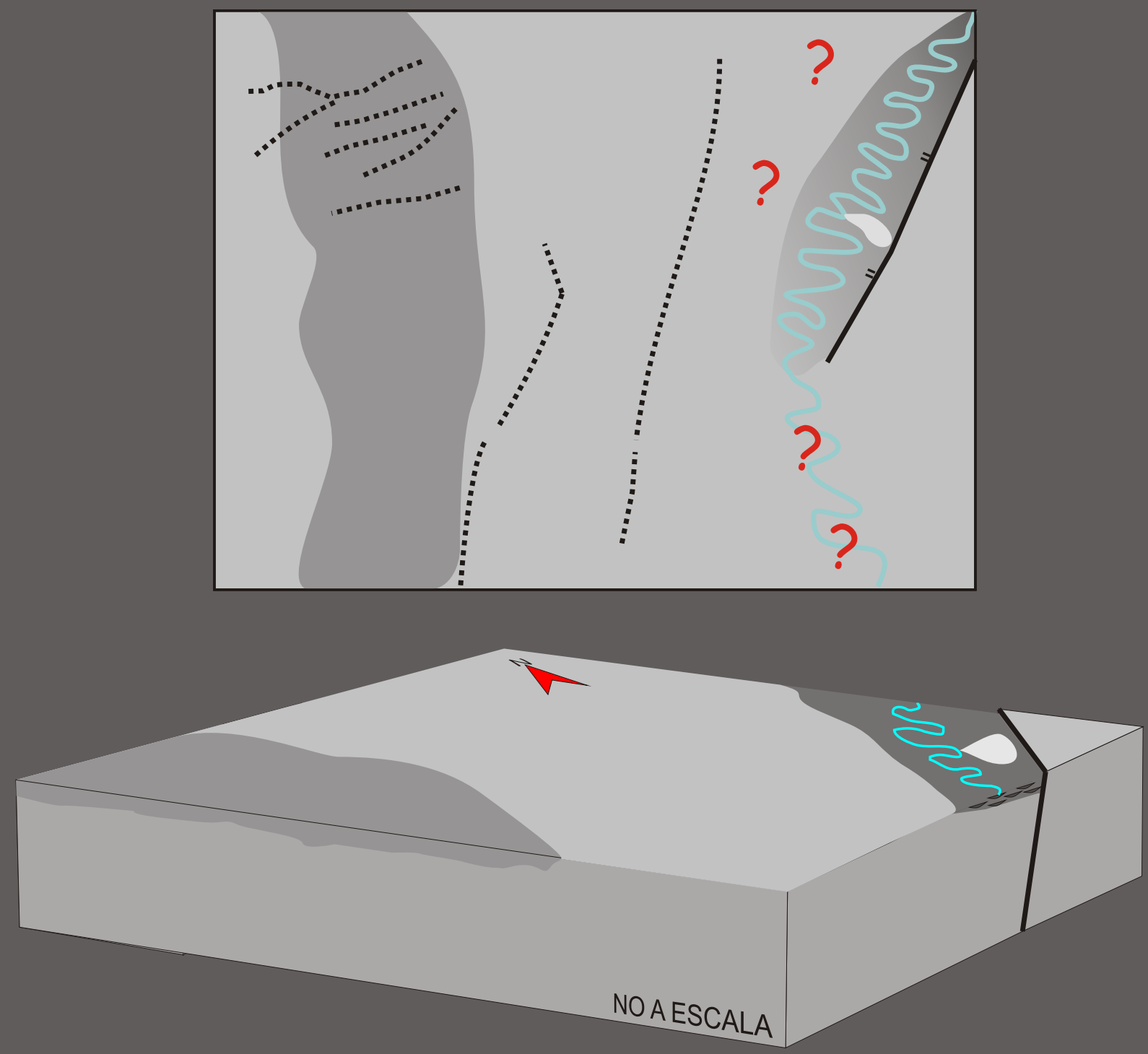

- Ambiente fluvial desarrollado en condiciones de alta acomodación.

- Aporte silicoclástico controlado por la relación entre la tasa de acomodación y la tasa de aporte, gobernada por la naturaleza del basamento (bedrock) y las características atmosféricas.

- La relación con las estructuras interpretadas para el depocentro indica depositación en el bloque bajo.

Unidad tecto-sedimentaria II: Sistemas fluviales de carga mixta

$\square$ Unidad tecto-sedimentaria I (Formación Paso Flores)

Basamento

Figura 6.8. Modelo paleoambiental y paleogeográfico del inicio de la UTS II. 
6.5). El análisis petrográfico y litogeoquímico indica un rango de composiciones desde andesitas basálticas hasta dacitas, con una relación claramente comagmática (fig. 6.9). La relación agradante que esta sección guarda respecto a los elementos estructurales presentes, conjuntamente con el rango composicional, sugiere la existencia de aparatos volcánicos agradacionales-poligenéticos de tipo estratovolcanes (Davidson y De Silva, 2000). Para la caracterización paleoambiental en detalle de esta sección, se puede tomar como ejemplo el sector sureste del depocentro de Sañicó en el área del Cerro Corona (fig. 6.5). En esta zona se puede apreciar cómo las fallas controlaron el espacio de acomodación, tanto longitudinalmente como transversalmente (fig. 6.5). En un panel transversal a las fallas, se observa cómo al sureste del Cerro Corona dominan los diques alimentadores y coladas y coladas dómicas. Contrariamente, hacia el noroeste, predominan las coladas y coladas dómicas y domos pequeños en la base de la sucesión y hacia arriba los ambientes aluviales (sistema aluvial dominado por avalanchas de detritos y flujos de detritos y sistemas aluviales denominados por flujos hiperconcentrados alojados en depresiones) (fig. 6.5). Asimismo, en un panel longitudinal a las fallas principales, se puede observar como en la zona oeste y noroeste del Cerro Corona, la base se encuentra dominada por elementos lávicos y hacia arriba se desarrollan los sistemas aluviales anteriormente mencionados en conjunto con depósitos de corrientes piroclásticas alojados en depresiones (fig. 6.5). El aumento en el registro de facies primarias hacia el sector sureste, indica que la parte proximal del aparato volcánico se habría desarrollado en el área del Cerro Corona. La escasa preservación de las zonas proximales en el registro se adjudica a dos fenómenos. Por un lado, estos aparatos se habrían ubicado en un alto del depocentro, no habiéndose desarrollado espacio de acomodación; por el otro, las zonas proximales habrían agradado por arriba del umbral geomorfológico, sujetas a intensos fenómenos de erosión (Cas y Wright, 1987). Hacia la aparte interna del depocentro, la posición de la zona de vent y el espacio de acomodación habrían controlado la polaridad de la facies hacia condiciones más distales. La abundancia de avalanchas de detritos volcánicos descripta para muchos estratovolcanes del mundo (p.e. volcán Cantal -Francia- (Schneider y Fisher, 1998); Reubi y Hernandez, 2000; volcán Mombacho -Nicaragua- (Shea et al., 2008); Paranicota -Chile- (Clavero et al., 2002); Volcán Shiveluch -Rusia- (Belousov et al., 1999), entre otros), sumado a la aparición de depósitos de corrientes piroclásticas alojadas en depresiones y sistemas aluviales atrincherados sistemas aluviales dominados por flujos hiperconcentrados alojados en depresiones- (p.e. Volcán Ruapehu -Nueva Zelanda- (Palmer et al., 1993); volcanes de sur de Campania -Italia(Zanchetta et al., 2004)), sugieren una posición proximal de la bajada volcaniclástica (ring plain) (Davidson y De Silva, 2000). Tomando a este sector del depocentro como representante de la sección inferior, el ciclo magmático que caracteriza a la UTS II (Ciclo Precuyano) habría comenzado con el desarrollo de estratovolcanes dominantemente andesíticos, junto con el 


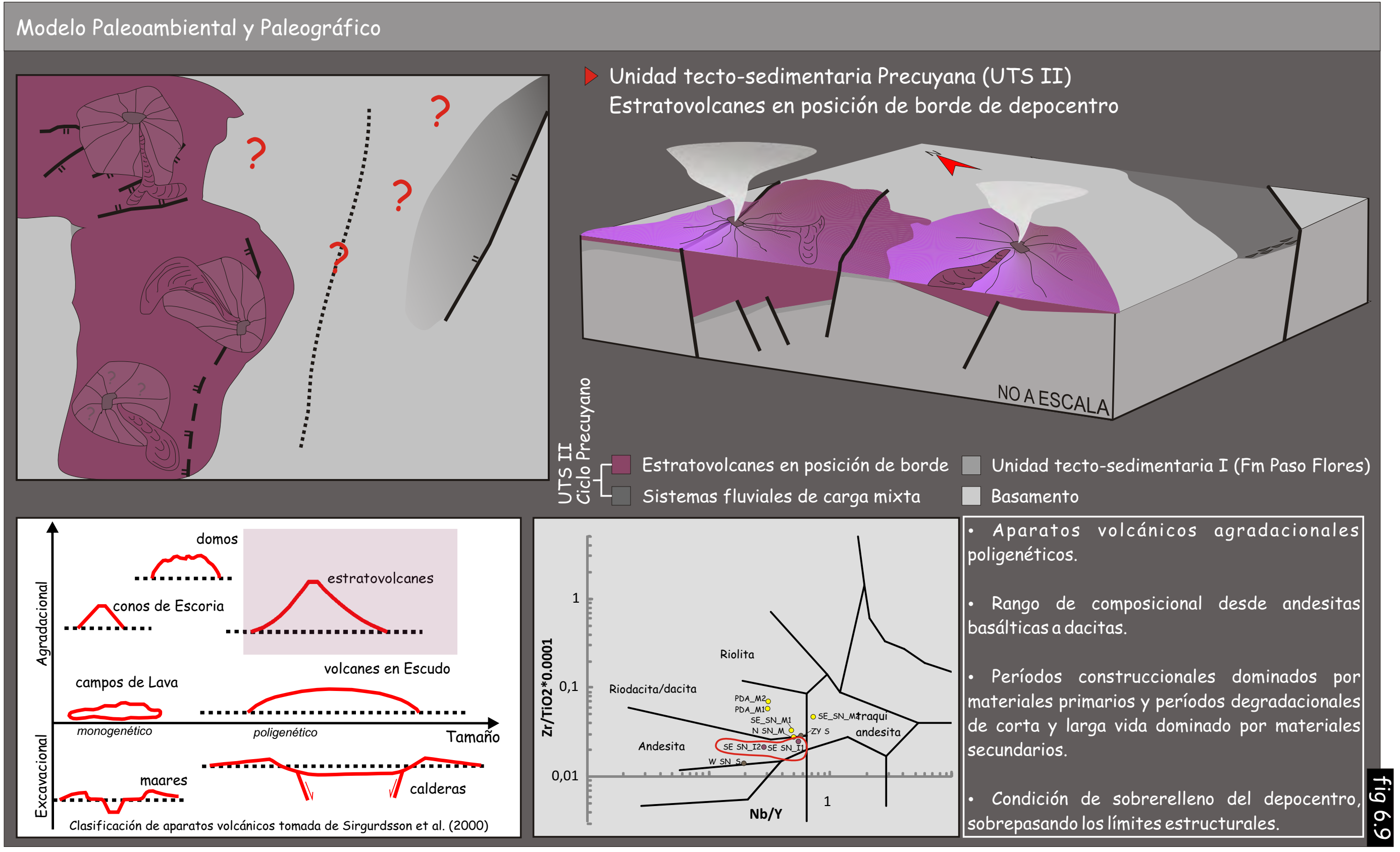

Figura 6.9. Modelo paleoambiental y paleogeográfico del inicio de la actividad volcánica que representó a la UTS II. 
desarrollo del hemigraben de Sañicó de rumbo NE-SW, el cual acomodó hasta 1100 m de esta sección en su borde de mayor actividad (fig. 6.9). La posición de los conductos y diques alimentadores identificados, simultáneamente con la polaridad de las facies, sugiere que los aparatos volcánicos se habrían ubicado con preferencia hacia las posiciones de borde del depocentro (fig. 6.9), probablemente controlados por los elementos estructurales de primer orden que intervinieron en la generación del hemigraben. Estos aparatos generaron condiciones de sobrerelleno para el espacio de acomodación disponible.

La evolución de la unidad tectosedimentaria Precuyana (UTS II) continúa con el desarrollo de un periodo dominado por volcanismo explosivo desarrollado tanto en el depocentro de Sañicó (sección DS-2) (fig. 6.5) como en el de Piedra del Águila (sección DPDA2) (fig. 6.6). Estas secciones se hallan integradas mayoritariamente por depósitos de corrientes piroclásticas de gran distribución areal y minoritariamente por unidades lávicas y aluviales asociadas (fig. 6.5 y 6.6). La geometría planar de la sección media en el depocentro de Sañicó, indica que la superficie de $6^{\circ}$ orden que la separa de la sección anterior representaría un periodo degradacional importante de los estratovolcanes (fig. 6.4). En el área de Piedra del Águila, la sección media inauguró la instauración en este depocentro del abundante volcanismo que representa UTS II. Se deposita encima de una superficie de $6^{\circ}$ orden sobre la sección inferior interpretada como un ambiente fluvial de carga mixta. Al no haberse registrado el volcanismo andesítico previo, descripto para el depocentro de Sañicó, esta superficie representaría un hiato depositacional (fig. 6.4). La generación de espacio de acomodación de manera sincrónica con el desarrollo de las unidades piroclásticas fue constatado en el depocentro de Sañicó (fig. 4.21, 4.23). A su vez, en ambos depocentros, la sección media conforma sucesiones de hasta $1100 \mathrm{~m}$, con más del 90 \% de depósitos de corrientes piroclásticas (fig. 6.5 y 6.6). Estas características permiten sugerir que durante este periodo los depocentros conformaron un tipo de calderas denominadas depresiones vocano-tectónicas (Moore y Kokelaar, 1997; Moore y Kokelaar, 1998; Lipman, 2000). La sección inferior del depocentro de Sañicó, caracterizada por un volcanismo andesítico, habría constituido parte del volcanismo precaldérico (fig. 6.10). Algunos autores señalaron que el volcanismo previo a la actividad caldérica puede estar ausente (Cole et al., 2005), lo cual permitiría explicar la carencia de éste en el depocentro de Piedra del Águila. El análisis realizado sobre las unidades de acumulación piroclásticas de gran distribución areal muestra que éstas se habrían generado a partir del colapso de erupciones plinianas que desarrollaron corrientes piroclásticas sostenidas desde el borde de los depocentros (multivents) (Branney y Kokelaar, 2002) (fig. 4.21, 4.23, 4.25 y 6.10). Respecto al colapso de la caldera, las variaciones en los espesores registrados en el depocentro de Sañicó, sumados al reconocimiento de diferentes unidades de acumulación, en ocasiones separadas por sistemas aluviales (fig. 4.31), indicarían una subsidencia volcanotectónica asimétrica, diferencial e incremental (Cole et 


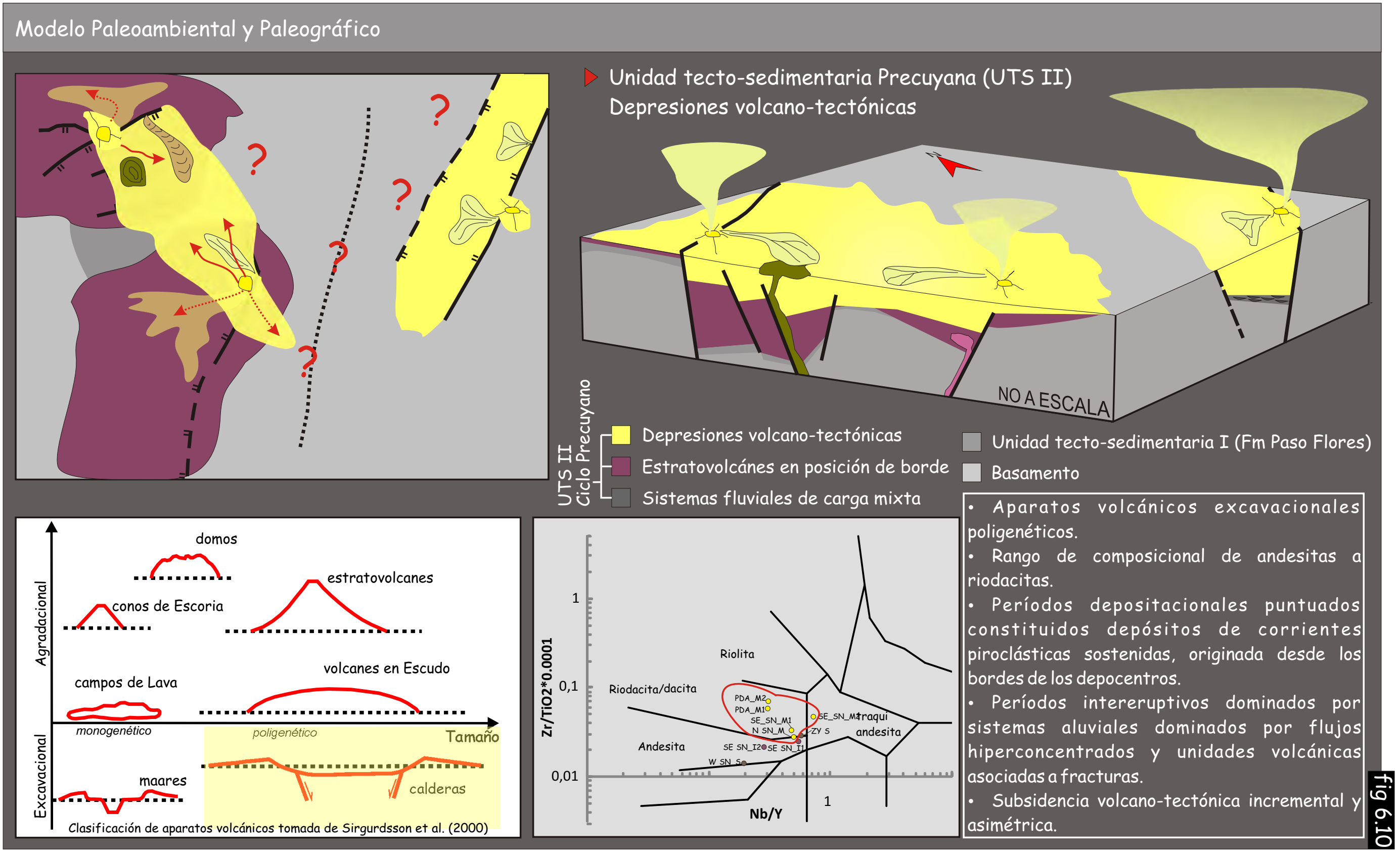

Figura 6.10. Modelo paleoambiental y paleogeográfico de las depresiones volcáno-tectónicas desarrolladas en los depocentros de Sañicó y Piedra del Águila para la parte media de la UTS II. 
al., 2005). La extensión reducida e incompleta del depocentro Piedra del Águila hace imposible determinar la simetría/asimetría del colapso, aunque se puede mencionar que al igual que en el depocentro de Sañicó, fue incremental. Las mesobrechas y megabrechas son un elemento común sugerido para el colapso de calderas (Lipman, 2000; Cole et al., 2005). La ausencia de estas facies se puede explicar por la participación en el colapso de elementos estructurales previos y debido a que las escarpas de fallas se habrían mantenido coherente durante el colapso (Moore y Kokelaar, 1998). Es importante destacar, que siendo el relleno netamente volcaniclástico, la presencia de facies de brechas líticas (mlBr) (fig. 3.10, 4.21 y 4.23) con abundantes clastos del basamento tanto en los sectores basales como medios de las unidades piroclásticas, estarían probablemente relacionadas a la producción de fragmentos durante el colapso. Asimismo, la presencia de sistemas aluviales reducidos y la ausencia de superficies de erosión mayores, permiten suponer que los eventos de colapso no estuvieron muy distanciados en el tiempo. Es importante destacar que los periodos de inactividad volcánica de tipo explosiva también estuvieron acompañados por actividad magmática intrusiva/efusiva de escaso volumen, donde se desarrollaron domos y lavas andesíticas y riodacíticas asociados a las principales estructuras.

Depresiones volcano-tectónicas fueron descriptas en muchos ambientes extensionales (p.e. Long Valey, Cuenca de Basin and Range -EEUU- (Cole et al., 2005); Graben de Glencoe Escocia- (Moore y kokelaar, 1997; Moore y kokelaar, 1998); Caldera de Sierra Madre Occidental, sur de la Cuenca de Basin and Range -Méjico- (Aguirre-Díaz et al., 2008); Caldera de Scafell -Inglaterra- (Branney y Kokelaar, 1994); Caldera de Taupo y Caldera de Okataina, Zona Volcánica del Taupo -Nueva Zelanda- (Spinks et al., 2005)). El reconocimiento de este tipo de aparato volcánico en el registro geológico no es una tarea sencilla, ya que la mayoría de las descripciones de calderas son de edades actuales o neógenas y muchos de los elementos que definen este tipo de aparato volcánico - volcanismo precaldérico, actividad hidrotermal, colapso, volcanismo postcaldera (Lipman, 2000) - pueden ser difíciles de identificar en el análisis de sucesiones antiguas. El rasgo anular, históricamente pensado como uno de los elementos más diagnósticos de calderas, no es tan común en ambientes tectónicamente activos, donde las estructuras controlan el desarrollo de calderas con formas poligonales (Moore y kokelaar, 1997; Moore y kokelaar, 1998; Cole et al., 2005; Spinks et al., 2005). La tipificación y descripción de un aparato volcánico de esta índole no tiene precedentes dentro del relleno Precuyano y su identificación pone de manifiesto el control probablemente más repentino que puede ejercer el volcanismo sobre los ambientes sedimentarios y paisajes geomorfológicos.

Por último, la unidad tecto-sedimentaria Precuyo (UTS II) finaliza con las sección superior de ambos depocentros (DS-3 y DPDA-3) (fig. 6.5 y 6.6). Estas secciones marcan el retorno de un volcanismo de composición andesítica, asociado con el desarrollo de ambientes 
sedimentarios aluviales, deltaicos y lacustres (fig. 6.11). El retorno de la actividad volcánica a posteriori de los aparatos caldéricos, podría ser interpretado como un volcanismo postcaldera (Lipman, 2000). Las características del pasaje de la sección superior en los depocentros de Sañicó y Piedra del Águila muestran diferentes tipos de relación con los eventos volcanotectónico anteriores (fig. 6.11). En el depocentro de Sañicó, una vez finalizado el último periodo de colapso, la instauración de la sección superior habría sido inmediata. La superficie de $6^{\circ}$ orden que limita la sección media de la inferior marcaría sólo un cambio abrupto en las condiciones del volcanismo, sin registrarse un hiato depositacional marcado. El escaso hiato depositacional puede ser inferido por la abundancia de lavas postcaldéricas con fracturación hidráulica relacionadas a la circulación de fluidos calientes a altas presiones (Gifkin et al., 2005) y por el desarrollo sistemas lacustres con estructuras de silicificación probablemente relacionadas a la acción de soluciones volcánicas (Kralner y Spöl, 1998). Estos procesos podrían ser sincrónicos con los procesos deutéricos postdepositacionales registrados en las unidades de corrientes piroclásticas con gran distribución areal. En el depocentro de Piedra del Águila, en cambio, una vez finalizado el último proceso de colapso, la sección media desarrolla una potente sucesión de sistemas aluviales terminales, los cuales desarrollan secuencias progradacionales internas que marcan un mayor control autocíclico (fig. 6.6) (Miall, 2006). Estas características indican, por un lado, la creación de espacio de acomodación tectónico posteriormente al último evento de colapso (Moore y Kokelaar, 1998) y, por otro lado, un periodo de degradación, donde la presencia de controles autocíclicos evidencian mayor tiempo de evolución de los ambientes sedimentarios y menor influencia de controles extrínsecos (Orton, 2002; Reading y Level, 2002). La superficie de 6ºrden que separa la sección media de la superior en el depocentro de Piedra del Águila, denotaría un tiempo mayor al observado en el depocentro de Sañicó entre el final del evento caldérico y la instauración del volcanismo postcaldera. En ambos depocentros la sección superior se ha depositado en un área más restringida del depocentro. No obstante, la evolución ambiental de las secciones es diferente. En el depocentro de Sañicó, hacia el borde activo se desarrollan unidades de acumulaciones lávicas, sistemas aluviales dominados por flujos de detritos y, hacia el tope, sistemas deltaicos de grano grueso con disposición transversal (fig. 6.11), los cuales confluyeron en lagos. La naturaleza volcanigénica de variada procedencia y la participación de rocas del basamento en la composición, sugieren una red de drenaje más integrada y menor control por parte del volcanismo dentro del relleno. En cambio, hacia el margen sureste del depocentro, se desarrolla una sucesión compuesta por unidades lávicas dominadas por lavas coherentes (fig. 6.6 y 6.11). En el depocentro de Piedra del Águila esta sección corresponde al tope del registro mesozoico. Se integra de unidades lávicas y minoritariamente de unidades aluviales y corrientes piroclásticas. A pesar de presentar mayor distribución que en el depocentro de Sañicó, hacia el 


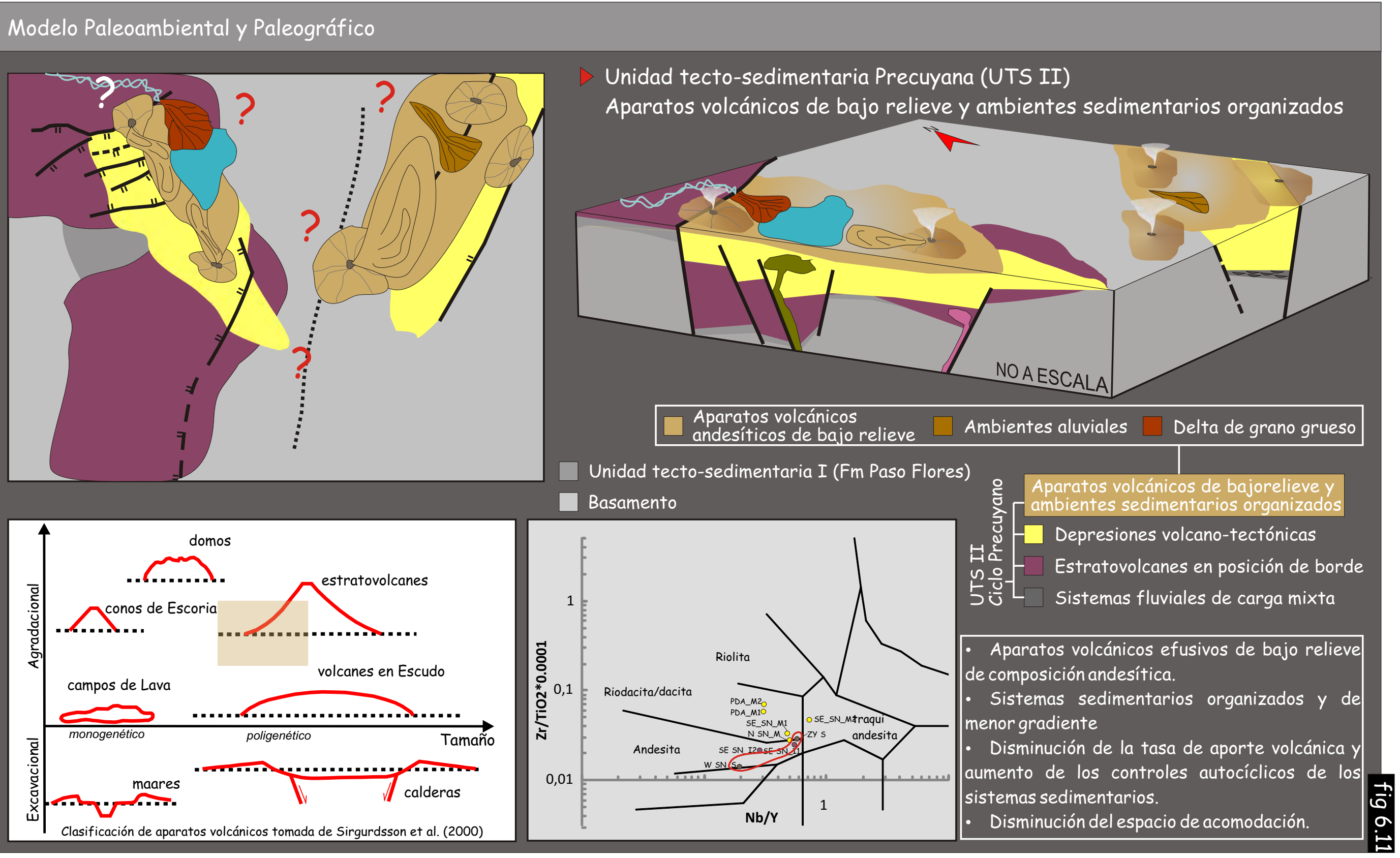

Figura 6.11. Modelo paleoambiental y paleogeográfico para los estadios finales de la UTS II. 
oeste se desarrolla con poca preservación por sobre el basamento, sugiriéndose que al igual que en el depocentro de Sañicó hay un déficit de acomodación. Es importante destacar que la sección superior de ambos depocentros presenta atributos comunes, como la presencia de sistemas aluviales sin facies de avalanchas de detritos y mayor abundancia de unidades lávicas donde dominan las lavas coherentes. Estas características sugieren que el volcanismo no desarrolló aparatos volcánicos de alturas considerables (Brown y Bell, 2007). Con todo, este periodo involucró el fin del evento volcánico que representa la unidad tecto-sedimentaria II, caracterizándose por la reducción de las áreas de acomodación, aparatos volcánicos agradantes andesíticos de bajo relieve y sistemas sedimentarios más organizados.

Los periodos evolutivos para la UTS II, caracterizados principalmente por un relleno asociado a la evolución de diferentes ambientes volcánicos (construccionales y excavacionales), permiten sugerir que los depocentros de Piedra del Águila y Sañicó constituyeron hemigrábenes volcánicos (Aguirre-Díaz et al., 2008). Es significativo destacar que diferentes autores han establecido subdivisiones dentro del Ciclo Precuyano, las cuales se efectuaron en función de unidades formales (p.e. Leanza, 1990; Leanza et al., 2005; Llambías et al., 2007), unidades tecto-sedimentarias (p.e. Lanés et al., 2008) o secciones definidas por los procesos depositacionales (p.e. Franzese et al., 2006; Franzese et al., 2007). Estas subdivisiones del relleno precuyano también constituyen o podrían constituir diferentes tramos evolutivos dentro del Ciclo al igual que lo observado en el área de Sañicó y Piedra del Águila en este trabajo.

La UTS III “Cuyana” corresponde al último periodo de sinrift del rifting inicial de la cuenca en el área austral de la misma. Este último evento se caracteriza por una reorganización total de las áreas de acomodación y una merma abrupta del volcanismo. Se desarrolla principalmente en el depocentro de la Pintada, el cual por su orientación debe haber cortado, a las estructuras que controlaron la UTS II (fig. 5.2 y 6.12). En esta etapa cesa la depositación en el depocentro de Piedra del Águila, mientras que el depocentro de Sañicó es inundado, desarrollándose por encima una superficie de discontinuidad de $7^{\circ}$ orden (una superficie transgresiva) el comienzo de la sedimentación marina que caracteriza a esta UTS (fig. 6.4). El arreglo y tipo de unidades de acumulación en los depocentros de Sañicó y de la Pintada es muy diferente. En sentido transversal en el depocentro de Sañicó, en las proximidades de la falla de borde, se desarrolla un ambiente marino somero carbonático, seguido de una secuencia deltaica de grano fino, con características agradantes (fig. 5.4). Hacia el tope de la secuencia, depósitos de corrientes piroclásticas de escaso volumen hacen notar la aparición eventual del volcanismo. Las paleocorrientes medidas para este ambiente son escasas y deben ser consideradas con cautela. Las mismas arrojan direcciones de transporte hacia el sur y hacia el oeste (fig. 4.35). Por arriba de esta sucesión deltaica se desarrolla nuevamente un ambiente marino carbonático y, 


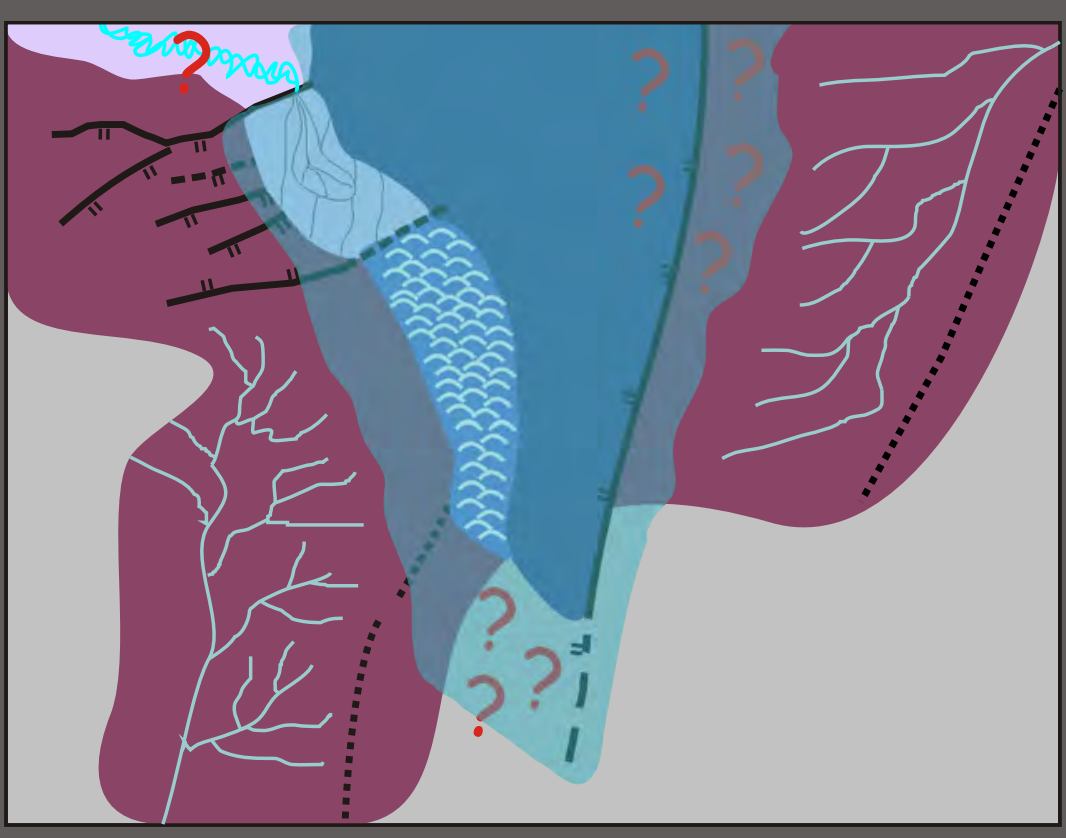

$\square$ Ambiente marino de costa afuera

Ambiente deltaico de grano fino

$\square$ Ambiente marino somero carbonático

Unidad tecto-sedimentaria III (Ciclo Cuyano) Unidad tecto-sedimentaria II (Ciclo Precuyano)

$\square$ Unidad tecto-sedimentaria I (Fm Paso Flores)

Basamento
Unidad tecto-sedimentaria Cuyana basal (UTS III)

Ambiente marino en condiciones desde someras a profundas

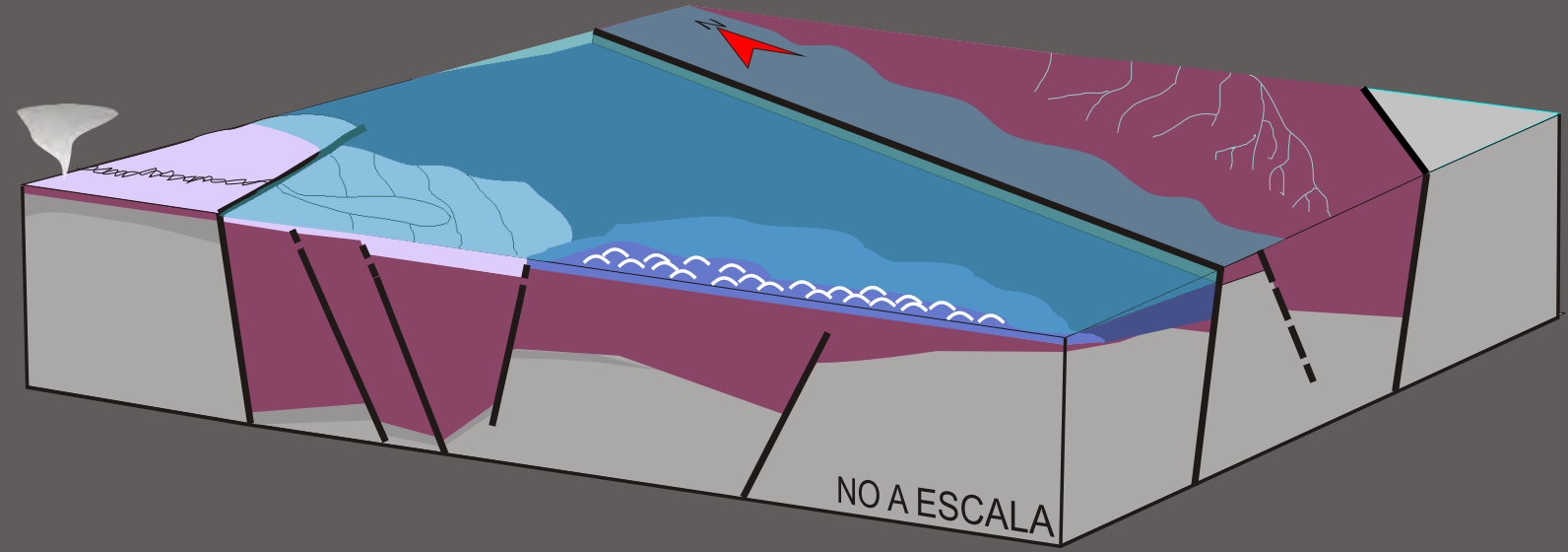

- El comienzo de la UTS III se caracteriza por una reorganización total de las áreas de acomodación y una merma abrupta del volcanismo.

- Los tipos de unidades de acumulación en el depocentro de Sañicó y de la Pintada indican arreglos de alta frecuencia que estarían relacionados a cambios relativos del nivel del mar asociados principalmente a la creación de espacio de acomodación por tectónica.

- Las unidades de acumulación muestran un arreglo transgresivo en todos los sitios evaluados, sugiriendo, para un orden de baja frecuencia, que el aumento relativo del nivel del mar podría estar relacionado a procesos eustáticos o a un descenso del datum a escala regional. 
finalmente, se pasa a un ambiente marino profundo (fig. 6.7 y 6.12). Hacia el borde sureste del depocentro de Sañicó, de menor acomodación, la UTS III comienza con un ambiente marino carbonático, desarrollándose sobre ésta una potente sucesión de ambiente marino profundo (fig. 6.7 y 6.12). Respecto al depocentro de la Pintada, el borde de menor acomodación se desarrolla hacia el oeste, sobre el depocentro de Sañicó (fig. 6.7 y 6.12). Transversamente al depocentro (fig. 6.7 y 6.12), hacia la falla de borde del hemigraben, no se desarrollan ambientes marinos someros, generándose rápidamente condiciones por debajo del tren de olas en un ambiente de bajada submarina (fig. 6.12). Las direcciones de paleocorrientes indican transporte de materiales en sentido NE-SW, reflejando aporte casi transversal al depocentro desde el bloque colgante (fig. 4.36). A grandes rasgos, considerando el arreglo vertical del inicio de la UTS III, se puede notar que en todos los sectores siempre hay una evolución desde ambientes marinos someros hacia ambientes marinos más profundos (fig. 6.7). Algunos autores han propuesto que la inundación de la cuenca estuvo relacionada a causas tectónicas, superpuestas con un ascenso del nivel del mar a escala global (Legarreta y Uliana, 1996). El arreglo transgresivo, que denota un aumento del espacio de acomodación para toda la zona, sería por lo tanto independiente de los elementos estructurales, sugiriéndose para un orden de baja frecuencia un aumento relativo del nivel del mar relacionado a procesos eustáticos o a un descenso del datum regional. Si tenemos en cuenta el arreglo litofacial y los diferentes tipos de unidades de acumulación dentro del depocentro de Sañicó y de la Pintada, se pueden identificar ciclos de alta frecuencia que estarían relacionados a cambios relativos del nivel del mar asociados principalmente a la creación de espacio de acomodación por tectónica (Jackson et al., 2005). Algunos autores señalaron que durante la ingresión marina del Ciclo Cuyano los depocentros iniciales fueron integrados dentro de una gran área depocentral, donde el relleno estuvo controlado por cambios eustáticos, subsidencia termal y por la topografía heredada de los hemigrábenes iniciales (Legarreta y Uliana, 1996, Burgues, 2000). El control tectónico sobre los depósitos cuyanos fue mencionado recientemente en diferentes áreas de la cuenca (Vergani et al., 1995, Franzese et al., 2006, Muravchik, 2008a; Muravchik, 2008b). Los resultados obtenidos sugieren que los cambios de baja frecuencia podrían estar relacionados a variaciones eustáticas o de subsidencia regional (comienzo de la subsidencia termal ?), mientras que los cambios de alta frecuencia estuvieron relacionados a subsidencia local por el accionar de fallas.

6.2.2) Los controles sobre las unidades tecto-sedimentarias Precuyana y Cuyana

\subsubsection{1) Los controles tectónicos}

El estudio del estilo estructural de los depocentros de rift es esencial para entender el delicado balance que existe entre las estructuras, el espacio de acomodación, el emplazamiento 
del volcanismo y el tipo, variabilidad y polaridad de los ambientes sedimentarios desarrollados en estos escenarios. En función del control estratigráfico y estructural se han definido tres áreas depocentrales que albergaron las unidades tecto-sedimentarias identificadas en el presente estudio. En sentido amplio, los tres depocentros fueron definidos como hemigrábenes en función de las características asimétricas de su relleno. El depocentro de Sañicó corresponde a un hemigraben volcánico que registra hasta 1850 m de relleno. Posee una orientación NE-SW, polaridad hacia el sureste, limitado por fallas NE-SW y ENE y presenta $27 \mathrm{~km}$ de ancho y $9 \mathrm{~km}$ de largo aflorantes (fig. 6.13). Internamente se desarrollan estructuras oblicuas sintéticas y antitéticas y desarrollo de altos internos. El hemigraben de la Pintada presenta una orientación N-S y polaridad hacia el oeste y acomoda principalmente los depósitos del Ciclo Cuyano (UTS III) con espesores mayores a los $220 \mathrm{~m}$. Muestra un ancho máximo de $20 \mathrm{~km}$ y el largo aflorante en el área de estudio es de unos $30 \mathrm{~km}$ (fig. 6.13). El depocentro de Piedra del Águila que muestra características poco diagnósticas, fue definido como un hemigraben volcánico que albergó hasta 1500 m de relleno y habría presentado una orientación NE-SW, con polaridad hacia el noroeste, contraria al depocentro de Sañicó. Presenta un largo aflorante de 9 km y un ancho máximo continuo de alrededor de 2,5 km (fig. 6.13).

Dadas las características de los depocentros de la Pintada y Piedra del Águila es dificultoso establecer un estilo estructural y modelo de hemigraben. Para el depocentro de Sañicó, su perfil de relleno asimétrico, con bloques que presentan subsidencia diferencial (fig. 5.3, 6.3 y 6.9) y las fallas sintéticas internas que presentan una distribución variable con rumbos NE-SW, ENE-WSW y NNW-SSE (anexo I y fig. 6.13), indicarían un modelo de tipo dominó (Schlische, 1991). Es importante destacar que hacia el borde de menor acomodación del hemigraben, en el área del Cerro Corona, se identificó una geometría sinforme longitudinal a las fallas presentes (fig. 6.5), la cual podría representar una variación de la acomodación sobre el rumbo (Schlische y Anders, 1996), explicándose más probablemente con un modelo de tipo de falla de crecimiento (Schlische, 1991). La relación geométrica que los diferentes dominios de fallas del depocentro guardan con el relleno, indica que las mismas actuaron al mismo tiempo. La orientación de las fallas es coincidente con las fábricas encontradas por otros autores para el basamento de la región (fig. 6.14), quienes señalaron orientaciones NE-SW, E-W y NW-SW (Varela et al., 1991). Teniendo en cuenta que el depocentro de Piedra del Águila presenta la misma orientación que el de Sañicó, en conjunto ambos definirían un rift oblicuo probablemente controlado por las anisotropías del basamento (Morley, 1999b). Rifts controlados por la fábrica del basamento fueron descriptos por otros autores (Morley, 1999a; Morley, 1999b; Morley, 1999c; Moustafa, 2002; Morley, 2004) para diferentes cuencas del mundo (p.e. Rift de Tailandia, Rift de Suez, Rift del Este Africano). La misma mecánica de rifting fue propuesta recientemente por algunos autores para algunos depocentros del norte de la Cuenca Neuquina 
fig 6.13

Controles estructurales

Depocentro de Sañicó
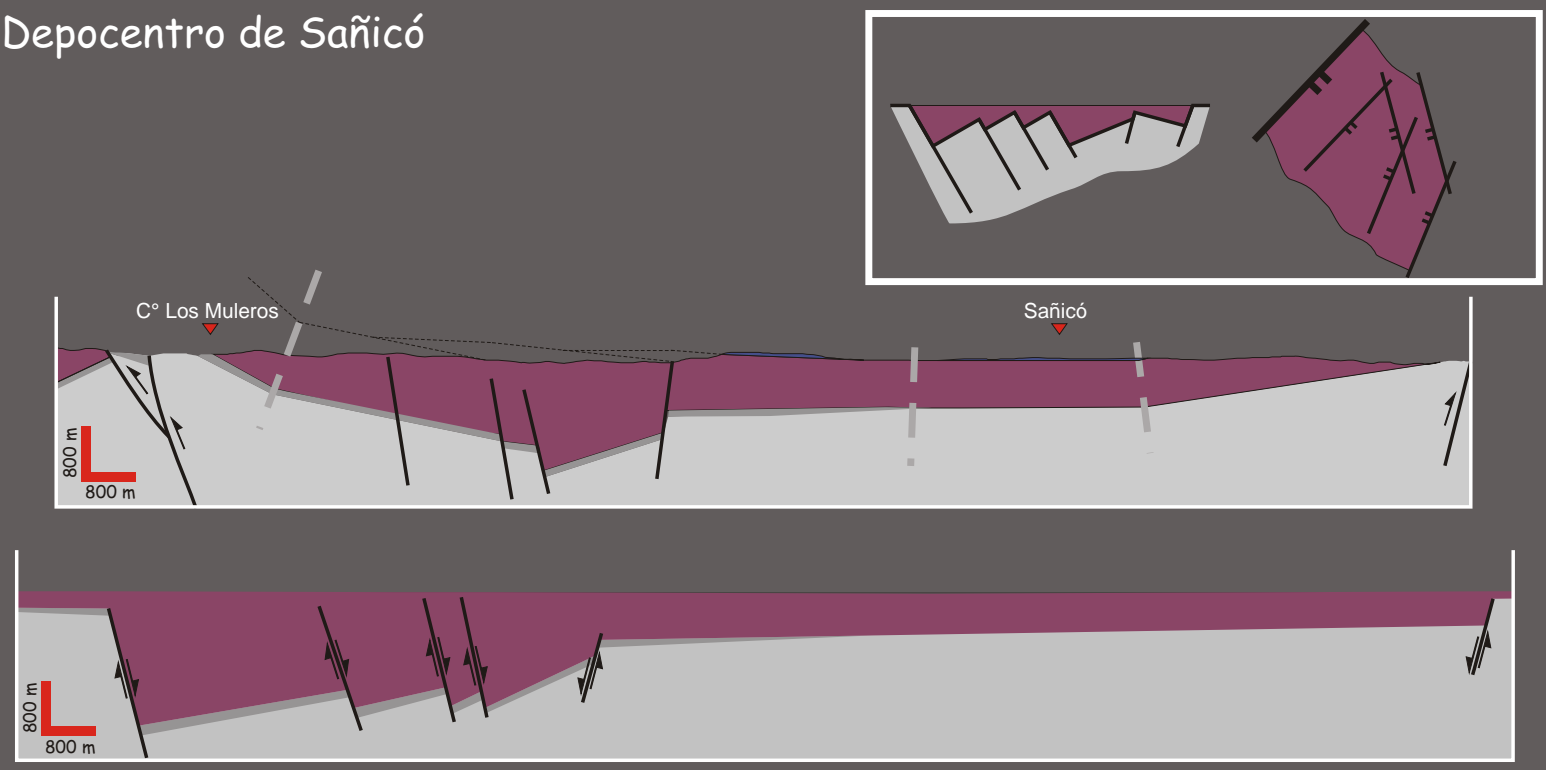

\section{Depocentro de la Pintada}
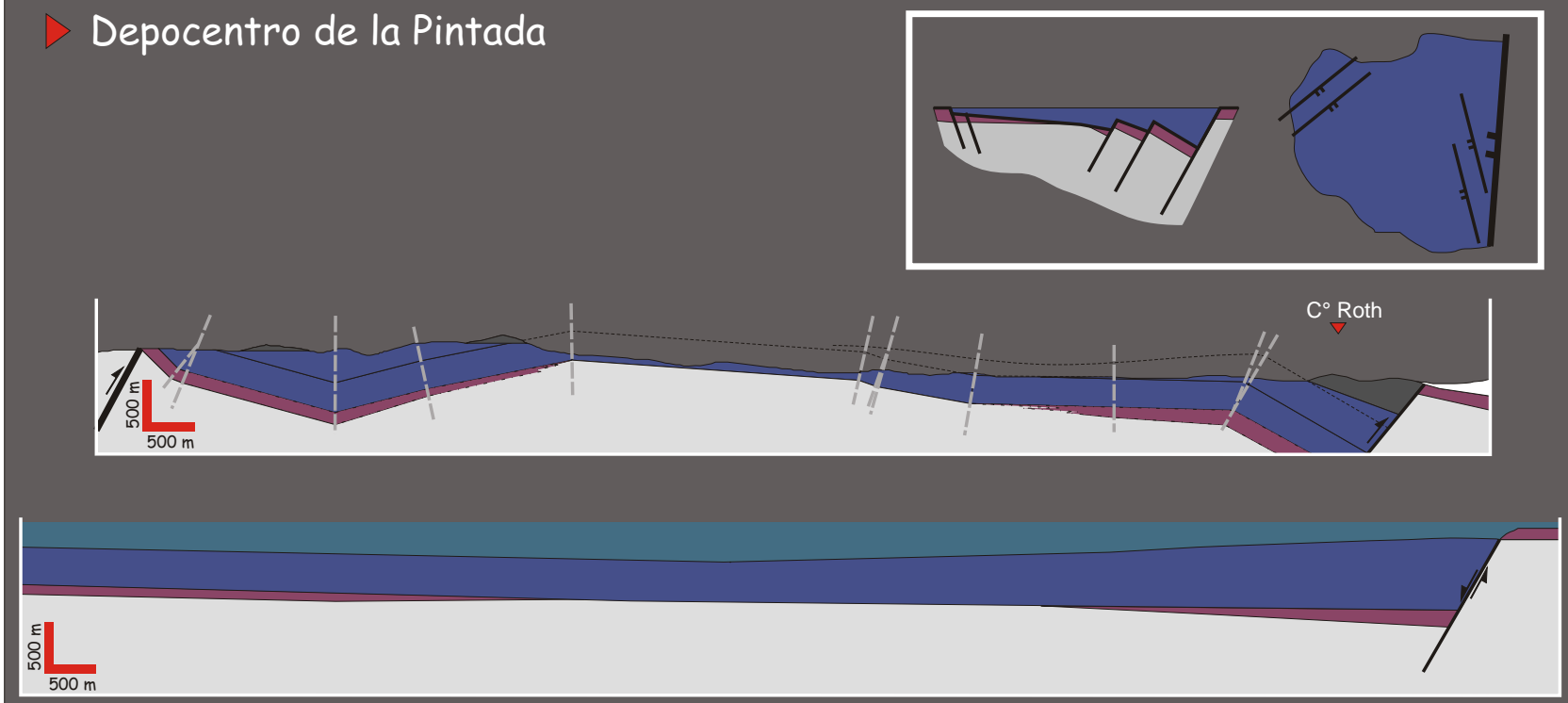

Depocentro de Piedra del Águila
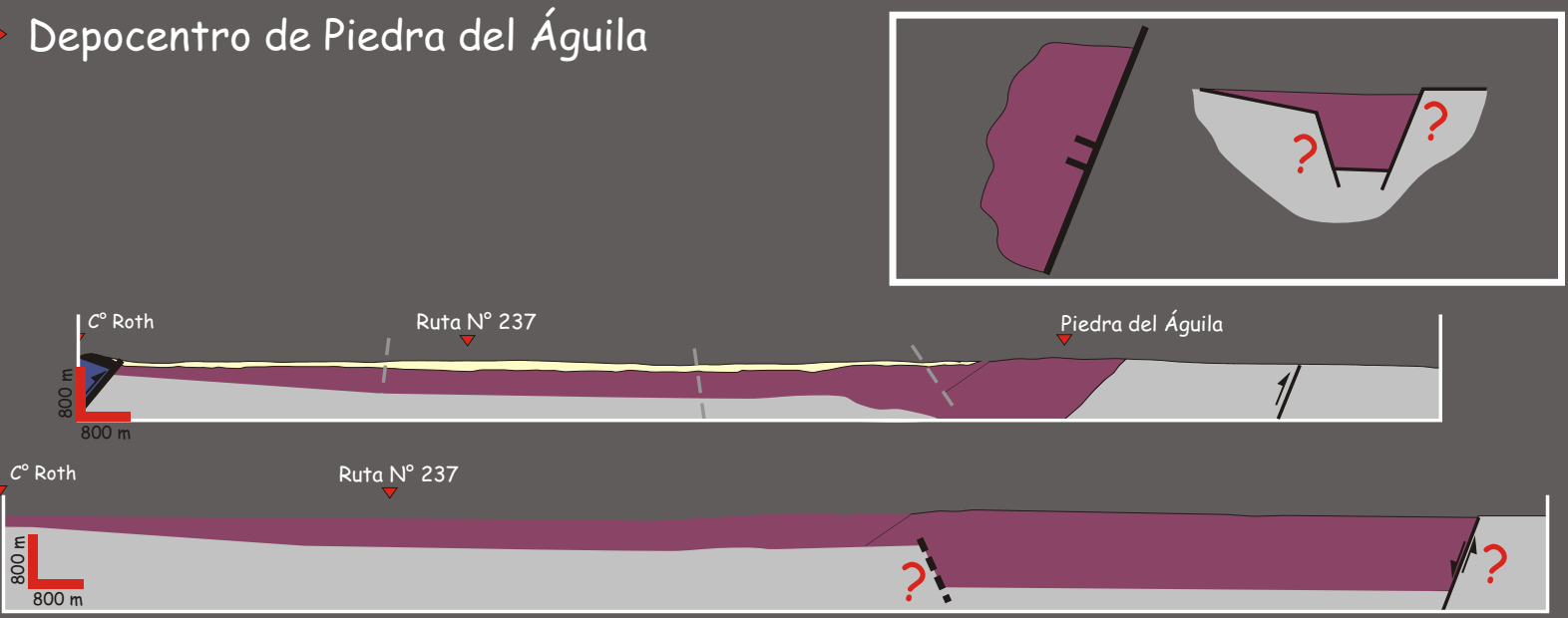
(Giambiagi et al., 2008a; Giambiagi et al., 2008b). Es importante destacar que el modelo estructural presentado en este trabajo no coincide con el propuesto por Gulisano y Pando (1981), quienes sugirieron un solo depocentro para toda la región, con una falla de borde posicionada en las cercanías de la localidad de Piedra del Águila, con rumbo N-S y polaridad hacia el oeste. De acuerdo al análisis realizado en este trabajo no existe ninguna evidencia que soporte la existencia de esa estructura en el sentido que le dan esos autores.

El estilo estructural de las cuencas de rift es controlado por la estructura térmica de la corteza y el manto, por la cantidad de extensión y las variaciones en su dirección, por el modelo de rift y por el tipo de litosfera (Morley, 1999a; Morley, 2004; Ziegler y Cloetingh, 2004). En el presente trabajo no se ha avanzado en los datos necesarios para dilucidar las causas dinámicas y cinemáticas del estilo estructural. Aunque las observaciones con las que se cuenta presentan poco rigor, es interesante destacar que el inicio del ciclo magmático Precuyano (UTS II), podría haber sido una causa fundamental de la reorganización de la cuenca. El impacto del magmatismo en la organización de un rift ha sido considerado como un factor de primer orden por diferentes autores (Ziegler y Cloetingh, 2004; Buck, 2004). Respecto a los indicadores cinemáticos, los mismos deben ser considerados con precaución. En general se cuenta con mediciones de rumbo y minoritariamente de inclinación de fallas, sin conservarse indicadores del sentido de movimiento (fig. 6.14). Algunos autores señalaron que la intrusión de diques en zonas tectónicamente activas, se orienta preferentemente en forma perpendicular a la dirección del esfuerzo principal mínimo o3 (Marinoni y Gudmundson, 2000; Anchochea et al., 2008). El sistema de diques observado en el depocentro de Sañicó con una orientación longitudinal NWSE, que conforma un set conjugado sintético-antitético a las fallas del borde sureste del depocentro (fig. 6.14), es el único indicador probable de la dirección de máxima elongación con que se cuenta. La cantidad de datos obtenidos para el depocentro de la Pintada no permite siquiera hacer una estimación local. Es importante destacar que la dirección de máxima elongación NE-SW obtenida a partir del sistema de diques, es similar a la propuesta recientemente para la mayoría de los depocentros del sector norte de la cuenca (Giambiagi et al., 2008a; Giambiagi et al., 2008b; Giambiagi et al., 2008c, Cristalini, 2009). De ser correcta esta dirección para el segundo evento de sinrift, la relación que ésta guarda con los elementos estructurales definidos para los depocentros de Sañicó y Piedra del Águila, de orientación NESW, ENE-WSW y NNW-SSE, habría producido un escenario de deformación mixta (extensional-transtensiva). Otra posibilidad, es que, como producto del control que ejercen las estructuras del basamento, la dirección de máxima elongación se haya apartado de la dirección regional y los datos con los que se cuenta podrían estar indicando sólo una dirección de máxima elongación local. Es conveniente destacar que en los últimos años otros depocentros transversales o casi transversales a la dirección NE-SW propuesta, fueron citados para la cuenca 


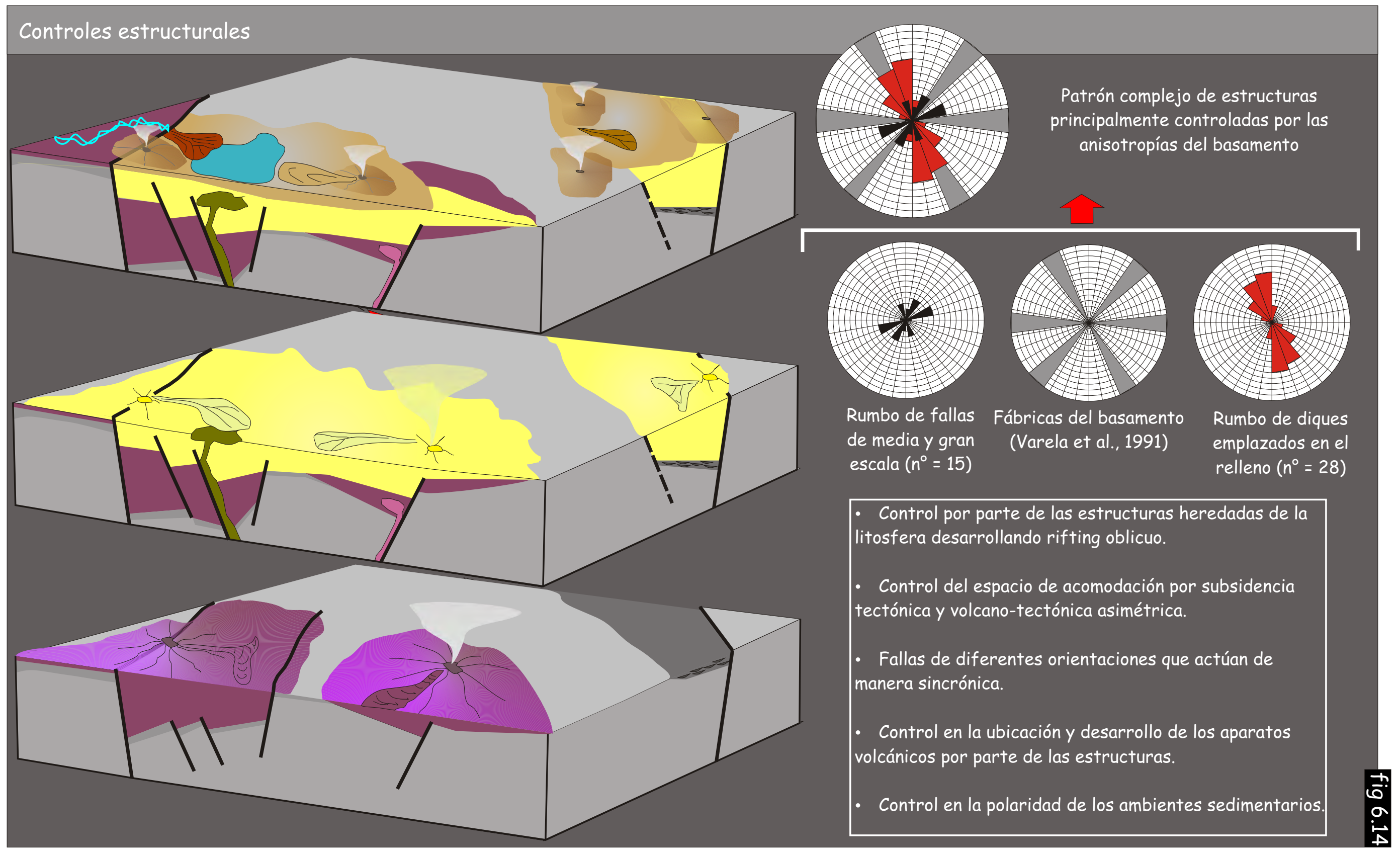

Figura 6.14. Controles estructurales y litosféricos en la orientación de los depocentros identificados para Ciclo Precuyano. 
- depocentro de Chacaico (Franzese et al., 2007) y depocentro de Sierra de Reyes y Cara Cura (Giambiagi et al., 2008a; Giambiagi et al., 2008b).

Procesando de manera conjunta la orientación, polaridad y el estilo estructural, simultáneamente con el orden cronológico, los depocentros que acomodan a la UTS II (Sañicó y Piedra del Águila) conformarían hemigrábenes volcánicos de rumbos NE-SW-con polaridades opuestas, desplazados en el rumbo (fig 6.15). El depocentro de la Pintada que acomoda la UTS III, se habría desarrollado como un hemigraben de rumbo N-S, con polaridad hacia el W que cortó en parte a las estructuras anteriores (fig 6.15).

Los controles tectónicos no sólo tienen influencia en el estilo estructural de los depocentros de una cuenca, sino también ejercen un control fundamental sobre los sitios de ascenso magmático y el tipo de volcanismo (Abebe et al., 2007; Spinks et al., 2005; Cassidy et al., 2009), el tipo y polaridad de los ambientes sedimentarios (Schlische, 1991; Morley, 1995; Gawthorpe y Leeder, 2000) y el cambio relativo del nivel mar a escala local dentro de un depocentro (Gawthorpe et al., 2003; Young et al., 2003; Jackson et al., 2005). Todos estos controles se ponen de manifiesto y actuaron durante el desarrollo del Ciclo Precuyano (UTS II) y el inicio del Cuyano (UTS III) del área de estudio. La relación entre las estructuras y el volcanismo queda evidenciada en el sistema de diques longitudinal que se desarrolla como fracturas sintéticas y antitéticas a las fallas ubicadas hacia el borde sureste del depocentro de Sañicó (fig. 4.13 y 6.14). Asimismo, la vinculación entre las fracturas y cuerpos volcánicos satélites también puede ser notada en este depocentro, por el desarrollo de criptodomos riodacíticos y domos andesíticos relacionados a las fallas internas al depocentro (fig. $4.8 \mathrm{y}$ 4.15). El control en el ascenso y tipo de volcanismo también se registra en la sección media de los hemigrábenes volcánicos de Sañicó y Piedra del Águila, donde los elementos estructurales de la extensión controlaron la acomodación durante el desarrollo de depresiones volcanotectónicas (fig. 4. 21, 4.23, 6.5, 6.6 y 6.4). En este sentido, las zonas de mayor extensión facilitarían el ascenso y la reserva de grandes volúmenes de magmas y la producción de conductos emisores (Spinks et al., 2005).

El control tectónico también se puede apreciar en el desarrollo de los paleoambientes ampliamente relacionados al volcanismo, como en la organización de los ambientes sedimentarios. Para la sección inferior del depocentro de Sañicó la distribución de las facies sedimentarias, volcánicas y los datos de paleocorrientes y ejes de paleodepresiones indican una polaridad proximal-distal de los aparatos volcánicos compuestos hacia adentro del depocentro (fig. 6.5 y 6.9). Las fallas no sólo controlaron el espacio de acomodación y facilitaron el ascenso del magma que habría dado origen a los aparatos, sino también, el colapso de éstos, evidenciado por la distribución de las facies de avalanchas de detritos (fig. 6.5). Modelos análogos de 
Controles estructurales

\begin{tabular}{|c|c|c|c|}
\hline & Depocentro de Sañicó & $\begin{array}{c}\text { Depocentro de Piedra } \\
\text { del Águila }\end{array}$ & $\begin{array}{l}\text { Depocentro } \\
\text { de la Pintada }\end{array}$ \\
\hline $\begin{array}{l}\text { Estructuras } \\
\text { mayores }\end{array}$ & Orientación NE - SO y NNE - SSO & Aflora NE - SO & $N-S$ \\
\hline $\begin{array}{l}\text { Estructuras } \\
\text { menores }\end{array}$ & $\begin{array}{l}\text { Fallas normales oblicuas y } \\
\text { paralelas a las estructuras de } \\
\text { borde. Bloques internos con } \\
\text { geometría romboidal }\end{array}$ & Sin estructuras visibles & Estructuras internas oblicuas \\
\hline Largo & $9 \mathrm{Km}$ aflorantes & $10 \mathrm{Km}$ aflorantes & $30 \mathrm{Km}$ aflorantes \\
\hline Ancho & $27 \mathrm{Km}$ & $2,5 \mathrm{Km}$ aflorantes & $20 \mathrm{Km}$ \\
\hline $\begin{array}{l}\text { Espesor } \\
\text { máximo }\end{array}$ & $1850 \mathrm{~m}$ & $1310 \mathrm{~m}$ & $<500 \mathrm{~m}$ \\
\hline $\begin{array}{l}\text { Espesor } \\
\text { mínimo }\end{array}$ & $0 \mathrm{~m}$ & $500 \mathrm{~m}$ & $0 \mathrm{~m}$ \\
\hline $\begin{array}{l}\text { Tipo de } \\
\text { relleno }\end{array}$ & $\begin{array}{l}\text { Volcánico y piroclástico con } \\
\text { sistemas aluviales asociados }\end{array}$ & $\begin{array}{l}\text { Volcánico y unidades piroclásticas } \\
\text { de gran espesor con desarrollo } \\
\text { de sistemas aluviales hacia } \\
\text { el tope de la sucesión }\end{array}$ & $\begin{array}{l}\text { Sedimentario marino somero } \\
\text { a profundo, con participación } \\
\text { de unidades piroclásticas } \\
\text { en el comienzo }\end{array}$ \\
\hline \multicolumn{4}{|l|}{$\begin{array}{l}\text { Vista en } \\
\text { planta }\end{array}$} \\
\hline $\begin{array}{l}\text { Sección } \\
\text { transversal }\end{array}$ & & & \\
\hline
\end{tabular}

Falla de borde de graben activas $\begin{aligned} & \text { Falla de borde de graben inactivas } \\ & \text { o parcialmente activas }\end{aligned}$
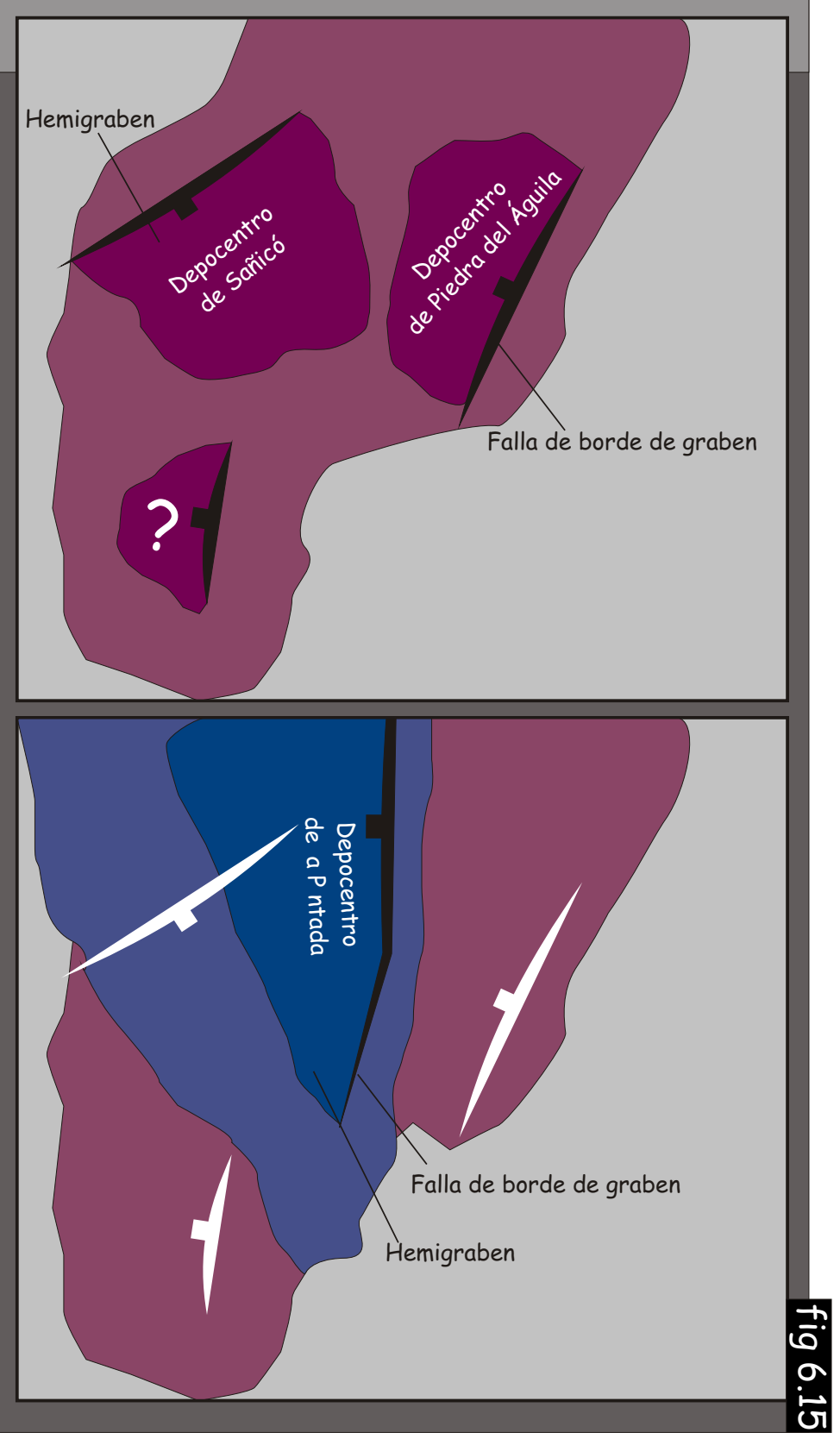

Figura 6.15. Resumen de las características de los depocentros identificados para el área de estudio y su relación espacial. 
colapso de construcciones volcánicas relacionadas a estructuras extensionales, recientemente realizados, apoyan esta condición (Wooller et al., 2009). El control tectónico también se pone de manifiesto en la distribución de los ambientes sedimentarios organizados desarrollados hacia el tope de la sección superior de la UTS II y el inicio de la UTS III en el depocentro de Sañicó (fig. 6.5 y 6.11). Asociados a la falla que limita el depocentro se desarrollaron deltas de grano grueso (fig. 4.34 y 6.11) y deltas de grano fino transversales (fig. 4.35 y 6.12), adosados al borde. Para el tope de la UTS II la entrada de los sedimentos transversal al depocentro habría facilitado el posicionamiento de ambientes lacustres hacia áreas centrales (fig. 4.34 y 6.11).

Finalmente, el efecto tectónico del control del nivel relativo del mar, se puede apreciar en un perfil transversal al depocentro de Sañicó para el inicio de la UTS III (Ciclo Cuyano) (fig. 6.7). Hacia la falla de borde, la generación de espacio de acomodación albergó una sucesión deltaica de grano fino, la cual se presenta por encima y por debajo de unidades carbonáticas (fig. 6.7). Hacia el borde opuesto del depocentro se generó una sucesión carbonática de ambiente marino somero que representaría una sucesión condensada (fig. 5.4) análoga a la observada en otras localidades de la Cuenca Neuquina - Fm. Chachil - (Legarreta y Uliana, 1996; Burgues, 2000). Esta situación denotaría que mientras se generaba espacio y aporte en condiciones agradacionales en el borde noreste del depocentro, probablemente con el desarrollo de ciclos de alta frecuencia (relacionados a los tramos carbonáticos), en el borde suroeste se generaron secuencias delgadas carbonáticas, controladas por una ubicación paleogeográfica que restringió considerablemente el aporte de materiales silicoclásticos.

\subsubsection{2) Los controles volcánicos}

Históricamente el Precuyano fue definido como un ciclo ampliamente dominado por el volcanismo (Gulisano y Pando, 1981; Gulisano et al., 1984; Riccardi y Gulisano, 1990). La actividad volcánica eventual también fue registrada para el inicio del Ciclo Cuyano en otros sitios de la cuenca (Suárez y de la Cruz, 1997; Gómez-Pérez, 2003; Llambías et al., 2007). El volcanismo comprende la expresión superficial de un sistema magmático complejo, el cual generalmente no se presenta de manera aislada (Cas y Wright, 1987). Genera aparatos volcánicos agradacionales o excavacionales (Sigurdsson, 2000); modifica el relieve y los gradientes de una región (Smith, 1991, Thouret, 1999); rompe el equilibrio entre la tectónica, el clima y la naturaleza de las zonas de aporte (bedrock) y la tasa de aporte en las cuencas sedimentarias, originando gran suministro de materiales terrígenos intracuencales volcaniclásticos en cortos periodos de tiempo (Reading y Level, 2002); modifica la cobertura vegetal (Smith, 1991; Orton, 2002); provoca sismos y áreas con intensa actividad hidrotermal que pueden disminuir la estabilidad del terreno (Orton, 2002). Dadas las características de los procesos, su duración es difícil de medir, en contraposición con las sucesiones sedimentarias 
(Németh y Ulrike, 2007). Además el volcanismo puede modificar los esfuerzos y los patrones de fallas (van Wyk de Vries y Merle, 1996; van Wyk de Vries y Matela, 1998), modificar la estructura térmica de la litosfera, produciendo una relación positiva con los procesos extensionales y aumentar la subsidencia (Buck, 2004). Por último, las características litogeoquímicas del magmatismo pueden representar la impronta de procesos litosféricos particulares acaecidos en un determinado ambiente geodinámico. Los resultados del presente trabajo indican que son numerosos los controles que ejerce el volcanismo dentro del Ciclo Precuyano y la base del Ciclo Cuyano. El control por parte de los tipos de aparatos volcánicos puede ser notado en la diferencia de distribución areal entre la sección inferior del depocentro de Sañicó, asociada al desarrollo de volcanes compuestos andesíticos, y la sección media del depocentro de Sañicó y Piedra del Águila, atribuida a una depresión volcano-tectónica (fig. 6.5 y 6.8). La sección inferior del depocentro de Sañicó, al generar construcciones volcánicas agradacionales, se distribuye ampliamente por fuera de los límites del depocentro (fig. 6.4), mientras que la sección media de ambos depocentros, generada como un aparato excavacional, sólo encuentra preservación en las áreas depocentrales (fig. 6.4 ). La naturaleza de estos dos tipos contrastantes de aparatos volcánicos poligenéticos, también se expresa en el relieve, gradiente y tipo de ambientes sedimentarios desarrollados. Los volcanes compuestos habrían generado construcciones elevadas, en tanto que la naturaleza primariamente efusiva genera el predominio de materiales gruesos (Németh y Ulrike, 2007). En este marco, los periodos degradacionales de corta vida y larga vida (Thouret, 1999; Davidson y De Silva, 2000) estuvieron controlados por materiales mayoritariamente gruesos, representativos de condiciones de alto gradiente -avalanchas de detritos y flujos detritos- (Blair y Mc Pherson, 1994). Las depresiones volcano-tectónicas se generaron excavacionalmente aprovechando las estructuras previas. El relleno súbito de estos aparatos genera anegamiento del espacio de acomodación y, la naturaleza explosiva, gran cantidad de material volcaniclástico de granulometría psamítica (Németh y Ulrike, 2007). En este escenario los sistemas intereruptivos se generan bajo la dominación de materiales tobáceos, mientras que el tipo de material y el escaso desnivel fomentan sistemas aluviales de bajo gradiente, dominados por flujos hiperconcentrados de sedimentos (Smith, 1986; Smith y Lowe, 1991; Blair y Mc Pherson, 1994). Más allá de las diferencias genéticas entre los dos tipos de aparatos volcánicos, la relación geométrica del relleno primario y secundario, conjuntamente con los tipos de ambientes sedimentarios desarrollados, indicarían condiciones de sobrerelleno de los depocentros (Schlische, 1991). Una condición diferente se observa en la sección superior de la UTS II (Ciclo Precuyano) del depocentro de Sañicó, donde una disminución del volcanismo habría favorecido una mayor organización de los ambientes sedimentarios, generándose ambientes deltaicos de grano grueso y sistemas lacustres. La influencia del volcanismo, aunque local, eventualmente también puede 
ser observada en el inicio del Ciclo Cuyano. El sistema de delta de grano fino presenta depósitos de flujos eventuales dominados por materiales tobáceos y pumíceos (fig. 4.35), los cuales podrían ser coincidentes a los esperados en la redepositación subácuea de unidades piroclásticas primarias (Allen y Freundt, 2006). Es importante destacar que por arriba de esta unidad sobreyace una unidad piroclástica primaria, interpretada como subácuea (fig. 4.26) en función de su control estratigráfico. Esto indica que la actividad volcánica que caracteriza al ciclo magmático Precuyano, a pesar de mermar abruptamente, como es de esperar, tiene representación en la base del Ciclo Cuyano.

Como fuera oportunamente mencionado, el tiempo es un factor difícil de evaluar en las sucesiones volcánicas antiguas. La naturaleza tan disímil de los procesos volcánicos y piroclásticos y la preponderancia de depósitos eventuales de flujos gravitatorios de sedimentos, hacen que las superficies identificadas en estas secuencias sólo se puedan comparar desde el punto de vista físico - véase apartados anteriores - (Németh y Ulrike, 2007). A diferencia de los ambientes sedimentarios, las superficies identificadas en los principales productos desarrollados en los ambientes volcánicos, generalmente presentan diferentes órdenes temporales de magnitud. La figura 6.16 compara los distintos tiempos que involucran los principales procesos identificados para el Ciclo Precuyano (lávicos, piroclásticos y sedimentarios), los cuales fueron tomados de contribuciones realizadas en ambientes sedimentarios y volcánicos actuales (Palmer, 1993; Thouret, 1999; Kilburn, 2000; Cioni et al., 2000; Lipman, 2000; Davidson y De Silva, 2000; Orton, 2002; Branney y Kokelaar, 2002; Zancheta et al., 2004; Miall, 2006; Németh y Ulrike, 2007). En esta figura se puede apreciar el contraste que hay entre los principales elementos volcánicos y piroclásticos que modelaron el paisaje precuyano y los sedimentarios. Los ambientes volcánicos del Ciclo Precuyano podrían haberse mantenido en actividad por un tiempo de hasta 1 ma (alrededor del 25\% de la duración del ciclo), mientras que la depositación eventual de los principales productos se habría desarrollado en un lapso menor a los 10 días. Esta condición se evidencia en la sección DS-1 y DS-2 del depocentro de Sañicó, donde se manifiestan cortos periodos agradacionales dominados por la actividad volcánica, seguidos de etapas de inactividad. La pausa en el volcanismo puede ser interpretada por la geometría planar de la superficie de $6^{\circ}$ orden que separa la sección DS- 1 de la sección DS-2 (fig. 6.3), indicándose un largo periodo degradacional de los aparatos volcánicos compuestos antes de la instauración de las depresiones volcano-tectónicas. Por el contrario, el lapso que involucra el desarrollo de ambientes sedimentarios organizados (p.e. sistemas de deltas de grano grueso, sistemas aluviales terminales), indica que éstos sólo pudieron haber tenido lugar mediante una merma del control extrínseco del volcanismo de entre 5000 y 50000 años, o superior a esta última, sugiriéndose que en los tramos superiores del ciclo precuyano comenzó a ser evidente la merma del volcanismo. 
Controles volcánicos

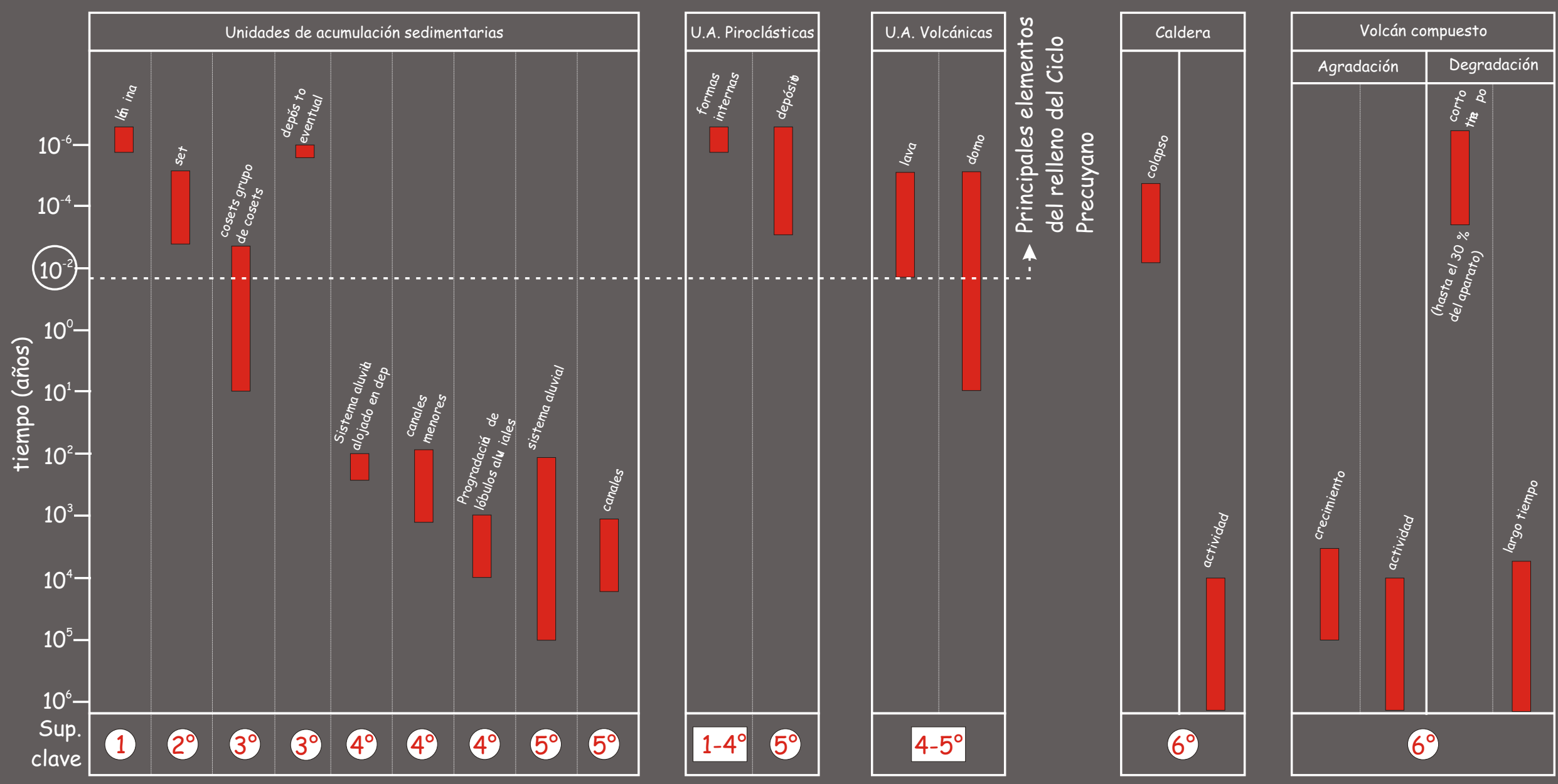

Flujos eventuales: Avalanchas de detritos, flujo de detritos, flujos hiperconcentrados. Formas internas dentro de las corrientes piroclásticas: láminas, estratificación, estratificación entrecruzada a pequeña y gran escala.

Lapsos de los procesos tomados de: Palmer, 1993; Thouret, 1999; Kilburn, 2000; Cioni et al., 2000; Lipman, 2000; Davidson y De Silva, 2000; Orton, 2002; Branney y Kokelaar, 2002; Zancheta et al., 2004; Miall, 2006; Németh y Ulrike, 2007. 
epiclásticas de procedencia volcánica en estadios de diagénesis temprana. Estas observaciones coinciden con los tipos de fábricas post-depositacionales, donde los empaquetamientos se desarrollan con contactos generalmente tangenciales o rectos y minoritariamente flotantes y cóncavo-convexos, evidenciando poco sepultamiento (Scasso y Limarino, 1997).

El modelo petrogenético para el Ciclo Precuyano puede ser evaluado desde dos puntos de vista diferentes: la relación volcanismo-zona de aporte magmático superficial y la relación magma-fuente de origen. Referente a la relación entre el volcanismo y las zonas de aporte magmático, en muchas cuencas de rift, debido a su naturaleza extensional y al fuerte adelgazamiento cortical, se registran materiales magmáticos de diferentes fuentes, provenientes de las zonas de generación, sin presentar prácticamente residencia en la corteza (Best y Chirstiansen, 2000). En el presente trabajo son muchas las evidencias para sustentar que el magmatismo precuyano estuvo relacionado a cámaras magmáticas superficiales multinyectadas, donde se consolidaron parte de los procesos MASH - melting asimilation storage and homogenization - (fig. 6.17) (Best y Chirstiansen, 2000; Marsh, 2000). Entre éstos se destacan:

- La presencia de aparatos volcánicos poligenéticos agradacionales y degradacionales (Sigurdsson, 2000) relacionados a rocas de un rango composicional continuo entre andesitas basálticas a riodacíticas (fig. 6.17), con diagramas de variación y patrones de los elementos mayoritarios y trazas consistentes con rocas comagmáticas (Best y Christiansen, 2000) (fig. 6.17).

- El desarrollo de depresiones volcano-tectónicas, con cámaras magmáticas superficiales, habría involucrado un mecanismo de ascenso de stopping, el cual habría ayudado al mayor tiempo de permanencia de los magmas en la corteza, favoreciendo la diferenciación (Best y Christiansen, 2000).

- $\quad$ El desarrollo de texturas desde microporfíricas, porfíricas, hasta seriadas con 45\% de abundancia de fenocristales, indican una historia de enfriamiento lenta del líquido magmático, donde los cristales nucleados crecen bajo "dominios de enfriamiento plutónico” en el seno una cámara magmática (Best y Christiansen, 2000). La variación en la cantidad de fenocristales sugiere la extracción de diferentes sitios de una cámara magmática estabilizada (zona de suspensión, zona de captura y zona de mush) (fig. 6.17) (Marsh, 2000).

- Las variaciones composicionales recurrentes, hacia rocas volcánicas menos evolucionadas de gran expresión volumétrica dentro del relleno, indicarían reinyección de las cámaras magmáticas o cámaras magmáticas diferentes (Best y Christiansen, 2000). 
Tal como se ha manifestado en el capítulo 3, las rocas del Precuyano se hallan parcialmente alteradas. La alteración registrada para los depósitos del Ciclo Precuyano es de diferente naturaleza: a) relacionada a procesos hidrotermales asociados al volcanismo efusivo, b) vinculada a procesos deutéricos acaecidos en los estadios postdepositacionales de las unidades volcánicas ácidas y piroclásticas de gran distribución areal y c) asociada a procesos diagenéticos. La alteración hidrotermal se manifiesta particularmente en la sección inferior del depocentro de Sañicó, en las proximidades de las zonas de fracturas y conductos de emisión del volcanismo efusivo. Se muestra de manera no penetrativa y habría sido generada por soluciones a altas presiones que generaron fracturas hidráulicas y pseudobrechas (fig. 4.10). Exceptuando las zonas de fracturas, donde se pueden presentar de manera avanzada, los grados de alteración van desde débiles a moderados (sensu Gifkins et al., 2005), destacándose la alteración cloríticasericítica y encontrándose de manera eventual alteración potásica, carbonática y silícica. La alteración deutérica está controlada por los procesos postemplazamiento desarrollados a alta temperatura (Best y Chirstiansen, 2000). La alteración silícea penetrativa sólo fue encontrada en los domos riodacíticos, coladas riodacíticas e ignimbritas de gran distribución areal (fig. 4.15, 4.16, 4.20, 4.22 y 4.24). Estas características evidencian que la alteración estuvo controlada primariamente por la composición original de los materiales. Las texturas y distribución hallada en las unidades volcánicas indican que fue de manera penetrativa, relacionada tanto a procesos de desvitrificación, como de alteración de soluciones acuosas (Mc Phie et al., 1993; Gifkins et al., 2005). La alteración deutérica encontrada en las unidades piroclásticas es común en este tipo de depósitos (Streck y Grunder 1995; Mc Arthur et al., 1998; Quane y Russel, 2005), registrándose dos tipos de patrones: a) unidades afectadas en la base por alteración sericíticaclorítica y hacia el tope por alteración en fase vapor (fig. 4.20), en ocasiones desarrollando estructuras de desvitrificación a alta temperatura (fig. 4.24) y b) unidades casi en su totalidad afectadas por alteración en fase vapor (fig. 4.22). No obstante, no se descarta que en este tipo de alteración no hayan participado soluciones acuosas provenientes del sustrato (Cas y Wright, 1987; Wilson, 1993; Mc Phie et al., 1993). La alteración diagenética puede percibirse tanto en las unidades lávicas y piroclásticas como en las sedimentarias. En las unidades lávicas, cuando las asociaciones de minerales de alteración se encuentran en condiciones incipientes, pueden ser características de alteración diagenética (Gifkins et al., 2005). Las unidades de corrientes piroclásticas de escaso volumen muestran una asociación de argilominerales, filosilicatos y óxidos y fiammes alineados perpendicularmente a la máxima dirección de deformación por compactación (fig. 4.19), rasgos que según algunos autores (Mc Phie et al., 1993; Gifkins et al., 2004; Gifkins et al., 2005) indicarían este tipo de alteración. En las rocas epiclásticas, los diferentes tipos de cementos (silíceos, clorita-esmectita y ferruginosos) son típicos de rocas 


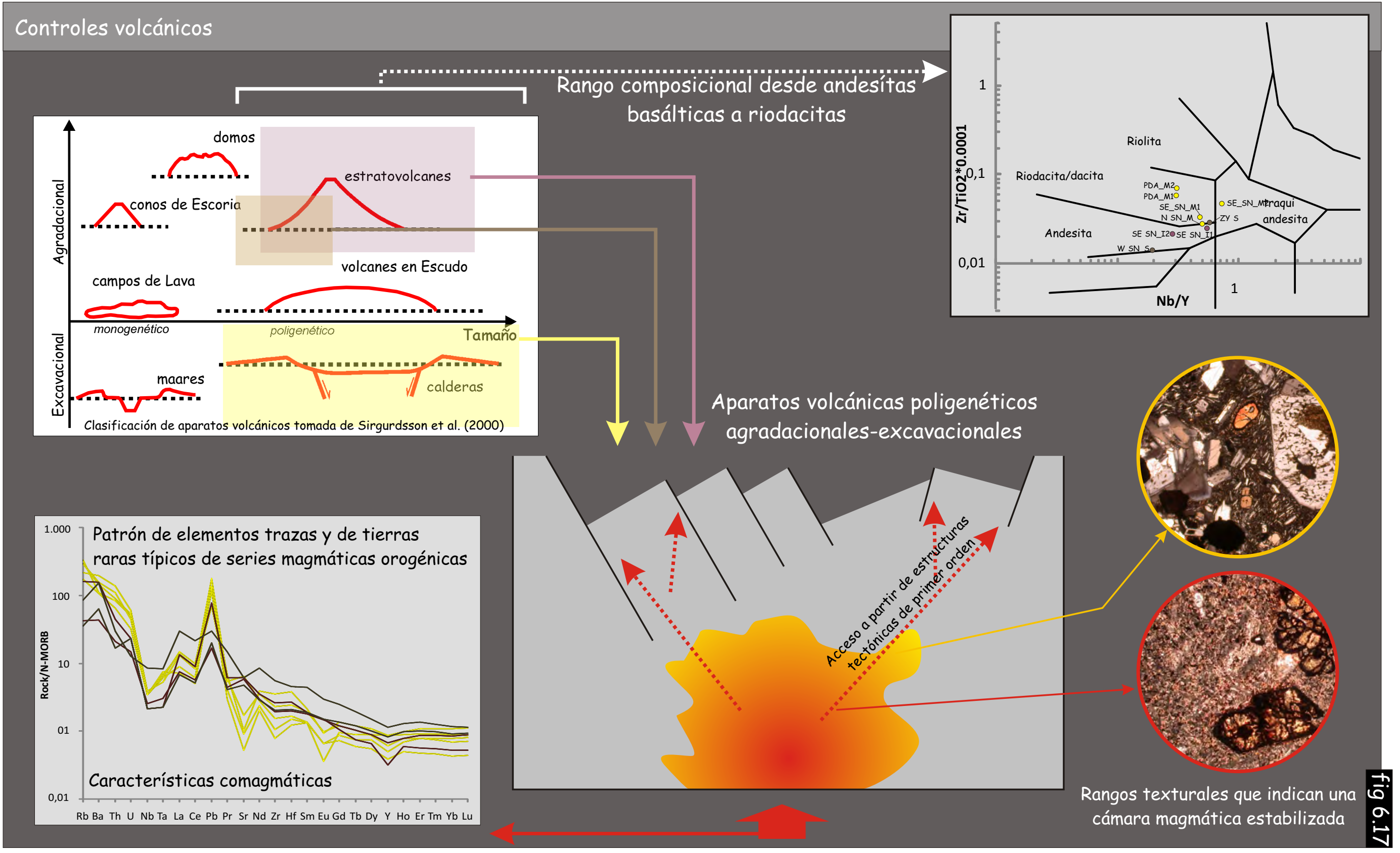

Figura 6.17. Modelo conceptual petrogenético para el Ciclo Precuyano: volcánismo-área de aporte y área de aporte-área fuente. 
Los altos valores de elementos no conservativos (LIL y LREE) y bajos valores de elementos conservativos (HFS y HREE) obtenidos en este trabajo (fig. 3.70 y 3.71) permitieron asociar el magmatismo del Ciclo Precuyano a una fuente con participación de fluidos (Pearce y Peate, 1995), ocurridos posiblemente en un ambiente geodinámico orogénico relacionado a procesos de subducción-deshidratación de la placa y metasomatismo (Pearce, 1982; Pearce, 1984; Gorton y SChandl, 2000). Las similitudes de las rocas del Ciclo Precuyano con las series magmáticas orogénicas son numerosas, entre ellas se pueden destacar: la amplia variación de rocas, desde andesitas basálticas a riodacítas, con un abundancia en los exponentes intermedios; la tendencia subalcalina calcoalcalina y el enriquecimiento en elementos litófilos (Best y Christiansen, 2000). La relación promedio de Th/Yb de las rocas del Precuyano otorga valores de 12, típicos de orógenos continentales activos (fig. 3.69) (Gorton y Schandl, 2000), habiéndose encontrado en algunas muestras (ZY-S,W-SN-S y SE-SN-I1; véase fig. 3.70 y 3.71) una tendencia hacia ambientes de intraplaca (fig. 3.69). Es importante destacar que recientemente diferentes autores han mencionado el carácter calcoalcalino, con características de series orogénicas para las sucesiones precuyanas en diferentes sectores de la cuenca depocentro de Cordillera del Viento (Llambías et al., 2007), en el ámbito de la dorsal de Huincul (Bemúdez et al., 2002; Schiuma y Llambías, 2008), depocentro de Chachil (Muravchik, 2009) -.

La vinculación magma-fuente de origen no puede ser evaluada sólo con los datos obtenidos en el área de estudio, sino que también se debe tener en cuenta el contexto geodinámico regional, tanto durante el Triásico Superior - Jurásico Inferior, como de los estadios previos al desarrollo de la cuenca que controlaron la estructura térmica, mecánica y composicional de la litosfera. En este sentido, a partir del Pérmico Superior-Triásico Inferior el colapso del orógeno paleozoico superior o la transición a un segmento de subducción lenta, habrían gobernado el marco geodinámico del margen occidental de Gondwana (Ramos, 2009). Las propuestas sobre los factores que habrían dado origen a las cubetas Triásico-Jurásicas del margen suroccidental de Gondwana son numerosas y todavía distan de conformar un panorama conciso (Legarreta y Uliana, 1996; Spalletti, 1999; Franzese y Spalletti, 2001; Franzese et al., 2003; Mpodozis y Ramos, 2008; Ramos, 2009). Para evaluar las características litogeoquímicas del Ciclo Precuyano es preciso utilizar un modelo que permita explicar la ausencia de volcanismo y sedimentación durante el Triásico Inferior y el Triásico Superior medio y la repentina aparición de un volcanismo calcoalcalino con características de arco. Algunos autores asocian el hiato depositacional y magmático al tiempo que habría durado la debilitación de la litosfera del orógeno (Franzese y Spalletti, 2001; Franzese et al., 2003). Posteriormente, el colapso orogénico, desarrollado en el marco de una subducción lenta o no subducción, habría dado origen a un conjunto de depocentros aislados (Sañicó, Piedra del Águila, Chacaico, 
Chachil, entre muchos otros) relacionados a un magmatismo con características de arco (Ciclo Precuyano), asociado a una litosfera metasomatizada. Es importante destacar que un caso similar fue registrado en la evolución del margen de baja California, donde la compleja transición de un régimen de tipo subductivo a uno transcurrente, asociado con el desarrollo de cuencas extensionales durante el Neógeno, ha generado como resultado un magmatismo de postsubducción y de sinrift con la impronta de las series orogénicas (Mora-Klepeis y McDowell, 2005; Negrete-Aranda y Cañon-Tapia, 2008). Por último, como fuera oportunamente mencionado, el lineamiento Río Limay ha sido considerado un elemento estructural de segmentación preandina, desarrollándose al sur de éste un segmento con subducción activa durante el Triásico Superior y el Jurásico Inferior (Franzese y Spalletti, 2001). Al sur del Río Limay aflora un conjunto de volcanitas Triásico-Jurásicas - Formación Los Menucos (Tr Sup) y Fm. Garamilla (J Inf) - con conspicuas semejanzas con las rocas del Ciclo Precuyano (Coira, 1979; Cucchi et al., 1998; Franzese et al., 2002; Lema et al., 2008). A su vez, en esta área también se han identificado batolitos con afinidades de arco para el Triásico Superior y Jurásico Inferior (Rapela y Pankhurst, 1992; Rapela et al., 2005). La similitud litológica y composicional de las rocas que componen al Ciclo Precuyano con las desarrolladas en el ámbito del Macizo Norpatagónico es evidente. En el presente trabajo no se han recolectado los datos suficientes para avanzar en un modelo geodinámico que integre a las unidades presentadas en ambas provincias geológicas. De todas maneras, se presume que, con fuertes diacronismos, el marco magmático desarrollado hacia el margen occidental de Gondwana durante el Triásico Superior-Jurásico Inferior, se podría haber manifestado en diferentes segmentos de margen protoandino, con diferente evolución tecto-estratigráfica.

A modo de corolario, se puede indicar que la evolución tecto-estratigráfica del margen sur de la Cuenca Neuquina resulta de la compleja interacción de fenómenos magmáticos, que inclusive superan los límites de la cuenca, y de fenómenos tectónicos acaecidos en diferentes segmentos del margen occidental de Gondwana. La evolución de las cubetas generadas en este escenario es compleja, con periodos de pasividad-actividad volcánica, reorganización de los depocentros y ambientes de índole continental y marino. Los controles que afectaron estas sucesiones fueron estructurales, volcánicos y eustáticos, y actuaron con diferente intensidad en las distintas etapas del rifting inicial de la cuenca (UTS I, UTS II y UTS III). En la figura 6.18 se presentan los diferentes controles identificados para las UTS II (Ciclo Precuyano) y UTS III (Ciclo Cuyano). 
Controles sobre el Ciclo Precuyano y Cuyano en el área de Piedra de Águila y Sañicó

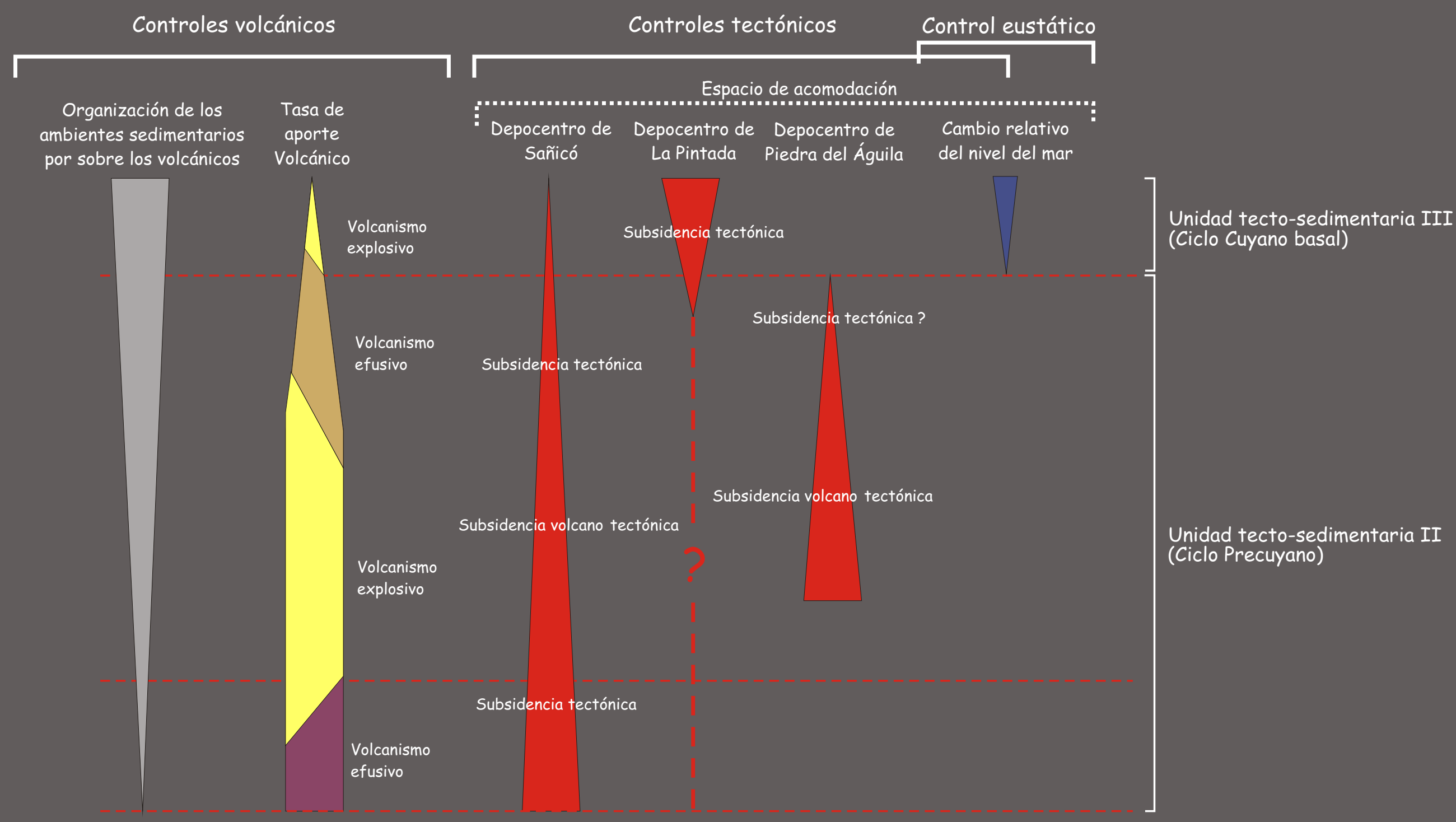




\section{Capítulo 6 - Conclusiones}

- $\quad$ En la zona de Sañicó y Piedra del Águila afloran depósitos continentales y marinos correspondientes a la etapa inicial Triásico Superior-Jurásico Inferior de la Cuenca Neuquina. En el presente estudio se constató que este relleno integrado por la Formación Paso Flores, el Ciclo Precuyano y el Cuyano, representa tres etapas claramente diferenciables en función de sus características genéticas y su distribución controlada por elementos estructurales disímiles.

La evolución tecto-estratigráfica Triásico Superior-Jurásico Inferior del margen sur de la Cuenca Neuquina resulta de la compleja interacción entre fenómenos tectónicos y magmáticos.

- El análisis tecto-estratigráfico permitió identificar tres áreas depocentrales diferentes: 1) depocentro de Sañicó, 2) depocentro de la Pintada y 3) depocentro de Piedra del Águila. El depocentro de Sañicó corresponde a un hemigraben volcánico que posee una orientación NE-SW, polaridad hacia el sureste, limitado por fallas NE-SW y ENE. Está relleno principalmente por depósitos precuyanos y minoritariamente por depósitos del Ciclo Cuyano. El hemigraben de la Pintada presenta una orientación N-S y polaridad hacia el oeste y acomoda principalmente a depósitos del Ciclo Cuyano. El depocentro de Piedra del Águila fue definido como otro hemigraben volcánico de una orientación NE-SW, con polaridad hacia el noroeste y está relleno en su totalidad por depósitos precuyanos.

- $\quad$ La relación entre las diferentes unidades que componen el relleno inicial con los elementos estructurales, sumado a la identificación y jerarquización de superficies clave dentro del mismo, permitieron definir a la Formación Paso Flores y los Ciclos Precuyano y Cuyano como unidades tecto-sedimentarias asociadas a eventos tectónicos extensionales. La unidad tecto-sedimentaria I (UTS I), equivalente a la Formación Paso Flores, corresponde a un periodo rift continental caracterizado por ambientes sedimentarios desde aluviales hasta lacustres. La unidad tecto-sedimentaria II (UTS II), "Precuyana”, corresponde a una etapa de rift con una conspicua actividad magmática. La unidad tecto-sedimentaria III (UTS III), “Cuyana”, pertenece en su parte basal, al último periodo de sinrift del rifting inicial de la cuenca en el área austral de la misma. Este último evento se caracteriza por una reorganización total de las áreas de acomodación y una merma abrupta del volcanismo.

- $\quad$ La observación en detalle del relleno permitió definir un marco cronológico más preciso para las unidades tecto-sedimentarias identificadas. La UTS I corresponde a una secuencia de sinrift continental acotada al Triásico Superior medio a alto. La UTS II comenzó en el Sinemuriano y se habría extendido durante todo este piso. La UTS III representa el inicio 
de un nuevo ciclo tectónico asociado a la disminución abrupta del volcanismo. La tectónica extensional se prolongó durante aproximadamente 30 ma, sin interrupciones mayores.

- $\quad$ En el área de estudio, el relleno inicial precuyano-cuyano de la cuenca se compone de rocas volcánicas, piroclásticas y sedimentarias epiclásticas y carbonáticas. La organización e interpretación del gran número de litofacies identificadas, se realizó mediante el modelo de facies. Esta metodología de análisis permitió la interpretación de los procesos depositacionales volcánicos, piroclásticos y sedimentarios. A su vez, se definieron diferentes tipos de alteración para los depósitos del Ciclo Precuyano: a) relacionada a procesos hidrotermales asociados al volcanismo efusivo, b) vinculada a procesos deutéricos acaecidos en los estadios postdepositacionales de las unidades volcánicas ácidas y piroclásticas de gran distribución areal y c) asociada a procesos diagenéticos. La alteración hidrotermal se manifiesta particularmente en la sección inferior del depocentro de Sañicó, en las proximidades de las zonas de fracturas y conductos de emisión del volcanismo efusivo. La alteración deutérica se pone de manifiesto en los estadios postdepositacionales de las unidades piroclásticas de gran volumen. La alteración diagenética puede percibirse tanto en las unidades lávicas y piroclásticas como en las sedimentarias. En las rocas epiclásticas el tipo de empaquetamiento y los diferentes tipos de cementos (silíceos, clorita-esmectita y ferruginosos) son típicos de rocas volcánicas en estadios de diagénesis temprana.

- Se identificaron unidades de acumulación volcánicas de conducto, diques, domos y coladas y coladas dómicas. Las unidades piroclásticas, fueron divididas en función de su depositación subácuea/subaérea y en de su distribución areal. Finalmente, entre las unidades sedimentarias reconocidas, se destacan: unidades epiclásticas volcaniclásticas, silicoclásticas y carbonáticas.

El arreglo espacio-temporal de las unidades de acumulación, conjuntamente con las características genéticas, permitió la subdivisión del relleno en secciones, que representan estadios evolutivos. La caracterización paleoambiental y paleogeográfica del relleno precuyanocuyano basal permitió definir diferentes tipos de ambientes sedimentarios o volcanosedimentarios: estratovolcanes en posición de borde del depocentro, depresiones volcanotectónicas, ambiente volcánico de bajo gradiente con sistemas sedimentarios asociados (aluviales, deltaicos de grano grueso/lacustre), fluviales de carga mixta, deltaicos de grano fino, marinos de costa afuera y marinos someros carbonáticos.

- $\quad$ El control tectónico sobre las sucesiones precuyanas y cuyanas fue identificado de diferente manera y escala: a) control en las áreas de acomodación b) control en la orientación de los depocentros por parte de las estructuras heredadas del basamento, c) control en la ubicación y polaridad de los ambientes volcano-sedimentarios y sedimentarios y d) control del nivel relativo del mar. 
- $\quad$ La expresión del volcanismo fue identificada tanto para el Ciclo Precuyano como para la base del Ciclo Cuyano. Su actividad afectó la naturaleza agradacional o excavacional de los aparatos volcánicos, el tipo y cantidad de materiales volcánicos y sedimentos ingresados a los depocentros. A su vez, durante los periodos intereruptivos, las características de la actividad previa tuvieron una influencia rotunda en el gradiente, tipo de materiales y procesos depositacionales de los periodos intereruptivos. Si se comparan los procesos y ambientes interpretados para el Ciclo Precuyano, con los lapsos establecidos para homólogos en ambientes actuales, se advierte la característica eventual e "instantánea” de los procesos volcánicos-piroclásticos.

- $\quad$ El modelo petrogenético para el Ciclo Precuyano fue evaluado desde dos puntos de vista: la relación volcanismo-zona de aporte magmático superficial y la relación magmafuente de origen. Las características comagmática de las rocas del Ciclo Precuyano, la presencia de aparatos volcánicos vinculados a cámaras magmáticas superficiales, y los atributos texturales presentes, denotarían un sistema de cámaras magmáticas superficiales multinyectadas, donde se consolidaron parte de los procesos MASH (melting asimilation storage and homogenization). Los diagramas multielemento, de tierras raras y de discriminación, indican una fuente con participación de fluidos, relacionados a un ambiente geodinámico orogénico (procesos de subducción-deshidratación de la placa y metasomatismo). Se comprobó una tendencia subalcalina calcoalcalina y un enriquecimiento en elementos litófilos. La relación promedio de $\mathrm{Th} / \mathrm{Yb}$ de las rocas del precuyano otorga valores típicos de orógenos continentales activos. 


\section{Bibliografía}

Abebe, B., Acocella, V., Korme, T y Ayalew, D. 2007. Quaternary faulting and volcanism in the Main Ethiopian Rift. Journal of African Earth Sciences 48:115-124.

Adams, A.E., Mackenzie, W.S. y Guilford., C. 1984. Atlas of sedimentary rocks under the microscope. Logman Scientific \& Technical. 104 pp. Essex, England.

Aguirre-Díaz,G.J., Labarthe-Hernández, G. Tristán-Gonzélez, M., Nieto-Obregón, J. y Guiérrez-Palomares, I. 2008. The ignimbrite flare-up and graben caldera of the Sierra Madre Occidental, México. En: Gottsmann, J. y Martí, J. (eds.). Caldera Volcanism: analysis, modeling and response: 143-174. Elsevier. Amsterdam.

Allen, S.R. y Freundt, A. 2006. Resedimentation of cold pumiceous ignimbrite into water: facies transformations simulated in flume experiments. Sedimentology 53: 717-734.

Allen, S.R. y McPhie, J. 2003. Phenocryst fragments in rhyolitic lavas and lava domes. Journal of Volcanology and Geothermal Research 126: 263-283.

Anchochea, E., Brändle, J.L., Huertas, M.J., Hernán y Herrera, R. 2008. Dike-swarms, key to the reconstruction of major volcanic edifices: The basic dikes of La Gomera (Canary Islands). Journal of Volcanology and Geothermal Research 173: 207-216.

Álvarez, P. P. y Ramos, V. A. 1999. The Mercedario rift system in the principal Cordillera of Argentina and Chile (32 ${ }^{\circ} \mathrm{LS}$ ). Journal of South American Earth Sciences 12: 17-31.

Askren, D.R., Roden, M.F. y Whitney J.A. 1997. Petrogenesis of tertiary andesite lava flows interlayered with large-volume felsic ash-flow tuff of the western USA. Journal of Petrology 38 (8): 1021-1046.

Bahk, J. J. y Chough, S. K. 1996. An interplay of syn- and interruption depositional processes: the lower part of the Jangki Group (Miocene), SE Korea. Sedimentology 43: 421-438.

Belusov, A. Belousova, M y Voight, B. 1999. Multiple edifice failures, debris avalanches and asociated eruptions in the Holocene historyof Shiveluch volcano, Kamchatka, Rusia. Bull Volcanol 61: 324-342.

Bermúdez, A.; Delpino, D. y Pángaro F. 2002. Volcanismo de arco asociado a procesos de subducción - extensión durante el Triásico Superior - Jurásico Inferior (Precuyano). Area Cerrro Bandera, Cuenca Neuquina, Argentina. V Congreso de Exploración y Desarrollo en Hidrocarburos, Actas en CD. Mar del Plata.

Bernard, B., van Wyck de Vries, B. y Leyrit, H. 2009. Distinguishing volcanic debris avalanche deposits from their reworked products: the Perrier sequence (French Massif Central). Bull Volcanol: on line.

Best, M. G. y Christiansen, E. H. 2001. Igneous Petrology. Blackwell Science, Inc. 460 pp 
Bilmes, A.; Muravchik, M.; D`Elia, L. y Franzese, J. R. 2008. Interacción entre las secuencias sineruptivas e intereruptivas en los depósitos precuyanos del sinrift de la Cuenca Neuquina, Sierra de Chacaico, Neuquén. XVII Congreso Geológico Argentino, Actas II: 746-747. San Salvador de Jujuy, Argentina, del 7 al 10 de noviembre de 2008.

Bhattacharya, J.P. 2006. Deltas. En: Posamentier, H. W. y Walker, R. G. (eds.) Facies Models Revisited. SEPM Special Publication 84: 237-292.

Blair, T. C. y McPherson, J. G. 1994. Alluvial fans and their natural distinction from rivers based on morphology, hydraulic processes, sedimentary processes, and facies assemblages. Journal of Sedimentary Research, A64 (3): 450-489.

Blair, T. C. y McPherson, J. G. 2008. Quaternary sedimentology of the Rose Creek fan delta, Walker Lake, Nevada, USA, and implications to fan-delta facies models. Sedimentology 55: 579-615.

Bracaccini, I. O. 1970. Rasgos tectónicos de las acumulaciones mesozoicas en las provincias de Mendoza y Neuquén. Revista de la Asociación Geológica Argentina 25 (2): 275-282.

Branney, M. J. y Kokelaar, P. 1994. Volcanotectonic faulting, soft-state deformation, and rheomorphism of tuffs during development of a piecemeal caldera, English Lake District. Geological Society of America Bulletin 106: 507-530.

Branney, M. J. y Kokelaar, P. 1997. Giant bed from sustained catastrophic density current flowing over topography: Acatlán ignimbrite, Mexico. Geology 25: 115-118.

Branney, M. J. \& Kokelaar, B. P. 2002. Pyroclastic density currents and the sedimentation of ignimbrites. Geological Society London. Memoir 27. 144pp.

Bret, L., Fevre, Y., Join, J., Robineau, B. y Bachelery, P. 2003. Deposits related to degradation processes on Piton des Neiges Volcano (Reunion Island): overview and geological hazard. Journal of Volcanology and Geothermal Research 123:25-41.

Bridge, J.S. 2006. Fluvial facies models: recent developments. En: Posamentier, H. W. y Walker, R. G. (eds.) Facies Models Revisited. SEPM Special Publication 84: 85-170.

Brown, D.J. y Bell, B.R. 2007. Debris flow deposits within the Palaeogene lava fields of NW Scotland: evidence for mass wasting of the volcanic landscape during emplacement of the Ardnamurchan Central Complex. Bull Volcanol 69:847-868.

Brown, R. J., Kokelaar, B. P. y Branney, M. J. 2007. Widespread transport of pyroclastic density currents from large silicic tuff, Scafell caldera, English Lake District, UK. Sedimentology 54 (5): 1163- 1190.

Buck, W. R. 2004. Consequences of asthenospheric variability on continental rifting. En: Karner, G. D.; Taylor, B.; Driscoll, N. W. y Kohlstedt, D. L. Rheology and deformation of the lithosphere at continental margins: 1-30. MARGINS Theoretical and Experimental Earth Science Series. Columbia University Press. 
Burgess, P. M.; Flint, S. y Johnson, S. 2000. Sequence stratigraphic interpretation of turbiditic strata: An example from Jurassic strata of the Neuquén basin, Argentina. Geological Society of America Bulletin 112 (11): 1650-1666.

Busby, C.J. y Bassett K.N. 2007. Volcanic facies architecture of an intra-arc strike-slip basin, Santa Rita Mountains, Southern Arizona. Bull Volcanol 70:85-103.

Cas, R. A. F. \& Wright, J. W. 1987. Volcanic successions: Modern and ancient. Unwin Hyamen, London, 528pp.

Cassidy, J., Ingham, M., Locke, C.A. y Bibby, H. 2009. Subsurface structure across the axis of the Tongariro Volcanic Centre, New Zealand. Journal of Volcanology and Geothermal Research 179: 233-240.

Cingolani, C., Dala Salda, L., Hervé, F., Munizaga, F. Pankhurst, R.J., Parada, M.A. \& Rapela, C.W. 1991. The magmatic evolution of northern of Patagonia; New impressions of preAndean and Andean tectonics. Geological Society of America, Special Paper 265: 2944.

Cioni. R., Marianelli, P., Santacroce, R. y Sbrana. A. 2000. En: Sigurdsson, H.; Houghton, B.; McNutt, S. R.; Rymer, H. y Stix, J. (eds.). Encyclopedia of Volcanoes: 477-494. Academic press.

Clavero, J.E., Sparks, R.S.J. Y Huppert, H.E. y Dade, W.B. 2002. Geological constraints on the emplacement mechanism of the Parinacota debris avalanche, northern Chile, Bull Volcanol 64:40-54.

Clifton, H. E. 2006. A reexamination of facies models for clastic shorelines. En: Posamentier, H. W. y Walker, R. G. (eds.) Facies Models Revisited. SEPM Special Publication 84: 293-338.

Cobbold, P. R. y Rossello, E.A. 2002. Phases of Andean deformation, foothills of the Neuquén Basin, Argentina. 5th. International symposium on Andean geodynamics: 153-156.

Coira, B., 1979. Descripción geológica de la Hoja 40d Ingeniero Jacobacci. Provincia de Río Negro. Servicio Geológico Nacional, Boletín 168: 1-104.

Cole, R. B.; Milner, D. M. y Spinks, K. D. 2005. Calderas and caldera structures: a review. Earth Science Reviews 69: 1-26.

Collinson, J.D. 2002. Alluvial sediments. En Reading H. G. (Ed) Sedimentary Environments: processes, facies and stratigraphy: 37-82. Blackwell Science, Oxford.

Condie, K. C. 1997. Plate Tectonics and Crustal Evolution. 4ta edición. ButterworthHeinemann. Oxford. 288 pp.

Coussot, P. y Meunier, M. 1996. Recognition, classification and mechanical description of drebris flows. Earth-Science Reviews 40:209-227. 
Coward, M.P. 1994. Inversion Tectonics. In: Hancock, P.L. (ed.), Continental Deformation. Pergammon Press, 280-304.

Cristallini, E.; Pando, G.; Martínez, J. M.; Buhler, M.; Tomezzoli, R.; Barredo, S. y Zambrano, O. 2008. Controles precuyanos en la estructura de la Cuenca Neuquina. XVII Congreso Geológico Argentino, Actas II: 759-760. San Salvador de Jujuy, Argentina, del 7 al 10 de noviembre de 2008.

Cucci, R. Espejo, P. \& González, R. 1998. Hoja Geológica 4169 I. Piedra del Águila. Subsecretaría de Minería de la Nación - Sevicio Geológico Minero Argentino - Instituto de Geología y Recursos Naturales. Boletin 242. 74pp.

Dasgupta, P. 2003. Sediment gravity flow - the conceptual problems. Earth Science Reviews 62: 265-281.

Davidson, J. y De Silva, S. 2000. Composite volcanoes. En: Sigurdsson, H.; Houghton, B.; McNutt, S. R.; Rymer, H. y Stix, J. (eds.). Encyclopedia of Volcanoes: 663-682. Academic press.

Dirasion, M., Cobbold, P.R., Rosello, E.A. \& Amos, A.J. 1998. Neogene dextral transpression due to oblique convergence across the Andes of northwestern Patagonia, Argentina. Journal of South American Earth Sciences. 11 (6): 519-532.

Damborenea, S.E., Manceñido, M.O. y Riccardi, A.C. 1975. Biofacies y estratigrafía del Liásico de Piedra Pintada, Neuquén, R. Argentina. I Congreso Argentino de Paleontología y Estratigrafía. San Miguel de Tucumán. Actas II: 173-228.

Damborenea, S. E. y Manceñido, M. O. 1993. Piedra Pintada. En: Riccardi, A. C. y Damborenea, S. E. (eds.). Léxico Estratigráfico de la Argentina, Volumen IX, Jurásico: 313. Asociación Geológica Argentina, Serie “B” (Didáctica y Complementaria) Nº 21. Buenos. Aires.

D’Elía, L. y Franzese, J.R. 2005. Caracterización litológica y estructural de ignimbritas precuyanas en la sierra de Chacaico, Neuquén, con énfasis en su potencial petrolero. VI Congreso de Exploración de Hidrocarburos. Trabajos técnicos, Reservorios y desarrollo.

D’Elia, L. y Cambon, I. 2006. Caracterización de los depósitos volcánicos y volcaniclásticos de la Formación Sañicó en el sector sur de la Cuenca Neuquina (provincia del Neuquén), Argentina. IV Congreso Latinoamericano de Sedimentología y XI Reunión Argentina de Sedimentología. Actas: 83.

D’Elia, L. 2008. Estratovolcanes en el Precuyano del sur de la Cuenca Neuquina: asociaciones de facies y unidades de acumulación en la Formación Sañicó. XII Reunión Argentina de Sedimentología. Actas: 65. 
D’Elia, L., Muravchik, M., Bilmes, A. Franzese, J.R. y Hernández M. 2008. Análisis estratigráfico y sedimentológico de las unidades de acumulación Mio-Pliocenas del suroeste de la provincia de Neuquén. XVII Congreso Geológico Argentino, San Salvador de Jujuy, del 7 al 10 de octubre de 2008. Actas III: 1003-1004.

Digregorio, R. E., Gulisano, C. A., Gutiérrez Pleimling y Minniti, S. A. 1984. Esquema de la evolución geodinámica de la Cuenca Neuquina y sus implicancias paleogeográficas. IX Congreso Geológico Argentino, Actas II: 147-162. San Carlos de Bariloche.

Doyle, M.G. y McPhie, J. 2000. Facies architecture of a silicic intrusion-dominated volcanic centre at Highway-Reward, Queensland, Australia. Journal of Volcanology and Geothermal Research 99: 79-96.

Dumas, S. y Arnott, R.W.C. 2006. Origin of hummocky and swaley cross-stratification - The controlling influence of unidirectioanl current strength and aggadation rate. Geology. v34, n12 ,p 1073-1076.

Ferello, R. 1947. Los depósitos plantíferos de Piedra del Águila (Neuquén) y sus relaciones. Boletín de Informaciones Petroleras, 8: 1-16. Buenos Aires.

Fink, J.H. y Anderson, W.A. 2000. Lava domes and coulees. En: Sigurdsson, H.; Houghton, B.; McNutt, S. R.; Rymer, H. y Stix, J. (eds.). Encyclopedia of Volcanoes: 291-306. Academic press.

Fisher, R. V. 1961. Proposed calssification of volcaniclastic sediments and rocks. Geological Society of America Bulletin 72: 1409-1414.

Fisher, R. V., 1966. Mechanism of deposition of pyroclastic flow. American Journal Science, 264, 350-363.

Fisher, R. V. y Schminke, H.-U. 1984. Pyroclastic Rocks. Springer-Verlag. 472 pp

Franzese, J. R. y Spalletti, L. A. 2001. Late Triassic-early Jurassic continental extension in southwestern Gondwana: tectonic segmentation and pre-break-up rifting. Journal of South American Earth Sciences 14: 257-270.

Franzese, J.R., Pankhurst, R.J., Rapela, C.W, Spalletti, L.A., Fanning, M. y Muravchik, M. 2002. Nuevas evidencias geocronológicas sobre el magmatismo Gondwanico en el noroeste del Macizo Norpatagonico. Actas del XV Congreso Geológico Argentino. El Calafate, 2002.

Franzese, J. R., Spalletti, L.A., Gómez Pérez, I. y Macdonald, D. 2003. Tectonic and paleoenviromental evolution of Mesozoic sedimentary basins along the Andean foothills of Argentina ( $\left.32^{\circ}-54^{\circ} \mathrm{S}\right)$. Journal of South American Earth Science, 16:81-90.

Franzese, J. R.; Salas, R. y Muravchik, M. 2004. Análisis 2D de subsidencia en la Cuenca Neuquina (República Argentina): un caso de superposición de mecanismos de subsidencia en cuencas marginales. Geotemas 6 (2): 145-148. 
Franzese, J. R.; Veiga, G. D.; Schwarz, E. y Gómez - Pérez, I. 2006. Tectonostratigraphic evolution of a mesozoic graben border system: the chachil depocentre, southern Neuquén Basin, Argentina. Journal of the Geological Society, London, 163: 707-721.

Franzese, J. R.; Veiga, G.D.; Muravchik, M.; Ancheta, D. y D' Elía, L. 2007. Estratigrafía de 'sin-rift' (Triásico Superior-Jurásico Inferior) de la Cuenca Neuquina en la sierra de Chacaico, Neuquén, Argentina. Revista Geológica de Chile 34 (1): 49-62.278.

Frengueli, J. 1948. Estratigrafía y Ead del llamado "Retico" en la Argentina. Anales de la Sociedad Argentina de Estudios Geográficos, GAEA, 8:159-309.

Fritz, W., Howells, M.F., Reedman, A.J. y Campbell. 1990. Volcaniclastic sedimentation in an Ordovician subaqueous caldera, Lower Rhyolitic Tuff Formation, North Wales. Geological Society of American Bulletin 102: 1246-1256.

Galli, C. A. 1953. Acerca de una nueva interpretación de las formaciones rético-lia'sica de la Patagonia septentrional. Rev. Asoc. Geol. Arg. VIII, 4.

Galli, C. A. 1969. Descripción Geológica de la Hoja 38c, Piedra del Águila (provincias del Neuquén y Río Negro). Dirección Nacional de Geología y Minería, Boletín 111. Buenos Aires.

García-García, F., Fernández, J., Viseras, C. y Soria, J.M. 2006. High frequency cyclicity in a vertical alternation of Gilbert-type deltas and carbonate bioconstructions in the late Tortonian, Tabernas Basin, Southern Spain. Sedimentary Geology 192:123-139.

García Morabito, E. y Ramos, V.A. 2008. Evolución tardío cenozoica del retroarco interno andino entre los $38^{\circ}$ y los $40^{\circ} \mathrm{S}$. XVII Congreso Geológico Argentino, San Salvador de Jujuy, del 7 al 10 de octubre de 2008. Actas I: 109-110.

Gawthorpe, R. L.; Jackson, C. A. L.; Young, M.; Sharp, I. R.; Moustafa, A. y Leppard, C. V. 2003b. Normal fault growth, displacement localisation and the evolution of normal fault populations: the Hammam Faraun fault block, Suez Rift, Egypt. Journal of Structural Geology 25: 883-895.

Gawthorpe, R. L. y Leeder, M. R. 2000. Tectono-sedimentary evolution of active extensional basins. Basin Research 12: 195-218.

Giacosa, R. E. y Heredia C., N. 2004. Structure of the North Patagonian thick-skinned fold-andthrust belt, southern central Andes, Argentina $\left(41^{\circ}-42^{a} S\right)$. Journal of South American Earth Sciences 18: 61-72.

Giambiagi, L.; Bechis, F.; Barredo, S. y Tunik, M. 2008a. Cinemática de la apertura de los depocentros Atuel y Cara Cura - Reyes, Cuenca Neuquina: Rift con múltiples sets de fallas. VII Congreso de Exploración y desarrollo de Hidrocarburos, Trabajos Técnicos: 431-442. Mar del Plata, Argentina, del 5 al 8 de noviembre de 2008. 
Giambiagi, L.; Bechis, F.; Tunik, M. y Barredo, S. 2008b. Cuencas de rift con múltiples sets de fallas: Caso de estudio del sector septentrional de la Cuenca Neuquina. XVII Congreso Geológico Argentino, Actas II: 767-768. San Salvador de Jujuy, Argentina, del 7 al 10 de noviembre de 2008.

Giambiagi, L.; Bechis, F.; Lanés, S.; Tunik, M.; García, V.; Suriano, J. y Mescua, J. 2008c. Formación y evolución triásico - jurásica del depocentro Atuel, Cuenca Neuquina, provincia de Mendoza. Revista de la Asociación Geológica Argentina 63 (4): 520-533.

Gifkins, C.; Herrmann, W. y Large, R. 2005. Altered Volcanic Rocks. A guide to description and interpretation. CODES - Centre for Ore Deposit Research, University of Tasmania. 286 pp.

Gómez-Pérez, I. 2003. An Early Jurassic deep-water stromatolitic bioherm related to possible methaneseepage (Los Molles Formation, Neuquén, Argentina). Palaeogeography, Palaeoclimatology, Palaeoecology 201: 21-49.

Gorton, M.P. y Schandal, E.S. 2000. From continents to island arcs: a geochemical index of tectonic setting for arc-related and within-plate felsic to intermédiate volcanic rocks. The Canadian Mineralogist 38: 1065-1073.

Groeber, P. 1918. Estratigrafía del Dogger en la República Argentina (Estudio sintético comparativo). Boletín Dirección General de Minería, Geología e Hidrología, Serie B: Geología, 18: 1-85.

Groeber, P. 1929. Líneas fundamentales de la geología del Neuquén, sur de Mendoza y regiones adyacentes. Dirección Nacional de Geología y Minería, Publicación 158: 1-110. Buenos Aires.

Groeber, P. 1946. Observaciones geológicas a lo largo del meridiano 70, Hoja Chos Malal. Revista de la Asociación Geológica Argentina, 1 (3): 177-208.

Groeber, P. 1947. Observaciones Geológicas a lo largo del Meridiano 70. 2, Hojas Sosneado y Maipo. Revista de la Sociedad Geológica Argentina, 2 (4):499-233.

Groeber, P.; Stipanicic, P. N. y Mingramm, A. 1953. Jurásico. Geografía de la República Argentina, 11: 143-347. Buenos Aires.

Groeber, P. 1956. Acerca de la edad del Sañicolitense. Revista de la Asociación Geológica Argentina, 11 (4): 67-98.

Gulisano, C. 1981. El ciclo cuyano en el norte de Neuquén y sur de Mendoza. VIII Congreso Geologico Argentino, Actas III: 579-592. San Luis.

Gulisano, C. y Pando, G. A. 1981. Estratigrafia y facies de los depositos jurasicos entre Piedra del Aguila y Sanico, Departamento Collon Cura, Provincia del Neuquén. VIII Congreso Geologico Argentino, Actas III: 553-577. San Luis. 
Gulisano, C. A., Gutiérrez Pleimling, A. R. y Digregorio, R. E. 1984. Esquema estratigráfico de la secuencia jurásica del oeste de la provincia del Neuquén. IX Congreso Geológico Argentino, Actas I: 236-259. San Carlos de Bariloche.

Gulisano, C. A. 1993. Precuyano. En: Riccardi, A. C. y Damborenea, S. E. (eds.). Léxico Estratigráfico de la Argentina, Volumen IX, Jurásico: 334. Asociación Geológica Argentina, Serie “B” (Didáctica y Complementaria) № 21. Buenos. Aires.

Gulisano, C. A. y Gutiérrez Pleimling, A. R. 1994. The Jurassic of the Neuquén Basin, Part (a) Neuquén Province. Asociación Geológica Argentina, Serie E-2, 111.

Hagel, E. 1979. Microscopia de menas. Instituto de Geología y Economía Aplicada. Serie monográfica y textos. 205pp. Universidad de Concepción. Chile.

Herbst, R. 1966. Revisión de la flora liásica de Piedra Pintada, provincia del Neuquén, Argentina. Revista del Museo de La Plata (n.s.) Paleontología, 5 (30):27-53.

Howell, J. A.; Schwarz, E.; Spalletti, L. A. y Veiga, G. D. 2005. The Neuquén Basin: an overview. En: Veiga, G. D.; Spalletti, L. A.; Howell, J. A. y Schwarz, E. (eds.). The Neuquén Basin, Argentina: A Case Study in Sequence Stratigraphy and Basin Dynamics. Geological Society, London, Special Publications, 252: 1-14.

Irvine, T.N. y Baragar, W.R.A. 1971. A guide to chemical classification of the common volcanic rocks. Can. J. Earth Sci. 8:523-548.

Jackson, C. A. L.; Gawthorpe, R. L.; Carr, I. D. y Sharp, I. R. 2005. Normal faulting as a control on the stratigraphic development of shallow marine syn-rift sequences: the Nukhul and Lower Rudeis Formations, Hammam Faraun fault blocks, Suez Rift, Egypt. Sedimentology 52: 313-338.

Kattenhorn, S. A. y Pollard, D. D. 2001. Integrating 3-D seismic data, field analogs, and mechanical models in the analysis of segmented normal faults in the Wytch Farm oil field, southern England, United Kingdom. AAPG Bulletin 85 (7): 1183-1210.

Kearey, P. y Vine, F.J. 1992. Global Tectonic. Blackwell Scientifiv Publications, Oxford, 302pp.

Kilburn, C.R.F. 2000. Lava flows and flow fields. En: Sigurdsson, H.; Houghton, B.; McNutt, S. R.; Rymer, H. y Stix, J. (eds.). Encyclopedia of Volcanoes: 307-320. Academic press.

Kokelaar, P., Raine, P. y Branney, M.J. 2007. Incursion of a large-volume, spatter-bearing pyroclastic density current into a caldera lake: Pavey Ark ignimbrite, Scafell caldera, England. Bull Volcanol 70:23-54.

Krainer, K. y Spötl, C. 1998. Abiogenic silica layers within a fluvio-lacustrine succession, Bolzano Volcanic Complex, northern Italy: a Permian analogue for Magadi-type cherts? Sedimentology 45: 489-505. 
Kraglievich, L. 1930. La Formación Friaseana del río Frias, río Fenix, Laguna Blanca, etc. (Patagónia) y su fauna de mamíferos. Physic, Revista de la Sociedad Argentina de Ciencias Naturales, 10 (35): 127-161.

Lambert, L.R. y Galli, C.A. 1950-51. Observaciones geológicas enla región situada entre Piedra del Águila y Paso Flores (Neuquén). Revista de la Asociación Geológica Argentina, 5 (4).

Lanés, S. 2005. Late Triassic to Early Jurassic sedimentation in northern Neuquén Basin, Argentina: Tectosedimentary Evolution of the First Transgression. Geologica Acta 3 (2): 81-106.

Lanés, S.; Giambiagi, L.; Bechis, F. y Tunik, M. 2008. Sucesiones del Triásico tardío - Jurásico temprano del depocentro Atuel: estratigrafía secuencial y controles tectónicos. Revista de la Asociación Geológica Argentina, 63 (4): 534-548.

Leanza, A.F. 1942. Los Pelicípodos del Lias de Piedra Pintada, en el Neuquén. Revis del Museo de La Plata (n.s) Paleotología, 2 (10): 143-206.

Leanza, H.A., Marchese, H. G. y Riggi, J. C. 1978. Estratigrafía del Grupo Mendoza con especial referencia a la Formación Vaca Muerta entre los paralelos $35^{\circ}$ y $40^{\circ} \mathrm{LS}$. Cuenca Neuquina-Mendocina. Revista de la Asociacion Geológica Argentina, 32 (3): 190-208.

Leanza, A.F. y Leanza, H.A. 1979. Descripción Geológica de la Hoja 37c, Catán Lil, provincia del Neuquén. Bol. Serv. Geol. Nac. (Argent.), 4 (4): 255-262.

Leanza, H. A. 1990. Estratigrafía del Paleozoico y Mesozoico anterior a los movimientos intermálmicos en la Comarca del Cerro Chachil, Provincia del Neuquén. Revista de la Asociación Geológica Argentina 45 (3-4): 272-299.

Leanza, H. A.; Llambías, E. J. y Carbone, O. 2005. Unidades estratigráficas limitadas por discordancias en los depocentros de la Cordillera del viento y la Sierra de Chacaicó durante los inicios de la Cuenca Neuquina. VI Congreso de Exploración y Desarrollo en Hidrocarburos, Actas en CD. Mar del Plata.282

Le Bas, M.J. y Streckeisen, A.L. 1991. The IUGS systematics of igneous rocks. Journal of the Geological Society 148: 825-833.

Leeder, M. 1999. Sedimentology and Sedimentary Basins, From turbulence to tectonic. Blackwell Science, Oxford, 592pp.

Legarreta, L. y Gulisano, C. A. 1989. Análisis estratigráfico secuencial de la Cuenca Neuquina (Triásico superior -Terciario inferior). En: Chebli, G. y Spalletti, L. A. (eds.). Cuencas Sedimentarias Argentinas. Universidad Nacional del Tucumán, Serie Correlación Geológica 6: 221-243. 
Legarreta, L. y Uliana, M.A. 1996. The Jurassic succession in west-central Argentina: stratal pattern, sequences and paleogeographic evolution. Palaeogeography, Palaeoclimatology \& Palaeoecology 120: 303-330.

Legarreta, L.; Villar. H.J.; Cruz, C.E.; Laffitte G.A. y Varadé, R. 2008. Revisión integrada de los sistemas generadores, estilos de migración-entrampamiento y volumetría de hidrocarburos en los distritos productivos de la Cuenca Neuquina. En: Cruz, C.E.; Rodríguez, J.F.; Hechem, J.J. y Villar, H.J.(eds). 2008. Sistemas Petroleros de las Cuencas Andinas. IAPG, Buenos Aires.

Lema, H., Busteros, A., Giacosa R. y Cucchi, R. 2008. Geología del complejo volcánico Los Menucos en el área tipo - Río Negro. Revista de la Asociación Geológica Argentina 63 (1): 3-13.

Linares, E., Cagnoni, M.C., Do Campo, M. y Ostega, H.A. 1988. Geochronology of metamorphic and eruptive rocks of southeastern Neuquén and northwestern Río Negro Provinces, Argentina Republic. Journal of South American Earth Sciences. 1 (1), 53-61.

Lipman, P. W. 2000. Calderas. En: Sigurdsson, H.; Houghton, B.; McNutt, S. R.; Rymer, H. y Stix, J. (eds.). Encyclopedia of Volcanoes: 643-662. Academic press.

Llambías, E. J., 2001. Geología de los cuerpos ígneos. Instituto Superior de Correlación Geológica INSUGEO. Serie de Correlación Geológica, 15. CONICET y Facultad de Ciencias Naturales e Instituto Miguel Lillo (Universidad Nacional de Tucumán). San Miguel de Tucumán 232 pp.

Llambias, E.J. 2008. Geología de los cuerpos ígneos. Asociación Geológica Argentina, Serie B, Didáctica y Complementaria № 29, Instituto Superior de Correlación Geológica, Serie Correlación Geológica 15: 222 pp. Buenos Aires.

Llambías, E. J. y Stipanicic, P. N. 2002. Grupo Choiyoi. En: Stipanicic, P. N. y Marsicano, A. C. (eds.). Léxico Estratigráfico de la Argentina, Volumen VIII, Triásico. Asociación.

Llambías, E. J.; Leanza, H. A. y Carbone, O. 2007. Evolución tectono-magmática durante el Pérmico al Jurásico temprano en la Cordillera del Viento ( $37^{\circ} 05^{\prime} \mathrm{S}-37^{\circ} 15^{\prime} \mathrm{S}$ ): Nuevas evidencias geológicas y geoquímicas del inicio de la Cuenca Neuquina. Revista de la Asociación Geológica Argentina, 62 (2): 217-235.

Lofgren. G. 1971. Experimentally produced devitrification textures in natural rhyolite glass. Geol Soc Am Bull 82 :553-560.

López, J.P. y Bellos, L.I. 2007. Texturas y estructuras de las rocas ígneas: significado petrológico e implicancias en las condiciones deformación de las rocas. Instituto Superior de Correlación Geológica (INSUGEO) 15: 58pp. San Miguel de Tucumán.

MacLean, W.H. y Barrett, T.J. 1993. Lithogeochemical techniques using inmobile elements: Journal of Geochemical Exploration 48:33-109. 
Manceda, R. y Figueroa, D. 1995. Inversion of the Mesozoic Neuquén Rift in the Malargüe Fold and Thrust Belt, Mendoza, Argentina. En: Tankard, A. J.; Suárez S., R.; y Welsink, H. J. (eds.). Petroleum basins of South America. AAPG Memoir 62: 369-382.

Marioni L.B. y Gudmundson, A. 2000. Dykes, fault and paleostresses in the Teno and Anaga massifs of Tenerife (Canary Island). Journal of Volcanology and Geothermal Research 103: 83-103.

Marshall, L., Pascual R.,Curtis, C.H. y Drake R.E. 1977. South America geocronology: radimetric time scale for Middle to Late Terciary mammal-bering horizons in Patagonia, Science 195, 1325-1328.

Mash, B.D. 2000. Magma chambers. En: Sigurdsson, H.; Houghton, B.; McNutt, S. R.; Rymer, H. y Stix, J. (eds.). Encyclopedia of Volcanoes: 191-206. Academic press.

Mazzoni, M. M. y Benvenuto, A. 1990. Radiometric ages of tertiary ignimbrites and the Collon Cura Formation, northwestern Patagonia. XI Congreso Geológico Argentino, Actas I: 87-90.

Mc Arthur, A.M., Cas, R.A.F. y Orton G.J. 1998, Distribution and significance of crystalline, perlitiv and vesicular textures in the Ordovician Garth Tuff (Wales). Bull Volcanol 60: 260-285.

Mc Phie, J., Doyle, M., y Allen, R. 1993. Volcanic textures: A guide to the interpretation of textures in volcanic rocks. Centre for Ore Deposits and Exporation Studies, University of Tasmania, 198pp.

Miall, A.D. 1996. The geology of fluvial deposits. Sedimentary facies, basin analysis and petroleum geology. Springer. 582 pp. Berlín.

Miall, A.D. 1997. The geology of stratigraphic sequences. Springer. 433 pp. Berlín.

Miall, A. D. 2006. The Geology of Fluvial Deposits. Springer, 4ta impresión. 582 pp.

Miller, T.P., Chertkoff, D.G., Eichelberger, J.C. y Coombs, M.L.. Mount Dutton volcano, Alaska: Aleutian arc analog to Unzen volcano, Japan. Journal of Volcanology and Geothermal Research 89:275-301.

Moore, I. y Kokelaar, P. 1997. Tectonic influences in piecemeal caldera collapse at Glencoe Volcano, Scotland. Journal of the Geological Society, London, 154: 765-768.

Moore, I. y Kokelaar, P. 1998. Tectonically controlled piecemeal caldera collapse: A case study of Glencoe volcano, Scotland. Geological Society of America Bulletin 110 (11): 14481466.

Mora-Klepeis, G. y Mc Dowell, F.W. 2004. Late Miocene calc-alkalic volcanism in the northwestern Mexico: an expression of rift or subduction-related magmatism ?. Journal of South American Earthe Sciences 17: 297-310. 
Morel, E. M. y Ganuza, D.G. 2002. Paso Flores. En: Stipanicic, P. N. y Marsiscano, C. A. (eds). Léxico Estratigráfico de la Argentina, Volumen VIII, Triásico: 208. Asociación geológica Argentina, Serie B (Didáctica y Complementaria) № 26. Buenos Aires.

Morley, C.K. 1995. Developments in the structural geology of rifts over the last decade and their impact on hydrocarbon exploration. En: Lambiase, J.J. (ed.). Hydrocarbon Habitat in rift basins. Geological Society Special Publication 80:1-32.

Morley, C.K. 1999a. Basin EvolutionTrends in East Africa. En: Morley, C.K. (ed.). Geoscience of rift systems - Evolution of East Africa. AAPG Studies in Geology 4: 131-150.

Morley, C.K. 1999b. Influence of pre-existing fabrics on rift structure. En: Morley, C.K. (ed.). Geoscience of rift systems - Evolution of East Africa. AAPG Studies in Geology 4: 151-160.

Morley, C.K. 1999c. How successful are analogue models in addressing the influence of preexisting fabrics on rift structure? Journal of Structural Geology 21: 1267-1274.

Morley, C.K. 2002, Evolution of large normal fault: Evidence from seismic reflection data. AAPG Bulletin 86:661-978.

Morley, C.K.; Haranya, C.; Phoosongsee, W.; Pongwapee, S.; Kornsawan, A. y Wanganan, N. 2004. Activation of rift oblique and rift parallel pre-existing fabrics during extension and their effect on deformation style: examples from the rifts of Thailand. Journal of Structural Geology 26: 1803-1829.

Mosquera, A. y Ramos, V.A. 2005. Intraplate foreland deformation in the Neuquén Embayment. VI Congreso de Exploración y Desarrollo de Hidrocarburos, Mar del Plata, Argentina. (actas en CD).

Moustafa, A. R. 2002. Controls on the geometry of transfer zones in the Suez rift and northwest Red Sea: Implications for the structural geometry of rift systems. AAPG Bulletin 86 (6): 979-1002.

Mpodozis, C. y Ramos, V.A. 2008. Tectónica Jurásica en Argentina y Chile: extensión, subducción oblicua, rifting, deriva y colisiones ?. Revista de la Asociación Geológica Argentina, 63 (4): 481-497.

Muravchik, M. y Franzese, J. R. 2005. Carbonatos lacustres someros en las facies volcaniclásticas del Precuyano de la Sierra de Chacaico, Neuquén. XVI Congreso Geológico Argentino, Actas III: 111-116. La Plata, 2005.

Muravchik, M. 2008a. Sistemas sedimentarios axiales y transversales a un depocentro de rift (Ciclo Precuyano) del suroeste de la Cuenca Neuquina. XVII Congreso Geológico Argentino. Actas II: 783-784. 
Muravchik, M. 2008b. Controles estructurales sobre la depositación de la base del Ciclo Cuyano en depocentros del suroeste de la Cuenca Neuquina. XVII Congreso Geológico Argentino, San Salvador de Jujuy, del 7 al 10 de octubre de 2008. Actas II: 781-781.

Muravchik, M.; D’Elia, L.; Bilmes, A. y Franzese, J. R. 2008. Caracterización de los depocentros de rift (Ciclo Precuyano) aflorantes en el sector sudoccidental de la Cuenca Neuquina, Argentina. VII Congreso de Exploración y desarrollo de Hidrocarburos. Trabajos Técnicos: 457-470.

Muravchik, M. 2009. Tesis doctoral inédita. Facultad de Ciencias Naturales y Museo. Universidad Nacional de la Plata.

Negrete-Aranda, R. y Cañon-Tapia, E. 2008. Post subduction volcanism in the Baja California Peninsula, Mexico: The effects of tectonic reconfiguration in volcanic systems. Lithos 102: 392-414.

Németh, K. y Martin, U. 2007. Practical Volcanology. Lecture notes for understanding volcanic rocks from field based studies. Occasional Papers of the Geological Institute of Hungary 27. $221 \mathrm{pp}$.

Nullo, F. 1979. Descripción geológica de la hoja 39 c, Paso Flores, Provincia de Río Negro. Servicio Geológico Nacional, Boletín 158.

Orchuela, I. A. y Ploszkiewicz, J. V. 1984. La Cuenca Neuquina. In: Ramos, V. A. (ed) Geología y Recursos Naturales de la Provincia de Río Negro. IX Congreso Geológico Argentino, Relatorio: 163-188.

Orton, G.J. 2002. Volcanic environments. En: Reading H.G. (ed.). 3rd ed. Sedimentary environments: Processes, Facies and Stratigraphy: 485-567. Blackwell Science. Oxford, 2002.

Palmer, B. A. y Walton, A. W. 1990. Accumulation of volcaniclastic aprons in the Mount Dutton Formation (Oligocene-Miocene), Mrysvale Volcanic Field, Utah. Geological Society of America Bulletin 102: 734-748.

Palmer, B.A., Alloway, B.V. y Neal, V.E. 1991. Volcani-debris-avalanche deposits in New Zealand - Lithofacies organization in unconfined, wet-avalnche flows. (ed. By R. V, Fisher \& G. A. Smith), 45, 89-98. SEPM special publication, Tulsa.

Palmer, B. A.; Purves, A. M. y Donoghue, S. L. 1993. Controls on accumulation of a volcaniclastic fan, Ruapehu composite volcano, New Zealand. Bulletin of Volcanology 55: 176-189.

Pángar, F., Corbera, R., Carbone, O. y Hinterwimmer, G. 2002a. Los reservorios del Precuyano. En: Schiuma, M., Hinterwimmer, G. y Vergani G.D. (eds) 2002. Rocas Reservorio de las Cuencas Producticas Argentinas. Instituto Argentino del Petroleo y del Gas, Buenos Aires, 229-254. 
Pángaro, F., Veiga, R. y Vergani, G.D. 2002b. Evolución tecto-sedimentaria del área de Cerro Bandera, Cuenca Neuquina, Argentina. V Congreso de Exploración y Desarrollo de Hidrocarburos. Mar del Plata. Argentina. (actas en CD).

Pankhurst, R. J., Rapela, C.W., Caminos, R. Llambias, E. y Párica, C. 1992. A revised age for the granites of the central Samuncura Batholith, North Patagonian Massif. Journal of South American Earth Science, 5: 321-326.

Pearce, J.A. 1982. Trace element characteristics of lavas from destructiuve plate boundaries. En: Thorpe, R.S (ed.). Orogenic Andesities and Related Rocks. Wyley, J. \& Sons, Chischester (UK): 230-249.

Pearce, J.A., Harris, N.B.W, Tindle, A.G. 1984. Trace elemen discrimination diagrams for the tectonic interpretations of the granitic rocks. Journal of Petrology 25: 956-983.

Pearce, J.A. y Peate, D.W. 1995. Tectonic implications of the composition of volcanic arc magmas. Annu Rev Earth Planet Sci 23: 251-285.

Ploszkiewicz, J. V., Orchuela, L. A., Vaillard, J. C. y Viñes, R.F. 1984. Compresión y desplazamiento lateral en la zona de Falla Huincul, estructuras asociadas, provincia del Neuquén. IX Congreso Geológico Argentino, Actas II:163-169. San Carlos de Bariloche.

Posamentier, H. W. y Walker, R. G. 2006. Deep-water turbidites and submarine fans. En: Posamentier, H. W. y Walker, R. G. (eds.) Facies Models Revisited. SEPM Special Publication 84: 397-520.

Quane, S.L. y Russell, J.K. 2005. Ranking welding intensity in pyroclastic deposits. Bull Volcanol (2005) 67:129-143.

Ramdohr, P. 1980. The ore minerals and their intergrawths. 2nd. Edition (International Series in Earth Sciences). Pergamon Press. Oxford.

Ramos, V. A. 1978. Estructura. VII Congreso Geológico Argentino. Relatorio, Geología y Recursos Naturales del Neuquén: 99-118.

Ramos, V. A. 1999. Plate tectonic setting of the Andean Cordillera. Episodes, 22 (3): 183-190.

Ramos, V. A. y Folguera, A. 2005. Tectonic evolution of the Andes of Neuquén: constraints derived from the magmatic arc and foreland deformation. En: Veiga, G. D.; Spalletti, L. A.; Howell, J. A. y Schwarz, E. (eds.). The Neuquén Basin, Argentina: A Case Study in Sequence Stratigraphy and Basin Dynamics. Geological Society, London, Special Publications, 252: 15-35.

Ramos, V.A. 2009. Anatomy ond global context of the Andes: Main geologic features and the Andean orogenic cycle. En: Kay, S.M., Ramos, V.A., and Dickinson, W.R. (eds.). Backbone of the Americas: Shallow Subduction, Plateau Uplift, and Ridge and Terrane Collision. Geological Society of America Memoir 204:31-65. 
Rapela, C. W. y Pankhurst, R. J. 1992. The granites of northen of Patagonia and the Gastre fault systems in the relation to the break-up of Gondwana. Magmatism and the causes of continental break-up. En: Alaster, B. y Pankhurst, R. (eds.). Geological Society of London, Special Publication, 68: 209-200.

Reading, H.G. y Levell, B.K. 2002. Controls on the sedimentary rock record. En: Reading H.G. (ed.). 3rd ed. Sedimentary environments: Processes, Facies and Stratigraphy: 5-35. Blackwell Science. Oxford, 2002.

Reading, H. G. y Collinson, J. D. 2002. Clastic coasts. En: Reading, H. G. (ed.). Sedimentary Environments: Processes, Facies and Stratigraphy. 3ra ed., pp. 154-231. Blackwell Science.

Reubi, O. y Hernandez, J. 2000. Volcanic debris avalanche deposits of the upper Maronne valley (Cantal Volcano, France): evidence for contrasted formation and transport mechanisms. Journal of Volcanology and Geothermal Research 102:271-286.

Riccardi, A. C. y Gulisano C. A. 1990. Unidades limitadas por discontinuidades. Su aplicación al Jurásico andino. Revista de la Asociación Geológica Argentina 45 (3-4): 346-364.

Riccardi, A.C., Damborenea, S., Manceñido, M., Scasso, R., Lanés, S. e Iglesia Llanos, M. 1997. Primer registro de Triásico marino fosilífero de la Argentina. Revista de la Asociación Geológica Argentina 52: 228-234.

Riggs, N. R.; Hurlbert, J. C.; Schroeder, T. J. y Ward, S. A. 1997. The interaction of volcanism and sedimentation in the proximal areas of a Mid-Tertiary volcanic dome field, Central Arizona, USA. Journal of Sedimentary Research 67 (1): 142-153.

Riva, O. 1989. Unidades tectosedimentarias y secuencias depositacionales. Rev. Soc. Geol. España 2: 189-198.

Rohais, S., Eschard, R. y Guillocheau, F. 2008. Depositional model and stratigraphic architecture of rift climax Gilbert-type fan deltas (Gulf of Corinth, Greece). Sedimentary Geology 210:132-145.

Rolleri, E. O. y Criado Roqué, P. 1970. Geología de la Provincia de Mendoza. IV Jornadas Geológicas Argentinas, Mendoza 1969. Actas II: 1-60.

Rolleri, E. O., Guichon,M.E., Rabasa, J y Scanavino, 1976. Estudio geológico del valle del río Limay entre Piedra del Águila y el Paso Limay (provincias del Neuquén y del Río Negro) VI Congreso Geológico Argentino. Actas I, 498-523.

Roth, S. 1899. Apuntes sobre la geología y la paleontología de los Territorios del Río Negro y Neuquén. Revista del Museo de La Plata, 9: 219.

Roth, S. 1902. La Lias de la Piedra Pintada. I, La découverte du gisement de la Piedra Pintada. Revista del Museo de La Plata, 10:225. 
Rutherford, M.J. y Gardner, J.E. 2000. Rates of magma ascent. En: Sigurdsson, H.; Houghton, B.; McNutt, S. R.; Rymer, H. y Stix, J. (eds.). Encyclopedia of Volcanoes: 207-218. Academic press.

Scasso, R.A. y Limarino, C.O. 1997. Petrología y diagénesis de rocas clásticas. Asociación Argentina de Sedimentología. Publicación especial Nº1. 258pp.

Schiuma, M. y Llambías, E. J. 2007. New ages on Lower Jurassic volcanism in the Dorsal de Huincul, Neuquén. III Simposio Argentino del Jurásico. Resúmes: 74. Mendoza.

Schiuma, M. y Llambías, E. J. 2008. New ages and chemical analysis on Lower Jurassic volcanism close to the Huincul High, Neuquén. Revista de la Asociación Geológica Argentina 63 (4): 644-652.

Schlische, R.W. 1991. Half-graben basin filling models: new constraints on continental extensional basin development. Basin Research 3: 123-141.

Schlische, R.W. 1992. Structural and stratigraphic development of the Newark extensional basin, eastern North America: Evidence for the growth of the basin and its bounding structures. Geological Society of America Bulletin 104: 1246-1263.

Schlische, R.W. y Anders, M.H. 1996. Stratigraphic effects and tectonic implications of the growth of normal faults and extensional basins. Geological Society of America Special paper 303: 183-203.

Schneider, J. y Fisher, R.V. 1998. Transport and emplacement mechanisms of large volcanic debris avalanches: evidence from the northwest sector of Cantal Volcano (France). Journal of Volcanology and Geothermal Research 83:141-165

Schwarzkopf, L. M., Schmincke, H-U. \& Cronin, S.J. (2005). A conceptual model for block and ash flow basal avalanche transport and deposition, based on deposit arquitecture of 1998 and 1994 Merapi flows. Journal of Volcanology and Geothermal Research 129:117134.

Sesana, F. 1969. Rasgos petrológicos de la comarca de Río Chico, Rio Negro. III Jornadas Geológicas Argentinas 3: 99-107.

Shanmugam, G. 2002. Ten turbidite myths. Earth-Science Reviews 58: 311-341.

Shea, T., van Wyk de Vries, B, y Pilato, M. 2008. Emplacement mechanisms of contrasting debris avalanches at Volcán Mombacho (Nicaragua), provided by structural and facies analysis. Bull Volcanol 70:899-921.

Sigurdsson, H., Houghton, B.F., McNutt, s.r., Rymer, H. y Stix, J. (eds). 2000. Encyclopedia of Volcanoes. Academic Press.

Smith RL (1960) Ash flows. Geol Soc Am Bull 71:795-842

Smith, G. A. 1986. Coarse grained nonmarine volcaniclastic sediment: Terminology and depositional process. Geological Society of American Bulletin 97:1-10. 
Smith, G. A. 1987. The influence of explosive volcanism on fluvial sedimentation: The Dischutes Formation (Neogene) in Central Oregon. Journal of Sedimentary Petrology 57: 613-629.

Smith, G. A. 1991. Facies sequences and geometries in continental volcaniclastic sequenses. In: Sedimentation in volcanic settings. (ed. By R. V, Fisher \& G. A. Smith) 45: 109-122. SEPM special publication, Tulsa.

Smith, G. A. y Lowe D.R. 1991. Lahars: Volcano-hydrologic events and deposition in the debris flow-hyperconcentrated flow continuum. Sedimentation in Volcanic Setting (ed. R. V, Fisher \& G. A. Smith) 45: 59-70. SEPM special publication, Tulsa.

Spalletti, L. A. y Morel, E. 1992. La sedimentación fluvial en la etapa inicial de evolución de una cuenca vinculada con fallas activas y vulcanismo explosivo: La Formación Chihuíu (Triásico), sur de Mendoza, Argentina. IV Reución Argentina de Sedimentología, Actas I: 159-166. La Plata.

Spalletti, L. A. 1997. Los sistemas deposicionales fluvio-lacustres en el rift triásico de Malargüe (sur de Mendoza, República Argentina). Academia Nacional de Ciencias Exactas, Físicas y Naturales (Argentina), Anales 49: 109-124.

Spalletti, L. A.; Arrondo, O. G.; Morel, E. y Ganuza, D. G. 1998. Estudio sedimentológico y paleoflorístico de la Formación Paso Flores (Triásico superior) en el sector occidental del Macizo Norpatagónico. Argentina. V Congreso Geológico Chileno, Actas II: 395413.

Spalletti, L. A. 1999. Cuencas triásicas del oeste argentino: origen y evolución. Acta Geológica Hispánica 32 (1-2): 29-50. Buenos Aires.

Spalletti, L.A., Franzese, J.R., Morel, E., D’Elia, L., Zúñiga, A. y Fanning C.M. En prensa. Consideraciones acerca de la sedimentología, paleobotánica y geocronología de la Formación Piedra del Águila (Jurásico Inferior, Neuquén, República Argentina). Revista de la Asociación Geológica Argentina.

Spinks, K.D, Acocella, V., Cole, J.W. y Bassett, K.N. 2005. Structural contrl of volcanism and caldera development in the transtensional Taupo Volcanic Zone, New Zealand. Journal of Volcanology and Geothermal Research 144: 7-22.

Stephen, T. Montana, A. 1992. Sieve-textured plagioclase in volcanic rocks produced by rapid descompression. American Mineralogist 77: 1242-1249.

Stewart, A. L. y McPhie, J. 2003. Internal structure and emplacement of an Upper Pliocene dacite cryptodome, Milos Island, Greece. Journal of Volcanology and Geothermal Research 124: 129-148.

Stewart, A. L. y McPhie, J. 2006. Facies architecture and Late Pliocene-Pleistocene evolution of felsic volcanic island, Milos, Greece. Boll Vulcanol 68: 703-726. 
Stipanicic, P. N. 1967. Consideraciones sobre las edades de algunas fases magmáticas del Neopaleozoico y Mesozoico. Revista de la Asociación Geológica Argentina 22 (2): 101-133.

Stipanicic, P. N.; Rodrigo, F.; Baulies, O. L. y Martínez, C. G. 1968. Las formaciones presenonianas en el denominado Macizo Nordpatagónico y regiones adyacentes. Revista de la Asociación Geológica Argentina 23 (2): 67-98.

Stipanicic, P.N. 1969. El avance de los conocimientos del Jurásico argentino a partir del esquema de Groeber. Revista de la Asociación Geológica Argentina 24 (4): 367-388.

Stow, D. A. V.; Reading, H. G. y Collinson, J. D. 2002. Deep Seas. En: Reading, H. G. (ed.). Sedimentary Environments: Processes, Facies and Stratigraphy. 3ra ed., pp. 395-453. Blackwell Science.

Streck, M.J. y Grunder, A.L. 1995. Crystallization and welding variations in a widespread ignimbrite sheet; the Rattlesnake Tuff, eastern Oregon, USA. Bull Volcanol 57: 151169.

Suárez, M. y de la Cruz, R. 1997. Volcanismo pliniano del Lías durante los inicios de la cuenca de Neuquén, Cordillera del Viento, Neuquén, Argentina. VII Congreso Geológico Chileno, Actas I: 266-270.

Sun, S.S., McDonough, W.F., 1989. Chemical and isotopic systematics of oceanic basalts: implications for mantle composition and processes. In: Saunders, A.D., Norry, M.J. (Eds.), Magmatism in the Ocean Basin. Geol. Soc. London Spec. Publ., vol. 42, pp. 313-345.

Talbot, M.R. y Allen, P.A. 2002. Lakes. En: Reading H.G. (ed.). 3rd ed. Sedimentary environments: Processes, Facies and Stratigraphy: 83-124. Blackwell Science. Oxford, 2002.

Tankard, A. J.; Uliana, M. A.; Welsink, H. J.; Ramos, V. A.; Turic, M.; França, A. B.; Milani, E. J.; de Brito Neves, B. B.; Eyles, N.; Skarmeta, J.; Santa Ana, H.; Wiens, F.; Cirbián, M.; López P., O.; Germs, G. J. B.; De Wit, M. J.; Machacha, T. y McG. Miller, R. 1995. Tectonic controls of basin evolution in southwestern Gondwana. En: Tankard, A. J.; Suárez S., R.; y Welsink, H. J. (eds.). Petroleum basins of South America. AAPG Memoir 62: 5-52.

Thouret, J.C. 1999. Volcanic geomorphology - an overview. Earth-Science Reviews 47: 95131.

Tucker, M. E. 2001. Sedimentary petrology, an introduction to the origin of sedimentary rocks. 3ra ed. Blackwell Scientific Publications. 262 pp. 
Uliana, M. A. y Biddle, K. T. 1988. Mesozoic-Cenozoic paleogeographic and geodynamic evolution of southern South America. Revista Brasileira de Geociências 18 (2): 172190.

Uliana, M. A.; Biddle, K. T. y Cerdán, J. 1989. Mesozoic extension and the formation of Argentine sedimentary basins. En: Tankard, A. J. y Balkwill, H. R. (eds.). Extensional tectonics and stratigraphy of the North Atlantic margins. AAPG Memoir 46: 599-614.

Uliana, M.A., Arteaga, M.E., Legarreta L., Cerdan, J.J. y Peroni, G.O. 1995. Inversion structures and hydrocarbon occurrence in Argentina. in: Buchanan, J.G. y Buchanan, P.G. (eds), 1995, Basin Inversion, Geological Society Special Publication. No 88: 211233.

van Wyck de Vries, B. y Merle, O. 1996. The effect in volcanic constructs on rift fault patterns Geology 24 (7): 643-646.

van Wyck de Vries, B. y Matela, R. 1998. Styles of volcano-induced deformation: numerical models of substratum flexure, spreading and extrusion. Journal of Volcanology and Geothermal Research 81: 1-18.

Varela, R., Dalla Salda, L., Cingolani, C. y Gómez, V. 1991. Estructura, petrología y geocronología del basamento de la región del Río Limay del Río Negro y Neuquén, Argentina. Revista Geológica de Chile, 18 (2): 147-163.

Varela, R., Teixeira, W., Cingolani, C. y Dalla Salda, L. 1994. Edad Rubidio-Estroncio de granitoides de Aluminé - Rahué, Cordillera Nordpatagónica, Neuquén, Argentina. VII Congreso Geológico Chileno, Actas 2: 1254-1258. Concepción.

Varela, R., Basei, M.A.S., Cingolani, C.A., Siga Jr, O. y Passarelli, C.R. 2005. El basamento cristalino de los Andes norpatagónicos en Argentina: geocronología e interpretación tectónica. Revista Geológica de Chile 32 (2): 167-187.

Vergani, G. D.; Tankard, A. J.; Belotti, H. J. y Weisink, H. J. 1995. Tectonic evolution and paleogeography of the Neuquén basin, Argentina. En: Tankard, A. J.; Suárez S., R.; y Welsink, H. J. (eds.). Petroleum basins of South America. AAPG Memoir 62: 383-402.

Vessell, R.K. y Davis, D.K. (1981). Non marine sedimentation in an active fore arc basin. En: Ethridge, F. G. \& Flores, R. M. (eds). Recent and ancient nonmarine depositional environments: Model for explorations. Society of Economic Paleontologist and Mineralogists. Special publication 31, 31-45.

Volkheimer, W. 1964. Estratigrafía de la zona extraandina del departamento de Cushamen (Chubut) entre los paralelos $42^{\circ}$ y $42^{\circ} 30^{\circ}$ y los meridianos $70^{\circ}$ y $71^{\circ}$. Revista de la Asociación Geológica Argentina. 19 (2), 85-107. 
Volkheimer, V.y Quattrocchio, M. 1975. Palinología estratigráfica del Titoniano (Formación Vaca Muerta) en el área de Caichigüe (Cuenca Neuquina), Paret A: Especies Terrestres. Ameghiniana, 12 (3): 193-241.

Walker, R. G. 1984a. General Introduction: facies, facies sequences and facies models. En: Walker, R. G. (ed.) Facies Models, Second Edition. Geoscience Canada, Reprint Series 1: 1-10.

Walker, R. G. 2006. Facies models revisited. En: Posamentier, H. W. y Walker, R. G. (eds.) Facies Models Revisited. SEPM Special Publication 84: 1-17.

Waresback, D. R. y Turbeville, B. N. 1990. Evolution of a Plio-Pleistocene volcanogenicalluvial fan: The Puye Formation, Jemez Mountains, New Mexico. Geological Society of America Bulletin 102: 283-314.

Weaver, C. E. 1931. Paleontology of the Jurassic and Cretaceous of West Central Argentina. Memoir of the University of Washington, 1: 1-469.

White, J. D. L. y Houghton, B. F. 2006. Primary volcanistic rocks: Geology 34: 677-680.

Wilson, C. J. N., 1993. Ignimbritas y calderas: perspectivas históricas, ideas actuales y desarrollos futuros. En: Marti J. y Araña V. (eds). La volcanología actual. Consejo de investigaciones científicas. Madrid, 1993. 578 pp. 197-275.

Winchester, J.A. y Floyd, P.A. 1977. Geochemical discrimination of different magma series and their differenciation products using inmobile elements. Chemical Geology 20: 325-343.

Wright, V. P y Burchette, T. P. 2002. Shallow-water carbonate environments. En: Reading, H. G. (ed.). Sedimentary Environments: Processes, Facies and Stratigraphy. 3ra ed., pp. 325-394. Blackwell Science.

Wooller, L., van Wyck de Vries, B., Cecchi, E. y Rymer, H. 2009. Analogue models of the effect of long-term basament fault movement on volcanic edifices. Bull Volcanol: on line.

Young, M. J.; Gawthorpe, R. L. y Sharp, I. R. 2003. Normal fault growth and early syn-rift sedimentology and sequence stratigraphy: Thal Fault, Suez Rift, Egypt. Basin Research 15: 479-502.

Yrigoyen, M. R. 1991. Hydrocarbon resources from Argentina. In: World Petroleum Congress, Buenos Aires, Petrotecnica, 13, Special Issue, 38 - 54.

Zapata, T. y Folguera, A. 2005. Tectonic evolution of the Andean Fol. And Thrust Belt of the southern Neuquén Basin. En: Veiga, G. D.; Spalletti, L. A.; Howell, J. A. y Schwarz, E. (eds.). The Neuquén Basin, Argentina: A Case Study in Sequence Stratigraphy and Basin Dynamics. Geological Society, London, Special Publications, 252: 37-56. 
Zancheta, G., Sulpicio, R. y Di Vito, M.A. 2004. The role of volcanic activity and climate in alluvial fan growth at volcanic areas: an example from southern Campania (Italy). Sedimentary Geology 168: 249-280.

Ziegler, P. A. y Cloething, S. 2004. Dynamic processes controlling evolution of rifted basins. Earth-Science Reviews 64: 1-50.

Zumel, J; Garcia, R y Pando, G. 2002. Los reservorios del Grupo Cuyo Inferior. En: Schiuma, M., Hinterwimmer, G. y Vergani, G. (eds). Rocas Reservorios. V Congreso de exploración y desarrollo de hidrocarburos. Actas: 255-276. 
Anexo I

Mapa geológico 


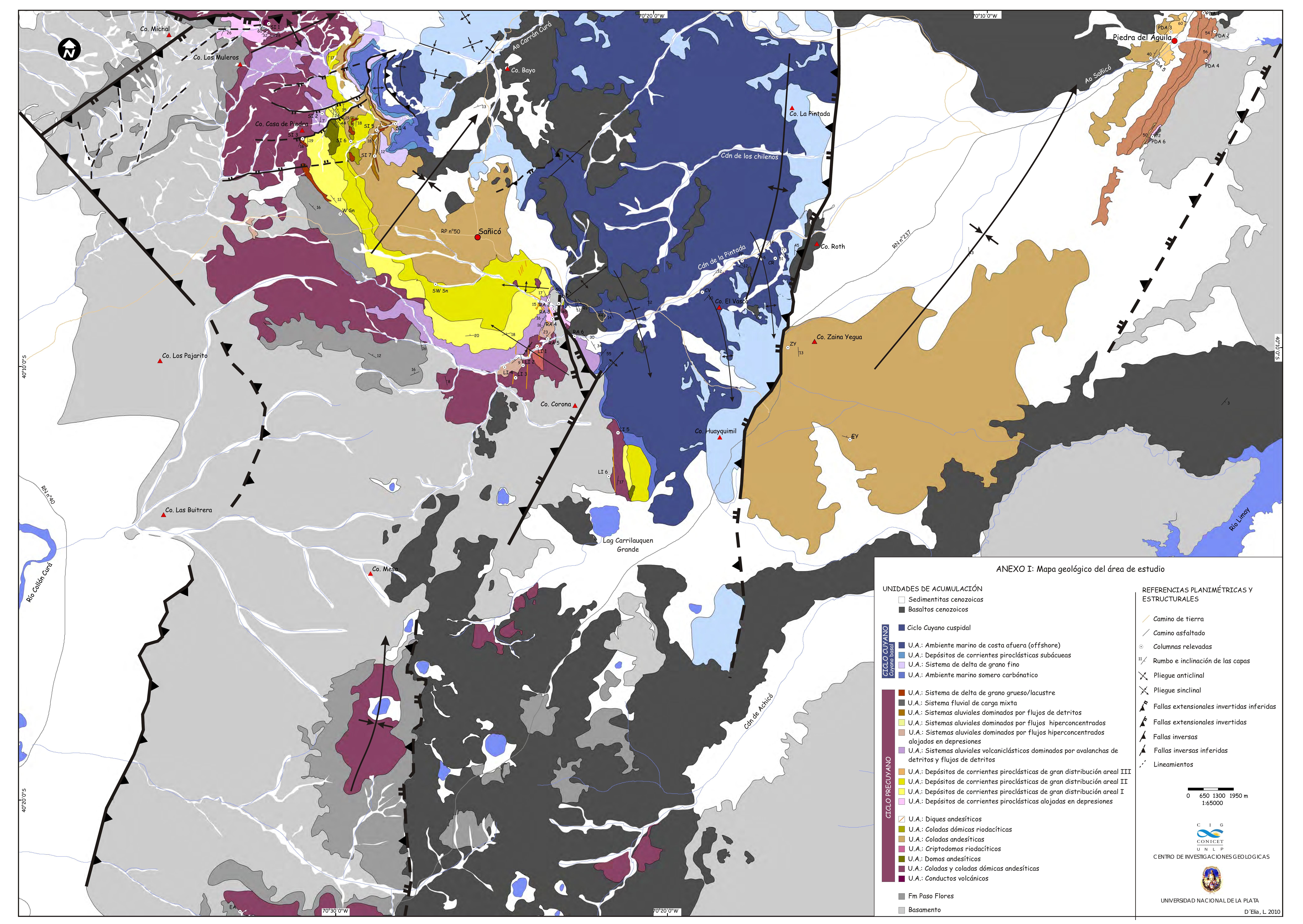


Anexo II

Perfiles litológicos de detalle 


\section{Anexo II-2: DEPOCENTRO DE SAÑICÓ}

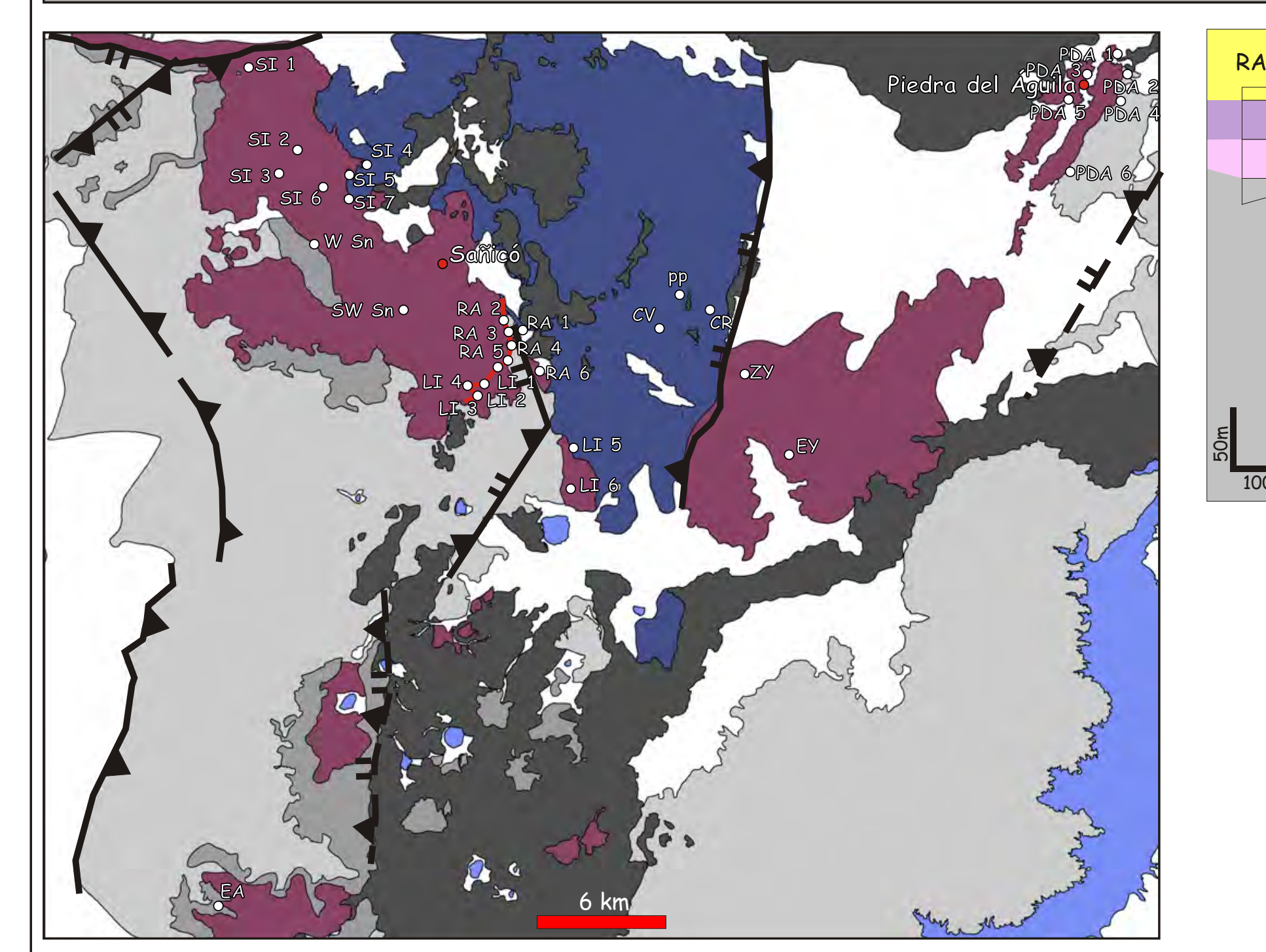

UNIDADES DE ACUMULACIÓN

$\square$ U.A.: Sistemas aluviales dominados por flujos

hiperconcentrados
U.A.: Domos andesíticos

U.A.: Ambiente marino de costa afuera

$\square$ U.A.: Depósitos de corrientes

$\square$ Uiroclásticas subácueas

U.A.: Depósitos de corrientes piroclásticas de gran distribución areal I

U.A.: Ambiente marino somero carbónatico

$\square$ U.A.: Sistemas aluviales dominados por flujos

hiperconcentrados alojados en depresiones

U.A.: Sistemas de delta de grano grueso/lacustre

U.A.: Sistemas aluviales dominados por

por avalanchas de detritos y flujos de detritos

flujos de detritos

U.A.: Depósitos de corrientes piroclásticas

U.A.: Depósitos de corrientes piroclásticas

de gran distribución areal II

U.A.: Coladas y coladas dómicas andesíticas

$\square$ U.A.: Depósitos de corrientes piroclásticas

- U.A.: Conductos alimentadores

de gran distribución areal II

Estructuras de rocas volcánicas

Diques volcánicos

$\begin{array}{ll} & \text { Lavas coherentes } \\ \text { Lavas foliadas }\end{array}$

Lavas autobrechadas

Vitroclastos pumiceos

Lavas con fracturación hidráulica

Estructuras de rocas piroclásticas

epiclásticas y carbonáticas

$\square$ Masiva

Estratificación horizontal

Laminación horizontal

Óndulas / laminación ondulítica

Estratificación entrecruzada planar

Estratificación entrecruzada monticular (HCS)

Deformación sinsedimentari

Estructura build up
Estructura en rompecabezos

Estructura en rompecabe
$\square$ Pipes de elutriación

$\nabla$ Gradación inversa

Gradación inversa-normal

Sentido de las paleocorrientes

${ }^{n=8}$ Composición

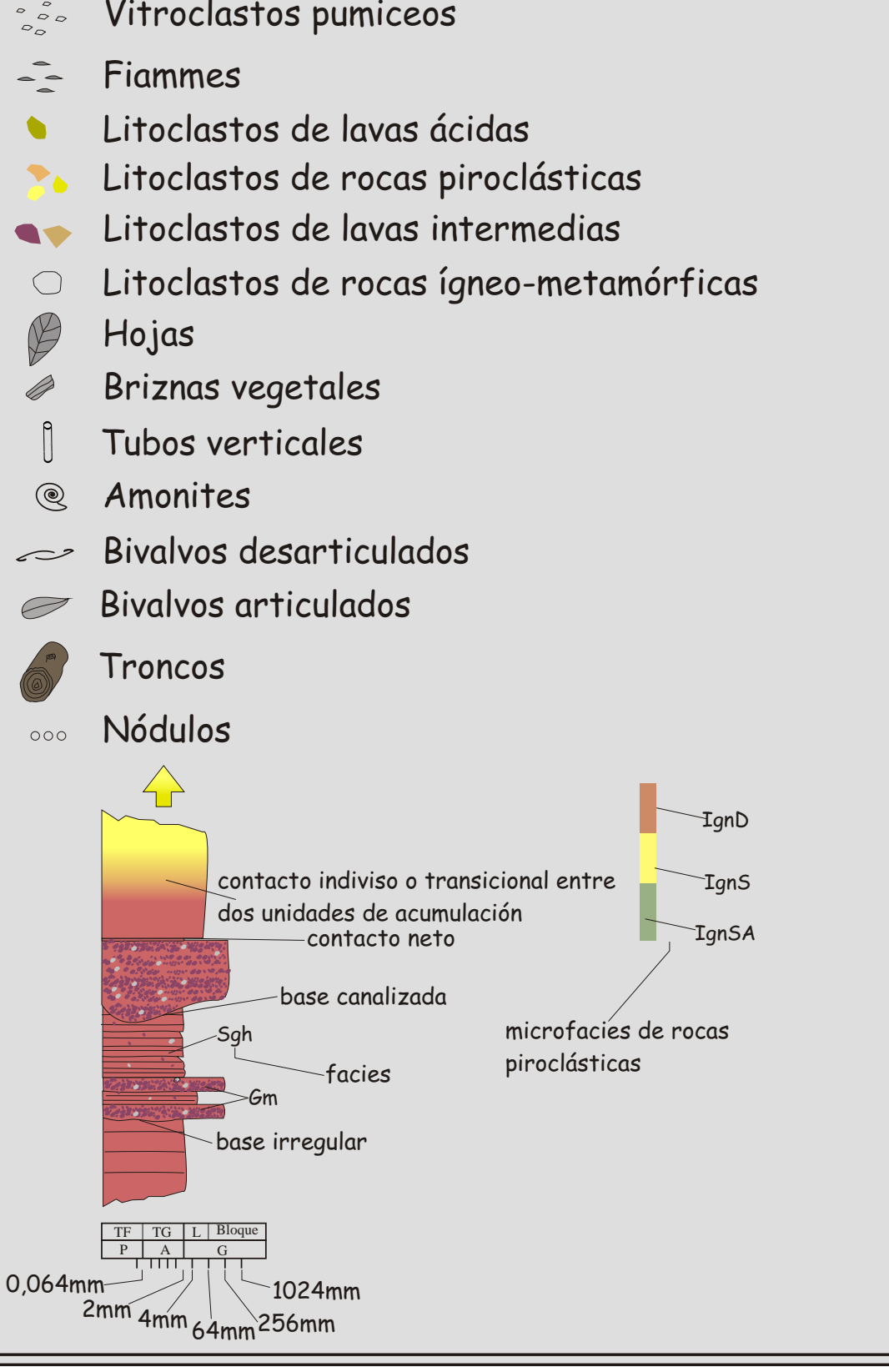

RA 4

RA 5

LI 1

LI2 LI 3 LI 4
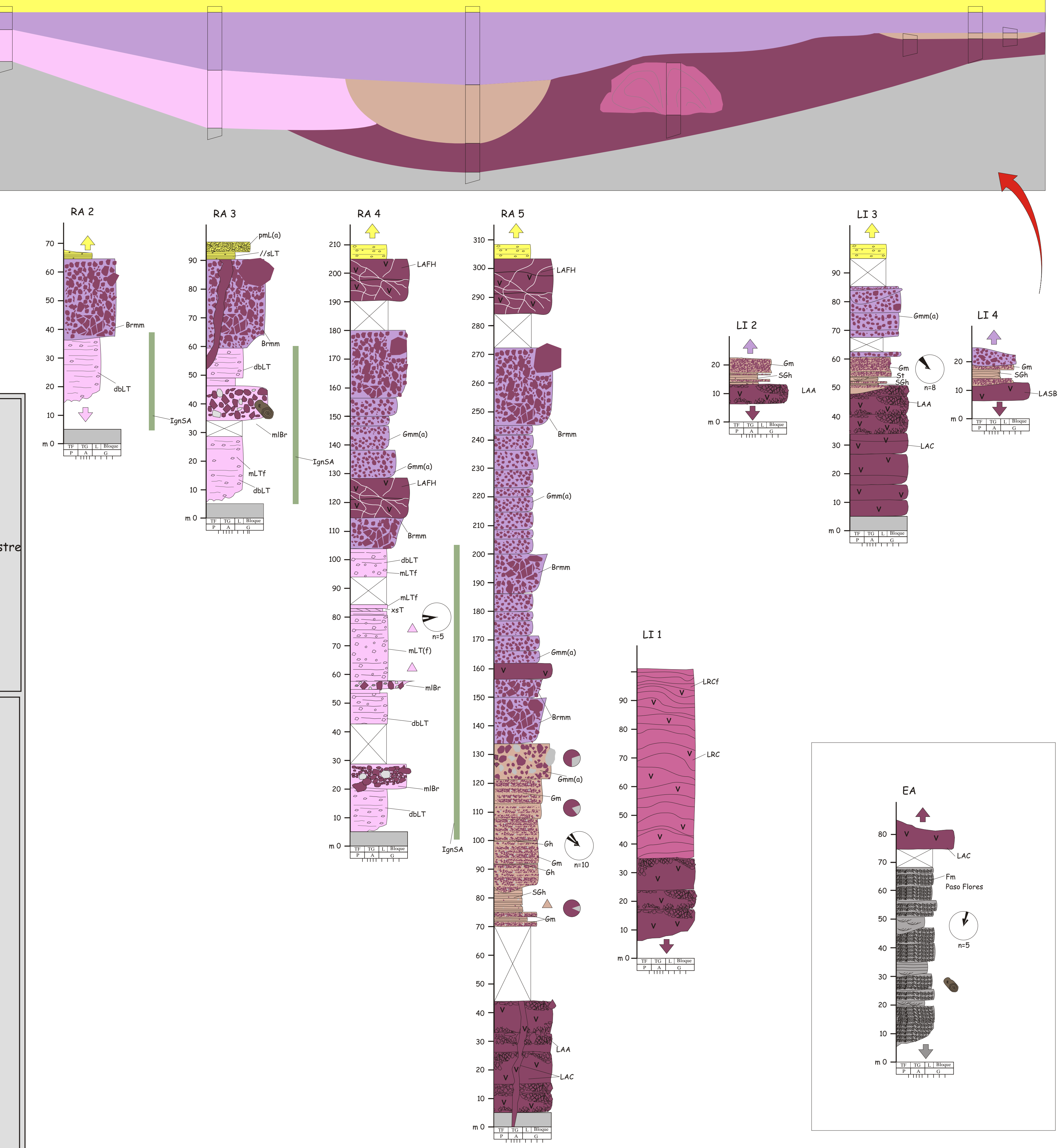

Anexo II-3: DEPOCENTRO DE LA PINTADA
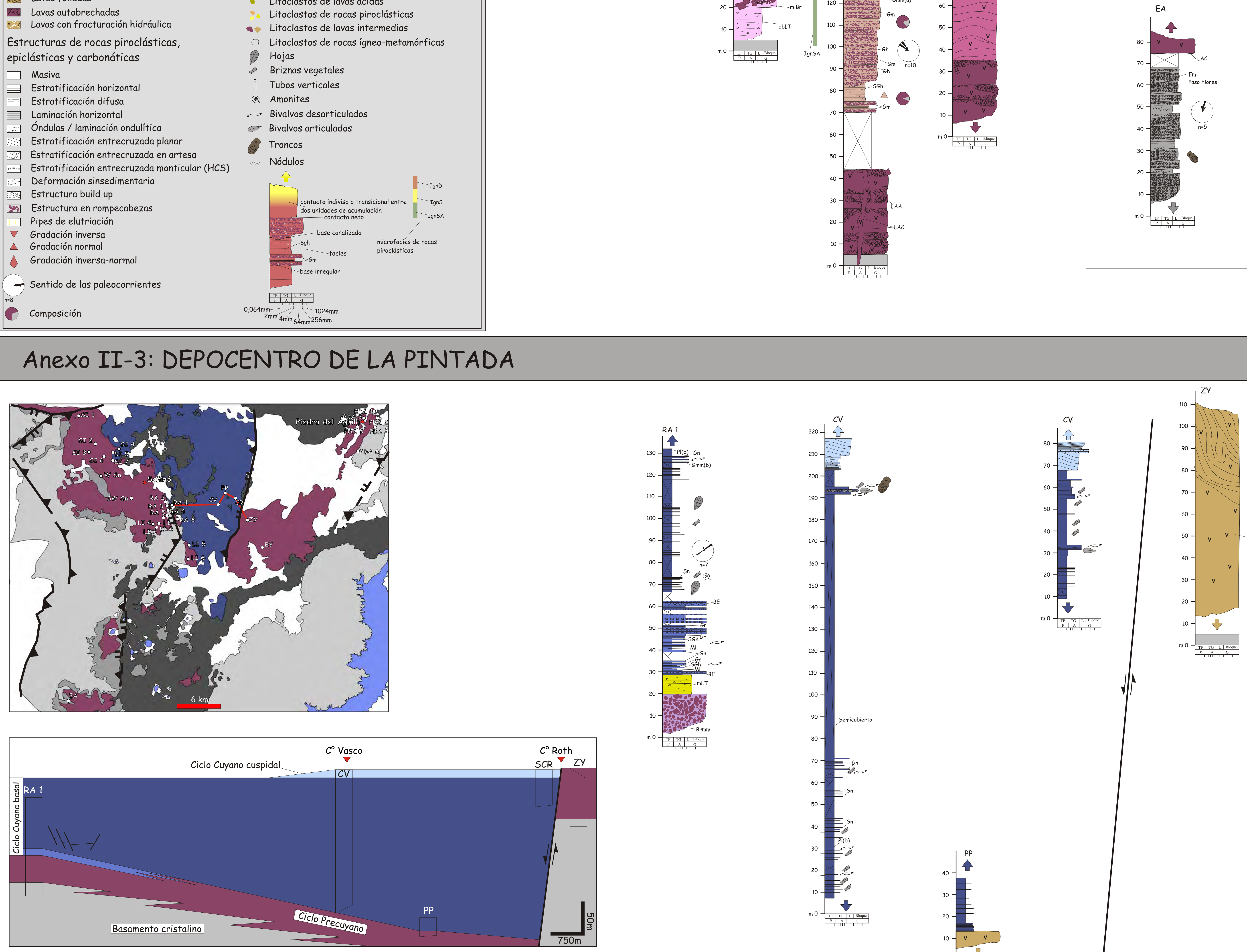

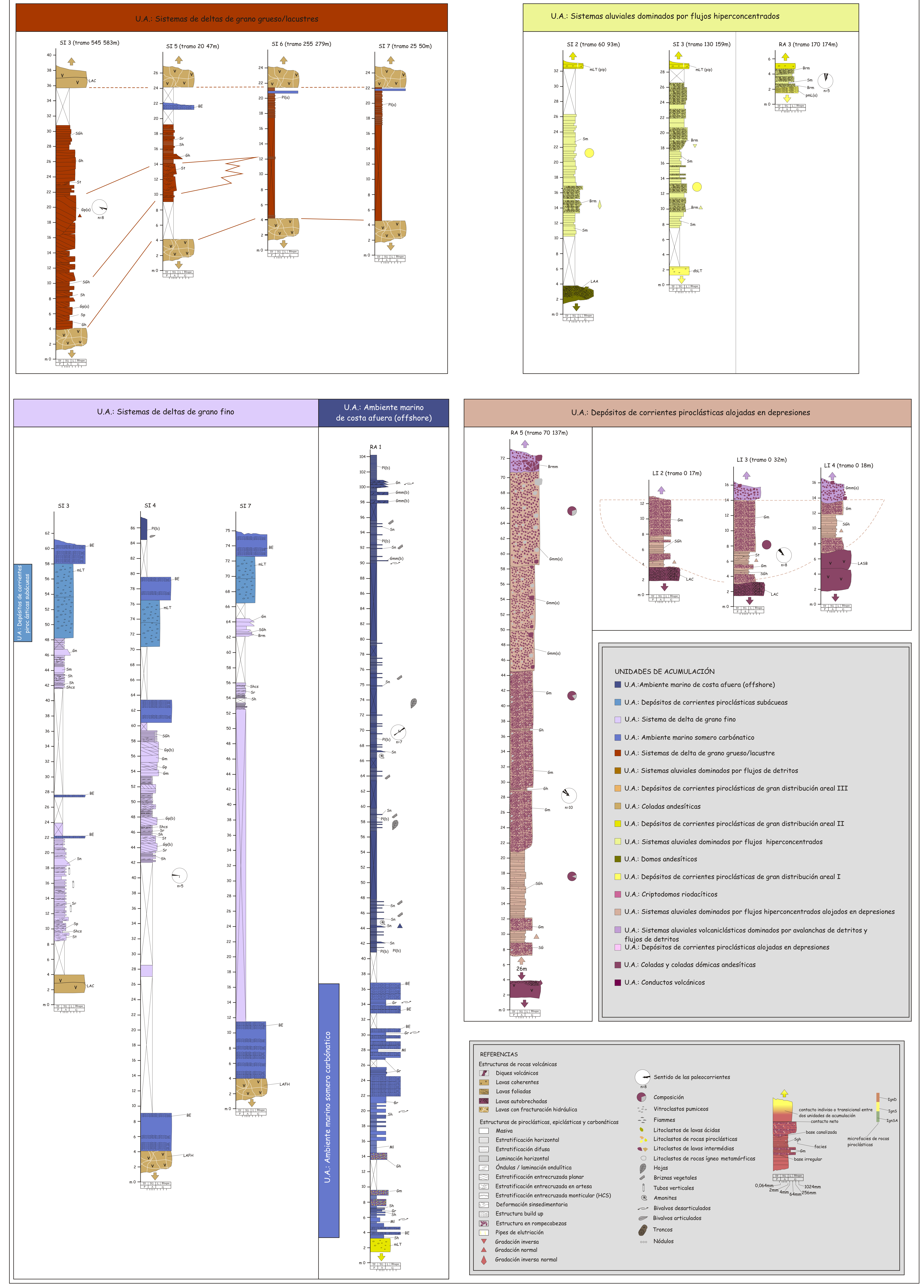


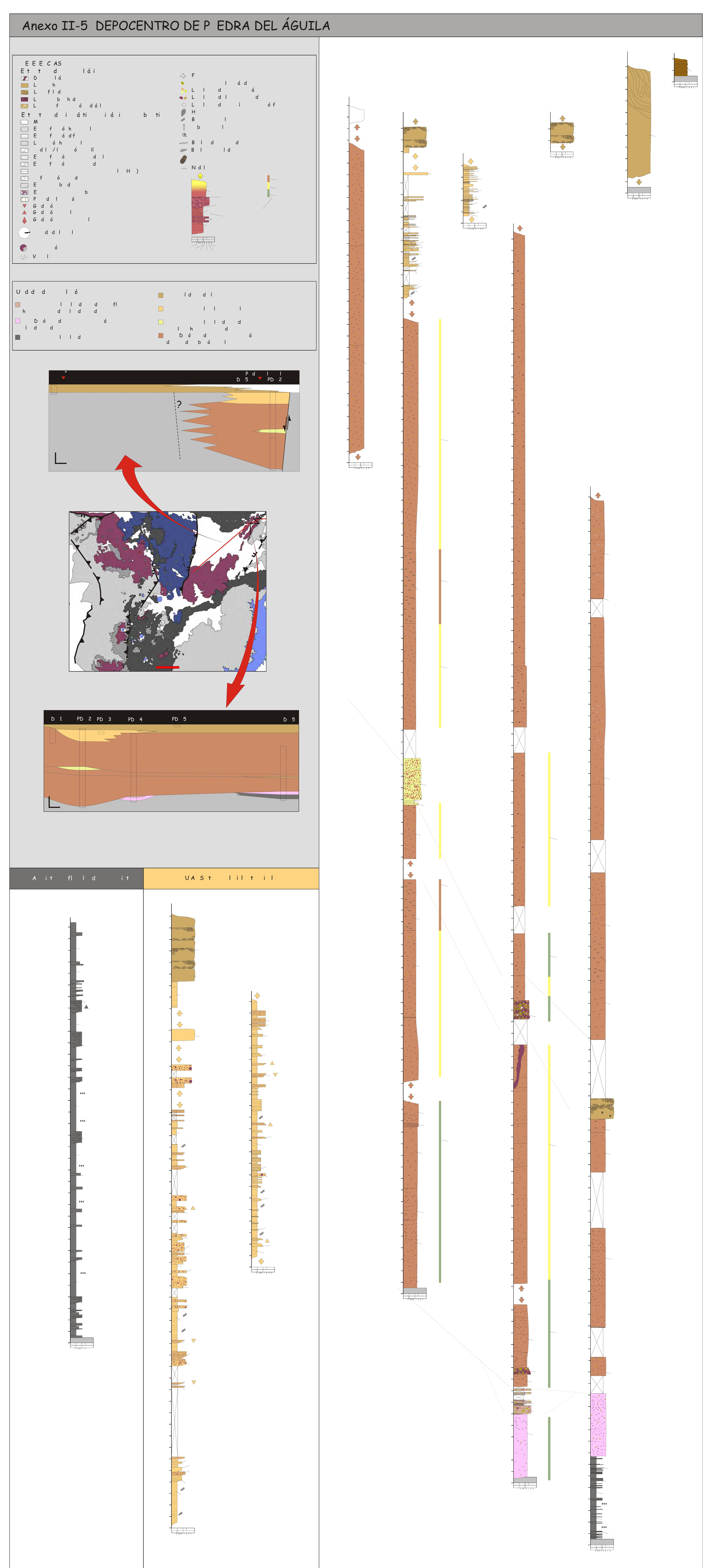


Anexo III

Análisis geoquímico 


\begin{tabular}{|c|c|c|c|c|c|c|c|c|c|c|c|c|c|c|c|c|c|c|}
\hline Analyte Symbol & $\mathrm{SiO} 2$ & Al2O3 & $\mathrm{Fe} 2 \mathrm{O} 3(\mathrm{~T})$ & $\mathrm{MnO}$ & $\mathrm{MgO}$ & $\mathrm{CaO}$ & $\mathrm{Na2O}$ & $\mathrm{K} 2 \mathrm{O}$ & $\mathrm{TiO}_{2}$ & P205 & LOI & Total & $\mathrm{Sc}$ & $\mathrm{Be}$ & & $\mathrm{Ba}$ & Sr & \\
\hline Unit Symbol & $\%$ & $\%$ & $\%$ & $\%$ & $\%$ & $\%$ & $\%$ & $\%$ & $\%$ & $\%$ & $\%$ & $\%$ & ppm & ppm & $\mathrm{ppm}$ & ppm & ppm & $\mathrm{ppm}$ \\
\hline Detection Limit & 0.01 & 001 & 0.01 & 0.001 & 0.01 & 001 & 0.01 & 001 & 0.001 & 0.01 & & 0.01 & 1 & 1 & 5 & 3 & 2 & \\
\hline Analysis Method & US-ICP & FUS-ICP & FUS-ICP & FUS-ICP & FUS-ICP & FUS-ICP & EUS-ICP & FUS-ICP & FUS-ICP & FUS-ICP & FUS-ICP & FUS-ICP & FUS-ICP & FUS-ICP & JS-ICP & FUS-ICP & \begin{tabular}{|l|l|} 
IS-ICP \\
\end{tabular} & SS-ICP \\
\hline PDA_M & 79,44 & 10,49 & 1,19 & 0,021 & 0,21 & 0,48 & 1,34 & 5,3 & 0,078 & 0,03 & 2,39 & 101 & 3 & 2 & 13 & 686 & 47 & 24 \\
\hline PDA_I & 70,33 & 13,86 & 3,03 & 0,016 & 0,36 & 0,62 & 3,13 & 3,91 & 0,406 & 0,12 & 2,97 & 98,77 & 6 & 1 & 43 & 979 & 92 & 24 \\
\hline $\mathrm{ZY} \_\mathrm{S}$ & 52,78 & 16,81 & 9,17 & 0,154 & 2,59 & 4,82 & 4,08 & 2,27 & 1,182 & 1,01 & 4,4 & 99,25 & 15 & 3 & 90 & 955 & 553 & 32 \\
\hline SE-SN_12 & 54,29 & 17,47 & 4,92 & 0,118 & 0,37 & 8,3 & 4,02 & 3,46 & 0,649 & 0,27 & 5,65 & 99,51 & 11 & 2 & 106 & 979 & 553 & \\
\hline N-SN_M & 73,24 & 12,61 & 2,64 & 0,029 & 0,17 & 0,54 & 2,58 & 4,71 & 0,298 & 0,08 & 1,4 & 98,3 & 7 & 1 & 36 & 683 & 83 & \\
\hline SE-SN_12 & 59,1 & 17,43 & 5,87 & 0,177 & 2,68 & 5,12 & 3,86 & 1,06 & 0,617 & 0,25 & 3,04 & 99,19 & 7 & 1 & 70 & 277 & 530 & 19 \\
\hline SE-SN_M1 & 69,35 & 14,2 & 1,95 & 0,036 & 0,33 & 2,56 & 2,73 & 3,39 & 0,436 & 0,11 & 3,76 & 98,84 & 8 & 2 & 59 & 908 & 154 & 17 \\
\hline W-SN_S & 61,94 & 15,56 & 7,31 & 0,081 & 1,08 & 5,46 & 3,29 & 0,93 & 0,938 & 0,26 & 2,49 & 99,35 & 17 & 1 & 97 & 400 & 427 & 23 \\
\hline SE-SN_M2 & 67,75 & 14,12 & 1,7 & 0,048 & 0,58 & 1,43 & 1,14 & 4,46 & 0,212 & 0,04 & 7,07 & 98,55 & & ? & 31 & 1242 & 583 & \\
\hline
\end{tabular}

\begin{tabular}{|c|c|c|c|c|c|c|c|c|c|c|c|c|c|c|c|c|c|c|c|c|}
\hline Analyte Symbol & $\mathrm{Zr}$ & $\mathrm{Cr}$ & $\mathrm{Co}$ & Nif & $\mathrm{Cu}$ & $\mathrm{Zn}$ & $\mathrm{Ga}$ & $\mathrm{Ge}$ & As & $\mathrm{Rb}$ & $\mathrm{Nb}$ & Mo & $\mathrm{Ag}$ & $\mathrm{n}$ & $\mathrm{Sn}$ & $\mathrm{Sb}$ & $\mathrm{Cs}$ & $\mathrm{La}$ & $\mathrm{Ce}$ & \\
\hline Unit Symbol & $\mathrm{ppm}$ & $\mathrm{ppm}$ & $\mathrm{ppm}$ & ppm & ppm & $\mathrm{ppm}$ & $\mathrm{ppm}$ & $\mathrm{ppm}$ & ppm & $\mathrm{ppm}$ & $\mathrm{ppm}$ & ppm & $\mathrm{ppm}$ & $\mathrm{ppm}$ & $\mathrm{ppm}$ & $\mathrm{ppm}$ & $\mathrm{ppm}$ & $\mathrm{ppm}$ & $\mathrm{ppm}$ & \\
\hline Detection Limit & 4 & 20 & 1 & 20 & 10 & 30 & 1 & 1 & 5 & 2 & 1 & 2 & 0.5 & 0.2 & 1 & 0.5 & 0.5 & 0.1 & 0.1 & \\
\hline Analysis Method & FUS-ICP & \begin{tabular}{|l|} 
FUS-MS \\
\end{tabular} & FUS-MS & FUS-MS & FUS-MS & FUS-MS & FUS-MS & FUS-MS & FUS-MS & FUS-MS & FUS-MS & FUS-MS & FUS-MS & FUS-MS & FUS-MS & FUS-MS & FUS-MS & FUS-MS & FUS-MS & \\
\hline PDA_M & 58 & \begin{tabular}{|l|}
30 \\
\end{tabular} & 1 & $<20$ & $<10$ & $<30$ & 13 & 2 & 19 & 186 & 8 & 9 & 1 & $<02$ & \begin{tabular}{|r}
2 \\
\end{tabular} & 5,3 & 2,7 & 17,7 & 37,3 & \\
\hline PDA_I & 263 & $<20$ & 6 & 50 & $<10$ & 60 & 17 & 2 & 6 & 165 & 8 & $<2$ & $<0.5$ & $<02$ & 2 & 9,3 & 2 & 36,7 & 73,9 & \\
\hline $\mathrm{ZY} \_\overline{\mathrm{S}}$ & 408 & 40 & 28 & $<20$ & 60 & 150 & 24 & 2 & $<5$ & 48 & 20 & $<2$ & $<0.5$ & $<02$ & 2 & 2,4 & 0,9 & 73,9 & 163 & \\
\hline SE-SN_12 & 192 & 30 & 10 & $<20$ & 30 & 110 & 22 & 3 & 6 & 90 & 5 & 2 & $<0.5$ & $<02$ & 2 & 5,3 & 1,8 & 33,3 & 66,4 & \\
\hline N-SN_M & 79 & $<20$ & 4 & $<20$ & 10 & 40 & 14 & 3 & 9 & 97 & 8 & $<2$ & $<0.5$ & $<02$ & 2 & 7,6 & 0,8 & 22,2 & 46,3 & \\
\hline SE-SN_12 & 142 & $<20$ & 9 & $<20$ & $<10$ & 70 & 19 & 2 & $<5$ & 24 & 6 & $<2$ & $<0.5$ & $<02$ & $<1$ & 4 & $<0.5$ & 18,6 & 42,6 & \\
\hline SE-SN_M1 & 169 & $<20$ & 4 & $<20$ & $<10$ & 80 & 19 & 3 & 10 & 164 & 8 & $<2$ & $<0.5$ & $<02$ & 3 & 9,1 & 4,7 & 33,9 & 67,5 & \\
\hline W-SN_S & 152 & 30 & 15 & $<20$ & 20 & 70 & 18 & 2 & 9 & 20 & 5 & 2 & $<0.5$ & $<02$ & 1 & 4 & 0,6 & 16,8 & 38,2 & \\
\hline SE-SN_M2 & 113 & $<20$ & 213 & 300 & 20 & 50 & 15 & 2 & 11 & 122 & 9 & 16 & $<0.5$ & $<02$ & 1 & 5,3 & 1,9 & 32,9 & 62,8 & \\
\hline Analyte Symbol & $\mathrm{Pr}$ & $\mathrm{Nd}$ & $\mathrm{Sm}$ & $\mathrm{Eu}$ & Gd & $\mathrm{Tb}$ & Dy & $\mathrm{Ho}$ & Er & $\mathrm{Tm}$ & $\overline{\mathrm{Yb}}$ & Lu & $\mathrm{Hf}$ & $\mathrm{Ta}$ & $\bar{W}$ & TI & $\mathrm{Pb}$ & $\mathrm{Bi}$ & Th & $\mathrm{U}$ \\
\hline Unit Symbol & $\mathrm{ppm}$ & $\mathrm{ppm}$ & $\mathrm{ppm}$ & $\mathrm{ppm}$ & $\mathrm{ppm}$ & $\mathrm{ppm}$ & $\mathrm{ppm}$ & ppm & $\mathrm{ppm}$ & $\mathrm{ppm}$ & $\mathrm{ppm}$ & ppm & $\mathrm{ppm}$ & $\mathrm{ppm}$ & $\mathrm{ppm}$ & $\mathrm{ppm}$ & $\mathrm{ppm}$ & $\mathrm{ppm}$ & $\mathrm{ppm}$ & $\mathrm{ppm}$ \\
\hline Detection Limit & 0.05 & 0.1 & 0.1 & \begin{tabular}{ll|} 
& 05 \\
\end{tabular} & 0.1 & 0.1 & 0.1 & $\begin{array}{l}0.1 \\
\end{array}$ & 0.1 & 0.05 & 0.1 & 0.04 & 0.2 & 0.1 & 1 & 0.1 & 5 & 0.4 & 0.1 & 0.1 \\
\hline Analysis Method & FUS-MS & FUS-MS & FUS-MS & FUS-MS & FUS-MS & FUS-MS & FUS-MS & FUS-MS & FUS-MS & FUS-MS & FUS-MS & FUS-MS & FUS-MS & FUS-MS & FUS-MS & FUS-MS & FUS-MS & FUS-MS & FUS-MS & FUS-MS \\
\hline PDA_M & 3,91 & $\begin{array}{l}14,9 \\
\end{array}$ & 3,5 & \begin{tabular}{|l|}
0,37 \\
\end{tabular} & 3,5 & 0,6 & 4 & \begin{tabular}{|l|}
0,9 \\
\end{tabular} & 2,7 & 0,42 & \begin{tabular}{|l|}
2,7 \\
\end{tabular} & \begin{tabular}{|l|}
0,39 \\
\end{tabular} & 2,5 & 1 & \begin{tabular}{|l}
3 \\
\end{tabular} & \begin{tabular}{|l|}
1 \\
\end{tabular} & 37 & $\begin{array}{r}4,5 \\
\end{array}$ & 10 & 2,4 \\
\hline PDA_I & 8,87 & 28,8 & 5,6 & 0,95 & 5 & 0,8 & 4,9 & 1 & 3,2 & 0,5 & 3,3 & 0,51 & 7,9 & 0,8 & $<1$ & 0,9 & 34 & $<0.4$ & 13,2 & 2,1 \\
\hline ZY_S & 19,6 & 62,8 & 11,7 & 3,01 & 9,2 & 1,3 & 6,9 & 1,3 & 4 & 0,58 & 3,6 & 0,52 & 9,4 & 1,1 & $<1$ & $<0.1$ & 9 & $<0.4$ & 3,6 & 0,6 \\
\hline SE-SN_12 & 8,19 & 25,9 & 4,9 & 1,54 & 3,9 & 0,5 & 3 & 0,6 & 1,7 & 0,25 & 1,6 & 0,24 & 5,5 & 0,3 & 2 & 0,3 & 23 & $<0.4$ & 5,3 & 1,1 \\
\hline N-SN_M & 5,43 & 17,1 & 3,5 & 0,67 & 3,2 & 0,5 & 3,4 & 0,7 & 2,3 & 0,36 & 2,4 & 0,37 & 3,1 & 0,8 & 1 & 0,8 & 40 & 0,4 & 7,7 & 1,5 \\
\hline SE-SN_12 & 5,82 & 21,5 & 4,7 & 1,51 & 4,4 & 0,7 & 4 & 0,8 & 2,6 & 0,4 & 2,6 & $\begin{array}{ll}0,4 \\
\end{array}$ & 4,1 & 0,4 & $<1$ & $<0.1$ & $<5$ & $<0.4$ & 2,5 & 0,7 \\
\hline SE-SN_M1 & 7,94 & 25,6 & 5,1 & 1,01 & 4,4 & 0,7 & 3,9 & 0,8 & 2,3 & 0,34 & 2,1 & 0,32 & 5 & 0,9 & $<1$ & 1,2 & 53 & 0,4 & 10,9 & 2,5 \\
\hline W-SN_S & 5,42 & 20,9 & 4,9 & 1,52 & 5 & 0,8 & 4,6 & 1 & 3 & 0,45 & 2,8 & 0,42 & 4,3 & 0,3 & $<1$ & $<0.1$ & 6 & $<0.4$ & 2 & 1,1 \\
\hline SE-SN_M2 & 7,17 & 20,6 & 3,6 & 0,67 & 2,7 & 0,4 & 2,5 & 0,5 & 1,4 & 0,21 & 1,3 & 0,2 & 3,4 & 0,7 & & 1,3 & 21 & 1,8 & 16,4 & 2,8 \\
\hline
\end{tabular}


Final Report

\section{Activation Laboratories}

\begin{tabular}{|c|c|c|c|c|c|c|c|c|c|c|c|c|c|c|c|c|c|c|c|c|}
\hline Analyte Symbol & SiO2 & Al2O3 & $\mathrm{Fe} 2 \mathrm{O} 3(\mathrm{~T})$ & $\mathrm{MnO}$ & $\mathrm{MgO}$ & $\mathrm{CaO}$ & $\mathrm{Na2O}$ & $\mathrm{K} 2 \mathrm{O}$ & TiO2 & $\mathrm{P} 205$ & LOI & Total & $\mathrm{Sc}$ & $\mathrm{Be}$ & $\mathrm{v}$ & $\mathrm{Ba}$ & $\mathrm{Sr}$ & $\mathrm{Y}$ & $\mathrm{Zr}$ & $\mathrm{Cr}$ \\
\hline Unit Symbol & $\%$ & $\%$ & $\%$ & $\%$ & $\%$ & $\%$ & $\%$ & $\%$ & $\%$ & $\%$ & $\%$ & $\%$ & ppm & $\mathrm{ppm}$ & $\mathrm{ppm}$ & $\mathrm{ppm}$ & $\mathrm{ppm}$ & $\mathrm{ppm}$ & $\mathrm{ppm}$ & $\mathrm{ppm}$ \\
\hline Detection Limit & 0.01 & 0.01 & 0.01 & 0.001 & 0.01 & 0.01 & 0.01 & 0.01 & 0.001 & 0.01 & & 001 & 1 & 1 & 5 & 3 & 2 & 2 & 4 & 20 \\
\hline Analysis Method & FUS-ICP & FUS-ICP & FUS-ICP & FUS-ICP & FUS-ICP & FUS-ICP & FUS-ICP & FUS-ICP & FUS-ICP & FUS-ICP & FUS-ICP & FUS-ICP & FUS-ICP & FUS-ICP & FUS-ICP & FUS-ICP & FUS-ICP & FUS-ICP & FUS-ICP & FUS-MS \\
\hline GXR-1 Meas & & & & & & & & & & & & & & & & & & & & $<20$ \\
\hline GXR-1 Cert & & & & & & & & & & & & & & & & & & & & 12 \\
\hline WMG-1 Meas & & & & & & & & & & & & & & & & & & & & 800 \\
\hline WMG-1 Cert & & & & & & & & & & & & & & & & & & & & 770 \\
\hline NIST 694 Meas & 11,65 & 1,91 & 0,76 & 0,012 & 0,33 & 43,31 & 0,88 & 0,51 & 0,113 & 30,2 & & & & & 1670 & & & & & \\
\hline NIST 694 Cert & 11,2 & 1,8 & 0,79 & 0,0116 & 0,33 & 43,6 & 0,86 & 0,51 & 0,11 & 30,2 & & & & & 1740 & & & & & \\
\hline DNC-1 Meas & 47,44 & 18,58 & 9,92 & 0,152 & 10,3 & 11,41 & 1,91 & 0,24 & 0,489 & 0,07 & & & 31 & $<1$ & 153 & 103 & 144 & 14 & 32 & 250 \\
\hline \begin{tabular}{|l} 
DNC-1 Cert \\
\end{tabular} & 47 & 18,3 & 9,93 & 0,149 & 10,1 & 11,3 & 1,87 & 0,234 & 0,48 & 0,09 & & & 31 & 1 & 148 & 114 & 145 & 18 & 41 & 285 \\
\hline GBW 07113 Meas & 72,32 & 12,93 & 3,18 & 0,142 & 0,15 & 0,58 & 2,46 & 5,48 & 0,286 & 0,06 & & & 5 & 4 & $<5$ & 490 & 41 & 46 & 428 & \\
\hline GBW 07113 Cert & 72,8 & 13 & 3,21 & 0,14 & 0,16 & 0,59 & 2,57 & 5,43 & 0,3 & 0,05 & & & 5 & 4 & 5 & 506 & 43 & 43 & 403 & \\
\hline GXR-2 Meas & & & & & & & & & & & & & & & & & & & & 40 \\
\hline GXR-2 Cert & & & & & & & & & & & & & & & & & & & & 36 \\
\hline LKSD-3 Meas & & & & & & & & & & & & & & & & & & & & 80 \\
\hline LKSD-3 Cert & & & & & & & & & & & & & & & & & & & & 87 \\
\hline MAG-1 (Depleted) Meas & & & & & & & & & & & & & & & & & & & & 90 \\
\hline MAG-1 (Depleted) Cert & & & & & & & & & & & & & & & & & & & & 97 \\
\hline NIST 1633b Meas & 47,94 & 27,91 & 10,88 & 0,016 & 0,74 & 2,06 & 0,26 & 2,27 & 1,276 & 0,51 & & & 39 & & 297 & 691 & 1033 & & & \\
\hline NIST 1633b Cert & 49,2 & 28,4 & 11,1 & 0,02 & 0,8 & 2,11 & 0,27 & 2,35 & 1,32 & 0,53 & & & 41 & & 296 & 709 & 1040 & & & \\
\hline SY-2 Meas & 60,04 & 12,06 & 6,25 & 0,322 & 2,61 & 8 & 4,2 & 4,57 & 0,142 & 0,46 & & & 7 & 22 & 72 & 455 & 278 & 128 & 293 & \\
\hline SY-2 Cert & 60,1 & 12,12 & 6,27 & 0,32 & 2,7 & 7,98 & 4,34 & 4,48 & 0,14 & 0,43 & & & 7 & 23 & 52 & 460 & 275 & 130 & 280 & \\
\hline W-2a Meas & 52,86 & 15,42 & 10,87 & 0,173 & 6,43 & 11,04 & 2,2 & 0,58 & 1,104 & 0,15 & & & 35 & 1 & 279 & 170 & 196 & 18 & 90 & 100 \\
\hline W-2a Cert & 52,4 & 15,4 & 10,7 & 0,163 & 6,37 & 10,9 & 2,14 & 0,626 & 1,06 & 0,13 & & & 36 & 1,3 & 262 & 182 & 190 & 24 & 94 & 92 \\
\hline NIST 696 Meas & 3,76 & 52,26 & 8,18 & 0,004 & 0,01 & $<0.01$ & & $<0.01$ & 2,536 & 0,05 & & & & & 384 & & & & 1020 & \\
\hline NIST 696 Cert & 3,79 & 54,5 & 8,7 & 0,004 & 0,012 & 0,018 & & 0,009 & 2,64 & 0,05 & & & & & 403 & & & & 1040 & \\
\hline CTA-AC-1 Meas & & & & & & & & & & & & & & & & & & & & \\
\hline CTA-AC-1 Cert & & & & & & & & & & & & & & & & & & & & \\
\hline BIR-1a Meas & 48,44 & 15,87 & 11,42 & 0,176 & 9,68 & 13,33 & 1,82 & $<0.01$ & 0,985 & 0,03 & & & 44 & $<1$ & 336 & 7 & 111 & 13 & 14 & 410 \\
\hline BIR-1a Cert & 47,8 & 15,4 & 11,3 & 0,171 & 9,68 & 13,2 & 1,75 & 0,03 & 0,96 & 0,05 & & & 44 & 0,58 & 313 & 7 & 108 & 16 & 16 & 382 \\
\hline LAC 2 Orig & 49,99 & 15,27 & 8,83 & 0,157 & 8,24 & 9,68 & 2,65 & 0,65 & 0,965 & 0,22 & 2,47 & 99,13 & 29 & 1 & 224 & 160 & 718 & 15 & 87 & 420 \\
\hline LAC 2 Dup & 49,7 & 15,19 & 9,06 & 0,157 & 8,23 & 9,7 & 2,62 & 0,61 & 0,957 & 0,23 & 2,47 & 98,93 & 29 & 1 & 220 & 159 & 713 & 14 & 86 & 400 \\
\hline T_IGN_MED Orig & 67,75 & 14,12 & 1,7 & 0,048 & 0,58 & 1,43 & 1,14 & 4,46 & 0,212 & 0,04 & 7,07 & 98,55 & 3 & 2 & 31 & 1242 & 583 & 11 & 113 & $<20$ \\
\hline T_IGN_MED Split & 67,69 & 14,11 & 1,7 & 0,048 & 0,59 & 1,44 & 1,14 & 4,39 & 0,211 & 0,04 & 7,12 & 98,48 & 4 & 2 & 33 & 1238 & 581 & 12 & 113 & $<20$ \\
\hline T_IGN_MED Orig & & & & & & & & & & & & & & & & & & & & $<20$ \\
\hline T_IGN_MED Split & & & & & & & & & & & & & & & & & & & & $<20$ \\
\hline Method Blank Method Blank & & & & & & & & & & & & & & & & & & & & $<20$ \\
\hline Method Blank Method Blank & & & & & & & & & & & & & & & & & & & & $<20$ \\
\hline
\end{tabular}


Final Report

\section{Activation Laboratories}

\begin{tabular}{|c|c|c|c|c|c|c|c|c|c|c|c|c|c|c|c|c|c|c|c|c|}
\hline Analyte Symbo| & $\mathrm{Co}$ & $\mathrm{Ni}$ & $\mathrm{Cu}$ & $\mathrm{Zn}$ & $\mathrm{Ga}$ & $\mathrm{Ge}$ & As & $\mathrm{Rb}$ & $\mathrm{Nb}$ & Mo & $\mathrm{Ag}$ & $\operatorname{In}$ & Sn & $\mathrm{Sb}$ & Cs & $\mathrm{La}$ & $\mathrm{Ce}$ & $\operatorname{Pr}$ & $\mathrm{Nd}$ & $\mathrm{Sm}$ \\
\hline Unit Symbol & ppm & ppm & ppm & $\mathrm{ppm}$ & ppm & ppm & $\mathrm{ppm}$ & ppm & ppm & ppm & ppm & $\mathrm{ppm}$ & ppm & $\mathrm{ppm}$ & ppm & $\mathrm{ppm}$ & $\mathrm{ppm}$ & $\mathrm{ppm}$ & $\mathrm{ppm}$ & $\mathrm{ppm}$ \\
\hline Detection Limit & 1 & 20 & 10 & 30 & 1 & 1 & 5 & 2 & 1 & 2 & 0.5 & $\begin{array}{l}0.2 \\
\end{array}$ & 1 & 0.5 & 0.5 & 0.1 & 0.1 & $\begin{array}{l}005 \\
\end{array}$ & 0.1 & 0.1 \\
\hline Analysis Method & FUS-MS & FUS-MS & FUS-MS & \begin{tabular}{|l|} 
FUS-MS \\
\end{tabular} & FUS-MS & FUS-MS & FUS-MS & \begin{tabular}{|l|} 
FUS-MS \\
\end{tabular} & FUS-MS & FUS-MS & FUS-MS & FUS-MS & FUS-MS & FUS-MS & FUS-MS & FUS-MS & FUS-MS & FUS-MS & FUS-MS & FUS-MS \\
\hline GXR-1 Meas & 9 & 50 & 1110 & 760 & 17 & & 424 & \begin{tabular}{|l|}
3 \\
\end{tabular} & 3 & 18 & 29,8 & 0,8 & 54 & 121 & 2,9 & $\begin{array}{l}7,7 \\
\end{array}$ & 15 & & 8,3 & 2,9 \\
\hline GXR-1 Cert & 8,2 & 41 & 1110 & 760 & 13,8 & & 427 & 14 & 0,8 & 18 & 31 & 0,77 & 54 & 122 & 3 & 7,5 & 17 & & 18 & 2,7 \\
\hline WMG-1 Meas & 248 & 4320 & 6340 & 170 & 11 & & 18 & & 4 & $<2$ & 2,8 & & 2 & 12,4 & $<0.5$ & 7,9 & 16,7 & & 8,9 & 2,4 \\
\hline WMG-1 Cert & 200 & 2700 & 5900 & 110 & 10,3 & & 7 & & 6 & 1,4 & 2,7 & & 2,2 & 1,8 & 0,48 & 8,2 & 16 & & 9 & 2,3 \\
\hline \multirow{2}{*}{\multicolumn{21}{|c|}{ NIST 694 Meas }} \\
\hline & & & & & & & & & & & & & & & & & & & & \\
\hline DNC-1 Meas & 36 & 170 & 50 & $<30$ & 10 & $<1$ & $<5$ & 5 & $<1$ & $<2$ & $<0.5$ & & & 1 & $<0.5$ & 3,5 & 7,8 & 1,1 & 4,5 & 1,3 \\
\hline DNC-1 Cert & 54,7 & 247 & 96 & 66 & 15 & 1,3 & 0,2 & 4,5 & 3 & 0,7 & 0,027 & & & 0,96 & 0,34 & 3,8 & 10,6 & 1,3 & 4,9 & 1,38 \\
\hline \multicolumn{21}{|l|}{ GBW 07113 Meas } \\
\hline \multicolumn{21}{|l|}{ GBW 07113 Cert } \\
\hline GXR-2 Meas & 10 & $<20$ & 90 & 620 & 38 & & 29 & 85 & 10 & $<2$ & 19,3 & $<0.2$ & 2 & 60,2 & 5,9 & 25,9 & 52,7 & & 19,7 & 3,8 \\
\hline GXR-2 Cert & 8,6 & 21 & 76 & 530 & 37 & & 25 & 78 & 11 & 2,1 & 17 & 0,252 & 1,7 & 49 & 5,2 & 25,6 & 51,4 & & 19 & 3,5 \\
\hline LKSD-3 Meas & 36 & 50 & 30 & 120 & & & 47 & 78 & 8 & $<2$ & 1,6 & & 2 & 7,1 & 2,5 & 47 & 88,8 & & 41,3 & 7,8 \\
\hline LKSD-3 Cert & 30 & 47 & 35 & 152 & & & 27 & 78 & 8 & 2 & 2,7 & & 3 & 1,3 & 2,3 & 52 & 90 & & 44 & 8 \\
\hline MAG-1 (Depleted) Meas & 24 & 20 & 20 & 70 & 20 & & 20 & 147 & 13 & $<2$ & $<0.5$ & $<0.2$ & 3 & 6,6 & 8,1 & 41,3 & 85,2 & 10,5 & 35,6 & 7,1 \\
\hline MAG-1 (Depleted) Cert & 20,4 & 53 & 30 & 130 & 20,4 & & 9,2 & 149 & 12 & 1,6 & 0,08 & 0,18 & 3,6 & 0,96 & 8,6 & 43 & 88 & 9,3 & 38 & 7,5 \\
\hline \multicolumn{21}{|l|}{ NIST 1633b Meas } \\
\hline \multicolumn{21}{|l|}{ NIST 1633b Cert } \\
\hline \multicolumn{21}{|l|}{ SY-2 Meas } \\
\hline \multicolumn{21}{|l|}{ SY-2 Cert } \\
\hline W-2a Meas & 53 & 50 & 110 & 80 & 18 & 2 & 13 & 21 & 6 & $<2$ & $<0.5$ & & & 7,7 & 0,9 & 10,7 & 23,4 & & 12,5 & 3,3 \\
\hline W-2a Cert & 43 & 70 & 110 & 80 & 17 & 1 & 1,2 & 21 & 7,9 & 0,6 & 0,046 & & & 0,79 & 0,99 & 10 & 23 & & 13 & 3,3 \\
\hline \multicolumn{21}{|l|}{ NIST 696 Meas } \\
\hline \multicolumn{21}{|l|}{ NIST 696 Cert } \\
\hline CTA-AC-1 Meas & 2 & & 60 & 60 & & & & & & & & & & & & $>2000$ & $>3000$ & & 1130 & 170 \\
\hline CTA-AC-1 Cert & 2,72 & & 54 & 38 & & & & & & & & & & & & 2176 & 3326 & & 1087 & 162 \\
\hline BIR-1a Meas & 66 & 280 & 170 & 120 & 16 & 2 & $<5$ & $<2$ & $<1$ & $<2$ & $<0.5$ & & $<1$ & 4,7 & $<0.5$ & 0,7 & 2,1 & 0,42 & 2,4 & 1,1 \\
\hline BIR-1a Cert & 51,4 & 166 & 126 & 71 & 16 & 1,5 & 0,44 & 0,25 & 0,6 & 0,5 & 0,036 & & 0,65 & 0,58 & 0,005 & 0,62 & 1,95 & 0,38 & 2,5 & 1,1 \\
\hline LAC 2 Orig & 45 & 150 & 70 & 100 & 20 & 3 & $<5$ & 16 & 6 & $<2$ & $<0.5$ & $<0.2$ & 1 & 6,1 & 7,3 & 14,9 & 35 & 4,99 & 19,3 & 4,4 \\
\hline LAC 2 Dup & 48 & 160 & 80 & 130 & 19 & 3 & $<5$ & 17 & 5 & $<2$ & $<0.5$ & $<0.2$ & 1 & 12,3 & 7,6 & 14,2 & 33,6 & 4,78 & 18,2 & 4,2 \\
\hline T_IGN_MED Orig & 213 & 300 & 20 & 50 & 15 & 2 & 11 & 122 & 9 & 16 & $<0.5$ & $<0.2$ & 1 & 5,3 & 1,9 & 32,9 & 62,8 & 7,17 & 20,6 & 3,6 \\
\hline T_IGN_MED Split & 3 & $<20$ & $<10$ & 40 & 16 & 1 & $<5$ & 123 & 9 & $<2$ & $<0.5$ & $<0.2$ & 1 & 1,9 & 1,9 & 34,9 & 66,8 & 7,61 & 21,5 & 3,9 \\
\hline T_IGN_MED Orig & 213 & 300 & 20 & 50 & 15 & 2 & 11 & 122 & 9 & 16 & $<0.5$ & $<0.2$ & 1 & 5,3 & 1,9 & 32,9 & 62,8 & 7,17 & 20,6 & 3,6 \\
\hline T_IGN_MED Split & 3 & $<20$ & $<10$ & 40 & 16 & 1 & $<5$ & 123 & 9 & $<2$ & $<0.5$ & $<0.2$ & 1 & 1,9 & 1,9 & 34,9 & 66,8 & 7,61 & 21,5 & 3,9 \\
\hline Method Blank Method Blank & $<1$ & $<20$ & $<10$ & $<30$ & $<1$ & $<1$ & $<5$ & $<2$ & $<1$ & $<2$ & $<0.5$ & $<0.2$ & $<1$ & $<0.5$ & $<0.5$ & $<0.1$ & $<0.1$ & $<005$ & $<0.1$ & $<0.1$ \\
\hline Method Blank Method Blank & $<1$ & $<20$ & $<10$ & $<30$ & $<1$ & $<1$ & $<5$ & $<2$ & $<1$ & $<2$ & $<0.5$ & $<0.2$ & $<1$ & $<0.5$ & $<0.5$ & $<0.1$ & $<0.1$ & $<0.05$ & $<0.1$ & $<0.1$ \\
\hline
\end{tabular}


Final Report

\section{Activation Laboratories}

\begin{tabular}{|c|c|c|c|c|c|c|c|c|c|c|c|c|c|c|c|c|c|}
\hline Analyte Symbo| & Eu & $\mathrm{Gd}$ & $\mathrm{Tb}$ & Dy & $\mathrm{Ho}$ & Er & $\mathrm{Tm}$ & $\mathrm{Yb}$ & Lu & $\mathrm{Hf}$ & $\mathrm{Ta}$ & $\bar{W}$ & $\mathrm{TI}$ & $\mathrm{Pb}$ & Bi & Th & \\
\hline Unit Symbol & $\mathrm{ppm}$ & $\mathrm{ppm}$ & ppm & $\mathrm{ppm}$ & ppm & ppm & $\mathrm{ppm}$ & $\mathrm{ppm}$ & ppm & ppm & ppm & $\mathrm{ppm}$ & $\mathrm{ppm}$ & ppm & ppm & ppm & $\overline{\mathrm{ppm}}$ \\
\hline Detection Limit & 0.05 & 0.1 & 0.1 & 0.1 & 0.1 & 0.1 & 0.05 & 0.1 & 0.04 & 0.2 & 0.1 & 1 & 0.1 & 5 & 0.4 & 0.1 & 0.1 \\
\hline Analysis Method & FUS-MS & FUS-MS & FUS-MS & FUS-MS & FUS-MS & FUS-MS & FUS-MS & FUS-MS & FUS-MS & FUS-MS & FUS-MS & FUS-MS & FUS-MS & FUS-MS & FUS-MS & FUS-MS & FUS-MS \\
\hline GXR-1 Meas & 0,64 & 4,1 & 0,8 & 4,9 & & & 0,42 & 2,3 & 0,3 & 0,9 & 0,2 & 164 & 0,4 & 519 & 1380 & 2,5 & 33,7 \\
\hline GXR-1 Cert & 0,69 & $\overline{4,2}$ & 0,83 & 4,3 & & & 0,43 & 1,9 & 0,28 & 0,96 & 0,175 & 164 & 0,39 & 730 & 1380 & 2,44 & 34,9 \\
\hline WMG-1 Meas & 0,78 & & 0,4 & 2,6 & 0,5 & & 0,23 & 1,3 & 0,2 & 1,5 & 0,3 & $<1$ & & 44 & & 1,1 & 0,7 \\
\hline WMG-1 Cert & 0,82 & & 0,3 & 2,8 & 0,5 & & 0,2 & 1,3 & 0,21 & 1,3 & 0,5 & 1,3 & & 15 & & 1,1 & 0,65 \\
\hline \multirow{2}{*}{\multicolumn{18}{|c|}{ NIST 694 Meas }} \\
\hline & & & & & & & & & & & & & & & & & \\
\hline DNC-1 Meas & 0,59 & 2 & 0,4 & 2,7 & 0,6 & 1,9 & 0,31 & 1,9 & 0,29 & 0,9 & $<0.1$ & $<1$ & $<0.1$ & $<5$ & $<0.4$ & 0,2 & $<0.1$ \\
\hline \begin{tabular}{|l|} 
DNC-1 Cert \\
\end{tabular} & 0,59 & 2 & 0,41 & 2,7 & 0,62 & 2 & 0,38 & 2,01 & 0,32 & 1,01 & 0,098 & 0,2 & 0,026 & 6,3 & 0,02 & 0,2 & 0,1 \\
\hline \multicolumn{18}{|l|}{ GBW 07113 Meas } \\
\hline \multicolumn{18}{|l|}{ GBW 07113 Cert } \\
\hline GXR-2 Meas & 0,77 & 3,2 & 0,5 & 3,1 & & & 0,3 & 1,9 & 0,28 & 7,2 & 0,8 & 2 & 1 & 771 & $<0.4$ & 8,8 & \\
\hline GXR-2 Cert & 0,81 & 3,3 & 0,48 & 3,3 & & & 0,3 & 2,04 & 0,27 & 8,3 & 0,9 & 1,9 & 1,03 & 690 & 0,69 & 8,8 & 2,9 \\
\hline LKSD-3 Meas & 1,48 & & 0,9 & 5,1 & & & & 2,7 & 0,4 & 4,8 & 0,6 & $<1$ & & 15 & & 10,6 & 4,5 \\
\hline LKSD-3 Cert & 1,5 & & 1 & 4,9 & & & & 2,7 & 0,4 & 4,8 & 0,7 & 2 & & 29 & & 11,4 & 4,6 \\
\hline MAG-1 (Depleted) Meas & 1,5 & 5,9 & 1 & 5,3 & 1 & 2,9 & 0,44 & 2,6 & 0,38 & 3,5 & 1,2 & 1 & $<0.1$ & 10 & $<0.4$ & 11,6 & 2,9 \\
\hline MAG-1 (Depleted) Cert & 1,6 & 5,8 & 0,96 & 5,2 & 1,02 & 3 & 0,43 & 2,6 & 0,4 & 3,7 & 1,1 & 1,4 & 0,59 & 24 & 0,34 & 11,9 & 2,7 \\
\hline \multicolumn{18}{|l|}{ NIST 1633b Meas } \\
\hline \multicolumn{18}{|l|}{ NIST 1633b Cert } \\
\hline \multicolumn{18}{|l|}{ SY-2 Meas } \\
\hline \multicolumn{18}{|l|}{ SY-2 Cert } \\
\hline W-2a Meas & 1,16 & & 0,7 & 4,1 & 0,8 & 2,4 & 0,36 & 2,1 & 0,31 & 2,6 & 0,5 & $<1$ & $<0.1$ & $<5$ & $<0.4$ & 2,2 & $\overline{0,6}$ \\
\hline W-2a Cert & 1 & & 0,63 & 3,6 & 0,76 & 2,5 & 0,38 & 2,1 & 0,33 & 2,6 & 0,5 & 0,3 & 0,2 & 9,3 & 0,03 & 2,4 & 0,53 \\
\hline \multicolumn{18}{|l|}{ NIST 696 Meas } \\
\hline \multicolumn{18}{|l|}{ NIST 696 Cert } \\
\hline CTA-AC-1 Meas & 49,4 & 124 & 15,7 & & & & & 11,3 & 1,09 & 1,5 & 2,6 & & & & & 23,9 & 4,3 \\
\hline CTA-AC-1 Cert & \begin{tabular}{ll|}
46,7 \\
\end{tabular} & 124 & 13,9 & & & & & 11,4 & 1,08 & 1,13 & 2,65 & & & & & 21,8 & 4,4 \\
\hline BIR-1a Meas & 0,56 & 1,9 & 0,4 & 2,8 & 0,6 & 1,9 & 0,29 & 1,7 & 0,26 & 0,6 & $<0.1$ & $<1$ & $<0.1$ & 7 & 0,9 & $<0.1$ & $<0.1$ \\
\hline BIR-1a Cert & 0,54 & 1,85 & 0,36 & 2,5 & 0,57 & \begin{tabular}{|c|}
1,7 \\
\end{tabular} & 0,26 & 1,65 & 0,26 & 0,6 & 0,04 & 0,07 & 0,01 & 3 & 0,02 & \begin{tabular}{l|l|}
0,03 \\
\end{tabular} & 0,01 \\
\hline LAC 2 Orig & 1,45 & 4,4 & 0,7 & 4 & 0,8 & 2,4 & 0,34 & 2,1 & 0,32 & 2,8 & 0,4 & $<1$ & $<0.1$ & $<5$ & $<0.4$ & 1,4 & 0,4 \\
\hline LAC 2 Dup & 1,39 & 4,2 & 0,6 & 3,8 & 0,8 & 2,3 & 0,33 & 2 & 0,31 & 2,7 & 0,3 & $<1$ & $<0.1$ & 9 & $<0.4$ & 1,3 & $\overline{0,4}$ \\
\hline T_IGN_MED Orig & 0,67 & 2,7 & 0,4 & 2,5 & 0,5 & 1,4 & 0,21 & 1,3 & 0,2 & 3,4 & 0,7 & 2 & 1,3 & 21 & 1,8 & 16,4 & 2,8 \\
\hline T_IGN_MED Split & 0,72 & 2,9 & 0,5 & 2,7 & 0,5 & \begin{tabular}{l|l}
1,5 \\
\end{tabular} & 0,23 & 1,4 & 0,21 & 3,8 & 0,8 & $<1$ & 0,5 & 14 & \begin{tabular}{l|l}
1,5 \\
\end{tabular} & 17,2 & 2,9 \\
\hline T_IGN_MED Orig & 0,67 & 2,7 & 0,4 & 2,5 & 0,5 & 1,4 & 0,21 & 1,3 & 0,2 & 3,4 & 0,7 & 2 & 1,3 & 21 & 1,8 & 16,4 & 2,8 \\
\hline T_IGN_MED Split & 0,72 & 2,9 & 0,5 & 2,7 & 0,5 & 1,5 & 0,23 & 1,4 & 0,21 & 3,8 & 0,8 & $<1$ & 0,5 & 14 & 1,5 & 17,2 & 2,9 \\
\hline Method Blank Method Blank & $<0.05$ & $<0.1$ & $<0.1$ & $<0.1$ & $<0.1$ & $<0.1$ & $<0.05$ & $<0.1$ & $<0.04$ & $<0.2$ & $<0.1$ & $<1$ & $<0.1$ & $<5$ & $<0.4$ & $<0.1$ & $<0.1$ \\
\hline Method Blank Method Blank & $<0.05$ & $<0.1$ & $<0.1$ & $<0.1$ & $<0.1$ & $<0.1$ & $<0.05$ & $<0.1$ & $<0.04$ & $<0.2$ & $<0.1$ & $<1$ & $<0.1$ & $<5$ & $<0.4$ & $<0.1$ & $<0.1$ \\
\hline
\end{tabular}

